\title{
Chomskyan (R)evolutions
}

Edited by Douglas A. Kibbee

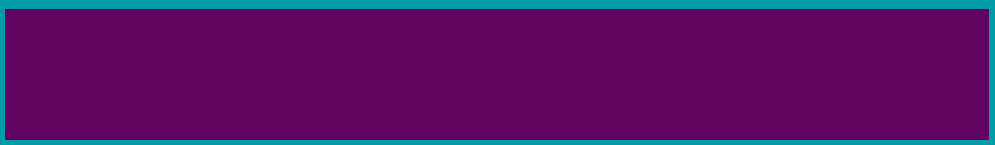

John Benjamins Publishing Company 
Chomskyan (R)evolutions 



\section{Chomskyan (R)evolutions}

Edited by

Douglas A. Kibbee

University of Illinois

John Benjamins Publishing Company

Amsterdam/Philadelphia 
The paper used in this publication meets the minimum requirements of American National Standard for Information Sciences - Permanence of Paper for Printed Library Materials, ANSI z39.48-1984.

\section{Library of Congress Cataloging-in-Publication Data}

Chomskyan (r)evolutions / edited by Douglas A. Kibbee.

$$
\text { p. cm. }
$$

Includes bibliographical references and index.

1. Chomsky, Noam. 2. Generative grammar. I. Kibbee, Douglas A.

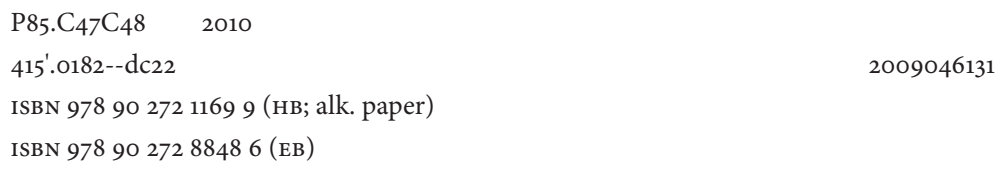

An electronic version of this book is freely available, thanks to the support of libraries working with Knowledge Unlatched. $\mathrm{KU}$ is a collaborative initiative designed to make high quality books Open Access for the public good.

The Open Access isbn for this book is 9789027288486 .

(C) 2010 - John Benjamins B.V.

This e-book is licensed under a Creative Commons CC BY-NC-ND license. To view a copy of this license, visit https://creativecommons.org/licenses/by-nc-nd/4.o/. For any use beyond this license, please contact the publisher.

John Benjamins Publishing Co. · P.O. Box 36224 · 1020 ME Amsterdam · The Netherlands John Benjamins North America · P.O. Box 27519 · Philadelphia PA 19118-0519 · USA 
To

E.F. Konrad Koerner on the occasion of his 70th birthday 



\section{Table of contents}

Foreword and Acknowledgments

Chomsky's Atavistic Revolution (with a little help from his enemies)

John E. Joseph

The equivocation of form and notation in generative grammar Christopher Beedham

Chomsky's paradigm: What it includes and what it excludes

Joanna Radwanska-Williams

PART I. The young revolutionary (1950-1960)

'Scientific revolutions' and other kinds of regime change

Stephen O. Murray

Noam and Zellig

103

Bruce Nevin

Chomsky 1951a and Chomsky 1951b

Peter T. Daniels

Grammar and language in Syntactic Structures: Transformational progress and structuralist 'reflux'

Pierre Swiggers

PART II. The cognitive revolution

Chomsky's other Revolution

R. Allen Harris

Chomsky between revolutions

Malcolm D. Hyman

\section{PART III. Evolutions}

What do we talk about, when we talk about 'universal grammar', and how have we talked about it? 
Migrating propositions and the evolution of Generative Grammar

Marcus Tomalin

Universalism and human difference in Chomskyan linguistics:

The first 'superhominid' and the language faculty

Christopher Hutton

The evolution of meaning and grammar: Chomskyan

theory and the evidence from grammaticalization

T. Craig Christy

Chomsky in search of a pedigree

Camiel Hamans \& Pieter A.M. Seuren

The 'linguistic wars': A tentative assessment by an outsider witness

Giorgio Graffi

PART IV. The past and future directions

British empiricism and Transformational Grammar: A current debate 423 Jacqueline Léon

Historiography's contribution to theoretical linguistics

Julie Tetel Andresen

Name index

Subject index

Index of cited works 


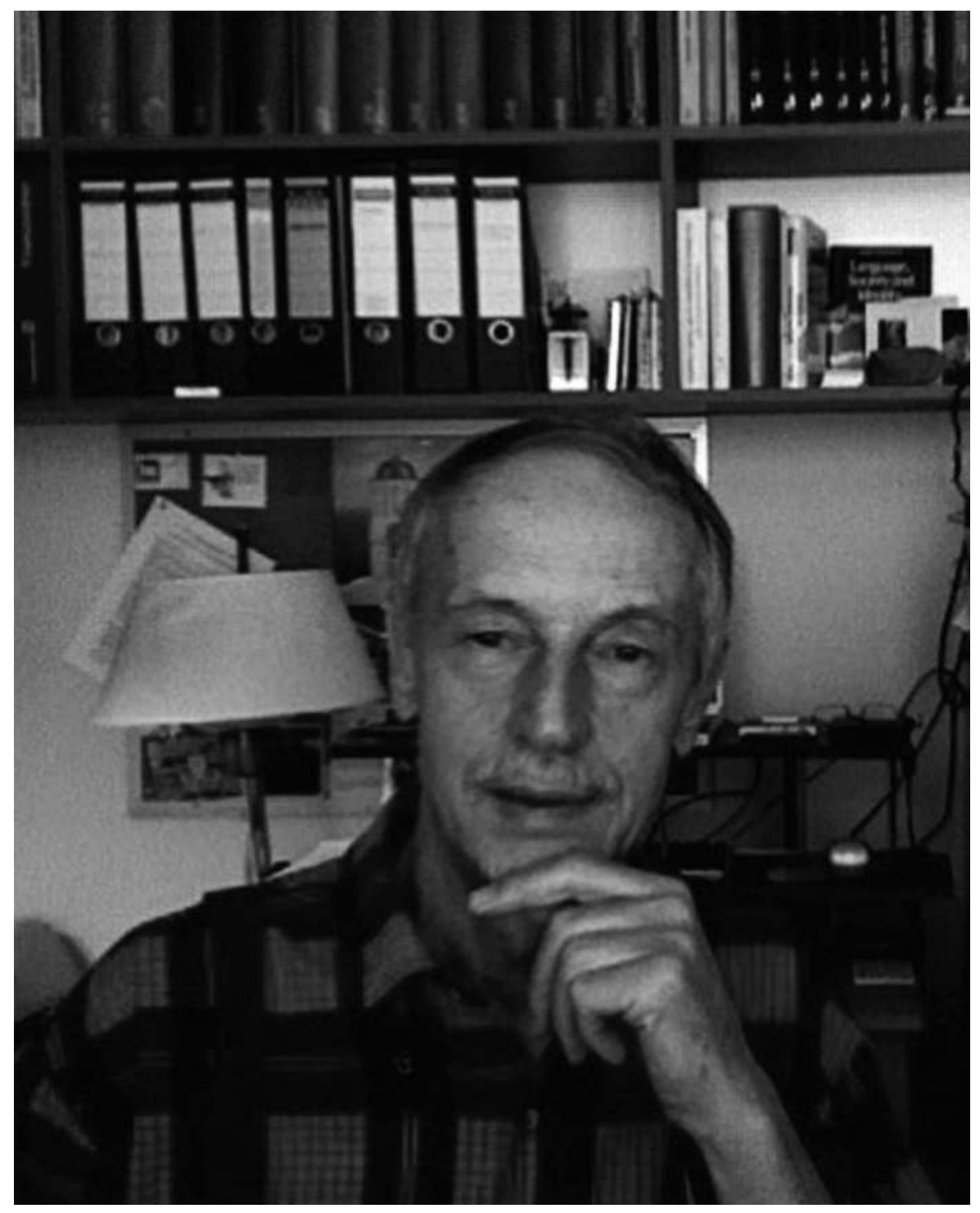

E.F.K. Koerner 



\section{Foreword and Acknowledgments}

Since the first meeting of the International Conference on the History of the Language Sciences in Ottawa in 1978, Konrad Koerner has been a dominant figure in the history of the study of language. His own immense list of scholarly publications, the journal he founded (Historiographia Linguistica), the triennial international conferences and the important monograph series have provided an institutional structure and an intellectual perspective for this research area. Even those who have disagreed with one of his stances or another are quick to acknowledge the vital role he has played in promoting the historiography of linguistics.

Modern attention to the history of linguistics might be dated to a spectacular failure, Noam Chomsky's attempt to trace, in Cartesian Linguistics (1966), the origins of his approach to linguistics to the Grammaire générale et raisonnée of Arnauld and Lancelot (1660). More importantly, though, the relationship between the whole of Chomskyan linguistics and its predecessors and competitors has frequently been described in hyperbolic terms - a 'revolution', to start with, and then ongoing 'counterrevolutions', 'revolts' and 'wars'. The weapons are words, and contentious rhetoric has been the hallmark of linguistic discourse since Chomsky's review of Skinner in 1959. Fortunately, the only real casualties in these events are egos.

These conceptions of linguistics from 1950 to the present have naturally aroused great interest among historians of the discipline, even as we recognize the dangers of writing a history of almost contemporaneous events. In 2002 Konrad Koerner published his chapter on "The 'Chomskyan Revolution' and its Historiography", a reprise of his 1983 article in Language and Communication and part of a continuing dialogue between himself and John Joseph on this topic (see Joseph 1991, 1995; Koerner 1983, 1989, 1999). It seemed therefore a fitting tribute to Konrad Koerner, on the occasion of his 70th birthday, to ask a number of distinguished scholars to comment on this theme.

John Joseph notes in that 1995 review article that all linguists want to consider themselves revolutionary, and he describes Noam Chomsky as a "Serial Revolutionary" (1995: 380). Historians of linguistics, as the pieces in this volume attest, also like to see themselves as revolutionary. The history of linguistics provides us with perspective on the wide variety of goals a science of language can have, the different types of data that become relevant depending on the goal, and the diverse methodologies that best suit the goals and the data. Different histories also have different goals, data and methodologies. 
The contributions of this volume challenge the fundamental bases for linguistic theorizing in the past sixty years and encourage all of us fascinated by the phenomenon of language to think in new ways about this most human trait. This is why we study the history of our discipline, a lesson we have all learned through our association with Konrad Koerner and the rich institutions that he has helped to create for this discipline. The seventeen articles that follow are a fitting tribute to Professor Koerner's passion for linguistics and its histories.

It deeply saddens us all that Malcolm Hyman, a contributor to this volume, passed away before he could see the fruit of his labor in print. He was far too young, and had far too many talents to meet such a fate. His boundless intelligence and curiosity will be much missed among his friends and colleagues in the history of linguistics.

This volume would have been impossible without the encouragement and assistance of John Joseph and, at Benjamins, of Anke de Looper. It has been a pleasure and an honor to work with them on this project. On the practical side, the project would have been equally impossible without the supreme professionalism and expertise of Karen Lichtman, she who returned corrected bibliographies from deep in the jungles of Guatemala, among many other miracles. I am also deeply appreciative of my administrative assistant, Marita Romine, whose efforts free me from many snares of academic administration.

The writing and editing of books like these require many evenings and weekends planted in front of a computer screen surrounded by books. Not to diminish the sacrifice of the authors and editors, we should recognize that the real sacrifice in such endeavors is performed by those we love. For this reason, I dedicate this book to the love of my life, Jo Kibbee. 


\title{
Chomsky's Atavistic Revolution (with a little help from his enemies)
}

\author{
John E. Joseph \\ University of Edinburgh
}

The Oxford English Dictionary defines Modernism as a "movement characterised by a deliberate break with classical and traditional forms or methods". This is borne out by examination of how 'modern' linguists have routinely established an ironic distance between their own work and what went before. The exception is Chomsky, whose 'atavistic' revolution, harking back to putative early modern roots, broke all the rules in terms of the stance one could take toward intellectual predecessors in the wake of modernism. It showed how "a deliberate break with classical and traditional forms or methods" could be brought about by, not ignoring traditional methods, or taking an ironic distance from them, but reinterpreting them with a greater time depth. The ultimate irony lies in how Chomsky's opponents forced an ironic distance on him, turning him into a mere garden-variety modernist - and by so doing, helped to guarantee the success of his generativist programme.

ATAVISM. Resemblance to grandparents or more remote ancestors rather than to parents. MODERNISM. Movement characterised by a deliberate break with classical and traditional forms or methods.

REVOLUTiOn. 1. A single act of rotation round a centre. 2. An instance of great change or alteration in affairs or in some particular thing. - Oxford English Dictionary (abridged)

\section{Modernism and ancestry}

For over a quarter of a century E.F.K. Koerner (1983, 1989, 2002) has not merely led the charge in denying that what is commonly referred to as the Chomskyan Revolution in linguistics was a revolution at all. He has been the charge, a one-man brigade, with others gradually lining up safely in the rear. Lagging still further behind to clear up after the horses, I argued in Joseph $(1991,1995)$ that no revolution, whether political or 
academic, would ever qualify as such by the strict criteria Koerner was demanding. Revolutions are above all rhetorical, a matter of belief and linguistic performance, always with partial continuity of methods, agenda, institutions, even personnel. In any event, what is the point of carrying on an argument that boils down to how one defines the word 'revolution' in one of its metaphorical senses?

My inclination in such a case is to follow common usage and continue to speak of a Chomskyan Revolution. But casting about for an alternative that might satisfy Koerner, one word that suggests itself is 'modernism'. As defined above, it implies a deliberate break with traditional methods - with the emphasis on deliberate, since, again, the break will never be more than partial. If to call something revolutionary implies not just great change but scientific progress, labelling it modernist does not. It designates a limited period, a few decades either side of the two World Wars. The style and thought of the period embodied an ideology of progress, but today the term is a historical designation and implies no judgement as to whether any enduring progress was actually achieved.

Certainly Chomsky has been neither a traditionalist in the usual sense, nor a postmodernist, whatever that means. So Chomskyan Modernism would seem an apt term - except that modernist is a label we associate with the generation before his, that of Edward Sapir (1884-1939) and Leonard Bloomfield (1887-1949), those contemporaries of Le Corbusier and Stravinsky. This is despite the fact that Sapir never broke from the methods of his teacher Franz Boas (1858-1942) to the same extent as Chomsky did from the Bloomfieldians and Sapirians. As for Bloomfield, he effectuated a very modernist break through his behaviourist-framed distributionalism, yet insisted privately that the influence of Ferdinand de Saussure (1857-1913) was on every page of his 1933 book Language (Cowan 1987: 29; see Joseph 2002: 135).

Further on I shall consider in more detail how these figures and others relate to the previous linguistic tradition. But it first has to be pointed out that, even if the deliberateness of Chomsky's break was greater than that of the generation before him, he did not cast it as a rejection of classical and traditional forms or methods, but as a return to them. It was the Bloomfieldians, in his view, who were the modernists, and who had set linguistics on the wrong track. Chomsky was bringing about a 'revolution' in the first, most literal sense of the word, the completion of a circle. An atavistic revolution: a return to an understanding and methods more akin to those of his intellectual grandparents and remote ancestors, as he understood them, than of his parents.

That might still qualify Chomsky as a 'late modernist', since atavism and modernism are by no means diametrically opposed. One thinks of the pre-Raphaelites, those supreme early modernists who broke with contemporary practice by a deliberate return to the style of pre-modern masters. They trumped the authority of their teacher's generation by an appeal to a still higher authority, long-ago artists whose genius their teachers vaunted even while sneering at their primitive techniques. In Stravinsky's case, 
he managed a second modernist revolution in mid-career by abandoning his earlier expressionism for a neo-classicism that harked back to the 18th century; these works remain firmly in the canon, unlike those of his third, non-atavistic atonal phase. This ambivalence toward historical authorities is what makes intellectual atavism a powerful means for a modernist break - again a revolution in the literal sense, regardless of whether we choose to call it one metaphorically.

Looking across the wide range of journals and books in a range of academic fields, both humanistic and scientific, the normal state appears to be one in which individuals situate their enquiries within some framework that is already in wide use, sometimes in direct competition with an alternative framework though more often simply ignoring rival approaches. This is in line with the positivist ideal of a steady accumulation of rigorously controlled observations gradually adding either to the scope of the model, by showing how it accounts for new data and cases, or to its precision, by excluding data and cases previously assumed to be covered by it. ${ }^{1}$

In these conditions, it is typical for the attitude toward the field's past to be one of simple progress. Figures from the past will be regarded as further from the truth the further back they are in time - with the proviso that, as argued by Cram (2007), an 'ebb tide' effect can make figures from the immediate past temporarily less authoritative than those a bit more distant. The most revered figures will be those who rethought the framework itself or made discoveries of such magnitude that they validated or reshaped the framework. Their importance relative to one another is a balance between the impact they had and their point on the timescale, so that, of two figures who had a roughly equal impact, the more recent one will be treated as more authoritative, except among antiquarians, or unless nationalistic or other identity

1. There was a time not long ago when it would have been necessary to ascribe this view to Thomas S. Kuhn (1922-1996). That time is past, not because Kuhn's work has ceased to be authoritative, but because its impact on the history of science has been so profound. It is now hard to imagine that anyone could have been startled by Kuhn's contention that sciences do not simply progress from darkness to light, but are shaped by social, political and rhetorical forces. This is not to say that Kuhn (1962) has become some sort of bible, its every statement exactly what one would repeat today as truth. It is, for example, oddly uniformitarian — ahistorical, in other words - in its assumption that we could or would want to apply a single model of development to all of science, across vastly different cultural contexts. Kuhn was not a trained historian, but a physicist who became a philosopher. His aim was to break the stranglehold which a single, simple idea of positive science had in the modernist period, and to do so he harked back to Copernicus as his perfect model. It worked because of the way in which the Copernican revolution had been singled out and idealised in modern science, as one of a handful of paradigm cases along with Newton, Darwin and maybe Einstein, though there was still some residual nervousness about Einstein in that time of nuclear paranoia. 
motives are in play, or if the figure has achieved fame well beyond the field that claims him or her as its identity marker.

For the practitioner working in the present, the appeal to the past is central to the argument from authority, which is the main valve controlling what I like to call the 'economy of dreams', the limited degree to which any new work is allowed to innovate rather than reproduce existing knowledge and still find acceptance from the 'gatekeepers' of the field, the journal reviewers and editors, grant reviewers and boards, hiring and promotion committees. We face the paradox that our work is considered particularly valuable insofar as it is original and novel - yet is evaluated within a system that exists in order to keep novelty to a critical minimum, so as to limit the imagination and fantasy of any individual and constrain it to the shared dream of the group.

So how do practitioners in an academic field manage this economy of dreams? In part, rhetorically, through how they position their findings and conclusions relative to the field as a whole. It is here that the ancestral giants play a crucial double role. First, as authorities to whom one can appeal, and in so doing perform one's mastery of the field's past. Secondly, as figures who, by virtue of being remote in time, both allow and demand that much more interpretation to make their work meaningful in the present context. The remoteness is, as noted above, generally viewed as signifying distance from the truth as built up by later methods. But this creates a sort of rhetorical release valve in the plumbing system of dreams. An innovation that might otherwise be rejected as excessive within a conservative field can be made acceptable by claiming that it is actually part of the field's heritage - what it has always believed, even if it has temporarily forgotten that it believes it - by tying it to an authoritative figure from the past. Texts written by that figure can usually be interpreted and contextualised in a way that appears to support whatever present-day view one is upholding. That is the advantage of intellectual atavism, but also its disadvantage, since one's opponents can equally well reinterpret and contextualise the same texts in their own favour. To continue with my dubious plumbing metaphor, this sort of atavism is a lead-pipe cinch; but the softness that makes lead so pliable is also what makes it so poisonous.

\section{Ironic distance}

In the modernist period, atavistic rhetoric faced a further obstacle in the imperative to detach practice from tradition. In academic terms, the rejection of tradition can take a number of forms, all of which amount to a sharp and deliberate revaluation of the currency of scholarly work. The old does not become worthless, but its value is adjusted downward relative to the new. At the same time, what was marginalised in the past is sometimes brought to the centre, and vice-versa, which is another way of revaluing the currency. 
The need for detachment complexified the paradox. It did not eliminate the motives for appealing to the past, but required practitioners to perform rhetorically their simultaneous understanding of how the past was both right and wrong. The principal rhetorical means for this performance was what is sometimes called 'ironic distance' or 'ironic detachment', where the irony lies in the ambivalent relationship between the modern writer and the ancestral authority figure, rather than in any overt sarcasm in the language used. Sarcasm is in fact one possible way of achieving the distance, though not the one most commonly found in academic discourse in the modernist period. Returning to the analogy of pre-Raphaelite painting, there was never any question of mistaking it for work from the 15th century. ${ }^{2}$ Nor could any musically literate person hearing Stravinsky's Pulcinella (1920) for the first time confuse it with compositions by Pergolesi and his contemporaries from 200 years earlier, whose themes inspired it. The melodies may be borrowed, the harmonies authentic, but the driving rhythm, strongly contrasting dynamics and rich orchestration create the ironic distance that makes Pulcinella an unmistakably modern composition.

The lack of awareness of how ironic distance functions in academic writing can be seen in a 1998 exchange between Margaret Thomas and a foursome led by Susan Gass. Thomas contends that the field of Second Language Acquisition (SLA) suffers from ahistoricity. SLA ignores the wide range of studies from earlier decades and centuries which supply it with an impressive pedigree. In a highly defensive response, Gass et al. attempt to deny the charge. Much as arguments over Chomsky's impact boil down to definitions of 'revolution', here the debate is ultimately over what does and does not count as 'modern' and as 'history'. The argument offered by Gass et al. for why their field is not ahistorical is, for me, and no doubt for Thomas, a perfect demonstration of why it is.

[W] do not wish to deny premodern texts, only to say that they do not seem to have played an informing role in the development of the field of SLA. It is only in the ' 50 s, ' 60 s, and '70s that we begin to see a flurry of intellectual activity that converges on a coherent body of scholarly work - a body of work that begins to ask the important how and why questions of second language learning to which widely accepted methods of analysis are applied. (Gass et al. 1998: 412)

The authors are right to recognise how historicity is linked to continuity. Without that criterion of having "played an informing role in the development of the field", interest in the past can be simply antiquarian — not a bad thing to be, though neither is it the

2. The same is not always true of the neo-Gothic style which the pre-Raphaelites precipitated. The cathedral near our house which most visitors assume to be medieval is actually a product of the 1870s Gothic Revival; and I myself thought that the wooden chest in our bedroom must be Jacobean, until I became familiar with this particular brand of Victorian atavism. 
same as being historicist in a continuist way, something which Gass, Thomas and I all agree is much richer. But what do Gass et al. mean by "deny premodern texts", if not to say that "they do not seem to have played an informing role"? To deny that they exist? That would be lunacy. The authors are first of all introducing a surreptitious distinction of modern and pre-modern, treating it as a given when it is in fact not only subjective but circular within a discussion of historicity. What is modern is what is continuist with today's work, and that continuity, they resolutely claim, does not extend back beyond the 1950s. This shallowness of time depth is precisely what Thomas means by ahistoricism. The criteria for continuity are evident in the rhetoric used by Gass et al.: converges, coherent, body of work, important questions, widely accepted methods.

We can see that history begins for them with an institutional recognition extending into the present time, which is a perfectly modernist view. It is as though the past of an academic field divides into a preterite (like English wrote) and a present perfect (have written), where the former is used in the context of a time period that does not include the present, the latter in one that does. I wrote five pages this morning is what one says in the afternoon, a time when one might also say I have written five pages this afternoon. For the continuist Thomas, history starts at daybreak, and ahistoricity means imagining that it only started at noon. For the discontinuist Gass, until noon there is nothing coherent to write a history about, so to speak of ahistoricity is absurd.

To substantiate their insistence on disciplinary coherence, Gass et al. structure a history of SLA that traces it back to a 1967 article by S. Pit Corder (1926-1990), and they point to work since then that recognises this lineage. They are right to identify Corder's article as a breakthrough event. However, they fail to appreciate how even those within the lineage they trace ironically distance themselves from Corder, even while claiming to extend his heritage. This example by Antonella Sorace, a former student of Corder's and sometime collaborator of Gass's, is a textbook example of ironic distancing:

While Corder's theories clearly were on the right track, they had a speculative flavour that, with hindsight, is easy to ascribe to a lack of conceptual and methodological tools for analysis; like other early second language theorists (e.g. Krashen 1981), he was in a sense 'ahead of his time', which meant that many of the innovative concepts he proposed could not receive either a full theoretical interpretation, or an empirical validation, until much later. (Sorace \& Robertson 2001: 264)

Undoubtedly a sincere tribute to Corder is intended. ${ }^{3}$ The ironic distance arises through a rhetorical imperative for constant reassurance to ourselves and our paymasters that we are achieving progress - an enduring modernist heritage.

3. More doubtful is whether Corder would have appreciated being bracketed together with Krashen, whose approach was very different from his own, or whether Krashen, closer in age to Sorace than to Corder, did not feel ambivalent about being treated as a historical figure while still academically active. 
One can look into any work on linguistics from the late 19th century onward that contains discussion of historical predecessors and find instances of ironic distance. The first 'modernist' linguistic work is arguably that by William Dwight Whitney (1827-1894), and no small part of what qualifies him for the label is his very abrupt disjuncture from the multiple traditions that feed into his understanding of language. Alter (2005: 71-76) has shown for example that the Scottish philosophy of Thomas Reid (1710-1796) and Dugald Stewart (1753-1828) had a shaping influence on Whitney's thought, in particular through the Rhetoric (1776) of George Campbell (1719-1796), a foundational book in Whitney's studies (see also Joseph 2002: 30-32). But it gets no mention in Whitney's work, which gives brief attention only to a handful of 18th-century figures who are treated as either dealing in "speculations" or adding piecemeal "facts and first classifications" to create a sort of puzzle that then more or less solved itself. Linguistics came into being, he writes,

by the suggestive and inciting deductions and speculations of men like Leibniz and Herder, by the wide assemblage of facts and first classifications of language by the Russians under Catherine and by Adelung and Vater and their like, and by the introduction of the Sanskrit to the knowledge of Europe, and the intimation of its connections and importance, by Jones and Colebrooke. No one thing was so decisive of the rapid success of the movement as this last; the long-gathering facts at once fell into their proper places, with clearly exhibited relations, and on the basis of Indo-European philology was built up the science of comparative philology. (Whitney 1875: 317-318)

He does go on to give the familiar litany of German names - Friedrich Schlegel (1772-1829), Franz Bopp (1791-1867), Jakob Grimm (1785-1863) and those who followed them - along with just three non-Germans, Rasmus Rask (1787-1832), Eugène Burnouf (1801-1852) and Graziado Ascoli (1829-1907), who he says "have most right to be mentioned on the same page with the great German masters" (ibid., p. 318). Yet even this tip of the hat to his predecessors calls for the requisite modernist ironic distancing.

But while Germany is the home of comparative philology, the scholars of that country have, as was hinted above, distinguished themselves much less in that which we have called the science of language. There is among them (not less than elsewhere) such discordance on points of fundamental importance, such uncertainty of view, such carelessness of consistency, that a German science of language cannot be said yet to have an existence. (ibid., pp. 318-319)

Whitney's 1867 book had been so thorough in its ironic detachment that its German translator, Julius Jolly (1849-1932) felt obliged to add two chapters tracing the history of historical-comparative linguistics in detail.

Whitney's modernism was no small part of why he was so 'revered' by Saussure (see Joseph 2002: 44), who followed Whitney's lead in ironically distancing himself from the Germans. Saussure's Mémoire (1879) on the original Indo-European vowel 
system opens with a "Review of different opinions put forward on the system of $a$ 's", briefly tracing the history of treatments of the subject from Bopp, to Georg Curtius (1820-1885) and August Fick (1833-1916), to August Schleicher (1821-1868), and warning readers that

No subject is more controversial; opinions are almost infinitely divided, and rarely have the various authors given a perfectly rigorous application of their ideas. (Saussure 1879: 1, my translation) ${ }^{4}$

When he paid to have this book printed Saussure was a student at Leipzig, just turned twenty-one and yet to receive any university degree. One of the "various authors" whose intellectual rigour he was questioning was Curtius, his university's senior professor of comparative linguistics. The young man in a hurry was so impelled by the double imperative, first to locate his system at the endpoint of the evolution of the discipline, and secondly to establish its complete originality, that he badly mismanaged the economy of dreams. The result was a life-long alienation from the German linguistics establishment that helped shipwreck his career. This is a danger inherent in distancing oneself too far from the immediately preceding generation, as Chomsky would rediscover 80 years later, though in career terms he would stay nicely afloat however stormy the seas.

Much safer was the sort of historicism undertaken by Sapir in his master's thesis on Johann Gottfried Herder (1744-1803). Early on he displays a scholarly humility absent from Whitney and Saussure before him, and most other linguists after.

Despite the vast accumulation of linguistic material that has been collected since Herder's time, and the immense clarification that has been attained in linguistic conceptions, processes, and classifications, we cannot today make bold to assert that this problem is satisfactorily answered, or apparently in a way to be satisfactorily answered in the immediate future. (Sapir 1907: 110)

By the end, however, Sapir is fiercely staking out his ironic distance from the subject of his thesis.

Contradictions even of no small significance and lack of clearness in the terms used will have been noticed in the course of our exposition of Herder's essay [...]. Setting aside faults in the essay itself, it is evident that the new vistas of linguistic thought opened up by the work of Karl Wilhelm von Humboldt, and the more special labors of Bopp and Grimm, speedily relegated Herder's treatise to the limbo of things that were. (ibid., pp. 139-140)

4. “Aucune matière n’est plus controversée; les opinions sont divisées presque à l'infini, et les différents auteurs ont rarement fait une application parfaitement rigoureuse de leurs idées". Examples could be drawn as well from the Cours de linguistique générale (Saussure 1916), but I have confined myself to a text which Saussure himself published. 
For the rest of his career Sapir would be the ultimate modernist of the period's major linguists, discussing no predecessors at all in his book Language (1921) or in any of his widely-read papers.

Bloomfield's approach to his intellectual ancestors is, by contrast, more muted and immediately balanced. One gets the impression that his decision to discuss a particular predecessor already reflects a judgement that his work is valuable, and the ironic distance comes in quite matter-of-factly. Of Whitney $(1867,1875)$ he says that "today they seem incomplete, but scarcely antiquated, and still serve as an excellent introduction to language study" (Bloomfield 1933: 16). Hermann Paul's (1846-1921) great work of 1880 is judged by Bloomfield (ibid.) to be "Not so well written as Whitney's, but more detailed and methodical", adding that "students of a more recent generation are neglecting it, to their disadvantage". Yet when the next sentence delivers the ironic distancing, it is pitiless:

Aside from its very dry style, Paul's Principles suffers from faults that seem obvious today, because they are significant of the limitations of nineteenthcentury linguistics. One of these faults is Paul's neglect of descriptive language study. [...] The other great weakness of Paul's Principles is his insistence upon "psychological" interpretation. (Bloomfield 1933: 16-17)

A subtler form of distancing is found in Bloomfield's earlier review of the Cours de linguistique générale, which ends as follows:

I should differ from de Saussure chiefly in basing my analysis on the sentence rather than on the word; by following the latter custom de Saussure gets a rather complicated result in certain matters of word-composition and syntax. The essential point, however, is this, that de Saussure has here first mapped out the world in which historical Indo-European grammar (the great achievement of the past century) is merely a single province; he has given us the theoretical basis for a science of human speech. (Bloomfield 1924: 319)

This appears at first to move from an initial distancing toward an out-and-out compliment. But the compliment turns somewhat back-handed when one realises how little importance Bloomfield accorded to a "theoretical basis" divorced from practical applications (see Joseph 2002: 139).

Again, examples from the modernist period could be multiplied ad infinitum. All those cited, from Whitney to Sorace and Robertson, illustrate the general principle of how figures closer in time - in Whitney's case, Bopp and Wilhelm von Humboldt (1767-1835) - are taken as closer to the truth than those more remote, even by just one generation. Sapir though shows an awareness displayed by none of the others, least of all the young Saussure, that the first and perhaps most valuable lesson gained from historicity is the realisation that any sense we may possess of being the first to arrive at the truth is an illusion that will last only until the next generation falls victim to it. 


\section{The exceptional Mr Chomsky}

All these modernists reject tradition either by ignoring their predecessors or keeping an ironic distance from them, in varying degrees and using a range of rhetorical devices. It is so much a part of the fabric of modernist discourse that to find it virtually absent in the writings of just one linguist is stunning. To be precise, Chomsky's early work is very much concerned with distancing itself from the generation of his teachers, and from their principal master, Bloomfield. But it does this in an unprecedented way, by wholeheartedly embracing tradition, as represented by a series of figures prior to Bloomfield whose approaches he perceives as being closer to his own understanding of language than what was being professed in the 1940s and 1950s. Not a ray of ironic sunlight separates Chomsky from his claimed ancestors.

In Joseph (2002: 147-150) I have shown how in the early 1960s Chomsky's search for an intellectual ancestor took him back first to Saussure, then to Humboldt. ${ }^{5}$ This shift can be traced through the various versions of the address Chomsky gave to the Ninth International Congress of Linguists in 1962. He first presents his own work as fitting within "the classical Saussurian framework" (Chomsky 1964: 512), and while he notes two ways in which his approach differs from Saussure's, they are treated neither as insurmountable obstacles nor as progress from his predecessor's relative primitiveness. Saussure is discussed as though he were Chomsky's contemporary. Even when Chomsky's subsequent reading takes him back a further hundred years to Humboldt (1836), in whom he discovers a far more deeply kindred spirit, he does not distance himself ironically from Saussure.

Through the later versions of this paper he maintains his earlier remarks about Saussure, though they come to be dwarfed by the growing amount of far more glowing admiration of, first Humboldt, then René Descartes (1596-1650), Gérauld de Cordemoy (1626-1684) and the authors of the Port-Royal grammar, Claude Lancelot (c.1616-1695) and Antoine Arnauld (1612-1694). This is the 'Cartesian' linguistic tradition that Chomsky identifies as culminating with Humboldt, before subsequently being undone by the line that extends from Whitney to Bloomfield and his followers. Subtly, Chomsky comes to detach Saussure from his earlier linkage of him to Humboldt, and to associate him instead with Whitney and the anti-Cartesian-Humboldtian-Chomskyan line. Finally Chomsky (1965) will cut himself off from Saussure absolutely: the three mentions of

5. This is a fitting opportunity to answer Koerner's (2002: 138) question about the basis for statements I have made concerning Chomsky's "earliest" published references to Saussure; it is that I spent untold hours in the Georgetown University Library in 1989-90 digging out and reading through all of Chomsky's early publications, with much appreciated guidance from Koerner \& Tajima (1986). 
him occur in conjunction with the words "reject" (p. 4), "naïve" (pp. 7-8), and worst of all, "taxonomic" (p. 47). The preface to the book begins:

The idea that a language is based on a system of rules determining the interpretation of its infinitely many sentences is by no means novel. Well over a century ago, it was expressed with reasonable clarity by Wilhelm von Humboldt, in his famous but rarely studied introduction to general linguistics (Humboldt, 1836). (Chomsky 1965: v)

Those whom this encomium inspired to read Humboldt's book were surely taken aback to find that whatever rules had determined Chomsky's interpretation of "introduction to general linguistics" were idiosyncratic, and accorded only remotely with what one expected of such an introduction in the wake of Saussure (1916), Bloomfield (1933) and the more recent textbooks by Henry A. Gleason Jr. (1917-2007; 1955) and Charles F. Hockett (1916-2000; 1958). Nor would they have had an easy time working out where Humboldt said anything about a system of rules determining interpretation. Never mind; the point is that, when Chomsky transfers his allegiance, it is completely. If he agrees with a predecessor on the basics, he does not quibble about particulars. In the original version of his International Congress of Linguists paper, written when his loyalty still lay with Saussure, Humboldt is criticised, along with Paul, for failing to take account of "creativity" in language production (Chomsky 1964: 512; cf. Chomsky 1964: 22). Such criticisms of Humboldt now disappear, and he no longer has a positive word to say about Saussure.

It is necessary to reject his [Saussure's] concept of langue as merely a systematic inventory of items and to return rather to the Humboldtian conception of underlying competence as a system of generative processes. (Chomsky 1965: 4)

Come Cartesian Linguistics (1966) and Saussure has been air-brushed from history almost entirely. The name appears twice in a list of those - including Paul, Bloomfield, Otto Jespersen (1860-1943), Hockett and "many others" - "who regard innovation as possible only "by analogy" (p. 55), and are responsible for the fact that "Modern linguistics has $[\ldots]$ failed to deal with the Cartesian observations regarding human language in any serious way" (p. 12).

Cartesian Linguistics is an extraordinary book in any number of ways. One of its claims to uniqueness lies in how these figures from a past that would seem as remote as it is possible to be from M.I.T. in the 1960s are discussed as if they were active members of its faculty. The book is a condescension-free zone for linguists before Paul. It stays true to the programme announced in its Introduction:

I will limit myself here to [...] a preliminary and fragmentary sketch of some of the leading ideas of Cartesian linguistics with no explicit analysis of its relation to current work that seeks to clarify and develop these ideas. The reader acquainted with current work in so-called "generative grammar" should have little difficulty in drawing these conclusions for himself. (Chomsky 1966: 2) 
The continuity between his own work and that of his 17th-century predecessors, in other words, is so complete as to be self-evident. ${ }^{6}$

\section{Love your enemies}

The demolition of Chomsky's claimed intellectual pedigree came in two waves. Salmon (1967) was the first to cast serious doubt on Chomsky's historical framework. Her review is a tour de force, a virtual encyclopaedia of relevant works from the medieval period onward; Chomsky's book necessarily ends up looking very thin indeed by comparison. Treating Chomsky's argument seriously, Salmon acknowledged that he limited his claims of a 'Cartesian' tradition to imply only the sharing of certain key ideas that derive from Descartes. She showed however that even with these limitations the Cartesian categorisation made little historical sense. The key ideas in question were already present in medieval grammars and treatises on language, and this was known to those who revived them in the 17th century, independently of Cartesian philosophy. She showed too that British linguistic enquiry was not so monolithic as Chomsky tended to portray it in his occasional references, and that the Bloomfieldian approach, which assumed language to be arbitrarily structured rather than grounded in any innate, universal mental principles, was no 20th-century innovation but had its own 17th-century counterparts.

Robin Lakoff's 1969 review of an annotated facsimile edition of the Port-Royal grammar, while not citing Salmon's review, drew a similar conclusion about the earlier provenance of the ideas Chomsky ascribed to Descartes. Lakoff's review focussed as much on Minerva (1587) by Franciscus Sanctius (1523-1601) as on Port-Royal. Despite some concern about "doing violence to the thoughts of" these predecessors, she "would state definitively" that they were "in some sense, generative grammarians" (R. Lakoff 1969: 346). The review thus upheld the basic historical framework put forward by Chomsky, but differed from him greatly on what belonged where within the framework. The fact that it appeared in Language - a journal which carried no review of Cartesian Linguistics until the book's reissue in the present decade (Falk 2005) - and was written by someone who had until recently been associated with Chomsky's transformational-generative grammar, meant that the criticisms stung, even if the overall thrust was supportive. Finishing off this first, historically-oriented wave, Aarsleff (1970), again in Language, dwelt on figures Chomsky did not discuss, particularly John Locke

6. To be clear, I am passing no judgement here about the validity of the claimed continuity; on that question, see Koerner (2002: 131-150). 
(1632-1704), and Aarsleff's own hobby-horse, Condillac (1714-1780). ${ }^{7}$ Idiosyncratic in its focus and vitriolic in its tone, ${ }^{8}$ Aarsleff's piece redeemed most of the damage done by Lakoff the year before, since it only adds credibility to one's position to have an opponent appear irrational.

The really serious critiques came in a second wave, starting with an article by John Searle in the New York Review of Books, where he had the following to say about Cartesian Linguistics.

Chomsky is really making two claims here. First, a historical claim that his views on language were prefigured by the seventeenth-century rationalists, especially Descartes. Second, a theoretical claim that empiricist learning theory cannot account for the acquisition of language. Both claims are more tenuous than he suggests. Descartes did indeed claim that we have innate ideas, such as the idea of a triangle or the idea of perfection or the idea of God. But I know of no passage in Descartes to suggest that he thought the syntax of natural languages was innate. Quite the contrary, Descartes appears to have thought that language was arbitrary; he thought that we arbitrarily attach words to our ideas. Concepts for Descartes are innate, whereas language is arbitrary and acquired. Furthermore Descartes does not allow for the possibility of unconscious knowledge, a notion that is crucial to Chomsky's system. Chomsky cites correctly Descartes' claim that the creative use of language distinguishes man from the lower animals. But that by itself does not support the thesis that Descartes is a precursor of Chomsky's theory of innate ideas. (Searle 1972)

The readership of the New York Review of Books was on the order of one hundred times that of the most widely read linguistics journal, Language. And being a philosopher indeed the new heavyweight champion of the philosophy of language - Searle could be expected to know a thing or two about Descartes. What he wrote was devastating for Chomsky's perceptions and claims of continuity. Eight months later the same

7. When in 1988 Aarsleff did something similar in his introduction to a translation of Humboldt (1836), Cambridge University Press soon issued a second edition with a new introduction that was actually about Humboldt. All this is a pity because, at his best, Aarsleff is an inspiring historian of linguistic ideas.

8. For example: "I do not see that anything at all useful can be salvaged from Chomsky's version of the history of linguistics. That version is fundamentally false from beginning to end - because the scholarship is poor, because the texts have not been read, because the arguments have not been understood, because the secondary literature that might have been helpful has been left aside or unread, even when referred to" (Aarsleff 1970: 583). For his part, Chomsky attributes the end of his engagement with the history of linguistics to what he sees as Aarsleff's intellectual dishonesty (Barsky 1997: 105), claiming that the flaws so vehemently denounced in Aarsleff's article are absent from Chomsky (1966) but abound in Aarsleff (1967). 
periodical published a letter to the editors arguing that Searle actually did not go far enough in distancing Chomsky from his claimed intellectual ancestors.

Chomsky's account of so-called Cartesian linguistics is as inaccurate as his portrayal of structural linguistics. Searle has criticized Chomsky for inaccurately interpreting Descartes' writings, but he ignores the devastating critiques of Chomsky's treatment of the Port Royal grammarians and of Locke that have appeared in the linguistic literature. Chomsky claims in Cartesian Linguistics that Cartesian rationalism gave birth to a linguistic theory like transformational grammar in its essential respects. He bases his claims on the Grammaire Générale et Raisonée by Antoine Arnauld (a disciple of Descartes') and Claude Lancelot (a language teacher), published in 1660. The Grammaire Générale followed a series of other grammars by Lancelot, the most extensive being his Latin grammar.

Chomsky appears not to have read this Latin grammar (an English translation of which was in Widener Library) but Robin Lakoff studied it and published her findings [R. Lakoff 1969]. She discovered that in the introduction Lancelot credited all of his interesting findings to Sanctius [...]. In short, what Chomsky called Cartesian linguistics had nothing whatever to do with Descartes, but came directly from an earlier Spanish tradition. Equally inconsistent with Chomsky's claims is the fact that the theories of Sanctius and the Port Royal grammarians differ from the theory of transformational grammar in a crucial way. They do not acknowledge the existence of a syntactic deep structure in Chomsky's sense, but assume throughout that syntax is based on meaning and thought. Chomsky has steadfastly opposed this position from his earliest works straight through to his most recent writings. (G. Lakoff 1973)

Lakoff was here doing more here than questioning Chomsky's historical knowledge and interpretations. The last two sentences portray Chomsky's Cartesians as forerunners of generative semantics, the approach based precisely on that belief "that syntax is based on meaning and thought" which "Chomsky has steadfastly opposed". It is a hard blow indeed to be told that your own grandparents are working for the enemy.

Chomsky's (1973) reply to Lakoff's letter took aim at a discrepancy between the conclusions drawn by the two Lakoffs, with Robin basically endorsing the Cartesian framework and George discrediting it. He chastised them both for failing to mention the footnote to the introduction of Cartesian Linguistics which stated that

Apart from its Cartesian origins, the Port-Royal theory of language [...] can be traced to scholastic and renaissance grammar; in particular, to the theory of ellipsis and 'ideal types' that reached its fullest development in Sanctius's Minerva (1587). (Chomsky 1966: 97, n. 67)

Chomsky insisted further that his views on language had been distorted by George Lakoff. But he did not address the charge that his claimed link with the 17th century was spurious. Ostensibly the misrepresentation of his views removed any need for this, 
yet it is striking all the same that, from this point forward, he would not develop the 'Cartesian' connection further. With Language and Mind (1968) the emphasis began shifting toward David Hume (1711-1776), who would come to be Chomsky's most frequent reference by the time of Reflections on Language (1975), as Humboldt retreated to the background. The allegiance to his 'Cartesians' was never given up, however. They never became the target of Chomsky's criticism.

By now the atavistic revolution was over, in the sense that Chomsky was no longer focussed on developing historical links. Victory had been achieved over the Bloomfieldian generation, now retired and starting to die off. Despite the competition from generative semanticists and other rivals, Chomsky himself was becoming the ultimate authority on linguistics - and a more run-of-the-mill modernist on the rhetorical level. For example, when Saussure resurfaces at a couple of points in Language and Mind (1968; see Joseph 2002: 152), it is in the standard pattern of invoking his authority by calling him "the great Swiss linguist", then creating ironic distance by showing how Saussure supposedly limited linguistics to segmentation and classification (p. 17). From this point on, Chomsky's discussions of earlier linguists tend increasingly to treat them as historical figures, not timeless intellectual contemporaries.

We can never know for certain whether the success of Chomsky's programme would have been diminished if his enemies had not done him the service of discrediting the historical framework he had worked so hard to construct. It was, however, a crucial part of the economy of his dreams, something that bought him credibility in an early phase of his career when he needed it desperately. Had the framework endured in a more robust form, it might have limited his claims, or rather those made on his behalf, to be the most original, the most 'revolutionary' linguistic thinker of the 20th century. By undoing it, his opponents brought about the equivalent of financial deregulation. For half a century one linguist's dreams would know no limits beyond those he imposed on himself.

\section{Conclusion}

Chomsky's atavistic revolution was revolutionary in more than its approach to language. It broke all the rules in terms of the stance one could take toward intellectual predecessors in the wake of modernism. It showed how "a deliberate break with classical and traditional forms or methods" could be brought about, not by ignoring traditional methods, or taking an ironic distance from them, but reinterpreting them with a greater time depth. The ultimate irony lies in how Chomsky's opponents forced an ironic distance on him, turning him into a mere garden-variety modernist - and by so doing, helped to guarantee the success of his generativist programme. 
The broader question of whether Chomsky brought about a revolution in linguistics may, as I said at the outset, be a matter of semantics. 'Atavistic modernism' offers a possible alternative for those who want to stay unambiguously neutral by avoiding any endorsement that 'revolution' may seem to them to imply. But that Chomsky revolutionised the rhetoric of the field is an observation which I doubt even Koerner would dispute, though he does not believe, as I do, that revolutions are rhetorical first and foremost. While this paper has done no more than scratch the surface where Chomsky's rhetoric is concerned, I hope to have pointed the way toward what should be, in the decades ahead, a three-faceted project for the history of modern linguistics, as we strive to understand the sources of Chomsky's linguistics, the verbal means through which he manufactured consent among a critical mass of linguists, and the complex reception of his work, so complex in fact that enemies could end up as unwitting collaborators.

\section{References}

Aarsleff, Hans. 1967. The study of language in England, 1780-1860. Princeton, N.J.: Princeton University Press.

Aarsleff, Hans. 1970. “The History of Linguistics and Professor Chomsky”. Language: Journal of the Linguistic Society of America 46: 3. 570-585.

Alter, Stephen G. 2005. William Dwight Whitney and the science of language. Baltimore, Md.: Johns Hopkins University Press.

Barsky, Robert F. 1997. Noam Chomsky : a life of dissent. Toronto: ECW Press.

Bloomfield, Leonard. 1924. "Rev. of Saussure (1922 [1916])". Modern Language Journal 8. 317-319. Bloomfield, Leonard. 1933. Language. New York: H. Holt \& Company.

Campbell, George. 1776. The philosophy of rhetoric. London: W. Strahan.

Chomsky, Noam. 1964. “The Logical Basis of Linguistic Theory”. Preprints of Papers from the Ninth International Congress of Linguists, 27-31 August 1962, 509-574. Cambridge, Mass. Chomsky, Noam. 1964. Current issues in linguistic theory. The Hague: Mouton.

Chomsky, Noam. 1965. Aspects of the theory of syntax. Cambridge: M.I.T. Press.

Chomsky, Noam. 1966. Cartesian linguistics: a chapter in the history of rationalist thought. New York: Harper \& Row.

Chomsky, Noam. 1968. Language and mind. New York: Harcourt Brace \& World.

Chomsky, Noam. 1973. "In response to "Deep language"” [July 19, 1973]. The New York Review of Books.

Chomsky, Noam. 1975. Reflections on language. New York: Pantheon Books.

Corder, S.P. 1967. “The Significance of Learners' Errors”. International Review of Applied Linguistics 5. 161-170.

Cowan, J Milton. 1987. “The Whimsical Bloomfield”. Historiographia Linguistica 14. 23-37.

Cram, David. 2007. "Shelf Life and Time Horizons in the Historiography of Linguistics". Historiographia Linguistica 34: 2/3. 189-212.

Falk, Julia S. 2005. “Review of Chomsky (2002 [1966])”. Language 81. 774-775. 
Gass, Susan, Catherine Fleck, Nevin Leder \& Ildiko Svetics. 1998. "Ahistoricity Revisited: Does SLA Have a History?" Studies in Second Language Acquisition 20: 3. 407-421.

Gleason, Henry A. 1955. An introduction to descriptive linguistics. New York: Holt.

Hockett, Charles F. 1958. A course in modern linguistics. New York: Macmillan.

Humboldt, Wilhelm von. 1836. Über die Verschiedenheit des menschlichen Sprachbaues und ihren Einfluss auf die geistige Entwickelung des Menschengeschlechts. Berlin: Königl. (English transl., On Language: On the diversity of human language construction and its influence on the mental development of mankind, by Peter Heath, with preface by Hans Aarsleff, Cambridge: Cambridge University Press, 1988; 2nd ed., with preface by Michael Losonsky, Cambridge: Cambridge University Press, 1999).

Joseph, John E. 1991. “Review of Koerner (1989)”. Word 42. 216-219.

Joseph, John E. 1995. “The Structure of Linguistic Revolutions”. Historiographia Linguistica: International Journal for the History of the Language Sciences/Revue Internationale pour l'Histoire 12: 3. 379-399.

Joseph, John E. 2002. From Whitney to Chomsky : essays in the history of American linguistics. Amsterdam/Philadelphia, PA: John Benjamins.

Koerner, E.F.K. 1983. “The Chomskyan 'Revolution' and Its Historiography: A Few Critical Remarks". Language \& Communication 3: 2. 147-169.

Koerner, E.F.K. 1989. Practicing linguistic historiography : selected essays. Amsterdam/Philadelphia: John Benjamins.

Koerner, E.F.K. 2002. Toward a history of American linguistics. London ; New York: Routledge.

Koerner, E.F.K., Matsuji Tajima (with the collaboration of Carlos P. Otero). 1986. Noam Chomsky: a personal bibliography, 1951-1986. Amsterdam/Philadelphia: John Benjamins.

Krashen, Stephen D. 1981. Second language acquisition and second language learning. Oxford; New York: Pergamon Press.

Kuhn, Thomas S. 1962. The structure of scientific revolutions. Chicago: University of Chicago Press. Lakoff, George. 1973. "Deep language” [February 8, 1973]. The New York Review of Books.

Lakoff, Robin. 1969. "Review of Grammaire generale et raisonnee, ou La grammaire du Port Royal. (By C. Lancelot \& A. Arnauld.) Ed. Herbert H. Brekle. 2 vols. Stuttgart-Bad Cannstatt, Friedrick Fromann Verlag. 1966". Language: Journal of the Linguistic Society of America 45. 343-364.

Paul, Hermann. 1880. Principien der Sprachgeschichte. Halle: Max Niemeyer.

Salmon, Vivian 1969. "Review of Cartesian Linguistics (Chomsky 1966)”. Journal of Linguistics 5. 165-187.

Sanctius Brocensis, Franciscus [Francisco Sanchez de las Brozas]. 1587. Minerva, seu de causis linguae latinae. Salamanca: Joannes \& Andreas Renaut Fratres.

Sapir, Edward. 1907. "Herder's Ursprung der Sprache”. Modern Philology: A Journal Devoted to Research in Medieval and Modern Literature 5: 1. 109-142.

Sapir, Edward. 1921. Language, an introduction to the study of speech. New York: Harcourt Brace \& company.

Saussure, Ferdinand de. 1879. Mémoire sur le système primitif des voyelles dans les langues indoeuropéennes. Leipsick: B.G. Teubner.

Saussure, Ferdinand de, Charles Bally, Albert Sechehaye \& Albert Riedlinger. 1916. Cours de linguistique générale. Paris: Payot.

Searle, John R. 1972. "Chomsky's revolution in linguistics" [June 29, 1972]. The New York Review of Books. 
Sorace, Antonella \& Daniel Robertson. 2001. "Measuring Development and Ultimate Attainment in Non-native Grammars". Experimenting with Uncertainty: Essays in honour of Alan Davies, ed. by C. Elder et al. 264-274. Cambridge: Cambridge University Press \& University of Cambridge Local Examinations Syndicate.

Thomas, Margaret. 1998. "Programmatic Ahistoricity in Second Language Acquisition Theory". Studies in Second Language Acquisition 20: 3. 387-405.

Whitney, William Dwight. 1867. Language, and the study of language. Twelve lectures on the principles of linguistic science. New York: C. Scribner \& Company.

Whitney, William Dwight. 1875. The life and growth of language. London: King. 


\title{
The equivocation of form and notation in generative grammar
}

\author{
Christopher Beedham \\ Department of German, University of St Andrews
}

Generative grammar is a misguided approach which makes two interrelated errors. Firstly, the generativists seem to believe that you can do science by assumption or postulation alone; the assumptions are never tested, because that is not the point. Secondly, the generativists seem to believe that notations are forms. They 'formalize' their assumptions in a notation, in the belief that by doing so they are producing formal theories which are scientific and explanatory. In fact, all they are doing is expressing the figments of their imagination in their own ad hoc notation, thus engaging in a process which is pseudo-scientific and trivial.

The above critique is illustrated by the passive in English. It is shown that various problems raised by a voice analysis of the passive - deriving passives from an underlying active - are explained by analysing the passive as an aspect. Both these descriptive accounts of the passive are shown to be formal and explanatory, with notation and generative style assumptions playing no role in them whatsoever. Three generative accounts of the passive are then presented, all of which formalise the voice analysis, each with its own idiosyncratic assumptions, each with its own ad hoc notation, a notation consisting of symbols borrowed from mathematics, computer science, and logic, combined with a mixture of abbreviations, mnemonics, and drawings. It is argued that the generative accounts are notational variants of the voice analysis, an analysis which has been shown to be incorrect. It is further argued that the way to correct the voice analysis is not to construct 'formal models', but to seek a solution within descriptive linguistics, of which the aspect analysis is an example.

The paper concludes with a brief mention of 'the method of lexical exceptions' as an example of a reinvigorated data oriented, descriptive and Saussurean linguistics.

\section{Introduction}

In generative grammar the linguist constructs a formal model which explains, it is claimed, why some sentences of a language are grammatical and others not, how sentences mean what they mean, and how children acquire their first language so quickly 
and so easily. Generative grammar began with the publication of Chomsky 1957 and still exerts a fundamental influence on theoretical linguistics today (see Chomsky 1995, 1986; Martin et al. (eds.) 2000; Bresnan 2001; Radford 2004; Sag et al. 2003; Lyons 1991; Gazdar et al. 1985). And yet it is highly controversial, evoking a huge amount of criticism and censure, especially in its early days (see Gross 1979; Lamb 1967; Hall 1987; Putnam 1967; Harman (ed.) 1982; Bolinger 1960; Robinson 1975; Hammarström 1971; Beedham 2005: 61-105). ${ }^{1}$ But what exactly is wrong with generative grammar? The answer, in a nutshell, is that the generativists confuse form and notation. There are two fundamental errors in the generative method. Firstly, generativists seem to believe that the mere act of assuming or postulating something makes it real. Secondly, they seem to believe that the notations in which they express their assumptions are formal both in the natural language sense and the mathematical sense. Hence their theories purport to be formal explanations of language structure, and when you add the innateness hypothesis to the mixture, they even purport to be models of the mind. The truth is that they are nothing of the sort. In this paper, to see why, we will examine the passive construction in English. It is well recognised that the passive played and continues to play a major role in the development of generative grammar, so it is a good construction to put to the test. We will look at some descriptive (i.e. non-generative) accounts of the passive, then some generative accounts. We will then compare the two types of explanation, to see how they differ and how they are similar, and where the generative accounts go wrong.

\section{Linguistics and language teaching}

Before we begin let me just say briefly where the origins to my descriptive approach to linguistics lie. I am first and foremost a language teacher, a foreign language teacher, a German teacher, and it is from the insights gained in learning and teaching a foreign language that my interest in grammar arose. A consequence of this is that my grammatical analyses are both theoretical and practical at the same time. They are theoretical because grammar is by its very nature a theoretical subject, ${ }^{2}$ and they are practical because the ultimate test of whether they are valid or not is whether they are taken up by pedagogical grammarians and incorporated into their grammars and language

1. For two very different accounts of the history of generative grammar see Koerner 2002 and Newmeyer 1986.

2. Grammar is concerned with theoretical notions such as sentence, verb, subject etc., notions which apply to all actually occurring verbs and subjects etc. in actual texts (spoken or written). 
courses for students. To say that pedagogical grammars are useful to theoretical linguists is an understatement. A pedagogical grammar is a wonderful thing, because what it is is a summary of all the scientific knowledge we have about a particular language, expressed in a way which students can understand. And it does all this as a by-product of its main purpose, without intending to, without realising it, and without caring about it. All the more useful is it, that way.

Of course, the question needs to be asked, what scientific knowledge? What counts as knowledge here? And that is the point. The writers of pedagogical grammars pick and choose from what is on offer, and obviously they pick explanations which they think work, and leave out those explanations which they encounter in the theoretical literature but which they think are not valid. In making their choices they have one big motivating factor, and that is, when the student asks, "why does the verb go here," or "why does the adjective have that ending," they want to have an answer. (It goes without saying that it has to be an answer which the students can understand, for which the prerequisite is that the pedagogical grammarian himself understands it). For theoretical-descriptive linguists, pedagogical grammars play a major role both at the start and at the end of our work. They both provide us with problems to solve, when questions arise to which there is no answer, neither in theoretical works nor in pedagogical grammars; and pedagogical grammars confirm that the problem has been solved when they incorporate an answer proposed by a theoretician. One of the indications that there is something wrong with the generative approach is that generative grammar has no relevance for or applicability to language teaching (Lamandella 1969).

\section{The passive in English}

\subsection{Two descriptive accounts of the passive}

We will look here at the passive in English, because generative grammar arose and continues to exist primarily on the basis of English. We will focus on the actional passive, and not touch upon the statal passive. The passive in English is formed with be + V-ed, as exemplified in 1 below:

(1) The room was painted by my wife.

That much is data. ${ }^{3}$ Let us move now to theory. Firstly, we need to know what be $+\mathrm{V}$-ed means. In attempting to answer that question a rather unusual feature of the subject of

3. It is data to a sentence-grammarian, though not to a corpus linguist. In its purest versions corpus linguistics does not consider the invented sentences of the sentence-grammarian to be data, it only considers attested utterances in real texts (spoken or written) to be data. 
passives becomes immediately apparent. The most common role for subjects is agent, but the subject of passives is patient, i.e. the entity designated by the subject is affected by the action of the verb (Quirk et al. 1985: 741; Fillmore 1968: 25) or created by the action of the verb (Conrad et al. 1975: 193). The problem of the passive is sometimes summarised by asking why the subject of passives serves as the patient. Secondly, we need to know what are the constraints on the occurrence of $b e+\mathrm{V}$-ed, i.e. with which verbs can it appear and from which verbs is it precluded. In other words, what is the syntax of the passive (syntax in the sense of combinatorial possibilities)? ${ }^{4}$ And thirdly, we need to know which grammatical category the passive belongs to, i.e. is it a tense, voice, mood, aspect, etc.

Let us start with some descriptive answers to those questions, before we look at some generative answers. The first descriptive answer we will look at is the traditional voice analysis of the passive, i.e. the practice of deriving passives from an underlying active (see Quirk et al. 1985: 159-171). For as long as anyone can remember grammarians have proposed that passives have a meaning roughly equivalent to what has come to be called 'an underlying active.' The underlying active of 1 would be 2:

(2) My wife painted the room.

There is a difference of theme/rheme organisation between the two sentences - in 1 the room is theme, whereas in 2 my wife is theme - but in essence the two sentences are synonymous, according to this account. Moreover, this ancient analysis explains why the subject of passives is patient by proposing that we derive a passive from its underlying active. Taking the derivation of 1 from 2 as an example, the subject my wife in 2 is demoted to the object of $b y$, the object the room in 2 is promoted to subject, be $+\mathrm{V}$-ed is introduced, and $b y$ is introduced. It is now clear why the subject of passives is patient. Usually the patient of a sentence is the grammatical object. The reason why in passives the thing designated by the subject is patient is that it started out as an object, in the underlying active. When it arrives as subject of the passive it retains the meaning it had when it was object in the underlying active, i.e. patient. The verb is said to have two 'voices', the active voice and the passive voice, and we call this account of the passive 'the voice analysis'.

4. The term syntax has three meanings in linguistics: (i) word order; (ii) combinatorial possibilities; (iii) a synonym for generative grammar. In the present paper we use the term syntax mostly in the second meaning, combinatorial possibilities, unless indicated otherwise. Syntax as combinatorial possibilities is equivalent to the structuralist tenet that a language is a system whose elements are determined by their place in the system. Here we have a particularly awkward and ironic example of the often-commented upon phenomonen of 'systematic ambiguity' in Chomsky's writings and in generative grammar. 
As regards constraints on the occurrence of the passive, in other words the syntax in the sense of combinatorial possibilities of the passive, the voice analysis says that all and only transitive ${ }^{5}$ verbs can form a passive. Transitivity as the criterion for passivizability follows from the decision to derive passives from an underlying active, during which process the object of the active becomes subject of the passive. Obviously, for that to happen there has to be an object in the first place.

Regarding which grammatical category the passive belongs to, as the name implies according to the voice analysis the passive belongs to the category 'voice.' This again follows from the decision to derive passives from the active. The category voice and the term 'active' are both designed specifically to cater for the passive, i.e. for the form $b e+\mathrm{V}$-ed. Transitive verbs are said to have two voices, the active and the passive (Quirk et al. 1985: 162).

The second descriptive analysis we will examine is the analysis of the passive as an aspect of the verb, not a voice of the verb. In order to do that we will first adumbrate some problems which arise from the voice analysis of the passive. The most striking problem is that there are five formal differences between actives and passives, and yet they are supposed to be (cognitively) synonymous. The differences are that the subjects appear in different places in the sentence, as do the objects, two extra words, $b e$ and $b y$, are introduced, and the verb changes from finite to non-finite, the 2nd participle. The notion that those five big formal differences can happen with no effect on meaning is contrary to common sense, not to mention structuralism, in which the bilateral sign, consisting of signifiant (form) and signifié (meaning), is indivisible, i.e. there can be no difference in form without a difference in meaning (Saussure 1983; Tobin 1990; Bolinger 1977). The five formal differences between actives and passives suggest that there must also be a difference in meaning between the active and the passive, a semantic difference more substantial than merely a theme/rheme difference.

Another problem for the voice analysis of the passive is that some transitive verbs cannot (easily) form a passive, e.g. to resemble:

(3) a. The current banking crisis resembles the Wall Street Crash of 1929.

b. ${ }^{\star}$ The Wall Street Crash of 1929 is resembled by the current banking crisis.

5. A transitive verb is followed by an object. In languages with a case system there is a narrow definition of transitive verb which covers objects in the accusative case only, and a broad definition which incorporates objects in other oblique cases, e.g. dative, genitive. For some linguists a verb has to be passivizable to be transitive, e.g. phrasal verbs in English which can form a passive may be said to be transitive (because they form a passive). This is fine if you are only discussing transitivity, not the passive, but it leads to circularity if you are trying to understand the passive in terms of its relationship with transitivity: only transitive verbs form a passive; but how do you know if a verb is transitive?; because it forms a passive. See Hopper and Thompson 1980. 
Such verbs are commonly listed, but the voice analysis is unable to provide an explanation as to why they do not form a passive. The problem is compounded by the fact that some tinkering with a sentence can often render an ungrammatical passive grammatical, and even the classic non-passivizable transitive verb to resemble can be made to passivize:

(4) Mary isn't resembled by any of her children.

(Halliday 1967: 68, quoted in Huddleston 1971: 94)

Once again, the voice analysis cannot say why this is so.

The final problem to be mentioned here is that the voice analysis has to come up with a whole new grammatical category, 'voice' (and 'active'), to treat the passive, be $+\mathrm{V}$-ed. In other words, the passive, the construction $b e+\mathrm{V}-e d$, is not put into relation with any other part of the grammar, it stands alone, isolated. Be as the passive auxiliary is a unique element in the grammar, and V-ed as the passive participle is also a unique element in the grammar. Once again, this is contrary to structuralism. According to structuralism a language is 'un système où tout se tient', a system where everything hangs together (Meillet 1893:318-319). ${ }^{6}$ If everything is connected, why is the passive, with its be and $\mathrm{V}$-ed, not connected to the rest of the grammar? Clearly, if an analysis were found which used only already existing categories in a language, i.e. which established links between the passive, $b e+\mathrm{V}-e d$, and other parts of the grammar without the need to postulate new parts, that analysis would be preferred. ${ }^{7}$

There is such an analysis, and that is the analysis of the passive as an aspect (Beedham 2005: 33-60). According to this account the passive, $b e+\mathrm{V}-e d$, is an aspect of the type Auxiliary + Participle, like the perfect, have + V-ed, and the progressive, be + V-ing, in English. The meaning of $b e+\mathrm{V}$-ed is that it expresses an action and the state which ensues from that action, i.e. it means 'action + state. ${ }^{8}$ In the meaning 'action + state' the

6. On the history of this famous quotation see Koerner 1999.

7. We will add two more problems associated with the voice analysis, one from German and one from Russian. German is capable of forming a passive from an intransitive verb, e.g. Es wurde getanzt lit. it was danced 'there was dancing'. Such passive sentences should not exist, because there is no object in a mooted underlying active to become the subject, and indeed they have no subject (es is a place-filler here, not a subject). But in German they do exist. How is it possible?

In Russian there is a constraint which is well-known but which under the voice analysis has no explanation. Russian has two constructions traditionally called passive: byt' 'to be' + passive participle, and a reflexive construction with -sja 'self'. The byt'-passive is restricted on the whole to the perfective verb, the reflexive passive to the imperfective verb. The question is, why?

8. The theoretical background to this paper is Saussurean structuralism (Saussure 1983, 1972; Koerner 1973; Joseph (Ed.) forthcoming, Sanders (Ed.) 2004; Helbig 1983: 33-45). 
entity designated by the subject of the passive is affected or created by the action of the verb, i.e. it is semantically speaking patient (Poupynin 1996: 133; Abraham 2000: 151). The syntax (in the sense of combinatorial possibilities) of the passive is that to form a passive a verb has to be telic, i.e. it has to have a built in end-point, capable of becoming the state part of the meaning 'action + state'. Atelic verbs do not form a passive, because they do not have an end-point in their semantics which can become the end-state of the meaning 'action + state'.

The aspect analysis of the passive explains the three above-mentioned problems caused by the voice analysis. Firstly, the reason for the formal discrepancy between the passive and the active is that there is a semantic discrepancy, i.e. passive and active are not synonymous, viz. whilst the active expresses only an action the passive expresses an action and the state which follows from that action. Secondly, non-passivizable transitive verbs are atelic, i.e. they lack an inherent end-point in their semantics which could become the state part of the meaning 'action + state' of the passive. Evidence in support of this view is provided by the resultative perfect. The resultative perfect in English is a variant of the perfect which expresses an action and the result which emerges from that action, as seen in 5:

(5) She has broken the doll.

In 5 an action is carried out whose result is that the doll is now broken. The result ensuing from a resultative perfect can often by expressed by a statal passive in the present tense, as here, 'the doll is (now) broken' (Leech 1971). To be interpreted as a resultative perfect a verb needs to be telic, as just mentioned for the passive, i.e. it needs to have an inherent potential end-point in its meaning which can become the result part of the meaning 'action + result'. The verb to break in English has that potential end-point in its meaning, and consequently lends itself to a resultative interpretation in the perfect. A verb like to live, in contrast, is atelic, it does not embody an end-point, and hence in a perfect will be interpreted as a continuous perfect, as shown in 6:

(6) I have lived in Scotland for 25 years.

Here the implication is 'and I continue to live in Scotland': it is a continuous perfect, not a resultative perfect. It could not be interpreted to mean something like 'I lived in Scotland with the result that Scotland is now lived in (by me).' That would not make sense.

Although Saussure does not say this (John Joseph, personal communication), a consequence of structuralism in my view is that form determines meaning. In the context of our current discussion, then, the voice analysis of the passive creates the meaning of synonymy with the active, whilst the aspect analysis of the passive creates the meaning 'action + state. On the relationship between language and reality see Beedham 2009. 
Given the similarity in meaning between the actional passive - 'action + state' and the resultative perfect - 'action + result' - and their identical syntactic behaviour, viz. they each require a telic verb, one would expect that they are precluded from the same verbs. And that does indeed turn out to be largely the case. In research carried out in Leipzig from 1976-1978 I used dictionaries and native-speaker informants to identify all the non-passivizable transitive verbs of English and German and tested them for their ability to form a resultative perfect. It was found that approximately two-thirds of the non-passivizable transitive verbs in each language also did not form a resultative perfect (Beedham 1982: 59-74, 92-113). Furthermore, it was found that amongst the one-third of verbs which did not fit the correlation, there was invariably something special about their lexical semantics which caused them to behave differently from the two-thirds majority. Our verb to resemble is a verb which fits the correlation, i.e. it forms neither a passive - see 3 above - nor a resultative perfect - see 7 below:

(7) The current banking crisis has resembled the Wall Street Crash of 1929.

Sentence 7 cannot be interpreted as a resultative perfect, to mean something like some resembling went on which led to a particular result, viz. the Wall Street Crash is now resembled (by something). That would make no sense whatsoever. It could be interpreted as a different kind of perfect, e.g. as an experiential perfect - at some point in the past the current banking crisis resembled the Wall Street Crash of 1929 - but not as a resultative perfect.

It is accepted in linguistics that the perfect in English is an aspect of the type Auxiliary + Participle. It is also now accepted that Auxiliary + Participle aspects react to the lexical aspect of a verb, e.g. in British English the progressive is incompatible with stative verbs: He knows the answer but ${ }^{*}$ He is knowing the answer (Palmer 1974: 70-77). What we are seeing here is that the passive behaves like the perfect: it is sensitive to lexical aspect, like the perfect, and indeed needs the same lexical aspect as the resultative perfect needs, viz. telic, for it to work. The fact that the passive behaves syntactically like the perfect is the most telling evidence in support of the view that the passive belongs to the same category as the perfect, viz. Auxiliary + Participle aspect. Furthermore, the passive is sensitive to the same lexical aspect as the resultative perfect because the two constructions are so similar in meaning: 'action + state' and 'action + result'. Note also the morphological similarity between the passive and the perfect: be $+\mathrm{V}$-ed and have $+\mathrm{V}$-ed. The passive and the perfect are morphologically similar, semantically similar, and syntactically similar; therefore we can say that the passive, like the perfect, is an aspect of the type Auxiliary + Participle.

The other part of the non-passivizable transitive verb problem, the fact that the passivizability of a verb varies from sentence to sentence, also receives a clear explanation from the recognition that the passive is an aspect, and the explanation is that aspect is 
compositional (Verkuyl 1972, 1993). The aspect of a sentence is not determined by the verb alone, but by other elements in the sentence as well: the subject, the object, and adverbials. If the passive is an aspect it is therefore entirely natural that its possibility of occurrence is determined by the type of subject, object of by, and adverbials with which it occurs. There are several elements in sentence 4, our rare example of a passivized to resemble, which are well known for influencing aspect: in particular negation and indefiniteness. They influence passivizability because the passive is an aspect of the verb, not a voice of the verb. The syntax of the passive is determined by lexical and compositional aspect, not by transitivity. ${ }^{9}$

The third problem of the voice analysis discussed above was that the voice analysis proposes a whole new category, 'voice' (including 'active'), just to deal with the passive, $b e+\mathrm{V}$-ed. It does not link be $+\mathrm{V}$-ed in with anything else in the grammar. We have already said enough to show that the aspect analysis does link the passive, be $+\mathrm{V}$-ed, to other parts of the grammar: it lives up to the aspiration of language as a 'système où tout se tient'. It uses categories and phenomena which are already there in the grammar and quite well known. English has two recognised aspects of the type Auxiliary + Participle, the perfect and the progressive, and we add the passive to that already established grammatical category:

$\begin{array}{ll}\text { Perfect: } & \text { have }+\mathrm{V} \text {-ed } \\ \text { Progressive: } & \text { be }+\mathrm{V} \text {-ing } \\ \text { Passive: } & \text { be }+\mathrm{V} \text {-ed }\end{array}$

The morpheme be of the passive is already there in the progressive, and the morpheme V-ed of the passive is already there in the perfect. The processes needed to explain the passive, viz. the sensitivity of Auxiliary + Participle aspects to lexical and compositional aspect, are already there in the grammar. This is 'syntactic generalization', 'minimalism', and 'formal' in a real and practical sense, as opposed to catch-phrases of generative grammar. ${ }^{10}$

9. Transitivity is relevant in that it affects compositional aspect, but only in that sense is transitivity relevant to the passive.

10. The explanations to the problems of German and Russian mentioned in fn. 7 are as follows. The German intransitive verb tanzen 'to dance' can form a passive, Es wurde getanzt, because passivizability is determined by lexical/compositional aspect, not by transitivity. The sentence Es wurde getanzt must have a compositional aspect which is compatible with the German passive. I cannot say yet precisely what that aspect is, but what one can see and say immediately is that sentences of this type in German always involve intensity - Es wurde laut gesungen 'there was loud singing', Es wurde viel gelacht 'there was much laughter' - and intensity is a nuance which crops up frequently in studies of aspect. Once again an aspectual factor is seen to be at work on the passive, corroborating the view that the passive is an aspect (Beedham 1987). 
Thus we see that out of the two descriptive accounts of the passive which we have examined, the voice analysis raises a host of questions and problems, which are answered and solved by the aspect analysis. We therefore conclude that the passive, be $+\mathrm{V}-e d$, is an aspect of the verb, not a voice of the verb.

Before we move on let us first clarify what counts as 'formal' in descriptive linguistics. Form in the descriptive sense is based on contrast in a substance. The substance of language is sound. The contrasts you get are of two kinds. There is contrast in the order of sounds - John hit Bill as opposed to Bill hit John - this is syntactic form (syntax in the sense of word order); and there is contrast in the phonological shape of a sound Latin dominus (Nom.) 'master' versus dominum (Acc.) - this is morphological form. To give an example, the subject of a sentence can be defined formally or semantically. Formally, the subject in an SVO language is the noun phrase occupying the first position in the stylistically neutral sentence. Semantically, the subject is usually the agent or performer of the action expressed by the verb. Notice that the definition of form here, in descriptive grammar, does not involve a notation. Notations have nothing to do with the concept of form in descriptive grammar. The notion of form was fundamental to our presentation of both accounts of the passive in descriptive grammar, the voice analysis and the aspect analysis, but we never once needed to rely on a notation.

\subsection{Three generative accounts of the passive}

We are now ready to turn to some generative accounts of the passive in order to elucidate the generativists' confusion of form and notation. We will examine an account of the passive presented in Radford 1997 based on Chomsky's Minimalist programme (Chomsky 1995, 2005), an account of the passive by Joan Bresnan within LexicalFunctional Grammar, and an account of the passive which appeared in the journal Linguistic Inquiry. In generative grammar the semantic roles of noun phrases, i.e. agent, patient, etc., are known as theta roles. In $8 \mathrm{a}$ and $8 \mathrm{~b}$ the noun phrase the students has the same theta role, viz. patient:

(8) a. They arrested the students.

b. The students were arrested.

If the Russian byt'-passive is an aspect of the type Auxiliary + Participle, meaning 'action + state', then the reason why it is compatible with the perfective but not the imperfective aspect is clear. The imperfective aspect views an action from within, whereas the perfective aspect views an action from outside it, with an overview over the whole of it (Wade 1992: 257-312). Thus only the perfective aspect has a view of the result or resulting state of an action. In other words, the perfective aspect is telic, whilst the imperfective aspect is atelic. Therefore only the perfective aspect is capable of expressing the state part of the byt'-passive's 'action + state' meaning (Бидэм 1988; Schoorlemmer 1995). 
According to Radford (1997: 342-343) if we assume that Universal Grammar correlates thematic structure with syntactic structure in a uniform manner, it follows that two noun phrases having the same theta role with respect to a given verb must occupy the same underlying position in the syntax. This assumption is known as the uniform theta assignment hypothesis, or UTAH for short. If we adopt UTAH it follows that passive subjects must originate in the same position as active complements. But if that is so, how does the complement the students in $8 \mathrm{a}$ end up as the subject in $8 \mathrm{~b}$ ? Radford suggests that the noun phrase the students, which in keeping with Minimalism he calls a determiner phrase (DP), is raised in a successive cyclic fashion to become first the subject of the passive participle arrested and then the subject of the auxiliary be, in each case leaving a trace $t$ of itself in its former position behind, as shown in 9 (where TP stands for tense phrase):

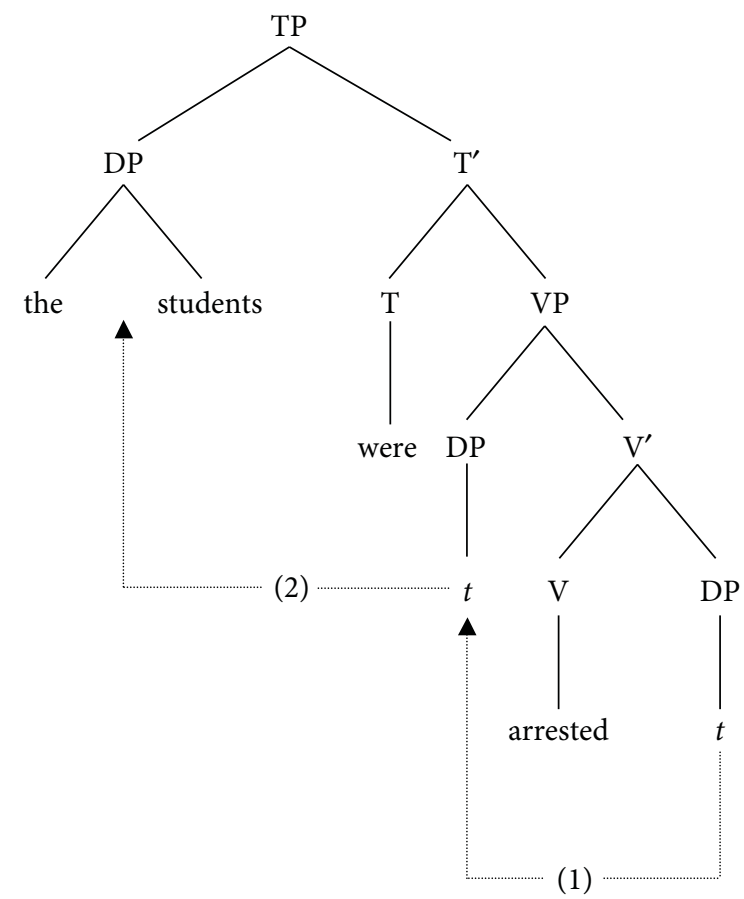

In 9 the students originates as the complement of the passive participle arrested, then undergoes 'passivization', i.e. movement from being complement of arrested to being its subject, leaving a trace $t$ behind in its former position, and finally undergoes 'raising', i.e. movement from being subject of arrested to subject of were, again leaving a trace. This, then, is the formal-syntactic explanation for how the subject of passives is interpreted as patient, not agent. Moreover, the claim is that this formal(ized) structure 
must be in the child's head when the child is born, i.e. the (generative) grammar of language is innate. Furthermore, under Pinker 1994's interpretation the grammar of language (including by implication the formal(ized) structure shown in 9 or its equivalent in other models), is in our genes: it is a human genetic endowment. Generative grammar claims to be a linguistic, mathematical, psychological and now even genetic discipline all at once.

Bresnan 2001 rejects Chomsky's serial and configurational approach in favour of a relational approach in her model, Lexical-Functional Grammar (LFG), whose inception was motivated in large part by dissatisfaction with other generative treatments of the passive. LFG assumes three parallel structures: argument structure (e.g. agent, patient), functional structure (e.g. subject, object), and categorial structure (e.g. noun phrase, verb phrase). All three structures carry equal weight in the grammar: one structure does not serve as a deep structure for the others. Furthermore, there are no movement rules in LFG. Instead it posits relations between structures; the relations between the three structures are made explicit in the model's relational design. The relational design of LFG allows it to handle what the generativists call non-configurational languages, by which they mean highly inflected languages with little syntax in the sense of word order. Bresnan notes that whilst in the active the subject is agent, in the passive the subject is patient, with the agent expressed in an optional prepositional phrase. In Chomsky's configurational design of Universal Grammar, this remapping of roles to functions is carried out by movement rules. In the relational design of Universal Grammar, on the other hand, the remapping is characterized as follows:

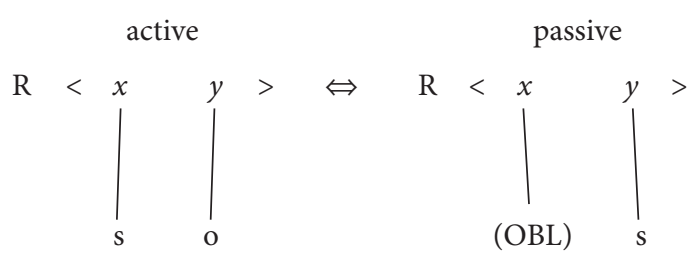

Here the mapping of agent $(\mathrm{x})$ to subject (s) or oblique (OBL) and of patient (y) to object (o) or subject (s) are indicated relationally (R), not by means of transformations and movement rules:

This characterization abstracts away from the language particular realizations of subject, object, and oblique (OBL) relations, which may be configurational or nonconfigurational.

In LFG, relation changes are thus lexical alternations in predicate-function mappings. (Bresnan 2001: 26) 
Now, in Bresnan's model, this is why the subject of passives is interpreted as patient: the grammar contains the relational structure shown in 10. Bresnan (2001:29) gives the analysis shown in 11 and 13 of an active-passive pair of sentences in Malayalam, a non-configurational Dravidian language spoken in southern India, which translate into English as The child worshipped the elephant and The elephant was worshipped by the child:

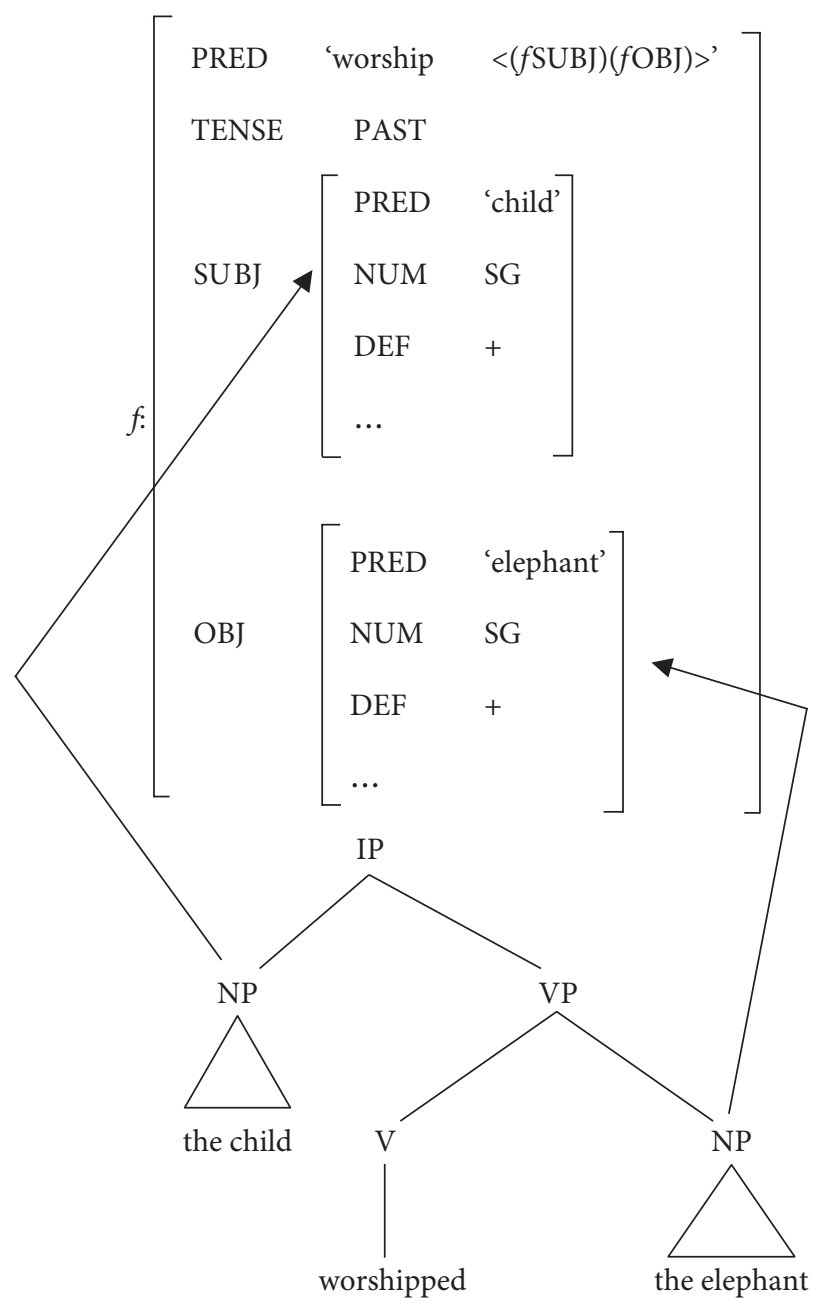

Let us now turn to a generative account of the passive which attempts to treat the crucial problem of non-passivizable transitive verbs, and which will reveal in a particularly clear manner the confusion in the generative method of form and notation. 
Wilkins 1980, following Chomsky's Extended Standard Theory of the time, assumed that passives are derived by a single rule of NP-preposing, given in 12 :

$$
\Delta-\mathrm{V}-\mathrm{NP} \Rightarrow \mathrm{NP}-\mathrm{V}-\varnothing
$$

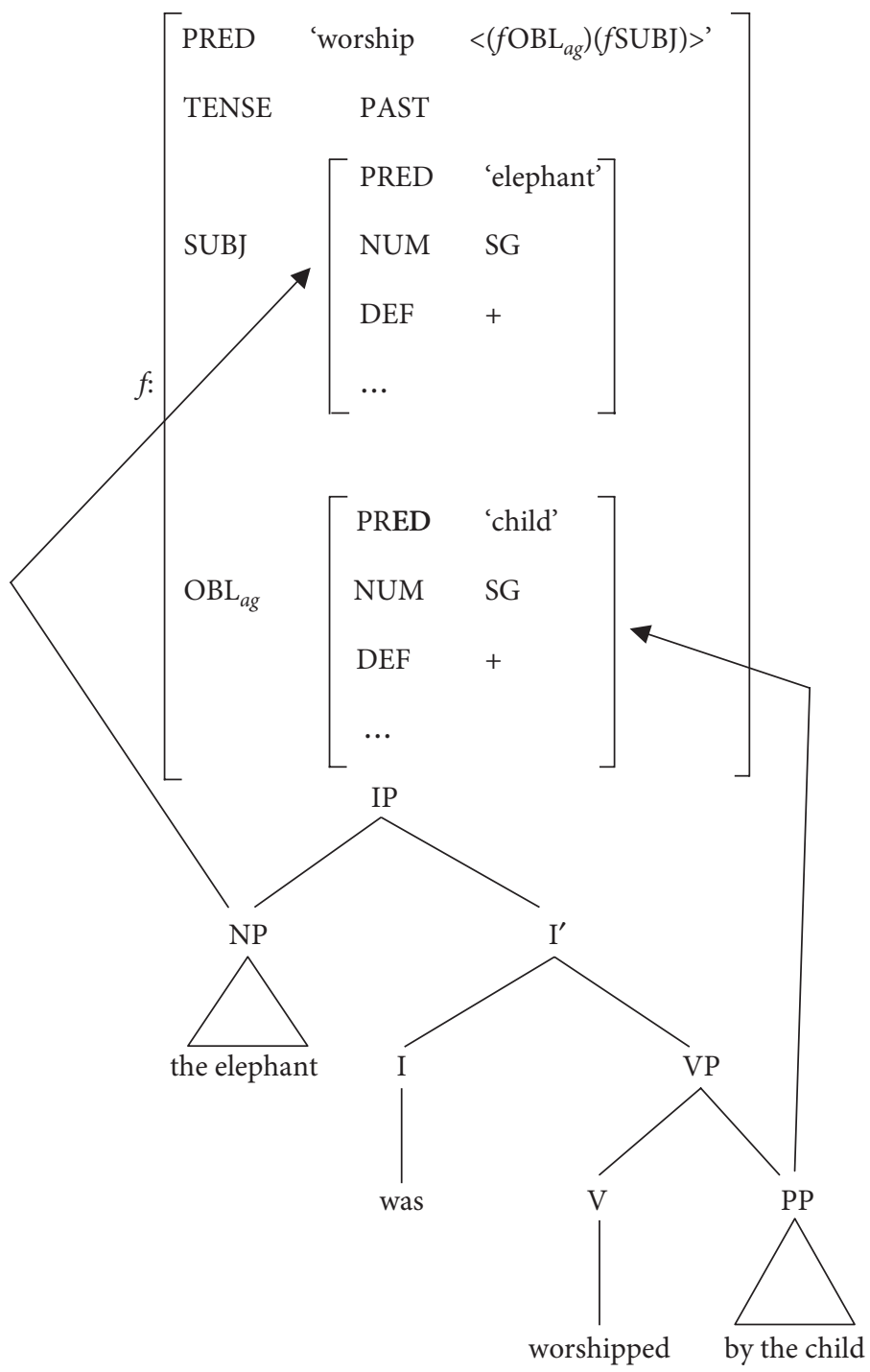

In this account the Greek letter delta $\Delta$ stands for a dummy subject in the active. The object noun phrase in the active is moved to subject position, filling the position provisionally held by $\Delta$. It retains the meaning it had in object position, viz. patient. Now, in this model, this is the explanation for why the subject of passives is patient: it is because the grammar contains the structure shown in 13. Wilkins then takes us a step 
further and tackles the question of how to explain why some verbs which have an object in the active do not allow that object to be preposed, i.e. why some transitive verbs are non-passivizable. Here she proposes that transitive verbs are marked in the lexicon as having an optional subject (i.e. in the active), formalized as in 14:

$$
+(\mathrm{NP})-
$$

The brackets around NP indicate that the subject is optional. Thus the subject of a transitive verb can be demoted to object of by to allow the object to fill the position previously occupied by the original subject. But some verbs have an obligatory subject, formalized as in 15:

$$
+\mathrm{NP}-
$$

The absence of brackets around the NP in 15 indicates that the subject is obligatory, and cannot be moved. These are the non-passivizable transitive verbs. The formal explanation for why some transitive verbs cannot form a passive is this: they are marked in the lexicon as having obligatory subjects which cannot move to make way for a preposed object, as shown in 15 .

\subsection{The descriptive side of generative grammar}

Generative grammar has two sides to it, a descriptive side and a uniquely generative side consisting of assumptions and the formalization of those assumptions. In the above three generative accounts of the passive, the descriptive side to all of them is the derivation of the passive from an underlying active, or 'the active-passive relationship', as the generativists prefer to call it. Thus descriptive grammar and generative grammar do have something in common, viz. descriptive grammar. It is this factor which goes a long way to answering the question: how did we get into this mess? In footnote 4 we spoke of the systematic ambiguity of much of Chomsky's terminology, including one of the very names of generative grammar, the term 'syntax'. Another example is the term 'formal': sometimes generativists use it in the descriptive sense, as presented above in Section 3.1, sometimes in a uniquely generative sense to mean notational. This is what I am calling here the equivocation of form and notation. It is through this double-sided nature of generative grammar, a descriptive side and a uniquely generative side, that many data and descriptively oriented linguists have been misled into thinking that there might be something to the generative approach.

\section{Form and notation in descriptive versus generative grammar}

We have looked at two descriptive accounts of the English passive, and three generative ones. We are treating the passive as a test case for how well the generative method performs, because the passive was a crucial construction in the beginnings of genera- 
tive grammar and still is crucial to it. Let us now look back at the five accounts and examine the role of form and notation in them. First off it is easy to see that all three generative accounts have 'formalized' (to use their terminology) the wrong descriptive analysis. They have all taken the voice analysis as the basis for their models, and indeed it is common practice in generative grammar to refer to the active-passive relationship as 'data', to be explained in a formal model. But we saw in Section 3.1 that the passive, $b e+\mathrm{V}-e d$, is not a voice of the verb, it is an aspect of the verb. Analysing be $+\mathrm{V}$-ed as a voice of the verb raises a long series of problems and contradictions, none of which arise when treating $b e+\mathrm{V}-e d$ as an aspect of the verb, and none of which are solved by recasting the voice analysis in a generative model. We saw in Section 3.1 that the active-passive relationship is theory, not data. The data is the morphological form be $+\mathrm{V}$-ed. How you analyse that data is the theory, whether as a voice (the active-passive relationship), an aspect, or whatever. Descriptive linguistics is itself a theoretical and analytical discipline, putting forward theories and analyses.

But if descriptive linguistics is itself a theoretical discipline, what are the 'theories' of generative grammar? To answer that question let us look more closely at the three accounts presented in Section 3.2. Each account makes different assumptions. The Minimalist account assumes that the subject of passives starts off in underlying structure in object position and is 'raised' twice, each time leaving a trace, to end up as subject in surface structure. The LFG account assumes that semantic roles, grammatical relations and constituent structure are three equally important givens in the grammar, and it is the relations between them that are fundamental and provide explanations. Wilkins' version of Chomsky's Extended Standard Theory assumes a single rule of NP-preposing, and that verbs are marked in the lexicon as having an optional or an obligatory subject.

Furthermore, each account uses its own notation. The Minimalist account uses the tree diagram shown in 9, with upper case letters of the Latin alphabet, arrows to indicate movement, and a lower case letter written in italics. The LFG account uses upper case letters, e.g. $\mathrm{R}$ to indicate a relationship, angled brackets to indicate semantic roles, square brackets on a tree diagram to indicate clusters of morphological properties, and arrows on a tree diagram to indicate which clusters of morphological properties go with which constituents, as shown in 10-12. Wilkins' account uses upper case Latin letters, one Greek letter, one symbol taken from mathematics, a double arrow to indicate 'transformation', and rounded brackets to indicate optional versus obligatory, as shown in 13-15.

We are told by the generativists, or perhaps more accurately it is implied, that by using a notation the method is formal, both in the linguistic sense and the mathematical sense. I have to disagree with that. I would like to meet the mathematician who would agree that by borrowing symbols from mathematics, computer programming languages, and formal logic, and combining them with a mixture of abbreviations mnemonics and 
drawings, you achieve anything that resembles mathematics (see Gross 1979: 874-875; Section 1.2 'The Ascent of the Formalism as Explanation' in Givón 1979: 3-22). And as regards formal in the linguistic sense, we encountered 'formal' frequently in our discussion of the two descriptive accounts of the passive in Section 3.1, without ever using a notation, as mentioned at the end of that section: e.g. the five formal differences between active and passive, the form $b e+\mathrm{V}$-ed, the formal similarity of passive, perfect, and progressive, etc. In descriptive linguistics form is defined as contrast in a substance, as mentioned above at the end of Section 3.1, in which notations have no part to play whatsoever. Chomsky famously dismissed generative semantics as a notational variant of his own theory, but he should realise that any generative grammar is at best a notational variant or reformulation of the descriptive analysis which it embodies, at worst a fairy-tale of formalizations. Wilkins' explanation of non-passivizable transitive verbs is a particularly telling example of the emptiness of the generative rhetoric. We saw above in Section 3.1 that some verbs are transitive yet do not form a passive because they are atelic, and the passive is an aspect which requires a telic verb, i.e. one with a potential end-point capable of becoming the end-state of the passive's meaning 'action + state'. Wilkins' explanation of non-passivizable transitive verbs is that they are marked ' $+\mathrm{NP}-$ ' in the lexicon. The descriptive account is formal, explanatory by any normal understanding of the word 'explain', and accessible to anyone with a modicum of familiarity with grammatical terms and concepts. The generative account, on the other hand, is notational, not formal; and is in no way explanatory, at the very least because it remains oblivious to all the aspectual factors surrounding the passive which were discussed above in Section 3.1; and is accessible to no one except other followers of the faith. ${ }^{11}$

Another good illustration of the way in which generative grammar mistakes notation for form is the practice of some generativists to 'formalize' the notion of agent by writing the English word agent in upper case letters of the Latin alphabet, thus AGENT. Let us be clear about this: to write down on paper the notion of 'agent' as AGENT is not formalization, not mathematics, not explanatory, and not scientific. It is a trivial and eccentric thing to do. The formal side of 'agent' is - to take a formal-syntactic (syntax

11. It is, of course, entirely possible to formalize the aspect analysis of the passive generative-style in a model. But anyone who did that would be missing a crucial inference of the aspect analysis of the passive, viz. that it shows us that the generative practice of 'explaining' the problem of the passive by 'formalizing' it is misguided methodologically. Incidentally, Schoorlemmer 1995 commits two errors in this respect: she formalizes her own aspectual analysis of the Russian passive (whereby I agree with her aspectual analysis (Beedham 1998) but not its formalization (Beedham 2001)); and she advocates both her aspectual analysis and the voice analysis, not realising that her own aspectual analysis explains in itself why the subject of the be-passive is patient, thus rendering the voice analysis otiose. 
in the sense of word order) definition in SVO languages - initial position in the stylistically neutral sentence, as mentioned at the end of Section 3.1 above. The formal side or 'formalization' of the notion agent is not AGENT.

We see here the two pillars of the generative method, assumptions or postulations and the 'formalizing' of those assumptions in a notation. The assumptions are not hypotheses in the scientific sense, since they are never tested empirically. Obviously, we cannot accept the generative version of empirical testing, which is to construct a grammar in order to explain a set of data, and then run the grammar to see if it generates the sentences it was constructed to generate. The assumptions are the mainstay of the method: assume is what generativists do: for generativists, to assume is to explain. Once you have accepted that you can do science by assumption, the number and type of assumptions you can make is endless. One generative grammarian published a book called Thirty Million Theories of Grammar (McCawley 1982) - many a true word spoken in jest. The assumptions are given an appearance of reality, and indeed of higher mathematics and advanced science, by being expressed in a notation. But assumptions are not explanations, and notations are not formal, i.e. the generative method does not lead to formal explanations.

\section{The model-building approach in other sciences}

Linguists are entitled to ask, if the (mathematical) model-building approach does not work in linguistics, does it then also not work in other sciences, notably physics? The answer is that there are scientists in other disciplines, including physics, who reject the mathematical model-building approach in their discipline. I strongly recommend two works on physics and scientific method to linguists, Dingle 1972 and Theocharis and Psimopoulos 1987. You will find there many of the hallmarks of the generative method criticised, though admittedly not all, since in its equivocation of form and notation, generative grammar exceeds even the worst excesses of theoretical physics criticised and warned about in those two works. Dingle says that from the 18th century there has been a movement in science away from data and observation to postulation and hypothesis, until we have reached the point today where physicists assume that everything in mathematics exists in nature. But that is manifestly not the case, says Dingle, who himself used to work in this 'theoretical' way, until he turned against the method. Some mathematical entities and operations exist in nature, i.e. have a counterpart in nature, but others do not. For example, in mathematics $1+1=2$. But in nature it is not always the case that the addition of one object to another object results in two objects. It does if you add one apple to another apple, i.e. you get two apples. But if you add one drop of water to another drop of water you don't get two drops of water you get one (bigger) drop of water. If we add one idea to one idea we may get a philosophy (Dingle 1972: 125). 
In mathematics there are minus numbers but minus objects do not exist; the number pi does not exist in nature, nor does the square root of 3 - these are mathematical abstractions. And yet theoretical physicists construct elegant mathematical models of the universe - those parts of the universe which cannot be examined empirically, such as the origins of the universe or subatomic structure - and assume that their models will by definition, or at least by the methodology used, have a counterpart in nature. In the history of science we have moved, says Dingle, from the observation of nature to the tentative (mathematical) formulation of hypotheses (i.e. a hypothesis might be true) to the belief that any (mathematically formulated) hypothesis must necessarily be true. In linguistics generative grammar commits the same fallacy but takes it further in that it is not really a mathematical discipline, rather it is a notational indiscipline whose adherents believe that their notational models exist in the human mind or even in the human genome. One might say of generative grammar:

By denying truth and reality, the [theoretical approach] reduces science to a pointless, if entertaining game; a meaningless, if exacting, exercise; and a destinationless, if enjoyable, journey. The aim of the game is just to play; the object of the exercise is merely to keep one busy; and the purpose of the journey is but aimless wandering. (Theocharis \& Psimopoulos 1987: 597)

Except that the quotation refers to theoretical physics. The generative method is fallacious, but it is a fallacy which is found right across science today.

\section{The way forward}

\subsection{Data, descriptivism, and structuralism}

Having considered in Section 3.3 how we got into this mess let us conclude by thinking about how we get out of it. Despite its apparent success, generative grammar has been criticised by innumerable people from the outset. And yet the generative approach has survived it all. Why? The answer is because the criticisms were either wrong or did not get to the heart of the matter. One criticism frequently made is of Chomsky's distinction between competence and performance: the argument is made that linguists should study performance, not competence, e.g. texts or speech acts. But the competence-performance distinction is in essence the same as Saussure's langue-parole dichotomy, and (sentence-) grammar (i.e. including the descriptive approach) is by its very nature firmly embedded in langue, albeit supported by studies of parole. Other critics of generative grammar have concentrated their attacks on the innateness hypothesis, i.e. the claim that a generative grammar is innate to the human species and that children are born with a generative grammar already in the brain. But the innateness hypothesis was added later to the generative enterprise, in Chomsky 1959 and 1962, some years after the method 
itself - the construction of mathematical models to explain the structure and semantics of sentences - was established in Chomsky 1955 and 1957. One prominent group of generativists within computational linguistics who rejected the innateness hypothesis whilst using the Chomskyan method wrote very forcefully about this:

In view of the fact that the packaging and public relations of much recent linguistic theory involves constant reference to questions of psychology, particularly in association with language acquisition, it is appropriate for us to make a few remarks about the connections between the claims we make and issues in the psychology of language. We make no claims ... that our grammatical theory is eo ipso a psychological theory. ... Our general linguistic theory is not a theory of how a child abstracts from the surrounding hubbub of linguistic and nonlinguistic noises enough evidence to gain a mental grasp of the structure of a natural language. Nor is it a biological theory of the structure of an as-yet-unidentified mental organ. (Gazdar et al. 1985: 5)

The innateness hypothesis is a red herring as regards the erroneous nature of generative grammar.

The core of the generative method is the belief that one can do science by assumption alone, together with the equivocation of form and notation. It is on these two elements of the Chomskyan approach that we should concentrate, in order to bring out the error of the generative method and put linguistics back on the firm foundation of data, descriptivism ${ }^{12}$ and Saussurean structuralism.

\subsection{The method of lexical exceptions}

The aspectual analysis of the passive given in 3.1 was arrived at using a particular method of research which I call 'the method of lexical exceptions' (Beedham 2005: 153-164). The method involves taking a grammatical rule or construction which is formally present in (preferably) two or three languages - in this case the passive with $b e+$ passive participle, in English, German and Russian - and which has a substantial set of unexplained (lexical) exceptions, in this case non-passivizable transitive verbs. A second construction is sought which has the first construction's unexplained exceptions (or most of them) as its unexplained exceptions. In this case the second construction turned out to be the resultative perfect. The syntactic ${ }^{13}$ correlation thus discovered

12. Hopefully it can be seen from this paper that descriptive linguistics is analytical (i.e. theoretical) and explanatory, it is not taxonomic, as the generativists claim. It has to be said that the term 'descriptive' is thus misleading. However, it is a term in common currency and I do not propose to suggest changing it.

13. Syntax in the sense of combinatorial possibilities. 
throws up hitherto unnoticed similarities between the first and the second construction, allowing the first construction to be given a new analysis which explains various problems associated with the old analysis. In this case the passive was re-analysed as an aspect of the type Auxiliary + Participle, with the meaning 'action + state, which can only occur with telic verbs or in telic sentences. The method is based on language as a Saussurean system whose elements are determined by their place in the system. ${ }^{14}$

I am currently attempting to use the method again, this time on irregular verbs in English, German and Russian, e.g. the verb drink drank drunk in English (Beedham 2005: 107-133). Thus far the discovery has been made that the vowel + consonant sequences (VCs) of the irregular verbs, e.g. in drink the VC [Ink], tend not to occur on structurally comparable regular verbs, and thus serve as phonotactic markers of 'irregular' conjugation. For German it has been discovered that $74 \%$ of separable prefixes contain a strong verb VC. Given that prefixes in German make a verb perfective, this discovery suggests that the German strong verbs may also be perfective (Beedham Ms). This research is on-going, but its aim is to find rules for the formation of the 'irregular' verbs and a meaning for them (e.g. perfective or resultative, perhaps), distinct from the meaning of the regular verbs. The Saussurean point here is the indivisibility of the linguistic sign, i.e. no difference in form without a difference in meaning.

I hope that other linguists will try out the method of lexical exceptions on their own rules and constructions in their own languages, and indeed this process has already begun. In 2007 a summer school and conference on the method was held at the University of St Andrews, Scotland (http://www.st-andrews.ac.uk/modlangs/events/ pastevents/). Warwick Danks has recently submitted a Ph.D. thesis, co-supervised by the author and Catherine Cobham, Dept. of Arabic, in which he has attempted to apply the method to Modern Standard Arabic (Danks 2009). Danks 2009 presents evidence which suggests that the vowel-lengthening verbal patterns in Modern Standard Arabic - patterns III and VI - have in broad terms atelic aspectual meaning, rather than simply the mutual/reciprocal meaning usually attributed to them as their most common meaning. One of the consequences of this is that passive participle forms from patterns III and VI are rare (it is already well recognised by Arabic grammarians that the Arabic participial passive has a statal or resultative meaning). In September 2009 Vivika Cairns started a PhD, supervised by the author, in which she is attempting to apply the method of lexical exceptions to irregular verbs in German and Russian. Also in September 2009 Daniel Honert started a PhD, co-supervised by the author and Kormi Anipa, Dept. of Spanish, in which he is attempting to apply the method to

14. Language as a system, compositional aspect, and syntax as combinatorial possibilities are really three ways of saying the same thing. They all find their instantiation in the sentence. 
English, German, and Spanish. And Gregory 2006 presents arguments and examples which indicate that the Spanish passive has aspectual characteristics similar to those sketched above for English.

A return to data-oriented descriptive linguistics, and further testing of the method of lexical exceptions, will require the recognition that the generative model-building approach is fundamentally misguided. We hope to have shown in the present article that the essence of the generative fallacy is the generativists' belief that you can do science by postulation alone, made possible by their equivocation of form and notation.

\section{References}

Abraham, Werner. 2000. "Das Perfektpartizip: seine angebliche Passivbedeutung im Deutschen”. Zeitschrift für germanistische Linguistik 28: 2. 141-166.

Beedham, Christopher. 1982. The passive aspect in English, German, and Russian. Tübingen: Narr. Beedham, Christopher. 1987. "Das deutsche Passiv: Aspekt, nicht Genus verbi”. Deutsch als Fremdsprache 24. 160-165.

Beedham, Christopher. 1998. "The perfect passive participle in Russian.” A review of Participial passive and aspect in Russian, by Maaike Schoorlemmer. Lingua 105. 79-94.

Beedham, Christopher. 2001. "A critique of the model-building approach. Review of Schoorlemmer 1995". Word 52. 79-94.

Beedham, Christopher. 2005. Language and meaning : the structural creation of reality. Amsterdam/ Philadelphia: John Benjamins Publishing.

Beedham, Christopher. 2009. "La méthode des exceptions lexicales et la relation entre la langue et la réalité". Res per nomen, ed. by Pierre Frath, C. Gledhill \& J. Pauchard, 215-229. Reims: Editions et Presses Universitaires de Reims.

Beedham, Christopher. Ms. Eine phonotaktische Korrelation und semantische Verbindung zwischen starken Verben und trennbaren Präfixen der deutschen Gegenwartssprache.

Bolinger, Dwight. 1960. "Linguistic Science and linguistic engineering”. Word 16. 374-391.

Bolinger, Dwight. 1977. Meaning and form. New York: Longman.

Bresnan, Joan. 2001. Lexical-functional syntax. Malden, Mass.: Blackwell.

Chomsky, Noam. 1955. “The Logical Structure of Linguistic Theory”. Ms., date June 1955. Available from Columbia University Psychology Library.

Chomsky, Noam. 1957. Syntactic structures. The Hague: Mouton.

Chomsky, Noam. 1959. "Review of Verbal Behaviour, by B.F. Skinner”. Language 35: 1. 26-59.

Chomsky, Noam. 1962. "Explanatory Models in Linguistics". Logic, methodology, and philosophy of science; proceedings, ed. by Ernest Nagel, 528-550. Stanford, Calif.: Stanford University Press.

Chomsky, Noam. 1964. "The Logical Basis of Linguistic Theory". Proceedings of the Ninth International Congress of Linguists, Cambridge, Mass., August 27-31, 1962, ed. by Horace Gray Lunt. The Hague: Mouton.

Chomsky, Noam. 1965. Aspects of the theory of syntax. Cambridge: M.I.T. Press.

Chomsky, Noam. 1986. Knowledge of language : its nature, origin, and use. New York: Praeger.

Chomsky, Noam. 1995. The Minimalist Program. Cambridge, Mass.: M.I.T. Press.

Chomsky, Noam. 2005. “Three Factors in Language Design” [Winter]. Linguistic Inquiry 36: 1. 1-22.

Conrad, Rudi, Brigitte Bartschat, W. Heinemann, G. Richter \& A. Steube. 1975. Kleines Wörterbuch sprachwissenschaftlicher Termini. Leipzig: VEB Bibliographisches Institut. 
Danks, Warwick. 2009. The Arabic verb: Form and meaning in the vowel-lengthening patterns. Ph.D. thesis submitted on 22.9.2009, University of St. Andrews, Scotland.

Dingle, Herbert. 1972. Science at the crossroads. London: Martin Brian and O'Keefe Ltd.

Fillmore, Charles. 1968. “The Case for Case”. Universals in Linguistic Theory, ed. by Emmon Bach and Robert T. Harms, 1-88. New York: Holt, Rinehart \& Winston.

Gazdar, Gerald, E. Klein, Geoffrey K. Pullum \& I. Sag. 1985. Generalized phrase structure grammar. Cambridge, Mass.: Harvard University Press.

Givón, Talmy. 1979. On understanding grammar. New York: Academic Press.

Gregory, Amy. 2006. “Review of Beedham 2005”. Linguist List 17: 3168.

Gross, Maurice. 1979. “On the Failure of Generative Grammar”. Language: 55: 4. 859-885.

Hall, Robert Anderson. 1987. Linguistics and pseudo-linguistics : selected essays, 1965-1985. Amsterdam/Philadelphia: John Benjamins.

Halliday, M.A.K. 1967. "Notes on transitivity and theme in English. Part 1." Journal of Linguistics 3. 37-81.

Hammarström, Göran. 1971. “The Problem of Nonsense Linguistics.” Acta Societatis linguisticae Upsaliensis 2: 4. Uppsala.

Harman, Gilbert, ed. 1982. On Noam Chomsky: Critical Essays. Second Edition. Amherst: University of Massachusetts Press.

Helbig, Gerhard. 1983. Geschichte der neueren Sprachwissenschaft. Opladen: Westdeutscher Verlag.

Hopper, Paul J. \& S.A. Thompson. 1980. “Transitivity in grammar and discourse”. Language 56. 251-299.

Huddleston, Rodney D. 1971. The sentence in written English; a syntactic study based on an analysis of scientific texts. Cambridge, England: University Press.

Joseph, John E., ed. Forthcoming (2010). Ferdinand de Saussure, 2nd ed. With a new introduction by John E. Joseph. London: Routledge.

Koerner, E.F.K. 1973. Ferdinand de Saussure; origin and development of his linguistic thought in Western studies of language, a contribution to the history and theory of linguistics. Braunschweig: Vieweg.

Koerner, E.F.K. 1999. “Three Saussures - One 'Structuralist' Avant la Lettre”. Langue and Parole in Synchronic and Diachronic Perspective: Selected Proceedings of the XXXIst Annual Meeting of the Societas Linguistica Europaea, St. Andrews, 1998, ed. by Christopher Beedham, 19-34. Oxford: Elsevier/Pergamon.

Koerner, E.F.K. 2002. The 'Chomskyan Revolution' and its Historiography. London ; New York: Routledge.

Lamandella, J. 1969. "On the Irrelevance of Transformational Grammar to Second Language Pedagogy”. Language Learning and Development 19. 255-270.

Lamb, Sidney M. 1967. "Review of Chomsky 1964 and 1965”. American Anthropologist 69. 411-415. Leech, Geoffrey N. 1971. Meaning and the English verb. London: Longman.

Lyons, John. 1991. Chomsky. Third Edition. Fontana Modern Masters. Hammersmith: Fontana.

Martin, Roger, D. Michaels \& J. Uriagereka, eds. 2000. Step by Step: Essays on Minimalist Syntax in Honour of Howard Lasnik. Cambridge, Mass.: M.I.T. Press.

McCawley, James D. 1982. Thirty million theories of grammar. Chicago: University of Chicago Press. Meillet, Antoine. 1893. "Les lois du langage I: Les lois phonétiques". Revue internationale de sociologie (Paris) 1. 311-321.

Newmeyer, Frederick J. 1986. Linguistic theory in America. Orlando: Academic Press.

Palmer, Frank Robert. 1974. The English verb, 2d ed. London: Longman.

Pinker, Steven. 1994. The language instinct. New York: W. Morrow and Co. 
Poupynin, Youri A. 1996. "Central and Peripheral Connections between Aspect and Voice in Russian”. Folia Linguistica 30. 129-140.

Putnam, Hilary. 1967. "The 'Innateness Hypothesis' and Explanatory Models in Linguistics". Synthese 17. 12-22.

Quirk, Randolph, Sidney Greenbaum, Geoffrey Leech \& Jan Svartvik. 1985. A Comprehensive grammar of the English language. London ; New York: Longman.

Radford, Andrew. 1997. Syntactic theory and the structure of English : a minimalist approach. Cambridge, U.K. ; New York, NY: Cambridge University Press.

Radford, Andrew. 2004. English Syntax: An introduction. Cambridge: Cambridge University Press.

Robinson, Ian. 1975. The New Grammarians' Funeral: A critique of Noam Chomsky's linguistics. Cambridge: Cambridge University Press.

Sag, Ivan A., Thomas Wasow \& E. Bender. 2003. Syntactic Theory: A Formal Introduction. Stanford, Calif.: CSLI Publications.

Sanders, Carol, ed. 2004. The Cambridge companion to Saussure. Cambridge ; New York: Cambridge University Press.

Saussure, Ferdinand de. 1972 [1922]. Cours de linguistique générale. Paris: Payot.

Saussure, Ferdinand de. 1983. Course in general linguistics. London: Duckworth.

Schoorlemmer, Maaike. 1995. Participial Passive and Aspect in Russian, Utrecht, OTS [Onderzoeksinstituut voor Taal en Spraak/Research Institute for Language and Speech].

Skinner, B.F. 1957. Verbal behavior. New York: Appleton-Century-Crofts.

Theocharis, T. \& M. Psimopoulos. 1987. "Where science has gone wrong”. Nature 329. 595-598.

Tobin, Y. 1990. Semiotics and linguistics. London ; New York: Longman.

Verkuyl, H.J. 1972. On the compositional nature of the aspects. Dordrecht: Reidel.

Verkuyl, H.J. 1993. A theory of aspectuality : the interaction between temporal and atemporal structure. Cambridge; New York: Cambridge University Press.

Wade, Terence L.B. 1992. A comprehensive Russian grammar. Oxford: Basil Blackwell.

Wilkins, Wendy. 1980. "Adjacency and Variables in Syntactic Transformations". Linguistic Inquiry 11. 709-758.

Бидэм, Кр. 1988. “Видовое значение конструкции 〈〈быть + сртадательное причастие 〉”. Вопросы Языкознания 6: 63-68. 


\title{
Chomsky's paradigm
}

\section{What it includes and what it excludes}

\author{
Joanna Radwańska-Williams \\ Macao Polytechnic Institute
}

"Remember that you are a human being with a soul and the divine gift of articulate speech [...]"

George Bernard Shaw, Pygmalion ${ }^{1}$

In the structuralist tradition, the semiotic nature of the linguistic sign was seen as grounded in the psychological association between sound and meaning. On the one hand, this association is arbitrary, since sound and meaning are dissimilar in nature; on the other hand, the language system as a whole is partially motivated through various associations by similarity, which group paradigmatic relations and are a factor in semantic change. The system relies on the social fact of language use as the guarantor of the stability of conventionalized form-meaning associations, but also as the agent of change, which is a slow disruption and restructuring of the stability of the system.

The article discusses evidence for the semiotic nature of language from the domain of poetic iconicity, which heightens and highlights the possibility of non-arbitrary association between meaning and form. The importance of the dimension of language use is also discussed with reference to Mufwene's $(2001,2005,2007)$ 'uniformitarian' theory of language contact, according to which idiolectal contact is the linguistic locus of social interaction and language change. It is argued that, in discounting language use, i.e., 'linguistic performance' and 'E-language', the Chomskyan theoretical framework is incomplete as an account of the nature of language.

A paradigm, according to Thomas Kuhn's (1970 [1962]) definition, is 'a prevailing consensus of opinion' among the practitioners of an academic discipline. It is less clear,

1. Retrieved February 9, 2009 from http://classiclit.about.com/od/pygmaliongbshaw/fr/ aa_pygmalion.htm. 
however, what constitutes the boundaries within which the consensus of opinion should prevail. The consensus is the result of either a critical mass of 'conversions', or a change of generations, among members of an academic community. Again, what precisely delimits the boundaries of the community? Are the boundaries national, institutional, or are they delimited by the nature of the phenomena that constitute the object of study of the discipline?

In this article, I am concerned primarily with the last of the above criteria - the nature of the phenomena of language - and only secondarily with the social boundaries of the cultural transmission of knowledge constrained by national and institutional traditions. My approach is primarily epistemological, secondarily social.

From the point of view of epistemology, a paradigm - the prevalent consensus of opinion - is necessarily opinion about something, the object of study. In the study of linguistics, broadly conceived, that something is language. Even at this juncture the delimitation of 'study' becomes problematic. To inject a little social dimension, the slightly different terms for 'linguistics' in different national languages indicate the boundaries of the problem. In German, it is 'Lingwistik' and 'Sprachwissenschaft' thus, the object of study, etymologically speaking, is both language and speech. In Russian and Polish, it is both 'lingvistika'/'lingwistyka' and 'jazykoznanie'/'językozn awstwo, where the latter term, etymologically speaking, can be roughly paraphrased as 'the sphere of knowledge about language', and it remains ambiguous (since Russian and Polish do not have an indefinite article) whether the object of study is language in general ('human language', as Chomsky would have it) or a particular language/ family of languages. While this may seem like quibbling over terminology, already the problem of boundaries is evident. If 'speech' is explicit in the definition of the academic discipline, then surely experimental phonetics is within the scope of its study. If studying a particular language or languages is as important as studying language in general, then surely a systematic description and comparison of particular languages is within the scope of its study. These are areas of study that have been of focal concern to many linguists over the course of the history of linguistics, but not within the Chomskyan paradigm. Which brings me to the question posed in this article: what does Chomsky's paradigm include, and what does it exclude?

The simple answer, which I hope to explore in greater depth, is that it includes a focus on human language, conceived as Universal Grammar, and it excludes the study of the phonetic properties of speech, the semiotics of the linguistic sign, and of the many aspects of language use and language variation. To what extent this approach has generated a 'prevalent consensus of opinion' among the practitioners of linguistics is a social question. However, I shall try to address it through the prism of the epistemological question - what insight has Chomsky provided into the nature of language (what is included?), and has this insight served to narrow the scope of the discipline (what is excluded?) 


\section{Universal Grammar}

Commentators on Chomsky's political thought have pointed out a common ground with his linguistic thought - his universalism, the belief in the equality of all human beings, and also in the uniqueness of the human being as a biological species. Peter Hallward (2008: 9) comments:

It is no accident, notwithstanding dramatic differences in outlook and orientation, that the most forceful proponents of a prescriptive politics tend to ground its conditions of possibility in autonomous, "auto-poetic," and extra-political faculties or capacities - Noam Chomsky in a mental-cognitive faculty, Gandhi in a spiritual faculty, Sartre in a faculty of imagination or negation, Rancière in a discursive capacity, Badiou in a capacity for unabashedly "immortal" truth. It is precisely the autonomy of such capacities that is at issue in the divergence, for instance, between Chomsky and his more conservative student Stephen Pinker, a divergence that is as much scientific as it is political. For Pinker our "language instinct" evolved more or less smoothly as an adaptive solution to the pressures imposed by natural selection; for Chomsky language comes to function at an essential distance from any coordination with nature, that is, at a distance from principles other than those of a critical autonomy itself. It is this distance that underlies our ability to think rather than simply behave.

Chomsky's argument for the existence of a uniquely human 'language faculty' goes back to his critique of behaviorism. Language is not acquired by imitation and reinforcement, he argues, because of the 'logical problem of language acquisition' or the 'poverty of the stimulus': small children are not given systematic instruction in their native language and are usually not provided with the 'negative evidence' of error correction. It is paradoxical that small children acquire their native language fluently by age 4 , at a time when they may still be cognitively daunted by tasks such as tying their shoelaces or counting to $10 .^{2}$

In the popular introductory linguistics textbook by Fromkin \& Rodman (1998), this capacity of small children for language acquisition is vividly illustrated by means of a Mother Goose nursery rhyme: ${ }^{3}$

This is the farmer sowing his corn,

That kept the cock that crowed in the morn,

2. I witnessed good evidence of this just this Christmas (December 2008), when my niece, aged 4 and 1 month, and already competently bilingual in French (her mother tongue) and Polish (her heritage language), was trying to count to 10 , and had mastered the count from $1-5$, but counted randomly on the other hand when trying to reach 10 ; her problem was clearly cognitive/numerical, not linguistic.

3. Text retrieved on February 9, 2009 from http://www.amherst.edu/ rjyanco94/literature/ mothergoose/rhymes/thisisthehousethatjackbuilt.html; I did not have Fromkin \& Rodman 1998 at hand when writing this paper. 
That waked the priest all shaven and shorn, That married the man all tattered and torn, That kissed the maiden all forlorn,

That milked the cow with the crumpled horn,

That tossed the dog,

That worried the cat,

That killed the rat,

That ate the malt

That lay in the house that Jack built.

It is argued that children have no difficulty understanding this poem, which is in fact a very complex sentence with many relativized embedded clauses, and that they delight in language play. By the 'poverty of the stimulus' argument, children have not received any systematic instruction in the grammar of complex sentences, and indeed, they may not even have encountered a sentence of the order of complexity of the sentence of this poem prior to encountering the poem, and yet they have no difficulty in understanding it. Therefore, in the Chomskyan argument, the child's cognitive construction of the internalized grammar of his/her language (or, the I-language) is instinctually predetermined by the human genetic endowment, a 'language faculty' containing a 'universal grammar' which provides the basic rudiments of language structure and which constrains (by means of 'principles and parameters') the nature and number of choices that need to be made when internalizing the grammar of a particular language. When encountering the input of his/ her native language, the child's brain is able to make these choices quickly and efficiently.

\section{Language use}

The Chomskyan 'paradigm shift' in theoretical perspective on language study consisted in what Chomsky (2006: ix) has called the 'cognitive revolution' - a recasting of the understanding of the nature of language structure. In Chomsky's view, which is socially contextualized within the historical tradition of American linguistics, the 'structuralist' (pre-Chomskyan) approach to language study did not admit any predetermined categories of language structure, but was descriptively driven by the data of field work. Chomsky claims that

The prominent linguist Martin Joos hardly exaggerated in a 1955 exposition when he identified the "decisive direction" of contemporary structural linguistics as the decision that language can be "described without any preexistent scheme of what a language must be." (Joos 1955: Chapter 3, note 12, quoted in Chomsky 2006: vii) ${ }^{4}$

4. Chomsky (2006) does not give the complete bibliographical information for this citation; the citation may perhaps be Joos (1957); cf. the article by Thomas (2002). 
However, this view of the structuralist perspective on language structure is something of a caricature. The structuralist categories of description, such as the phoneme and the morpheme, were arrived at as a result of a mass of comparative observation of language data. The study of language typology was taxonomic, somewhat analogously to the biological sciences' classification of different species. The intent of Martin Joos' remarks, I think, was that the taxonomy should not prejudice the description of real data, since new, as yet undescribed languages could always be discovered and new or unexpected categories emerge from the description. To take an example, some languages have noun classifiers, a grammatical category not present in Indo-European languages: in Bantu languages, these appear as agreement markers, while in Chinese, as count words (measure words, liàngcí 量词 or 量詞) 5 used between the numeral and the noun (Aikhenvald 2003: 8-9). This is the kind of category that might be missed by a typologically predetermined description that does not proceed inductively. Thus, the structuralist anthropological procedure was inductive, but that need not invalidate its theoretical categories.

In the cognitivist perspective, the categories of language structure are mental rather than physical or social. Any physically observable language fact - pronunciation, lexical item, word order - is interpreted in terms of mental categories of knowledge that enable its acquisition by the human brain. Paradoxically, the human brain is a physical entity, but it is not directly the object of study. The object of study the structures of the linguistic aspect of the mind - is not directly accessible. Also paradoxically, the language that is produced by the human organism - speech - is also not the object of study. Chomsky (1965: 3-4) insists that linguistics should study 'language form', not 'language use', where language form is understood as an idealized 'native speaker competence':

Linguistic theory is concerned primarily with an ideal speaker-listener, in a completely homogeneous speech-community, who knows its language perfectly and is unaffected by such grammatically irrelevant conditions as memory limitations, distractions, shifts of attention and interest, and errors (random or characteristic) in applying his knowledge of the language in actual performance. [...] We thus make a fundamental distinction between competence (the speakerhearer's knowledge of his language) and performance (the actual use of language in concrete situations.) [...] The distinction I am noting here is related to the langue-parole distinction of Saussure; but it is necessary to reject his concept of langue as merely a systematic inventory of items and to return rather to the Humboldtian conception of underlying competence as a system of generative processes.

This insistence on the idealized study of language form seems to throw out the baby with the bath water. The 'baby' is observable language data, while the 'bath water' is

5. Retrieved on February 9, 2009 from http://digchinese.com/measure-words. 
Chomsky's dismissal of descriptive methodology. However, in terms of the central question of this article - the extent of the Chomskyan paradigm shift - the attempt to throw out the baby with the bath water has resulted in the failure of the Chomskyan paradigm to provide a comprehensive account of language, i.e., of the set of phenomena under the purview of linguistics as its object of study. Other linguists have rescued the baby, creating new subfields such as sociolinguistics and discourse analysis, operating with entirely different categories of description than the Chomskyan framework.

My criticism of Chomsky as not adhering to observable language data may seem unfair. Chomsky has avowed the empirical nature of his approach. The touchstone of sentence structure is its grammaticality according to 'native speaker intuition' - a methodology Chomsky may well have inherited from the 'bath water' of American anthropological structuralism and its use of 'native informants' in determining the phonemes and morphemes in a structuralist description of a language. I do not mean that sentence structure is unobservable. Rather, I mean that Chomsky's insistence that language use is not the object of language study (linguistics) seems logically fallacious. In terms of the 'prevailing consensus of opinion', it has created a fragmentation within the field of linguistics, a kind of crisis of identity, where many different 'kinds of linguistics' are practiced side by side and sometimes have little to say to each other. In the state of the art of the discipline, there is no consolidated paradigm which encompasses all the phenomena of language. Since we are used to the state of the art, it is difficult to step outside of the contemporary scene. Therefore, a historical comparison may be instructive.

\section{The social and semiotic nature of language in the structuralist tradition}

According to Chomsky's own admission, quoted above, the distinction between 'competence' and 'performance,' 'language form' and 'language use', can be traced back to Ferdinand de Saussure's distinction between 'langue' and 'parole.' In the structuralist tradition, the system was both psychological and social. It was psychological because of the symbolic 'association' between sound and meaning - the signifier and the signified in the linguistic sign, and the 'paradigmatic relations' between morphemes within word families and inflectional paradigms. It was social because the association between sound and meaning, being arbitrary, is dependent on social convention as the guarantor of its stability. In the synchronic dimension, 'langue' is the language system, the relational structure of language, abstracted from 'parole' as the agent of variation and change. Abstracting 'langue' as a synchronic system allows for the study of its relational structure, held as a constant, a slice of time, just as a sagittal section of the human anatomy allows for the study of the relative positioning of anatomical organs - facilitating morphological study. However, this synchronic abstraction of 
the 'langue' was for Saussure only one of the dimensions of language - the other being diachrony and 'parole.' 'Parole, language use, language as activity and speech, is the psychological and social reality of language, the interface between the individual's participation in the system and the system itself, which slowly changes as a result of this participation. Language changes because social convention changes. In their daily negotiation of meaning, individuals interact. Different idiolects, understandings and misunderstandings, pronunciations and mispronunciations, accents and dialects, languages and language codes, enter into the daily process of contact and interaction in language use. Saussure's metaphor of the chess game is but a tiny microcosm of language and its multiple interactions - a chess board has 32 pieces and 64 spaces, which, mathematically speaking, produces a very large number of configurations, but how many elements does a language have? It is indeed remarkable that the system changes as slowly as it does, maintaining a relative stability of association between sound and meaning over the span of each generation. Nevertheless, language change and language use is a preeminent reality, a necessary condition (sine qua non) of the existence of language.

In logic, there is a difference between a necessary and a sufficient condition. Chomsky emphasizes the uniqueness of the human biological endowment. It is true, as attempts to teach human sign language to chimpanzees and gorillas have shown, that an animal does not fully function at the cognitive level of a human being, even if it masters some elements of human symbolic communication. ${ }^{6}$ It does not acquire the entire system that human beings are capable of acquiring. But that seems to be begging the question. Admittedly, our genetic endowment is a necessary condition for the existence of language; a human being cannot acquire language without having a human brain and being a human being. The argument is somewhat redundant: a logical paraphrase of this proposition is that a (biological) entity cannot acquire (human) language without being a human being. But a necessary condition is not the same as a sufficient condition. In order to acquire the full system of language, is being a biological human being a sufficient condition? No, as the rare cases of 'feral children' have shown, social interaction is needed for acquisition, and without it, the capacity for acquisition seems to atrophy after the 'critical period' (Lightbown \& Spada 2006: 17-19). It seems that biological endowment alone is not sufficient; it needs to be coupled with social interaction for sufficient conditions for the acquisition of language to exist. But if the social dimension of language is essential for the existence of language, then we cannot simply discount it as less theoretically important, an afterthought in linguistic theory, as Chomsky's position seems to imply.

6. For video clips of Koko the gorilla using human sign language, see http://www.koko.org/ world/signlanguage.html, retrieved on February 2, 2009. 
In my opinion, Saussure never intended the study of language to be only the study of synchrony and 'langue', to the exclusion of diachrony. In the words of Konrad Koerner (1995: xxxii):

Contrary to what the 'vulgata' text of the Cours suggests, Saussure did not plan to divorce synchrony from diachrony to the extent that these become two separate compartments of language study as we find it practiced in Bloomfield's Language of 1933 and the work of his followers down to the present day, Chomsky included.

The postulation of 'langue' was a heuristic abstraction to facilitate the comparison of language and languages across time. In the nineteenth century, the goal of linguistics was an account of language change. It is against this backdrop that questions of the nature of language - what is it that changes, and how does it change? - came to be asked.

According to Konrad Koerner (1973: 148-165; 1986; 1995), some of Saussure's conception of language goes back to the thought of the Polish linguist working in imperial Russia, Mikołaj Kruszewski (1851-1887). These historical roots were strongly (even polemically) emphasized by Roman Jakobson (1967: xxiv, quoted in Radwańska-Williams 1993: 168):

The second part of [Saussure's Cours], "Synchronic Linguistics", especially its last chapters, definitely has its source in the abovementioned synthetic work of Kruszewski's.

The "abovementioned synthetic work" refers to Kruszewski's 'course in general linguistics', given to students at Kazan University and defended as his doctoral dissertation, Očerk nauki o jazyke [An outline of the science of language $]^{7}$ (1883). Considering Kruszewski's influence, it is worth taking a closer look at these historical roots of structuralist theory.

If Chomsky had been Kruszewski's contemporary, he may perhaps have sensed in Kruszewski a kindred spirit, for Kruszewski throughout his life was obsessed with discovering the scientific laws of language. Even before he embarked on his study of linguistics, he wrote to his mentor, Jan Baudouin de Courtenay (1888-1889: 138-139, quoted in Radwańska-Williams 1993: 15):

Does linguistics have some single general law which would apply to all the phenomena it investigates, and what namely is that law? A general law [...] without which, as logic correctly maintains, science is not science. Is there not any work or article where linguistics would be examined from the standpoint of logic, in the manner in which, for example, other sciences are examined at the end of the second volume of Mill's Logic?

7. Available in English as Outline of Linguistic Science in Kruszewski (1995). 
Kruszewski adopted the associationism of John Stuart Mill (1843) as the grounding for his theory. According to Mill, the categories of experience were structured through mental associations: association by similarity and association by contiguity. Similar experiences associate with each other in human memory, as do experiences which occur together (association by contiguity). Kruszewski adopts this insight to explain the semiotic nature of language. Sound and meaning are dissimilar, but they are remembered together because of their co-occurrence in the linguistic sign (association by contiguity). Syntactic relations are also based on contiguity, the co-occurrence of words in the stream of speech. On the other hand, morphological relationships are structured by similarity. For Kruszewski, morphological relationships include not only grammatical paradigms, but also derivational word families (Radwańska-Williams 1993: 69-133).

For Kruszewski, the basic element of language is the word as a linguistic sign, an association between phonetic form and conceptual meaning. At the same time, he recognizes phonetic form as being the physical aspect of language. Thus the nature of language, in Kruszewski's conception, is dual - it is psychophysical; moreover, it is semiotic, in its association between these two dimensions. Like Chomsky, and drawing the criticism of his mentor Baudouin de Courtenay (1888-1889), Kruszewski does not focus on the social dimension of language. Rather, he focuses on the structuring principles of language and on the explanatory principles of language change conceived as semiotically motivated change in the structure of the system:

According to Kruszewski, the linguistic system consists of structural families of words, systems of types. The structural families constitute grammatical categories which correspond to a similarly organized representation of objects and phenomena of objective reality. Kruszewski conveys a deep belief that structural systems, the systems of types, are connected and correlated with processes of typification, that is the ability of human thinking to classify and generalize objects and phenomena of the objective world into definite systems or types of concepts (qualities, properties, features, etc.). (Berezin 2001: 222, quoted in Radwańska-Williams 2002: 398)

In Kruszewski's theory, the explanatory principle of language change is "perintegration", defined as "the law of correspondence of the world of words to the world of thoughts" (Kruszewski 1883: 68, quoted in Williams 1993: 82). ${ }^{8}$ Through association by similarity, the similarity of phonetic form is perceived by the speakers, and paradigms, word structure and word meaning tend to be reordered/restructured so as to make similarity more transparent. Under this tendency, Kruszewski (1879, 1995: 153-172) subsumes the phenomena of 'analogy' and 'folk etymology'. On the other hand, through

8. A slightly different translation is given in Kruszewski (1995: 99): "the law of the correspondence between the world of words and the world of ideas". 
association by contiguity, high-frequency vocabulary may preserve morphological irregularity, a tendency which was reiterated by Kuryłowicz and has also been called Kruszewski and Kuryłowicz's law (Berezin 2001: 225, cited in Radwańska-Williams 2002: 399-400).

A central phenomenon which Kruszewski aims to explain, in the context of 19th century linguistics, is that of sound change. His account is quite different from that of his contemporaries. Kruszewski agrees with the 'neogrammarians' Osthoff \& Brugmann (1878) that the discovery of regular 'sound laws' places linguistics on a par with the natural sciences, but disagrees about the nature of the phenomena. For Kruszewski, the only 'sound laws' are those which operate in the static (Saussure's 'synchronic') dimension of language. They are the laws of phonetic accommodation, what we would term in the 20th century as phonological laws or processes, such as assimilation. For Kruszewski, these are part of the physical nature of language, a consequence of the functioning of the organs of speech. The 'Kazan School' of Mikołaj Kruszewski, Jan Baudouin de Courtenay and Vasilij Alekseevič Bogorodickij, based in Kazan University in Russia, developed a rich tradition of experimental phonetics, going back as far as the 1880s, to study the physiological properties of speech (RadwańskaWilliams 2006: 365-369). On the other hand, according to Kruszewski, historical sound laws such as Grimm's law are the morphophonemic vestiges of static phonetic accommodation. If the process of accommodation is no longer operative in the language, the regularity of morphophonemic sound correspondences can be disrupted by psychologically based processes such as analogy and folk etymology, which are grounded in the mechanisms of the psychological association of sound and meaning.

\section{Iconicity as evidence of the semiotic nature of language}

One of the insights of structuralism, at least in the lineage that can be traced from Kruszewski and Saussure to Roman Jakobson, is that language is a semiotic system. The idea of the semiotic, in its broader sense, extends beyond the commonly accepted concept of the symbolic nature of language, i.e., the arbitrary association of sound and meaning. As Saussure (1986: 131) observed, the arbitrariness of language is limited by 'relative motivation':

Everything having to do with languages as systems needs to be approached, we are convinced, with a view to examining the limitations of arbitrariness. It is an approach which linguists have neglected. But it offers the best possible basis for linguistic studies. For the entire linguistic system is founded upon the irrational principle that

9. This quotation, and Saussure's position vis-à-vis the problem of the 'naturalness' of language first posed in Plato's Cratylus, is discussed by John Joseph (2000) in Limiting the Arbitrary. 
the sign is arbitrary. Applied without restriction, this principle would lead to utter chaos. But the mind succeeds in introducing a principle of order and regularity into certain areas of the mass of signs. That is the role of relative motivation.

Kruszewski would have expressed the same idea of motivation as the association by similarity between word forms, resulting in inflectional paradigms, derivational word families, and various other patterns in the lexicon, and motivating change by the principles of analogy and of the reinterpretation of etymological meaning and semantic relationships. An implication of Kruszewski's position is that a system that would be entirely arbitrary (remembered by the contiguity of co-occurrence), would pose too much strain on the memory. Thus, while the nature of the physical speech signal and mental thought is dissimilar, and their coupling is arbitrary, the system of language which encodes their coupling seeks to limit the extent of its arbitrariness. To put words into Kruszewski's mouth, language, through semiotically motivated language change, is something like a self-regulating system. The self-regulation is not volitional on the part of any individual participant in the system, but is motivated in its aggregate tendency, because of the principle of the 'correspondence of the world of words to the world of thoughts.' Language, as a tool with which we are able to represent and manipulate reality, seeks a state that is optimally homologous to our thoughts about reality. By reality I mean, loosely speaking, the referent in the world, to which the signifier points or refers. Language allows us to manipulate the signified conceptually, thereby representing our potential manipulation of entities in the world. A simple example would be an imperative: "Give me that book" is a directive for action (potentially) performed on an object in (non-verbal) reality.

The opposite of arbitrariness is iconicity, which can be defined as a similarity between form and meaning (in Saussure's terms, between signifier and signified), or more narrowly speaking, between form and referent (since meaning, being a mental entity, is abstract and not inherently similar to anything that is physically existent.) In Jakobson's insight, Saussure's terminology is somewhat limited if we are to account for the whole range of iconicity in language. Kruszewski's terminology, we may add, was somewhat too mentalist, from the perspective of the behaviorist bent of psychology in the first half of the 20th century. Therefore, Jakobson adopted the terminology of the semiotics of Charles Sanders Peirce, as well as his own functionalist perspective on language, to account for a wider range of iconicity. Masako Hiraga (2005), in her theoretical framework for the study of iconicity, advocates the continued relevance of Jakobson's analysis of language and poetry to contemporary linguistic theory:

Jakobsonian analysis has been criticised on the grounds that it excludes the role of the reader (Fish 1996 [1973]; Attridge 1996 [1987]; Weber 1996). But if Jakobsonian methodology is put in the new context of cognitive poetics with its emphasis on the conceptual processing of both the writer and the reader, the status and the rigour of Jakobson's argument must be re-evaluated. (Hiraga 2005: 23) 
Jakobson conceived of Kruszewski's two mental dimensions, association by similarity and association by contiguity, as two dimensions of language - the 'axis of selection' and the 'axis of combination' (Waugh 1985: 149-153). Language, it may be inferred, is a morphophonemic system of lexical resources; it is 'langue', in that it is a system bound by social convention, and it is mental, to the extent that the speaker can acquire it, remember it and draw upon it. However, defining language in terms of 'selection' and 'combination' gives it a behaviorist angle appropriate to early 20th century psychology - it skirts the issue of mental entities by emphasizing the action the speaker can perform upon them. It also bridges the gap between language use and language form: action is use, system is form.

A very interesting confrontation between language use and language form is in the domain of poetic iconicity. The poetic function of language, in Jakobson's (1960: 358, quoted in Hiraga 2005: 46) definition, "projects the principle of equivalence from the axis of selection into the axis of combination." That is, elements of language which in and of themselves, taken as discrete lexical items, may be considered arbitrary, acquire a non-arbitrariness in their mutual relational patterning in the context of a poetic text. In a poem, the sound reinforces the meaning. The iconicity is not just a matter of the traditional rhyme and/or metric form of the poem, be it sonnet, haiku, etc., but typically is individual to each poem, the poem's own specific subtle coupling of meaning and form, and functions on many levels, not just the phonological one, but involving what Hiraga (2002, 2003, 2005: 52) has termed the "interplay between metaphor and iconicity."

This "interplay of metaphor and iconicity" works through the coupling of meaning with the patterns of lexical/phonetic selection and repetition (Hiraga 2005: 46-50). As an example, let's examine the iconic coupling of meaning and lexical selection in Robert Frost's (1920) poem, The Road Not Taken (Radwańska-Williams 2009). ${ }^{10}$

On the conceptual level of meaning, as remarked by George Lakoff (1993: 238), the poem is an instantiation of the common cognitive metaphor LIFE IS A JOURNEY. In the poem a choice in life is represented as a choice between two roads (RadwańskaWilliams 2009). 'Life' and 'death' are not mentioned by name in the poem, but are implied through the visual evocation of the cognitive metaphor. The image of the 'yellow wood' strikingly evokes both light and shadow (cognitively associated with life and death). At the moment of choice, the speaker hesitates and 'looks down' one of the roads (the one not taken), then chooses the other one, though not yet fully aware of the consequences of his decision. At the moment of speaking/writing, however, he is already aware that the decision was the right one, as implied by the phrase "and that has made all the difference".

10. For the text of the poem, please see the Appendix. 
This metaphorical/conceptual level of the poem is iconically reinforced through the sound symbolism of lexical/phonetic repetition. As an example, take the repetition of "Two roads diverged" (line 1, line 18), and "and I-/I" (lines 18-19). The fact that two roads diverged is repeated twice, iconically reinforcing the number two. The prefix di- means "two". The divergence is metaphorical for a critical decision in the life of an individual - a choice between two life paths, or, metaphorically speaking, two different persons that he could have become; this is iconically reinforced by the bifurcation of the " $I$ " (of the self) in the ellipsis at the juncture of lines 18-19:

(18) Two roads diverged in a wood, and I -

(19) I took the one less traveled by,

(20) And that has made all the difference.

The phonetic choices in the lexical items function at the subliminal level: the prefix $d i$ - is homophonous with the word die, which, although not mentioned explicitly in the poem, is invoked as the moment of death, the final accounting of one's life choices. The divergence is also subliminally echoed in the final word of the poem, 'difference', in the phonetic similarity of diver [...] and differ [...].

Iconic patterning has been called 'subliminal' by Jakobson (1987b). It is not clear to what extent the poet is consciously aware of the pattern. Nevertheless, it is an imprint of the mind of the poet, a trace of the process of creation. In a tightly structured poem such as Frost's, it is part of the conceptual whole, like glue holding together meaning and form.

While Jakobson drew the concept of iconicity from Peirce, in Peirce's original conception iconicity was triadic rather than binary. In Peirce's semiotics, the sign is not a dyadic binary relation between form and meaning, but a triadic relation between the form, the meaning, and the interpretant - or, in Peirce's terminology, the representamen, the object, and the interpretant. Without an 'interpretant', there is no representation (Peirce 1955: 99):

A sign, or representamen, is something which stands to somebody for something in some respect or capacity. It addresses somebody, that is, it creates in the mind of that person an equivalent sign, or perhaps a more developed sign. That sign which it creates I call the interpretant of the first sign. The sign stands for something, its object. It stands for that object, not in all respects, but in reference to a sort of idea, which I have sometimes called the ground of the representamen. "Idea" is here to be understood in a sort of Platonic sense, very familiar in everyday talk; I mean in that sense in which we say that one man catches another man's idea, in which we say that when a man recalls what he was thinking of at some previous time, he recalls the same idea, and in which when a man continues to think of anything, say for a tenth of a second, in so far as the thought continues to agree with itself during that time, that is to have a like content, it is the same idea, and is not at each instant of the interval a new idea. 
The concept of the 'interpretant' is somewhat ambiguous, because strictly speaking, the 'interpretant' is not the interpreter, i.e., the human being understanding the meaning, and yet, in the case of language, the human being is present in the act of interpretation (Liszka et al. 2000: 2589-2588):

[A] sign is not just a two-termed relation between itself and what it refers to or represents, but involves a third aspect, the interpretant or system of interpretants, by which means it continues to develop meaning, provide information, and grow in significance for its sign users. The interpretant is not to be confused with signinterpreters or semiotic agencies, but is the significate effect of a sign on any such agency.

In my loose construal of Peirce, to take some liberty with his terminology, the 'interpretant', in the case of language, could be conceived as including the meaning (let's say, interpretant 1 ), and the individual grasping the meaning (let's say, interpretant2), and the social convention of language which makes the representation of meaning possible (let's say, interpretant3). With respect to the complex iconicity of a poem, I would argue that Peirce's triadic conception helps to explain the phenomenon of poetic iconicity. The interpretant - the mind of the poet, interpretant 2 - is able to forge links between different verbal elements (in Saussure's terms, signifier/signified couplets) to create a complex web of meaning, interpretant 1 - which (re)enters the life of language and by virtue of the verbal elements' participation in a socially shared symbolic system (interpretant3) is grasped anew in various interpretations by the readers of the poem.

Many poems have now been analyzed within the framework of iconicity and cognitive poetics (Freeman 1995, 1997, 2000, 2007a, 2007b; Hiraga 1994, 2002, 2003, 2005; Jakobson 1960, 1985, 1987a, 1987b, 1987c; Radwańska-Williams 1991a, 1994, 2000, 2009; Ross 2000; Shapiro 1998; Violi 2000). That even a single poem is susceptible to such an analysis is proof that there is something remarkable in the structure of language and in our ability to draw upon its resources. This something is a profound semiotic capacity of language. Surely, this merits closer scrutiny in linguistic theory. And yet in Chomsky's conception, such a phenomenon, belonging to the realm of language use, would be beyond the pale of the object of investigation of linguistic theory.

The phenomenon of poetic iconicity can be seen as a challenge to Chomsky's theoretical perspective because the non-arbitrary coupling of meaning and form at the discourse/textual ${ }^{11}$ level necessarily includes the sentence level. The sentences that

11. I concede that the poet may be working with the written rather than the spoken medium, which would allow for a greater degree of reflection and feedback. However, (1) Chomsky does not claim that his syntactic theory excludes written composition - indeed, many of the example sentences quoted in the syntactic literature were probably 'generated' in written form; (2) poetic composition is not an entirely conscious written process, but often occurs in a contemplative or 
make up a poem - for example, the highly iconic lines 18-20 quoted above - were cognitively generated by the poet. This means that, at a sentence level, a feedback loop must be available between (a) conceptual meaning, (b) lexical selection, and (c) phonetic form. But, as pointed out by Seuren (2004: 51-96), in the Chomskyan framework the modular 'architecture of the language faculty' does not allow for a feedback loop between meaning and form. Seuren (2004: 57-61) characterizes this as a nonmotivational view of the nature of language, which he terms the 'random generator model'. In the Chomskyan framework, the syntactic component is regarded as central or most important. The syntactic generation of the structure of the sentence involves 'lexical insertion' of words from the lexicon. Once the syntactic structure is generated, it 'interfaces' with 'phonetic form' on the one hand and 'logical form' or the 'logicalconceptual interface' on the other hand. Although the directionality and temporal sequence of this interfacing is highly unclear, these linguistic modules are conceived of as separate from the generation of the syntactic structure itself. In other words, it would be very difficult to explain, in the Chomskyan framework of sentence generation, how poets come up with such iconic couplings of meaning and form, where the whole poem seems to be glued together in one indissoluble whole. In the Chomskyan model, word choice, i.e., lexical insertion, does not directly interface with the 'phonetic form' nor with the 'logical/conceptual' level of the whole sentence. It is therefore difficult to explain how poets can simultaneously access the phonetic and conceptual form of the entire sentence while generating the sentence and forge the strong iconic form-meaning links.

\section{The goals of linguistic theory}

In the 'minimalist program', the most recent version of Chomsky's theory, the conception of language form has been reformulated as that of I-language. What does Chomsky mean by I-language, and how does he envisage the scope of linguistic theory? In the evolution of Chomsky's thought, there has been a progressive narrowing of the vision of the goals of linguistic theory, vis-à-vis the question of the inclusion or exclusion of language use, now termed the E-language.

'E-language' can be defined as “'external language' as manifested in actual instances of (written or spoken) language performance", "a collection of sentences

even trance-like mental state, an extreme example of which is the famous alleged composition of the poem Kubla Khan by Samuel Taylor Coleridge under the influence of an opium-induced dream (http://en.wikipedia.org/wiki/Kubla_Khan, retrieved on August 13th, 2009.).

12. http://www.hw.aca.uk/langWWW/icsla/ICSLAGLO.htm, retrieved on October 7th, 2008. 
understood independently of the properties of the mind, and in this sense contrasted with I-language" (Crystal 2008: 164). By contrast, "I-language" is "internalized language, a term suggested by Noam Chomsky to refer to a language viewed as an element of the mind of a person who knows the language, acquired by the learner, and used by the speaker-hearer" (Crystal 2008: 236).

According to Chomsky (2006: 173), the 'minimalist program' adopts a 'biolinguistic' approach to the study of language, asking the questions of (1) "the extent to which apparent principles of language [...] are unique to this cognitive system", and (2) "how much of language can be given a principled explanation, whether or not homologous elements can be found in other domains or organisms." As the object of study, a language can be defined as an I-language:

[I]f we adopt the biolinguistic perspective, a language is a state of the faculty of language - an I-language in technical usage, where "I" underscores the fact that the conception is internalist, individual, and intensional ${ }^{13}$ (with an "s", not a " $\mathrm{t}$ ") - that is, the actual formulation of the generative principles, not the set it enumerates. (Chomsky 2006: 175)

Thus, according to Chomsky, the object of study of linguistic theory is the nature of the faculty of language viewed as part of the human intellectual capacity, human "cognoscitive powers" (Chomsky 2006: 178), i.e.,

[...] the human capacities for creative imagination, language and other modes of symbolism, mathematics, interpretation and recording of natural phenomena, intricate social practice and the like, a complex of capacities that seem to have crystallized fairly recently, perhaps a little over 50,000 years ago, among a small breeding group of which we are all descendants - a complex that sets humans rather sharply apart from other animals, including other hominids, judging by the archeological record. (Chomsky 2006: 175-176)

A particular language, such as English, is not so much studied for its own sake but as an instantiation of the human capacity for language (viewed as Universal Grammar), as "a state of the faculty of language", a mental state (I-language), rather than as any set of language data; it is studied for the sake of "the actual formulation of the generative principles, not the set it enumerates."

13. Compare the definition of "intensional philosophy" used in computing: "A description of properties, e.g., intensional equality, that relate to how an object is implemented as opposed to extensional properties which concern only how its output depends on its input.(1995-01-12)" The Free On-line Dictionary of Computing. Retrieved February 02, 2009, from Dictionary.com website: http://dictionary.reference.com/browse/intensional. 
An I-language is a mental entity, not a social entity. To paraphrase Chomsky, I think he would claim that an individual speaks according to 'English' generative principles, i.e., according to the instantiation of English generative principles in the individual's I-language, but that it is meaningless to say that s/he speaks 'English' as an ontologically existent entity. Chomsky's perspective denies the ontological status of what in the structuralist tradition is termed as language as 'social fact', and thus removes the scientific legitimation of the study of the social aspects of language. Chomsky's idea of 'principles and parameters' in Universal Grammar provides an account of the presence of language variation (as parameter setting), but denies the importance of the study of variation as a goal in itself, apart from the evidence it provides for parameter setting.

\section{Language variation, diachrony and the biological perspective}

The Chomskyan theoretical framework, from its inception, has been predicated on the model of the idealized speaker-hearer "in a completely homogeneous speech community" (Chomsky 1965: 3). Chomsky holds all the variables of speech constant. Speech, 'parole' in its dynamic aspect, gets discounted altogether. It is postulated that the 'native speaker' acquires the system of his/her language perfectly, as if s/he were born with it (though not de facto born with it), eliminating any interfering vicissitudes of life history, such as change of place of residence or of caregivers (and hence of the input), bilingualism or multilingualism. It is assumed that the system, once acquired, remains perfect and static - once a native speaker, always a native speaker - and does not undergo any language shift or attrition, or language change of the system itself, to which the speaker might accommodate. It is also assumed that, once acquired, the system (language competence) is what matters as far as linguistic data are concerned (accessed through native speaker intuition about grammatically well formed sentences), and speaking itself - 'performance' - is irrelevant, since it is by its very nature imprecise and imperfect.

Chomsky's 'idealized speaker-hearer' has been satirized by sociolinguists as a "homunculus" (Schlieben-Lange 1974, cited in Paradowski 2008). In the brain of this homunculus, linguistic competence resides, and only its structural properties are worthy of study. In this conception, one may see an interestingly odd biological reification of Saussure's 'langue' - the language system itself, divorced from diachrony and 'parole'. For Saussure, 'langue, the possibility of the synchronic study of the language system, was also an idealization, but I don't think that he meant to discount the dimension of diachrony altogether. Saussure's intention was apparent from the very beginning of his professional work as a linguist, in the Mémoire sur le système primitif des voyelles dans les langues indo-européennes (1879). Examining the synchronic system and the 
relationship of its elements to each other enables the linguist to describe its structure more precisely, indeed, to predict structural elements - in Saussure's case, to postulate missing elements in the reconstruction of proto-Indo-European, which were to be confirmed many years later by Kuryłowicz's (1927) internal reconstruction of Hittite (Radwańska-Williams 2002: 402-404; 2006: 378-379). Saussure does not discount the social dimension; the stability of language as a system of signs is ensured by social convention, i.e., by the continued and continuous use of the system by its speakers.

I believe that in his biological reification of language as a system, Chomsky discounts the social dimension. The parameters of time and space - historical and geographical extent - are discounted. They do not figure in the life of the individual speaker or the "homogeneous" speech community. Therefore, language variation and language change are discounted. The language system in the brain of the homunculus is supremely static.

Little wonder, then, that having posited no need for an account of change as part of a speech community extending across time and space, Chomsky draws far-reaching conclusions about human evolution. The evolution of language, as the key to the human 'cognoscitive' endowment, must have been relatively instantaneous:

The simplest account of the "Great Leap Forward" in the evolution of humans would be that the brain was rewired, perhaps by some slight mutation, to provide the operation Merge, at once laying a core part of the basis for what is found at that dramatic moment of human evolution: at least in principle; to connect the dots is far from a trivial problem. There are postulations about the evolution of language that postulate a far more complex process: first some mutation that permits two-unit expressions, perhaps yielding selectional advantage by reducing memory load for lexical items; then further mutations to permit larger ones; and finally the Great Leap that yields Merge. Perhaps the earlier steps really took place, though there is no empirical or serious conceptual argument for the belief. A more parsimonious speculation is that they did not, and that the Great Leap was effectively instantaneous, in a single individual, who was instantly endowed with intellectual capacities far superior to those of others, transmitted to offspring and coming to predominate. (Chomsky 2006: 184)

Like Athena, language sprang fully formed from the head of Zeus - or from a proto-Adam. This is Chomsky's biological perspective, but I think it ignores some facts about human biology. For one thing, in articulatory phonetics it is argued that the 'descent of the larynx' is an important evolutionary adaptation for speech, allowing the human vocal mechanism a much wider range of sounds, and hence making possible the 'double articulation' of language - its ability to combine phonemes, a small set of distinctive sounds, into words, a large open set of symbols (Lieberman 1984, cited in Seuren 2004: 18). For another thing, there is a whole complex of human anatomical characteristics: a larger skull accommodating an enlarged cortex; an opposable thumb; 
upright posture; a change in the position of the hips accompanied by a modified birth canal and resulting in a baby (whose large skull is made partly of cartilage, to pass through the birth canal) being born without yet having undergone the development necessary for an upright posture, and without the larynx having descended down the throat; and hairlessness, the "naked ape" (Morris 1967) - that surely could not have been the result of a single spontaneous "rewiring" of the brain or of the genetic code. It is not language alone that is uniquely human, but the whole complex of anatomical features taken together. And this complex, taken together, suggests a history - and no doubt, also a geographical extent of some kind - leading to the adaptations that anthropologists know well: man the toolmaker, able to use his hands for various purposes, while only the feet are used for locomotion; able to communicate precisely, among other purposes, for the cultural transmission of the skills of making tools and other cultural artifacts; man the maker of clothes and shelters, which obviate the need for thick body hair; woman, the nurturer, who is able to take care of children that are born helpless and bring them up to adulthood; and humans, social animals, whose entire lifestyle, made possible by these anatomical adaptations, revolves around the sense of belonging to a social group.

If we accept Chomsky's idea that the goal of linguistic theory is not the description of particular languages, but the explanation of the 'human endowment', does his model of language really provide a full explanation? I would argue that it is a partial explanation (conceding that language is a part of our genetic endowment), but not the whole story. Even from the biological perspective, it fails to explain the nature of language fully.

This can be seen more clearly if we confront Chomsky's idea of what language is with an entirely different theoretical perspective. An excellent account of the dynamics of diachrony is provided by Salikoko Mufwene's theory of language contact.

Language contact, Mufwene $(2001,2005,2007)$ argues, is the result of population contact. He draws upon the analogy of ecology - population biology - to explain the dynamics of human language. He advocates a 'uniformitarian' (2007: 75) hypothesis of creolization, whereby the genesis of creoles should not be regarded as different in kind than the formation of any language varieties, but as an example of the same process of structural differentiation which is always the result of language contact, an aspect of the restructuring of human populations. Seen in this light, the code - language structure - is rooted in language use, in human interaction: "the current literature has usually omitted to consider population structure as an ecological factor that can account for structural differences" (2007: 81). Moreover, Mufwene (2007: 86) argues that the locus of language contact is ultimately inter-idiolectal, since population interaction is the aggregate of individual interactions:

To the extent that contact, situated at the idiolectal level, is acknowledged as a critical ecological factor in the actuation of change, the distinction between 
externally and internally-motivated change becomes simply sociological, and the distinction between changes induced by contact and those independent of contact becomes misguided. Moreover, like evolutionary biology, genetic linguistics (which could also be called evolutionary linguistics) has everything to gain from being interested in issues of language vitality, which can then deal with the demise of languages by structural erosion or by language shift and with the emergence of new varieties. In all these cases of language evolution, the action of competition and selection among competing variants and/or systems is evident.

Recasting Mufwene's argument in Saussurean terms, we can see that 'langue' is ultimately the outcome of an aggregate of individual acts of 'parole', when these are considered in diachronic perspective as the agents of the evolution or 'speciation' of language varieties, i.e., the formation of different structural systems. From the point of view of implications for the evaluation of Chomsky's theory, Mufwene's argument is significant in that it offers an entirely different 'genetic' perspective on language than that offered by Chomsky. In Mufwene's perspective, language structure is rooted in language variation. While Chomsky's idealization of the 'native speaker' assumes that the individual acquires linguistic competence - the internalized knowledge of the language system - statically in abstraction from any variation, ${ }^{14}$ Mufwene's argument implies the opposite - each individual is dynamically embedded, throughout his/her shifting lifetime, in a web of social interactions of language use that affect language acquisition, and, in the aggregate and over the long run of space and time (geographical and historical extent), also affect language structure, the code itself.

\section{Historiography as Metatheory}

It is controversial whether paradigms in linguistics, as well as in other human and social sciences, can replace each other completely. Chomsky, in his reconstruction of the development of his paradigm, seems to imply that this is the case. While he looks for antecedents of his thought in the philosophical tradition, e.g., of Descartes, he denies the relevance of pre-1950s linguistics to linguistic theory today, seeing the "cognitive revolution" (Chomsky 2006: ix) that came about as a result of his rebuttal of Skinner as a watershed and a paradigm shift.

14. For my criticism of the Chomskyan concept of the native speaker, see Radwańska-Williams 2008 . 
In contrast, as argued by Konrad Koerner (1977, 1978a, 1978b, 1989a, 1989b, 1990; Radwańska-Williams 1993: 1-13), the history of linguistics can be seen as a layering of paradigms and approaches. The enterprise of linguistic historiography is the examination of the complex web of relationships in the intellectual history of the discipline. This enterprise makes accessible for us, in the present, the entire gamut of thought about language that has existed in the past. It can highlight currents of influence and it can make possible the discovery of relevant insights. For example, I have argued that the thought of Mikołaj Kruszewski is a covert paradigm in the history of linguistics, an undercurrent that has exercised a subtle influence on the discipline, in its transmission through the thought of Roman Jakobson and the structuralist tradition (Radwańska-Williams 1991b, 1993, 1996, 2002, 2006).

The nature of language as a phenomenon may preclude a tidy replacement of paradigms. Even in a discipline as naturalistic as theoretical physics, the picture has become notoriously complicated, because it has turned out that the material universe itself has a dual nature - as matter and energy - and possibly more than a dual nature, with the dimensions of space and time being elastic (e.g., they disappear at the central point or 'singularity' of a black hole ${ }^{15}$ ) and, at least according to Heisenberg's uncertainty principle, the observer - c.f. Peirce's interpretant? - also playing a role not only in the observation, but possibly in the nature (the state) of the observed. ${ }^{16}$ In the case of language, even Chomsky disavows a reductionistic naturalism: "confidence in 'reduction' to the little that is understood is not necessarily appropriate" (Chomsky 2006: 174). In the Chomskyan paradigm, the language faculty is modular, with syntax being the core component, interfacing with semantics (the logical/conceptual interface) and phonology (phonetic form). As pointed out by Seuren (2004), Chomsky's view of the architecture of the language faculty is somewhat inconsistent: on the one hand, he adheres to a "random generator" (Seuren 2004: 57-61) rather than a mediational view of the centrality of syntax, but on the other hand, he insists that syntax makes possible the creative power of human thought. From the latter position, it is difficult to see how syntax could make possible the creativity of human conceptual

15. http://en.wikipedia.org/wiki/Black_hole,http://en.wikipedia.org/wiki/Gravitational_singularity, and http://cosmology.berkeley.edu/Education/BHfaq.html, retrieved on February 2nd, 2009. It is postulated that at the center of a black hole, matter becomes infinitely dense.

16. http://en.wikipedia.org/wiki/Uncertainty_principle and http://plato.stanford.edu/entries/ qt-uncertainty/, retrieved on February 2nd, 2009. Strictly speaking, the uncertainty principle is not simply an instance of the 'observer effect' that the observation affects the observed (known in anthropology and the social sciences), but of the nature of physical reality at the quantum level being different than (our epistemological construct of) reality at the macro-level according to the 'classical laws of motion'. 
expression without mediating the semiotics of thought - the association between concept and phonetic form.

Thus language, even as conceded in the Chomskyan paradigm, has a triadic nature. Moreover, as I have argued above, the dimension of social variation and diachrony is essential, not accidental, to language as a phenomenon. Thus, mysteriously, language is even more than a triad, or more accurately, a double triad, like a four-dimensional polygon, projecting the triadic semiotics of thought into the fourth dimension, which is space-time, the dimension/extent/extension of social life.

This exponential triadic conception of language is in contradiction to Chomsky's claim that E-language (external, extensional language) is non-essential to the nature of the phenomenon, and therefore outside the scope of linguistic theory. But perhaps this correction is long overdue. At least one cannot fault Chomsky for having sought ever more precisely to define the terms of his genetic theory. Thus the above conception of a double triad can also be recast in Chomskyan terms, but taking care to point out that (1) E-language is essential, not accidental (in the philosophical sense of essence and accidence ${ }^{17}$ ), and (2) that in the semiotic triad of I-language, linguistics has been more successful so far in defining the formal terms of the triad, the language code, i.e., in the Chomskyan paradigm, the axis of phonology-syntax-semantics, than in defining the relationship between code and thought, and defining the nature of thought. The relationship between code and thought is itself triadic, in that the interpretant, psyche/ spirit/volition (interpretant2), is the 3rd term, freely directing thought to whatever one wills, or, if not exactly directed, the thought arising spontaneously as reaction to/interpretation of the world. Possibly, we have a triple triad.

Peirce would be happy if language could be shown to be a triple triad. However, given the multidimensional nature of language, it may be difficult to attain a 'unified theory' of language, just as it has been found difficult in theoretical physics to provide a 'unified theory' of the material world, ${ }^{18}$ one that would marry Einstein's theory of relativity and Heisenberg's uncertainty principle, and unify the account of the four forces of physical nature - electromagnetism, the strong and weak nuclear forces, and gravity.

As articulated in the structuralist tradition, including the work of Mikołaj Kruszewski, Ferdinand de Saussure and Roman Jakobson, the nature of language as a complex phenomenon is psychophonetic, semiotic, and social. For Chomsky, the nature of language is mental/cognitive, genetic and biological. It is possible that these two perspectives can complement each other, or rather, that the historically examined intersection between them can yield a more unified view of the entire scope of the discipline.

17. http://en.wikipedia.org/wiki/Essence, retrieved on February 2nd, 2009.

18. http://en.wikipedia.org/wiki/Unified_field_theory, retrieved on February 2nd, 2009. 
Firstly, Chomsky's theory of the genetically determined human language faculty has served to focus the scope of linguistic inquiry on the biological uniqueness of human beings. Paradoxically, this biological uniqueness, as pointed out in the quotation from Hallward (2008) at the outset of this paper, sets human beings, and the human capacity for language, at a distance from the rest of the natural world. I think that this distance is maximized by Chomsky's emphasis on syntax. Our closest natural relatives, chimpanzees and gorillas, have been shown not to have the capacity for syntactic structure of the kind demonstrated by the nursery rhyme The house that Jack built, i.e., the property of recursion and relativization that makes human language a vehicle for the precise expression of complex and abstract thought, displaced in spacetime from the 'here and now'. And yet the animal studies have shown that the great apes are capable of acquiring some of the vocabulary of human sign language, i.e., of acquiring a rudimentary lexicon of linguistic signs. They do have a rudimentary semiotic capacity. To that extent, human beings are not biologically unique. By arguing that pre-1950s linguistics is no longer relevant to linguistic inquiry, Chomsky sets aside the structuralist insights into semiotics and thereby excludes an area of inquiry into the nature of language that is essential even for the biological question itself, as posed by Chomsky, the question of the extent to which human beings are unique and the extent to which it is language that makes them unique in the natural world and/or sets them apart from the natural world.

Secondly, Chomsky's exclusion of the domain of language use from the scope of linguistic inquiry has done a disservice to linguistics as a profession. The study of language use has continued in various subfields of linguistics, for example in discourse analysis, poetics, and sociolinguistics, and yet these subfields have been to some extent perceived as marginalized, on the periphery with respect to what is perceived as the hard core of linguistics, centered around generative syntax and to a lesser extent, generative phonology. In the Chomskyan perspective, there seems to be a subtle equation or conflation between the 'genetic' and the 'mental': human beings have unique genes and unique minds, and it is language that makes them unique, ergo, what is (uniquely) worthy of study is that aspect of the phenomenon of language, complex/relativized syntactic structure, which is correlated with the unique capacity of the human mind for generating sentences. This does not directly serve to explain how the sentences come to be meaningful, which, I think, touches on the semiotic question - how language form is associated with meaning - and on the social question, as articulated in structuralism, of language as a 'social fact', the social fact of a shared system being the stabilizer and guarantor of its meaningfulness. The emphasis on language as a mental entity also excludes large bodies of language data - speech, discourse and text - as 'external' to the mind, merely the 'excretions' of the brain. But language data are the only directly observable access we have to language. One can study the 
electrical pattern of neuronal activation in the brain, or the psycholinguistic response time to verbal stimuli, but the direct data accessed in such studies are the electrical patterns or the response times. In the typical socially meaningful linguistic exchange between speaker-hearers, signers-seers, or writers-readers, it is language data that are exchanged - bits of speech (or of sign language), discourse and text. Language use is the basic stuff of the fabric of human society. Chomsky is fond of saying (metaphorically) that language is like an organ of the body. Taking up that metaphor, one could say that studying language form without studying language use is like studying the anatomy of the heart without studying the cardiovascular system of blood circulation. The heart makes circulation possible, and syntax makes possible the generation of sentences and hence the expression of complex and abstract thought. But the life of the body is sustained through the circulation of blood, and the vitality of human society is sustained through the exchange of language. Just as cardiology studies both heart and blood, linguistics should study both language form and language use.

Finally, Chomsky's conflation of the genetic and the mental, coupled with his exclusion of the social, has served to marginalize what had traditionally been a central area of language as a phenomenon - the dimension of diachrony. Granted that language is (in part) a biological phenomenon, the human species does not change through time as fast as society changes. Language, as an integral part - the lifeblood - of society, changes through time. On the micro level, as shown by Mufwene, diachronic change can be traced to language variation, which has a geographical (spatial) extent as well as various vertical or cross-sectional sociolinguistic layers. Thus the dimension of diachrony is in large part social, although the passage of time is a physical phenomenon. The pace of social change sets us apart from the natural world, where animal societies, to the extent that they change, change at a biological pace without the overlay of linguistic heritage and with little if any cultural transmission. Language change is a part of human uniqueness. Indeed the existence of different languages and dialects is a sort of cultural speciation unique to humans. Human beings tend to think of their identity not primarily as "human" (vs. "chimpanzee", "gorilla", "lion", "gazelle", etc.) but as linguistic/ethnic/regional/national (Chinese vs. Japanese vs. Indian vs. American, etc). In today's globalized world, identity boundaries are blurring, but they are still potent. The historical existence of and formation of different languages is an essential part of our identity as human beings. Historical linguistics, going all the way back to 19th century comparative grammar, has extensively studied diachronic change. The historical study of language deserves to be a central part of linguistic inquiry.

Chomsky is such a towering figure that one hesitates to point out lacunae in his thought. I have tried to do so from an epistemological perspective, which, I hope, objectifies my criticism. The question which I hope to have addressed is that of the boundaries and scope of the discipline of linguistics and of the complex nature of the 
phenomenon of language. I have argued that the apparent failure of the Chomskyan paradigm to encompass the full scope of linguistics is due to his exclusion of two significant areas of language as a phenomenon: the semiotic nature of language, and the dimension of language use and language variation.

\section{References}

Aikhenvald, Alexandra Y. 2003. Classifiers: a typology of noun categorization devices. Oxford: Oxford Univ. Press.

Attridge, Derek. 1996 [1987]. "Closing Statement: Linguistics and Poetics in Retrospect". The stylistics reader: from Roman Jakobson to the present, ed. by Jean Jacques Weber, 36-53. London; New York: Arnold \& St. Martin's Press.

Baudouin de Courtenay, Jan. 1888-1889. "Mikołaj Kruszewski, Jego życie i Prace Naukowe [Mikołaj Kruszewski, His Life and Scholarly Works]”. Prace Filologiczne 2: 3. 837-849, 3: 1. 116-175.

Berezin, Fedor Mixajlovič. 2001. "Mikolaj Kruszewski and 20th-Century Linguistics". Towards a history of linguistics in Poland: from the early beginnings to the end of the twentieth century, ed. by E.F.K. Koerner \& A.J. Szwedek, 209-231. Amsterdam/Philadelphia: John Benjamins Pub. Co.

Chomsky, Noam. 1965. Aspects of the theory of syntax. Cambridge: M.I.T. Press.

Chomsky, Noam. 2006. Language and mind. Cambridge; New York: Cambridge University Press.

Crystal, David. 2008. A dictionary of linguistics and phonetics. 6th edition. Malden, Mass.; Oxford: Blackwell.

Fish, Stanley. 1996 [1973]. "What is Stylistics and Why are They Saying Such Terrible Things about It?" The stylistics reader: from Roman Jakobson to the present, ed. by Jean Jacques Weber, 94-116. London, New York: Arnold \& St. Martin's Press.

Freeman, Margaret H. 1995. "Metaphor Makes Meaning: Dickinson's Conceptual Universe". Literary pragmatics: cognitive metaphor and the structure of the poetic text. Special issue of the Journal of pragmatics, v. 24, no. 6, ed. by Masako K. Hiraga \& Joanna Radwańska-Williams, 643-666. Amsterdam/New York: Elsevier.

Freeman, Margaret H. 1997. "Grounded Spaces: Deictic-Self Anaphors in the Poetry of Emily Dickinson". Language and Literature 6: 1. 7-28.

Freeman, Margaret H. 2000. "Poetry and the Scope of Metaphor: Toward a Cognitive Theory of Literature". Metaphor and Metonymy at the Crossroads, ed. by Antonio Barcelona, 253-280. New York: Mouton de Gruyter.

Freeman, Margaret H. 2007a. "The Fall of the Wall between Literary Studies and Linguistics: Cognitive Poetics". Applications of Cognitive Linguistics: Foundations and Fields of Application, ed. by Gitte Kristiansen, Michel Achard, Rene Dirven \& Francisco Ruiz de Mendoza. Berlin: Mouton de Gruyter.

Freeman, Margaret H. 2007b. "Poetic Iconicity". Cognition in language : volume in honour of professor Elżbieta Tabakowska, ed. by Władyslaw Chłopicki, Andrzej Pawelec \& Agnieszka Pokojska, 472-501. Kraków: Tertium.

Fromkin, Victoria, Robert Rodman \& Nina M. Hyams. 2003 [1998]. An introduction to language. Boston: Thomson/Heinle. 
Frost, Robert. 1920. “The Road Not Taken”. Retrieved on June 3, 2007 from Bartleby.com Great Book Online, http://www.bartleby.com/119/1.html.

Hallward, Peter. 2008. “The Politics of Prescription”. Retrieved on July 17th, 2008 from http:// slash.interactivist.net/node/10935.

Hiraga, Masako K. 1994. "Diagrams and Metaphors: Iconic Aspects of Language". Metaphor and iconicity. Special issue of the Journal of Pragmatics, Vol. 22, no. 1 (July 1994), ed. by Masako K. Hiraga \& Joanna Radwánska-Williams, 5-21. Amsterdam: Elsevier Science.

Hiraga, Masako K. 2002. "The Interplay of Metaphor and Iconicity: A Cognitive Approach to Poetic Texts”. Special Issue on Metaphor, ed. Tomasz Komendziński, Theoria et Historia Scientiarum: International Journal for Interdisciplinary Studies VI:1. 179-244.

Hiraga, Masako K. 2003. "How Metaphor and Iconicity Are Entwined in Poetry: a Case in Haiku”. From Sign to Signing, ed. by Wolfgang Muller and Olga Fisher, 317-335. Amsterdam: John Benjamins.

Hiraga, Masako K. 2005. Metaphor and iconicity: a cognitive approach to analysing texts. Houndmills, Basingstoke, Hampshire ; New York: Palgrave Macmillan.

Jakobson, Roman. 1960. "Linguistics and Poetics". Style in language, ed. by Thomas A. Sebeok, 350-377. Cambridge: Technology Press of M.I.T.

Jakobson, Roman. 1967. “Znaczenie Kruszewskiego w rozwoju językoznawstwa ogólnego [The significance of Kruszewski in the development of general linguistics]”. Wybór pism [Selected writings], ed. by Kruszewski, x-xxv. Warszawa-Kraków: Zakład Narodowy im. Ossolińskich. Jakobson, Roman. 1971. Selected Writings. Vol. II. The Hague: Mouton.

Jakobson, Roman. 1985. Verbal art, verbal sign, verbal time. Minneapolis: University of Minnesota Press.

Jakobson, Roman. 1987a [1961]. "Poetry of Grammar and Grammar of Poetry”. Language in literature, ed. by Krystyna Pomorska \& Stephen Rudy, 121-144. Cambridge, Mass.: Belknap Press.

Jakobson, Roman. 1987b. “Subliminal Verbal Patterning in Poetry”. Language in literature, ed. by Krystyna Pomorska and Stephen Rudy, 250-261. Cambridge, Mass.: Belknap Press.

Jakobson, Roman. 1987c. Language in literature. Cambridge, Mass.: Belknap Press.

Joos, Martin. 1957. Readings in linguistics 1: the development of descriptive linguistics in America, 1925-56. Chicago: University of Chicago Press.

Joseph, John E. 2000. Limiting the Arbitrary: Linguistic naturalism and its opposites in Plato's Cratylus and modern theories of language. Amsterdam/Philadelphia: John Benjamins.

Koerner, E.F.K. 1973. Ferdinand de Saussure; origin and development of his linguistic thought in Western studies of language, a contribution to the history and theory of linguistics. Braunschweig: Vieweg.

Koerner, E.F.K. 1977. “The Humboldtian Trend in Linguistics”. Studies in descriptive and historical linguistics: Festschrift for Winfred P. Lehmann, ed. by Paul J. Hopper, 145-158. Amsterdam: John Benjamins.

Koerner, E.F.K. 1978a. Toward a historiography of linguistics: selected essays. Amsterdam: John Benjamins.

Koerner, E.F.K. 1978b. "Towards a Historiography of Linguistics: 19th and 20th century paradigms". Toward a historiography of linguistics: selected essays, ed. by E.F.K. Koerner, 21-54. Amsterdam: John Benjamins.

Koerner, E.F.K. 1986. “Mikolaj Kruszewski's Contribution to General Linguistic Theory”. Linguistics across historical and geographical boundaries, ed. by Dieter Kastovsky \& A.J. Szwedek, vol. 1, 53-75. Berlin; New York: Mouton de Gruyter. 
Koerner, E.F.K. 1989a. Practicing linguistic historiography: selected essays. Amsterdam/Philadelphia: John Benjamins.

Koerner, E.F.K. 1989b. "Continuities and Discontinuities in the History of Linguistics". Practicing linguistic historiography : selected essays, ed. by E.F.K. Koerner, 69-78. Amsterdam/ Philadelphia: John Benjamins.

Koerner, E.F.K. 1990. “On 'Unrewriting' the History of Linguistics”. History and historiography of linguistics: papers from the Fourth International Conference on the History of the Language Sciences (ICHoLS IV), Trier, 24-28 August 1987, ed. by Hans-Josef Niederehe \& E.F.K. Koerner, vol. 1, 63-78. Amsterdam/Philadelphia: John Benjamins.

Koerner, E.F.K. 1995. “Editor’s Introduction: Mikołaj Kruszewski’s Contribution to General Linguistics." Writings in general linguistics, by Mikolaj Kruszewski ed. by E.F.K. Koerner, xi-xxxix. Philadelphia: John Benjamins.

Kruszewski, Mikołaj. 1879. “Ob 'analogii' i 'narodnoj etimilogii' ('Volksetymologie') [On 'analogy' and 'folk etymology' ('Volksetymologie')]”. Russkij Filologičeskij Vestnik 2: 3. 109-120

Kruszewski, Mikołaj. 1883. "Očerk nauki o jazyke [An outline of the science of language]”. Učenye zapiski imperatorskago Kazanskago Universiteta 50: 1 (January-April 1883), Supplement.

Kruszewski, Mikołaj \& Ernst Frideryk Konrad Koerner. 1995. Writings in general linguistics. Philadelphia: John Benjamins.

Kuhn, Thomas S. 1962. The structure of scientific revolutions. Chicago: University of Chicago Press. Kuryłowicz, Jerzy. 1927. “ə Indo-europeen et h Hittite”. Symbolae grammaticae in honorem Ioannis Rozwadowski, vol. I, 95-104. Cracoviae: Gebethener \& Wolff.

Lakoff, George. 1993. “The Contemporary Theory of Metaphor”. Metaphor and thought, ed. by Andrew Ortony, 202-251. Cambridge; New York: Cambridge University Press.

Lieberman, Philip. 1984. The biology and evolution of language. Cambridge, Mass.: Harvard University Press.

Lightbown, Patsy \& Nina Margaret Spada. 2006. How languages are learned. Oxford: Oxford University Press.

Liszka, James Jakob, Edwin Battistella \& Michael Haley. 2000. "Linguistics and Semiotics II: C.S. Peirce's influence on 20th-century linguistics". History of the language sciences: an international handbook on the evolution of the study of language from the beginnings to the present = Geschichte der Sprachwissenschaften: ein internationales Handbuch zur Entwicklung der Sprachforschung von den Anfängen bis zur Gegenwart = Histoire des sciences du langage: manuel international sur l'évolution de l'étude du langage des origines à nos jours, ed. by Sylvain Auroux, E.F.K. Koerner, Hans- J. Niederehe \& Kees Versteegh, vol. 3, 2589-2600. Berlin ; New York: Walter de Gruyter.

Mill, John Stuart. 1843. A system of logic, ratiocinative and inductive: being a connected view of the principles of evidence, and methods of scientific investigation. London: J.W. Parker.

Morris, Desmond. 1967. The naked ape: a zoologist's study of the human animal. New York: Dell.

Mufwene, Salikoko S. 2001. The ecology of language evolution. Cambridge, UK; New York: Cambridge University Press.

Mufwene, Salikoko S. 2005. Créoles, écologie sociale, évolution linguistique: cours données au Collège de France durant l’automne 2003. Paris, France: L'Harmattan.

Mufwene, Salikoko S. 2007. "Population Movements and Contacts in Language Evolution". Journal of Language Contact - THEMA 1.63-91.

Osthoff, Hermann \& Karl Brugmann. 1878. "Vorwort". Morphologische Untersuchungen auf dem Gebiete der indogermanischen Sprachen 1.iii-xx. Leipzig: S. Hirzel. 
Paradowski, Michal. 2008. "ELF, ICC, and the N/NEST — the challenges for English-language education in the 21st Century". Proceedings of the 1st International Conference on English, Discourse and Intercultural Communication. University of Louisville, Kentucky: Intercultural Forum Online Monograph Series.

Peirce, Charles S. 1955 [1940]. Philosophical writings of Peirce. New York: Dover Publications.

Radwańska-Williams, Joanna. 1991a = Williams, Joanna Radwańska. 1991a.

Radwańska-Williams, Joanna. 1991b = Williams, Joanna Radwańska, 1991 b.

Radwańska-Williams, Joanna. 1993 = Williams, Joanna Radwańska. 1993.

Radwańska-Williams, Joanna. 1994. “The Problem of Iconicity”. Metaphor and iconicity = Journal of pragmatics, Vol. 22, no. 1 (July 1994), ed. by Masako K. Hiraga and Joanna RadwánskaWilliams, 23-36. Amsterdam: Elsevier Science.

Radwańska-Williams, Joanna. 1996. “Mikołaj Kruszewski’s Semiotics”. Multiple perspectives on the historical dimensions of language, ed. by Kurt R. Jankowsky, 153-159. Münster: Nodus Publikationen.

Radwańska-Williams, Joanna. 2000. = Williams, Joanna Radwańska. 2000.

Radwańska-Williams, Joanna. 2002. “The Polish Tradition in Linguistics”. Historiographia Linguistica 29: 3. 391-430.

Radwańska-Williams, Joanna. 2006. "Examining Our Patrimony: The Case of the Kazan' School”. Historiographia Linguistica 33: 3. 357-390.

Radwańska-Williams, Joanna. 2008. “The 'Native Speaker' as a Metaphorical Construct”. Metaphors for Learning: Cross-cultural Perspectives, ed. by Erich Adalbert Berendt. Amsterdam/ Philadelphia: John Benjamins.

Radwańska-Williams, Joanna. 2009. “The Hidden Iconic Structure of a Poem”. Proceedings of the 1st International Conference on English, Discourse and Intercultural Communication. University of Louisville, Kentucky: Intercultural Forum Online Monograph Series.

Ross, John R. 2000. “The Taoing of a Sound: Phonetic Drama in William Blake's The Tyger”. Phonosymbolism and poetic language, ed. by Patrizia Violi, 99-145. Turnhout: Brepols.

Saussure, Ferdinand de. 1879. Mémoire sur le système primitif des voyelles dans les langues indoeuropéennes. Leipsick: B.G. Teubner.

Saussure, Ferdinand de. 1916. Cours de linguistique générale. Paris: Payot.

Schlieben-Lange, Brigitte. 1974. Soziolinguistik. Stuttgardt: Kohlhammer.

Seuren, Pieter A.M. 2004. Chomsky's minimalism. New York: Oxford University Press.

Shapiro, Michael. 1998. “Sound \& meaning in Shakespeare's sonnets”. Language 74: 1. 81-103.

Thomas, Margaret. 2002. "Roger Bacon and Martin Joos: Generative Linguistics' Reading of the Past”. Historiographia Linguistica 29: 3. 339-378.

Violi, Patrizia. 2000. Phonosymbolism and poetic language. Turnhout: Brepols.

Waugh, Linda R. 1985. “The Poetic Function and the Nature of Language”. Verbal art, verbal sign, verbal time, ed. by Roman Jakobson, Krystyna Pomorska and Stephen Rudy, 143-168. Minneapolis: University of Minnesota Press.

Weber, Jean Jacques. 1996. The stylistics reader : from Roman Jakobson to the present. London; New York: Arnold \& St. Martin's Press.

Williams, Joanna Radwańska. 1991a. "Metaphor in a Translation by Boris Pasternak of Shakespeare's Sonnet 73”. Cross-Cultural Communication, East and West, ed. by Paul George Fendos. Taiwan: National Cheng Kung University.

Williams, Joanna Radwańska. 1991b. "Baudouin de Courtenay and his Place in the History of Linguistics”. Historiographia Linguistica 18: 2/3. 349-367. 
Williams, Joanna Radwańska. 1993. A paradigm lost: the linguistic theory of Mikołaj Kruszewski. Amsterdam/Philadelphia: John Benjamins.

Williams, Joanna Radwańska. 2000. “Arbitrariness and Iconicity”. Phonosymbolism and poetic language: Semiotic and cognitive studies ; 7, ed. by Patrizia Violi, 85-97. Turnhout: Brepols.

\section{Appendix}

\section{The Road Not Taken \\ by Robert Frost ${ }^{19}$}

Two roads diverged in a yellow wood, And sorry I could not travel both And be one traveler, long I stood And looked down one as far as I could

To where it bent in the undergrowth; Then took the other, as just as fair, And having perhaps the better claim, Because it was grassy and wanted wear; Though as for that the passing there Had worn them really about the same,

And both that morning equally lay In leaves no step had trodden black. Oh, I kept the first for another day! Yet knowing how way leads on to way, I doubted if I should ever come back.

I shall be telling this with a sigh Somewhere ages and ages hence:

Two roads diverged in a wood, and I I took the one less traveled by, And that has made all the difference.

19. Retrieved on June 3, 2007 from Bartleby.com Great Book Online, http://www.bartleby. com/119/1.html. 

PART I

The young revolutionary (1950-1960) 



\title{
"Scientific revolutions" and other kinds of regime change
}

\author{
Stephen O. Murray*
}

I find it curious that "revolution" is such a positively valued label in the history of science. Innovation and novelty are, I realize, highly valued, both in academic fields and in other realms, which accounts for the widespread claims put out on at least a weekly basis that someone or another has "revolutionized" something or another. In his morphology of "scientific revolutions," (or, I suspect in "revolutions in cosmological models") Thomas S. Kuhn (1962) contrasted "revolutionary" science with "normal" science. The former connotes "bold," the latter "boring," and people understandably prefer to be thought of as bold rather than boring, as making leaps to new understandings rather than incremental steps.

Kuhn himself wrote of the high cost of "retooling" conceptually, and of the difficulties of convincing those accustomed to a set of assumptions that they have been using to discard those assumptions and ways of working. Kuhn (1970: 150) quoted German physicist Max Planck's pungent generalization: "A new scientific truth does not triumph by convincing its opponents and making them see the light, but rather because its opponents eventually die and a new generation grows up that is familiar with it." That is, most of those already established in a science or any other field are not willing (or able!) to "retool," do not "radically" rethink the bases of their field.

With pitched generational battles during the late 1960s in the United States and western Europe, Chomskian linguists retroactively elevated what had seemed in 1957 as an incremental advance of the transformational syntactic method of Zellig S. Harris $(1946,1951)$ by his most famous student, Noam Chomsky, as a "revolution." One early leader of the theory group told me: “'Our' little Kuhnian revolution was in some ways actually more typical than his physics case" (Robert Lees, personal communication, 26 April 1977), while Leiber (1975) hailed Chomsky "Einstein of linguistics."

\footnotetext{
*In addition to my gratitude to Konrad Koerner for encouragement over the course of many years to my sociological approach to theory groups in linguistics (and for causing the discussion of what "grammar" meant to the predecessors of neo-Bloomfieldians), and to Douglas Kibbee for inviting me to the fest and for enhancing the readability of this chapter; I would like to acknowledge the guidance and encouragement of this line of work by Keith Basso, Regna Darnell, John Fought, John Gumperz, Dennis Magill, Robert Nisbet, and William Samarin, way back when I was a graduate student.
} 
The neo-Bloomfieldian generation (of which Zellig Harris was a particularly distinguished member) mostly focused on phonology (phonemic analysis) and morphology and did not have much stake in or commitment to any method or theory of syntactical analysis. That is, they were not working in any particular "paradigm" of syntactical analysis or - with the exception of Harris - on syntactical analysis at all. Making syntax the focus of linguistics was a radical change, and in this sense of trying to explain a class of phenomena that formerly had been peripheral, it would be difficult to dispute that there was a "Chomskian revolution," albeit one that began with Harris's work, not with the "revelations" of Syntactic Structures (Chomsky 1957). It is necessary to stipulate that neo-Bloomfieldians did not regard syntax as unimportant. Rather they had mostly postponed trying to figure out syntax until after they were satisfied they had explained the more basic/elemental "levels" of phonology and morphology (levels they believed were distinct). They maintained a taboo on mixing "levels" of analysis, condemning violations of this taboo by Kenneth L. Pike or anyone else who used data from one level in analyzing another.

My sense of the late 1950s is that neo-Bloomfieldians generally believed that phonemic analysis was well established, and had only to be deployed on sound patterns of languages not yet analyzed, and that the tools for laying out morphological structures was also well established, so that the time to tackle the complexity of grammar had arrived. The approach of Chomsky (1957) was pleasingly (to neo-Bloomfieldians) formalist and mathematical-looking, and was not perceived as a threat to structuralist linguistics in its American incarnation.

The middle-1950s in the USA were a time in which there was considerable interest in and work on "grammar" as grammar was and had been understood in the linguistic anthropology tradition of Franz Boas, Edward Sapir, and Benjamin Whorf; that is, in obligatory grammatical categories in natural languages, particularly the unwritten ones for which anthropological linguists were writing grammars (as well as dictionaries). Especially during the Whorfian vogue of the early 1950s, grammar (grammatical categories) was already a central concern - and one very directly related to cognitive processes (so that a "cognitive revolution" was not possible).

Before returning to senses in which there was one or more "Chomskian revolution" and the lure of the "revolutionary" label during and after the 1960s, I am going to review traditions of grammatical study available by the mid-1950s. There was much that was not explained - indeed, much that was not even asked — in theories of grammar (and descriptions of grammars). These were not "anomalies" in Kuhn's sense of the term, because there was no generally accepted "paradigm." There may have been an expectation that the methodological dogma "text reveals structure" would someday account for syntax, but I don't think that anyone in the mid-1950s thought that there was a remotely finished edifice of syntactic theory, though there were certainly traditions that believed that "grammar" (albeit 
not in the sense of what "grammar" encompassed in any of the waves of Chomskian "revolutions") was a "window to the mind" (of those raised in particular language cultures). Moreover, simultaneously with the work of Harris and Chomsky, others in the US were approaching theorizing syntax, including Kenneth Pike and André Martinet and (two of whose work Chomsky was unarguably aware during the late-50s), Victor Yngve and Yehoshua Bar-Hillel).

\section{The unsatisfying state of grammatical analysis, ca. 1955}

\subsection{Boas}

Franz Boas (1858-1942) was a German-trained Columbia University anthropologist who fostered work on North American Indian tribes and languages He was the prime mover of institutionalization of anthropology within American universities in the late-19th and early 20th centuries, and actively involved with two younger scholars whose ideas are discussed below (Edward Sapir and Leonard Bloomfield) who, with Boas and others, founded the Linguistic Society of America in 1924 and sought to raise standards of linguistic description and analysis and to professionalize linguistics in US universities (see Murray 1994: 121-25; 2001). For Boas, the classifications that are obligatory in a particular language provide insight into how users of each language are predisposed to think. In the Herderian tradition, Boas was interested in showing the particular "genius" of each particular people, as their thought processes are revealed in their language's "inner form," that is, in mapping the world through differing obligatory and optional grammatical features such as gender, number, animateness, definiteness, tense, or aspect. Boas (1911:20) reasoned, "Since the total range of personal experience which language serves to express is infinitely varied, and its whole scope must be expressed by a limited number of phonetic groups, it is obvious that an extended classification of experience must underlie all articulate speech," and continued,

Since ideas must be expressed by being reduced to a number of related ideas, the kinds of relation become important elements in articulate speech, and it follows that all languages must contain formal elements... In each language, only a part of the complete concept that we have in mind is expressed. Each language has a peculiar tendency to select this or that aspect of the mental image." (Boas 1911: 23, 39)

That is, in "various languages, different fundamental categories will be found" (p. 39). As Dell Hymes (1964: 117) explained Boas's point, "We would be immobilized if we tried to notice, report, and think of all possible discriminations in experience at each moment." Jakobson (1959: 140-1) provides an example contrasting the requirement of English that the definiteness or indefiniteness of an object must be explicit and the 
contrasting requirement of Russian that the gender of a person and the completion or non-completion of an act must be specified:

To denote time or plurality, those languages which have no tense or grammatical number resort to lexical means. Thus, the true difference between languages is not in what may or may not be expressed, but in what must or must not be conveyed by the speakers. If a Russian says: Ja napisal prijatelju — "I wrote a friend", the distinction between definiteness and indefiniteness of reference ("the" vs. "a") finds no expression, whereas the completion of the letter is expressed by the verbal aspect and the sex of the friend by the masculine gender. Since in Russian these concepts are grammatical, they cannot be omitted in communication, whereas after the English utterance "I wrote a friend," interrogations whether the letter has been finished and whether it was addressed to a boy-friend or to a girl-friend can follow.

Most of the time we rely on the discriminations to which our language is calibrated A language channels thought and expression by compelling that some of these must be made explicit in utterances. Different languages require different distinctions. What must be noted in one language is optional in another. For Boas (1911: 77), it is the task of the analyst [linguist] to discover the obligatory, but largely unconscious structures of actual languages. Analytical groupings (of grammar, phonology, and lexicon) "depend entirely upon the inner form of each language" and the analyst's goal for Boas was to describe the forms of thought in a language by an analysis of the forms of speech of native speakers (transcribed into texts), without preconceptions about the structure of the language. In particular, Boas and those influenced by him who described North American languages, rejected forcing these languages into the "parts of speech" categories of Latin (or, more properly, Aristotelian) grammar (Boas 1911: 31,38,77; Sapir 1921: 117-19).

Nonetheless, in the grammatical section (pp. 14-24) of the one description of a language (Pochultan Nahuatl from the Mexican state of Oaxaca) that Boas himself provided in the first volume of The International Journal of American Linguistics (a journal which he founded), the categories are quite traditional: plural; possessive; composition (mostly diminutives directly parallel to Mexican Spanish); pronouns; preterite, present, imperfect, and imperative verb forms; along with the grammatical processes (see below) of reduplication, and composition (Boas 1917: 14-24). Those papers written by others appearing in the first two volumes of IJAL (between 1917 and 1923) which were not texts, lexicons, proposed historical reconstructions, or phonological analyses, dealt with verb stems, prefixes, and reduplication. None analyzed sentences.

Generally, Boas presented massive amounts of native texts with little or no analysis. The lexicon listing for Pochultan Nahuatl exceeds in length the grammatical inventory listed, which exceeds the phonological description. The descriptions of languages in The Handbook of American Indian Languages, that Boas also edited, similarly neglect analyses of sentences in favor of cataloging kinds of particles and affixes. For instance, 
there is less than a page on sentence structure in Frachtenberg's (1922) description of Siuslawan, in contrast to 46 pages on grammatical processes and 13 thirteen on phonology. There are 40 pages on phonology, 202 on morphology, and none on syntax in Bogoras [and Boas]'s (1922) description of Chuckchee [Chukchi]. The greatest exemplar of a Boasian description of a language, Sapir's (1922) Takelma, also focuses on morphology, as is discussed in the next section below. ${ }^{1}$

Although all languages classify, some classify more than others. Boas (1938: 133) was quick to warn that there is no correlation between the amount of obligatoriness in a language and the degree of civilization of the language's speakers, nor does a paucity of obligatory categories imply muddled, obscure speech. Distinctions which are not grammatically obligatory can be lexicalized. Indeed, Boas (1911: 122) suggested that there is an inverse correlation between the extent of obligatory classification in a language and the size of a language's vocabulary (lexicon).

\subsection{Sapir}

As a critic of simplistic 19th century schemes of human nature and of human evolution, Boas emphasized the differences between the focuses and the means of different languages, especially those of Pacific Coast North American native peoples, rather than seeking to identify universal grammatical features. Despite the considerable variation which he documented, Boas accepted some grammatical relations as probably universal, specifically, a distinction between a subject and a predicate, and between predication and attribution. Boas's student Edward Sapir (1884-1939; see Darnell 1989) was far more interested in universals than was his teacher, and sought to order and explain diversity.

According to legend (codified by Sapir's protégé Morris Swadesh 1939: 132), Boas showed Sapir, then a graduate student studying Germanic philology "by indubitable example from American Indian languages that there were counter-examples for every generalization about languages that Sapir thought to be certain and exceptionless." The

1. It might be argued (indeed, Charles Hockett did) that phonological sketches take less space just because their structures were better understood by Americanists in the first third of the twentieth century, so that more economical means could account for the phenomena. It is impossible for me to believe that anyone considered sentence formation so transparent that the brief mentions in the "grammars" accounted for the range of syntactical phenomena in any language, and permitted a similar economy of means. Rather, I would gloss an attitude continuing at least through the Second World War as "We've figured out phonology, and are progressing through morphology. Soon we'll get around to syntax." I would not attribute this attitude to Leonard Bloomfield. As will be shown below, he was interested in syntax early in his career (aware not merely of Port Royal grammarians, but steeped in Pānini; see Bloomfield 1987 [1916]: 47, note 1; Rogers in Hall \& Koerner 1987), and had several goes at syntax (Bloomfield 1933: 170-206 and in Bloch \& Trager 1942). 
timing for this story is off: Murray and Dynes 1986 showed that Sapir took a course from Boas as an undergraduate. Nonetheless, this possibly apocryphal story condenses the basic pattern of the relationship between Sapir seeking valid generalizations about language and Boas posing exceptions into one dramatic conversion experience. In reality, Sapir's posing of generalizations being met by skeptical suggestions of counter-examples from Boas continued for the rest of Sapir's life.

Sapir tried to bring order both in space and in time to the diversity of data on human languages with which he was familiar. In proposing historical links between what other Americanists saw as distinct languages, Sapir drew frequently upon phonetic laws and occasionally upon comparison of lexicon, but viewed syntactical evidence as the best evidence of genetic relationship. While "borrowing" (and adapting the sounds in "borrowed" words) is very common, he believed that "those fundamental features of structure, hidden away at the very core of the linguistic complex" are nearly impervious to outside influence: "Language is probably the most self-contained, the most massively resistant of all social phenomena. It is easier to kill it off than to disintegrate its individual forms" Sapir (1921: 205-6) wrote. Thus, in proposing typologies of linguistic structure and historical reconstructions, he drew almost exclusively on the core of languages - their grammars.

As for Boas, what Sapir called "grammatical categories" are the classes of morphemes which must be explicit in a particular language. As Sapir (1921: 98) put it, there is in all languages a "tendency to construct schemes of classifications into which all the concepts of language must be fitted." Gender for all objects is a familiar case. Such obligatory categorization make up a system of dogma surviving original expressive functions - form for form's sake. Indeed,

Language is not merely a more or less systematic inventory of the various items of experience which seem relevant to the individual, as is so often naively assumed, but is also a self-contained, creative, symbolic organization, which not only refers to experience... but actually defines experience for us by reason of its formal completeness and because of our unconscious projection of its implicit expectations into the field of experience. (Sapir 1931: 578)

To a far greater extent than the philosopher realized, he is likely to be a dupe of his [native language's] speech-forms The mould of his thought, which is typically a linguistic mould, is apt to be projected into his conception of the world. (Sapir 1949 [1924]: 157)

This strand of Sapir's thought was developed by his student Benjamin Lee Whorf (1897-1941; see Whorf 1945, 1956). Like Sapir, in discussing language channeling the usual flow of thought, Whorf focused on differences between grammatical categories of genetically unrelated languages. Most of the work attempting to test what has come to be known as 'the Sapir-Whorf hypothesis' has dealt with lexical 
differences, rather than with the grammatical processes which Sapir and Whorf viewed as fundamental. ${ }^{2}$ Although both Sapir and Whorf believed that language makes some thoughts easier and some thoughts more difficult, Sapir thought that ideas could be conveyed in any language, though perhaps with difficulty (for some ideas in some languages).

For Sapir, a grammatical process was the relation between morphemes. "Every language possesses one or more formal methods for indicating the relation of a secondary concept to the main concept of the radical element" (Sapir 1921a: 59). For Sapir, preference for particular methods distinguishes types of language: "All languages evince a curious instinct for the development of one or more grammatical processes at the expense of others" (p. 60).

Sapir distinguished six main types of grammatical processes: word order, composition, affixation, internal modification, reduplication, and accent Word order is a powerful means of expressing grammatical relationships. It is relatively important in English, in contrast, for instance, to Latin, so that there is no grammatical difference between Hominem femina videt, Femina hominem videt and Videt femina hominem. All mean "The woman sees the man" (p. 63). The relationship between words is indicated by case endings (an internal modification) not by word order. Languages with rigid word orders, such as English or Chinese, frequently also use composition (e.g., typewriter, blackbird, or t'ien tsz, literally 'heaven son, the usual term of reference for a Chinese emperor). The most widely-used of all grammatical processes, according to Sapir, is affixing (although there are Chinese and Southeast Asian languages that do not use them), e.g., $s$ added to the end of English words to indicate plurality, or inprefixing a word, as in incomprehension, to indicate negation. Some languages indicate plurality (and/or other relations) by internal modification. For instance, the plural of the Bala word kitesha is bitesha, as in Arabic the plural of balad is bilad. Reduplication may accomplish the same function: in Washo one buffalo is gusu; the plural is gususu. Finally, intonation may also serve grammatical functions. In Shilluk, yit with high tone means 'ear'; with low tone, 'ears.' Intonation as a grammatical device includes stress as well as pitch differences. The example Sapir gave was Navaho ta-di-gas. Accent on the first syllable indicates that a third male other than the speaker or the auditor is the agent ("He washes himself"). Accent on the second syllable indicates the person spoken to is the agent ("You wash yourself").

In Takelma, a native Oregon language which was the first Native American language he analyzed extensively (for his Ph.D. dissertation), Sapir described in detail three of his six grammatical processes: affixation (the most important, specifically suffixation),

2. On Whorf's career and posthumous vogue see Murray (1982; 1994: 190-202). For a counter-example of the focus on lexicon, see Malotki (1983). 
reduplication, and vocalic change (viz. ablaut). He considered intonation in Takelma to be "of grammatical importance, but most probably a product of purely phonetic causes" (1912: 55). Although he described pronouns, adjectives, numerals, adverbs and particles in Takelma, more than half his analysis of the language deals with 'the verb' and its affixes. In his description of Chasta Costa, there is a page (1914: 334) on syntactic combinations of verbs. In contrast there are fifteen pages on phonology and 43 on morphology (the traditional categories of pronouns, nouns, numerals, adjectives, adverbs, postpositions and verbs - in the order of Sapir's presentation), and texts with no analysis of sentences.

"Every language has its special method or methods of binding words into a larger unity. The importance of these methods is apt to vary with the complexity of the individual word," Sapir (1921: 109) wrote. The unimportance of word order in Latin has already been mentioned as an example. Sapir suggested that word order and stress are especially important and frequent means for expressing grammatical relations. Concord tends to be prominent in languages not using word order for indicating relations. Concord is nearly always realized through the repetition of sound, as in what Sapir called the "relentless rhyme" of "Vidi illum bonum dominum" (I saw that good master).

Like Boas, Sapir believed that subject and predicate are the basic universal units: "No language wholly fails to distinguish noun and verb" (Sapir 1921: 119; also see 36-37), although they may be combined in a single word (e.g., Latin Vidi - I saw). Together, subject and predicate form sentences. Sentences express propositions. Underlying a particular sentence "is a living sentence type of fixed formal characteristic." The habitual types are the grammar of a human language. "New sentences are being constantly created, but always on strictly traditional lines," as Sapir (1921:37) wrote of what later generations would call "generativity."

Although Sapir stressed the psychological reality of what later writers would call a 'deep structure' of propositions realized through particular formal patterns, he did not develop a theory of sentence formation for any language. He was interested in historical and typological comparison of the grammatical devices used by various languages, not with devising a theory of syntax. Models of phonology and morphology had priority for Sapir, as for other linguists of his generation and the following one.

\subsection{Bloomfield}

Leonard Bloomfield (1887-1949) was, like Sapir, a scholar trained in Germanic philology who rejected the superiority of written languages, scoffed at the adequacy and universality of Aristotelian logical categories for delineating the constituents of speech, and who undertook the structural study of unwritten languages (especially the Algonquian languages of the Great Lakes region of North America, Burmese, and the Austronesian languages Ilocano and Tagalog) as well as written ones (English, German, and Russian). 
Although Bloomfield is most remembered for phonemic work, he was very interested in grammatical analysis from early in his career.

As early as 1914, he unequivocally stated, "The first and original datum of language is the sentence (Bloomfield 1987 [1914]: 38). Similarly, in praising Cours de Linguistique générale (Saussure 1916), he noted, "I should differ from de Saussure chiefly in basing my analysis on the sentence rather than on the word" (Bloomfield 1987 [1923]: 64). Both in his first general book (1914), and in his first extended analysis of an unwritten language (1917), Bloomfield wrote far more extensively about grammar than about phonology.

In his first book, Bloomfield (1914: 60-61) had taken the Wundtian view, defining a sentence as "an utterance analyzing an experience into elements," the primary ones of which are subject and predicate and subject and attribute. In his analysis of the Tagalog language of Luzon, he rejected subject and predicate as basic, or even necessary constituents of a sentence. ${ }^{3}$ There are examples from Tagalog in a 1916 paper in which he dismissed the subject/predicate model as illegitimate equation of language and logic, but he appealed first to 'single-word' Latin and Slavic sentences (such as Veni, I came) and, 'worst of all' for the purported universal pattern:

We deny the name of sentence to such utterances as 'Yes' or to answers such as 'Yesterday... Homo mortalis est, and "Maria is mortal" are propositions. "Maria wrote a book," however, is a narration. 'Wrote a book' is not a logical predicate of the subject.... [English] uses for many non-logical utterances the same distinctive word-forms as for the expression of a logical judgment" and, furthermore, often inverts the 'normal order' so that 'predicates' precede 'subjects.' (Bloomfield 1987 [1916]: 47, 50-51)

3. On this, he broke with Sapir's (1921: 119) retention of 'noun' and 'verb' as 'essential ingredients'. Although Bloomfield (1917: 151) wrote that "most [Tagalog] sentences consist of a subject and a predicate," he also wrote that "much of the syntax is determined by the use of constructions which lack subject-and-predicate structure." (Tagalog provides something of an archetype of topic:comment constructions.) Perhaps reflecting the complexity more than the relative importance of the phenomena discussed, Bloomfield's (1917) discussion of attributes occupies $441 / 2$ pages in contrast to $81 / 2$ pages for discussion of subject-and-predicate structure. In Kess's (1991: 208) view, Bloomfield's Wundtian mentalistic approach to 'topic' "took root and formed the basic paradigm for generations of descriptions of Philippine languages, which tied descriptive terms like 'focus' and 'topic' to cognitive states and the speaker's focus of attention." Kess more or less endorses the one contemporary review of Bloomfield (1917) as deceptively arranged and phrased: "Bloomfield did make Tagalog look too different [from Latinate parts of speech analysis] in too many ways” (in Bloomfield 1970: 207). 
After having been pummeled for having abandoned 'logical' Indo-European categories by Blake (1919), the only reviewer of his Tagalog Texts, Bloomfield (1987 [1922]: 57), with the zeal of a convert, was to object to "the irrelevant subject-and-predicate notion of logic, controverted by his own material" in Sapir's (1921) Language. In Bloomfield's post-Wundtian view, not all utterances - indeed, probably not even the majority of utterances in any natural language - are propositions to be mapped as if they were approximations to formal logic, and subject and predicate are not among the basic units of Bloomfield's later outlines for the study of language (1926, 1933, 1942). Indeed, in his mature synthesis in Language (Bloomfield 1933: 174), he challenged the necessity of binary analysis of sentences, noting that "not all favorite sentence-forms have bipartite structure," let alone a subject and a predicate. "Features which we think ought to be universal," Bloomfield (1933: 20) wrote,

may be absent from the very next language that becomes accessible. Some features, such as, for instance, the distinction between verb-like and noun-like words as separate parts of speech are common to many languages but lacking in others. The fact that some features are, at any rate, widespread, is worthy of notice and calls for explanation.

In working at the University of Illinois with engineering student Alfredo Viòla Santiago, Bloomfield found three basic relations between words in Tagalog sentences: attribution, predication, and serial relations (1917: 146). As in his later work on Native North American languages, Bloomfield laid out an exhaustive listing of the grammatical devices used in the texts dictated by Santiago. In particular, he described an elaborate inventory of particles. He also provided examples of sentences without the subject/predicate relationship he had considered universal a few years before: Tagalog exclamations and impersonal anaphoric sentences, especially answers to questions and statements of meteorological conditions, such as Bumábahà (which he rendered as "Flood!" rather that "the water rises") or Taginit nà (which he translated as "Summer now" rather than "It's summer already"). There was no effort to relate one part of the grammatical description to another. Description of one kind of particle followed description of another kind of particle.

After moving from the University of Illinois to Ohio State University in 1921, Bloomfield decisively superseded his earlier Wundtian associative psychology with behaviorist psychology (see Murray 1982, 1994: 112-13), and abandoned any attempt to discern the experience underlying utterances. As he developed his own elaborate set of neologisms for grammatical analysis, grammar remained for him "the meaningful arrangement of forms" (Bloomfield 1933: 163) through processes such as word order, government, concord, modulation (pitch and stress), phonetic modification (e.g., keep $\rightarrow$ kept), and selection (prince $\rightarrow$ princess, but king $>$ queen, not king $\rightarrow$ kingess). A fundamental assumption for Bloomfield (1987 [1926]: 75) was that "each position in a construction can be filled only by certain forms," so that positions have 
'functional meaning' separable from the meaning of what fills the position ('slot' in tagmemic terminology). He continued, "All forms having the same function constitute a form class. Examples of English form-classes are: noun-stems, number affixes, object expressions, finite verb expressions" (p. 76). In Bloomfield's view it was necessary to analyze the form classes of a language inductively, rather than looking for Aristotelian or Port-Royal parts of speech in a corpus.

\subsection{The Whorf vogue}

The "Whorf hypothesis," or "linguistic relativity," though often reduced from the level of obligatory grammatical categories to examination of lexical items, came into vogue in the 1950s. There was prolonged discussion of Whorf "at the major anthropological conference of the era (Kroeber 1953), an important conference of anthropologists and linguists (Lévi-Strauss et al.1953) and a conference entirely devoted to the 'Sapir-Whorf hypothesis' (Hoijer 1954)” (Hymes \& Fought 1975: 999). The Southwest Project organized by the Social Science Research Council, funded by the Carnegie Foundation, and directed by John Carroll (editor of the main collection of Whorf writings) was not successful in testing the "Whorf hypothesis," (see Murray 1994: 192-97), which, in the strongest form, is probably untestable (Kay \& Kempton 1984).

What had seemed promising of revelation about cognition in (often vulgarized) Whorf had failed to pan out in the Southwest Project (a final report of which was never made). From within the Prague School/Linguistic Circle (see Vachek 1966; Vilém Mathesius (1882-1946) was the primary syntactician. His basic distinction, analogous to the Gestalt psychology distinction between a figure (the rheme) standing out from the ground (the theme), might have been clearer if he had written about the many topic-comment languages of Asia and the Pacific, rather than Slavic and Germanic languages, (contrasting Czech and English) - even if the Czech work was as well known in North American during the mid-1950s as that of the Russian members of the Linguistic Circle of Prague (Roman Jakobson and Nikolai Trubetzkoy). Pragueinfluenced French grammatical functionalism (Gougenheim 1938; Martinet 1962) did not excite interest or development in North America. "London School" work by the Polish émigré anthropologist Bronislaw Malinowski $(1920,1923)$ and his student J. R. Firth maintained traditional Latinate categories, especially "noun" and "verb" (see Langendoen 1968: 65-69). Firth published no syntactical descriptions at all.

\subsection{Echoes of Jespersen's English grammar(s)}

The Danish linguist Otto Jespersen (1860-1943) was far and away the most famous theorist of grammar in the first five decades of the 20th century. He published an enormous body of work, including The Philosophy of Grammar (1924) and a chaotically discursive seven-volume work with copious examples (and non-native intuitions) 
entitled Modern English Grammar (1904-49; condensed to Jespersen 1963). He wrote, "English grammar forms a system, but is not everywhere systematic" (1949 [1933]: 528). Many of those who have tried to use Modern English Grammar have wondered what the system of his analysis is, or even what the basis for ordering the constituent parts of it might be. As with the writings of Franz Boas, there is a seemingly endless profusion of details that never add up to a model of a system - nor, indeed, even to a set of disconnected rules.

Unlike the descriptivist Americanists, Jespersen largely ignored grammatical categories. He attempted to replace them as basic units of analysis with his own categories of rank, junction, and nexus, focusing on the ideas underlying sentences, not on the distribution of forms. What Jespersen meant by rank is easily comprehended. In the nominalization "an insanely stupid gesture," gesture is primary, stupid is secondary, insanely is tertiary. (The quatenary rank is rare in Germanic languages, including English; e.g., "very insanely stupid gesture" is overkill, if not precisely redundant.)

A nexus in Jespersen's use is a rather amorphous (but supposedly psychologically salient) category for combinations of two or more ideas (including a subject and a predicate or an object and an attribution). A junction contains a single idea. (Nexuses may also be ranked). For instance, "Sally found the empty cage" is a junction for Jespersen, whereas "Sally found the cage empty" is a nexus of "Sally found the cage" and "the cage was empty" (Jespersen 1937: 42; see Levin’s [1968: vii-viii] and Francis’s [1989: 82-92] attempts to explain Jespersen's analysis). In various works he used different quasi-algebraic symbols to represent nexus, rank, and grammatical processes such as composition or apposition, culminating in the representations of grammatical functions in Analytical Syntax (1937), ${ }^{4}$ e.g., for "Sally found the cage empty," S V O (S 2 P) for subject verb object and subject predicate - cage being both $\mathrm{O}$ and $\left(\mathrm{S}_{2}\right)$ Although later generations of syntacticians have also developed abstract representations and although Jespersen's symbols are not particularly opaque (indeed, many have been reapplied independently of his usage), there does not appear to have been any direct influence of Jespersen's example (as Falk 1992 bemoans). Similarly, other than a few of his University of Copenhagen students, the typologies of junction and nexus or ranked nexuses have not been found heuristic by later generations. ${ }^{5}$

4. Jespersen earlier (1889) created his own set of symbols for sounds, using Greek letters for the active organs of speech, numerals for the amount of opening, small letters for the place of articulation, and more.

5. The synonymousness of nexus and junction in general English usage is an obstacle to use by speakers of English. 


\subsection{The lack of help from Saussure lectures}

Ferdinand de Saussure (1857-1913; see Koerner 1973) is as famous now as Jespersen was during his lifetime. Saussure is widely regarded as "the father of structuralism" by virtue of the notes his students at the University of Geneva took between 1907 and 1911 and published in 1916 as Cours de linguistique générale (Saussure 1974). Saussure advocated analyzing language not by describing discrete elements, but by showing the relations between elements. Whether influenced by Saussure, or independently, structural work on phonology by American ethnolinguists and Prague School scholars between the world wars proceeded to examine the sound patterns of languages in terms of binary oppositions (such as aspirated, not-aspirated).

There is a real sense in which Saussure produced no syntactic theory. Certainly, he proposed no theory of syntax as a distinct "level" of language. Indeed, he regarded a distinction between morphology and syntax as illusory. ${ }^{6} \mathrm{He}$ asserted that "linguistic unit' and 'grammatical fact' are only different names for designating aspects of the same general phenomenon: the play of linguistic opposition... [They] would not be similar to one another if linguistic signs were made up of something beside differences. But... language is form and not substance" (1964: 121-22). Saussure proposed two basic relations: paradigmatic (termed "associative" in the Cours) and syntagmatic. Paradigmatic relations are contrasts which produce distinctive alternatives (e.g., breed vs. bred, French grand_vs. grande, or case inflections in Latin). Syntagmatic relations are combinatory possibilities of at least two units (e.g, in English un + do is acceptable, pre + do is not; some people can throw a sheep, others throw fits, but cannot throw a yellow nor throw a sheepishness).

Although work after his death attempted to sort out a distinct level of syntax and to reveal paradigmatic and syntagmatic structures within it, Saussure made no attempt to include sentences within what he analyzed as "linguistic system." The only monograph Saussure published during his lifetime (1878) dealt with Indo-European vowels. He did not attempt to write a grammar of any language, nor does the Cours include a grammatical theory, or even any sustained attention to syntactical phenomena. ${ }^{7}$ In particular, Saussure did not attempt to analyze the sentence as a unit. He appears to

6. "The arrangement of the subunits of the word obeys the same fundamental principles as the arrangement of groups of words in phrases" (Saussure 1974: 136).

7. There is, however, an argument that "abstract entities are always based on concrete entities.... To think that there is an incorporeal syntax outside material units distributed in space would be a mistake... The material units alone actually create the value by being arranged in a certain way." He shows derision for "immaterial abstractions hovering over the terms of the sentence" (1974: 138-9). 
have regarded sentences as part of the unanalyzable parole (actual speech), rather than as part of langue (the system of language), which could be analyzed. Chomsky (1964: 23) saw Saussure as regarding la langue as

a store of word-like elements, fixed phrases, and, perhaps, certain limited phrase types. He was thus quite unable to come to grips with the recursive processes underlying sentence formation, and he appears to regard sentence formation as a matter of parole rather than langue, of free and voluntary creation rather than systematic rule.

Culler (1976: 99) elaborated this:

[Saussure] did not know how to reconcile the fact that we can produce totally new sentences with the fact that a language contains phrase types. What he lacked was a notion of rule-governed creativity. He did not realize that it is possible to construct a finite set of rules which will generate structural descriptions for an infinite number of sentences. This can be done, as Chomsky says, by recursive rules: rules which can be applied over and over again, such as a rule which enables one to attach a relative clause to a noun clause [in English], e.g., This is the dog that chased the cat that worried the rat that ate the cheese, and so on). [Above, I already staked the claim that Sapir considered generativity in this sense.]

Structuralist work on syntax by Saussure's successors focused on classifying paradigmatic relations. ${ }^{8}$ Even the transformational grammar pioneered by Zellig Harris and his more famous student Noam Chomsky isolated paradigmatic classes (such as the noun phrase) on which the rules operate (to form syntagmatic patterns).

\section{Syntactic Structures}

Structuralism in the first half of the twentieth century focused on phonology and morphology. I contend that there was no dominant - let alone ruling — paradigm in syntax during the 1950s. That is, there was no ancien régime to overthrow, no paradigm of syntactical analysis to undergo a "crisis." (Human sciences are "preparadigmatic" in the view espoused by Kuhn (1962), though I think there is some sense in which there was a "phonemic paradigm.")

My own earliest publication on the history of linguistics explored the absences of the generational warfare with the older generation rejecting the purportedly

8. One "Geneva School" figure who worked on syntax was Albert Sechehaye (1870-1946) whose doctorate at Göttingen, published in 1905, was on the French subjunctive tense. Saussure's most famous student and one of the editors of the Cours, Charles Bally (1865-1947) wrote primarily about stylistics. See Koerner (1972: 299, 246-7). 
"revolutionary" new ideas that those schooled by Kuhn (1962) expected in the history of a "revolution." There was indeed - eventually - very bitter genealogical conflict. However, scrutiny of the historical record suggests that Chomsky and his followers instigated the conflict rather than reacting to rejection from their established neo-Bloomfieldian elders. That is, in this case, the putative result preceded the supposed cause. To get ahead of the story, this analogy to a post-revolutionary "reign of terror" came later, and really came into relief with the rejection of phonemics (Chomsky \& Halle 1968).

Neo-Bloomfieldian gatekeepers, particularly Bernard Bloch, who was, from 1940 until his death in 1965, editor of the Linguistic Society of America's official journal, Language, was a sponsor rather than an opponent of visibility for transformational grammar. Bloch accepted a long, rapturous exegesis of Chomsky's (1957) Syntactic Structures (SS) and published it in Language within a few months of the book's publication. Reviews do not usually appear in professional journals for at least a year after publication, and are not usually accepted from persons at the same institution as the book's author, and especially not from students of the book's author. ${ }^{10}$ Nevertheless, Bloch printed Lees's (1957) unsolicited ${ }^{11}$ review of Chomsky's first book immediately upon its submission.

Chomsky disingenuously recalled,

I always found him [Bloch] sympathetic, though I don't know how interested he was in the work I was doing. He requested a copy of LSLT [The Logical Structure of Linguistic Theory] and also of MMH [The Morphophonemics of Modern Hebrew] and also invited me several times to speak at the Yale Linguistics Club. We had several discussions on these occasions. I recall them quite well, particularly because interest in the work I was doing on the part of professional linguists was extremely rare (30 May 1977 letter). ${ }^{12}$

9. I submitted my article on gatekeepers and Chomsky's submissions in the early part of 1977. After a long delay by reviewers whose preconceptions of what must have happened were similar to my own initial expectations (they had particular difficulty believing that Bloch knew what he was publishing in Chomsky's 1959 review of Skinner's 1957 Verbal Behavior), my article was published in 1980 .

10. In my view, one can be a 'student' of more than one scholar, and a dissertation supervisor is not necessarily the major influence on a graduate student (examples include Paul Postal and George Lakoff). The first graduate students in M.I.T.s linguistic department began in 1961. Lees went to M.I.T. in 1956 to work on the machine translation project directed by Victor Yngve, and received a Ph.D. in Electrical Engineering in 1959.

11. Lees:Bloch, 22 February 1957; Lees:author, 30 May 1977.

12. I have discussed the non-rejection by publishers of Chomsky's early work in Murray (1999a.b). See Daniels (2006) on changes made in what was supposedly the 1951 text of MMH. 
It seems reasonable to suppose that Chomsky did know that Bloch was interested in his work and, indeed, was actively promoting his career. Bloch first sought reviews for Language from Chomsky in 1953. He had Chomsky refereeing articles for Language by 1954 . Most tellingly, Chomsky listed Bloch as a reference. Bloch produced such encomia as the following.

I'm an admirer of Chomsky's from way back, and an admirer of Harris's of even longer standing; and I'm convinced that transformation theory is a tremendously important advance in grammatical thinking. I expect great things of it (Bloch: Lees, 31 July 1959).

Chomsky has not only contributed to the literature of structural linguistics, he has fired the imagination of dozens of scholars throughout the country. It is interesting to note that young workers in the field, especially the most brilliant among them, are particularly susceptible to his spell. One of the liveliest and most promising developments in grammatical theory in recent years is Chomsky's transformation grammar. I call it Chomsky's even though Zellig Harris was perhaps the original proponent. It is above all Chomsky who has developed the theory and has given it its current vogue (Bloch:William Locke, 26 October 1960).

Further evidence that Bloch facilitated the diffusion of Chomsky's 'revolutionary' ideas is provided by his publication of Chomsky's (1959) ferocious attack on behaviorism. Bloch's behaviorism may not have been Skinnerian, ${ }^{13}$ but surely Bloch shared the antimetaphysical/anti-introspection metascience Chomsky attacked. Lest it be believed that Bloch somehow missed the force of Chomsky's argument and naively accepted

13. For that matter, the behaviorism that Chomsky attacked was partly Hullian, partly a straw man. It was not Skinnerian, and particularly not that of Skinner's (1957) Verbal Behavior. As MacCorquodale (1970: 98) noted, “The declaration of war has been unilateral, probably because the behaviorist cannot clearly recognize why he should defend himself." Skinner did not reply to critics in psychology, either. Before Chomsky began publishing, operant conditioning was already a theory group with its own institutions that could not be bothered with polemical exchanges (Skinner wrote me (6 Sept. 1977 letter),

I did not at the time (1947-59) know who Chomsky was. [...] I have never been able to understand why Chomsky becomes almost pathologically angry when writing about me but I do not see why I should submit myself to such verbal treatment. If I thought I could learn something which might lead to useful revisions of my position, I would, of course, be willing to take the punishment, but Chomsky simply does not understand what I am talking about and I see no reason to listen to him.

As MacCorquodale (1970: 83) wrote, "the fact that the review has never been systematically replied to has become the basis for an apparently wide-spread conclusion that it in fact unanswerable." He proceeded to show Chomsky's blatant misrepresentation of the book he supposedly was reviewing. 
the onslaught because it attacked an interloper from another discipline, it is useful to quote from the letter Chomsky wrote Bloch when he sent him the review he had volunteered to do:

It [Skinner 1957a] presents the kind of treatment of language that will always appeal to many linguists, particularly those who are influenced by the general tenor, if not the details of Bloomfield's behaviorism and 'anti-mentalism.' Since behaviorism has been such an important part of recent thought, and since this book is after all the only serious attempt to discuss linguistic behavior in the manner which has often been claimed possible and necessary, it seemed to me appropriate to give it very serious attention. [...] It would have been easy to concentrate on many defects in the book that stem from lack of acquaintance with linguistics. [...] But it seemed to me that in this case this would be a mistake. It is not important to show that Skinner's work is inadequate in areas where he has no special competence, and concentration on this would have failed to bring out clearly what I think are fundamental defects in his whole approach to language, an approach which is of course quite widely shared in its general outline. (27 October 1958)

Chomsky quite explicitly presented his review to Bloch as an attack on behaviorism. That is how it has been read by the many who have cited it approvingly (generally without having read Skinner 1957a). Considerably fewer non-linguists would have been interested in the defense of disciplinary boundaries than in the attack on behaviorism. Bloch was neither asleep nor stupid, and embraced "this superb job of constructive destruction," writing that "I thoroughly enjoyed the review" (Bloch: Chomsky, 30 October 1958).

Just contrasting the published reviews of Skinner's Verbal Behavior and Chomsky's Syntactic Structures should give pause to anyone believing the 'Chomskian revolution' was brought about by the rejection of Chomsky's work by an older generation of Bloomfieldian behaviorists. These two 1957 books put forth radically different approaches to language to vie for attention. ${ }^{14}$ One was published in the US by a wellknown (53-year-old) scholar speaking from a career of success under the auspices of a prestigious lecture series at Harvard. His book was thoroughly behaviorist, and behaviorism was the accepted psychological doctrine of the then-dominant linguistic orthodoxy. The second book was written by an then-all-but-unknown 29-year-old and was published in the Netherlands. The editor in sole charge of the official journal of the Linguistic Society of America was an ardent Bloomfieldian, and, like Bloomfield, a behaviorist. Yet a combination paean/exegesis of the latter work was printed almost simultaneously with the book's publication, written by a student of the author. Two

14. Cf. also the neo-Bloomfieldian establishment's rejection of Brown (1958) discussed in Murray (1994: 275-76). 
years later, a merciless attack on the former book appeared, written by not just any hostile competitor, but by the author of the other book.

While obsequious praise for SS appeared in the pages of Language, the book was not reviewed at all in Word, the organ of the counter-tradition to neo-Bloomfieldian linguistics in America (see Martinet 1994). The only linguistics paper by Chomsky that ever seems to have been rejected was rejected for being too neo-Bloomfieldian rather than for not being neo-Bloomfieldian enough. It came from André Martinet, who wrote me that Chomsky's submission

was forwarded to me by Uriel Weinreich, a co-editor of Word, who favored publication. I was against it and adamant. The article was not rejected "because it was too Bloomfieldian." In such a case, I would have sent it to Bloch. To my mind, it was a reaction against the self-imposed limitations of the Bloomfieldian approach, but one retaining all of its formalistic prejudices with a few additional ones. I was hardly conscious of all of this when reading the paper for the first time. Actually, my impression was one of utter drabness unrelieved by any glint indicating some hidden awareness of what a real language is.

(29 November 1977 letter)

Importantly, it was in Word, not in Language, that a critique of the early Chomskian notion of grammaticality was published (Hill 1961). The other founder of Word and major carrier of European structuralism to America, Roman Jakobson (1959) expressed dismay at Chomsky's eschewal of consideration of meaning - a continuation of the tradition of Bernard Bloch, George Trager and Zellig Harris. ${ }^{15}$

Linguists schooled in European structuralism perceived Chomskian work as a continuation of Bloomfieldian principles (see Koerner 1989: 115). They did not perceive Chomsky as an ally, nor did neo-Bloomfieldians yet perceive him as an enemy. He was trained by one of the most respected of their number, and his work manifestly built on Harris's work. As Dell Hymes, who also received his Ph.D. in 1955, recalled, "Noam was seen as Harris's student” (1978 referee comment). Harris's longtime collaborator C. F. Voegelin (1958) was troubled by the difficulties of studying languages other than one's mother tongue using the principles advanced in SS, but he deemed the book an

15. "A great deal of effort has been expended in attempting to answer the question: 'How can you construct a grammar with no appeal to meaning?" Chomsky (1957: 93) wrote. "The question itself, however, is wrongly put, since the implication that obviously one can construct a grammar with appeal to meaning is totally unsupported. One might with equal justification ask 'How can you construct a grammar with no knowledge of the hair color of the speaker?'” Also see 1975[1955]: 87, 1965: 142. 
important contribution (and had earlier invited Chomsky to review books in the journal he edited, the International Journal of American Linguistics).

Even after Chomsky's all-out attack on behaviorism, neo-Bloomfieldians were sympathetic to Chomsky's linguistic work. Joos (1961), for instance, accepted Chomsky's violation of the basic principle "text reveals its structure" and applauded Chomsky's work as an advance in the study of syntax. Hill invited Chomsky to air his position at Texas conferences.

The work of Chomsky's students began appearing regularly in Language during the early 1960s, while the 'truest Bloomfieldian,' Bernard Bloch, still edited it. Chomsky himself was invited to contribute to the memorial issue for Bloch. In the estimation of Robert Lees, whose relationship with Bloch also predated 1957, "I can't see that he ever acted as an obstacle" (26 April 1977 letter). One of Bloch's 1950s students recalled that Bloch "waved encouragement" at the use of symbolic logic to do semantics, but "didn't feel up to doing it himself" (R. Harris 1993: 51).

In sum, during the late 1950s and early 60s, Chomsky's views on methodology and syntactic structure were perceived as new formalist positions within American structuralism. With elite sponsorship, Chomsky had access to publication. "In the late 1950s, he was seen as an up and coming man, maybe blind to some things, but a force to be reckoned with" (Hymes, 21 November 1977 letter).

Rationalist, 'Cartesian' linguistics was yet to appear. Finding it in SS or in LSLT is a task of invention equivalent to reading "socialism in one country" into Marx's writing. SS and LSLT dealt with philosophy of science themata (R. Harris 1990: 108-110), not with assertions about the structures of any particular language - or with 'universal grammar.' Although he had attacked behaviorism in the pages of Language, Chomsky had yet to attack neo-Bloomfieldian linguistics frontally. The ultra-rigorist wing of neo-Bloomfieldians (Bloch and Joos, if not the chronically querulous Trager) "were ready for Syntactic Structures. They weren't ready... for what followed Syntactic Structures" (R. Harris 1993:51; see Hill 1966, 1980), particularly the rejection of phonemics — which, unlike any syntactic theory, they did care about.

\section{3. "Revolutions" and rhetorics of continuity or breaks}

In psychology there was a transformation from behaviorist dominance to cognitive conceptions. This has been called the "cognitive revolution," though the psychologist/ psycholinguist whose work I know best, Roger Brown, seems to me to have moved from behaviorist to cognitivist work with local (to Cambridge, MA) influences by Chomsky but without a dramatic ("road to Damascus") break (see Brown 1989; Murray 1994: 273-82). 
As far as I know, Chomsky himself has never claimed to have "revolutionized" linguistics or even to have dominated it. (Indeed, he claims that hardly any linguists have ever been interested in what he's done!) Whether it is considered "revolution," "a dark age," "progress," “counter-revolution," or "a reign of terror," Chomsky-dominated American linguistics of the 1970s or 80s looks quite different from the neo-Bloomfieldian American linguistics of the 1950s. Arguments have been made that Chomsky developed the "structuralism" of Zellig Harris in general and Harris's beginnings of formalist synchronic(ist) transformational analysis in particular (see Antilla 1975). A rise to prominence of syntacticians supplanting phonologists is pretty clear, but the question of how much change qualifies some development as having been a "revolution" seems to me impossible to specify.

In academic/scientific instances as in sociopolitical ones or religious ones, there is never absolute discontinuity in the realm of ideas. Thus, establishing that there was some continuity does not suffice to dismiss any particular case from the category "revolution." Even before I read Kuhn for the first time (in 1972), I had read (a translation of) Alexis de Tocqueville's L'ancien régime et la révolution (originally published in 1856). Tocqueville showed that many of the "revolutionary" changes in French social arrangements were underway before the storming of the Bastille and guillotining of the king and queen. Tocqueville certainly was not denying that there had been a reign of terror in what he insouciantly used the singular, definite article (la) to label. I had been introduced to Tocqueville's Democracy in America by M. Richard Zinman as an undergraduate. My first graduate school mentor, Robert A. Nisbet, was at that time (in the years preceding the US bicentennial) talking and writing about the extent to which the less fratricidal (but not entirely unfratricidal) "American Revolution" marked significant social (as well as political) change, so was a "real revolution," not just a successful war of independence from a European colonial power. ${ }^{16}$

In my (University of Toronto) dissertation research I contrasted groups for which claims of "revolution" were made with ones claiming "continuity." My original contrast was between the ethnography of speaking (which stressed building on tradition) with ethnoscience (for which claims of being the "new ethnography" were made). As I extended my social history of American theorizing of language, the much heralded "Chomskian revolution" loomed. The leaders of the two linguistic anthropology groups completed Ph.D. dissertations and took up academic positions in the mid-1950s, as did Chomsky, and all three groups attracted students at a time of rapid

16. See Nisbet 1969, 1976, 1977. Nisbet had long been interested in the critique of the French Revolution by Bonald, Maistre, et al. and the prehistory of sociology in concerns about the smashing of traditional social structures (Nisbet 1943, 1966). 
growth in the size of US universities. That is, they blossomed in the same era within the same country's system of universities, enhancing comparability - at least in terms of the zeitgeist and the era of academic expansion, particularly the Cold War National Defense Act influx of funding for linguistic research and creation of new positions for linguists that produced a demographic surge in the production of linguists (Murray 1980: 85).

For both contrasts to the ethnography of speaking paradigm (transformational/ generative grammar [TGG] and ethnoscience), I had difficulty in being convinced that discontinuities outweighed continuities. This led me to take as the dependent variable (the variable to be explained by social structural independent variables, which I drew from Mullins 1975) "rhetoric of revolution" rather than "revolution":

Because (l) there are always cognitive continuities and shared assumptions between subsequent scientific paradigms, (2) no context-free indicators of degree of continuity have been suggested, and (3) claims of novelty seem to have more serious consequences for generational conflict than actual discontinuities, the notion of scientific revolution has been relativized here to consideration of 'revolutionary rhetoric', i.e., claims to break with the guiding ideas and assumptions of past work. 'Revolutionary rhetoric' refers to claims (by group members) to major discontinuities, not to claims of persecution/rejection at the hands of an establishment. Choice of rhetoric (between a rhetoric of revolution and one of continuity) depends on the relative eliteness, professional age and access to recognition of group participants. (Murray 1994: 23)

The cases I examined in my dissertation (revised as Murray 1994) show that the rhetoric of 'continuity' is no more transparent than the rhetoric of 'revolution'. The focus on 'rhetoric' of continuity/discontinuity rather than 'substance' is/was not intended to deny that ideas matter. Observing that many seemingly good ideas that might have been taken up for testing and development are not tested or developed ("Many are called [out], but few are chosen,") and that those that are taken up do not always seem in retrospect to have been the best ones available at any particular time, led me to the view that "Good ideas are not enough" (1994: 22), a statement that is not equivalent to "Ideas do not matter".

Kuhn's comparison of "scientific revolutions" certainly does not provide any measure of "revolutionariness," and Kuhn himself dropped the essentially contested term "revolution". Even in his original presentation, Kuhn (1962: 91-92) noted that changes may seem small when viewed from outside (a paradigm).

In academic/scientific instances as in sociopolitical ones there is never absolute discontinuity in the realm of ideas. In the particular instance of TGG, enumerating continuities between the approaches of Chomsky in the 1950s and (various) 
neo-Bloomfieldians does not disprove that there was a 'Chomskian revolution' in linguistics and/or in syntactic theorizing. In my first publication on history of linguistics, I wrote:

Revolutions - whether scientific, religious, or political - never totally annihilate all facets of the preceding system and never substitute entirely novel ideas.... Those who believe there are qualitative differences, so that "scientific revolution" is a useful concept (preferably a variable) in the study of changes in science, need to specify criteria which have been met in at least some cases in order to classify changes as "revolutions." Absolute novelty is not such a realistic criterion, nor is total victory. No paradigmatic community has ever been coterminous with an entire discipline, whether in behavioral, biological, or physical science. In spheres other than science we speak of "revolutions" which were partly successful or failures. There is no reason to expect purer cases in science than in the situations to which they are supposedly analogous. (Murray 1980: 84)

I have never attempted to distinguish "real revolutions" from "rhetorical revolutions." Indeed, I am pretty sure that this is the first time I have transposed the noun (my dependent variable) with the adjective ("revolutionary"). I am disappointed by the lack of specification of context-free criteria for "revolution" in human sciences in the decades since I abandoned "revolution" as a heuristic concept, even as arguments continue about whether there was a TGG "revolution" and/or multiple "Chomskian revolutions." In my early article I suggested three rationales of classifying TGG as a "revolution" - group members' own use of the label, revolutionary rhetoric, and similarities of the social characteristics of the group to other groups that adopted an eclipsing stance to the work of predecessors.

\subsection{After the success of "revolutions"}

I began with a mild expression at surprise that "revolutionary" is so eagerly sought an appellation. A lot of blood has been spilled in "revolutions," the results (revolutionary regimes) of which have very often disappointed advocates. ${ }^{17}$ In political revolutions, many "revolutionaries" have been slain by the faction that prevails; it at least seems that this "fratricide" after a revolution "succeeds" is greater than the "parricide" of the

17. Many of my generation were drawn to Chomsky's ideas about cognition and language in part from admiring his leadership in opposing US military involvement in Vietnam. Having seen how the North Vietnamese dominated the unified Vietnam, marginalizing former Viet Cong, has not convinced me that the US should have been there, but there is a great deal in regimes that took power in peasant revolutions and/or ending colonial domination to disappoint those who had high hopes for them - including Algeria, Cuba, and Zimbabwe, and, especially, in Cambodia, the Khmer Rouge whose atrocities were obfuscated by Chomsky and Herman $(1977,1979)$. It is not clear to me that being chastened by seeing what such revolutionary regimes did has reduced the attractiveness of "revolution" as an analogy for linguistics, however. 
revolution itself' (the Bolshevik and Maoist revolutions leap to mind as examples more recent than the French one). In linguistics and other learned societies and academic departments, revolutionaries are not allowed to execute past opponents or former allies in "making the revolution." Thus, in an important sense, I think that "revolutions" don't happen in American academia. Members of "establishments" viewed as "outmoded" are not executed. Even their tenure is not retracted. Feeling bypassed strikes me as less serious than being jailed and executed or condemned to years in re-education camps.

If we are going to strain the analogy of "revolutions" from those forcibly overthrowing social patterns and monopolizing economic and political power to the considerably less lethal-to-opponents reign of academic theories, it seems to me that the kind of recurrent purging of followers to renew the revolution during the 1970 and 1980s bears resemblances to the new waves of revolutionary fervor (and purges) that Mao Zhedong (1893-1976) fomented in the last two decades of his life. Within the very different worlds with radically different kinds and extents of power available, I see Mao encouraging the Red Guards as analogous to Chomsky encouraging or at least implicitly licensing generation after generation of zealots to attack their elders (even if these "elders" to a new generation of graduate students were junior to Chomsky himself), especially his own comrades after they attained some status in the field of linguistics and the possibility of independent influence (various Lin Biaos and Liu Shaoqis of American linguistics).

Along with ritualized humiliation of those who had risen to high status either before the revolution or in the post-revolutionary regimes, the later Chomsky "revolutions" offered (at least nominally) opportunities for 'sincere self-criticism' and 're-education' and redirection to what Chomsky at the moment found worth doing (see R. Harris 1993; Murray 1994: 431-46). Purging former allies who might become rivals (and then writing them out of official histories) is a recurrent feature of 'real' (sociopolitical) revolutions and of 'Chomskian' ones (especially in the obliteration by incorporation by Chomsky of ideas of former students and his failures to mention them in his statements about the development of his theories; consider the bitterness evident in Levine and Postal (2004)). This is a feature very hard not to notice, even to outside observers immune to the pain of being cast aside within the discipline of linguistics.

\section{Conclusions}

I see "revolution" as a very problematic and not very heuristic concept, and the ardor with which the concept has been embraced suspect. I have not set myself up to judge whether there have been "revolutions" in American linguistics or how many of them there may have been. I think that there was a sort of unfilled niche for syntactic theorizing during the mid-1950s (though not quite a "power vacuum"). If there are 
"revolutions" in linguistics (not just rises to degrees of dominance), it seems to me that analogies to regimes of revolutionaries in power are licit. Whether analogies of post-revolutionary regimes are heuristic, I leave for other historians of linguistics to decide.

\section{References}

Bloch, Bernard \& George L. Trager. 1942. Outline of linguistic analysis. Baltimore, Md.: Linguistic Society of America at the Waverly Press.

Bloomfield, Leonard. 1914. An introduction to the study of language. New York: H. Holt \& Company.

Bloomfield, Leonard. 1917. Tagalog Texts with grammatical analysis. Urbana: University of Illinois.

Bloomfield, Leonard. 1926. "A Set of Postulates for the Science of Language”. Language 2. 153-164. Bloomfield, Leonard. 1933. Language. New York: H. Holt \& Company.

Bloomfield, Leonard. 1942. Outline Guide for the Practical Study of Foreign Languages. Baltimore: Linguistic Society of America.

Bloomfield, Leonard. 1987. A Leonard Bloomfield anthology. Chicago: University of Chicago Press.

Boas, Franz. 1966 [1911]. "Introduction to the Handbook of American Indian Languages". Bulletin of the Bureau of American Ethnology Bulletin (Reprinted by University of Nebraska Press) 40. $1-83$.

Boas, Franz. 1917. "El dialecto Mexicano de Pochulta, Oaxaca”. IJAL 1. 9-44.

Boas, Franz. 1938. General anthropology. Boston; New York: D.C. Heath and Co.

Bogoras, Waldemar. 1922. "Chuckchee". Bulletin of American Ethnology [prepared for posthumous publication by Franz Boas] 40: 2. 631-903.

Brown, Roger. 1989. "Roger Brown”. A History of Psychology in Autobiography, vol. 8, ed. by G. Lindzey, 36-60. Stanford: Stanford University Press.

Chomsky, Noam. 1957. Syntactic structures. The Hague: Mouton.

Chomsky, Noam. 1964. Current issues in linguistic theory. The Hague: Mouton.

Chomsky, Noam. 1965. Aspects of the theory of syntax. Cambridge: M.I.T. Press.

Chomsky, Noam. 1975. The logical structure of linguistic theory. New York: Plenum Press.

Chomsky, Noam \& Morris Halle. 1968. The sound pattern of English. New York: Harper \& Row. Chomsky, Noam \& Edward S. Herman. 1977. "Distortions at Fourth Hand” [June 25th, 1977]. The Nation.

Chomsky, Noam \& Edward S. Herman. 1979. After the cataclysm:postwar Indochina and the reconstruction of imperial ideology. Boston: South End Press.

Culler, Jonathan. 1976. Ferdinand de Saussure. Middlesex: Penguin.

Daniels, Peter T. 2006. "Two Morphophonemics of Modern Hebrew". Paper presented at the Annual meetings of the American Orientalist Society in Seattle.

Darnell, Regna. 1989. Edward Sapir: linguist, anthropologist, humanist. Berkeley: University of California Press.

Falk, Julia S. 1992. "Otto Jespersen, Leonard Bloomfield and American Structuralist Linguistics". Language 68: 3. 465-491.

Frachtenberg, Leo J. 1922. “Siuslawan”. Bulletin of American Ethnology 40: 2. 431-629. 
Francis, W. Nelson. 1989. "Otto Jespersen as Grammarian”. Otto Jespersen : facets of his life and work, ed. by Arne Juul \& Hans Frede Nielsen, 79-99. Amsterdam/Philadelphia: John Benjamins.

Gougenheim, Georges. 1938. Système grammatical de la langue française. Paris: Bibliothèque du Français modernemm J.L.L. d'Artrey A. Ronteix-d'Artrey.

Hall, Robert Anderson \& E.F.K. Koerner. 1987. Leonard Bloomfield, essays on his life and work. Amsterdam/Philadelphia: John Benjamins.

Harris, Randy Allen. 1993. The linguistics wars. New York: Oxford University Press.

Harris, Zellig S. 1946. "From Morpheme to Utterance”. Language: Journal of the Linguistic Society of America 22: 3. 161-183.

Harris, Zellig S. 1951. Methods in structural linguistics. Chicago: The Univ. of Chicago Press. (Repr. as "Phoenix Books P 52" with the title Structural Linguistics, 1960; 7th impression, 1966; 1984.) [Preface signed "Philadelphia, January 1947"].

Hill, A.A. 1961. "Grammaticality”. Word 17. 1-10.

Hill, A.A. 1966. The Promises and Limitations of the Newest Type of Grammatical Analysis. Cincinnati, OH: University of Cincinnati Press.

Hill, A.A. 1980. "How Many Revolutions Can a Linguist Live Through?” First Person Singular, ed. by Boyd H. Davis \& Raymond K. O’Cain, 67-76. Amsterdam: John Benjamins.

Hoijer, Harry. 1954. "Language in Culture: Proc. of a conference on the interrelations of language and other aspects of culture". American Anthropological Association Memoir 79.

Hymes, Dell H. 1964. Language in culture and society; a reader in linguistics and anthropology. New York: Harper \& Row.

Hymes, Dell H. \& John G. Fought. 1975. American structuralism. The Hague: Mouton.

Jakobson, Roman. 1959. "Boas' view of Grammatical Meaning”. American Anthropologist 61,5: 2. 139-145.

Jespersen, Otto. 1889. The articulations of speech sounds represented by means of analphabetic symbols. Marburg: Elwert.

Jespersen, Otto. 1924. The philosophy of grammar. London: George Allen \& Unwin.

Jespersen, Otto. 1949. Selected Writing. London: Allen \& Unwin.

Jespersen, Otto. 1963 [1933]. Essentials of English grammar. University, Ala.,: University of Alabama Press.

Joos, Martin. 1961. "Linguistic Prospects in the US". Trends in European and American Linguistics, ed. by Christine Mohrmann, et al., 11-20. Utrecht: Spectrum.

Kay, Paul \& Willett Kempton. 1984. "What is the Sapir-Whorf Hypothesis?" American Anthropologist 86. 65-79.

Kess, Joseph F. 1991. "Review of Robert A. Hall, Jr., A Life for Language: A biographical memoir of Leonard Bloomfield (1990)”. HL 18. 205-210.

Koerner, E.F.K. 1972. Bibliographia Saussureana 1870-1970 : An annotated, classified bibliography on the background, development and actual relevance of Ferdinand de Saussure's general theory of language. Metuchen, N.J.: Scarecrow Press.

Koerner, E.F.K. 1973. Ferdinand de Saussure; origin and development of his linguistic thought in Western studies of language, a contribution to the history and theory of linguistics. Braunschweig: Vieweg.

Koerner, E.F.K. 1989. “The Chomskyan 'Revolution' and Its Historiography: A Few Critical Remarks”. Language and Communication 3: 2. 147-169.

Kroeber, Alfred L. 1953. Anthropology Today. Chicago: University of Chicago Press. 
Kuhn, Thomas S. 1962. The structure of scientific revolutions. Chicago: University of Chicago Press. Kuhn, Thomas S. 1993. "Afterwords". World Changes: Thomas Kuhn and the nature of science, ed. by Paul Horwich, 311-341. Cambridge, MA: M.I.T. Press.

Langendoen, D. Terence. 1968. The London School of Linguistics: A Study of the Linguistic Theories of B. Malinowski \& J. R. Firth. Cambridge: M.I.T. Press.

Lees, Robert B. 1957. "Review: Syntactic Structures by Noam Chomsky". Language 33. 375-408. Leiber, Justin. 1975. Noam Chomsky : a philosophic overview. New York: St. Martin's Press.

Lévi-Strauss, Claude, C.F. Voegelin, Roman Jakobson \& Thomas Albert Sebeok. 1953. "Results of the Conference of Anthropologists and Linguists". IJAL Memoir 8.

Levin, Samuel R. 1968. "Foreword”. Analytical Syntax, ed. by Otto Jespersen. New York: Holt, Rinehart \& Winston.

Levine, Robert D. \& Paul Postal. 2004. "A Corrupted Linguistics”. The anti-Chomsky reader, ed. by Peter Collier \& David Horowitz, 203-231. San Francisco: Encounter Books.

MacCorquodale, Kenneth. 1970. “On Chomsky's Review of Skinner's Verbal Behavior”. Journal of the Experimental Analysis of Behavior 13. 83-99.

Malinowski, Bronislaw. 1920. "Classificatory Particles in the Language of Kiriwina”. Bulletin of the School of Oriental \& African Studies [of the London School of Economics] 1. 33-78.

Malinowski, Bronislaw. 1923. “The Problem of Meaning in Primitive Languages”. The Meaning of Meaning, ed. by C.K. Ogden \& A. Richards, 451-452. London: Paul.

Malotki, Ekkehart. 1983. Hopi time: A linguistic analysis of the temporal concepts in the Hopi language. Berlin \& New York: Mouton.

Martinet, André. 1962. A functional view of language. Oxford: Clarendon Press.

Martinet, André. 1994. "Early History of Word, 1-25”. Word 45. 27-31.

Mullins, Nicholas C. 1975. "A Sociological Theory of Scientific Revolutions". Determinants and controls of scientific development, ed. by Karin D. Knorr, Hermann Strasser \& Hans Georg Zilian, 185-203. Dordrecht: Reidel.

Murray, Stephen O. 1980. "Gatekeepers and the "Chomskian Revolution"”. Journal of the History of the Behavioral Sciences 16: 1.73-88.

Murray, Stephen O. 1982. “A Latter-day Yankee Prophet: Benjamin Lee Whorf”. Historiographia Linguistica 9. 156-161.

Murray, Stephen O. 1994. Theory groups and the study of language in North America: a social history. Amsterdam/Philadelphia: John Benjamins.

Murray, Stephen O. 1999a. "How The Logical Structure of Linguistic Theory Did Not Appear During the 1950 s or $60 \mathrm{~s}$ ". The emergence of the modern language sciences : studies on the transition from historical-comparative to structural linguistics in honour of E.F.K. Koerner. Vol. 2, Methodological perspectives and applications, ed. by Sheila M. Embleton, John E. Joseph, Hans-Joseph Niederehe, 259-264. Philadelphia/Amsterdam: John Benjamins.

Murray, Stephen O. 1999b. "More on Gatekeepers and Noam Chomsky's Writings of the 1950s". Historiographia Linguistica 26: 3. 343-353.

Murray, Stephen O. 2001. "Attempts at the Professionalization of American Linguistics: The role of the Linguistic Society of America". History of the language sciences: Vol. 2, ed. by Sylvain Auroux, E.F.K. Koerner, Hans-Joseph Niederehe \& Kees Versteegh, 1932-1935. Berlin; New York: Walter de Gruyter.

Murray, Stephen O. \& Wayne R. Dynes. 1986. "Edward Sapir's Coursework”. Historiographia Linguistica 13. 125-130.

Nisbet, Robert A. 1943. “The French Revolution and the Rise of Sociology in France”. American Journal of Sociology 49. 156-164. 
Nisbet, Robert A. 1966. The sociological tradition. New York: Basic Books.

Nisbet, Robert A. 1969. Social change and history; aspects of the Western theory of development. New York: Oxford University Press.

Nisbet, Robert A. 1976. “The Social Impact of the Revolution”. America's Continuing Revolution, ed. by S. Tonsor, 73-98. Garden City, N.Y.: Doubleday.

Nisbet, Robert A. 1977. "Hannah Arendt and the American Revolution". Social Research 44. 63-80.

Sapir, Edward. 1912. “The Takelma Language of Southwestern Oregon. Published separately in advance of its place as pp. 1-296 of part 2 of the Handbook of American Indian Languages". Bureau of American Ethnology Bulletin 40. 192.

Sapir, Edward. 1914. "Notes on Chasta Costa Phonology and Morphology". Univ. of Pennsylvania Anthropology Publications 2: 2. 273-340.

Sapir, Edward. 1921. Language, an introduction to the study of speech. New York: Harcourt Brace \& company.

Sapir, Edward. 1922 [1909]. “The Takelma Language of Southwest Oregon”. Bulletin of American Ethnology 40: 2. 1-296.

Sapir, Edward. 1931. “Conceptual Categories in Primitive Languages”. Science 74. 578.

Sapir, Edward. 1949. Selected Writings of Edward Sapir in Language, Culture, Personality. Berkeley: Univ. of California Press.

Saussure, Ferdinand de. 1974 [1916]. Course in general linguistics. London: Fontana.

Sechehaye, Albert. 1905. "Der Konjunktiv Imperfecti und seine Konkurrenten in den normalen hypothetischen Satzgef, gen im Franzsischen”. Romanische Forschungen 29: 2.

Swadesh, Morris. 1939. "Edward Sapir”. American Anthropologist 15. 132-135.

Tocqueville, Alexis de. 1856. Lancien régime et la révolution. Paris: Michel Lévy frères.

Vachek, Josef. 1966. The linguistic school of Prague; an introduction to its theory and practice. Bloomington: Indiana University Press.

Vogelin, C. F. 1958. "Review of Chomsky (1957)”. IJAL 2: 4. 229-231.

Whorf, Benjamin Lee. 1945. “Grammatical Categories”. Language 21. 1-11.

Whorf, Benjamin Lee. 1956. Language, thought, and reality; selected writings. Cambridge: Technology Press of M.I.T.. 



\title{
Noam and Zellig
}

\author{
Bruce Nevin
}

In this paper, we explore when and how the work of Noam Chomsky diverged from that of his mentor, Zellig Harris, and identify the origins and character of their differences. Considering evidence that they never fully understood each other, the rhetorical vehicle for this exploration is speculation as to how much this divergence is due to differences of temperament, to "post-war" generational differences, or, with more importance for the field, to different conceptions of the proper conduct of science. A number of questions are addressed, such as: Is truth attained by winning arguments, or is the appropriate role of argument to do everything possible to prove oneself wrong? Is a theory of language a prerequisite to or an outcome of linguistic analysis? And what are the fundamental data of linguistics?

Here at the outset, please understand that by the use of first names in the title and throughout this paper I mean no affront or disrespect for either Zellig Harris or Noam Chomsky, but rather the intimation that we are talking about them as persons. Discussion of their respective achievements cannot entirely avoid the quasi-mythical personae that have become institutionalized around them in public discourse, so it has seemed well to place the divergences in their work more accurately in context of their relationship. The central theme of this paper is that they never fully understood each other, due to differences that we may variously ascribe to personality, or temperament, or cognitive style. This is an essentially irenic supposition, but to demonstrate and give substance to it requires several excursions into regions where it is possible that responses to what I say may be less pacific. Let me make explicit here, for it is implicit throughout, that the same considerations of comprehension and incomprehension apply as well to those responses. I know this does not apply to you, dear reader, whose perspicacity and fair-mindedness are unquestioned; it is those other readers that concern me.

I must consequently ask your patience with the cyclical structure of this paper. It is a truism of psychology that we understand in terms of what we have previously understood, and sometimes perhaps we understand too quickly. In order that they might insinuate themselves through this perfectly normal cognitive hedgerow, themes and topics recur in a recycling kind of way, each time from a different angle, with a different emphasis, or in a different combination.

That said, let us begin at the beginning. 


\section{B'Reshit $^{1}$}

In 1945 or 1946, William Chomsky (1896-1977) asked Zellig Harris (1909-1992), a neighbor and family friend teaching and doing linguistic research as a Professor at the University of Pennsylvania, to take his brilliant but erratic son Avram Noam (b. 1928) under his wing. ${ }^{2}$ Both families had immigrated in the first decade or so of the century (Zellig's family when he was four years old) from the terrible political and social conditions in Ukraine to this tight-knit neighborhood in Philadelphia. Zellig had obtained his degrees at Penn as a specialist in Semitic linguistics in 1934 and 1936, then taught and continued research there, becoming Assistant Professor in 1943. Funding for wartime and post-war linguistic research enabled him to develop a wide range of courses encompassing his many research interests.

It was literally the case that in the beginning years Zellig was the department, and its formation involved no more than bringing together, as a program in 'linguistic analysis,' a number of courses that Zellig had developed during the war years under the aegis of either the anthropology or the Oriental Studies Departments of the University. (Hiż n.d.).

He established the new Department of Linguistic Analysis in 1946 and was advanced to Full Professor in 1947. The concern that Mr. Chomsky brought to his friend was that young Noam had just entered Penn as an undergraduate, but was impatient with his classes, and was considering dropping out. Maybe he would move to a kibbutz in Israel. Noam was then about 17 years of age, Zellig in his late thirties. The Harrises essentially took the teenager into their family, sharing meals with him and so on. Zellig supported and encouraged him to study mathematics, logic, and philosophy, sponsoring him to

1. The first two words of Genesis in Hebrew, usually translated "In the beginning".

2. Noam has said that his "formal introduction to the field of linguistics was in 1947, when Zellig" gave him the proofs of Harris (1951), but in the preface that was signed in January 1947 he is credited for help with reading those proofs. Either his memory is wrong, or the preface was revised after the signature date. In any case, he almost certainly means the manuscript rather than the proofs, that is, galley proofs from a publisher, which would not have been available until perhaps 1950. Harris 2002.2 says the book was "completed and circulated in 1946, though it appeared only in 1951", so copies of the manuscript were available. Zellig seems always to have had numerous manuscripts in progress concurrently, and considerable time could elapse before publication, particularly with the austerities of the war years. See for example (Wells 1947: 81n1): "The central importance of the problem of immediate constituents was driven home to me in many valuable conversations with Zellig S. Harris, who also let me read a number of his manuscripts, of which not all have yet been published." This was his continued practice with students. In the late 1960s, I and other students had copies of the manuscript of Harris (1968), which we discussed in seminars with him, and of course copies of various papers and monographs. 
excellent teachers, including Nathan Fine (1916-1994) for mathematics, and Nelson Goodman (1906-1998) and Richard Martin (1916-1985) in philosophy and logic. ${ }^{3}$

What was it like, having this unusual young man in their home? One family member" says "He would follow you from room to room arguing, arguing, arguing you down to dust!" and also told me, with sadness, that they tried for many years "to establish a human relationship with him". These clues, while conclusive of nothing, suggest a disparity of temperament. The aim of this paper is to explore how differences in temperament suggested by these and other indicators may underlie fundamental differences in their ways of working and help to explain the sundering of the results of their work and the peculiar extension of 'graduate student amnesia ${ }^{5}$ through an entire academic lifetime.

\section{Two uses of argument}

It can hardly be doubted that Noam is a master of debate. His extraordinary prowess as a polemicist is well documented. More, it is very important to him to win arguments.

3. The Wikipedia article on Richard Milton Martin has this relevant passage about an important influence on Noam who has been hitherto invisible in the standard accounts:

Martin was especially fond of applying his first-order theory to the analysis of ordinary language, a method he termed logico-linguistics. He often referenced the work of the linguists Zellig Harris (admiringly) and Henry Hiz (more critically); Martin, Harris, and Hiz all taught at Penn in the 1950s. Yet Martin was dismissive of the related theoretical work by Noam Chomsky and his M.I.T. colleagues and students. Ironically, Martin appears to have been Chomsky's main teacher of logic; while a student at Penn, Chomsky took every course Martin taught.

4. Who asked not to be identified.

5. The phrase is Lila Gleitman's:

I rapidly fell under the influence of Harris, whose thinking has guided the rest of my intellectual life. In light of that fact, I have been surprised, looking back over my own writings, to find that citations and references to Harris are conspicuously absent from most of them. ... I have tried to think about why. The answer is that so much did Harris's approach to language get into my skin, become the sure and self-evident basis of my own thinking, as eventually to feel like my own quite clever inventions; that is, to lead to the well-known academic malady called Graduate Student Amnesia. (Gleitman 2002: 209)

Needless to say, this cutely named 'malady' is neither universal nor inevitable, and while it is one of the joys of teaching (and a mark of its success) when a student makes one's ideas their own, taking them in their own directions, nonetheless a failure to credit sources is wrong, as Gleitman obviously agrees. 
As Bob Ingria said to me once, "If you want to talk to Chomsky, wear boxing gloves." He has been called an intellectual bully, ${ }^{6}$ and has been accused of all sorts of intellectual malfeasance, from incorporating the supposedly vanquished positions of his opponents into his own 'revised standard view' without acknowledgement, to peppering his argument with citations and references that cannot be checked until too late (and which then turn out, it is said, to be not quite as represented), to outright lying. ${ }^{7}$ And if he cannot win, the argument or the terms proposed are dismissed as unimportant, or trivial, or uninteresting. ${ }^{8}$ Countless anecdotes are told, and many have been published. Though such testimony abounds, I will not put any weight on what could after all be no more than the discontent of poor losers thwarted by a brilliant mind. That said, I doubt that any who have engaged with or witnessed Noam in action would gainsay the proposition that when he does enter an argument, winning it is very important to him. ${ }^{9}$

6. Said e.g. in Barsky, forthcoming.

7. All these points are documented in e.g. R. Harris 1993, 1998.

8. See e.g. Lin (1999) for examples.

9. Any verbatim transcript of dialog affords examples to the attentive eye. Because the issues and the progress of the encounter are especially accessible and transparent, and perhaps more importantly because the exchange is neutral with respect to linguistics, consider the interaction reported in MacFarquhar (2003: 66). The situation is that Noam has invited any student present to articulate an opposing view. One takes him up on it. He then counters with "Suppose the goal is to liberate Iraq. How come it's not proposed in the United Nations?" The student starts to respond, “There are a lot of answers to that, like I think — " and Noam interrupts with "Really? I don't know of any" and launches into a proposal that the US should support Iran in an invasion of Iraq. The student tries to respond with "But —" and is cut off with "Excuse me...." (not everyone is allowed to interrupt) and what turns out to be a reductio ploy rolls on to the rhetorical question "What's the downside?"

The student looked baffled. "Are you honestly advocating that we help Iran invade Iraq?" he asked. "No. You are." [...] Chomsky continued to berate the student for a long time, ignoring his attempts to break in. People cried out "Let him talk!" but to no avail. Another student stood up and called out a request that he be allowed to help, but Chomsky ignored him. People made loud, disgruntled noises in protest at this treatment, but Chomsky ignored those too. Finally, the first student sat down.

Other examples are documented in Huck \& Goldsmith (1995), e.g. on p. 70 "Chomsky never directly addressed this facet of McCawley's argument, which clearly constituted a serious problem for an Interpretive approach", in R.A. Harris $(1993,1998)$ and elsewhere. 
Further, Noam believes that argument is the way that you arrive at truth. An anecdote brought this home to me. ${ }^{10} \mathrm{He}$ and a friend were discussing the conflict of Israel and the Palestinians. The friend said that it was not just a matter of a rational negotiation of interests, and that because such intense and deeply founded emotions were involved it could not be resolved by logical argument. Somewhat to the friend's surprise, this occasioned a pause, and as Noam thought about it he grew sad, saying that it may be then that it can never be resolved. This suggests that he sees argument as the only way (or at the least, the best and the most preferred way) to arrive at truth. ${ }^{11}$

This, I submit, is a temperament well suited to philosophical disputation. I take it as no accident, then, that Noam has on occasion characterized linguistics as a branch of philosophy, too immature yet to be considered a science. ${ }^{12}$ Let us take a brief excursion to consider the other side of this distinction which he has drawn between linguistics as philosophy and linguistics as science.

Science seeks truth without claiming to arrive at it. Scientists do this by interrogating nature and then corroborating what they find, an inherently communal process. The tension between individual exploration and collaborative confirmation is well expressed in the following excerpt from a letter that Zellig wrote to Albert Goetze (December 27, 1940): ${ }^{13}$

Thanks for your paper and review. I have just read them hastily, and will soon go over it point by point. Let me assure you that not only do I not consider it 'unpleasant' but am glad of the controversy. No person, certainly not I, can be

10. As told me by a friend who asked to remain anonymous, and who didn't want to indulge in psychological speculation because of not wanting to lose Noam's friendship - a telling comment in itself.

11. To those readers who share these assumptions - that the road to truth is by winning arguments (or if you're not as good at it as Noam is, then by agreeing with those arguments that have won) - I am not trying to dissuade you, nor is any denigration intended, of you or of Noam. After all, I only ask you to suspend disbelief, for the present anyway, that there may be alternative modi operandi; and I ask this not least because otherwise you may find this paper rather incomprehensible. Mindful attention to the kindling of counterarguments, etc. may disclose for you a kind of implicit meta-point of the paper concerning how that incomprehension works.

12. Although more recently he has considered linguistics to be a subpart of psychology, apparently without concern for arguments e.g. in LSLT (Chomsky 1951, 1955a, 1956a, 1975) for the autonomy of linguistics.

13. I am indebted to Robert Barsky for bringing to my attention this and other letters preserved at Yale University, by way of an unpublished ms. of his that was provided for my review by Seymour Melman. 
sure of his judgments as 'always right'; the best way to get closer to the 'truth' after I have figured out whatever I could — is to get the divergent opinions which arise from a different scientific analysis. The only fun in science is finding out what was actually there.

The place of argument in this is important, but its role is distinctly secondary, properly relegated to the design of experiments and the interpretation of results. Indeed, the aim of the scientist - when doing science - is to try as hard as he can to lose the argument. This is because a working scientist knows the perils of wishful thinking. Consequently, before a finding or hypothesis is published, the scientist will, ideally, try to destroy it in every way that can be imagined, and when it is published, the presentation must point out its vulnerabilities and weaknesses, inviting others to devise challenges that the author failed to imagine. ${ }^{14}$ This is not for the sake of constructing an

14. "Science is not a monument of received Truth but something that people do to look for truth." (Overbye 2009). Science and the arts both require patronage. Patrons expect a return on investment, to be sure, and too loose oversight of their beneficiaries can be exploited and abused. It is possible that excessive 'enjoyment' of military funding for linguistics in the 1960s contributed to poisoning the well. But critics of funded projects have too often demonstrated their incomprehension of the nature of science, as witness some of Senator Proxmire's Golden Fleece Awards for 'wasteful' government spending. Science has means of internal discipline that are far less available to the arts, or perhaps only far less well defined, but peer review cannot be more free of ulterior motives than the scientists themselves are who constitute that peerage. Quis custodiet ipsos custodes?

The influence of patents and profits in the life sciences provides striking illustration. Roger J. Williams refused to patent any of his discoveries, notably pantothenic acid (one of the B vitamins), in order to ensure that no ulterior motive should undermine his integrity as a scientist, nor any imputation of such sully his reputation. Since patent law was changed in the 1980s, corporations, universities, and individual scientists now routinely patent new discoveries, even new living organisms and bits of DNA. A consequence is a shutting down of that sharing of information which is essential to science as a communal endeavor. (See e.g. Butkus 2009 for discussion.) The epidemic of Lyme and other tick-borne diseases provides a tragic demonstration of consequences that can follow. Pharmaceutical companies seek a circumscribed disease definition so they can more easily design drugs and get them through FDA trials. Insurance companies demand a narrow definition to exclude profit-sapping long-term treatment of patients with indeterminate responses. Diagnostic tests are designed to excessively narrow definitions. Researchers and physicians are paid as consultants by manufacturers of test kits as well as by pharmaceutical and insurance companies. And there are the usual all too human ego issues - my theory, my disease definition, the organism I discovered, etc. The devastation to sufferers of tick-borne diseases, a population exceeding that of AIDS victims, has until very recently been denied and relegated to baseless diagnoses (Epstein-Barr syndrome, fibromyalgia, neurosis) that have no effective treatment, and remains controversial (Weintraub 2008). It can be seen, then, that the ideals of science are serious stuff indeed, with serious consequences, and not 'mere idealism'. We will see farther on that even 
unassailable position, but in order to find out "what is actually there." And while logic is important in these challenges, its import is as to whether or not one's conclusions are warranted by empirical observations and sound methodology.

The operative words here are "when doing science" and "ideally". There is no doubt that scientists also do philosophy, and that they energetically argue for their favored views as means of promoting their careers, attracting students, ensuring that students are recognized by others to be their students, and so on. And there are many corrosive influences making the ideals of science difficult to maintain in practice. The strengthened demand by government funding agencies and patrons of science in industry that deliverables of research be specified in advance and subsequently delivered on spec and on schedule is understandable, but at odds with the essentially exploratory nature of research, the role of serendipity, and so forth. This reflects a too-common misapprehension of the hand-off between science and engineering. A related corrosive influence is the social demand that the scientist be an Authority. Certainty is a cardinal requirement of engineering; uncertainty is indispensable for doing science. It is too little understood that science proves nothing, and that proof is possible only for logic and mathematics. The complex interrelationships of mathematics, science, and engineering have obvious pertinence to the politics of science and to our present discussion.

It has been demonstrated many times that peer review, one of the bulwarks against investigator bias, can easily become instead a bulwark of shared bias. Referees become gatekeepers. This is the meat and contested bone of any discussion of revolutions in science. The ultimate safeguard of the methods and results of science therefore rests in the integrity of the individual researcher. Confirmation bias is a well-documented hazard. ${ }^{15}$ The common or garden variety - seeing what you expect to see - can become greatly strengthened in science and in philosophy, because when data are fitted into an intellectually satisfying explanatory system, data that don't fit may be selectively set aside. Thomas Huxley wryly identified "the great tragedy of science - the slaying of a beautiful hypothesis with an ugly fact." Given this universal human foible, the price of the pursuit of an ever-expanding, ever-receding truth is vigilance of a peculiar kind, and to this peculiar attitude of counter-advocacy some are more alert, or more suited by temperament, than others.

in linguistics there are parallel effects on funding, reputation, precedence, and intellectual property, albeit with less dire consequences, to be sure.

No one ever said that doing science was easy.

15. Hymes \& Fought (1975: 172) give a striking example of Hockett's own students misreading a paper of his in consequence of their being "in the grip of preconceptions in a climate of opinion." 


\section{Founding a science}

Zellig lived in a milieu of working scientists and mathematicians; his brother Tzvi and sister-in-law Susannah are immunologists; his wife Bruria Kaufmann (b. 1918) is a mathematician and theoretical physicist, and was Einstein's (1879-1955) assistant at Princeton, responsible for helping him to clarify and simplify his restatement of relativity and his work toward a unified field theory; his close friend and colleague was the Polish logician, Henry Hiż; and his interest in re-founding linguistics in linear algebra was nourished by conversations and correspondence with mathematicians including Marcel-Paul 'Marco' Schützenberger (1920-1996), the latter’s student André Lentin, Max Zorn, and of course Bruria. As he pointed out in the 1986 Bampton lectures which became Language and Information (Harris 1988), there are two kinds of applied mathematics: calculational, of which there is very little in language, and the finding of mathematical objects in the world, of which there are many in language. His essential effort, developed consistently through almost sixty years, was "to see how a little mathematics might become linguistics," applying set theory and linear algebra to the elements and sets of linguistic analysis. ${ }^{16}$ According to Leigh Lisker, ${ }^{17}$ Zellig was teaching him and his fellow students transformations as early as the late 1930s. Subsequently, Zellig "had conversations about transformations with many people: with Piaget, and the psychologist David Rapaport, with Carnap and his follower Y. Bar-Hillel, with Max Zorn (of the lemma) to whom [he] showed the whole system at the Indiana Linguistic Institute, and with others" (Harris 2002.4). ${ }^{18}$

16. Lentin (2002: 1) says that Zellig approved the felicity of this phrase. Mathematical Structures of Language (Harris 1968) is the most complete expression of his effort to lay the basis for more capable mathematicians to identify homomorphisms, rings, and other structures, prove theorems, etc. One of his interests was in how language might develop additional capabilities; and as language is the (or an) interpretation of the mathematical structures that he did find, so might additional developments of the mathematics have their interpretation in extensions or specializations of language. See also (Harris 1962b) furthering an interest that he shared with Sapir.

17. In an e-mail message to the author, 1 March 2000.

18. Here, we must pause to clear up some potential terminological confusion. In abstract algebra, a homomorphism is termed more or less equivalently a linear transformation, linear map, linear operator, or linear function. (The related term 'kernel' is also from abstract algebra.) Zellig used this algebraic term 'transformation' quite literally and directly to refer to a mapping from subset to subset in the set of sentences. Noam's subsequent use of the same word to refer to deformations of abstract tree structures is only related by common subject matter, and derives not from algebra, but from Carnap's notion of 'rules of transformation' as a correlative of 'rules of formation'. The role of phrase-structure grammar in the sundering of Noam's work from Zellig's is an important thread that extends beyond the scope of this 
As we have seen one critical ingredient of the scientific temperament is scepticism. Another is often called curiosity, meaning by that not the idle collection of trivia, but rather a peculiarly focused probing behind the surface appearance of things. A letter that Zellig wrote to Bernard Bloch (August 20,1949) gives some personal insight into this aspect of his temperament:

I get my main interest or pleasure out of consuming - in my case it's specialized not into food but into subject-matter and information. It is quite important for me to find out what gives - whether with linguistics, or with human language, or with politics, or with physics. ${ }^{19}$

But while he was temperamentally a scientist, he thought of himself as a methodologist more than as a linguist. ${ }^{20}$ Why a methodologist? To understand this, we must place ourselves in the milieu of linguistics in the years before, during, and after WWII. Linguists were acutely aware of creating a new science. ${ }^{21}$ Problems of recursion and regress then under discussion in logic and mathematics suggested that this

paper; likewise the visual impact of branching tree diagrams in the branding and packaging of Generative Grammar, and in the ready identification of in-group presentations vs. out-group presentations.

19. It was this characteristic need to "find out what gives," which I share, that drew me particularly to Harris, although (for this and other reasons) I was already committed to linguistics when I came to Penn in 1966. The talk of an interest or pleasure being "specialized" may be in reference to the typology of Fromm.

20. The title of the first of his several major books famously begins with the word "methods." He also supposed that linguists would not be interested in his work, though people interested in language would be, and that his work was not part of linguistics as it is institutionally defined. Such remarks possibly reflect in some measure the ways in which 'linguist' had been redefined by that time in the late 1960s, and the polemics then raging. However, while he knew the lasting value of what he was doing, Zellig neither demanded nor expected to retain a leadership role in the field on the strength of what he had done in the past. Anarchism means no institutionalized leadership. Many espouse anarchist and libertarian principles, Zellig embodied them in practice.

21. "What was at stake, in short, was the possibility of a science at all: the possibility of taking as problematic, exploring, and proving linguistic phenomena, rather than having inquiry cut off by conventional habits of explanation" (Hymes \& Fought 1975: 162) .

[T] he cast given methodological ideas in the United States was probably due to their institutional value, combined with the common tendency of a younger generation to delight in shocking an established order. Extreme differentiation of 'scientific linguistics' from 'philology' probably had adaptive value in efforts to secure a novel place in the academic sun. This essential social role of the Bloomfieldian idiom goes far to explain its general acceptance as central reference point, even by linguists whose own work continued or developed ideas in conflict with it. (Hymes \& Fought 1975: 117) 
new science might be subject to unique restrictions and requirements because of its peculiar subject matter, language. It was obvious to them, as quickly becomes apparent to any student in the sciences, that the language of scientific discourse - the very means of formulating and communicating hypotheses, methods, results, theories, and so on - is constrained or disciplined in ways that general usage is not. This is because in the sublanguage of the science, objects and operations are explicitly defined, either in common parlance or in terms of logically or methodologically prior sciences, ${ }^{22}$ with the consequence that sense and nonsense are sharply distinguished, as they cannot be in general usage. How might this affect discourse in a science whose subject matter is language itself? Discussions of metalanguage vs. object language, in the air since Bertrand Russell's (1872-1970) tremendously influential essay "On Denoting" (Russell, 1905) and Alfred Tarski's (1901-83) monograph on the truth-functional semantics of formalized languages (Tarski 1933), informed thinking about the relationship between linguistic descriptions and the languages that they described:

[T] he explicit structure of statements in logic and mathematics had made it clear that the statements about this structure could not be expressed within this structure: the metalanguage of mathematics was outside mathematics. (See for example [Church 1956]. While the term 'metalanguage' as used in the linguistic work is an extension of the use in [Carnap 1934], it also satisfies the more stringent (finitary) condition for the term 'meta' in [Kleene 1952].) The structure of the metalanguage had been left undescribed, the view being that it, or its metalanguage in turn in infinite regress, has to be undescribed and indeed not fully specifiable, simply given in natural language. This conforms to the common view in philosophy that natural language is amorphous, or in any case not fully specifiable. (Harris 2002.7-8)

There were other reasons that this new science had to find its own footing. Consider its relationship to neighboring fields. Physics bears obvious relevance to acoustic phonetics, but to nothing else in language; similarly biology is pertinent only through physiology and the study of articulation. ${ }^{23}$ Psychology as then constituted had really nothing to contribute to linguistics regarding either that which was unique to individual languages or that which was common to all.

22. In a sublanguage, such use of a prior and external metalanguage is possible, as it is not for language as a whole. Use of analogy and metaphor extending the distribution of a word from one subject-matter domain to another is very much related, as illustrated, famously, by the adaptations of nautical terminology in common parlance. The main distinction to be made is that this is a folk process, whereas definitions in science are deliberate and disciplined.

23. Setting aside undisprovable speculations about genetics as anachronisms here. 
By the time Bloomfield became a behaviorist in psychology, he was committed to the belief that linguistics was an autonomous science... Thus, one's preference for one psychological theory or another did not matter to the linguistic analysis done. (Murray 1994: 121)

As Bloomfield (1933: 32) said,

The findings of the linguist, who studies the speech-signal, will be all the more valuable for the psychologist if they are not distorted by any prepossessions about psychology.... We shall all the more surely avoid this fault ... if we survey a few of the more obvious phases of the psychology of language.

Consequently, claims that Bloomfield and other American linguists were behaviorists are essentially vacuous, ${ }^{24}$ and any supposed influence of anthropology or any of the social sciences on the methods or theories of linguistics is so weak as to be scarcely ever heard of. ${ }^{25}$ Rather, specialists in other fields looked to the scientific study of language for answers to some of their difficulties, and still do. Thus, Noam's various claims of providing insight from language into the nature of mind says more about the paucity of such insight in psychology than it does about the converse relevance of psychology, as presently constituted, to linguistics.

At the time we are discussing, the mid 1940s, American linguists had long been confronted with the complex and daunting task of describing exotic languages in understandable and useful ways, and this task grew enormously in scope in the "hothouse atmosphere of the wartime work" (Joos 1957: 108) as both demand and

24. Even if they were in some sense adherents of behaviorism (which is debated), so what? The methodology and practice of linguistics took no direction from operative conditioning or the like, resting instead on their own foundations and grappling with the unique requirements attendant upon using language to describe language. The determining factor was patterning in language. Attempts were made to justify this preoccupation with patterning by reference to 'habits' and the like, but it came to be seen (by Zellig perhaps most clearly) that no justification is required. Even Sapir, who was very attentive to the interrelation of language with culture and with personality, plainly recognized the autonomy of this patterning in language, and affirmed (so far as he concurred with Whorf) that what influence there was went the other way, from language to psychology. We know now, for example, about the social motivation of sound changes, thanks to Labov, but those motivations arise out of processes of social identification (conformity and differentiation) and can do no more than adjust the relative placement of sounds within patternings of contrast whose basis is informational rather than psychological.

25. Pace the efforts of Whorf to intrigue students and draw them into the field with the so-called Whorf-Sapir hypothesis (which continues to be remarkably effective in that function even today). The complaint goes rather the other way, e.g. from Dell Hymes and his students, that anthropology and ethnology have had too little influence on linguistics. See e.g. Hymes (1971). 
funding increased for useful descriptions of languages deemed critical for the war effort. Bloomfield, Sapir, and their students, like Boas before them, had abundant direct experience of the propensity of experienced researchers, and not just new students, to project onto an unknown language expectations derived from their native tongue, overlaid with whatever they had been taught in school about alphabets, grammatical categories, paradigms, declensions, and the like. They well understood the need to take each language on its own terms, and Sapir sent his students questing after the unique 'genius' of each language. They also recognized genetic, areal, and typological commonalities across languages, which in some ways simplified, but in other respects complicated and confused their task. Sapir conveyed his methods inductively in sink-or-swim seminars, disclosing the patterning in great arrays of linguistic forms. Pike, Nida, and others developed training materials for student missionaries. With the wartime demand for competent linguists and scientific descriptions of languages there emerged with even more urgency a critical need for guidance how to proceed when confronted with an unknown language in the field. It was in response to this, for example, that Bloomfield wrote his 1942 Outline guide for the practical study of foreign languages. ${ }^{26}$

In the pages of the International Journal of American Linguistics (founded by Boas in 1917) and Language (founded in 1925), published analyses of languages accumulated, exemplifying the more scientific methods. But to report the diversity of exotic language structures, linguists were devising almost equally diverse and exotic modes of describing them. So at the same time, in an almost parallel stream of articles and monographs, they searched for common theoretical and methodological ground. Implicit in the background was the question: which of the manifest differences between their presentations of language structure genuinely reflected the essential character or 'genius' of each language, and which amounted to what we might now call 'notational variants'?

26. Sapir and Bloomfield obviously were strong influences in linguistics and on Zellig Harris. However, it is a peculiar distortion of the polemics of the 1960s to consider him a Bloomfieldian. Sapir thought very highly of Zellig's work, beginning with a very positive review of his Phoenician Grammar (Harris 1936, the published form of his 1934 Ph.D dissertation), and children of Sapir have recalled that he considered Zellig to be his intellectual heir. The esteem was mutual. Zellig also greatly admired Bloomfield's work, and him as a person. $\mathrm{He}$ studied formally with neither. The term 'neo-Bloomfieldian' is a rhetorical device equivalent to talk in the 1960s of the mythical 'hegemony' of 'taxonomic linguistics'. Once this way of framing discussion is accepted, it becomes difficult to perceive the diversity that in fact obtained in the post-Bloomfield/Sapir era, and the spirit of collegiality in the presence of diversity - see the letter to Goetze quoted below for an instance - is misperceived as mere conformity. 
To address this question as part of the necessary spadework for establishing the mathematical foundations of the field, Zellig wrote a series of brief 'structural restatements' of language descriptions that had been published by his peers (drawing also on other materials that were available to him, both published and in manuscript), mapping each to a kind of normal form. He was careful to present these not as a prescriptive norm, but rather as a formal basis by which they might fairly be compared, and by which essential linguistic differences might be distinguished from accidental differences of organization and presentation. ${ }^{27}$ It should be realized that this was merely a published portion of a lifelong practice of reviewing and carefully analyzing linguistic descriptions written by others. Aside from familiarizing himself with the structures of diverse languages, the primary purpose was to test his methods (and, later, his emerging theory) at every stage. The related benefit was to avoid being hedged in by his own preliminary conclusions.

\section{Carnap's rules of transformation}

Noam's divergence from Zellig can be seen at an early stage in their respective interpretations of Carnap. Zellig contrasted Carnap's enterprise with that of linguistics. Quoting Carnap (1928), he says:

It is widely recognized that forbidding complexities would attend any attempt to construct in one science a detailed description and investigation of all the regularities of a language. Cf. Rudolf Carnap, Logical Syntax of Language 8: "Direct analysis of (languages) must fail just as a physicist would be frustrated were he from the outset to attempt to relate his laws to natural things - trees, etc. (He) relates his laws to the simplest of constructed forms - thin straight levers, punctiform mass, etc." Linguists meet this problem differently than do Carnap and his school. Whereas the logicians have avoided the analysis of existing languages, linguists study them; but, instead of taking parts of the actual speech occurrences as their elements, they set up very simple elements which are merely associated with features of speech occurrences. (Harris 1951a: 16n17, italics added)

From the context of this footnote (which we will consider presently), we know that these "very simple elements" are "set up," not in any arbitrary way, but in the very process of identifying points of contrast between utterances, as perceived by native speakers. It is these differential elements, the contrasts, which are "associated with

27. "The justification ...is... the testing and exploring of statements of morphological structure.[...] The present restriction to distributional relations carries no implication of the irrelevance or inutility of other relations of the linguistic elements" etc. (Harris 1947a: 47). 
[phonetic] features of speech occurrences" and thereby given a convenient and manipulable representation. ${ }^{28}$

This passage (and others like it) may provide a good example of confirmation bias. Experience has taught me that many readers will understand here what they expect to read, instead of what is written. I have actually had linguists read this or other passages quoted below and say "he didn't really mean that." The usual expectation is that a relationship obtains between entities that exist as such prior to and independent of that relationship. A book is on a shelf. The relationship of one being on the other does not affect the book-ness of the book or the shelf-ness of the shelf. In the case of the primitive elements of language, however, it is the relationship of contrast which confers upon certain phonetic features (or feature bundles, to use Bloomfield's term) the status of being "what are called phonemes" (Harris 1951a: 72n28).

For Noam, however, the fundamental elements are not the contrasts of the given language, they are phonetic descriptors that apply universally to any language. His understanding of the procedures of (Harris 1951a) was that they "were essentially procedures of segmentation and classification ... designed to isolate classes of phones, sequences of these classes" etc. (Chomsky 1975: 29). Subsequently, he took the fundamental elements to be predefined phonetic descriptors.

The alphabet of primitive symbols is determined by general linguistic theory, in particular, by universal phonetics, which specifies the minimal elements available for any human language and provides some conditions on their choice and combination. (Chomsky 1975: 5)

In the Introduction to (Chomsky 1951), Noam aligns himself with Carnap (1928):

Thus Carnap in the Aufbau, ${ }^{* *}$ for example, begins with a primitive relation between slices of experience and attempts to construct, by a series of definitions, the concepts of quality class, quality, sensation, etc., i.e., he tries to construct concepts for the most general description of experience. Similarly, it can be shown that the theoretical part of descriptive linguistics, beginning with three 2-place predicates of individuals, and restricting its individuals to a tiny domain of experience (i.e. speech sounds $s^{*}$ ) can construct concepts such as 'phoneme', 'morpheme', etc., which are available for a general description of that part of experience called linguistic phenomena. (Chomsky 1951: 1-2)

(The first footnote gives the citation for Carnap 1934; the second reads: "Or, perhaps, segments of magnetic tape on which speech is recorded.") Thus, Noam is committed to the usual view that speech sounds, not speaker judgments of contrasts, are the primitive

28. Adapting Bishop Berkeley's familiar example, if a recording of an utterance in some language is played in a forest, and no user of that language is there to hear it, what is the status of the sounds from the recorder? 
elements from which phonemes and higher-level elements are 'constructed.' He simply did not grasp this radical difference in Zellig's formulation of the foundations of linguistics, nor understand its importance for liberating linguistics from the strictures in which the philosophers felt themselves bound. ${ }^{29}$

\section{The Morphophonemics of Modern Hebrew}

Let us now return to the mid 1940s to consider again the situation as Noam was entering the field as an undergraduate four or five years before writing this. Zellig had just completed the manuscript of his first book (Harris 1951a), and had just published (1945) or was then completing $(1947 a, 1947 b)$ his brief series of structural restatements of descriptions by other linguists. This, then, was for young Noam the paradigm of linguistics - on the one hand using anecdotal examples and fragments of language data to demonstrate methodological and theoretical points, and on the other hand reframing someone else's description of a language as a way of substantiating such points. Noam's Master's thesis, Morphophonemics of Modern Hebrew (Chomsky 1951 ) is a 'structural restatement' (without citation) of materials that Zellig gave him; ${ }^{30}$

29. Lest it be thought that the pair test is an instance of a "2-place predicate of individuals," note that Carnap's notion of 'primitive dyadic predicate' is satisfied if two individuals 'resemble' each other, but in the judgment of a native speaker, a repetition is categorially identical, not merely resemblant.

30. Barsky (2007: 148) quotes a letter

that Harris wrote to Bernard Bloch ... on December 19, 1950...: "A student of mine, A. N.Chomsky has been doing a great deal of work in formulation of linguistic procedures and has also done considerable work with Goodman and Martin. Last year I [gave] him the morphological and morphophonemic material which I had here...."

Noam obviously also had access to Zellig's description of the classical language (Harris 1941a), and his dialect study (Harris 1939), which would have been useful for the historical validation of morphophonemics. Zellig was a fluent speaker and writer of Modern Hebrew, a lifelong resident part of the year at kibbutz Mishmar Ha'emek in Israel. His continued work on the linguistics of Modern Hebrew during Noam's studentship at Penn is testified by (Harris 1948, 1951b). The closest Noam comes to acknowledging his dependency on Zellig's prior descriptive analyses is in Section 1.3, “The present paper will confine itself to step two in the description of Modern Hebrew." Step one he identifies as the 'discovery' of elements and "the determination of the relevant sequences, classes, sequences and classes of classes, etc., of these elements." Step two, then, is "the construction of a descriptive statement based on the results of this process of discovery" (sic). Of course to 'discover' and 'determine' all this is precisely to formulate a descriptive statement, since the very definitions (or determinations, if you will) of all of the relevant elements, sequences, classes, etc. are statements of their interrelations. This therefore amounts to an acknowledgement of relying upon a prior descriptive organization 
and LSLT (Chomsky 1955a, 1956a, 1975), from which his (1955b) Ph.D dissertation was extracted, employs the same sort of organization and use of data as does Harris (1951a). And this of course has been the paradigm of Generative linguistics from its beginnings to the present. ${ }^{31}$

As to transformations, Noam only experienced them as means for regularizing the successive periods of a discourse. "As a student of Harris's, I participated in seminars on discourse analysis from the outset until leaving for Harvard in 1951, along with Fred Lukoff, A.F. Brown, and a few others" (Chomsky 1975: 53n77). Noam's Master's thesis has nothing of syntactic transformations in it. He applies the terms 'transform,' 'transformation,' etc. to morphophonemic statements, in the sense of 'rule of transformation' borrowed evidently from Carnap: ${ }^{32}$

of the data of the language (step one) and restating it (step two). So far as I am aware, Noam never returned to the grammar of Modern Hebrew in any subsequent writing, not even to cite examples. Much later, Noam proposed (Chomsky 1969: 33) that progress in linguistics in the 1950s depended on someone coming along who was familiar both with the mathematical work on recursive systems and with the tradition of historical linguistics. This describes Zellig far better than it does Noam, whose work demonstrates neither interest nor competence in historical linguistics, but who we may suppose was familiar with Zellig's historical Semitic writings, and presumably also his own father's. Murray (1994: 228n3) reports that Noam dismissed his proposal that he was referring to himself as this person, calling this a "malicious distortion" but evidently without clarifying who he in fact did mean.

31. The literature of generative grammar relies upon anecdotal examples taken in isolation, and in particular, in discussions of 'taxonomic linguistics' from the 1960s onward, Noam has repeatedly (one might say obdurately) selected distributional regularities that do not generalize as purported demonstrations that distributional methods are inadequate. His talk about having to choose between a large number of alternative grammars is supported only by such fragmentary examples. The choices are greatly reduced when full-coverage descriptions are considered, and dwindle even more under the requirement for a 'least grammar' articulated in Zellig's last publications. Throughout his career, Zellig always aimed for and worked within a broad-coverage grammar. Methods (Harris 1951a), his most prominent work when Noam was a student at Penn, appears to have many exceptions to this generality, as it employs anecdotal examples to demonstrate particular points, but even there considerations such as "simplicity of statement" - the very considerations that have been most vexing to Noam - boil down to asking what works out best in the grammar as a whole. The basic principle of Optimality Theory captures the spirit of this.

32. In the published Introduction to LSLT (Chomsky 1975: 37) Noam says that (Chomsky 1951 ) is a nontransformational grammar. Its morphophonemic statements are 'rules of formation' and 'rules of transformation' in the sense of Carnap (1934). There is no evidence that Noam ever understood Zellig's origination of the notion of grammatical transformation in algebra. Zellig's transformations are a property of language, Noam's are a formal device for representing that property by 'enriching' the rules of a phrase-structure grammar. Rules of grammar may be widely variant in form, as a matter of notation and system, but transformations in the algebraic sense are variable only insofar as language varies, and changes, and 
Here it will be shown how sequences of morphemes (of [word classes] $M$ and $U$, the basic words) are transformed by the morphophonemic statement into their constituent phonemes. Adjunction of this set of examples to the previous pair gives a complete exemplification of the transformation of all possible sentences into phonemic sequences. (Chomsky 1951a: 59) ${ }^{33}$

And on p. 22:

The statements have the form of rules of transformation. Given a sequence of a certain shape, they direct you to alter the shape in a specified way. If the directions are followed, any sequence of morphemes, properly selected from $\mathrm{M}$ and $\mathrm{U}$, will be transformed step by step into a sequence of phonemes.

In fact, syntax is presented only in a very simple manner, no more than a concatenation of construction classes into larger construction classes, first elementary sentences ES, and then sentences, which can be either ES or (recursively) Sentence + Conn + Sentence. ${ }^{34}$ The concatenation possibilities within ES are represented by a table of the sort seen e.g. in Harris (1951a: 153,353), a notational variant of a simple phrasestructure grammar. The discussion of sentence forms and construction forms is perfunctory, sufficient merely to provide context for the morphophonemics by sketching (with great optimism!) what a complete grammar might look like. The main focus, as the title indicates, is on a system of 'rules of transformation' specifying the morphophonemic alternations in Modern Hebrew. Some of these statements are also in

possibly evolves (or is modified) to develop new capacities. Zellig developed a description of language as a mathematical object, and of linguistic information as its interpretation; Noam developed a formal system, the procedural steps of which produce (many, by intention all) sentences of a language, and advanced the hypothesis (couched as a necessary presupposition) that this system describes or corresponds to the cognitive means by which speakers of the language produce those sentences.

33. The page references are to the manuscript, or, more exactly, to a photocopy of the original ms. made for me by the staff of the Rare Book and Manuscript Library in the Van Pelt Library at The University of Pennsylvania, catalogued as 378.748PoA / 1951.60 (RBC). This passage is found in Section 5 "Derivations".

34. The form class Conn is defined by a list of morphemes. Over 30 years later (Chomsky 1975: 169), Noam described these and the construction rules that follow "phrase structure rules supplemented by extensive use of long components". The use of the string-rewriting ('tag machine' or 'Post canonical system') notation that Noam adapted (without credit) from Post (1943) is limited to the morphophonemic statements. It is known that Zellig made use of Rosenbloom's Elements of Mathematical Logic (Rosenbloom 1950), Chapter 4 of which contains a nice summary of Post's work. Noam could have read either or both, and there were developments of it elsewhere. It was Post who generalized the notion of an algorithm from its classical expression in arithmetic. 
table form; some are definitions of morpheme classes and subclasses; and the rest are ordered morphophonemic rules, as in Bloomfield's (1939) Menomini Morphophonemics, cited in Harris (1951a: 236) as an instance of 'descriptive order' (ordered rules). ${ }^{35}$ The demarcation between syntax and semantics is avowedly arbitrary: "It is convenient to consider the morphophonemic statement as being initiated at this point, although there is no systematic break." 36

More pertinent to our present considerations is the discussion of criteria for selecting the 'correct' grammar. They have nothing to do with the psychological capacities of the language user. As we have seen, Noam distinguishes (1.3) a first step, determining the elements and their combinations by distributional analysis, from a "second step ... the construction of a descriptive statement based on the results of this process of discovery [sic]."

$[T]$ he statement of the grammar, the presentation of the results of the completed distributional analysis, must meet wholly different criteria which involve, essentially, considerations of elegance and considerations of adequacy as determined by the particular purposes of the grammar. (Chomsky 1951:4)

For these criteria of elegance, he takes his authority from Goodman (1943: 107): “The motives for seeking economy in the basis of a system are much the same as the motives for constructing the system itself" (Chomsky 1951: 5n). He elaborates on this theme in Section 4:

The fundamental question about this preceding grammatical statement, aside from the question of its adequacy in describing the facts, is: in accordance with what general considerations was it constructed the way it was, and, in particular, to what extent is an order imposed upon the statements by these considerations? It will now be shown that the statements are, to a large degree, ordered by the criteria of 'elegance'. [...] (Chomsky 1951: 47)

The general considerations which have been regarded as relevant criteria are as follows:

1. Simplicity of statements

2. Maximization of the number of derivations in which a statement will occur relevantly.

35. Chapter 9 of Koerner (2002b) questions Noam's claim that he did not know about Bloomfield's treatment of morphophonemics with ordered rules until much later.

36. Last paragraph of Section 2. The spelling of 'morphophonemic' here and in the title of Section 3 is inconsistent with the spelling of 'morphoneme', etc. elsewhere, with the additional '-pho' later inserted supra. The term seems to have originated with the Prague School. Anderson (1985: 113, in a section of Chapter 4 entitled "Morpho(pho)nology") attributes the shorter term to Henryk Ułaszyn (1874-1956), a student of Jan Niecisław Baudouin de Courtenay (1845-1929), citing Trubetzkoy (1934: 30), then proceeds to use the short form thenceforth. 
3. Minimization of irrelevant applications.

4. Maximization of similarity among statements, and amalgamation of statements involving the same elements.

[...] 2 and 3 are applied only when 1 or 4 are not thereby violated. 1 is outweighed by 4 when the difference in complexity of the formulations under consideration is simply a matter of the addition of one or two symbols, with the structure of the statement remaining unaltered. (Chomsky 1951: 49-50)

This metagrammatical question of how to determine which of various alternative grammars is the 'correct' one is the central purpose motivating LSLT (Chomsky 1955a). The proposed means of adjudication is "a general theory of language structure, a metagrammar" (Ryckman 1986: 131). For Noam, theory construction is a prerequisite to linguistic analysis; for Zellig, his methods neither require nor constitute "a theory of the structural analyses which result from" their application (Harris 1951a: 1), and a theory of language or of grammar is an outcome which must not be leaped at too quickly, lest it prejudice analysis and obscure the real properties of language behind 'realities' of presupposed theory. Noam makes the point that no observation or analysis is theory free, and this is true, but Zellig keeps his theoretical assumptions to a very minimum.

I have quoted Zellig to the effect that he crafted his structural restatements not to tell other linguists what they should do but to demonstrate the interconvertibility of their alternative types of description, making it possible to peel away differences that are merely artifacts of notation or descriptive style, thereby more clearly disclosing what is essentially distinct in each language ${ }^{37}$ It was not in his purpose, in his interest, or in his nature to demand that others conform to one way of doing things, nor, in his view, was it in the interest of the developing field of linguistics to presume to have the final answer and attempt to squelch alternatives, because "the best way to get closer to the 'truth' - after I have figured out whatever I could - is to get the divergent opinions which arise from a different scientific analysis." (letter to Goetze quoted above).

Noam, however, frames the problem in terms of competing alternatives, and restatements in the Generativist literature (almost always 'aspects' of a grammar, that is, grammar fragments on a smaller scale than Harris 1947a, 1947b, are made only for the purpose of asserting superiority of one view over another, and deciding what properly belongs in the metagrammar that should guide further 'discovery'. We see a glimmering of this even in (Chomsky 1951: 49n):

Actually, if these considerations [1-4 enumerated above] are dropped, almost any order can be shown to function successfully, simply by enumerating in each statement the cases which lead to an incorrect result, and adjoining to each statement a correction for each such instance.

37. An obvious extension of Sapir's interest in characterizing the unique 'genius' of each language. 
The prospect of eliminating all criteria produces the appearance of a great number of alternative grammars. Then, instead of criteria for choosing one partial analysis over another within a single continuously refined description, as in (Harris 1951a), Noam frames the process as adjudicating between grammars and reducing a thus inflated set of possible grammars until (ideally) only one is left standing. Logically, they may be equivalent; practically, they are not.

From this and other discussions of that period and later, it is evident that Noam felt that where there are two alternative statements, one must be incorrect and the other correct. This is of course consistent with the difference of temperament posited at the beginning of the present paper. We noted earlier how the aim of the procedures in Harris (1951a) is to verify that conclusions, however reached, have a valid relationship to the data of the language. Chomsky (1955a: I-9) offers the peculiar interpretation (citing it as Methods of [sic] Structural Linguistics) that these procedures "provide a practical mechanical way of validating [a grammar], i.e., of showing that it is in fact the best grammar of the language." In this, Noam appears to be attributing to Zellig his own desire for an algorithm, albeit at this stage no longer an algorithm of discovery, but rather of adjudication among alternative descriptions. As John Goldsmith says, "Generative grammar is, more than it is anything else, a plea for the case that an insightful theory of language can be based on algorithmic explanation" (Goldsmith 2004: 1), or indeed that it must be so based in order to be 'interesting,' 'non-trivial,' etc. Any non-algorithmic description is dismissed as 'vague. ${ }^{38}$

You will look in vain for the above quotations in the published version of The Morphophonemics of Modern Hebrew (Chomsky 1979a). In that revision, Carnap disappears from sight. The growth in maturity of thought and expression, the greatly increased differentiation from the locutions and principles of (Harris 1951a), and indeed the sheer extent of these revisions, in six short months of 1951, is quite remarkable. Noam has said (1975) that he intended to include it as an appendix to LSLT. It seems extremely unlikely that it was never revised for that purpose between 1951 and 1956. Bearing in mind the extent of unacknowledged revisions differentiating (Chomsky 1975) from the several 1955-1956 versions of LSLT, ${ }^{39}$ it seems at least possible that the published version may include late revisions for (Chomsky 1975), or even later. How likely is it that Noam would send to publication any but the most recent revision? No wonder that it "addresses the subject right from the start in a surprisingly self-assured manner”, as Koerner (2002b: 24) says. For a detailed analysis of the

38. On the algorithmic nature of generative grammar, and the pitfalls of an algorithmic approach, see also Gross (1979:882-883).

39. Murray (1999), Koerner \& Tajima (1986: 3-5, 56), Ryckman (1986, chap.3, esp.pp. 143-147n). 
differences between the original ms. and the publication of 1979 , see the contribution by Peter Daniels to this volume.

\section{Discovery and restatement}

Noam was steeped in Hebrew language studies in his family, and he may have done some linguistic fieldwork with Hebrew-speaking informants in Philadelphia, but the 'discovery' phase of linguistic analysis of Hebrew had already been done in Zellig's publications when he undertook the restatement in (Chomsky 1951). On that borrowed basis, this is the only work approaching a comprehensive grammar that he has ever done. All his subsequent work has been a succession of restatements of fragments of the grammar of English. This is deemed sufficient because his primary aim is a metagrammar of all languages ('Universal Grammar'), and he proposes that the grammar of any one language cannot be written properly until that is achieved.

Did Zellig write about discovery procedures? Based on extensive fieldwork experience, both his own and that of others, eliciting information from informants about unknown languages, Zellig did not seek and did not expect to find any discovery procedures to simplify and short-cut the work of linguistic analysis.

These procedures are not a plan for obtaining data or for field work. [... They] also do not constitute a necessary laboratory schedule in the sense that each procedure should be completed before the next is entered upon. In practice, linguists take unnumbered short cuts and intuitive or heuristic guesses, and keep many problems about a particular language before them at the same time.[...] The chief usefulness of the procedures... is therefore as a reminder in the course of the original research, and as a form for checking or presenting the results, where it may be desirable to make sure that all the information called for in these procedures has been validly obtained. (Harris 1951a: 1-2)

Nor did he develop formal language-like structures such as the ramifications of PSG that so engrossed Noam. His interest was in "differences in how the language data responded to identical methods of arrangement" (Harris 1951a: 3) and in how diverse methods disclose different properties of language. The structures disclosed by his methods could be formalized as language-like systems (types of formal grammars), but this work was largely left to others. ${ }^{40}$ Many years later, he noted this algorithmic

40. Principally Aravind Joshi and his students, who formalized string analysis as adjunction grammars and as the major component of tree-adjoining grammars. Naomi Sager and her colleagues developed the previously mentioned systems at NYU by extending the string parser developed at Penn. Stephen B. Johnson is working on the formalization of Operator 
aspect of Noam's work in his remark that "the tree representation could be considered a representation not so much of the sources of the sentence as of the ordered choices to be made in that system for producing the given sentence" (Harris 2002 [1990]: 6). As we have seen, his effort from an early stage was to identify what is essential in language, avoiding artifacts due to any particular mode of analysis or presentation.

[T] he data, when arranged according to these procedures, will show different structures for different languages. Furthermore, various languages described in terms of these procedures can be the more readily compared for structural differences, since any differences between their descriptions will not be due to differences in method used by the linguists, but to differences in how the language data responded to identical methods of arrangement. [...] The central position of descriptive linguistics in respect to the other linguistic disciplines and to the relationships between linguistics and other sciences, makes it important to have clear methods of work in this field, methods which will not impose a fixed system upon various languages.... (Harris 1951a: 3)

By the end of 1946 he had summarized this work, as far as it had then gone, in the hefty manuscript that was published five years later in 1951 as Methods in Structural Linguistics. ${ }^{41}$ As we have seen, the recurrent theme of this book is that linguists of course

Grammar, using the Lexicon Grammar framework of Maurice Gross for the system of reductions. (Due to an error by the publisher, his name as co-editor of Nevin \& Johnson 2002 is given as Stephen M. Johnson because that is another author's name previously entered in the publisher's database.)

41. There can be no doubt that it was revised in the interim. In an undated letter to Bernard Bloch (probably early August 1949), he wrote "this g-d d----d (for the hyphens, substitute od, and amne) methods in descriptive linguistics book was revised by me for the $(n+1)$ th time last spring. Several people who saw it said I ought to try a couple of commercial publishers before sending it to you (even though, as I explained to them, I had an informal understanding about it with you), in order to see if a wider audience (of non-linguists) could be reached." The title in 1946 and as late as 1949 was Methods in Descriptive Linguistics. Zellig told me he was not certain who made the change, he or the publisher, and I have supposed that the publisher substituted a word with more marketing sizzle. However, Joos (1957: 96) says:

An older term for the new trend in linguistics was 'structural'. It is not idle to consider how the term 'descriptive' now [1942] came to replace it, even if not all the reasons can be identified. The Sapir way of doing things could be called structural, but the term was more often used for the stimulating new ideas that were coming out of Europe, specifically from the Cercle Linguistique de Prague.

So, although it may have been a restoration of an older term, the publisher's motivation may have been to align with the sales appeal of European linguistics. The notion that 'neoBloomfieldians' rejected European ideas seems ill supported. 
have freedom to work in diverse ways (Zellig was after all an anarchist), employing all kinds of heuristics and hunches as they wrestle their data into a form that makes useful sense, but as scientists aware of their all too human proclivity to perceive what they expect to perceive, and as linguists aware of the all too human suggestibility of informants, especially in politically and economically subordinated cultures, it was incumbent upon them to verify that their conclusions continue to bear a valid relationship to their data. It was Noam, and not Zellig, who by his own account was avid for discovery procedures. ${ }^{42}$

\section{Fundamental data}

Judgments of meaning are among the heuristics that linguists use (Harris 1951a: 365n6). Indeed, Zellig plainly indicates that among all the possible distributional regularities that may be found, just those are sought which establish "elements which will correlate with meanings" (Harris 1951a: 188). A late statement is found in Zellig's last book, A theory of language and information, in Section 2.4, entitled "Can meaning be utilized?": "All this is not to deny the usefulness of considering meaning in formal investigation..." etc. (Harris 1991: 42). Not only is it incorrect, therefore, to say that he avoided meaning, as is commonly alleged; we must rather acknowledge that identifying the fundamental data of linguistics depends upon "the meaning-like distinction

42. This is not to say that Noam was interested in discovering data about languages. I see no evidence of that. Rather, he seems to have had the conviction that Zellig's "presentation of the methods ... of research in descriptive, or, more exactly, structural, linguistics... in procedural form and order" (Harris 1951a: 1) should be, despite disclaimers on the page just cited and elsewhere, algorithmic procedures corresponding to the process by which children learn language. Noam's lifelong penchant for abstract analysis in preference to breadth of data, increasingly prominent in his later career, seems to have been the dominant factor in this early work "devoted to the problem of revising and extending procedures of analysis so as to overcome difficulties that arose when they were strictly applied" (Chomsky 1975: 30). The procedure described in (Harris 1955, 1967) for identifying morpheme boundaries (or rather, the boundaries of morpheme alternants, or allomorphs) is the closest thing to a discovery algorithm in his publications; it depends upon a prior representation of the contrasts (standard orthography suffices for an approximation) and requires subsequent morphophonemic and morphemic analysis to establish the morphemes of a language. Note that (Harris 1955: n1) acknowledges Noam's input. The Turing-machine-like system for sentence recognition (Harris 1966) was presented as a demonstration of distributional principles, not as a discovery procedure. "The detailed problem here is ... the word-representation methods which made it possible to apply so simple a device. Indeed ... it can be studied as a notation for the modalities of requirement and permission [which a given word has to all environing words]." 
between utterances which are not repetitions of each other" (1951a: 363$).{ }^{43}$ We will return to the nature and role of meanings again farther on.

This brings us to a subtle point, central to Zellig's work, namely that the fundamental data of linguistics are not phonetic records or notations, but rather speaker judgments of what is different and what is a repetition. Phenomena cannot be repeated exactly; categorical perceptions of those phenomena can. In consequence, these most basic linguistic elements, the phonemic contrasts, are not segments or features of sound as discriminated by phoneticians, they are perceptual distinctions made by native speakers, which we keep track of by associating them with such phonetic segments or features. ${ }^{44}$ Sounds are associated with the contrasts by the very process of the substitution tests that identify them, a process which requires segmenting utterances such that one segment can be substituted for another. ${ }^{45}$ But the contrasts are primary, and can be represented by segmenting the speech stream in alternative ways. This crucial point is stated in numerous places, for example in the extended statement at (1951a: 16-21), and in the following: ${ }^{46}$

Since the representation of an utterance or its parts is based on a comparison of utterances, it is really a representation of distinctions. It is this representation of differences which gives us discrete combinatorial elements (each representing a minimal difference). (1951a: 367)

Yet, despite the frequent reiteration with different words in a variety of contexts, so far as I know, none of his contemporaries recognized this. ${ }^{47}$ Bernard Bloch, for example,

43. Likewise in many other places, e.g. (Harris 1942), where is cited also Bloomfield (1933: 161) to the same effect. See also (Hiż 1979: 344), quoted farther on below.

44. This is consistent with the development of logic and mathematics from the making of a distinction in a space, see Spencer-Brown (1969).

45. Ideally, but not necessarily, the pair test. The segments need not all be made by 'vertical' cuts of the phonetic record; the substitution of 'horizontal' features or simultaneous components is also possible.

46. See also (Harris 1941b), especially the third paragraph, beginning "It is in the second step, selection of the contrast-criterion...."

47. See e.g. Joos (1957: 108) “[Hockett's] segmentation into 'sounds' is not so much logically justified as taken for granted. Today it is even considered possible to defend the thesis that such segmentation can't be done strictly until after phonemic segmentation has been somehow (say distributionally) established." Had he "today" (1956 or so) understood the pair test and its consequences as to the ontology of phonological contrast, he would have understood that an initial segmentation is inseparable from, and in a sense is effected by, the determination of contrasts. In particular, he could not have employed that last phrase, "somehow (say distributionally) established," for the non-substitutability of contrasting segments in the pair test (or more generally in substitution tests) is precisely a distributional establishment of 
assumed that phonemic distinctions can only be derived from distributional analysis of phonetic data (Bloch 1948). ${ }^{48}$ Certainly it is no part of phonology today, and, although in several places Noam recognizes the utility of the pair test (e.g. 1975: 93, 147) for determining the phonemes without appeal to meanings, there is absolutely no evidence that he understood the consequences for the ontological status of phonemic distinctions and of linguistic elements established on that basis. Everything in his phonological work is grounded in a universal alphabet of descriptors or features, each of which is defined by some phonetic characteristic. ${ }^{49}$

Those descriptors are considered to be universal phonological elements. The effort to achieve universality for them has turned out to be difficult through many successive revisions, and remains inconclusive. The features are considered to be phonological rather than merely phonetic because they cohere in a system; that is, their interrelations constitute an a priori abstract system which is taken to be more important phonologically than the equally or even more systematic considerations of their distribution in utterances.

them. See also the comments earlier on confirmation bias. Harris's writing is always careful and exceptionally clear, and (unless the matter itself is exceptionally complex) difficulties are usually where what he says is contrary to the reader's expectation. As Jane Robinson once observed (pc): "If I have an idea what he's talking about, I can understand him. As someone said of Quine, once you've understood what he means, you realize he couldn't have said it any other way. Harris is that way for me. It's just that what he's trying to say is difficult."

48. The critique of Bloch and others and the rejection of distributional methods in (Chomsky 1964) appears to be intended to apply, incorrectly, to Harris (1951); see Nevin 1993a, 1999 for discussion. Some readers have been confused by e.g. “This procedure takes the segmental elements of Chapter $5 \ldots$ and groups them into phonemes on the basis of complementary distribution" (Harris 1951: 59). What is overlooked, leading to this misunderstanding, is that "the segmental elements of Chapter 5" are not 'phones', that is, elements of a phonetic transcription; rather, they already constitute a preliminary phonemic representation, since they indicate speakers' phonemic distinctions, albeit inefficiently, and it is those inefficiencies or redundancies that distributional analysis removes.

49. Some work on a hierarchy of features that enter progressively, as it were, into the phonemic contrasts of a language (e.g. Dresher 2003) amounts to a statement of affordances for contrast (if I may borrow Gibson's $(1977,1979)$ terminology without importing with it his conclusions about the environmental causation of behavior). This principle is most clearly seen where in certain articulatory regions differences of articulation have little acoustic effect, and in adjacent regions slight differences of articulation result in a change in categorial perception. An example is the so-called quantal vowels (Stevens 1972). It remains that the contrasts of a language cannot be predicted from phonetic data, and the crucial factor is still human perception. See also Kirchner (1995). 


\section{The attack on distributional analysis}

At the end of Chapter X of (Chomsky 1956a), we read the following approbation of distributionalism:

Within the general limits of formal distributional analysis, there are many avenues of investigation beyond those that have been followed here, notably, the whole study of the statistical structure of language. ... In short, there seems to be considerable unexplored territory within the boundaries of formal distributional analysis, and the possibilities and potentialities of such analysis show no sign of having been exhausted. It is surely premature to insist that the basis of linguistic theory be extended to include obscure and intuition-bound concepts, on the grounds that the clear notions of formal analysis are too weak and restricted to lead to interesting and illuminating results. (Chomsky 1956a: X751-752)

This Chapter X became ${ }^{50}$ the Summary Chapter 1 of (Chomsky 1975), but when we consult the latter, such language has entirely disappeared. What happened?

In his plenary presentation at the 1962 Ninth International Congress of Linguists, as later expanded to (Chomsky 1964), several aspects of the divergence that we are discussing are in sharp relief. A full analysis of this tour de force of reframing ${ }^{51}$ would require treatment of at least equal length, but a few exemplary extracts will help illustrate the extent and nature of the divergence in views at this stage, beginning here with the question of phonetics and phonological contrast. Most of what Noam says

50. "In the spring of 1956, I began to revise the manuscript for publication. In the original, the tenth and final chapter was a summary. In the version that I was preparing for publication, I placed the summary chapter first, otherwise leaving the chapter order unaltered. During that year I did manage to rewrite the new summary chapter (Chapter I) and the first five chapters of the original (Chapters II-VI). The manuscript as published here consists of a preface written in 1956 and the chapters (here numbered I-VI) of this edited version.” (Chomsky 1975: 3) However, Chomsky (1956a) shows the summary chapter (from which I have quoted here) in its original position at the end as Chapter X. Ryckman (1986) has shown that extensive revisions in addition to the rewriting in 1956 intervened before publication of (Chomsky 1975).

51. I use the term 'reframing' in the sense of Lakoff $(1987,2002)$. (It is likely that he adopted the term from Bandler 1982. See the Wikipedia article on reframing for an account of the origination and earlier usage of the term.) Reframing shifts the terms of debate in presuppositional ways. In this instance, the diversity of descriptive linguistics was reframed as a unified, hegemonic 'taxonomic linguistics' straw man. This collapsing of diversity into a convenient form for argument is admitted e.g. at (Chomsky 1964:75): “Though modern phonologists have not achieved anything like unanimity, a body of doctrine has emerged to all or part of which a great many linguists would subscribe" etc. Developments in phonology that are too diverse to be made to fit are dismissed as inexplicit and vague (ibid. fn. 13), as measured against a standard of suitability for formalization in an algorithm. 
is perfectly compatible with Zellig's views. He has told me (letter of September 18, 1995) that this apparent compatibility is only because Zellig is 'vague', but it is more accurate to say that Zellig did not demand that only one of several alternative formulations must be true. For Zellig, these are not rules in an algorithm, they are tools of analysis. It is true, as Noam says, that he held that these tools are useful for different purposes, yielding results which in the very nature of science are provisional. But more than that, each type of analysis (constituency, expansions, string analysis, transformations, least differences, discourse analysis, sublanguage analysis, etc.) reveals a different aspect of "what gives" in language. Where Noam looks for rules, Zellig offers methods. For example

It should be clear that while the method of 7.3 [grouping segments having complementary distribution] is essential to what are called phonemes, the criteria of 7.4 [phonetic and environmental symmetry] are not essential 'rules' for phonemicization, nor do they determine what a phoneme is. (Harris 1951a: 72n28, italics added)

Zellig developed diverse methods of analysis, and showed how each method discloses some of the properties of language well, and others not so well. His approach was to honor the method, apply it with neutral care, and see what emerges.

Zellig Harris's work in linguistics placed great emphasis on methods of analysis. His theoretical results were the product of prodigious amounts of work on the data of language, in which the economy of description was a major criterion. $\mathrm{He}$ kept the introduction of constructs to the minimum necessary to bring together the elements of description into a system. His own role, he said, was simply to be the agent in bringing data in relation to data.... [I]t was not false modesty that made Harris downplay his particular role in bringing about results, so much as a fundamental belief in the objectivity of the methods employed. Language could only be described in terms of the placings of words next to words. There was nothing else, no external metalanguage. The question was how these placings worked themselves into a vehicle for carrying the 'semantic burden' of language.... His commitment to methods was such that it would be fair to say that the methods were the leader and he the follower. His genius was to see at various crucial points where the methods were leading and to do the analytic work that was necessary to bring them to a new result. (Sager \& Ngô 2002: 79)

Noam understands matters in terms of argument, of which there must be a winner. These are for him not tools of analysis, but theories of grammar which are either correct or incorrect. For example, central to the project of Generative Phonology, as we have seen, is the stipulation that the phonological features constitute a system which is independent of any particular language in which those features might be employed to make the contrasts between different utterances. Noam (1964: 77) sets this against the position that "languages could differ from each other without limit and in unpredictable 
ways" (attributed to Boas by Joos 1957: 96). ${ }^{52}$ In his (1941b) review of Trubetzkoy, Zellig does not reject what Noam (op. cit.) calls 'systematic phonetics' (also 'structural phonetics'); although he says "it is pointless to mix phonetic and distributional contrasts" [sic], and he asserts that the former are secondary to the latter:

[I]n order to study the relations between phonemic contrasts one must first have selected what kind of contrast to investigate. Those which Trubetzkoy studies are the phonetic contrasts. He does not say that he is intentionally selecting these rather than any other. He merely uses them as though they were the natural and necessary ones to consider. [...] But there are other criteria in terms of which one may study the contrasts.... Chief among these is the positional distribution.... Trubetzkoy was quite aware of this....he discusses the importance of considering [this]... and... modifies the patterning of the phonetic contrasts by some results from distributional contrasts. However, it is pointless to mix phonetic and distributional contrasts... [and phonetic parallels among the phonemic contrasts] must be independently proved. (Harris 1941b.348, italics added)

This passage invites the quoting of sound bites (or 'text bites') out of context. Compare the more careful formulation of his (1951a) in which speaker perceptions of contrast are the primary data which are distributionally associated with discrete features of phonetic data by substitution tests, and then these associations are wrestled by various criteria into one of the several possible more efficient and useful representations "that are called phonemes". ${ }^{53}$ The difficulty is that he is using the term 'contrast' ambivalently

52. Noam quotes only this phrase, and attributes it solely to Joos, who in fact attributed it to Boas and the tradition following him: "Trubetzkoy phonology tried to explain everything from articulatory acoustics and a minimum set of phonological laws taken as essentially valid for all languages alike, flatly contradicting the American (Boas) tradition that languages could differ from each other without limit and in unpredictable ways, and offering too much of a phonological explanation where a sober taxonomy would serve as well. Children want explanations, and there is a child in each of us; descriptivism makes a virtue of not pampering that child." One cannot but wonder if Noam took this last as being aimed at himself, and rankled at it. But see also Thomas (2002) on the now institutionalized misinterpretation of this quotation from Joos.

53. "At a time when phonemic operations were less frequently and less explicitly carried out, there was discussion as to what had to be done in order to arrive at 'the phonemes' and how one could discover 'the phonemes' of a language. Today we can say that any grouping of complementary segments may be called phonemic. [Bear in mind that the 'segments' here are not 'phones', having been established in substitution tests that identified the phonemic contrasts. - BN] As phonemic problems in various languages came to be worked out, and possibilities of alternative analysis were revealed, it became clear that the ultimate elements of the phonology of a language, upon which all linguists analyzing that language could be expected to agree, were the distinct (contrasting) segments (positional variants, or allophones) rather than the phonemes. The phonemes resulted from a classification of complementary segmental elements, and this could be carried out in various ways. For a particular language, one 
in this passage. The phrase which I have italicized above, "other criteria in terms of which one may study the contrasts," distinguishes the "contrasts" from two kinds of criteria for studying them, (a) "other [i.e. distributional] criteria" on the one hand and (b) the previously discussed phonetic criteria that produce what he equivocally called Trubetzkoy's "phonetic contrasts," on the other.

The thrust of this part of the review is that "phonemes are in the first instance determined on the basis of distribution" and phonetic criteria are secondary. This is because the substitution tests (idealized as the pair test) establish the "first instance" by identifying which parts of the speech stream may be substituted for each other without contrast, and which may not, and it is the substitution within an environment which makes the very establishing of them distributional in character.

Noam (1964:77) continues quoting Joos (1957: 228) as saying

that "distinctive features are established ad hoc for each language or even dialect", and that "no universal theory of segments can be called upon to settle the moot points" (228). Similarly, Hjelmslev appears to deny the relevance of phonetic substance to phonological representation.

What Joos is discussing here, with reference to Hockett (1947), is the variety of phonetically defined distinctive feature systems that had emerged within 'taxonomic linguistics. Consequently, it is neither a "rejection of the level of structural phonetics" qua level nor of "the relevance of phonetic substance," as Noam says. Rather, it is a rejection of applying any a priori solution universally. It is unclear whether or not Joos understood Zellig's reason for such rejection. This reason, as we have seen, was that the terms of contrast must be determined for each language on the basis of distribution (substitution tests identifying speaker perceptions of contrast and thereby associating phonetic features with them), and that phonetic criteria are therefore necessarily secondary.

The difficulty is that the universality of any system of distinctive features had (and has) yet to be demonstrated, and to presume it in advance, begging the question, would actually hinder that demonstration. As an illustration, at a certain stage in the long and complicated (and still unfinished) history of this universal alphabet, so-called 'pharyngeal' or 'faucal' sounds in languages like Arabic and Achumawi have been represented by a retracted tongue root (RTR) feature. The actual articulatory gesture is

phonemic arrangement may be more convenient, in terms of particular criteria, than other arrangements. The linguistic requisite is not that a particular arrangement be presented, but that the criteria which determine the arrangement be explicit." (Harris 1951: 72n28) The fact that the allophones are contrasting affirms that the contrasts are yet more basic, although of course they (the contrasts) are established simultaneously with the allophones by the same substitution tests. 
epiglottideal (Laufer \& Condax, 1979), with secondary effects on the tongue, pharynx, and larynx. In Achumawi, certain phenomena are simpler to describe if the epiglottideal aspirate (like that of Arabic) is treated in parallel with the glottalized consonants of the language, to which no one would apply this RTR feature. Yet convenience for the 'universal' feature hierarchy dictated the existence of RTR and that it should be used to distinguish this aspirate from the ordinary one, complicating the description of those laryngeal phenomena (Nevin 1998).

Noam continues (1964: 77):

Nevertheless, it seems to me correct to regard modern taxonomic phonemics, of all varieties, as resting squarely on assumptions concerning a universal phonetic theory of the sort described above. Analysis of actual practice shows no exceptions to the reliance on phonetic universals. No procedure has been offered to show why, for example, initial $\left[\mathrm{p}^{\mathrm{h}}\right]$ should be identified with final $[\mathrm{p}]$ rather than final $[\mathrm{t}]$ in English, that does not rely essentially on the assumption that the familiar phonetic properties ... are the "natural" ones. Harris might be interpreted as suggesting that a non-phonetic principle can replace reliance an [sic] absolute phonetic properties when he concludes (1951a, 66) that "simplicity of statement, as well as phonetic similarity, decide in favor of the $\mathrm{p}-\mathrm{p}^{\mathrm{h}}$ grouping"; but this implication, if intended, is surely false. The correct analysis is simpler only if we utilize the familiar phonetic properties for phonetic specification. With freedom of choice of features, any arbitrary grouping may be made simpler.

There are several equivocations here. First, what is at stake is not a universal theory of phonetic description, but a universal theory of phonetically defined phonological features - in other words, of all possible phonetic descriptors, just that subset which is presumed to account for all contrasts in all languages, in such a way as to support the most perspicuous account of alternations in all languages.

Now, place what Zellig said about "simplicity of statement" in context:

It is also convenient to have the relation among segment definitions within one phoneme identical with the relation in other phonemes. This requires that the segments be grouped into phonemes in such a way that several phonemes have correspondingly differing allophones ... in corresponding environments.[...] We could have grouped $[\mathrm{p}]$ and $\left[\mathrm{t}^{\mathrm{h}}\right]$ together, since they are complementary. But the above criterion directs us (barring other relevant relations) to group [p] with $\left[\mathrm{p}^{\mathrm{h}}\right] \ldots$... For if we do so, we can say that the /\#__V/ member of all these phonemes is virtually identical with the /s__ member except that $\left.{ }^{\mathrm{h}}\right]$ is added; such a simple general statement would not have been possible if we had grouped the segments differently. (Harris 1951a, 66)

It is in a footnote that Zellig says we could in principle violate this, combining e.g. [p] with $\left[\mathrm{t}^{\mathrm{h}}\right]$, etc., but that doing so would complicate the description. The definition of phonemes would have to say that in addition to adding $\left.{ }^{\mathrm{h}}\right]$ the point of articulation 
changes. This would also complicate any statement (rule) applying to phonemes defined in this way. Therefore, "simplicity of statement, as well as phonetic similarity, decide in favor of the $[\mathrm{p}]-\left[\mathrm{p}^{\mathrm{h}}\right]$ grouping."

What Zellig says here cannot coherently be construed as "replacing" a reliance on phonetic features, since the statements or rules in question cannot be compared as to their simplicity except by reference to phonetic features that $[\mathrm{p}],\left[\mathrm{p}^{\mathrm{h}}\right],\left[\mathrm{t}^{\mathrm{h}}\right]$, etc. do or do not have in common. This is of course what Noam paraphrases in the quoted passage at (1964: 77), but it is so obvious that we have to wonder why he bothered to flog the point.

In the larger context of the section quoted above, what Zellig is saying is that at this (hypothetical!) early point in phonemic analysis many items in the preliminary segmentation are in complementary distribution, so complementarity is not always a sufficient criterion for associating two segments with the same speaker-identified contrast. By a second criterion, we may group segments so that "several phonemes have correspondingly differing allophones" - in other words, so that phonological rules can refer to such phonemes together as a set, or alternatively can refer to the features that they have in common. This is what he calls "simplicity of statement." It is difficult to imagine what Noam could fault about making a phonological rule more general.

To suggest that the criterion of "simplicity of statement" somehow replaces "reliance on absolute phonetic properties" is so curiously obtuse that we must wonder at its possible motivation. In this context, consider how peculiar it is for Noam to wonder what Zellig meant here. After all, he could just ask him, if he had not already done so in the preceding 15 years or so of their association. The explanation evidently is that it was rhetorically useful for his argument.

What Noam is gearing up for here is a rejection of distribution as a criterion. This is necessary in order to supplant the distributional identification of contrasts (by substitution tests) with a universal alphabet of phonetically defined terms of contrast. He does not come right out and assert his own exclusive reliance on phonetic descriptors which are claimed to be 'absolute' universal phonological features. Perhaps the reason he does not say this is because it is convenient for his argument at this point to assert as a straw man that Zellig, by using other criteria in addition to shared phonetic properties, is doing the converse of what Noam is in fact doing - that is, rejecting the criterion of shared phonetic properties - a classic innoculation move in polemic argument. This need not have been nefarious abuse of rhetorical prowess. It has been suggested (e.g. R. Harris 1998) that it is difficult for Noam to perceive what someone is saying in any terms other than his own. This is of course a cognitive trap to which we are all subject, but is perhaps exacerbated by the characteristic cognitive style that I have attributed to him.

The Noam of (1951a, 1955a) was entirely in accord with Zellig on this point, placing "simplicity of statement" first in rank among criteria for choosing the 'correct' 
description (1951a: 49-50); he of (1964) rejects it, giving paramount importance instead to an a priori system of phonetic descriptors (their systematicity apparently that which makes them 'phonological'), with a parallel shift respecting syntax. This shift, and the ratcheting up of polemical rhetoric, coincides with the emergence of 'universal grammar' in Noam's doctrine.

\section{Sounds and contrasts}

Noam has acknowledged (letter of 9/18/1995 to the author) that his (1964) critique of linearity, invariance, biuniqueness, and local determinacy does not apply to Zellig's work. In this, he may have backed off from the claim (Chomsky 1964: 98) that "The only general condition that they [Zellig's procedures] must meet is the biuniqueness condition, which is not justified on any external count, but simply is taken as defining the subject." 54 But here again they are not referring to the same thing. Noam is talking about the correspondence of 'taxonomic phonemes' to the 'phones' of a phonetic transcription. Zellig is talking about the correspondence between two phonemic representations of the contrasts attested by speaker judgments: a preliminary and relatively disorganized representation achieved by associating phonetic descriptors with the contrasts, and a more efficient representation achieved by distributional analysis yielding "the scientific arrangement" (Harris 1941b: 345) of those phonetic data. Both "arrangements of data" depend upon the segmentation of the utterance by those acts of substitution that identified the contrasts (that is, the speaker judgments of what is repetition and what is not) and which thereby associated phonetic data with them. The distributional analysis does not create or discover the phonemic contrasts; it merely maps a complex and redundant representation of the contrasts to "what are called phonemes," a clearer and more useful association of phonetic data to the contrasts.

Zellig usually referred to this mapping as a 'one-one correspondence,' but introduced the term 'bi-unique relation' in his 1944 paper on phonemic long components:

54. Zellig admits a one-many correspondence as follows: "In general, the representation is in one-one correspondence with each occurrence of the represented speech. In the case of intermittently present distinctions, however, it is in one-one correspondence only with a set of repetitions of the represented speeches" (Harris 1951: 364n5). The "external [ac] count" justifying this correspondence depends upon the purpose to which the representation is put. Typically it is important to have a well-defined mapping from speech to representation so that the recording of speech for the sake of further analysis is straightforward; and since utterances predicted by the analysis must be tested with native speakers, it is obviously important to be able to reconstruct from the representation something that they recognize as utterances in their language. 
Finally, if we are ready to admit partial overlapping among phonemes, we may agree to have different components in different environments represent the same phonetic value. So long as we do not have a component in one environment represent two phonetic values which are not freely interchangeable, or two components or component-combinations in the same environment represent the same phonetic value, we are preserving the bi-unique oneto-one correspondence of phonemic writing. (The term bi-unique implies that the one-to-one correspondence is valid whether we start from the sounds or from the symbols: for each sound one symbol, for each symbol one sound.) (1944a. 187-188, footnote suppressed)

This sounds like a correspondence of phones with phonemes. However, not any 'sound' will do, but only those that are associated with the contrasts by virtue of the segmentation established in substitution tests with informants to determine speaker judgments as to "phonemic distinctions, these being the ultimate and necessarily discrete primitives of the language structure. Phonemes were defined as a convenient arrangement of how these phonemic distinctions appeared in utterances" (Harris 2002.2, italics added).

Those speaker judgments necessarily pertain to the given language, and are not themselves universal. There may indeed be some set of universal 'affordances' (Gibson 1977) that people preferentially, perhaps even necessarily, use to make the contrasts of their respective languages. There is evidence of this in so-called quantal vowels and in phonological universals. From Zellig's point of view, that is an interesting and valuable result, but it cannot be presumed in advance. In any case, speaker judgments are the primary data.

Zellig concurs in the value of simultaneous features (e.g. 1951a: 64-65) as a representation of contrasts that may in some respects be more convenient than phonemic segments or phonemic long components, or combinations of these. Noam argues that phonological features are the only legitimate representation - when alternatives are offered, there can only be one winner. The argument has two aspects, firstly their convenience for stating phonological rules, and secondly their purported universality. Claims of their universality rest overtly on arguments for innateness. In this, Noam's earlier wish for an algorithmic solution to the problem of language description has been reframed as a biological solution to the problem of child language.

The case for exclusive use of features is the core argument against 'taxonomic phonemics' in (Chomsky 1964). Split and merger processes in the historical development of languages can produce an 'asymmetry' such as that reported for Russian in (Halle 1959), where voicing is contrastive for stops but not for the affricates /c, č/ and fricative $/ x /$, yet in all cases voicing is assimilated from a following obstruent. In a 'taxonomic' segmental representation, this must be described in the same way for all cases, but with two kinds of rules, morphophonemic rules for stops and allophonic rules for the affricates and fricative. "Simplicity of statement" requires a single rule 
stated in terms of features. Zellig of course had advocated "simplicity of statement" long before, but had greater variety of means to that end at his disposal. Noam does not consider alternative formulations that are possible using phonemic long components instead of universal features. ${ }^{55}$

\section{The relative nature of elements}

As we have seen, the substitution tests which establish native speaker judgments of contrast are inherently distributional in character, and establish phonemes relative to one another. This is why "phonemes are in the first instance determined on the basis of distribution" (Harris 1941b: 348). Given the relative nature of the contrasts, all the phonemic, morphophonemic, morphemic, constructional, and other elements are necessarily also relative in nature. For most practical purposes, these elements are treated as though they are records of things which happen to be different, but in fact each element is no more than a marker of differences.

Since each element is identified relatively to the other elements at its level, and in terms of particular elements at a lower level, our elements are merely symbols of particular conjunctions of relations: particular privileges of occurrence and particular relations to all other elements. It is therefore possible to consider the symbols as representing not the particular observable elements which occupy an environment but rather the environment itself, and its relation to other environments occupied by the element which occupies it. We may therefore speak of inter-environment relations, or of occupyings of positions, as being our fundamental elements. (Harris 1951a: 370-371)

Thus, when Zellig says things like the following, it is not 'hocus-pocus' or 'game playing', he is talking about something that is essential in the nature of language:

...morphemes may be regarded either as expressions of the limitations of distribution of phonemes, or (what ultimately amounts to the same thing) as elements selected in such a way that when utterances are described in terms of them, many utterances are seen to have similar structures. (1951a: 367$)^{56}$

55. In 1964, Zellig had not concerned himself with phonology for probably 20 years. Any representation of the contrasts, even conventional English orthography, is adequate for his investigations into the informational properties of language. Phonology is encapsulated relative to syntax and semantics in Generativist writings as well, for the same reasons.

56. The locution "as expressions of the limitations of distribution of phonemes" in this passage shows that Zellig was aware of the next-successor stochastic determination of morpheme boundaries in the 1940s, long before writing (Harris 1955, 1967). This is of course 
Thus, while intuitions of the meanings of morphemes (or lexical items) are suggestive, regularity and generality of structure in the description as a whole are criterial for determining by which distributional regularities to define the elements (phonemes, morphemes, etc.). Noam, however, sees here only a vague statement by a man who "did not believe there was any truth to the matter to be discovered" (letter to the author, 9/8/1995). It is not that Zellig did not believe that there was any truth to the matter to be discovered, but rather he did not believe that any of the diverse possible representations should be taken to be that which they represent. We have already noted that the findings of science may legitimately make no claims (or covert presuppositions) of absolute truth. See for example Hawking, who affirms (1988: 9) that a scientific theory "exists only in our minds and does not have any other reality (whatever that might mean)."

Zellig's recognition of the relative character of all linguistic elements, and his facility in shifting perspective between an element and its environment, conferred great freedom on his investigations of language data and his formulation of methods and, later, of theory. For Noam, the purpose of analyzing language data is to specify universal elements and metagrammatical principles when then can be known in advance of analyzing language data.

\section{The role of meaning}

In the 1975 Preface of $L S L T,{ }^{57}$ Noam clearly declared the autonomy of syntax from semantics:

Syntax is the study of linguistic form. Its ... primary concern is to determine the grammatical sentences of any given language and to bring to light their underlying formal structure. [...] Semantics, on the other hand, is [...] the study of how this instrument, whose formal structure and potentialities of expression are the subject of syntactic investigation, is actually put to use in a speech community. [...] We

related to information theory and to linguistic information, that aspect of meaning which is specific to language. Note also that the decade or so of incubation between the writing of this brief allusion in the 1940s and the publication of a scientific report in 1955 is typical of his way of working.

57. Although there is no Preface to the 1956 revision of the June $1955 \mathrm{~ms}$. as posted at http://alpha-leonis.lids.mit.edu/chomsky/, and this passage does not appear as such in that ms., we do read on page 2 that "no reliance is placed on the meaning of linguistic expression in this study, in part, because it is felt that the theory of meaning fails to meet certain minimum requirements of objectivity and operational verifiability, but more importantly, because semantic notions, if taken seriously, appear to be quite irrelevant to the problems being investigated here." 
shall study [syntax] as an independent aspect of linguistic theory. [...][S]emantic notions ... appear to assist in no way in the solution of the problems that we will be investigating. We will see, however, that syntactic study has considerable import for semantics. This is not surprising. Any reasonable study of the way language is actually put to work will have to be based on a clear understanding of the nature of the syntactic devices which are available for the organization and expression of content. (Chomsky 1975: 57)

Although the conflation of semantics and pragmatics that is evident here has been somewhat clarified since this was written, Noam's view of semantics as the interpretation of the productions of syntax has persisted in generativist proposals of semantic features, a semantic component parallel to a phonological component, and so forth.

We may contrast

...the attitude of Harris toward semantics. In his work, he uses semantics both explicitly and in a syntactic guise. Contrary to general belief, in his early work (1950), Harris does not eliminate explicit semantics. Rather, semantics is reduced to a single, simple, and testable question: Are two utterances repetitions of each other, or do they contrast? Book and hook contrast and this is a fundamental semantic datum. From it, by formal manipulations, the linguist reconstructs two different phones $[s i c] / \mathrm{b} /$ and $/ \mathrm{h} /$. To contrast means to not be a repetition: to say or to mean something else. This rudimentary, explicit semantic element was never eliminated from Harris's work and - I may add - is assumed in all linguistic efforts, even if that fact is not always recognized. It is present in phonetics, in syntax, in discourse analysis, in field methods, and in comparative studies. In addition, Harris uses semantics implicitly. The entire effect of Harris's syntax ... is oriented toward rendering semantic differences by syntactic means. His syntax is always semantically motivated, in spite of the changes in form through the years. It is not that the result of the syntax - the derived sentences - will later receive semantic interpretation, but that each syntactic step reflects or records a semantic property, a paraphrase being a particular case of such a property. (Hiż 1979: 344)

Here, semantics (meaning, information) is not a projective interpretation of syntax (form), but rather form and information are two views of the same thing, and Zellig's work was to make the correspondence of these two faces of the coin explicit and obvious by distinguishing the information- content aspect of language from the presentational aspects..$^{58}$

58. The separation of content from its presentation has become familiar to a new generation of computer scientists with the development of (crudely) semantic markup 'languages' for texts, especially SGML and XML. 
Although the identification of phonological elements is semantic (as well as distributional) in nature, it is semantic to only a 'rudimentary' extent. They, or rather the contrasts that they represent, do not themselves correlate with meanings:

If in all the occurrences of a word the phonemes were replaced by others, we would simply have a variant form of the same word. But if we replaced some or all of the occurrences of a word by a word which had different selection, i.e. whose normal occurrences were different, we would have a different meaning. (Harris 1991: 322)

Zellig's recognition that "inter-environment relations, or ... occupyings of positions, [are the] fundamental elements" (Harris 1951a: 371, quoted above) has ramifications for semantics. If we accept the customary assumption that the meaning of a word determines in what environments it may occur (the word owl is only used in combination with those words with which it 'makes sense'), then we must accept the converse: that the distribution of an element is a formal specification of its meaning, or rather, of that part of its meaning with which we are most concerned in linguistics.

As Leonard Bloomfield pointed out, it frequently happens that when we do not rest with the explanation that something is due to meaning, we discover that it has a formal regularity or 'explanation'. It may still be 'due to meaning' in one sense, but it accords with a distributional regularity. (Harris 1954: 157)

If one wishes to speak of language as existing in some sense on two planes - of form and meaning - we can at least say that the structures of the two are not identical, though they will be found similar in various respects. (Harris 1954: 152)

Language is clearly and above all a bearer of meaning. Not, however, of all meaning. [...] Meaning itself is a concept of no clear definition, and the parts of it that can be expressed in language are not an otherwise characterized subset of meaning. Indeed, since language-borne meaning cannot be organized or structured except in respect to words and sentences of language ..., we cannot correlate the structure and meanings of language with any independently known catalogue or structure of meaning. (Harris 1991: 321)

In Zellig's original form of discourse analysis there is a transform of the sentences of a discourse that regularizes its structure so that all repeated phrases and their 'local synonyms' can be placed in the same column of a table. Each row is a successive period of the discourse, each cell is a lexical item in the specialized lexicon of that discourse, and the column heads are the classifier vocabulary of that semantic domain. Zellig extended this in two ways. First, all discourses of a constrained subject-matter domain have discourse structures in common, exemplifying the sublanguage of that domain. They employ the same sublanguage lexicon and the same classifier vocabulary in a common specialized sublanguage grammar. This is especially clear in a technical 
domain, such as the sublanguage of a science (Harris et al. 1989). Secondly, in the language as a whole there is a subset of sentences in which the correspondence of distribution with meaning is much more direct and transparent. This subset constitutes an informationally complete sublanguage with no ambiguity and no paraphrase (Harris 1969). The sentences of the language in which the correlation of form with meaning is less clear are paraphrases of sentences in this subset.

The correlation between distribution and meaning is sharpened progressively in Zellig's work, until with operator grammar we are concerned with the fuzzy acceptability gradation of operator-argument dependencies which, for a sublanguage, approach or reach a completely binary selection, where a given dependency is either fully acceptable or is rejected as nonsense (or non-science), and such fuzziness of selection as remains is a marker of controversy or change in the field (Harris et al. 1989).$^{59}$ From this work results a theory of linguistic information (Harris 1991).

This is a theory of the information that is 'in' language by virtue of its structure. Language users associate additional meanings with this information. "Correlations between the occurrence of linguistic forms and the occurrence of situations (features of situations) suffice to identify meanings; the term 'to signify' can be defined as the name of this relation." (Harris 1940: 228 [704 of reprint]).

\section{The language, the whole language, and nothing but the language}

To give more palpable substance to our understanding of how the work of Noam and Zellig has diverged, consider Noam's requirement (echoing Carnap) that a grammar is required to account for "all and only the sentences of the language." This is an idealization that omits many pertinent aspects of language structure, including on the one hand the sentence fragments that pepper ordinary discourse, and on the other hand most ${ }^{60}$ restrictions that cross sentence bounds. For of course "Language does not occur in stray words or sentences but in connected discourse - from a one word utterance to a ten-volume work, from a monolog to a Union Square argument" (Harris 1952: 3). Even the conjunction of two sentences imposes word-sharing requirements. Consider this simple conjoining of sentences taken from two different books:

59. In some degree corroborating the so-called Whorf-Sapir hypothesis.

60. The treatment of pronouns and other referentials in a sentence grammar fudges this without addressing the larger questions of inter-sentential regularities. 
${ }^{\star}$ Let us make the assumption that a string $X$ of $I$ which is $n$ phonemes in length is carried by $\Phi \mathrm{Pm}$ into a string $Y$ which is $n$ phones in length and other views of Heidelberg can be seen in emblems, here reproduced for the first time. ${ }^{61}$

There is nothing wrong with this example from the point of view of a sentence-grammar of 'the language', because such grammars cannot discriminate different domains of discourse. By that I do not refer to matters of presentation such as dialect, register, and style, but rather to subject-matter domain or (equivalently) the sublanguage of such a domain. The regularities that are found, and the elements and operations upon them adduced in a grammar, depend upon the domain or sublanguage being considered as well as the scope under consideration.

For instance the sentence The antibody titer rose on the fourth day (as may occur in a text of cellular immunology) can be represented in various ways by different sentence grammars: as having the phrase structure

$\left({ }_{\mathrm{S}}\left({ }_{\mathrm{NP}}\right.\right.$ the antibody titer $)\left(_{\mathrm{VP}}\left({ }_{\mathrm{V}}\right.\right.$ rose $)\left(_{\mathrm{PP}}\left({ }_{\mathrm{P}}\right.\right.$ on $)\left(_{\mathrm{NP}}\right.$ the fourth day $\left.\left.\left.)\right)\right)\right)$

or a partially-ordered word dependence structure [as in Operator Grammar (Harris 1982, 1991)], representable as a semilattice

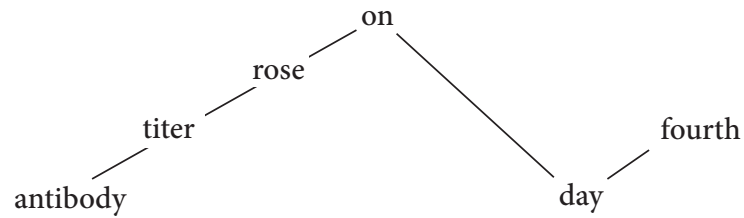

As occurring in a text in a sublanguage of cellular immunology, the sentence might be reconstructed, showing its similarities with other sublanguage sentences, as: On the fourth day following the reinjection of viral antigen into the footpad of rabbits of the same strain, the titer of antibody rose in the lymph follicles, which can be represented as an instance of the word class sequence GJB : AVT, with : = on the fourth day following; $\mathrm{G}=$ viral antigen; $\mathrm{J}=$ (re)injection; $\mathrm{B}=$ rabbits of the same strain; $\mathrm{A}=$ antibody; $\mathrm{V}=$ titer present in; $\mathrm{T}=$ the lymph follicles. (Ryckman 1986:246n)

This last representation is underwritten by the analysis and grammar of an immunology sublanguage as detailed in Harris et al. 1989. Each of these three representations

61. The first sentence is from (Chomsky 1975: 160), and the second is from (Yates 1972: 59), Ryckman (1986: 247) offers this illustration:

${ }^{*}$ Manifestation is a relation of a whole and its parts and it was all characteristically Teutonic, and, critically examined, not very tactful; but tact was never Wagner's strong suit when trying to convince the world that its only hope of salvation lay in hitching itself to the German chariot. 
of sentence structure enables one to reconstruct the well-formedness of the example sentence in accord with the sentence-defining elements and operations of a certain type of grammar. The elements and operations specified in each such grammar capture regularities shared by sentences that occur normally together in a discourse (or set of discourses in a sublanguage domain). But the project of "generating all and only the sentences of the language" entails an idealization that can capture only sufficient structure to assure that the sentence is sayable, regardless of whether it expresses any coherent meaning or has any likelihood of ever being actually said. This has artificially limited the notion of 'grammaticality' so that it contrasts with acceptability or meaningfulness. ${ }^{62}$ However, language users recognize structure (or "have intuitions of grammaticality") much more extensively in respect to sentences as they occur together in a discourse.

Consider the utterance It doesn't me either (spoken in my hearing recently by my brother). Immediately prior context was a series of sentences of this sort: He might have wanted to X. Or it might have been because of $Y$. I had to remember four or five sentences prior, where his wife said It doesn't make sense to me. It is only in that distant context that the words make sense to are redundant so that zero allomorphs of them can occur in It doesn't me either. A classical Generativist gapping operation on a PSGbased tree structure is quite useless here.

Example sentences isolated in the metalinguistic context of grammatical discussion are not an idealization so much as a willful ignorance, which can warrant only very limited conclusions about the nature of language, and which gives rise to pseudoproblems.

62. Whereas for Zellig these attributes concur (grammaticality, acceptability, meaningfulness), Noam relegates acceptability to 'performance' in his revisionist Introduction to LSLT (Chomsky 1975: 7). He claims that Section 100.2 is an instance of making this distinction, although that section merely identifies a phenomenon that he does not know how to explain (and which not all informants recognize as an actual phenomenon, eerily suggestive of the disputes about Generative Semantics). In Section 11.1 (Chomsky 1975: 81-82) he rejects "informant response tests to determine the degree of acceptability or evocability of sequences" in favor of "a revealing general theory of which all [grammars thus approved] are exemplifications." He may be obliquely rejecting the criterion for transformation that Zellig discussed in 1955 or earlier but only later in (Harris 1965) advanced as a replacement for ungraded selection-preservation (the foremost criterion in Harris 1957). However in correspondence with the author he has disclaimed any familiarity with Zellig's writings since about 1955 (although clearly from the comment (Chomsky 1975: 38 and fn. 70) he had read (Harris 1965)). The 'general theory' or metagrammar that he posits as a desideratum in the above quotation is what he elsewhere reframes as a biologically innate Universal Grammar. 


\section{Pseudoproblems}

As an example of such pseudoproblems, consider the notion that language users have an intuition of ambiguity, e.g. that a sentence such as flying planes can be dangerous is ambiguous. When such a sentence is no longer artificially isolated there is of course no ambiguity. Such context is called 'disambiguating', but it is rather the case that the isolation of sentences by linguists is 'ambiguating', and what are called intuitions of ambiguity are no more than the ability to imagine more than one context in which the isolated sentence might naturally occur. Noam has rejected this view, however:

Apparently many linguists hold that if a context can be constructed in which an interpretation can be imposed on an utterance, then it follows that this utterance is not to be distinguished, for the purposes of study of grammar, from perfectly normal sentences $[\ldots]$, though the distinction can clearly be both stated and motivated on syntactic grounds. [...] This decision seems to me no more defensible than a decision to restrict the study of language structure to phonetic patterning. (Chomsky 1964: 7n2)

There is a distinction, surely, but the proposal that it is a matter of grammaticality is coherent only given a prior commitment to restricting 'grammar' to a grammar of isolated sentences (with anaphora and other cross-reference a marginal problem).

A more extended class of pseudoproblems are the so-called island phenomena. These are problematic for grammatical operations on abstract phrase-markers derived from phrase-structure grammar. When Haj Ross was visiting Joshi's class at Penn in 1969, and spoke, as one might expect, about island phenomena, ${ }^{63} \mathrm{I}$ told him that they are not an issue in string adjunction grammars (Harris 1962a, Joshi et al. 1968, 1972a, 1972b). He asked, with evident concern, "Is that true, Aravind?" and Joshi replied "Yes, but they [adjunction grammars] have their problems, too," whereupon he relaxed and the discussion moved on. What Joshi meant was that rewrite rules and adjunction rules are complementary: rewrite rules handle exocentric constructions well but not endocentric constructions, and the converse is true for adjunction rules, for which the small set of center strings and adjunct strings is simply specified in a list. ${ }^{64}$ At the time, Joshi

63. The subject of his 1967 dissertation (Ross 1967).

64. "[E] ach style [of formal grammar] ... is well suited for characterizing certain aspects of natural language structure and is awkward for characterizing certain other aspects. The awkwardness can be due to either an inherent difficulty in characterizing a certain aspect (e.g., the characterization of the notion of the 'head' of a constituent in a PSG) or actually a counter-intuitive characterization (e.g., this often happens in a PSG, especially in the context of transformational grammars, because a PSG allows an 'uncontrolled' introduction of new 'non-terminals').... The main purpose is to set up a class of grammars which has no more 
and his students were working on grammars combining the two types of rules so as to exploit this complementarity. ${ }^{65}$ This led to tree-adjoining grammars (TAGs, see e.g. Joshi 1985), in which the (exocentric) center strings and adjunct strings are generated by very simple rewrite rules rather than being listed, and adjunction rules then handle the much more complex endocentric structures of language. ${ }^{66}$ There is a natural transition from an adjunction grammar to a transformational grammar, by deriving adjunct strings from sentences. ${ }^{67}$ In an Operator Grammar (Harris 1982, 1991), island phenomena fall out naturally from the linearization and reduction constraints, calling for no particular special attention (Nevin 1989). The exocentric properties of language arise from the dependency of operators on their arguments which must have previously entered into the construction of a sentence; the endocentric properties arise from the ('extended morphophonemic') reductions of the overt forms of the resulting strings.

To substantiate in more detail the assertion that island phenomena are pseudoproblems arising from use of phrase structure rules in the base would take us far too far afield in this context. ${ }^{68}$ It is well supported by the relevant literature. Two points are especially germane to our present narrative.

Firstly, adjunction grammars form a hierarchy distinct from the Chomsky hierarchy (more correctly, the Chomsky-Schützenberger hierarchy) of formal grammars, intersecting it in interesting ways. This is not widely understood. The Chomsky hierarchy is often thought of, at least by computer scientists of my acquaintance, ${ }^{69}$ as

power than necessary and which also can characterize different aspects of natural language structure in a natural way." (Joshi et al. 1968). Compare also Zellig's discussion of the relation of the Morpheme to Utterance grammar of string expansions to string analysis and to transformations in (Harris 2002: 3-4), quoted later in the present paper, and in the first section of (Harris 1965).

65. This may be why he was so close-mouthed.

66. Zellig had developed string analysis (published after some delay as Harris 1962a) as an alternative to constituent structure, providing the basis for the 1959 computational analysis system at Penn (Joshi 1959, 2002).

67. This was noted at the very beginning, in the 1930s and 1940s (Harris 2002: 3-4). Naomi Sager and her group exploited this relationship in implementing the very successful Linguistic String Processor (LSP) and the Medical Language Processor (MLP) at NYU. The MLP system uses XML (mentioned earlier) in the data-organization part of its implementation (Sager \& Ngô 2002). Most of the work is in refining the subclasses of the lexicon. The same may be said for the development of a sublanguage grammar and lexicon. This work is conveniently summarized in (Sager 1984; Sager \& Ngô 2002). Successful computer implementation is a demonstration that speaks far more strongly than argument.

68. For a detailed study from this point of view see (Nevin 1989).

69. Or in their case even a restricted subset of grammars in that hierarchy. See (ManasterRamer \& Kac 1990: 328-329): “[T]he term phrase structure grammar is often — in theoretical 
comprehending or outlining the full range of formal grammars, although it concerns only rewrite grammars of the sort invented (as noted earlier) by Emil Post. ${ }^{70}$ Yet PSG trees of abstract pre-terminal symbols have become in effect indicators of paradigm membership for writings on syntax.

Secondly, a principal reason that adjunction grammars, tree-adjoining grammars, and Operator Grammar are more suited to natural language than PSG-based formalisms is that semantic relations hold between adjacent morphemes and words. ${ }^{71}$ In adjunction grammars, the initial strings are simple enough to meet the contiguity requirement, and when adjunct strings that are inserted, creating discontiguities in the previously present host string, they are inserted next to their head word. ${ }^{72}$ There is no problem of constraints at a distance.

computer science always [...] - used to denote type-0 (unrestricted) grammars, which generate all the recursively enumerable languages, a proper superset of the context-sensitive languages. [etc.]"

70. The essential differences between language and language-like formal systems such as computer 'languages' should be borne in mind. Language subsists essentially in spoken form of which any graphic form is a representation for convenience. A formal language such as that generated by phrase-structure rules subsists essentially in graphic form, of which any spoken form is a representation for convenience. In his Mathematical Structures of Language, Zellig notes "certain apparently universal and essential properties of language, which are observable without any mathematical analysis, and which are such as to make possible a mathematical treatment" (1968: 6). These are that language elements are discrete, socially preset in speaker and hearer, and arbitrary, that combinations of these elements are linear and denumerable, that not all combinations constitute a discourse, that operations are contiguous, that the metalanguage is in the language, and that language changes. "Each of these properties has metatheoretical consequences for linguistics." In a formal language, the elements are discrete, preset by explicit definition, contingent on the terms and conventions of definition, operations need not be contiguous, the metalanguage is in natural language, and the language does not change (changed terms, definitions, etc. produce a different language).

71. Word-order phenomena are also defined locally. This is important computationally. See Joshi \& Rambow (2003).

72. Insertion of adjuncts accounts for almost all discontiguities. The adjunct that ends up most distant from the head is inserted first, and becomes separated from it by subsequent adjunctions. In string grammar, the head of an adjunct string may possibly be separated from the insertion point at the head word by other words in the adjunction string itself, but an alternate word order is available that permits contiguity. This is exploited by the extension to transformational grammar (and to operator grammar), in which e.g. an adjunction string in which a word is fronted may be a reduction from a sentence in which that word is fronted. The procedure of string analysis is to ask repeatedly what is a least part that can be excised from a sentence without destroying sentencehood. The result is to identify each least increment of information to the sentence. 
This is easier to see in Operator Grammar, where the source of all adjuncts is the reduction of an interrupting parenthetical sentence. For example:

a. ? books - books (same as prior) I like especially well - are in this box.

b. books which I like especially well are in this box.

This example demonstrates that the required metalanguage assertions that two words have the same reference are available in the language itself. (The metalanguage is a sublanguage in the language.) Co-reference is a condition for the reduction to whpronoun. In the example, co-reference of the two occurrences of the word books is expressed here by the phrase same as prior. ${ }^{73}$ If it were expressed by an index (e.g.

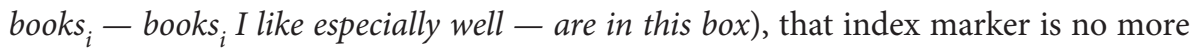
than a graphical representation of that metalanguage assertion in words. This is explicitly seen when the use of such index tags is explained or defined, as it must be. ${ }^{74}$

However, the indexed terms must be contiguous in order for this notational convention of subscript indices to be interconvertible with metalanguage assertions that are intrinsically available within language. ${ }^{75}$

Indices were invented precisely to address arbitrary points in a string, and points that are separated by arbitrarily long intervening strings cannot be addressed by stating a simple relationship in language (e.g. prior). Non-language indices are an unavoidable consequence of the use of rewrite rules in the base, because unbounded extraneous material may intervene between coreferential terms. But in Operator Grammar, as in adjunction grammar and tree-adjoining grammar, co-referential terms are contiguous at the time that the reduction takes place, becoming separated from each other only

73. For a more careful formulation, see Harris $(1968,1982,1991)$. It might be objected that same as prior is itself an adjunct phrase requiring a sentential source and reduction under metalinguistic sameness. Note that lexical items in a sublanguage lexicon often are lexically complex when considered in a broad-coverage grammar or in the grammar of another sublanguage. For example, has high fever might be a single lexical item in the Symptom class in a medical sublanguage. Other examples were seen in the quotation above from Ryckman (1986), e.g. rabbits of the same strain as a single lexical item in in the B lexical category of the immunology sublanguage.

74. And for comprehension such definitions in words must be in the hearer's context (tacit or overt) when reading examples that employ such index tags.

75. For some types of reductions, 'nearby' suffices. See (Harris 1982; Nevin 1984) for details. All anaphoric and epiphoric reference is handled by the same sort of zeroable metalinguistic sameness statement. So-called crossing coreference, as in The man who shows he deserves it will get the prize he desires, is not problematic for the reductions in Operator Grammar, since they are not defined in terms of constituent structure. 
by the subsequent entry of additional sentences which may be reduced to adjuncts. ${ }^{76}$ The same problem arises for semantic relations between words (selection restrictions), mandating in addition to indices an extra superstructure of semantic features or the like.

This illustrates a contrast between the two approaches to linguistics. Noam's construal of a particular 'tool of analysis' (immediate constituent analysis) as a theory of grammar (phrase-structure grammar enriched by transformation rules) and his commitment to it as the 'correct' theory until disproven and replaced by another, constrains what he takes to be worthy of consideration, and focuses attention on anecdotal examples set up as proof or disproof of one detail of theory or another. (Even after the radical reformulations in Government and Binding Theory and in Minimalism, the machinery of abstract phrase-markers has been retained.) The examples and counterexamples of one stage are only of historical interest at a later stage (rule ordering and island phenomena, for instance, are passé, no longer hot topics). Zellig used diverse 'tools of analysis' to disclose different properties of language (constituency is good at endocentric constructions, string analysis at exocentric constructions, etc.). "It is not that grammar is one or another of these analyses, but that sentences exhibit simultaneously all of these properties" (Harris 1965: 365). Properties of language, once identified, are not subsequently set aside or replaced, though they may be subject to further analysis (as in the factorization of transformations in Harris 1964, 1969). This freed him to develop broad-coverage grammars and enabled him to defer commitment to a theory of language and information until the relevant properties of language had become clear.

\section{Grammatical machinery is expressed in a metalanguage}

Zellig realized that ${ }^{77}$

There is no way to define or describe the language and its occurrences except in such statements said in that same language or in another natural language. Even if the grammar of a language is stated largely in symbols, those symbols will have to be defined ultimately in a natural language (1991: 274).

This means that any apparatus of grammar is only an abbreviation (or representation by symbols) of that which can also be expressed by metalanguage assertions conjoined

76. Note that Noam concurs in the obvious fact that the language in which grammars are formulated is a metalanguage of the language which they describe (Chomsky 1975: 116).

77. I recommend to your attention the more careful yet concise account of the thinking that led to recognizing the role and status of the metalanguage as a sublanguage, given at (Harris 2004[1990]: 7-9). 
to sentences, but which are not usually uttered in overt phonemic form because they are common knowledge. Examples of zero allomorphs like the zero form of the plural morpheme in sheep are of course well accepted. The zeroing of redundant or lowinformation morphemes in e.g. so-called gapping (John plays piano and Mary violin) is an obvious and uncontroversial reduction in Operator Grammar. The zeroing of common-knowledge conjuncts, such as the dictionary sentence in It's raining [and an umbrella is for protection from rain or sun] so I'll take an umbrella is a straightforward extension. It enables a simple statement of the word-sharing requirement for conjoined sentences illustrated above with a conjunction of sentences taken from two different books. Similar to this, then, is the zeroing of metalanguage assertions that constitute the machinery of grammar, e.g. for co-reference. (Noam's solution to this dilemma has been to assert that the machinery of grammar must be innate by "What else could it be?" arguments, as noted earlier.)

This also means that linguistics cannot rely upon any prior metatheory of language.

In the absence of an external metalanguage, the entities of each language can be identified only if the sounds, markers, or words of which they are composed do not occur randomly in utterances of the language. That is, the entities can be recognized only if not all combinations occur, or are equally probable. This condition is indeed satisfied by languages. A necessary step, then, toward understanding language structure is to distinguish the combinations of elements that occur in the utterances of a language from those that do not: that is, to characterize their departures from randomness. (Harris 1988: 3)

In addition, it imposes a requirement on the results of linguistic analysis:

This task entails an important demand: it calls for a least description, that is, for a characterization of the actually occurring combinations by means of the fewest and simplest entities and the fewest and simplest rules and conditions of their combination, and with no (or least) repetition. The reason for this demand is that every entity and rule, and every complexity and restriction of domains of a rule, states a departure from randomness in the language being described. Since what we have to describe is the restriction on combinations in the language, the description should not add restrictions of its own. If two descriptions, one more efficient than the other, characterize the same data, then the less efficient description must have overstated the actual restrictions in the language - by overstating and then withdrawing part, or by repeating a restriction, or whatever. (Harris 1988: 3-4)

[T] here is also a responsibility to formulate a theory based on self-organizing capacities: one that will present language as a system that can arise in a state in which language does not exist. This is so because of the unique status of language as a system which contains its own metalanguage. Any description we make of a 
language can only be stated in a language, if even only in order to state that some items of the description are properties of some other items (i.e. how to read the table). We cannot describe a language without knowing how our description can in turn be described. And the only way to avoid an infinite regress is to know a self-organizing description, which necessarily holds also for the language we are describing even if we do not use this fact in our description. (Harris 2002[1990]: 10)

There are two important contrasts here with Noam's work. First, Noam has asserted from an early stage that linguistics cannot proceed unless informed by a prior metatheory of language.

It is elementary that theoretical investigation and collection of data are independent activities. One cannot describe a linguistic system in any meaningful way without some conception of what is the nature of such a system, and what are the properties and purposes of a grammatical description. (Chomsky 1956a: 2-3)

Where Zellig stipulates only the restrictions on method (distributionalism) and on formulation (least grammar) due to absence of an external metalanguage, Noam rejects distributionalism and asserts a need to know "what is the nature of ... a [linguistic] system, and ... the properties and purposes of a grammatical description" of such a system. He simply asserts, without argument, that no alternative is possible.

For this reason, it is important to develop a precisely formulated and conceptually complete construction of linguistic theory, based on the clearest possible elementary notions, even when the more elaborate constructions based upon these notions cannot, because of insufficient evidence, be empirically supported. The establishment of such a theory may be an essential step towards obtaining this evidence. (ibid.)

Here, in the 1956 draft of LSLT, this amounts to a leap of faith. Formulating one's conclusions in advance may be an essential step towards obtaining evidence for those conclusions - or maybe not. Subsequently, as we know, that faith was placed in the innate biological endowment of humans. That is the second point of contrast, his attribution of metalanguage functions to a biologically innate Language Organ or (more recently) Language Function. ${ }^{78}$ In the event, what was ambitiously presented in 1956 as a sequence (first theory, then evidence) was later reverted to a bootstrapping operation

78. We would be remiss not to recognize the reduction of the Language Function in its narrow sense (exclusive to human language) to just the property of recursion, and the ensuing disputation. See Hauser, Chomsky, \& Fitch (2002); Pinker \& Jackendoff (2005); Fitch, Hauser \& Chomsky (2005); Jackendoff \& Pinker (2005). Zellig's discussion of the nature and probable evolutionary origin of language (Chapter 4 of Harris 1988 and Chapter 12 of Harris 1991, esp.pp. 365-373) is much more simple and straightforward, as a natural consequence of accounting for information-bearing constraints in language rather than accounting for formal 
in which theory guides investigation of examples and counterexamples which motivate revisions of theory, and so on, with no end in sight.

These matters constitute some of the substance of the divergence of views that we are considering, and they figure importantly in various miscommunications and misconstruals over the years, but lest we stray too far from our present theme, discussion elsewhere must suffice (Harris 1991, 2002[1990]; Nevin 1993b, 2002).

Noam has said (p.c.) that this talk of the metalanguage is not anything that he remembers hearing from Zellig. The importance and function of the intrinsic metalanguage is implicit in Zellig's writings of the 1940s and 1950s, being the essential motivation of distributionalism and what is commonly taken as "avoidance of meaning," although it may not have been clearly communicated until after Noam had (by his account) ceased to pay attention to what Zellig was saying and (by any account) was firmly established in his views on innateness. The crux of the matter for the present discussion is that Zellig recognized (and demonstrated) that the metagrammatical resources that are available within language itself suffice, and necessarily so; whereas Noam assumes that the requisite metagrammatical resources are necessarily external to and prior to language, given in the biological endowment of humans. Zellig's assumption freed him to employ diverse methods of analysis to disclose the properties of language, and at the end of his career he organized these properties into a theory of language and information (Harris 1988, 1991). Noam's assumption constrains him to treat each method as a theory of language, and to determine, by deploying examples as disproof, which one is correct.

\section{Generalization is not the same as abstraction}

As we have seen, Zellig's concept of transformation came directly from linear algebra. The discussion in (Harris 2002.3-4) is instructive:

The relevance of the hierarchy of word expansions [Harris 1946] ... was not simply in providing a direct procedure that yielded the structure of a sentence in terms of its words, but in opening a general method for the decomposition of sentences into elementary sentences, and thus for a transformational decomposition system. This unexpected result comes about because, first, the small sentence which is at the base of the expansions is recognizable as the grammatical core sentence of the given sentence, and, second, each expansion around a particular word can be seen to be a reduction or deformation of a component sentence within the given one. The status of expansions as component sentences was visible from the beginning: when the expansion method was presented at the Linguistic Institute, a question was raised as to how the method would distinguish the two meanings

properties of language-like mathematical systems that are proposed to be (or describe) the means by which language users produce and understand language. 
of She made him $N$ in She made him a good husband because she made him a good wife; the answer was in showing that two different expansions obtained from two different component sentences yielded here the same word sequence (sec. 7.9 in [Harris 1946]). The expansion analysis was formulated later as a decomposition of the given sentence into word strings $[. . .]^{79}$

While the machinery for transformations was provided by the "Morpheme to Utterance" equivalences, the motivation for developing transformations as a separate grammatical system was furthered by the paraphrastic variation in sentences that was found in discourses. In 1946, with the completion of Methods in structural linguistics, the structure of a sentence as restrictions on the combination of its component parts seemed to have gone as far as it could, with the sentence boundaries within an utterance being the bounds of almost all restrictions on word combination. I then tried to see if one could find restrictions of some different kind which would operate between the sentences of an utterance, constraining something in one sentence on the basis of something in another. It was found that while the grammatical structure of any one sentence in a discourse was in general independent of its neighbors, the word choices were not. [This is related to the word-sharing requirement noted earlier. $-\mathrm{BN}$ ]

In a discourse, the component sentences revealed by the Morpheme to Utterance expansions were often the same sentence appearing in different paraphrastic forms in neighboring sentences. The use of reductions and deformations of sentences

79. That is, string analysis is a later formulation of the expansion analysis. This refutes the common mistake of judging the expansion grammar of (Harris 1946) to be a notational variant of phrase structure grammar. Just prior to the above quotation he writes:

$[\mathrm{N}]_{\mathrm{o}}$ a priori justifiable general method was found to reach the structure of a sentence (or an utterance) by a hierarchy of constituent word sequences, or other parital structures of words. The problem was finally resolved by a single general procedure of building, around certain words of a given sentence, graded expansions in such a way that the sentence was shown to be an expansion of a particular word sequence in it, this word sequence being itself a sentence. (Harris 2002:3)

Where (Harris 1965: 363) contrasts string analysis with constituent analysis, he is not talking about the expansion grammar of 1946, but rather the immediate constituent analysis of Bloomfield. This distinction should be obvious upon reading even the first paragraphs of (Harris 1946). Constituent analysis depends upon native speaker judgments of where to bisect sentences and the resulting parts of sentences, on the assumption that such bisection is fundamental to human psychology. The expansion analysis, instead, depends upon judgments of the substitutability of strings of morphemes (with single morphemes being the limiting case). String analysis, conversely, depends upon judgments of successive least portions of a sentence that may be excised without destroying sentencehood. X-bar notation, head-driven PSG, and other innovations aim to capture the endocentric capacities of the expansion grammar. So-called bare phrase structure (BPS) proposed in Noam's Minimalist Program appears to be a more direct attempt to capture Zellig's original insight, to the extent that the notion of 'projection' corresponds to expansion from word-class to construction-class. 
both to produce expansions and also to produce separate paraphrastic forms of a sentence motivated the formulation of a whole transformational system, and [Harris 1952] was presented to the Linguistic Society of America in $1950 .{ }^{80} \ldots$ The transformational system...was presented to the Linguistic Institute at Indiana University in 1951-1952. The formal presentation, with detailed structural-linguistic evidence that the expansions were indeed transformed sentences, was given at the [LSA] meeting in 1955 ([Harris 1957]). (Harris 2002: 3-4, footnote added)

Taking the notion 'transformation rule' from Carnap, Noam thought of transformations as an algorithmic rule of a new type acting on the productions of the phrasestructure rules. In this we see a critical parting of ways in their treatment of language and their understanding of linguistics, and (quite apart from questions of temperament) the basis of many mischaracterizations of Zellig's work.

Noam's development of transformations as operations on abstract tree structures derived from PSG has led to an ever more abstract metatheory of grammar. Zellig's work demonstrates that such abstract treatment is not required, and that properties of this grammatical machinery actually obscure the essential properties of language. Zellig recognized this:

There is an advance in generality as one proceeds through the successive stages of analysis above [from structural linguistics through transformational linguistics to operator grammar]. This does not mean increasingly abstract constructs; generality is not the same thing as abstraction. Rather, it means that the relation of a sentence to its parts is stated, for all sentences, in terms of fewer classes of parts and necessarily at the same time fewer ways ('rules') of combining the parts, i.e. fewer constraints on free combinability (roughly, on randomness). But at all stages the analysis of a sentence is in terms of its relation to its parts - words and word sequences - without intervening constructs. Because of this fact, and because the parts which are determined are such that their meanings are preserved under the sentence-making operations, the meaning of a sentence as a particular combination of particular words is obtained directly as that combination of the meanings of those words. (Harris 1981: v-vi)

The abstractness of Generative Grammar seems to arise primarily from the abstractness of phrase structure trees. For Noam, language is at root a logico-mathematical system, and transformations are rules that operate on tree structures generated by phrase-structure rules. ${ }^{81}$ In recent years, the rules have been factored into interactive

80. And prior to that "was given at an anthropological congress held in 1949." (Hymes \& Fought 1975: 153).

81. I take the substantive differences to be in Zellig's and Noam's respective treatments of syntax and semantics. Setting aside for the present the claims of Generative Phonology, discussed earlier, we can see that they both start with the discrete elements of language, whether identified by language users (and by descriptive linguistics) in the speech stream or directly observable in 
modules with cumulative effect, but they still operate on abstract structures of preterminal symbols. ${ }^{82}$ In addition, abstract treatment has been useful to Noam for controlling the terms for argument and debate, a labyrinthine playing field with which he alone is most familiar, all the more so to the extent that others have not been so free as he to redefine the field from time to time (as exemplified by R. Harris 1993).

For Zellig, transformations are algebraic mappings from subset to subset of the set of sentences. For convenience, each subset is represented by an $n$-tuple of morpheme classes and constants ${ }^{83}$ (called a sentence form), but the relationship is between the actual correspondant sentence pairs that are the subset members. This illustrates what he means by generalization as distinct from abstraction. The set of transformations themselves turned out to be factorable into elementary sentencedifferences (Harris 1964, 1969). These in turn were restated as the effect or increment of an operator word entering on the words in its argument, with reductions ('extended morphophonemics') being carried out at the time that word entry creates the requisite string conditions ${ }^{84}$ (Operator Grammar, Harris 1982). Each tool of analysis that he developed and used along the way (word expansions, string structure, transformational structure, etc.) revealed or favored some of the properties of language and disfavored others.

It is not that grammar is one or another of these analyses, but that sentences exhibit simultaneously all of these properties. [...] Each of these properties can be used as the basis for a description of the whole language because the effects of the other properties can be brought in as restrictions on the chosen property. (Harris 1965: 364)

writing, and with the basics of morpheme classes and subclasses. Except for intonation, issues of phonology are encapsulated, that is to say, they do not enter into examples used in discussions of syntax and semantics, which even in an 'exotic' language are presented with nothing more phonologically sophisticated than a practical orthography.

82. Morphemes were initially understood to enter these structures by a subsequent step of lexical insertion at each terminal symbol. Subsequently, Noam introduced the Projection Principle to alleviate some of the problems that were encountered. Since these problems do not arise in Zellig's Operator Grammar or in sublanguage grammars, the Projection Principle is evidently an artifact of notation.

83. A single morpheme may function as a constant in a sentence form, as e.g. the -ing of the gerund.

84. The string conditions for reduction are created by the product of an operator word entering on the product of some prior operator(s) and the reductions previously carried out on them, or on primitive arguments (mostly concrete nouns). The linearization of operator and arguments is also determined at the time of operator entry into the construction of a sentence. See Harris $(1982,1991)$ for details. 
In a footnote, he added: "The pitting of one linguistic tool against another has in it something of the absolutist postwar temper of social institutions, but is not required by the character and range of these tools of analysis." ${ }^{35}$

With Operator Grammar all the identified properties of language could be accounted for in a reasonable and comprehensive way, and in a way that supports a theory of linguistic information. The role of redundancy in this theory (and, crucially, in the linguistic analysis that led to it) is clearly related to mathematical information theory, but whereas information theory concerns only quantity of information in a channel, the theory of linguistic information concerns information content.

The problem here was not to find a broad mathematical system in which the structure of language could be included, but to find what relations, or rather relations among relations, were necessary and sufficient for language structure. Then anything which is an interpretation of the model can do the work of natural language. Modifications of the abstract system are then considered, which serve as models for language-like and information-bearing systems. (Harris 1968: v)

I commented to Zellig once that descriptions by Generativist linguists seemed unnecessarily complex. He only said "They do seem to be over-structured," with a slight smile. Phrase-structure trees introduce layers of abstraction that are neither needed

85. In correspondence with the author (18 December 1999) Noam took this personally, as follows: " $[\mathrm{H}] \mathrm{e}$ had no comment, no suggestions, and as far as I am aware no familiarity with or interest in anything that I did in generative grammar, from my undergraduate thesis through later years. The only comment I recall in print is a remark about how it reflected the Cold War atmosphere." Noam has frequently disclaimed Zellig's involvement or interest in his work, e.g. Barsky (1997: 53). However, he reported a very different memory in his 1975 Introduction to LSLT: "While working on LSLT I discussed all aspects of this material frequently and in great detail with Zellig Harris, whose influence is obvious throughout" (Chomsky 1975:4). Zellig's student and friend Bill Evan has told me that on a visit to the Harrises at Princeton, where they lived during the time Zellig's wife, the physicist Bruria Kaufmann, was assistant to Einstein, he found Zellig and Noam "going at it hammer and tongs" with the manuscript of LSLT (Chomsky 1955) spread out on the kitchen table. The only explanation I have for this selfcontradictory denial of Harris's help and influence is that he was never able to convince him. If Zellig said "That's not what I'm doing, but you are welcome to try" (words very similar to what he did in fact say to me on one occasion), that wouldn't be enough. Noam would feel that if Zellig only just really understood, he would necessarily agree. So he would keep arguing. But for Zellig such argument was beside the point. If Noam had a different way of working, fine. Zellig wanted to see what would result from doing the work. As he wrote to Goetze, in the letter quoted earlier, "I [do] not consider it 'unpleasant' but am glad of the controversy. No person, certainly not I, can be sure of his judgments as 'always right'; the best way to get closer to the 'truth' - after I have figured out whatever I could - is to get the divergent opinions which arise from a different scientific analysis. The only fun in science is finding out what was actually there." 
nor desirable. Aravind Joshi has called this the pseudo-hierarchy of preterminal symbols. "Zellig Harris pursued the strategy of eschewing as much hierarchical structure as possible in describing sentence structure" (Joshi 2002: 121). In operator grammar, the hierarchy is of operators entering on their arguments; in tree-adjoining grammars (TAGs), Joshi has used rewrite rules because they are widely understood, but has also shown that dependency rules may be used for this limited hierarchy. The bulk of syntax is linear adjunction of words and strings of words (including morphophonemic reductions of words), requiring no hierarchy or nested bracketing.

In the comparison of theories, there is a diagnostic that to my knowledge has not been applied. If phenomena are reported as puzzles or issues by practitioners of one paradigm, but for another they are not problematic, or do not even merit status as phenomena, that disparity strongly suggests that what is involved is an artifact of method, of notation, or of proposed theory or metatheory. When we consider that issues with island phenomena, the Projection Principle, the Trace Erasure Principle, and so much else simply do not arise with Operator Grammar (nor with some other types of grammar, such as Stratificational Grammar), it is difficult to avoid the supposition that the Generative enterprise has been notationally entrapped.

\section{Psychological realities}

In Noam's writings of the 1950s, there is no suggestion of psychological or biological considerations, either as an interpretation of an assumed metagrammar called UG, or as its hypothetical origin. ${ }^{86}$ Only later is there any claim that 'linguistic competence' (particularly of children as language learners) derives from a biologically innate 'language organ. ${ }^{87}$ In (Chomsky 1951: 4), as we saw near the beginning of this paper,

86. Revisions in (Chomsky 1975), and statements in the Introduction to that work, might suggest the contrary, but in e.g. (Chomsky \& Ronat 1977: 123, Chomsky \& Ronat 1979: 113) Noam affirms that "The psychological point of view did not begin to appear until the end of the fifties". Just before this (Chomsky \& Ronat 1979: 111), Ronat asks "When did you think for the first time of proposing an explanatory theory in linguistics?". In English, Noam replies "That was what interested me about linguistics in the first place". In the earlier French publication, his reply is given as "En fait, c'est une préoccupation qui est apparue très tôt, dès mon travail sur la morpho-phonologie de l'hebreu moderne."

87. In passing, we should note that Bloomfield's 'failure' to propose an innate language organ was not because he was a behaviorist, but because that was (and is) an undisprovable explanatory principle, and in any case is not required for linguistics - as Zellig has decisively demonstrated. All that was disproved in Hauser et al. 2001 was the purported language specificity and human specificity of the cognitive capacities involved with language use (with recursion still hanging on by its fingernails). So innateness lives on, as explanatory principles must until 
[T] he statement of the grammar, the presentation of the results of the completed distributional analysis, must meet ... criteria which involve, essentially, considerations of elegance and considerations of adequacy as determined by the particular purposes of the grammar.

Around 1960, instead of the "purposes of the grammar" it is the speaker's linguistic competence that determines the relevant "considerations of adequacy". This psychologicization of generative grammar transpired after the commencement of Noam's association with a cohort of young psychologists in Cambridge who were forging the new field of cognitive psychology in rebellion against the behaviorists. We may presume that in their company he became familiar with one of their touchstones, Lashley's (1951) critique of behaviorism. ${ }^{88}$ Seuren (2009) suggests that the section of Lashley's paper that discusses language provides a kind of skeleton for much of the argument in Noam's own now famous (1959) review of Skinner (1957), which indeed cites and quotes that paper.

A proper discussion of psychology and linguistics must be reserved for another place, but two aspects require brief notice here. Firstly, I must acknowledge that Noam's algorithmic bent has a natural home in psychology. Whatever the structure and properties of language may be, humans are somehow able to use language so as to achieve ends which require the mutual understanding and cooperation of others. A generative model of that accomplishment should be able produce utterances as an individual human does, and to demonstrate understanding by acting appropriately upon hearing what one has said. Results so far have been limited - for example, question-answering systems correlate utterances in a highly restricted domain with database queries, so that it is a relational database system rather than linguistics that is doing the work. ${ }^{89}$ The reason for this is the same as the reason that robot systems are operational only in artificially constrained environments or when augmented with human direction. That reason is that the environment is unpredictably variable. Algorithms that can replicate observed behavior in unconstrained environments involve continuous negative feedback control of perceptual inputs in accord with internally maintained reference values

alternatives are recognized - "the slaying of a beautiful hypothesis with an ugly fact". It is unlikely that Zellig's demonstration that we have no need of that hypothesis will affect matters. Null is hard to recognize as an alternative or as a fact.

88. Based on his presentation at the Hixon Symposium in 1948, see (Gardner 1985: 10-14).

89. In an analogous way, the metagrammatical systems that Noam has developed correlate sentences with 'semantic representations' of one kind or another in which meanings are supposed to be formally indicated. As discussed earlier, Zellig has shown that the information carried by language is immanent in language itself. 
for those perceptions. ${ }^{90}$ The explanation of this is beyond the scope of this paper; the interested reader is directed to Powers (1973, 1998, 2008); Marken (1992, 2002); Cziko (1995, 2000); and Runkel (1990, 2003).

Secondly, we must touch on Noam's convictions about innate ideas. Lin (1999) provides a useful survey of the issues. Innateness is a stool with three legs: (1) infants' limited cognitive abilities, (2) paucity of data, and (3) complexity of language. Ideas about infant cognition which were available to Noam in the late 1950s and early 1960s have long been superseded by research showing the remarkable learning capacities of infants, and statistical learning theory has vitiated Noam's early claims that empirical learning from experience is not possible (see e.g. Gleitman 2002; Aslin \& Newport 2009; Gebhart, Newport \& Aslin 2009; Reeder, Newport \& Aslin, in press). One of the founders of Cognitive Psychology, Jerome Bruner, demonstrated (as others have elaborated since) the supportive social scaffolding within which children learn language (Bruner 1985), challenging the paucity of data thesis. ${ }^{91}$ And Zellig has shown that the structure of language is actually remarkably simple. ${ }^{92}$

90. In engineering control theory, these 'setpoints' are set by an agent or operator external to the 'plant'. In hierarchical perceptual control theory, or HPCT, they are set by the outputs of control loops at a higher level of the perceptual hierarchy. Error in control of biologically innate 'intrinsic values' necessary for survival triggers reorganization within the hierarchy, so infinite regress in a finite perceptual hierarchy is not an issue. By changing synaptic connections, reorganization can change any phase of the control loop, including the reference signal input. Error in control of other variables can also trigger reorganization. It is this that behaviorism studied as a theory of learning. Obviously, at any given time many perceptions are not controlled, and just as one may be aware of any given perception or not, so also may control of a perception be conscious or unconscious.

91. Bruner also opposed himself to Noam's philosophical Realism, holding that, rather than discovering the organization of phenomena, science invents the "scientific arrangement" of them (Bruner et al. 1962: 7), reminding us of that same locution in Zellig's review of Trubetzkoy (Harris 1941b).

92. " $[\mathrm{T}]$ he very simplicity of this system, which surprisingly enough seems to suffice for language, makes it clear that no matter how interdependent language and thought may be, they cannot be identical. It is not reasonable to believe that thought has the structural simplicity and the recursive enumerability which we see in language. So that language structure appears rather as a particular system, satisfying the conditions of Chapter 2 and perhaps also bound by a history, which may evolve not only in time but also by specialization in science languages, and which is undoubtedly necessary for any thoughts other than simple or impressionistic ones, but which may in part be a rather rigid channel for thought." (Harris 1968: 216) The reference to Chapter 2 is to the enumeration of essential properties of language summarized earlier in this paper, properties that make language amenable to mathematical treatment. 
Just in order to see what there is in language, and whether it is unique, we can even in principle count the demands (the departures from randomness) in language. We can count the demands that suffice to enable a person to speak a given language. [...] Nobody will do this counting, but we can see that there is nothing magical about how much, and what, is needed in order to speak. Finally, and this is perhaps more important, we can see roughly what kind of mental capacity is involved in knowing each contribution to the structure - in knowing phonemic distinctions; in knowing the phonemic composition of words; in knowing the requirement status of words, i.e., their dependence on the occurrence of other words; in knowing the (mostly pairwise) likelihoods of operator-argument choice and the rough meanings attached to each word; and finally, in knowing the reductions in phonemic shape of given words in operator-argument situations. The kind of knowing that is needed here is not as unique as language seems to be, and not as ungraspable in amount. (Harris 1988: 111-113)

Given the observation that language contains its own metalanguage, Zellig specified methods which themselves require no additional metalinguistic or metagrammatical assumptions, and followed where those methods led, disclosing essential properties of language, which he then formulated as a theory. Noam begins with the contrary assumption that research is impossible without a prior theory of language, and that this prior theory is justified by complex metalinguistic and metagrammatical resources provided by a biologically innate Universal Grammar existing prior to and external to any particular language. His arguments then are of the "What else could it be?" sort, in which you argue against not-X in order to prove X. But because science does not prove anything, tertium non datur (the law of the excluded middle) is not an appropriate argument form for science. Universals of language, for example, can exist without being genetically inherited, as for example quantal vowels and the universal preference for certain means of making contrasts have an acoustical basis. Zellig has shown how other universal properties of language have an informational basis, such that without them utterances could not embody and 'convey' the information that they do. To show this, he has not had need of Noam's hypothesis of an innate Universal Grammar.

\section{Revolutionaries}

We come now to the role of academic politics and the question of what can possibly be meant by 'revolution' as applied to Noam's career. Noam's portrayal of himself as isolated and disregarded in the 1950s because no one was interested in what he was doing, and that the old guard of 'taxonomic linguistics' opposed the rise of Generative Grammar, has been thoroughly debunked by (Murray 1994, Chapter 9). After signing off on his dissertation, Nelson Goodman and Zellig helped Noam to get a Research 
Fellowship at Harvard, which he held from 1951 through $1955 .{ }^{93}$ In 1956, Noam was one of the speakers at the Symposium on Information Theory held at M.I.T. (Chomsky 1956b), an occasion which the participants mark as the birth of Cognitive Psychology. ${ }^{94}$ In 1959, when Archibald Hill invited Noam to speak at a conference in Texas, he delivered an early version of the caustic attack on 'taxonomic linguistics' which was renewed at the Ninth International Congress of Linguists, held near M.I.T. in Cambridge in 1962. I have been told that Zellig had been invited as a plenary speaker, but was unable to attend, and promoted the acceptance of Noam to speak in his stead. One of the organizers was Noam's colleague and, as it were, co-conspirator, Morris Halle (a friendship dating from 1951 - Chomsky 1975: 30). The plenary session at which Noam spoke was devoted to "The logical basis of linguistic theory," practically identical to the title of LSLT (Chomsky 1955a, 1956a, 1975).

[O]rganizational leadership [of Generative Linguistics was provided] by Halle, who helped Chomsky obtain a position at M.I.T., instituted first a degree program and then a department which he headed..., connected Chomsky with the publisher Mouton (and with its raison dêtre, Roman Jakobson), and was involved in getting Chomsky into the spotlight in the 1962 international congress. (Murray 1994: 243)

He alone of all presenters at the International Congress was given opportunity and a free hand to revise and expand his remarks for the proceedings. His presentation in this plenary session was the attack on 'taxonomic linguistics' which was later expanded in CILT (Chomsky 1964 and its successive revisions), as discussed earlier.

It has been amply documented (e.g. Murray 1994 and elsewhere) that the rise and rapid expansion of Generative Linguistics in the 1960s was made possible by a sharp increase in the availability of government funding, analogous to but much greater than that during World War II.

It is tempting to speculate on the speed with which transformational [generative] grammar would have won general acceptance had Chomsky's and Halle's students had to contend with today's [late 1970s] more austere conditions, in which not just military, but ALL sources of funding have been sharply curtailed, and the number of new positions has been declining yearly (Newmeyer 1980: 52n8; other references at Murray loc. cit.).

93. Noam was also invited to Columbia for the 1957-58 year, with expectations of a permanent position (Murray 1994: 246). It seems likely that Zellig's connections in New York and at Columbia were instrumental in this. Zellig's friend Seymour Melman was on the faculty from 1949 until his retirement in 2003, and he himself repaired to Columbia when he left Penn.

94. See (Gardner 1985: 28-29). 
This was "striking...support for adherents of a supposedly persecuted perspective engaged in making a 'scientific revolution'"(Murray 1994: 242). In the extraordinarily polemical climate of the 1960s, prevalent in society at large as well as being cultivated in linguistics, there was talk of overthrowing the 'hegemony of taxonomic linguistics'. There were claims, baseless in fact, of being misunderstood and rejected by that supposed hegemony. ${ }^{95} \mathrm{~A}$ course about structural linguistics at M.I.T. was called 'The Bad Guys. ${ }^{96}$ In the event, the outcome manifestly was a hegemony of Generative Linguistics, and to suppose that this was not also the aim requires extraordinary credulity.

Chomsky was able to define linguistics as whatever he and his associates did. Success in this 'definition of the situation' was facilitated by the tenuousness of institutionalized linguistics and the paucity of neo-Bloomfieldians relative to the hordes of students. While there was a faculty-based core with claims to forming an elite specialty, it was the exponential increase in the number of linguists and M.I.T.s military funding that diluted the strength of opposition by those trained earlier. (Murray 1994: 244)

The rhetoric of revolution does not fit the facts in crucial ways. Noam's work and that of his followers was

...published, sought out and taken seriously by major neo-Bloomfieldians. The most central of them actively fostered Chomsky's and Lees's careers. In terms of aggression, the Chomskians struck first. Their revolutionary rhetoric was not a reaction to the incomprehension of the 'establishment', nor a defense against neophobia or persecution by angry elders. (Murray 1994: 244)

On the other hand, the rhetoric of revolution was extremely effective marketing. ${ }^{97}$

95. "The active contributors to linguistics in the period were themselves far from agreement on these points, and there is some reason to think that the program was being superseded, or at least significantly extended, by the beginning of the 1950s...." (Hymes \& Fought 1975: 122) "It would be quite mistaken to regard the period as a fortress of fixed opinions.... What would have been insisted upon was the necessity of the kind of work - development of explicit, abstract, wholly general models of the nature of linguistic structure." (ibid: 126).

96. In correspondence with me, Noam has rejected any responsibility to counter misrepresentations that his students or followers have made of Zellig or his work. To some extent, and perhaps a great extent, he may be genuinely innocent of their excesses, in the sense that he has been swept along by social phenomena that he neither created nor really guided, but was able to ride willy-nilly. But neither has he done anything to discourage or correct those who look to him for an insider's knowledge in these matters, and in that, certainly, my notions of responsibility differ from his.

97. It may be relevant that advertising and marketing texts were (perhaps pointedly) among those subjected to discourse analysis in seminars and discussions in which Noam was 
Revolutionary rhetoric seems to appeal to the enthusiasms of a new generation (with no stake in the old perspective and little knowledge of it) for meaningful and original work. (Murray 1994: 245)

As Generative Linguistics achieved the perception in other fields and in the public as 'mainstream linguistics', the new departments that were being formed fell in line, eager to share in the funding, and pushed by administrators anxious to maintain the reputations of their institutions in the eyes of parents, students, and alumni. Though peer review was freely available - and extraordinarily forbearing, given the ill-founded viciousness of many attacks - Generativists sidestepped regular publication channels in favor of circulating mimeographed papers. New journals were founded - Foundations of Language (1965), Papers in Linguistics (1969), and especially Linguistic Inquiry (1970) at M.I.T. - whose closed editorial policies were in sharp contrast to the openness of the 'establishment' journals Language and IJAL. ${ }^{98}$ Subsequently, despite the drying up of government largesse, and the consequent contraction or demise of many of the new Departments of Linguistics, these generativist benchmarks of establishment have all survived, except for one (Papers in Linguistics). While the status of Generative Linguistics as a scientific revolution is uncertain, there can be no doubt of its success as a revolution in academic politics.

Noam and his students had an open invitation to come down to Penn for collaboration. In the late 1980s, speaking with me of our student days twenty years earlier, Ellen Prince told me that the emissaries that were sent from M.I.T. were commissioned essentially to spy and take ideas back. "And Harris and Hiż invited them!" she exclaimed. "They were such suckers!" Recently, I connected this remark with certain sociological observations recounted on Ira Glass's radio program, "This American Life", about the Israeli concept of being a freier. ${ }^{99}$ Among many striking examples illustrating freierism, there is an interview with Tom Segev, an Israeli journalist and historian, who says:

You constantly hear it, constantly: don't be a freier. That is the worst thing for an Israeli to be, a freier, in his own eyes, and also in the eyes of other Israelis. So never ever be too generous, be always on guard. Somebody is out there to take what is due to you.

I think it would be impossible to understand Israelis without understanding the whole notion of freierism. It is at the heart of Israeli culture, affecting how

involved, as for example the "Millions Can't be Wrong!" text analyzed in Section 2.2 of Harris (1952).

98. The sole exception in North America was Word under the editorship of Martinet.

99. The program "Episode 222: Suckers" may be heard at http://www.thislife.org/Radio_ Episode.aspx?episode=222. There is more discussion at http://www.balashon.com/2007/10/ freier.html and http://www.wzo.org.il/en/resources/view.asp?id=2226 and elsewhere. 
people work, how they shop, how they vote, how they think about themselves and the people around them.

From an Israeli point of view, Jews were suckers for 2000 years in exile, constantly being tricked and persecuted. The whole idea of Israel is to create a place where Jews were in control, where Jews would never again be freiers. And even though Israel is now a powerful state, the fear of being taken advantage of hasn't gone away.

Part of the 'revolutionary' conflict here may be that low-synergy ${ }^{100}$ characteristics such as freierism became more prevalent during and after WWII, resulting in a generational difference in which Zellig and other elders of the field, as noted above, had the more forbearing nature of Sapir and Bloomfield, and Noam's already contentious temperament, joined with that of his new colleagues and students, was encouraged and amplified in an environment of "post-War absolutism" (Harris 1965: fn5). ${ }^{101}$ But while this sort of Zeitgeist effect may be part of the picture, it is no explanation. There were many students; there was only one Noam Chomsky.

For present purposes, however, these developments, by the same token, extend beyond the scope of this paper; for by the time the rising flood-tide of funding, the accretion of politically adept colleagues, and the peculiar institutional circumstances at M.I.T. came together in a kind of perfect storm, differences in temperament and predisposition had already set Noam on an increasingly divergent course from the family friend to whom his father had turned for help so many years before.

100. Borrowing the term from Ruth Benedict, as presented in Maslow \& Honigmann 1970. Coming from her experience of culture contact with Native Americans and in the Pacific before and during the war, she sought means for determining which of two juxtaposed culture traits or complexes is to be preferred. Simplistically put, that culture is best which is best for those enacting it, a subtle and sophisticated relative of utilitarianism. In a culture or trait that is low in synergy, such as frierism, there is a strong conflict between selfishness and altruism, while in systems that are very high in synergy, one cannot benefit others without benefit to oneself, and the converse, so that the vocabulary and concepts for selfishness and altruism may not even exist in the language of such a people. Kindred ideas are often expressed in terms of zero-sum games, etc.

101. It may be objected that Zellig lived in Israel a lot of the time, but he lived on one of the dwindling number of left-idealistic kibbutzim. This is not to say that he was naively insulated from these corrosive developments. The comment in Harris (1965 fn. 5) indicates his awareness of this social change, and as well his detachment from it. 


\section{References}

Aslin, R.N. \& E.L. Newport. 2009. "What statistical learning can and can't tell us about language acquisition". Infant pathways to language : methods, models, and research directions, ed. by John Colombo, Peggy D. McCardle \& Lisa Freund. New York: Psychology Press.

Bandler, Richard, John Grinder, Steve Andreas \& Connirae Andreas. 1982. Reframing : N L P and the transformation of meaning. Moab, Utah: Real People Press.

Barsky, Robert F. 1997. Noam Chomsky : a life of dissent. Toronto: ECW Press.

Barsky, Robert F. 2007. The Chomsky effect : a radical works beyond the ivory tower. Cambridge, Mass.: M.I.T. Press.

Barsky, Robert F. Forthcoming. "The Chomsky Effect: Episodes in Academic Activism (Chapter 6)". Beyond the Ivory Tower: Public Intellectuals, Academia and the Media, ed. by Saleem H. Ali \& Robert F. Barsky. [ms. available at http://www.mit.edu/ saleem/ivory/]

Bloch, Bernard. 1948. "A Set of Postulates for Phonemic Analysis". Language: Journal of the Linguistic Society of America 24: 1. 3-46.

Bloomfield, Leonard. 1939. "Menomini Morphophonemics". Travaux du Cercle Linguistique de Prague 8. 105-115.

Bruner, Jerome S., Jacqueline J. Goodnow \& George A. Austin. 1962. A study of thinking. New York: Wiley.

Bruner, Jerome S. \& Rita Watson. 1985. Child's talk: learning to use language. Oxford: Oxford University Press.

Butkus, Ben. 2009. “US Universities' Patent Policies Retard Plant Biology Research, Survey Suggests” [January 28, 2009 ]. Genomeweb Biotech Transfer Week http://www.genomeweb. com/biotechtransferweek/us-universities-patent-policies-retard-plant-biology-researchsurvey-suggests.

Carnap, Rudolf. 1928. Der logische Aufbau der Welt. Berlin-Schlachtensee: Weltkreis-verlag.

Carnap, Rudolf. 1934. Logische Syntax der Sprache. Wien: J. Springer.

Chomsky, Noam. 1951. Morphophonemics of Modern Hebrew. [Unpublished masters Thesis catalogued as 378.748 PoA/1951. 60 (RBC) in the Rare Book and Manuscript Library in the van Pelt Library at the University of Pennsylvania.]

Chomsky, Noam. 1955a. "The Logical Structure of Linguistic Theory”. Ms., date June 1955. Available from Columbia University Psychology Library.

Chomsky, Noam. 1955b. Transformational Analysis. Ph.D. dissertation, University of Pennsylvania.

Chomsky, Noam. 1956a. Logical Structure of Linguistic Theory [Indicated to be a revision of Chomsky 1955a. Preserved on microfilm at the M.I.T. Humanities Library. PDF available for download at http://alpha-leonis.lids.mit.edu/chomsky/. Further revision published as Chomsky 1975.].

Chomsky, Noam. 1956b. “Three Models for the Description of Language”. IRE(Institute of Radio Engineers) Transactions on Information Theory 2. 113-124.

Chomsky, Noam. 1959. "Review of Verbal Behaviour, by B.F. Skinner". Language 35: 1. 26-59.

Chomsky, Noam. 1964. Current issues in linguistic theory. The Hague: Mouton.

Chomsky, Noam. 1969. "Linguistics and Politics". New Left Review 57. 21-34.

Chomsky, Noam. 1975. The logical structure of linguistic theory. New York: Plenum Press. [Revision of Chomsky 1956a.]

Chomsky, Noam \& Mitsou Ronat. 1977. Dialogues avec Mitsou Ronat. Paris: Flammarion. [English translation revised and expanded as Chomsky \& Ronat 1979.] 
Chomsky, Noam. 1979a. "Morphophonemics of Modern Hebrew". Outstanding Dissertations in Linguistics, a Garland Series, ed. by J. Hankamer. [Substantial revision of Chomsky 1951.].

Chomsky, Noam \& Mitsou Ronat. 1979. Language and responsibility : based on conversations with Mitsou Ronat. New York: Pantheon Books. [Revised and expanded translation of Chomsky \& Ronat 1977.]

Church, Alonzo. 1956. Introduction to mathematical logic. Princeton: Princeton University Press.

Church, Alonzo. 1956. Introduction to mathematical logic. Princeton: Princeton University Press.

Cziko, Gary. 1995. Without miracles : universal selection theory and the second Darwinian revolution. Cambridge, Mass.: M.I.T. Press.

Cziko, Gary. 2000. The things we do: using the lessons of Bernard and Darwin to understand the what, how, and why of our behavior. Cambridge, Mass.: M.I.T. Press.

Dresher, B.E. 2003. "The contrastive hierarchy in phonology". Toronto Working Papers in Linguistics (Special Issue on Contrast in Phonology) 20. 47-62.

Fitch, W. Tecumseh, Marc D. Hauser \& Noam Chomsky. 2005. "The Evolution of the Language Faculty: Clarifications and Implications". Cognition: International Journal of Cognitive Science 97: 2. 179-210.

Gebhart, A.L., E.L. Newport \& R.N. Aslin. 2009. "Statistical learning of adjacent and nonadjacent dependencies among non-linguistic sounds". Psychonomic Bulletin \& Review 16. 486-490.

Gibson, James J. 1977. “The Theory of Affordances”, ed. by Robert E. Shaw \& John Bransford. Hillsdale, N.J.; New York: Lawrence Erlbaum Associates \& Halsted Press Division, Wiley.

Gibson, James Jerome. 1979. The ecological approach to visual perception. Boston: Houghton Mifflin.

Gleitman, Lila. 2002. "Verbs of a feather flock together II: The child's discovery of words and their meanings". The legacy of Zellig Harris : language and information into the 21st century, ed. by Bruce E. Nevin, 209-229. Amsterdam: John Benjamins.

Goldsmith, John A. 2004. "From algorithms to generative grammar and back again". Proceedings from the 40th Annual Meeting of the Chicago Linguistic Society 243-259. [Available at http://cls.metapress.com/index/P8JP462N387V142V.pdf and http://humanities.uchicago. edu/faculty/goldsmith/Papers/CLS2004Algorithms.pdf .]

Goodman, Nelson. 1943. "On the Simplicity of Ideas". Journal of Symbolic Logic 8. 107-121.

Gross, Maurice. 1979. “On the Failure of Generative Grammar”. Language: Journal of the Linguistic Society of America 55: 4. 859-885.

Halle, Morris. 1959. The sound pattern of Russian : a linguistic and acoustical investigation. The Hague: Mouton.

Harris, Randy Allen. 1993. The linguistics wars. New York: Oxford University Press.

Harris, Randy Allen. 1998. "Review of Noam Chomsky: A Life of Dissent". Books in Canada:March 1998. [Available at http://www.arts.uwaterloo.ca/ raha/reviews/Harris-Barsky.pdf .].

Harris, Zellig S. 1936. A grammar of the Phoenician language. New Haven, Conn.: American Oriental society.

Harris, Zellig S. 1939. Development of the Canaanite dialects; an investigation in linguistic history. New Haven: American oriental society.

Harris, Zellig S. 1940. “Review of Foundations of Language, by L.H. Gray”. Language 16. 216-230.

Harris, Zellig S. 1941a. "Linguistic Structure of Hebrew". Journal of the American Oriental Society 61: 3. 143-167.

Harris, Zellig S. 1941b. "Review of N[ikolaj] S[ergeevich] Trubetzkoy (1890-1938), Grundzüge der Phonologie (Prague: Cercle Linguistique de Prague, 1939)”. Language 17. 345-349. 
Harris, Zellig S. 1942. "Morpheme Alternants in Linguistic Analysis”. Language 18: 3. 169-180. Harris, Zellig S. 1945. "Navaho Phonology and [Harry] Hoijer's Analysis". IJAL 11: 4. 239-246. Harris, Zellig S. 1946. "From Morpheme to Utterance”. Language 22: 3. 161-183.

Harris, Zellig S. 1947a. "Structural Restatements I: Swadesh's Eskimo; Newman's Yawelmani”. IJAL 13: 1. 47-58.

Harris, Zellig S. 1947b. “Structural Restatements II: Voegelin's Delaware”. IJAL 13: 3. 175-186. Harris, Zellig S. 1948. “Componential Analysis of a Hebrew Paradigm”. Language 24: 1. 87-91. Harris, Zellig Sabbetai. 1951a. Methods in structural linguistics. Chicago The Univ. of Chicago Press. (Repr. as "Phoenix Books" P 52 with the title Structural Linguistics, 1960; 7th impression, 1966; 1984.) [Preface signed "Philadelphia, January 1947”].

Harris, Zellig S. 1951b. "Ha-Safah ha-Ivrit l'or ha-balshanut ha-chadashah ["The Hebrew language in the light of modern linguistics"]. "Lashenanu 17. 128-132.

Harris, Zellig S. 1952. "Discourse Analysis”. Language 28: 1. 1-30.

Harris, Zellig S. 1954. "Distributional Structure”. Word 10: 2. 146-162.

Harris, Zellig S. 1955. "From Phoneme to Morpheme”. Language 31: 2. 190-222.

Harris, Zellig S. 1957. "Co-Occurrence and Transformation in Linguistic Structure”. Language 33: 3. 283-340.

Harris, Zellig S. 1962a. String analysis of sentence structure (= Papers on Formal Linguistics, 1). The Hague: Mouton.

Harris, Zellig S. 1962b. "A Language for International Cooperation”. Preventing World War III, some proposals, ed. by Quincy Wright. New York: Simon \& Schuster.

Harris, Zellig S. 1964. The elementary transformations. (Transformations and Discourse Analysis Papers, 54.) Philadelphia: University of Pennsylvania.

Harris, Zellig S. 1965. “Transformational Theory”. Language 41: 3. 363-401.

Harris, Zellig S. 1966. "A Cycling-Cancellation Automation for Sentence Well-Formedness". International Computation Centre Bulletin 5. 69-94.

Harris, Zellig S. 1967. Morpheme boundaries within words: report on a computer test. (Transformations and Discourse Analysis Papers, 73.) Philadelphia: University of Pennsylvania.

Harris, Zellig S. 1968. Mathematical structures of language. New York: Wiley Interscience.

Harris, Zellig S. 1969. The two systems of grammar: report and paraphrase. (Transformations and Discourse Analysis Papers, 79.) Philadelphia: University of Pennsylvania.

Harris, Zellig S. 1970. Papers in structural and transformational linguistics. Dordrecht: Reidel.

Harris, Zellig Sabbettai. 1981. Papers on syntax. Dordrecht: Reidel.

Harris, Zellig S. 1982. A grammar of English on mathematical principles. New York: Wiley.

Harris, Zellig S. 1988. Language and information. New York: Columbia Univ. Press.

Harris, Zellig S. 1989. The form of information in science : analysis of an immunology sublanguage. Dordrecht/Holland \& Boston: Kluwer Academic Publishers.

Harris, Zellig S. 1990. "La genèse de l'analyse des transformations et de la métalangue" [Sept. 1990]. Langages 99. 9-19. [Tr. of Harris 2003]

Harris, Zellig S. 1991. A theory of language and information : a mathematical approach. Oxford; New York: Clarendon Press; Oxford University Press.

Harris, Zellig S. 2002. “The background of transformational and metalanguage analysis”. The legacy of Zellig Harris : language and information into the 21st century, ed. by Bruce E. Nevin. Amsterdam: John Benjamins.

Hawking, Stephen William. 1988. A brief history of time: from the big bang to black holes. Toronto: Bantam Books.

Hiż, Henry. 1979. "On Some General Principles of Semantics of a Natural Language”. Syntax and Semantics 10. 343-352. 
Hiż, Henry. n.d. Linguistics at the University of Pennsylvania: Internal document of the Linguistics Department at the University of Pennsylvania.

Hockett, Charles F. 1947. "Peiping Phonology". Journal of the American Oriental Society 67: 4. 253-267.

Huck, Geoffrey J. \& John A. Goldsmith. 1995. Ideology and linguistic theory : Noam Chomsky and the deep structure debates. London; New York: Routledge.

Hymes, Dell H. 1971. On communicative competence. Philadelphia: University of Pennsylvania Press.

Hymes, Dell \& John G. Fought. 1975. American structuralism. The Hague: Mouton.

Jackendoff, Ray \& Steven Pinker. 2005. "The nature of the language faculty and its implications for evolution of language (Reply to Fitch, Hauser, \& Chomsky)”. Cognition 97: 2005. 211-225.

Joos, Martin. 1957. Readings in linguistics 1 : the development of descriptive linguistics in America, 1925-56. Chicago: University of Chicago Press.

Joshi, Aravind K. 1959. "Recognition of local substrings". (= Transformations and Discourse Analysis Papers, 18.) University of Pennsylvania.

Joshi, Aravind K. 1985. "Tree-adjoining grammars: How much context sensitivity is required to provide reasonable structural descriptions?” Natural Language Parsing, ed. by D. Dowty, L. Karttunen \& A. Zwicky, 206-250: Cambridge University Press.

Joshi, Aravind K. 2002. "Hierarchical structure and sentence description". The legacy of Zellig Harris : language and information into the 21st century, Vol. 2: Computability of language and computer applications, ed. by Bruce E. Nevin \& Stephen B. Johnson. Amsterdam: John Benjamins.

Joshi, Aravind K., S.R. Kosaraju \& H.M. Yamada. 1968. String adjunct grammars ( = Transformations and Discourse Analysis Papers, 75.) University of Pennsylvania.

Joshi, Aravind K., S.R. Kosaraju \& H.M. Yamada. 1972a. "String adjunct grammars: I. Local and distributed adjunction". Information and Control 21: 2. 93-116.

Joshi, Aravind K., S.R. Kosaraju \& H.M. Yamada. 1972b. "String adjunct grammars: II. Equational representation, null symbols, and linguistic relevance". Information and Control 21: 3. 235-260.

Joshi, Aravind K. \& Owen Rambow. 2003. “A Formalism for Dependency Grammar Based on Tree Adjoining Grammar". International Conference on Meaning Text Theory (MTT) 2003. Paris.

Kirchner, Robert. 1995. "Contrastiveness is an epiphenomenon of constraint ranking”. Paper presented at the 21st Annual Meeting of the Berkeley Linguistics Society, University of California, Berkeley, February 1995.

Kleene, Stephen Cole. 1952. Introduction to metamathematics. New York: Van Nostrand.

Koerner, E.F.K. 2002. Toward a history of American linguistics. London ; New York: Routledge.

Koerner, E.F.K., Matsuji Tajima \& Carlos Peregrín Otero. 1986. Noam Chomsky : a personal bibliography, 1951-1986. Amsterdam/Philadelphia: John Benjamins.

Lakoff, George. 1987. Women, fire, and dangerous things : what categories reveal about the mind. Chicago: University of Chicago Press.

Lakoff, George. 2002. Moral politics : how liberals and conservatives think. Chicago: University of Chicago Press.

Lashley, Karl S. 1951. “The Problem of Serial Order in Behavior”. Cerebral mechanisms in behavior : the Hixon Symposium, ed. by Lloyd Alexander Jeffress. New York: Wiley.

Laufer, Asher \& I.D. Condax. 1979. “The epiglottis as an articulator”. UCLA Working Papers in Phonetics 45. 60-83. 
Lentin, André 2002. "Reflections on references to mathematics in the work of Zellig Harris". The legacy of Zellig Harris : language and information into the 21st century, Vol. 2: Computability of language and computer applications, ed. by Bruce E. Nevin \& Stephen B. Johnson, 1-9. Amsterdam: John Benjamins.

Lin, Francis Y. 1999. “Chomsky on the 'ordinary Language' View of Language”. Synthese 120. 151-192.

MacFarquhar, Larissa. 2003. “The Devil's Accountant” [March 31, 2003]. New Yorker 79: 6. 64-79.

Manaster-Ramer, Alexis \& Michael B. Kac. 1990. “The Concept of Phrase Structure”. Linguistics and Philosophy: An International Journal 13: 3. 325-362.

Marken, Richard. 2002. More mind readings: methods and models in the study of purpose. St. Louis, Mo.: Newview.

Maslow, Abraham H. \& John J. Honigmann. 1970. "Synergy: Some Notes of Ruth Benedict". American Anthropologist, N. S. 72: 2. 320-333.

Murray, Stephen O. 1994. Theory groups and the study of language in North America : a social history. Amsterdam/Philadelphia: John Benjamins.

Murray, Stephen O. 1999. "More on Gatekeepers and Noam Chomsky's Writings of the 1950s". Historiographia Linguistica 26: 3. 343-353.

Nevin, Bruce E. 1984. "Review of Harris 1982: A Grammar of English on Mathematical Principles”. Computational Linguistics 10: 3-4. 203-211.

Nevin, Bruce E. 1989. “Unbounded Dependencies in Constructive Grammar”. Ms.

Nevin, Bruce E. 1993a. "Harris the revolutionary: Phonemic theory”. History of Linguistics 1993, Papers from the Sixth International Conference on the History of the Language Sciences (ICHoLS VI), ed. by Kurt R. Jankowsky. Amsterdam/Philadelphia: John Benjamins.

Nevin, Bruce E. 1993b. "A Minimalist Program for Linguistics: The Work of Zellig Harris on Meaning and Information". Historiographia Linguistica: International Journal for the History of the Language Sciences/Revue Internationale pour l'Histoire 20: 2-3. 355-398.

Nevin, Bruce E. 1998. Aspects of Pit River Phonology, Unpublished Ph.D. dissertation, University of Pennsylvania, Available at http://repository.upenn.edu/dissertations/AAI9913504/.

Nevin, Bruce E. 1999[1993]. "Harris the revolutionary: Phonemic theory". History of Linguistics 1993, Papers from the Sixth International Conference on the History of the Language Sciences (ICHoLS VI), ed. by Kurt R. Jankowsky. Amsterdam/Philadelphia: John Benjamins.

Nevin, Bruce E., ed. 2002a The Legacy of Zellig Harris: Language and Information into the 21st Century. Volume 1: Philosophy of Science, Syntax and Semantics. Amsterdam: John Benjamins.

Nevin Bruce E. 2002b. “Foreword.” In Nevin 2002a: ix-xxxiv.

Nevin, Bruce E. \& Stephen B. Johnson. 2002. The legacy of Zellig Harris : language and information into the 21st century, Vol. 2: Computability of language and computer applications. Amsterdam: John Benjamins.

Newmeyer, Frederick J. 1980. Linguistics in America: The first quarter-century of transformational-generative grammar. New York: Academic Press.

Overbye, Dennis. 2009. “Elevating Science, Elevating Democracy” [January 26, 2009]. New York Times Available at http://www.nytimes.com/2009/01/27/science/27essa.html?_r=2.

Pinker, Steven \& Ray Jackendoff. 2005. “The faculty of language: what's special about it? “ Cognition 95. 201-236.

Post, Emil L. 1943. "Formal Reductions of the General Combinatorial Decision Problem”. American Journal of Mathematics 65: 2. 197-215. 
Powers, William T. 1973. Behavior: the control of perception. Chicago: Aldine Pub. Co.

Powers, William T. 1998. Making sense of behavior : the meaning of control. New Canaan, Conn.: Benchmark Publications.

Powers, William T., ed. 2008. Perceptual Control Theory: Science \& Applications - A Book of Readings. Hayward, CA: Living Control Systems Publishing.

Reeder, P.A., E.L. Newport \& R.N. Aslin. In press (2009). “The role of distributional information in linguistic category formation". Proceedings of the 31st Annual Meeting of the Cognitive Science Society, ed. by N. Taatgen, H. van Rijn, L. Schomaker \& J. Nerbonne.

Ross, John R. 1967. Constraints on Variables in Syntax, Ph.D. Dissertation, M.I.T.

Runkel, Philip Julian. 1990. Casting nets and testing specimens : two grand methods of psychology. New York: Praeger.

Runkel, Philip Julian. 2003. People as living things : the psychology of perceptual control. Hayward, CA: Living Control Systems.

Russell, Bertrand [Arthur William]. 1905. "On Denoting” [Oct. 1905]. Mind, New Series 14: 56. 479-493.

Ryckman, Thomas A. 1986. Grammar and Information: An investigation in linguistic metatheory. Unpublished Ph.D. dissertation, Columbia University.

Sager, Naomi. 1984. Natural language information processing : a computer grammar of English and its applications. Reading, Mass.: Addison-Wesley.

Sager, Naomi \& Ngô Thanh Nhàn. 2002. "The computability of strings, transformations, and sublanguage". The legacy of Zellig Harris : language and information into the 21st century, Vol. 2: Computability of language and computer applications, ed. by Bruce E. Nevin \& Stephen B. Johnson, 79-120. Amsterdam: John Benjamins.

Seuren, Pieter A.M. 2009. "Concerning the Roots of Transformational Generative Grammar". Historiographia Linguistica 36: 1. 97-115.

Skinner, B.F. 1957. Verbal behavior. New York: Appleton-Century-Crofts.

Spencer-Brown, G. 1969. Laws of form. London: Allen \& Unwin.

Stevens, Kenneth N. 1972. "The quantal nature of speech: Evidence from articulatory-acoustic data". Human communication: a unified view, ed. by Edward E. David \& Peter B. Denes, 51-66. New York: McGraw-Hill.

Tarski, Alfred. 1933. Der Wahrheitsbegriff in den formalisierten Sprachen [Tr. as The Concept of Truth in Formalized Languages]. Indianapolis, Ind.: 1983, Hackett Pub. Co.

Thomas, Margaret. 2002. "Roger Bacon and Martin Joos: Generative Linguistics' reading of the past.” Historiographia Linguistica 39(3). 339-378.

Trubetzkoy, Nikolaj Sergeevi. 1939. "Grundzüge der Phonologie”. Travaux du Cercle Linguistique de Prague 7.

Weintraub, Pamela. 2008. Cure unknown : inside the Lyme epidemic. New York: St. Martin's Press.

Wells, Rulon S. 1947. "Immediate Constituents". Language: Journal of the Linguistic Society of America 23: 2. 81-117.

Yates, Frances Amelia. 1972. The Rosicrucian enlightenment. London; Boston: Routledge \& Kegan Paul. 


\title{
Chomsky 1951a and Chomsky 1951b
}

\author{
Peter T. Daniels
}

The December 1951 version of Morphophonemics of Modern Hebrew that has been available to scholars since its publication in 1979 is very different from the original M.A. thesis accepted six months earlier. To assess the importance of this work to the history of linguistics, a number of factors must be studied: Chomsky's background in Semitic philology and linguistics; the other influences to which he was exposed to date; the degree to which those influences were assimilated and/ or transcended; the archival nature of the materials concerned and those that followed; and the nature and causes of the differences between the versions.

\begin{abstract}
"The earliest generative grammar in the contemporary sense was a (partial) grammar of Hebrew (Chomsky, 1951)." So wrote Noam Chomsky $(1989,87)$ in the memorial volume for the Israeli Arabist Haim Blanc. But neither the author nor the volume editors explain why the preeminent theoretical syntactician had been invited to contribute to a volume otherwise comprising Semitic, Arabistic, and Indo-European studies, nor why a mention of Chomsky's M.A. thesis was singularly appropriate. In two series of generously extended e-mail conversations, in August-September and DecemberJanuary 2007-8, Noam Chomsky answered this question and many others concerning the two very different extant versions of that thesis. ${ }^{1}$

The version of the thesis that has been known to the linguistics community since its publication in 1979 clearly states on its title page that it is the "December, 1951 Revision of / Morphophonemics of Modern Hebrew" (Chomsky 1951b, [v]; hereafter $M M H b) .{ }^{2}$ Anyone familiar with the thesis as deposited in the University of Pennsylvania
\end{abstract}

1. Versions of this chapter were presented at the annual meetings of the American Oriental Society in Seattle in March 2006, and of the North American Association for the History of the Language Sciences in conjunction with the annual meeting of the Linguistic Society of America in Chicago in January 2008. I am grateful for encouragement and assistance and for substantive comments to Woodford A. Beach, John Goldsmith, Robert D. Hoberman, John Huehnergard, Joshua T. Katz, Konrad Koerner, Peter Machinist, W. Keith Percival, and John U. Wolff.

2. The most cursory glance at the contents of this book shows that it is not a photographic reproduction of a work of 1951; it has obviously been retyped on an IBM Selectric, a form 
Libraries can see that it was a very thorough revision indeed; the revision is the only version Chomsky himself would consult. ${ }^{3}$ But very few people were familiar with the thesis before its 1979 publication. ${ }^{4}$ In 1971 or so, this author, while an undergraduate linguistics major at Cornell University with an incipient interest in Semitic linguistics, noted that Chomsky's M.A. thesis was one of the earliest publications concerning Israeli (or Modern) Hebrew, and requested it from Inter-Library Loan. Chomsky was well known to linguists but not yet a world-wide celebrity, and the slim volume arrived in due course. (It is now a valuable document sequestered among the Special Collections.) It proved not to be the ribbon copy ${ }^{5}$ of the work, but a bound "blue ditto." ${ }^{6}$ Cornell's graduate library had a primitive coin-operated photocopier, which unlike later models was not blind to the color blue. It used a heavy coated paper and a possibly ammonia-based (like a blueprint machine) chemical process that yielded copies that (protected from light) have survived for nearly forty years (whereas ditto copies can fade after some number of years even when not exposed to light).

of typewriter that was introduced in 1961. Chomsky did not remember any retyping and is certain that no changes were made during the process; John Goldsmith recalled that the retyping was done by a fellow M.I.T. graduate student, David Duncan. Mr. Duncan, now an attorney practicing in Boston, did not respond to an e-mail requesting reminiscences.

3. When I first contacted Chomsky about this project, requesting permission to quote from $M M H a$, he answered, "You can if you like, but I don't see the point. The late (I think December) 1951 version is vastly improved" (8/26/07). Later on, I noted, "But looking at antecedents is what historians (including of linguistics) do," to which he acceded, "Point taken.... As far as I can recall, no historian of linguistics has ever contacted me about this or about most relevant topics" (12/30/07).

4. Koerner and Tajima's (1986) entries for this work are inexplicably erroneous. That for the published version ("1979b") fails to note that it comprises the December revision of the June original and lists as a commentary on it a work written three years earlier (Chayen 1977); that for "1951" claims that it occupies 46 , rather than 71, typed pages, and fails to note that the thesis was accepted in June. It also asserts incorrectly that the thesis was "included as an appendix" to chapter VII of Chomsky 1975 (hereafter LSLT). Rather, a note of the intention to include it appears in both the typescript and the printed version. See below for further inconcinnities in Koerner's accounts of LSLT.

5. That is, the original typed copy, as opposed to carbon copies made during the same typing operation. (Notes on pre-photocopier methods of reproduction are necessary for readers who may never have seen carbon paper, ditto copies, or mimeographs.)

6. The work had been typed on "ditto masters," a reproduction method that pressure-transfers blue dye to a paper backing, from which a limited number of copies are run off by moistening the copy paper with an alcohol so that some of the dye is transferred. This process is not 
The title of the library copy is the same as that in the published version, omitting the first line and the indication "June" in the last line: "Morphophonemics of Modern Hebrew / Avram Noam Chomsky / 'A Thesis / In Linguistics / Presented to the Faculty of the / Graduate School of the University of / Pennsylvania in partial fulfillment of / the requirements for the degree of / Master of Arts' / 1951" (Chomsky 1951a, [i]; hereafter $M M H \mathrm{a}$ ). After the unnumbered title page, the work occupies 71 leaves, clearly typed by the author as no hired typist could have reliably dealt with the diacritics and the innovative notational devices, and as the occasional typographical error is corrected in the page (most obviously, the term "morphophonemics" is several times typed as "morphonemics," with "pho" inserted above the line likely with a different typewriter).

Only four references to this thesis before the 1979 publication have been traced: Gutman 1970, Levi 1972, Kilbury 1976 (103-7), and Chayen 1977. Daniel Gutman's Texas dissertation is a generative phonology of (Masoretic) Biblical Hebrew in the Sound Pattern of English (Chomsky \& Halle 1968, hereafter SPE) mold. He inspected Chomsky's thesis but "It consists of a very early generative grammar with a theoretically important discussion of ordered rules. However, it was written some fifteen years prior to the development of generative phonology as we now know it; the theory of a lexical component and especially of distinctive features was yet to be elaborated," so Gutman is only "indebted to it in a very general way" (Gutman 1970, 3). ${ }^{7}$ Chayen's squib takes the rather surprising opposite view, that nearly all of generative phonology is foreshadowed. Levi's M.A. thesis is a generative phonology of a subpart of Hebrew verbal morphology (see $n .44$ below).

Kilbury's Development of Morphophonemic Theory is a revision of his 1974 Ph.D. dissertation at Cornell. In those days, undergraduate and graduate linguistics majors took the same classes (only the coursework requirements were different), so Kilbury and I had many classes together and were well acquainted; neither of us specifically recalls the circumstances, but it is extremely likely that Kilbury took advantage of my borrowing of the book to make his own copy. He recalled that his was the same sort of odd-smelling coated paper copy, which he discarded when his interests changed (pers.

to be confused with a "mimeograph," where pressure as from typing removes a waxy substance from the master, leaving a stencil via which black ink is transferred from source to paper, and which with care can be used for a large number of copies. Chomsky registers $M M H b$ ("Cambridge, Mass.") as "mimeographed" in the reference list of Chomsky 1967; it is not evident that any copies exist outside private hands (cf. n. 8). A prepublication version of LSLT is registered as "mimeographed" in Chomsky 1964b, 975.

7. Gutman's dissertation committee comprised Aaron Bar Adon, Chair; Emmon Bach; Archibald A. Hill; and Edgar Polomé. 
comm.). ${ }^{8}$ Kilbury is impressed by Chomsky's reliance on Rudolf Carnap and on his teacher Nelson Goodman and notices that where Bloomfield (1939) employs sufficient conditions for rule ordering, Chomsky introduces necessary conditions as well. Both these topics recur below.

\section{Background: Semitics}

Noam Chomsky had the sort of Hebrew education that could be expected for a pre-war Jewish-American boy whose father happened to be a renowned scholar of Medieval Hebrew. ${ }^{9}$ He learned the language in Hebrew school, read it with his father on Friday nights, assisted with the proofreading of his father's magnum opus (W. Chomsky 1952), ${ }^{10}$ attended youth groups, and from the age of 14 went to the Hebrew-speaking Camp Massad in the Poconos (a resort area in northeast Pennsylvania), as camper, junior counselor, and counselor. It was there that he met his lifelong friend Haim Blanc (1926-1984), two and a half years his senior - "even as a teenager he was plainly someone remarkable, a heroic romantic figure who seemed to have come from a novel" (NC, $8 / 26 / 07$ ) - who was blinded and crippled in Israel's War of Independence a few weeks

8. W. Keith Percival informs me that microfilm copies of the thesis are deposited in several American libraries. WorldCat (accessed via Google Books 2/17/09) lists four with a microfilm and six with a paper copy. Cornell University's microfilm was made - coincidentally? in 1971. The University of Kansas's and Louisiana State University's microfilms were made in 1968; paper copies are found at Harvard University, the University of Nebraska, and the University of California (Los Angeles and Santa Barbara). Those seven copies are assuredly of the June 1951 original, because each numbers 71 leaves. The electronic catalog records at Ohio State University (paper) and Southern Illinois University (Carbondale) (microfilm) are insufficiently detailed to determine the version. WorldCat also returns a copy at the Sonoma County (California) Library, which is a false positive.

9. William Chomsky (1896-1977), professor and faculty president of Gratz College, near Philadelphia. His 1926 Ph.D. dissertation at Dropsie College was a study of the 12th/13thcentury Hebrew grammarian David Kimhị.

10. This is not an edition of nor a commentary on the Mikhlol of David Kimhi. Rather, it is a translation of a rearrangement of the entire contents of the work into the order of a 19th-century reference grammar of Hebrew, such as that by Gesenius (Kautzsch 1910), provided with extensive notes detailing the treatment of each topic by the other medieval Hebrew grammarians. The first 120 pages, representing the dissertation, covering the phonology, pronouns, and strong verbs, were published in 1933. The entire work was published in 1952; those first 120 pages were reproduced photographically, as evidenced by obvious typographic errors repeated on pp. 36 and 40, and by the presence of five pages of addenda to those chapters (373-77). It was thus the chapters on weak verbs, nouns, particles, and syntax that Noam Chomsky proofread. 
after arriving in Palestine early in 1948 but nonetheless carried out intensive fieldwork on Palestinian and Iraqi Arabic dialects over many years. That Chomsky could forge such a friendship when the gulf between 14 and 16/17 is usually unbridgeable speaks to his precocity (cf. n. 12); as does his admission to the University of Pennsylvania at 16 (for the 1945/46 school year).

Already fluent in Hebrew, both Classical and Modern, ${ }^{11}$ Chomsky, imbued with a vision of fostering a "socialist binationalist" Jewish-Arab state in Palestine, registered for Arabic; his classmates were missionaries-in-training from the Summer Institute of Linguistics (now SIL), students of Kenneth Pike's sent to learn Zellig Harris's methods, who seemed to him considerably older. ${ }^{12}$ Most were daunted to find themselves facing Giorgio Levi della Vida (1886-1967), "one of eleven professors in Italy who refused to take the fascist oath and therefore lost their posts" (Gordon 1986, 58), the preeminent Arabist of the first half of the twentieth century, who came to Penn in 1940. He entered the classroom armed with "Thatcher's Arabic Grammar, a pretty thick volume[, and] a slim volume. ... We would spend three weeks on Thatcher's grammar, and after we knew the language, we'd turn to the slim volume - of pre-Islamic poetry. ${ }^{13}$ There was a kind of shudder in the class, but he said something like 'Don't worry, it has explanatory notes in Latin" (NC, 8/26/07).

Some time later, Chomsky asked Levi della Vida for a class in Colloquial Arabic; he agreed to authorize it so long as he had nothing to do with organizing or teaching it, and with an informant at Penn who belonged to King Farouk of Egypt's royal guard, a small group had some success with the language, with Chomsky able to read newspaper Arabic (a skill not long maintained). Levi della Vida returned to Italy after the 1947/48 year, and his place was taken by the preeminent Arabist of the second half of the twentieth century, Franz Rosenthal (1914-2003). With Rosenthal Chomsky studied the Arab grammarian Sïbawayh. ${ }^{14}$ With the eminent Assyriologist E.A. Speiser (1902-1965) he studied Comparative Semitic, which was offered in his sophomore and junior years (Gordon 1986, 61-62).

11. Chomsky published one article in Hebrew, in 1957 (Koerner \& Tajima 1986, 6) - in the Festschrift for his father.

12. "They looked about 50 years old to me (I guess they were in their 20s)" (NC, 8/26/07). "I could never talk to them. Partly a substantial age difference (which matters at age 16-17)" (NC, 12/30/07).

13. Presumably the 4 th edition (Thatcher 1942), nearly 500 pages including chrestomathy and glossary, and Nöldeke 1890.

14. A sense of Western historians' of linguistics unfamiliarity with Arab grammarians generally in that era can be gathered from the opening pages of Semaan 1968 (1-5). 
In Philadelphia's small, close-knit Jewish community, the Chomsky and Harris families were acquainted, to the extent at least of an occasional Passover seder at the Harrises' home. Zellig S. Harris (1909-1992), who was to become Chomsky's mentor, had made his name in Semitic linguistics, with some of the first American Descriptivist grammars of ancient languages (Harris 1936, 1941) and an apparently unprecedented historical Descriptivist study that formulates changes (in phonology and morphology) as chronologically ordered rules (Harris 1939). The two books, at least, remain classics in their field; ${ }^{15}$ Hebrew had been a home language for Harris ${ }^{16}$ (his family immigrated to Philadelphia from Ukraine when he was four); he taught Modern Hebrew from 1940/41 (and subsequently Moroccan Arabic [cf. Harris 1942b], Hausa, and Swahili as wartime measures; Gordon 1986, 58, 60); and Hebrew and Arabic data figure prominently in Harris's best-known work (1951, 246-49, 285-89, 314-24, 352-60), yet Harris's biographers (e.g., Nevin 1992, Watt 1995) typically ignore this primary aspect of his work, the first fifteen years of his career, entirely. Harris founded the Linguistics Department of the University of Pennsylvania in 1947, one of many that claim to be the first such university department (Moses 2008). ${ }^{17}$ Chomsky properly met Harris at a socialist meeting, probably in the Harris home, early in 1946: "At the time, I was thinking of dropping out of college, mostly very boring. He was really quite a charismatic figure. I was very excited by what he had to say about these [linguistic] topics. He kind of took me under his wing, suggested readings, and also suggested that I sit in on some of his grad courses, which I found fascinating. Pretty soon he gave me the proofs of Methods to proof-read .... That was my introduction to linguistics" (NC, 3/8/09). Harris also encouraged Chomsky to study logic, philosophy, and the foundations of mathematics; and so he worked with Nelson Goodman (1906-1998) (Murray 1994, 227).

15. Though the latter must be used with caution in the earlier pages because Harris was misled by mistaken archeological dating of the recently discovered materials from Ugarit to 1500 вСE, or considerably earlier than the Amarna texts from ca. 1365, whereas they are now known to date from the period leading up to the destruction of the town about 1185 BCE.

16. Gordon 1986: 58. Harris published one article in Hebrew, in the prestigious Israeli linguistics journal Lěšonénu in 1951 (Koerner 2004b, 247).

17. Harris's first publication on general linguistics was his 1940 review article of the IndoEuropeanist L.H. Gray's Foundations of Language, the only one of the 37 articles in his selected writings to which he appended a note explaining its inclusion: "This material is reprinted here only because it contains an early expression of the modern linguistic viewpoint" (Harris 1970, 695). It is virtually an encyclopedia entry on linguistics. Remarkably, it was the second of two reviews of that book appearing side by side in Language: the journal's new editor, Bernard Bloch, may have been dissatisfied with the more conventional review by a Classicist, D.C. Swanson, and asked Harris to provide an up-to-date assessment. 


\section{Background: "Formal sciences"}

"Formal sciences" is the label assigned, faute de mieux, by Marcus Tomalin (2006, $2-3)$, to

various branches of pure mathematics and symbolic logic, but, in addition, ... various kinds of applied mathematics and logic ... a rather heterogeneous collection of related theories drawn mainly from mathematics and philosophy ... the theories grouped together beneath this umbrella term all utilize some form of the axiomatic-deductive method. ... In order for an axiomatic-deductive system to be constructed at all, it is necessary to be able to state initial assumptions, to identify primary elements of some kind, and to make valid deductive inferences from these assumptions and elements.

Tomalin stresses the importance of Rudolf Carnap (1891-1970) to the work both of Nelson Goodman and Chomsky's future teacher W.V.O. Quine (1908-2000). ${ }^{18}$ (It was Goodman, at Penn, who proposed Chomsky for the Harvard Society of Fellows in 1950.) Carnap's Logische Aufbau der Welt (1928) makes an almost ritual appearance at the start of $M M H a$, in an introduction justifying the combination of logic and linguistics in the investigation of a natural language. (As this introduction was removed from $M M H \mathrm{~b}$, it is reproduced below.) Chomsky did not read the Aufbau in German (an English translation was not published until 1967), but knew it from Goodman's seminars and from the manuscript of Goodman 1951. Chomsky's introduction stresses the notion of "elegance," derived from Goodman's (1943) notion of "simplicity."

The absence of acknowledgment to Harris in $M M H$ a might seem odd. Chomsky has always insisted that his work there owed nothing to Harris's methods (or, Methods). The work itself, though, owes its existence to Harris. He had suggested that Chomsky's senior honors thesis in 1949 be a "structural restatement" of Modern Hebrew grammar along the lines of those that Harris had published in the International Journal of American Linguistics a few years earlier (NC, 8/26/07). ${ }^{19}$ Chomsky tried working in accepted fashion with an Israeli informant but found both that he knew the language

18. Quine and Goodman became acquaintances, friends, and eventually collaborators during Quine's 1935 Harvard seminars on Carnap's Logical Structure of Language $(1934,1937)$ (Tomalin 2006, 78). Chomsky's first published article (1953) relies on Goodman and Quine 1947.

19. These reanalyses of the morphologies of Eskimo, Yawelmani, and Delaware (Harris 1970, 217-50) appeared in IJAL in 1947. They developed from an intended review article on the celebrated 1946 Franz Boas memorial volume Linguistic Structures of Native America, edited by Harry Hoijer, containing sketches of thirteen languages (Mithun 1996, 49). Apparently Harris intended to deal with all the languages described in the volume. His contributions to American Indian (and African) linguistics, published between 1939 and 1948, are also generally neglected. 
about as well as the informant did, and that the traditional structural sketch did not interest him. His mathematical interests took him in a new direction. ${ }^{20}$ Harris's structural sketch of Biblical Hebrew (1941) includes a series of 69 morphophoneme representations and replacements presented in prose in a table (154-59), and other prose tables of morpheme order and coexistence (160-63); and his "Componential Analysis of a Hebrew Paradigm" (1948) provides a model for dealing with morphological "components" recurring in a phrase, such as "feminine" and "plural," parallel with the phonological "long components" he had dealt with earlier (1944). Chomsky's diagrams of the Elementary Sentence and perhaps of Necessary Order (pp. 192 and 204 below) are very like those in Harris 1951, 153, 353. Goldsmith (2008) notes that it was Harris (1951, 79-89) who validated the indication of morpheme boundaries - under the name "juncture" - in phonological descriptions. Chomsky's footnote ${ }^{\star \star}$, occurring in the context

The fundamental linguistic fact is the sentence. ${ }^{* *}$

${ }^{* *}$ Actually, the fundamental linguistic fact, i.e., the unit presented in experience, is the discourse. A complete grammar in the sense of this paper would begin with a structural analysis of discourses, analyzing these into sentences. (MMHa, 9; omitted from $M M H b$ )

surely relates to the "seminars" on his latest work that Harris held for selected participants. $^{21}$

Vexed is the question of "influence" on $M M H$. For years, Koerner $(2002 \approx 2003 ; 22$ $2004 \mathrm{a} \approx 2001$ ) has been insisting (initially) that Chomsky must have read and assimilated

20. Chomsky is not certain that the undergraduate paper no longer exists. It may be on file at Penn, or he may have it in a carton somewhere (NC, 12/29/07).

21. "Harris, at least in the years I knew him well - ' 47 to mid-50s - had a kind of triple life. One life had nothing to do with Penn at all. It was socio-political .... The other two lives were at Penn. One was a normal academic life. Teaching a few classes, seeing students now and then. A second was with a small group of students who were working very closely with him. I was one of those from 1947. We didn't meet on campus. Sometimes we had 'seminars' at the Horn \& Hardart [restaurant, not Automat] across the street ..., more often [at Harris's home] in Princeton or New York .... During the days I was there, these small seminars were not on linguistics. The general assumption was that the field was basically over, after Methods was available (from 1947). They were on extending the methods of structural analysis to discourse. Some sense of the contents can be found in Harris's papers on discourse analysis in Language in the early 1950s" (NC, 9/7/07), i.e., Harris 1970, 313-72 = Language 28 (1952): 1-30, 474-94. Note that Chomsky in this quotation explicitly excludes the study of discourse from linguistics.

22. Neither of these versions mentions the other, so we cannot know which is considered definitive. 
Bloomfield's "Menomini Morphophonemics" (1939) ${ }^{23}$ or (more recently) that he must have known about it through others' discussions and publications; Bloomfield's article, at variance with all his previous and future work, ${ }^{24}$ observes that a parallel exists between historical and morphophonemic description. Chomsky continues to deny this source, and unless we are to believe that Chomsky is simply lying about his student years, we must carefully examine Koerner's claims. He notes that in the late 1940s there were only four American journals publishing linguistics: Language, IJAL, Word, and Studies in Linguistics (he overlooks the Journal of the American Oriental Society and all "area studies" journals) and very few books, and that a linguist could and should be familiar with all the literature in the field. One wonders, though, whether an undergraduate, even then, was expected to go directly to the journals. ${ }^{25}$ Koerner (2004a, 89) observes that Bloomfield 1939 is cited several times in Harris 1942a; what he fails to note is that the article is mined for data only, and nothing is said about Bloomfield's method; nothing would direct a student interested in such theoretical questions to seek it out (whether in a series volume ${ }^{26}$ or in an offprint sent to Harris by the author). Likewise Koerner (2004a, 90) identifies three mentions of the article in Harris 1951 $(231,237,336)$ but does not note that the first two are, again, simply as a source of data and the third disposes of (one of Bloomfield's cases of) rule ordering by reanalyzing it in terms of morphophonemes. Thus this cannot be taken as pointing to a source for Chomsky's notion of rule ordering.

Koerner's (2004a, 71) other piece of contemporary evidence involves some five degrees of separation. (1) Chomsky mentions Bloomfield 1939 side by side with Jakobson 1948 in LSLT (78 n. 2). (2) Harris 1951 does not mention Jakobson 1948,

23. Pierre Encrevé saw a preliminary version of this chapter and asked that an oversimplification of Encrevé 1997, 2000 be acknowledged as the source of Koerner's interpretation (pers. comm., 3/9/09).

24. And with Harris's; the burden of Harris 1940 is that historical information is utterly inadmissible in the analysis of a language.

25. (Note Chomsky's 1988 assertion, quoted by Koerner [2004a, 71 n. 7], that "no one ever read a word of Jakobson's" in his day.) Things were not all that different 22 years later, when I too became a linguistics major in my sophomore year at 17 . We had the great advantage, however, of Joos 1957, in which American Descriptivist orthodoxy was canonized. It is noteworthy that only two of the 43 items included are reprinted from Word. The next significant American journal, Linguistic Inquiry, did not begin until 1971.

26. Harris's note "Since many linguistic workers in America may want to have some idea of Trubetzkoy's method” (1970, 708), in his 1941 Language review of Trubetzkoy's Grundzüge, the previous volume of the Prague series in which Bloomfield 1939 was published, suggests that that series was not widely held in American libraries. 
but does mention earlier work by Jakobson (on zero markers, not on ordered rules). (3) Jakobson provided "important criticisms" of Harris 1951 before January 1947. (4) Harris "may well have seen" (when?) Jakobson 1948 in manuscript. ${ }^{27}$ (5) Chomsky assisted with the manuscript of Harris 1951 before January 1947. I fail to see how any of these observations connects Chomsky with Bloomfield 1939 at any point before the 1975 publication.

Koerner legitimately states that Chomsky was familiar with Bloomfield 1939 by 1962, as it is discussed in his plenary address (Chomsky 1964b) to the Ninth International Congress of Linguists, jointly hosted in Cambridge by Harvard and M.I.T. in August 1962..$^{28}$ It may indeed have "sounded as if he had been well aware of Bloomfield's Menomini paper for quite some time" (71), but I cannot fathom how this sentence can continue "at any rate much earlier than 1954" (ibid.). If, however, we consult the typescript that underlies $L S L T$, we find that this date is very unlikely to be earlier than January 1956. Koerner and Tajima $(1986,3)$, apparently based on LSLT (2-4) rather than on examination of the available materials, ${ }^{29}$ identify four stages in the

27. Koerner cannot both insist (passim) on dating Harris 1951 to 1947, and claim that Harris 1948 was "previously published" (2004a, 91).

28. Murray $(1994,240)$ appears to accept Koerner's, as it were, "vast left-wing conspiracy" view of how Chomsky secured the prestigious post of plenary speaker at that Congress. Chomsky's explanation is much simpler: "[The organizers, Roman Jakobson and Morris Halle,] wanted, naturally, to have an American for one of the keynote addresses, and invited Harris, who accepted. At the last minute, he withdrew, for unknown reasons. They were stuck, and asked me to fill in for him. I was quite reluctant ... But I agreed to give a talk, though I didn't stay for the conference" (NC, 12/30/07). Chomsky's address was in fact on the morning of the last day of the Congress (Lunt 1964: xxi).

29. Koerner $(2004 a, 70)$ creates the impression (with the claim that all references to Hjelmslev in version 2 were expunged from the published version) that at least version 2 was studied. However, tracing the missing reference to Koerner 1995, 99, we read: "We can find ... Chomsky referring to Hjelmslev's Prolegomena on various occasions in his 1955 LSLT. ... I am referring to Chomsky's Syntactic Structures as an early published instance where an explicit reference to the Prolegomena is made." There is in fact no reference to Hjelmslev on any footnote page of LSLTpdf. Syntactic Structures is not extracted from LSLT; it originated as notes for an undergraduate linguistics course at M.I.T., for budding engineers and mathematicians who had to be disabused of notions that "elementary Markov sources, information theory, Shannon's statistical order of approximation, Quine's version of radical behaviorism, etc." would provide "the answer" to problems of language; "the early material in SS, devoted to refutation of these notions, doesn't appear in LSLT at all, bccause it was mostly intended as a kind of Wittgensteinian therapy" (NC, 12/30/07). Interestingly, the substance of Chomsky's review of Skinner's Verbal Behavior (1959) was part of the same course materials (ibid.) though obviously in a different year. 
development of that work; the 1975 publication reflects version 3 . What appears to be the 918-page version 2 has been freely available for several years (Chomsky 1955-56, hereafter LSLTpdf). ${ }^{30}$ Thanks to the author index by Jan van Voorst appended to the 1985 Chicago reprint, we can isolate the two mentions of Bloomfield 1939 in the work. In the first (78 n. 2), it is linked with Jakobson 1948 "as examples of this general form," where "this" appears to me to be ambiguous between the "grammar" considered in the text, or "a different form" mentioned in the footnote and referenced to Harris (1951, $372-73 \$ 20.3$ ). In the second ( 115 n. 5), it is linked with $M M H$ as two examples among many of languages where "morphophonemes have wide distribution and are complexly interconnected[;] such analysis can lead to very great economy." LSLTpdf, i.e., version 2 , is a messy (though never illegible) manuscript, with many supplementary pages, much crossing-out, and many handwritten insertions. The vast majority of these insertions are in print-style handwriting and probably date to a single sustained period of revision. The first mention of Bloomfield 1939, however, is inserted before the typed Jakobson 1948 reference (LSLTpdf, 65 = ms.p. Ifn1), in cursive handwriting suggesting that it was hastily added subsequent to the main editing of version 2 in January $1956 .{ }^{31}$ The second mention does not appear in LSLTpdf at all; the first half of the published n. 5 is in the text at $98=$ ms.p. III-76, with footnote 3 (at $132=$ ms.p. IIIfn1) a cross reference to the intended insertion of $M M H \mathrm{~b}$ as an appendix to Chapter $\mathrm{V}^{32}$ (Interestingly, Chomsky also intended to insert a corresponding syntax of Modern Hebrew as an appendix to Chapter VII; LSLTpdf, $465=$ ms.p. VII-352.) The second reference to Bloomfield 1939 could thus have been added at any point from version 3 later in 1956 until publication in 1975. Chomsky recalls that Morris Halle and their student Thomas Bever discovered Bloomfield 1939 about 1960 (NC, 3/7/09).

We have already seen that two of MMHa's earliest commentators recognized that the work brought something entirely new to the study of morphophonemics: "a theoretically important discussion of ordered rules" (Gutman 1970, 3); and

30. As announced in LINGUIST List 18.1223 (4/23/07) by Prof. Robert Berwick, the work is available at http://alpha-leonis.lids.mit.edu/chomsky/.

31. The manuscript version of the passage and footnote is clearer than the published version: the Menomini and Hebrew treatments exemplify the style of analysis described in the main text.

32. Koerner and Tajima $(1986,3)$ claim that $M M H$ "was included as an appendix to chapter VII” [copying Chomsky's mistake from LSLT (4)] of (some ms. version of) LSLT, but this seems most unlikely, as the note in $\operatorname{LSLT}$ (169) in lieu of the appendix to chapter VI is identical to the note in LSLTpdf, 243 = ms.p. V-189, but for the insertion of a sentence and a half. I have wondered whether it was nothing but the typographic complexity of $M M H \mathrm{~b}$ that kept it from being included in the publication of LSLT, but Chomsky did not answer that question. 
Whereas earlier descriptions in terms of ordered morphophonemic rules, e.g., Bloomfield 1939, had been content merely to specify sufficient conditions of ordering (i.e., by arranging $n$ rules in a linear order from 1 to $n)^{5}\left[{ }^{5} \mathrm{Cf}\right.$. Chomsky 1964[a]: 70.], Chomsky's thesis attempts to specify necessary ordering and regards the set of morphophonemic rules as being only partially ordered. (Kilbury 1976, 106)

What, then, need Chomsky have taken specifically from Bloomfield 1939?

Another article has recently been put forward by John Goldsmith (2008) as a potential precursor of generative phonology: Wells 1949. Goldsmith convincingly shows that a number of characteristics of what was to become generative phonology appear - not foreshadowed, but explicitly — in this article. ${ }^{33}$ Not, perhaps, accidentally, neither Bloomfield 1939 nor Wells 1949 appears in Joos 1957; though Swadesh and Voegelin 1939 does: Joos's afterword to this article (Joos 1957, 92) together with Goldsmith's extended quotation from Joos 1964 suggest why. Goldsmith sees Bloomfield and Swadesh \& Voegelin as the heart of Wells's presentation. Chomsky's assessment is very different from Goldsmith's (and, presumably, Joos's):

It is pure description of surface forms and their arrangements, which is why the solutions he discusses are so intricate and complex, and miss the underlying principles and generalizations that emerge in generative morphophonemics .... It is a very careful discussion, Wells-style, of the familiar options in use in descriptive morphology .... He cites Bloomfield's Menomini but dismisses it. Rather, he cites Bloomfield's thesis in Language that descriptive order is "a fiction" - in Well[s]'s paraphrase, "fictive and metaphorical," therefore "avoidable," and he proceeds to discuss how to avoid it. He says that the standard use of such devices is an illegitimate borrowing from historical linguistics, and has a mocking and dismissive reference to the "theory" proposed by Swadesh and Voegelin that doesn't recognize that all of this is fiction..$^{34}(\mathrm{NC}, 1 / 23 / 08)$

\section{Content}

The contents of $M M H a$ are as follows:

1. Introduction

2. Syntax

3. Morphophonemics

4. General Statement-criteria, and Necessary Order

33. In asserting (n. 4) that this article contains the first expression of the notions "focus" and “environment," Goldsmith overlooks Wells's own reference (n. 7) to Wells 1947, \$ 11.

34. Chomsky's alacrity is extraordinary. I asked about Wells 1949 just past midnight on Tuesday, 1/22/08; he replied that he did not recall it, and at 1:25 pm the next day he had gone to the library and assessed the article. Note that the elaborate rewriting of $M M H \mathrm{H}$ into $M M H \mathrm{~b}$ took considerably less than six months. 
5. Derivations

A. Verbs 60

B. Nouns 65

Appendix

As nothing corresponding to the Introduction appears in $M M H \mathrm{~b}$, so that the connection with Carnap and the motivations for the approach are lost, it is reproduced here in full (with the author's permission, 8/26/07). ${ }^{35}$

1.0. This study has its roots in two fields, symbolic logic ${ }^{\star}$ and descriptive linguistics. But the work which constitutes the body of this paper is not an example of what is customarily done in logical construction, nor, for that matter, is it a typical representative of work in descriptive linguistics. In that case, its status remains undetermined. This introductory statement will attempt to explain the status of the present study in Modern Hebrew grammar, exhibiting:

1. The connection of logic and linguistics

2. The connection (or relevance) of this paper to logic

3. " " " " " " linguistics.

Sections 1.2. and 1.3., at the cost of some repetition, are self-contained units.

1.1. Logic and linguistics meet at several points. Perhaps the clearest way to perceive that connection relevant here is to consider the applications of logic to the construction of systems. Thus Carnap in the Aufbau, $\uparrow$ for example, begins with a primitive relation between slices of experience and attempts to construct, by a series of definitions, the concepts of quality class, quality, sensation, etc., i.e., he tries to construct concepts for the most general description of experience. Similarly, it can be shown that the theoretical part of descriptive linguistics, beginning with three 2-place predicates of individuals, and restricting its individuals to a tiny domain of experience (i.e., speech [p. 2] sounds 'phoneme', 'morpheme', etc., which are available for a general description of that part of experience called linguistic phenomena.

35. In the transcription of $M M H \mathrm{Ha}$ and $M M H \mathrm{~b}$, underlining in the typescript is replaced by italics; superscripting and subscripting are as typed, despite some possible inconsistencies; Chomsky's handwritten ligatures of NP and VP are set thus; and supralinear typed insertions (notably in the word "morphophonemics") are enclosed in '〉. A very few obvious typing errors are corrected silently. Chomsky's footnotes are marked ${ }^{*}, \dagger, \ddagger, \S$ (rather than the typed ${ }^{\star},{ }^{*}$, etc.). Page breaks in the typescript are indicated. Numbered footnotes are mine.

* More specifically, the constructional part of philosophy which uses logic as its essential tool.

$\dagger \quad$ Carnap, Der Logische Aufbau der Welt, Berlin, 1928.

‡ Or, perhaps, segments of magnetic tape on which speech is recorded. 
1.2. Suppose that a system such as that of the Aufbau is successfully established, and it is now desired to focus the powerful concepts developed on a small part of experience, e.g., on the experience of A in time range T. Suppose that it is desired to describe this part of the totality of experience, giving certain information about it, for instance, of what qualities, sensations, etc., is it an instance.\$ There would be two ways, essentially, of proceeding. One could list the occurring individuals and progressively develop the concepts of the system, restricting each predicate to the individuals (or sets, sums, etc., of individuals) for which it holds, thus proceeding in what will be called a synthetic process, i.e., in the direction of greater generality. Or, one could invert the whole process, list first the most general elements applying to the part of experience under consideration, analyze these into their actually occurring constituents (from among the totality of constituents permitted by the system), further analyze these, etc., until finally the whole experience would be specified in terms of the individuals of the system. This will be called an analytic process. Which method will be [p. 3] selected depends on considerations of elegance and relative adequacy for the particular purposes of the description.

Analogously, the theoretical linguistic system constructed is available for descriptions of small parts of the realm of experience constituted by the totality of its individuals. In one of the most interesting cases, the part to be described is an individual language. As above, the system can be applied in two ways. One can begin with the elementary phonetic units, construct the phonemes, morphemes, syntactic classes, etc., proceeding synthetically. Or one can state the most general unit (i.e., the sentence) in terms of its constituents (e.g., the particular phrases of the language), further analyze these into their constituents, etc., until finally every possible sentence is represented in terms of phonetic units, thus proceeding analytically. Again, this choice will depend on considerations of elegance and adequacy.

This paper will be an attempt to carry out an analytic statement of Modern Hebrew grammar. Thus, beginning with the sentence as the fundamental unit, the grammatical statements will progressively transform it into its more and more simple constituents, until all sentences of Modern Hebrew, an actual spoken language, are represented in terms of phonetic units. Of course, to actually describe such a complex part of experience as a spoken language is an enormously involved procedure, and certain parts of the total description, which will be specified, are only given in outline, or merely mentioned. But all of the essentials have, I think, been included, and a complete description of [p. 4] Modern Hebrew, from this point on, would be largely a matter of additional detail.

$\$$ It is here assumed that we actually know the basic facts but wish to state them. The actual process of discovery of the facts and of recording them would be comprehended by some science, not by philosophy, and would correspond to what will be called, in 1.3., step 1 in the process of descriptive analysis. 
1.3. The process of descriptive analysis of a language can be divided into two parts. The first step consists of the discovery of the basic substitutable elements, and the determination of the relevant sequences, classes, sequences and classes of classes, etc., of these elements. The second step is the construction of a descriptive statement based on the results of this process of discovery. It should be noted, of course, that the second step is also a creative, information-yielding process. The activities which constitute the first step are governed by certain criteria, and the elements obtained at each level must meet certain requirements. The various formulations of these criteria and requirements constitute the subject matter of researches in the methodology of distributional analysis. But the statement of the grammar, the presentation of the results of the completed distributional analysis, must meet wholly different criteria which involve, essentially, considerations of elegance and considerations of adequacy as determined by the particular purposes of the grammar. The present paper will confine itself to step two in the description of Modern Hebrew.

The task of rigourously defining the criteria which should govern grammatical statements is beyond the scope of this paper, although certain formulations will be given and the question will be discussed in section 4 . But it must be stressed here that the considerations of elegance cannot [p. 5] be regarded as trivial or merely 'esthetic'. It has been pointed out with reference to constructional philosophical systems*, and it is no less true for descriptive grammatical systems, that the demand for elegance (or economy) is essentially equivalent to the demand that there be a system at all. The amount of material under consideration by the linguist is finite, and it could be completely described in many ways, e.g., by listing every linguistic expression which can occur in terms of the various units appearing at various levels of analysis. Thus the morphophonemic statement of the present paper could be replaced by a complete set of paradigms for all morphemes; the syntactic statement, by a listing of all sentences, etc.

The argument against these and similar constructions is that (i) they are inefficient and (ii) do not exhibit relations and interconnections among linguistic expressions. (i) is simply a rephrasing, with a different emphasis, of the criterion of elegance. (ii) is equivalent to a demand for generality and for the constructability of elements from a set of more fundamental elements (e.g., of syntactic constructions from morphemes, morphemes from phonemes, etc.). But these considerations are immediately reducible to criteria of elegance, since generality is increased by reducing the number (and complexity, if it is to be real generality) of statements, while keeping the subject matter constant, and constructability is increased by reducing the [p. 6] number of basic elements (e.g., by a phonemic

* N. Goodman, "Simplicity of Ideas," Journal of Symbolic Logic, Dec. 1943, p. 107. “The motives for seeking economy in the basis of a system are much the same as the motives for constructing the system itself." 
statement) and by specifying with greatest generality the construction of other elements (e.g., morphemes, sentences, etc.) from these.

The purpose of the grammar outlined in this paper is to specify, in terms of phonemes (ultimately, in terms of phonetic units), all the sentences of Modern Hebrew. The grammar is composed of syntax, morpho<pho ^nemics, and phonemics. $\dagger$ The introductory syntactic statement breaks down the sentence into its parts. The morphophonemic statement specifies these parts in terms of phonemes. The phonological statement effects the transfer from symbolism to observable fact. Thus the grammar is a set of analytical statements each of which analyzes more closely the units presented to it by the preceding statement. Running through the list of statements in one way (i.e., with one set of choices) gives one sentence. Running through them in all possible ways gives all possible sentences.

The customary structure of a grammar is phonology, morphology, and syntax, in that order. A departure from custom should be justified. I think that there is methodological, and perhaps even psychological justification for the inversion of order carried out here.

Fundamentally, one may ask what the grammar structured in the customary pattern does. What it does is to tell you how to write, in the most general possible form, any actually occurring sound sequence. At every stage in the construction [p. 7] of this most general symbol sequence, information is imparted about the given sound sequence (e.g., of what phonemes, morphemes, etc., is it an instance) and about the interconnections and relations among units constructed at the intermediate stages. But the purpose of the present grammar, as presented previously, is different. It is to completely characterize and specify the totality of linguistic expressions of the language in terms of elementary units. To do this clearly requires an inversion of the customary pattern. The intermediate information is imparted with no loss. The question here is not which is the 'correct' purpose (although I think that the relevance of the position taken here can be defended), but simply, given the purpose, which is the better method of achieving it.

Another possible methodological consideration is as follows. One of the parts of any grammar will have to be a series of statements describing the phonemic form of morpho'pho'nemes. These are fundamentally analytic (in the sense that they break down more general units into less general ones) statements, as opposed to the essentially synthetic statements which characterize the grammar of customary structure. When the morpho<pho»nemic statement constitutes a large part of the grammar (as is the case of Hebrew), there is a certain gain in unity if the analytical morphophonemic statement is put into an analytic frame.

$\dagger$ The phonological statements are not actually given. Their place is, however, indicated. 
To put the matter differently, the 'synthetic grammar' will not lead directly even to its own goal, the symbolic generalization of a given sound sequence. For to [p. 8] do this directly would require a series of synthetic statements each of which recasts and combines the elements transferred to it by the preceding statement into more general units of which they are instances. But the morphophonemic statement would have to proceed in the other direction, analyzing the more general elements, morphophonemes, into their particular phonemic form.

The psychological consideration I advance hesitantly. In an 'analytic grammar' (as will be presented here), every time a unit is introduced it is immediately and automatically (i.e., by the very way it is introduced) placed in the broad context of which it is a part and in which it functions, and the way it functions in relation to the units around it is immediately and automatically determined. Thus one cannot really understand what a noun phrase is except in the contextual frame provided by other phrases, or until it is presented against the background of the sentence of which it is a part. But this is what has been called an analytic process. This consideration seems to have some relevance, at least on the higher levels of analysis, but, generally speaking, I do not know how much (if any) weight is to be attributed to it.

Initially, brief characterizations of the remaining chapters will suffice; their content will be exemplified below when $M M H \mathrm{a}$ and $M M H \mathrm{~b}$ are compared.

The Syntax chapter (9-18) includes 23 of what would come to be called "rewrite rules" (excerpted in II below), with definitions of symbols interspersed, as well as two sample analyses (III below). Harris's term "transformation” makes an appearance. M, $\mathrm{U}$, and $\mathrm{O}$ denote the precursors of $\mathrm{N}, \mathrm{V}$, and $\mathrm{P}$ - nouns, verbs, and prepositions. What seems to be a major innovation is the use of abstract markers in place of at least some phonological content.

The heart of the thesis is "Morphophonemics" (19-46). This includes 42 "statements" of the most disparate form (excerpted in V below); for years, generative phonology would consist of devising restrictions on the forms of statements - restrictions that would rule out the vast majority of these 42 rules. But they are preceded by a long discussion of notational conventions (called "terminology"), and by a list of ten subsets of consonantal roots - which, however, are not characterized, but only exemplified. There are no fewer than five groups of Middle-Yod roots, with no indication of which ones go in which class (see n. 44 on p. 194). ${ }^{36}$

36. In traditional Hebrew grammar, all verbs and most nouns are said to be formed from a triconsonantal root. One class of verbs that exhibit only two consonants in their surface form can be analyzed as having a semivowel, $w$ or $y$ (known by the letter-names Waw and Yod), as the second root consonant. "Double-Ayin" refers to another exceptional class. 
The fourth chapter, "General Statement-criteria, and Necessary Order" (47-64), presents a chart of the "necessary order" of application of the 42 "statements" (VI below). Chomsky observes that "this can be done completely by justifying the construction of each segment of a vertical line in the chart" (49). There are 51 such justifications (excerpted in VII below). Justifications are presented in the format

\begin{tabular}{l||l}
\hline $\mathrm{m}<\mathrm{n}$ & $\mathrm{J} \stackrel{\mathrm{n}}{\rightarrow} \mathrm{J}^{\prime} \stackrel{\mathrm{m}}{\rightarrow} \mathrm{J}^{\prime \prime} \rightarrow * \mathrm{~J}^{\prime \prime \prime}\left[\mathrm{J}^{\prime \prime \prime \prime}\right]$ \\
\hline
\end{tabular}

The meaning of such an expression is as follows: statement $\mathrm{m}$ precedes statement $\mathrm{n}$ because, were their order to be reversed, the element $\mathrm{J}$ (where $\mathrm{J}, \mathrm{J}^{\prime}, \ldots$ are any sequences of elements which appear at any point in the process of application of the statements of the grammar) would become (by $\mathrm{m}$ ) $\mathrm{J}^{\prime \prime}$, which would finally become (upon application of the remaining statements) $\mathrm{J}^{\prime \prime \prime}$, which is an incorrect form. The correct final form is $\mathrm{J}^{\prime \prime \prime \prime}$. Sometimes a clear counter-instance can not be constructed. In this case, the reason for the ordering will be stated to the right of the double vertical line. As has been brought out previously, considerations of elegance are a sufficient justification for a given ordering.*

The general considerations which have been regarded as relevant criteria are as follows:

1. Simplicity of statement

2. Maximization of the number of derivations in which a statement will occur relevantly.

3. Minimization of irrelevant applications.

4. Maximization of similarity among statements, and amalgamation of statements involving the same elements. (49-50)

Finally, 24 sample verb derivations and 23 sample noun derivations are given; they are not unhelpful in divining the purpose of each of the 42 "statements" (I below). The Appendix lists what has been omitted from the grammar: loanwords, primary nouns, suppletions, numerals, adjectival -ay or - $a^{\prime} i$, Double-Ayin verbs, directional $-a$, adverbs, pronominal verbal suffixes, and the infinitive construct and inflected infinitive. ${ }^{37}$

* Actually, if these considerations are dropped, almost any order can be shown to function successfully, simply by enumerating in each statement the cases which lead to an incorrect result, and adjoining to each statement a correction for each such instance. This is possible as long as the material is finite.

37. Some of these are phenomena of Biblical Hebrew with little or no occurrence in Modern Hebrew. 


\section{Reception}

Chomsky has always insisted that $M M H$ a fell on mostly deaf ears at the University of Pennsylvania; that only the Indo-Europeanist Henry Hoenigswald (1915-2003) read it and made comments (some of Hoenigswald's own work is highly formalized, and he was also steeped in Pānini; Chomsky missed the chance to work with Hoenigswald and master the third in the triumvirate of ancient grammarians, alongside Sibawayh and Kimhi). ${ }^{38} \mathrm{He}$ believed that Harris paid the work no attention; that Harris believed

38. These two distant antecedents may have been quite important, if only subconsciously, in Chomsky's formation. Bohas, Guillaume, and Kouloughli (1990: 38) observe regarding Sībawayh:

Typologically, grammatical and linguistic systems can be divided into two rough classes: on the one hand, those which analyse utterances in terms of formal relationships between their components; on the other hand, those which analyse them in terms of operations performed by the speaker in order to achieve a specific effect on the allocutee. Our claim is that Sibawayhi's approach basically belongs to the latter category .... Sỉbawayhi's system of analysis crucially presupposes that any utterance is the final result of a sequence of operations performed by the speaker, each one of these operations being simultaneously formal and semantic.

We do not know which portions of Sïbawayh's work were studied (Bohas et al. exemplify their point with a discussion of the early $\$ 30$ ), but this system may well have made a profound impression on Chomsky's voraciously integrative mind. Whichever passages a student reads, the structure of the work is clear:

After a few pages of high-level theoretical preliminaries, the work examines first the syntax of Arabic, then the morphology and finally its phonology. This sequence is seldom followed in Western descriptive grammars (and has even been implicitly criticized), though it does represent the natural order in which the data would present itself to the observer, who would have to start with the whole utterances before breaking them down into their morphological and phonological components. (Carter 2004: 38)

Carter's conclusion, "There is no need to look in Sībawayhi for the antecedents of any of the innovations of modern Western linguistics: no historical connection exists" (p. 145), may have been premature (cf.p. 184 above).

From his father's work on Kimhi (cf. n. 10), Chomsky may have absorbed - along with the traditional analysis of Hebrew grammar - the notion that classic works are not necessarily sacrosanct: that total rethinking of inherited wisdom is not beyond the pale.

If Chomsky had had the privilege of studying Pānini at that time, a quite different realization of "elegance" might have ensued. The relating of Pānini to generative linguistics fell, many years later, to Paul Kiparsky (e.g. 1994 with references). 
nothing more was to be said in linguistics about phonology, that the future lay in discourse studies (cf. n. 21). ${ }^{39}$ For the same reason, Chomsky may have been reluctant to show his work to Harris; given how quickly Chomsky works (cf. n. 34), he may have been unwilling to pause for cycles of drafts and comments.

There are, however, two concrete pieces of evidence that Chomsky was not so unappreciated as he has always believed. First, on February 7, 1991, Charles F. Hockett (1916-2000) wrote to John Goldsmith as follows:

Quite apart from publications, a number of us (Bloch, Trager, Harris, Voegelin, Smith, Joos) were in active correspondence in the late 1940s and early 1950s. I have (or did have; some of them are lost) letters from Zellig Harris that mention a young student named Chomsky. One of them speaks enthusiastically of Chomsky's work on Hebrew morphophonemics, saying that Chomsky had found a way to put the ordering of morphophonemic rules on a logical basis. ${ }^{40}$ (Goldsmith 2008, 48-49)

Harris was thus bragging about his student, aware of his innovation, and appreciative of it.

Second, Chomsky was asked by Harry Hoijer to review for IJAL two major books on phonology, Hockett's Manual (Chomsky 1957a) and Jakobson and Halle's Fundamentals (Chomsky 1957b). Chomsky had not yet published anything on phonology; for some time he had been concentrating on syntax. That means that the significance, if not the details, of $M M H$ was already widely recognized by 1955 .

In the summer of 1951, Chomsky moved to Cambridge to take up his five-year appointment to the Harvard Society of Fellows. There he encountered Yehoshua Bar-Hillel (1915-1975), whom he credits as the only person who seriously read and understood $M M H$ a. It was Bar-Hillel who

suggested to me that I ... postulate something very much like the reconstructed historical forms on the abstract morphophonemic level. It was with this in mind that I carried out the revision to the final 1951 version. I was struck by the fact that it led to considerable improvement. (LSLT, 29)

As he put it more recently,

Bar-Hillel's suggestion was that I should pursue more rigorously the general simplicity formalism, and that if I did, I might find that the loose analogy between

39. Chomsky may be right about Harris's lack of interest in his innovations; as late as his 1951 Language review of Sapir's Selected Writings, he still proffered a morpheme distribution model in preference to Sapir's (historico-)processual model (Harris 1970, 714).

40. Hockett's family and colleagues believe that Hockett's papers are archived at Rice University, Houston, Texas, with which he was affiliated toward the end of his life. However, an archivist/special collections librarian at Rice, Philip Montgomery, reports that Hockett's papers are not there (pers. comm., 2/21/08). Thus it seem impossible to determine just what Harris was saying to his colleagues, and when. 
historical linguistics, with its explanations in terms of sequentially ordered processes, and generative grammar, with its ordered rules, held much more closely than in my 1949 undergraduate honors thesis and the revision in my 1951 MA thesis. That turned out to be correct, a matter of more general importance. Incidentally, when Morris Halle and I worked on what ultimately became Sound Pattern of English we were guided by similar ideas. (NC, 12/29/07)

Still more recently, he acknowledges the importance of his early exposure to his father's work:

I'm pretty sure that ideas [like the analysis of begadkefat letters, see p. 209 below] have roots either in Kimhi or in my father's papers on history of Hebrew in the 1930s, I presume related to his work on Kimhi. ${ }^{41}$ I was reading these by the time I was a young teenager, maybe published, maybe in drafts. They don't appear in the first version of $\mathrm{MMH}$, but do in the second version, after Bar-Hillel's crucial suggestion, which led me to think back to what I remembered about history of Hebrew. (NC, 3/8/09)

It turns out that Chomsky had already published a note on this event several years earlier than LSLT, in 1969 - a "political" article of the sort that many linguists set aside as not relevant to Chomsky's linguistic work - discovered by Murray (1994, 228): "According to Chomsky, progress in linguistics depended on someone coming along who was familiar both with the mathematical work on recursive systems and with the tradition of historical linguistics." Murray "thought that Chomsky saw himself as this fortuitous combination." Chomsky denied this vehemently in letters to Murray, but evidently did not direct him to Bar-Hillel ${ }^{42}$ (who is absent from Murray's chapter on Chomsky).

It is difficult to recognize any connections between the underlying forms and the operations performed on them with historical forms in $M M H a$, while they are clearer in $M M H b$.

\section{Revision}

As mentioned, there are 47 sample derivations (24 verbs and 23 nouns) in $M M H a$; there are only 22 ( 14 verbs and 8 nouns) in $M M H b$. Fourteen of the derivations are of the same words ( 8 verbs and 6 nouns) in the two versions. We choose one verb derivation and one

41. W. Chomsky's discussion of begadkefat — including a mention of sequential rule ordering is found in 1952 (i.e. 1933, cf. n. 10 above): 40 n. 38.

42. Is it significant that Chomsky's extended contribution to the Bar-Hillel memorial volume (1976) contains no mention of $M M H b$ like that which was to appear, almost gratuitously, much later in the Blanc volume, nor any reference to Bar-Hillel's work? 
noun derivation to illustrate the differing approaches (on facing pages). Following the sample derivations are given all the syntactic (II below) and morphophonemic (IV-V below) statements that figure in the two derivations, and the tables of necessary order (VI below), together with the justifications involving any of the pairs that happen to be included in this list (VII below).

Beyond the two sample syntactic derivations (17-18), none of the examples in $M M H$ (and there are dozens interspersed within the presentation of the morphophonemic statements) are glossed. These two are, respectively, 'they (f.) were hungry' and 'her books'. In the strings of morphemes at the beginning of each derivation, $r^{\prime} B$ and $s P r$ represent the theoretical triconsonantal roots; ..a..á.. and ..é..e.. are the basic vowel patterns of these two items; $L a$ and $L b$ stand for the personal pronominal suffixes and the personal pronouns respectively; $P$ and $F$ denote plural and feminine respectively; $S$ is the construct state ("smixut"), used for a noun appearing before a noun or pronominal suffix. The absence of $m$ - or $F t$ from the verb definition shows that it is not a present or future form respectively; therefore it is a past tense. In $M M H a$, , “' + indicates concatenation between positions, '?' indicates concatenation within a position” (14), where "position" refers to the columns in the table that constitutes syntactic definitions 13-15 (reproduced below). In $M M H b$ this distinction is no longer used, and it was not considered necessary to define the concatenator “+”. [Discussion resumed on p. 208.] 


\section{Sample derivations}

A9. $r^{`} B \bullet . . a . a ́ . .+L b 3 \bullet P \bullet F$

1. raáB+Lb3.P.F

2. $L p \cdot L a 3 \cdot P \cdot F \#$ raáB $+L a 3 \cdot P \cdot F$

3. $L a 3 \cdot P \bullet F \#$ raáB $+L a 3 \cdot P \bullet F$

4. $h \cdot P \cdot F \#$ raćB $+P \cdot F$

5. $h \bullet e m \bullet F \#$ raáB $+u \bullet F$

6. h॰en\# raáB $+u$

7. hen\# ra'Bú

8. hen\# ${ }^{43}$ rāāBú

9. hen\# rāāBú

10. hen\# rāāvú

11. hén\# ra’avú
Sample derivations

A7. $L a 3+L p+P F \# \mathrm{r}^{ } \mathrm{B}+\mathrm{a}-\mathrm{a}+L a 3+P F$

(2) 1. La3LpPF\#raáB $+L a 3 P F$

(3i) 2. $L a 3 e P F \#$ rá́B $+L a 3 P F$

[MR3]

(3iii) 3. hePF\#raáB $+P F$

(7) 4. hemF\#raáB+uF

(12)

5. hen\#raáBuF

6. hen\# $\mathrm{ra}^{\mathrm{B}} \mathrm{Bu} F$

7. hen\#ráaBuF

8. hen\# $\mathrm{ra}^{a} \mathrm{aBu}$

(37) 9. hen\#ráavu

(39) 10. hen\#ra’avu

(40v, vii) 11. hén\#ra’avú
[MR7]

[MR10]

[MR12']

[MR13]

[MR28]

[MR30]

[MR33]

[MR34]

[MR42]

[MR45]

\begin{tabular}{|c|c|}
\hline \\
\hline \multicolumn{2}{|c|}{$\begin{array}{l}\mathrm{B} 18 . s P r \cdot . . e ́ . . e . .+P+S \cdot L a 3 \cdot H \\
1 . \text { séPer+P+S•La3•F}\end{array}$} \\
\hline 2. & séPer $+P+S \bullet h \bullet F$ \\
\hline 3. & séPar+im•A+S•h॰F \\
\hline 4. & $s P a r+i m \bullet A+S \bullet h \bullet F$ \\
\hline 5. & $s P a r+i m \bullet A+S \bullet h \bullet a$ \\
\hline 6. & $s P a r+i m+S \bullet h \bullet a$ \\
\hline 7. & sPār+ím+S•h॰a \\
\hline & sPār $+e ́ Y_{2}+h \bullet a$ \\
\hline & sPār+é $+h \bullet a$ \\
\hline 10. & fāréha \\
\hline & aréha \\
\hline
\end{tabular}

\section{B7.sPr+1́- $\emptyset+P+S+L a 3+F$}

(2) 1. síPr $+P+S+L a 3+F$

(7) 2. síPr $+P+S+\mathrm{h}+F$

(12) 3. síPar $+P+S+\mathrm{h}+F$

(14i) 4. síPar+im $+\mathrm{A}+\mathrm{S}+\mathrm{h}+F$

(17iv) 5. síPar+im $+\mathrm{A}+\mathrm{S}+\mathrm{ha}$

(25) 6. síPar+eY ${ }_{2}+S+$ ha

(26i) 7. síPar+eA+S+ha

(26vii) 8. sPar+eA+S+ha

(33iv) 9. sPareAha

(39) 10. sfareAha

(40v) 11. sfaréha
[MR3]

[MR10]

[MR12]

[MR12']

[MR13.8]

[MR20]

[MR22]

[MR23]

[MR31]

[MR34]

[MR35]

(MMHa, 61, 68)

(MMHb, 60-61, 65)

43. At some point in the derivation, the underlining (italics) should have been removed from hen, probably at this point. 


\section{Excerpts from 2. Syntax:}

3. $\mathrm{ES}=$

\begin{tabular}{|l|l|}
\hline \multirow{2}{*}{$\mathrm{NP}_{1}{ }^{1,2}$} & \multicolumn{2}{|c|}{$\mathrm{LP}$} \\
& \multicolumn{2}{|c|}{${ }^{2}$} \\
\cline { 2 - 2 } & $\mathrm{NP}_{2}{ }^{1}$ \\
\cline { 2 - 3 } & $\mathrm{VP}^{2}$ \\
\hline
\end{tabular}

Any element enclosed in a minimal polygon is called a phrase.

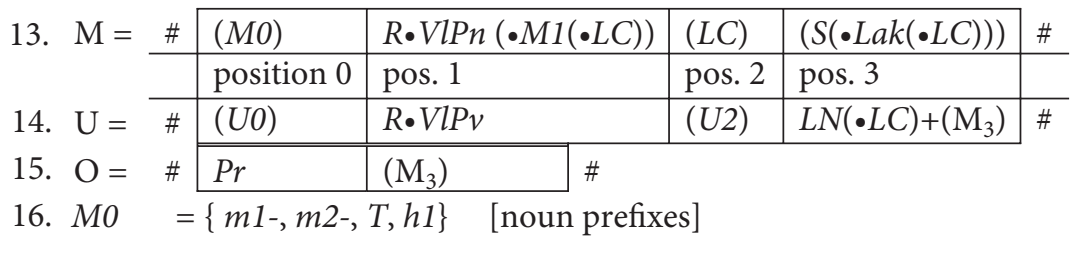

17. $L C=\{P, F\}$

[Def. 4, plural, feminine]

18. $U 0=\{h 1, h 2, N\}$ [verb prefixes,(passive, causitive, reflexive, etc.)]

19. $U 2=\{F t, m-\}$ [respectively, future and present tense]

20. $L n=\{L a k, L b k, L c\}$ $[1 \leq \mathrm{k} \leq 3$ ] [ $L a$ and $L b$, personal pronouns; $L c$, infinitive]

21. $M 1=\left\{\right.$ on, an $\left., i, e Y_{2}\right\}$ [noun suffixes]

22. $\operatorname{Pr}=\left\{b, l,{ }^{\prime} a l, m i N, \ldots\right\} \quad$ [a set of morphemes (prepositions) ...]

23. $\mathrm{N}_{\mathrm{n}}=\left\{\mathrm{M}_{0-2}, \mathrm{U}_{0-3}[\right.$ where $\left.U 2=m-, L n=L a]\right\}$

24. $\mathrm{V}_{2}=\left\{\mathrm{U}_{0-3}[\right.$ where $\left.U 0 \neq h 2, U 2=F t, U 3=L c]\right\}$

25. $\mathrm{V}_{1}=\{\mathrm{Va}, \mathrm{Vb}\}$ where $\quad \mathrm{Va}=\mathrm{U}_{0-2}$

$$
\mathrm{Vb}=\mathrm{U}_{0-3} \text {, and } L a 3 \text { occurs in pos. } 3
$$

$\mathrm{Va}$ and $\mathrm{Vb}$ are in complementary distribution, Va occurring in environment:

$$
\begin{aligned}
& \left\{\begin{array}{l}
L a \\
L b
\end{array}\right\} \text { 一, i.e., in ES when } \\
& \mathrm{ES}=\mathrm{NP} \mathrm{VP} \text { and } \mathrm{NP}=L a \text { or } L b
\end{aligned}
$$

28. A word is a sequence of morphemes enclosed by \# (i.e., in environment: \#-\#). Phrases and constructions (except for the long components) which are themselves morphemes (e.g., $L b 3, Z$ ) are words. $h a-\mathrm{U}$ and $h a-\mathrm{M}$ are words. ES must be represented completely in terms of words, i.e., no morpheme can occur which is not a word or part of a word. 


\section{Corresponding revisions:}

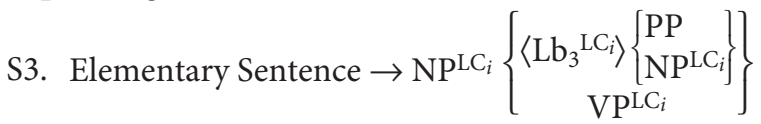

$$
[i=1, \ldots, 4]
$$

S4. $\mathrm{VP}^{\mathrm{LC}} i \rightarrow \mathrm{V}_{1}+\mathrm{LC}_{i}\left\langle\mathrm{~V}_{2}\right\rangle\left\langle\mathrm{V}_{2}\right\rangle \ldots\left\langle\mathrm{V}_{2}\right\rangle \mathrm{NP}^{\mathrm{LC}} \mathrm{C}_{j} \quad[\mathrm{j}=1, \ldots, 4]$

$\mathrm{S} 5 . \mathrm{PP} \rightarrow$ Preposition $+\mathrm{NP}^{\mathrm{LC}_{j}} \quad[\mathrm{j}=1, \ldots, 4]$

S6. $\left.\mathrm{NP}^{\mathrm{LC}} i=\left\{\left[\begin{array}{c}L a_{k} \\ L b_{k}\end{array}\right] \mathrm{LC}_{i}, \mathrm{Z}+\mathrm{LC}_{i},\left\{\begin{array}{c}\emptyset \\ \mathrm{N}_{1}+\mathrm{LC}_{i}+S\end{array}\right\} \delta\left\{\begin{array}{c}\mathrm{N}_{1}+\mathrm{LC}_{i} \\ \mathrm{~N}_{1}+\mathrm{LC}_{j} \\ L a_{k}\left(\mathrm{LC}_{n}\right)\end{array}\right\}\right\}\left\langle\delta \mathrm{N}_{2}+\mathrm{LC}_{q}\right\rangle\left\langle\delta \mathrm{Z}+\mathrm{LC}_{q}\right\rangle\right\}^{*}$ where (i) $\quad[j, n=1, \ldots, 4],[\mathrm{k}=1,2,3]$

(ii) $\quad q \rightarrow i\left[\right.$ or $j$ in env. $\left.\mathrm{LC}_{j} \ldots-\right]$

'..' does not extend outside of the NP

(iii) $\delta \rightarrow$ ha (or $\emptyset$ in env. $\left.\_\mathrm{N}_{1}\right) \dagger$

and all $\delta$ 's change simultaneously and identically since $\delta$ represents a long component.

(iv) $\quad \mathrm{ha} L a_{k} \rightarrow L a_{k}$

S13. LC $=\{\emptyset, F, P, F P\}$,

(v) $\mathrm{N}_{1}=\left\{\mathrm{N}_{1 \mathrm{a}}, \mathrm{N}_{1 \mathrm{~b}}\right\}$

where $\mathrm{LC}_{i} \rightarrow\left\{\begin{array}{c}P, \text { in env. a: } \mathrm{Y}_{2} \_ \\ F \text { or } P F \text { in env. u:__, and } \\ \mathrm{u}: \rightarrow \mathrm{u}: \mathrm{y} \text { in env. _ } P F\end{array}\right\}$

and if one $\mathrm{LC}_{i} \rightarrow \alpha$, then all instances of $\mathrm{LC}_{i}$ in the sentence $\rightarrow \alpha$. and $\mathrm{i} \rightarrow \emptyset$, sometimes, in env. $-P$.

S14. Z $\rightarrow\left\{\begin{array}{l}L p L a_{3} \text { in env. ha\# }\{\text {, sometimes } \\ \left\{\begin{array}{l}\text { zot in env. } \_F \\ \text { eyle in env._FP } F P\end{array}\right\} \text { and } F, P P \rightarrow \emptyset \\ \text { ze }\end{array}\right\}$

S15. $\mathrm{M}_{0}=\{\emptyset, m 1-, m 2, T-\}$

$\mathrm{U}_{0}=\{\emptyset, h-, N-, h-N-\}$

$\mathrm{U}_{2}=\{\emptyset, F t, m-\}$

(MMHb, 13-14, 16-17)

* Those morpheme designations which will appear in the morphology, and which are not given in morphophonemic spelling, will be underlined [italicized] to distinguish them clearly from sequences of morphophonemes.

$\dagger$ Common 'compound nouns' of the form $\mathrm{N}_{1} \mathrm{LCSN} \mathrm{N}_{1} \mathrm{LC}$ are often treated as a single $\mathrm{N}_{1}$, and the ha is prefixed to the first $\mathrm{N}_{1}$ rather than the second, giving forms like "habetséfer", "haxadar'óxel” instead of "bet haséfer" ('school'), “xadár ha'óxel” ('dining room').

$\neq$ I.e., if there is an $\mathrm{LC}_{i}$ in env. $\left[\begin{array}{c}\mathrm{a}: \mathrm{Y}_{2} \\ \mathrm{u}\end{array}\right]$, then $i \rightarrow\left[\begin{array}{c}3 \\ 2 \text { or } 4\end{array}\right]$ throughout. Thus all segments of any one long component become the same morpheme. 


\section{Illustration of the use of this syntactic system to analyze sentences into morphemes:}
A. 1. Let sentence $\Sigma=\mathrm{ES}$
2. $\mathrm{ES}=\mathrm{NP}_{1}{ }^{\mathrm{a}} \mathrm{VP}^{\mathrm{a}}+L C$
3. $L C=F$$$
\therefore \mathrm{ES}=\mathrm{NP}_{1}{ }^{\mathrm{a}} \mathrm{VP}^{\mathrm{a}}+F=\mathrm{NP}^{F} \mathrm{VP}^{F}
$$
4. $\mathrm{NP}_{1}=\mathrm{N}_{\mathrm{c}} ; \therefore \mathrm{NP}_{1} F=\mathrm{N}_{\mathrm{c}}+F$
5. $\mathrm{VP}=\mathrm{V}_{1} \mathrm{~V}_{2} ; \therefore \mathrm{VP}^{F}=\mathrm{V}_{1}{ }^{F} \mathrm{~V}_{2}$
6. $\mathrm{N}_{\mathrm{c}}=\operatorname{La2}$

$$
\therefore \Sigma=L a 2+F \mathrm{~V}_{1}^{F} \mathrm{~V}_{2}
$$
7. $\mathrm{V}_{2}=\# h 1+R \cdot V l P v+F t+L c \#$
8. $\mathrm{V}_{1}^{F}=\mathrm{Va}^{F}=\# R \bullet V l P v+F \#$
9. But, by 28 and comments following 22 , since $L a 2+F$ is not a word, it must fall in $\mathrm{U}_{3}$ of $\mathrm{V}_{1}$.

$$
\therefore \Sigma=\# R \cdot V l P v+L a 2 \cdot F \# \# h 1+R \cdot V l P v+F t+L c \#
$$
An example of A might be 'racít lhitraxéc' ('you (F) wanted to get washed').

It is now necessary to specify $R$ and $V l P$ in terms of morphemes. It is convenient to consider the morphophonemic statement as being initiated at this point, although there is no systematic break.

\section{3. Morphophonemics}

The roots $(R)$ and the vowel patterns $(V l P)$ are discontinuous morphemes. We will first define $R$ as a set of sequences of morpho<pho»nemes, each sequence having three members.

Let 'C' (with or without subscripts) be a variable ranging over elements of the following two sets:

i. $\mathrm{M}, \mathrm{f}, \mathrm{y}, \mathrm{x}$

ii. ', ', X, B, P, K, Y, N, g, d, h, v, z, t, l, m, n, s, c, k, r, š

$R=\{C C C\}$, where ' $C$ ' ranges over elements of (ii).

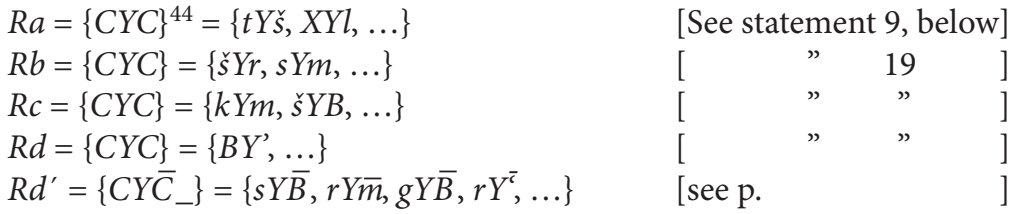

$R d^{\prime} \subset R d$. $R b, R c, R d$ are disjoint, and their union is $\{C Y C\}$.

- is a morphophoneme characteristic of some roots (those of $R d^{\prime}$, where it occurs with the third consonant) and of some vowel patterns (see below).

44. Levi (1972, 5-6 with nn. 3-4) identifies $R a$ as a noun pattern, $R b$ as verbs of the sam/ yasim pattern, $R c$ as kam/yakum, and $R d$ as ba/yavo. $R d^{\prime}$ appears to be a group of anomalous verbs and does not reappear in the rules. (Perhaps this accounts for the missing cross reference at $R d^{\prime}$-PTD.) [I found Levi's work in my papers after completion of this article.] 


\section{Illustration of the representation of a sentence in terms of morphemes} by development of the syntactic statements:

A. 1. Sentence

2. Elementary Sentence

3. $\mathrm{NP}^{\mathrm{LC}_{2}}+\mathrm{VP}^{\mathrm{LC}} 2$

4. $\mathrm{NP}^{\mathrm{LC}_{2}}+\mathrm{V}_{1}+\mathrm{LC}_{2}+\mathrm{V}_{2}$

5. $L a_{2}+\mathrm{LC}_{2}+\mathrm{V}_{1}+\mathrm{LC}_{2}+\mathrm{V}_{2}$

6. $\mathrm{V}_{1}+L a_{2}+\mathrm{LC}_{2}+\mathrm{V}_{2}$

7. $\# \mathrm{~V}_{1}+L a_{2}+\mathrm{LC}_{2} \# \# \mathrm{~V}_{2} \#$

8. $\# \mathrm{U}_{0}+\mathrm{R}+\mathrm{VlP}_{2}+\mathrm{U}_{1}+L a_{2}+\mathrm{LC}_{2} \# \# \mathrm{U}_{0}+\mathrm{R}+\mathrm{VlP}_{2}+F t+L c \#$

9. $\# \mathrm{U}_{0}+\mathrm{R}+\mathrm{VlP}_{2}+\mathrm{U}_{1}+L a_{2}+F \# \# \mathrm{U}_{0}+\mathrm{R}+\mathrm{VlP}_{2}+F t+L c \#$

10. $\# \mathrm{R}+\mathrm{VlP}_{2}+\mathrm{U}_{1}+L a_{2}+F \# \# h-+R+\mathrm{VlP}_{2}+F t+L c$

An example, filling in actual roots and vowel patterns, might be "racít lhitraxéc" ('you(F) wanted to get washed').

$(\mathrm{MMHb}, 18)$

Leading up to the analysis of roots and vowel patterns, we list several classes of morphophonemes, which will also be referred to later on.

S18. Let $\mathrm{G}=\{, ;, \mathrm{X}, \mathrm{h}\}$

$$
\begin{aligned}
& \mathrm{L}=\{, \mathrm{t}, \mathrm{n}, \mathrm{y}\}^{*} \\
& \mathrm{G}^{+}=\mathrm{G} \cup\{\mathrm{r}\}
\end{aligned}
$$

$\mathrm{L}^{+}=\mathrm{L} \cup\{1\}^{*}$

$\mathrm{C}^{\mathrm{R}}=\mathrm{G}^{+} \cup \mathrm{L}^{+} \cup\left\{\mathrm{B}, \mathrm{P}, \mathrm{K}, \mathrm{d}, \mathrm{k}, \mathrm{g}, \mathrm{v}, \mathrm{s}, \mathrm{z}, \mathrm{s}, \mathrm{c}, \mathrm{m}, \mathrm{N}, \mathrm{Y}_{1}, \mathrm{Y}_{2}, \mathrm{Y}_{3}\right\}$

$\mathrm{C}=\mathrm{C}^{\mathrm{R}} \cup\{\mathrm{M}, \mathrm{b}, \mathrm{p}, \mathrm{f}, \mathrm{x}, \mathrm{:}\}$

$\mathrm{V}=\left\{\mathrm{V}_{0}, \dot{\mathrm{V}}_{0}, \stackrel{\mathrm{V}}{0}_{0}:\right\}$, where $\mathrm{V}_{0}=\{\mathrm{i}, \mathrm{e}, \mathrm{a}, \mathrm{o}, \mathrm{u}\}$

S19. $\quad \mathrm{R} \rightarrow \mathrm{C}^{\mathrm{R}}{ }_{1} \mathrm{C}_{2}^{\mathrm{R}} \mathrm{C}_{3}^{\mathrm{R}}{ }_{3}\left(\right.$ : , sometimes, if $\left.\mathrm{C}_{2}=\mathrm{Y}_{2}\right)$

$$
\begin{aligned}
& \mathrm{Ra}=\{\check{s} Y r, \text { šYm, ... }\} \text {, all of form CYC } \\
& \mathrm{Rb}=\{\mathrm{kYm}, \check{s} \mathrm{YB}, \ldots\}, " \text { ” " }, \\
& \mathrm{Rc}=\{\mathrm{zYt}, 1 \mathrm{Yl}, \ldots\}, \quad \text { ” }, \quad \text { ” } \\
& \mathrm{Rd}=\left\{\text { šmr, KtB, ’sP, ... If } \mathrm{C}_{1}=\mathrm{Y}_{1}, \mathrm{R} \in \mathrm{Rd}\right.
\end{aligned}
$$

[see MR1]

[see MR2]

* Designated 'L' because these are the forms taken by $L a_{k}$ in certain positions. $L c \rightarrow 1$ (see MR4). 


$$
\begin{aligned}
& R e=\left\{y \check{s}^{\prime}, y r^{\prime}, m l^{\prime}, K B d, \ldots\right\} \\
& \text { [statement 20ii, 32vi] } \\
& R f=\{\check{s} m r, g m r, K t B, ' s P, \ldots\} \\
& R e \cap R f=\Lambda \text {, i.e., } R e \subset R g(R e \text { is a subset of } R g) \\
& R g=R-R f \\
& \text { [statement 30i, 32xi, 36iii] } \\
& R h=\{s P r, d g l, k r B, \ldots\} \\
& \text { [statement 28i] } \\
& R i=R-R h \\
& R j=\{m s ̌ l, X k r, r k z, l c r, \ldots\}
\end{aligned}
$$

The vowel patterns are single- or bi-vocalic discontinuous sequences made up of elements of the following set:

(i) i, e, a, o, u

' $\mathrm{V}$ ' is a variable ranging over these five elements.

In addition, each vowel pattern contains once the element' (accent).

(MMHa, 18-20)

\section{Grammatical statements:}

2. $\mathrm{C}_{1} \mathrm{C}_{2} \mathrm{C}_{3} \bullet . . V_{1} . . V_{2} . . \rightarrow \mathrm{C}_{1} \mathrm{~V}_{1} \mathrm{C}_{2} \mathrm{~V}_{2} \mathrm{C}_{3}$

3. (i) $L b k \rightarrow L a k$ and prefixation to $U$ of $\# L p \cdot L a k \bullet\left(\left\{\begin{array}{c}P \bullet F \\ P \\ F\end{array}\right\}\right) \#$

(ii) $\quad L b k \rightarrow L p L a k$

$$
\text { in env.: } \left.\mathrm{U},-\left(\left\{\begin{array}{c}
P \bullet F \\
P \\
F
\end{array}\right\}\right)\right\}[1 \leq \mathrm{k} \leq 3]
$$

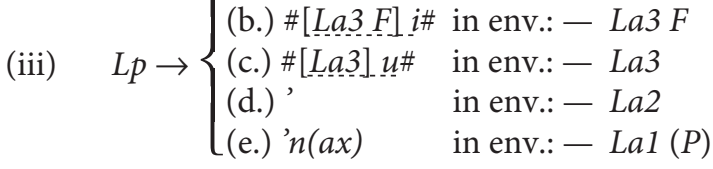

7. (i) $\quad$ Lal $\rightarrow i$

$$
\text { and } i \rightarrow\left\{\begin{array}{l}
n \text { in env.: }-P \\
\text { in in env.: }-R \\
t i \text { in env: } \mathrm{U}, R-
\end{array}\right.
$$

(ii) $\quad \mathrm{La} 2 \rightarrow \mathrm{ta}$

and $\quad \mathrm{a} \rightarrow \emptyset$ in env.: $-\left\{\begin{array}{c}R \\ L c\end{array}\right\}$

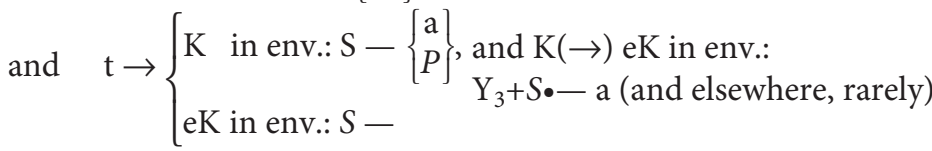


$\mathrm{Re}=\mathrm{R}-\mathrm{Rd}$; i.e., all members of $\mathrm{R}$ except those in $\mathrm{Rd}$

[see MR24]

If $C_{1}=y$, then $R \in R e$

If $\mathrm{C}_{2}=\mathrm{G}$, then $\mathrm{R} \in \mathrm{Re}$ (except, sometimes, when $\mathrm{C}_{2}=\mathrm{X}$, e.g., $\mathrm{mXk}, \mathrm{dXP}$ )

If $\mathrm{C}_{3}=\mathrm{G}$, then $\mathrm{R} \in \mathrm{Re}$ (unless $\mathrm{C}_{1}=\mathrm{Y}_{1}$ )

$\mathrm{Re}^{\prime}=\left(\mathrm{yšn}, \mathrm{yr} \mathbf{r}^{\prime}, \mathrm{ml}, \mathrm{KBd}, \ldots\right)$

[see MR1]

$\mathrm{Re}^{\prime}$ is a subset of $\operatorname{Re} \dagger$

$\mathrm{Re}^{\prime \prime}=\left\{\mathrm{mr},{ }^{\prime} \mathrm{Bd},{ }^{\prime} \mathrm{Kl},{ }^{\prime} \mathrm{BY}_{3},{ }^{\prime} \mathrm{PY}_{3}\right\}$, all of the form 'CC.

[see MR27]

$\mathrm{Re}^{\prime \prime}$ is a subset of $\mathrm{Re}$

$\mathrm{Rf}=\left\{\mathrm{KnP},{ }^{\prime} \mathrm{nP}, \mathrm{XBr}, \ldots\right\}$

[see MR26]

$\mathrm{Rg}=\{$ mšl $, \mathrm{Xkr}, \mathrm{rkz}, \mathrm{lcr}, \ldots\}$, mostly with $\mathrm{C}_{1}=1, \mathrm{r}, \mathrm{X}$.

[see MR24]

Vowel patterns are single or bi-vocalic discontinuous sequences of elements in the range of $\mathrm{V}$. The final vowel of each is accented.

(MMHb, 19-21)

\section{Grammatical statements:}

MR3. $\mathrm{C}_{1} \mathrm{C}_{2} \mathrm{C}_{3}\left\{\begin{array}{c}: \\ -\end{array}\right\}+\mathrm{Q}_{1}-(:) \mathrm{Q}_{2}\left[\begin{array}{c}: \\ -\end{array}\right] \rightarrow \mathrm{C}_{1} \mathrm{Q}_{1} \mathrm{C}_{2}(:) \mathrm{Q}_{2} \mathrm{C}_{3}\{:\}\left[\begin{array}{c}: \\ -\end{array}\right]$

and $:: \rightarrow: \quad$ where $\mathrm{Q}_{i}=\mathrm{V}_{i}$ or $\emptyset(i=1,2)$

MR7. $L p \rightarrow\left\{\begin{array}{l}\left\{\begin{array}{l}\mathrm{e} \\ \mathrm{i} \\ \mathrm{u}\end{array}\right\} \\ ,\left[\left[\begin{array}{l}\left.L a_{2}\right](\mathrm{e}) \\ \mathrm{n}(\mathrm{ax})\left[L a_{1}\right]\end{array}\right\}\right.\end{array}\right\}$ in env. $\left.\left\{\begin{array}{l}L a_{3}-\left\{\begin{array}{c}P \\ F \\ -\end{array}\right\} \\ \left\{L a_{2}\right\} \\ \left.L a_{1}\right\}-(+P)\end{array}\right\}\right)$

MR10.

(1)

(2) $\quad L a_{2} \rightarrow$ ta, and

$$
L a_{1} \rightarrow\left\{\begin{array}{l}
\mathrm{n} \text { in env. } \ldots . . . P \\
\text { in env. _.... } \mathrm{C}_{1} \\
{\left[\begin{array}{l}
\mathrm{t} \\
-
\end{array}\right] \text { i in env. }\left[\begin{array}{c}
\mathrm{U} \\
-
\end{array}\right]}
\end{array}\right\}
$$

$a \rightarrow \emptyset$ in env.

$\mathrm{t} \rightarrow(\mathrm{e}) \mathrm{x}$ in env. $S$

(a) (sometimes, but not in env. P..__)

(3) $\quad L a_{3} \rightarrow \mathrm{h}$, and

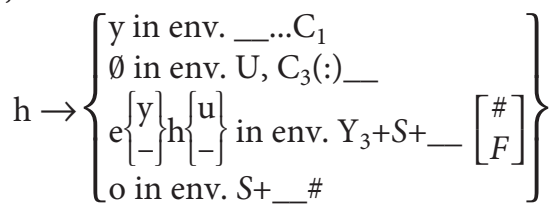

$\dagger$ It is apparently disappearing as a separate subset, partly through analogy (yašán, yošén-see MR1), partly through disuse in the distinctive forms (as verbs). 
(iii) $\quad L a 3 \rightarrow h$

and $h \rightarrow\left\{\begin{array}{lll}y & \text { in env.: } & -R \\ \emptyset & \text { in env.: } & \mathrm{U}, R- \\ e h(u) & \text { in env.: } & . . \mathrm{Y}_{3}+S \bullet-\{(\#) \\ \bullet & \text { in env.: } & S \bullet-\#\end{array}\right\}$ - \#

12. $P \rightarrow\left\{\begin{array}{l}i m \cdot A \text { in env.: }\left\{\begin{array}{l}\alpha \\ \beta\end{array}\right\} \text { and } \mathrm{e}_{2} \rightarrow \text { a in env.: } C V^{\prime} C-C \\ e m \text {, and } e m \rightarrow u \text { in env.: }\left\{\begin{array}{l}\mathrm{n} \\ \mathrm{C}_{3}\end{array}\right\}-\end{array}\right.$

14. $\left\{\begin{array}{l}\text { (i) } \\ (\text { ii) }\end{array}\right\} \mathrm{V}_{\mathrm{k}} \rightarrow \emptyset$ in env.: $\mathrm{M},\left\{\begin{array}{l}\mathrm{C}_{1}-\mathrm{C}_{2} \mathrm{VC}_{3} /+i m \\ \ldots \sqcup \ldots\left[\begin{array}{c}\mathrm{M} 1 \\ +/ F\end{array}\right]\end{array}\right\} \bullet A[\mathrm{k}=1,2]$

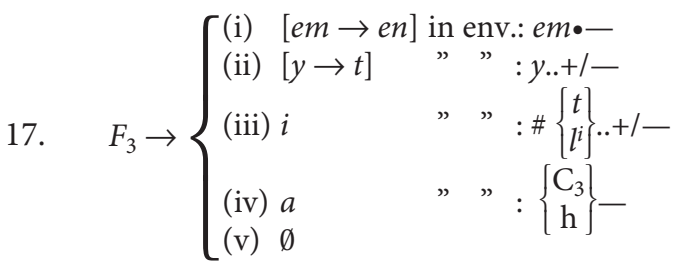

20. (i) $\quad$..a..á.. $\rightarrow$..ā..é.. in env.: $\left\{\begin{array}{c}\# l \# \\ \mathrm{~L}\end{array}\right\}+N+-$

(ii) $\quad$. a..á.. $\left.\rightarrow . .\left\{\begin{array}{l}a \\ \bar{o}\end{array}\right\} . * \begin{array}{l}\bar{e} \\ e\end{array}\right\} .$. in env.: $m /+\left\{\begin{array}{l}C_{a}-C_{b}-C_{c} \\ C_{1--}-C_{2}-C_{3}\end{array}\right\}$ where $C_{a} C_{b} C_{c} \in R e$

(iii) $\quad$..i..é.. $\rightarrow$..u...á.. in env.: $h 2+-$

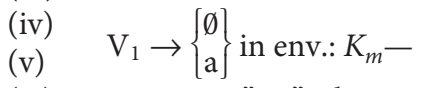

(vi) $\mathrm{a}_{2} \rightarrow \mathrm{i} \quad$ " $: h 1+. .-$

(vii) $\mathrm{V}_{2} \rightarrow \mathrm{a} \quad " \quad \cdots:-\mathrm{C}_{3}+\left\{\begin{array}{l}\mathrm{t} \\ \mathrm{n}\end{array}\right\}$

(viii) $\quad \mathrm{a}_{2} \rightarrow \overline{\mathrm{a}} \quad$ in env.: $m+$.. -

(ix) (a.) $\mathrm{V}_{2} \rightarrow \emptyset \quad$ " " : U, -

(b.) $\left.e_{2} \mathrm{Q} \emptyset \quad " \quad \cdots: \mathrm{M}, \mathrm{CC}-\right\} \mathrm{C}_{3}+\left(S_{\bullet}\right) \mathrm{Wj}$

where $\mathrm{Wj} \neq \mathrm{e}$ of $\breve{e} t$

and $\quad \mathrm{Q} \rightarrow \begin{cases}\rightarrow \text { when } \mathrm{e}_{2} \text { is in env.: } & \left.\begin{array}{l}\overline{\mathrm{C}} \\ \mathrm{NC}\end{array}\right\}- \\ \emptyset \quad, \quad, \quad \cdots \quad ":\left\{\begin{array}{l}\# \mathrm{C}_{1} \mathrm{C}_{2}- \\ -\mathrm{C}_{3} \mathrm{C} \\ h 1 . .-\end{array}\right\} \\ (\rightarrow) \text { elsewhere }\end{cases}$

$(\mathrm{x}) \quad \mathrm{a}_{2} \rightarrow$ o in env.: $\left\{\begin{array}{l}l+/ R \\ \mathrm{~L}+/ R f\end{array}\right\}-\left\{\right.$ unless $l=l^{\mathrm{i}}$ and $\left.\mathrm{C}_{3}=\left[\begin{array}{c}\prime \\ \mathrm{x} \\ \mathrm{X}\end{array}\right]\right\}$

* ehu may be eyhu in some dialects. 
MR12. $\emptyset \rightarrow\left\{\begin{array}{c}: \\ -\end{array}\right\}\left[\begin{array}{c}- \\ \left(\mathrm{Y}_{3}\right)\end{array}\right]$ in env. $\mathrm{C}_{2} \mathrm{C}_{3}\left\{\begin{array}{l}\mathrm{o}: \mathrm{n} \#, \mathrm{~V}_{1}=1 \text {, sometimes } \\ P(F, \text { sometimes })\end{array}\right\}$

where $\mathrm{R} \notin \mathrm{Rc}$

and if $\left[\begin{array}{l}\mathrm{C}_{1}=\mathrm{G} \\ \mathrm{C}_{3}=\mathrm{Y}_{3}\end{array}\right], \mathrm{V}_{1}=$ ó, then $\mathrm{V}_{1} \rightarrow \mathrm{V}_{1}:\left[\begin{array}{l}- \\ \text { sometimes }\end{array}\right]$

and $\mathrm{Y}_{2} \rightarrow \mathrm{y}$, sometimes

and $\mathrm{aY}_{3} \mathrm{C}_{3} \rightarrow \mathrm{C}_{3} \mathrm{a}: \mathrm{Y}_{3}$, sometimes

MR12' $P \rightarrow\left(\right.$ i) W(A, in env. $\mathrm{M}^{+}$, except in env. $\left.\left\{\begin{array}{l}\mathrm{Y}_{2} \\ \mathrm{~S}_{\ldots}\end{array}\right\}-\right)$ and $\mathrm{W} \rightarrow\left[\begin{array}{l}\mathrm{u} \text { in env. }\left[\mathrm{C}_{3}{ }_{3}\langle:\rangle\right] \\ \mathrm{m}\end{array}\right]$

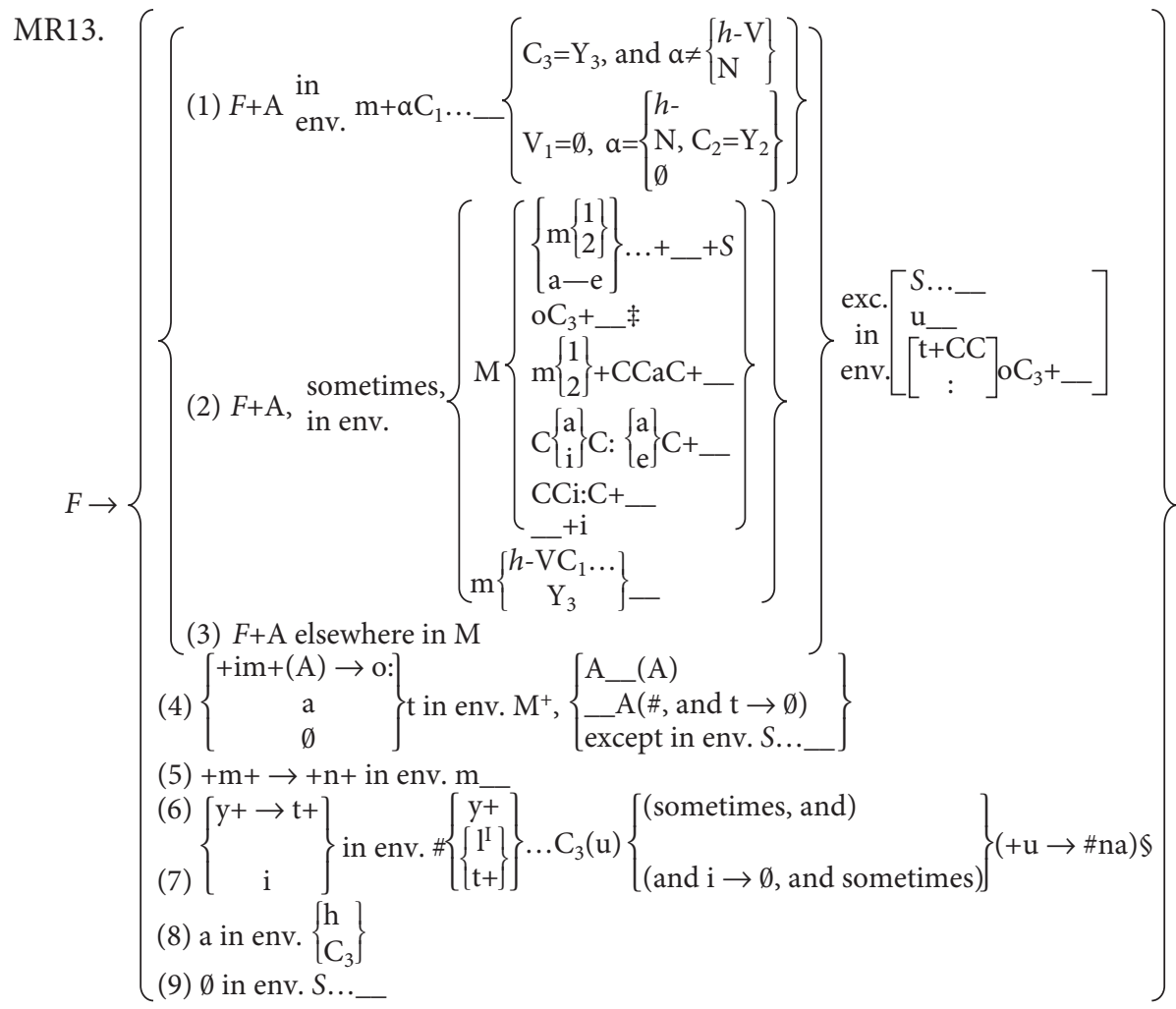

‡ Also in env. $\mathrm{uC}_{3}$ _ in the case of the quadriliteral 'šmr, giving "ašmurá" alongside of "ašmóret".

$\S$ The parenthesized transformation, when applied, leads to the rare and apparently disappearing second and third person feminine plural "tiCCóCna", etc., in Verb Future. In addition,

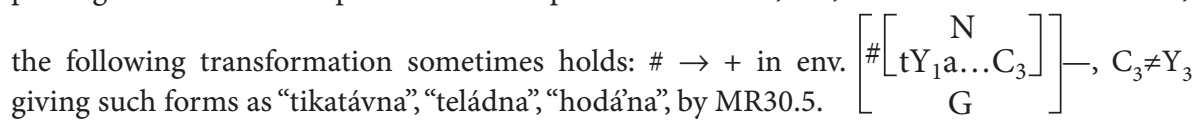


22. (i) $\left\{\begin{array}{l}N \\ h 1\end{array}\right\} \rightarrow\left\{\begin{array}{l}n \\ h\end{array}\right\} t$ in env.: $-+\mathrm{C}_{1} \mathrm{a} \overline{\mathrm{C}}$, and $\mathrm{Q}$ (see below), and $n \rightarrow h$ in env.: \#l\#-

$$
\begin{aligned}
& \text { and } \mathrm{td} \rightarrow \overline{\mathrm{d}} \dagger \\
& \quad " \mathrm{tz} \rightarrow \mathrm{t}\left\{\begin{array}{l}
\mathrm{s} \\
\mathrm{s} \\
\mathrm{c}
\end{array}\right\} \rightarrow\left\{\begin{array}{l}
\mathrm{s} \\
\mathrm{s} \\
\mathrm{c}
\end{array}\right\} \mathrm{t}
\end{aligned}
$$

(ii) $N \rightarrow h N$ in env.: \#l\#-, and Q

(iii) $h 1 \rightarrow h$, and Q

(iv) $h 2 \rightarrow\left\{\begin{array}{l}h o \\ h u\end{array}\right\}$ in env.: $-\mathrm{CC}$, and Q

(v) $h 2 \rightarrow \emptyset$

$$
\text { [always } h u \text { when } \mathrm{C}_{1}=\left\{\begin{array}{l}
\mathrm{N} \\
\mathrm{Y}
\end{array}\right\} \text { or } \mathrm{C}_{2}=\mathrm{Y} \text { ] }
$$

$$
\mathrm{Q}=\left\{\begin{array}{l}
\mathrm{h} \\
\mathrm{n}
\end{array}\right\} \rightarrow \emptyset \text { in env.: \#C- }
$$

25. $\ldots \mathrm{V}_{\mathrm{k}} \ldots \bullet A \rightarrow \ldots \mathrm{V}_{\mathrm{k}} \ldots$

26.

(i) $\left[\begin{array}{c}\underline{\mathrm{V}}_{2} \rightarrow \overline{\mathrm{V}}_{2} \\ \overline{\overline{\mathrm{o}}}_{1}(\rightarrow) \mathrm{o}_{1}\end{array}\right]$ in env.: $-\bullet\left\{\begin{array}{l}\left\{\begin{array}{c}\mathrm{e} m \\ \mathrm{im}\end{array}\right\}+S \ldots \mathrm{W}_{\mathrm{k}} \# \\ \mathrm{im} \\ \mathrm{ot}\end{array}\right\} \#$,

where $\mathrm{W}_{\mathrm{k}}=\mathrm{V}$ or $\mathrm{K}$

(ii) $\mathrm{V}_{\mathrm{k}}(\rightarrow) \emptyset$ in env.: $\left\{\begin{array}{l}\mathrm{C} \\ \mathrm{o}\end{array}\right\} \mathrm{C}-\mathrm{CV} \ldots+\mathrm{S}$

where ' $\mathrm{V}_{\mathrm{k}} \rightarrow \emptyset$ ' generally holds in env.: $-\bullet\left[\begin{array}{l}{\left[\begin{array}{l}i m \\ o t\end{array}\right]+S \#} \\ S \bullet K_{m}\end{array}\right]$

but where ' $\mathrm{Vk} \rightarrow \emptyset$ ' often does not hold in env.: $\mathrm{C}_{0} \bullet-$

(iii) $\breve{\mathrm{V}}_{\mathrm{k}} \rightarrow \emptyset$ in env.:..$- S$

$$
\text { unless } \mathrm{V}_{\mathrm{k}} \text { is ĕ of } \breve{e} m \text { or is final V of word }
$$

(iv) $\mathrm{C}_{\mathrm{k}}$ á $\rightarrow \mathrm{C}_{\mathrm{k}}$ át in env.: $-\mathrm{S}$

$$
\text { where } \mathrm{k}=3 \text { or } \mathrm{C}_{\mathrm{k}} \text { is } \mathrm{C} \text { of } M 1
$$

(v) $\left\{\begin{array}{c}\bullet e m+ \\ +i m+\end{array}\right\} S \rightarrow$ éy in env.: -\#

$\left.\begin{array}{c}\left.\text { (vi) }\left(\left[\begin{array}{c}e m \\ i m\end{array}\right]\right)+S \rightarrow \text { éy in env.: }\left\{\begin{array}{c}\left\{\begin{array}{c}\mathrm{W}_{\mathrm{k}} \\ o t\end{array}\right\}-\mathrm{nu} \\ \left(\mathrm{W}_{\mathrm{k}}\right) \\ o t\end{array}\right\}-\ldots \mathrm{C}_{\mathrm{k}} \#\right\} \\ \text { where } \mathrm{C}_{\mathrm{k}}=\mathrm{m} \text { or } \mathrm{n} \\ \text { (vii) }\left(\left\{\begin{array}{c}e m \\ i m\end{array}\right\}\right)+S \rightarrow \text { éY } \mathrm{Y}_{2} \text { in env.: }\left\{\begin{array}{c}\left(\mathrm{W}_{\mathrm{k}}\right) \\ o t\end{array}\right\}-K_{m} \mathrm{~W}_{\mathrm{k}} \text { is in pos. } 1\end{array}\right\}$

(viii) $S_{\bullet} . . V_{j} . . \rightarrow S_{\bullet} . . V^{\prime} j .$. , where $V j$ is first $V$ after $S$

$\dagger \quad$ May be td, dd, or may vary. The facts are not clear.

$\ddagger$ ey may be e in some dialects. 


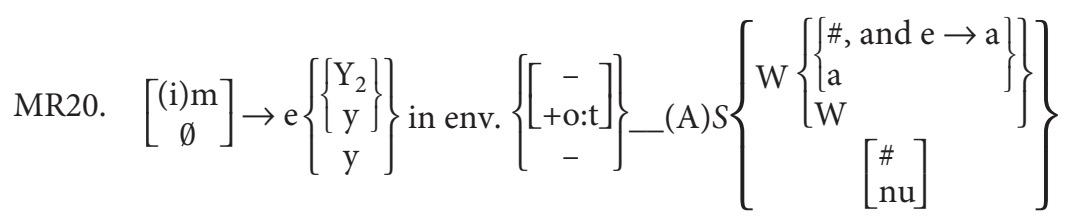

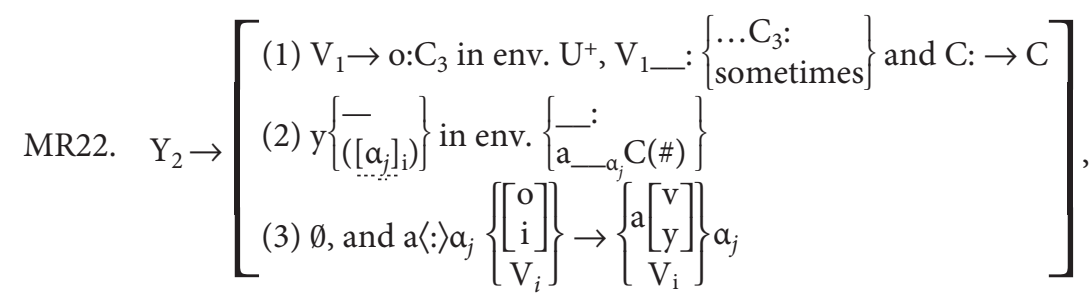
$a_{j}=\emptyset\langle\mathrm{A}\rangle\langle S\rangle$

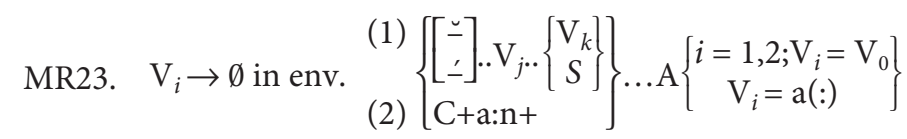

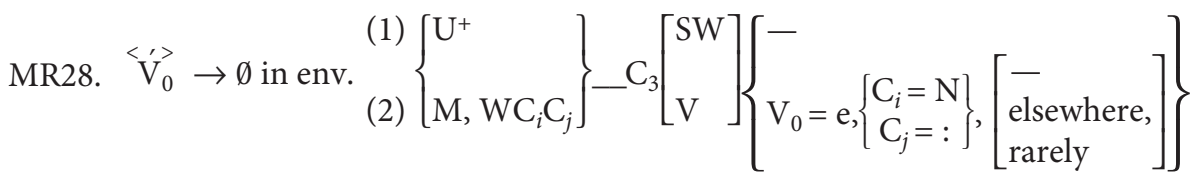


$(\mathrm{ix}) \quad h(\mathrm{e}) \rightarrow \emptyset($ á$)$ in env.: $S-\left\{\left(\begin{array}{c}\mathrm{a} \\ \mathrm{m} \\ \mathrm{n}\end{array}\right)\right.$
$(\mathrm{x}) \quad S \rightarrow \emptyset$

30. Intrusion of $i$

(i) $\mathrm{L}^{\prime} \frac{\mathrm{Y}_{1}}{\mathrm{C}}(\mathrm{V}) \mathrm{C}$, where $\mathrm{Y}_{1} \mathrm{CC} \in R g$

(ii) $\quad \# \mathrm{C}-\mathrm{C}_{\mathrm{k}} \mathrm{C}$, where $\mathrm{C}_{\mathrm{k}} \neq \mathrm{Y}_{2}$

(iii) $\mathrm{C}-\mathrm{eC}$

32. Intrusion of è sometimes e in (i)

(i) In $\mathrm{U}, \#\left\{\begin{array}{l}\mathrm{h} \\ \mathrm{m}\end{array}\right\} \overline{\mathrm{a}} \mathrm{CY}_{2}$, except in env.: -...ó

(ii) $(l+h a C) C_{2}-\left\{\begin{array}{l}\overline{\mathrm{C}}_{3} \\ \left(\mathrm{C}_{3} \#\right)\end{array}\right\}$, (sometimes) $\left\{\right.$ where $\left.\mathrm{C}_{2}=\mathrm{Y}_{2}\right\}$

(iii) $\quad \mathrm{m}_{\mathrm{i}} \mathrm{CC}(\mathrm{a}) \mathrm{C}$, where $\mathrm{CCC} \in R j$

(iv) $\overline{\mathrm{i}}\left\{\begin{array}{l}\overline{\mathrm{C}}_{\mathrm{k}} \\ \mathrm{NC}_{\mathrm{k}}\end{array}\right\}$, where $\mathrm{N} \neq \mathrm{C}_{1}$

$$
\text { and where } \mathrm{C}_{\mathrm{k}}=\left[\begin{array}{c}
\mathrm{X} \\
\mathrm{r} \\
\mathrm{h}
\end{array}\right]
$$

(v) $\quad \mathrm{L}_{\mathrm{i}}^{\prime} \mathrm{Y}_{1} \mathrm{C}\left(\frac{-}{\mathrm{o}}\right) \mathrm{C}$

(vi) $\quad\left\{\begin{array}{l}\mathrm{CV} \\ \mathrm{VC}\end{array}\right\} \mathrm{C}-\overline{\mathrm{a}}^{\prime} \mathrm{C}$, where $\mathrm{CC}^{\prime} \in\left\{\begin{array}{l}\mathrm{Re} \\ \mathrm{R}\end{array}\right\}$

(vii) $\overline{\mathrm{e}} \mathrm{e}$

(viii) $\left\{\begin{array}{l}\text { i } \\ \text { a }\end{array}\right\}$

(ix) $\quad \frac{}{\mathrm{i}}-\mathrm{C}$

(x) $\left.\left\{\begin{array}{l}\mathrm{h} \\ \mathrm{N}\end{array}\right\} \overline{\mathrm{i}}\left[\begin{array}{l}\mathrm{X}(-) \\ \mathrm{c} \\ \mathrm{h}\end{array}\right]-\right] \mathrm{C}_{2}$, except in env.: $\mathrm{Ni}^{\prime} \ldots \mathrm{Y}_{3}$.

(xi) In $\mathrm{U}, \mathrm{L}-\frac{\mathrm{h}-}{\mathrm{i}}\left\{\begin{array}{c}\mathrm{X}(-)\end{array}\right\} \mathrm{C}_{2}(\mathrm{~V}) \mathrm{C}_{3}$, where $C C_{2} C_{3} \in R g$

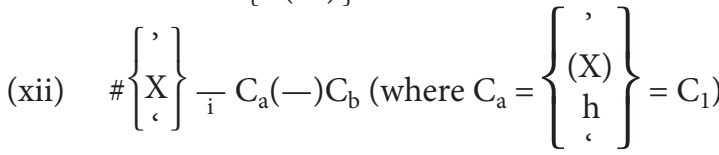

except where (a.) $a=b=2$

$\left.\begin{array}{l}\text { (b.) } \quad \mathrm{a}=2 \\ \text { (c.) } \\ \mathrm{a}=\mathrm{b}\end{array}\right\}$ sometimes

(xiii) In $\mathrm{M}, \# \mathrm{~h}-\mathrm{C}_{1} \mathrm{C}\left\{\begin{array}{c}\mathrm{V} \\ (-)\end{array}\right\} \mathrm{C}\left\{\begin{array}{l}\# \\ \mathrm{Wj}\end{array}\right\}$, where $\mathrm{Wj} \neq \mathrm{a}$, ó [of ót 
MR30. Intrusion of $a$

(1) $\mathrm{W}_{i} \rightarrow \mathrm{G}\langle:\rangle(\mathrm{SA}) \#, \mathrm{~W}_{i} \neq \mathrm{a}, \mathrm{G} \neq{ }^{\prime}$

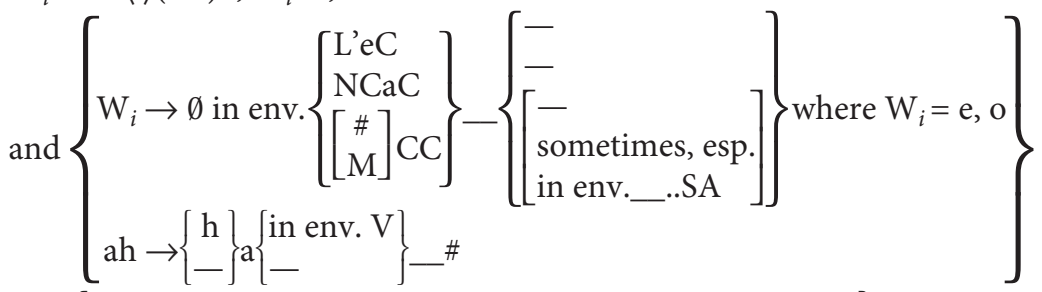

(2) $m- \begin{cases}\mathrm{NC}_{2} & \\ \mathrm{X}\left(\_\right) \mathrm{C}_{2} \ldots, & \text { where ... does not contain } \mathrm{C}_{3} \\ & \text { (but does not hold sometimes in env. }\end{cases}$

(3) \#G_C

(4) $\mathrm{l}+\frac{-}{\mathrm{e}} \mathrm{C}_{2}$

(5) In $U, \frac{i}{\mathrm{~V}_{2}} \mathrm{C}_{3}\left[\begin{array}{l}\mathrm{t} \\ \mathrm{n}\end{array}\right]$

(6) $\left\{\begin{array}{c}\frac{\left\langle^{\prime}\right\rangle}{\mathrm{V}_{j}} \\ \mathrm{~W}\end{array}\right\} \ldots \mathrm{G}\left\{\begin{array}{c}- \\ \langle:\rangle\end{array}\right\} \ldots-\mathrm{C}_{\mathrm{k}},{ }^{*}$ where $\ldots$ contains no W, $\mathrm{G}=\mathrm{C}_{3}$ only in $\mathrm{M}^{+}$or $\mathrm{l}+\ldots \ldots$

MR31. $S(\mathrm{~A}) \rightarrow \emptyset$ (in env.

MR33. $\left\{\begin{array}{c}\mathrm{I}(\mathrm{V}) \\ F\end{array}\right\} \rightarrow \emptyset$

* Only sometimes in env. X_. This is a complex and perhaps fluctuating situation which requires further investigation for a complete specification, although it could be given more explicitly than this.Apparently never in $\mathrm{M}$ except in env. _ $\mathrm{C}_{3} \#$.

$\dagger$ [text reference missing] Except when $\mathrm{R}=\mathrm{r}^{\text {'}} \mathrm{Y}_{3}$, which occurs in this form as "her'a', etc.

‡ Exceptions to (6) are "bóhen", “'óhel”, "léxem", "réxem", and forms from the root hyY (e.g., "yihyé"). "mixyá", "yixyé", etc., can be derived from the root $\mathrm{xyY}_{3}(\mathrm{x} \notin \mathrm{G})$. 
33. (i) In $\mathrm{U}, \overline{\mathrm{Y}}_{2}(\rightarrow)\left[\mathrm{V}_{1} \rightarrow \overline{\overline{\mathrm{o}}}_{3}\right]$

(ii) $\quad \overline{\mathrm{Y}}_{2} \rightarrow \mathrm{y}$

(iii) $\mathrm{éY}_{2} \breve{\mathrm{e}}_{\mathrm{k}} \rightarrow$ áyĭ $\mathrm{C}_{\mathrm{k}}$

(iv) $\quad \mathrm{Y}_{2} \rightarrow \emptyset$ and ei $\rightarrow$ ay, and eo $\rightarrow$ av

37. $\left\{\begin{array}{c}\mathrm{X} \\ \mathrm{x} \\ \mathrm{M}\end{array}\right\} \rightarrow\left\{\begin{array}{c}\mathrm{x} \\ , \\ \mathrm{m}\end{array}\right\}$

39. (i) $\left\{\begin{array}{l}B \\ P \\ K\end{array}\right\} \rightarrow\left\{\begin{array}{l}b \\ p \\ k\end{array}\right\}$ in env.: $\left[\begin{array}{c}=W \\ V C_{j}\end{array}\right]-$, where $j=0,1$

(ii) $\quad\left\{\begin{array}{l}\mathrm{B} \\ \mathrm{P} \\ \mathrm{K}\end{array}\right\} \rightarrow\left\{\begin{array}{l}\mathrm{v} \\ \mathrm{f} \\ \mathrm{x}\end{array}\right\}$

40. (i) $\quad \mathrm{V} \rightarrow \phi$ in env.: $-\mathrm{CV} . . . \mathrm{V}$, unless this would form \#CCC..

(ii) $\quad$ V $\rightarrow V^{\prime}$

(iii) $\quad \dot{V} \rightarrow \breve{V}$ in env.: $-\ldots \dot{V}$

(iv) $\left\{\left[\begin{array}{c}\mathrm{o} \\ (\mathrm{a})\end{array}\right]\right\} \rightarrow\left\{\begin{array}{c}\tilde{\mathrm{u}} \\ \mathrm{i}\end{array}\right\}$ in env.: $-\overline{\mathrm{C}}_{\mathrm{j}} \mathrm{W}$

$$
\text { where } C_{j} \neq\left[\begin{array}{l}
\cdot \\
r \\
x
\end{array}\right]
$$

(v) $\quad \overline{\mathrm{W}} \rightarrow \mathrm{W}$

(vi) $\mathrm{V}_{\mathrm{j}} \rightarrow \emptyset$ in env.: $\mathrm{C}_{\mathrm{n}}-\mathrm{V}_{\mathrm{k}}$, where $n \neq 2$ if $j \neq k$

(vii) If there is no V́, then the $\mathrm{V}$ nearest the end of the word becomes V́.

(MMHa, 27//45)

\section{4. General Statement-criteria, and necessary order}

NECESSARY ORDER

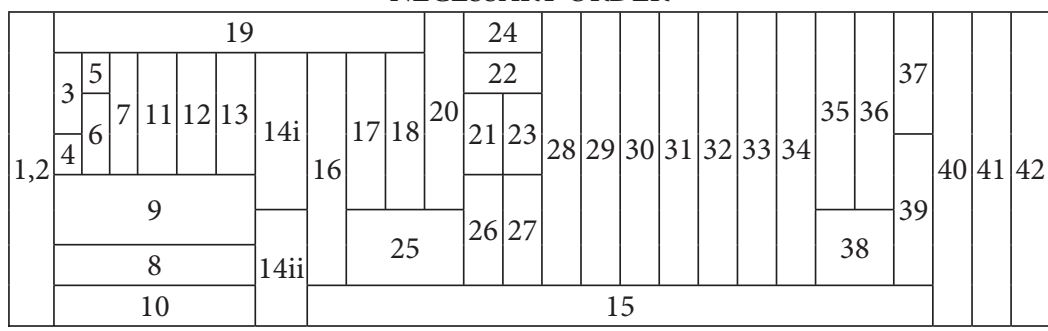

(MMHa, 48) 
MR34. $\left.\left[\begin{array}{c}\mathrm{B} \\ \mathrm{P} \\ \mathrm{K}\end{array}\right] \rightarrow\left\{\begin{array}{l}\left.\left[\begin{array}{l}\mathrm{b} \\ \mathrm{p} \\ \mathrm{k}\end{array}\right] \text { in env. }\left\{\begin{array}{l}: \mathrm{W} \\ {\left[\begin{array}{c}\# \\ \mathrm{v} \\ \mathrm{f} \\ \mathrm{N}\end{array}\right\} \mathrm{C}_{j}}\end{array}\right\}-\right\} j=0,1 ; \mathrm{C}_{j} \neq \mathrm{y} \\ \mathrm{x}\end{array}\right]\right\}$

MR35. $\left\{\begin{array}{l}- \\ \left(\mathrm{V}^{\prime}\right)_{j} . .\end{array}\right\} \mathrm{A} \rightarrow\left\{\begin{array}{l}\emptyset \text { in env. } \ldots . . . \mathrm{A} \\ \mathrm{V}, \text { where } \ldots \text { contains no } \mathrm{V}\end{array}\right\}$

MR42. ' $\rightarrow$ '

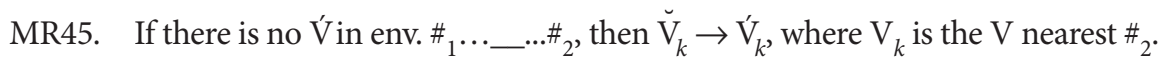

(MMHb, 28//49)

\section{Justification}

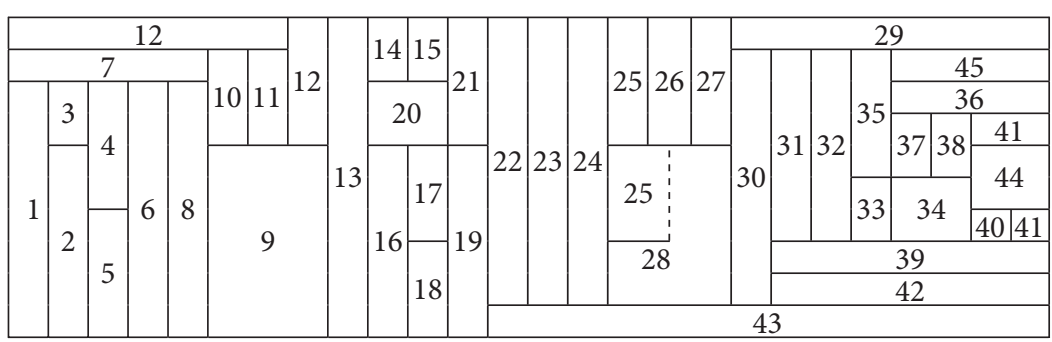

$(\mathrm{MMHb}, 50)$ 


\section{Necessary order arguments (for those rule pairs included above)}

$1,2<$ all statements

1 and 2 have the form of preliminary rules. Actually, they do not take effect until later, and they could be inserted later, but this would in some cases violate criterion $4,{ }^{45}$ and would in general, without any compensating advantage, confuse the systematic picture.

\begin{tabular}{|c|c|}
\hline $13<14 \mathrm{i}$ & $\begin{array}{l}\text { šóraš }+i m \bullet A \stackrel{14 j}{\rightarrow} \text { šraš }+i m \bullet A \rightarrow{ }^{*} \text { šraším [šoraším] } \\
\text { córaK }+i m \bullet A+S \stackrel{14 j}{\rightarrow} \operatorname{craK}+i m \bullet A+S \rightarrow{ }^{*} \text { cirxéy [corxéy] }\end{array}$ \\
\hline $20<22$ & $\begin{array}{l}h 2+\text { šitéP } \stackrel{22}{\rightarrow} \text { šitéP } \rightarrow \text { * šitéf [šutáf] } \\
t+h 1+\text { Pasák } \stackrel{22}{\rightarrow} t+\text { Pasák } \stackrel{20}{\rightarrow} t+\text { Psák } \rightarrow{ }^{*} \text { tifsák [tafsík] }\end{array}$ \\
\hline $20<26$ & $m+$ šamár $+i ́ m+S \stackrel{26}{\rightarrow} m+$ šmáréy $\stackrel{20}{\rightarrow} m+$ šmréy $\rightarrow{ }^{*}$ mišmréy [šomréy] \\
\hline $25<26$ & $\begin{array}{l}\text { Yéld }+a \bullet A+S \bullet K a \stackrel{26 \text { ii }}{\rightarrow} \text { Yéld }+A+S \bullet K a \rightarrow^{*} \text { yaldxá [yaldatxá]. } \\
\text { Also, } A \text { would have to be introduced into parts of } 26, \text { e.g., i,ii. }\end{array}$ \\
\hline $32<33$ & $\begin{array}{l}\text { Otherwise } 32 \mathrm{i} \text {, ii would have to be complexly rephrased, since } \\
\mathrm{Y}_{2} \stackrel{33}{\rightarrow} \emptyset \text {. }\end{array}$ \\
\hline $38<39$ & 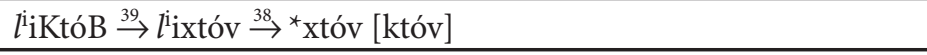 \\
\hline $37<40$ & Otherwise, 40iv must list "' as well as "', violating criterion 1. \\
\hline $39<40$ & kiB̄él $\stackrel{40}{\rightarrow}$ kiBél $\stackrel{39}{\rightarrow}{ }^{*}$ kivél [kibél] \\
\hline
\end{tabular}

(MMHa, 51-57)

45. The criteria are quoted on p. 186 above. 


\section{Necessary order arguments (for those rule pairs included above)}

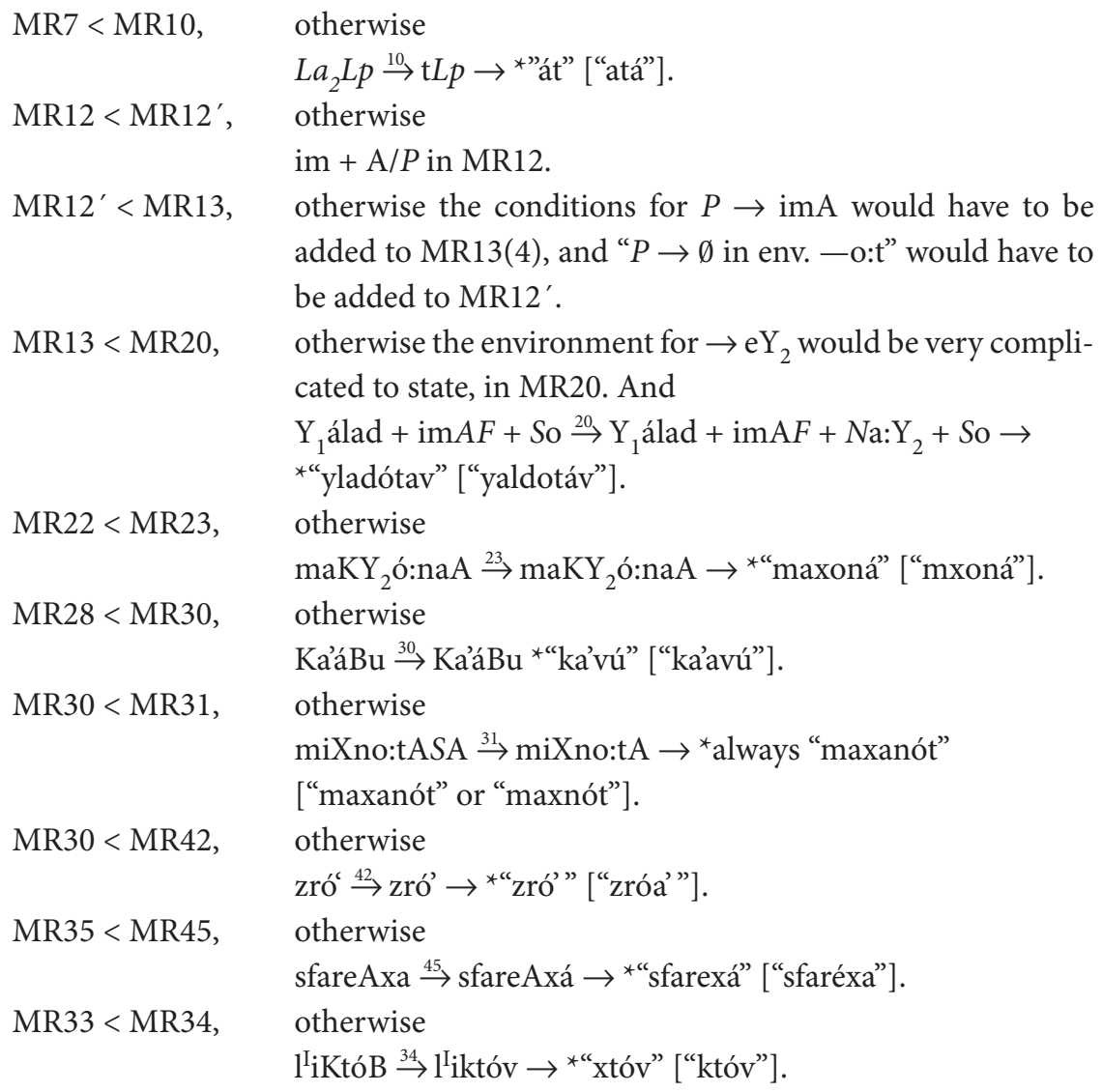




\section{Discussion}

The most obvious difference between the two versions of verb derivation (I above) is that the personal pronoun accompanying the verb is taken to be obligatory in $M M H a$, and therefore derived in the second step (" $L p$ " is a placeholder for the independent personal pronoun that operates within transformation 3); in $M M H \mathrm{~b}$ it is taken to be optional and must therefore be generated by the input to the morpheme string. The greatest difference in the noun versions (I above) is that in $M M H$ a the initial vowel pattern morpheme takes the shape corresponding to the unmarked singular séfer 'book', while in $M M H \mathrm{~b}$ it corresponds to ${ }^{*}$ sifr, the reconstructed Proto-Semitic ancestral form of this noun. ${ }^{46}$ This is a clear example of Chomsky's adoption of Bar-Hillel's suggestion to let the historical forms serve as the input to the morphophonemic component.

The first step in each derivation is the intercalation of the root and the vowel pattern. The morph(ophon)emes are then rewritten as phonemes, one at a time. Capital $\mathrm{B}, \mathrm{K}, \mathrm{P}$ represent the three stops that in Modern Hebrew spirantize postvocalically (in Biblical Hebrew, all six stops $b g d k p t$ did so); it is not clear why the archiphonemic notation with capital letters is used for P: $p$ has no non-alternating counterpart corresponding to ${ }^{*} \mathrm{q},{ }^{*} \mathrm{w}$ (which Chomsky renders as $\mathrm{k}, \mathrm{v}$ in the list of root consonants at IV above). Macrons in the MMHa derivations are purely diacritic - they do not relate to vowel length; acutes in both versions relate, in a sometimes roundabout way, to stress accent.

We consider the MMHa version of hén ráavú. Statement (2) begins every derivation, intercalating root and pattern. (3i) puts a copy of the pronominal material at the beginning of the word; herein could be seen the germ of "affix-hopping" ("Auxiliary Transformation" in Syntactic Structures (Chomsky 1957c, 113). (3iii) takes away the $L p$ that serves a purpose in other forms. (7iii) introduces the pronominal base $h$ twice, but the second line of the second part of (7iii) deletes the post-radical occurrence in a verb. (12) puts phonological meat onto the morphological bone "Plural," twice; again, the intermediate form em in invoked rather than simply saying $P \rightarrow u$ after $n$ or final radical. (17) does the same for "Feminine." (20) appears to jumble together morphological and phonological changes, but all of them serve to insert the correct vowel pattern allomorph into the stems and persons. (34) represents a statement-form that did not survive into subsequent phonology - "Intrusion of $\bar{a}$ " means 'write an à

46. The class of nouns of the form CVCC is known in Hebrew grammar as segolates, because in the fully vocalized Masoretic text of the Hebrew Bible, they appear as CVCeC, where e is notated with the vowel symbol called segol. Segolates are not treated in Harris 1941 because the resolution of the final cluster is understood to have been introduced along with the vowel markings by the Masoretes in the later first millennium $\mathrm{CE}$, and not to have been part of the language of са. 600 все described by Harris. 
where indicated' - and appears to undo (20), and also introduces the purely diacritic macron. (37) changes 'ayin to 'aleph ('ayin appears to be needed because of (32x) and (34i and viii), the only places where 'aleph does not occur alongside 'ayin). (39) is the aforementioned BeGaDKeFaT rule - interestingly, the stop is taken as conditioned and the fricative as the "elsewhere" outcome, contrary to the traditional teaching that the stop is fricativized after a vowel (Kautzsch 1910: $34 \$ 6 n$; Malone 1993: 64; cf. n. 41 above). (40) is a catchall cleanup statement that removes stray diacritics and also ensures that every word with no stress marking ends up with final stress.

Turning to the noun sfaréha, we have already seen the first three steps, but here the diacritic $A$ is introduced by (12); it is not clear that it does anything but add stress to whatever precedes. (14) does for nouns what (20) does for verbs; a different part of (17) appears; (25) changes the $A$ to stress; (26) makes the construct forms; (33) refines the construct marker; and (39) and (40) reappear.

How do the $M M H \mathrm{~b}$ derivations differ from the original? Superficially most obvious is that the rules have been largely recast. Both derivations have the same number of steps, though as we have seen the input is different. If Bar-Hillel's suggestion to use historical forms were his only contribution, it would have marked the foundation of the SPE approach to generative phonology. (In the reduced number of derivations in $M M H \mathrm{~b}$, it is not shown how to get from ${ }^{*}$ sipr to séfer.) The forms of rules are as bizarre-looking as in the earlier version; but among the justifications of the necessary ordering of the rules can be seen foreshadowings of future arguments concerning vacuous rule application (cf. Chomsky 1967) ${ }^{47}$ and "feeding" and "bleeding" order; compare the statements referring to MR22 and MR28 in VII above. MR13 does not look "elegant" in terms of later generative phonology (cf. n. 38 above, end), but the inclusion of every possible allomorph of $F$ in a single rule constitutes a different sort of elegance. Especially in the footnotes, there can be seen a concern for variation in the spoken language: in $M M H \mathrm{a}$ it is limited to several mentions of the fact that $\mathrm{e}$ and ey can alternate, but in $M M H b$ both grammatical change (cf. n. $\dagger$ on p. 193 above, n. $\dagger$ on p. 197 above, and n. $\$$ on p. 199 above) and synchronic variation (cf. the necessary order statement for MR30 < MR31 on p. 207 above) are recognized. Had the work been known earlier, variation studies might have gotten an earlier start.

Turning to other differences between $M M H \mathrm{a}$ and $M M H \mathrm{~b}$, lost with the omission of the introduction is the notion that "the syntactic statement [could be replaced] by a listing of all sentences" (quoted on p. 183 above), which could reflect Leonard Bloomfield's

47. Chomsky published only two articles in Language; this, his only appearance after the review of Verbal Behavior, is in the Bernard Bloch Memorial Number. Bloch was a close friend, and though he disagreed with what Chomsky was doing, he encouraged his students to study it (NC, 12/30/07), in contrast to other prominent members of the Linguistic Society of America. Chomsky is a Life Member of the LSA. 
"The totality of utterances that can be made in a speech-community is the language of that speech-community" (1926). Instead, $M M H b$ has

The linguistic analysis of a language $L$ [is] the process of determining the set of 'grammatical' or 'significant' sentences of $L \ldots$, or, in other words, it is the process of converting an open set of sentences - the linguist's incomplete and in general expandable corpus - into a closed ${ }^{*}$ set - the set of grammatical sentences and of characterizing this latter set in some interesting way. (1)

Compare this from Syntactic Structures: "A language [is] a set of sentences" (Chomsky 1957c, 13), but also

The fundamental aim in the linguistic analysis of a language $\mathrm{L}$ is to separate the grammatical sequences which are the sentences of L from the ungrammatical sequences which are not sentences of $\mathrm{L}$ and to study the structure of the grammatical sequences. (ibid.)

The notion of "grammaticality" does not appear in $M M H \mathrm{a}$, but it does in $M M H \mathrm{~b}$. "Transformation" appears in $M M H \mathrm{a}$, but in $M M H \mathrm{~b}$ it is promoted to the introduction to the new section Notation (6), albeit in a different sense: ${ }^{48}$ "The grammar, then, will be a set of transformation statements each of which transforms a given representation of a sentence into a more specific one." And "generate"? "It is assumed that the sole purpose of the grammar is to generate a closed body of sentences, these having already been determined" (3). "A complete grammar ... [is] a single set of 'transformational statements' generating, from the most general representation of any sentence ... the specific representations, i.e., all grammatical phone sequences" $(M M H b, 67 f . n .6)$.

The volume editor set the question, "Are there 'revolutions' in linguistic theory? (in the Kuhnian sense) and how does Chomsky's career support whichever conclusion one might reach to that question? (One could also use this consideration to reject Kuhn's theory of scientific revolutions, if one wished.)" I certainly will not take it upon myself to address such a question of the philosophy of science. In the early works considered here, what is clear is that Chomsky believed he was doing something that had not been done before; that he was blazing a new trail branching off from that which had

* Though not necessarily finite. Thus the resulting grammar will in general contain a recursive specification of a denumerable set of sentences.

48. "The term 'transformation' is used basically in the sense of 'rewriting rule,' which is different from transformations in Harris's sense (a description of cooccurrence relations) or mine (as a generative syntactic operation)" (NC 3/7/09). 
been paved by his mentor. He did not expect anyone would follow him through the rough new terrain; but his track did join two established thoroughfares, the way of linguistics and the way of "formal sciences." The former contributed the subject matter; the latter, notions of ordered rules and recursion, both already present in his earliest known work but not explicitly derived from any earlier linguistic source that he knew or recognized. These earliest formalisms are a far cry in complexity from the easily comprehended versions in his earliest publications $(1953,1957)$, and maybe they had to be worked through the extremely baroque versions in the thickets of LSLTpdf and LSLT in order to emerge in the sunshine on the other side. But somewhere along the way, the subject matter was diverted from phonology to syntax. A formal approach to phonology (not treated by Tomalin 2006) was attempted in the 1950s and 1960s but dead-ended before the publication of SPE (Daniels in preparation). I would thus agree with Murray (1994, 238-39) that if there was a "Chomskyan revolution," it was in phonology, not in syntax: but even so, a scholar whom Chomsky and Murray (1994, 238) identify as a principal obstacle in the old guard, Archibald A. Hill, served on the committee for one of the first non-M.I.T. dissertations in generative phonology, Daniel Gutman's.

\section{References}

Bloomfield, Leonard. (1926). A Set of Postulates for the Science of Language. Language 2, $153-64$.

- (1939). Menomini Morphophonemics. Travaux du Cercle Linguistique de Prague 8, $105-15$.

Bohas, Georges, Jean-Patrick Guillaume, \& Djamel Kouloughli. (1990). The Arabic Linguistic Tradition. London: Routledge. Reprint, Washington, D.C.: Georgetown University Press, 2006.

Carnap, Rudolf. (1928). Der logische Aufbau der Welt. Berlin: Weltkreis.

- (1934). Logische Syntax der Sprache. Vienna: Springer.

. (1937). The Logical Syntax of Language. Translated by Amethe Smeaton (Countess von Zeppelin). London: Kegan Paul, Trench Trübner.

- (1967). The Logical Structure of the World \& Pseudoproblems in Philosophy. Translated by Rolf A. George. Berkeley and Los Angeles: University of California Press.

Carter, M. G. (2004). Sïbawayhi. Oxford: I. B. Tauris.

Chayen, M. J. (1977). Generative Phonology Celebrates Its 25th Anniversary: An Evaluation of Chomsky's Hebrew Morphophonemics (1951). In Phonologica 1976: Akten der dritten Internationalen Phonologie-Tagung, Wien, 1.-4. September 1976, ed. Wolfgang U. Dressler \& Oskar E. Pfeiffer, 49-51. Innsbruck.

Chomsky, Noam. (1951a). Morphophonemics of Modern Hebrew. M.A. thesis, University of Pennsylvania.

—. (1951b). Morphophonemics of Modern Hebrew. New York: Garland, 1979.

- (1953). Systems of Syntactic Analysis. Journal of Symbolic Logic 18, 242-56. - (1955-56). The Logical Structure of Linguistic Theory. Massachusetts Institute of Technology, Cambridge. 
. (1957a). Review of A Manual of Phonology, by Charles F. Hockett. International Journal of American Linguistics 23, 223-34.

. (1957b). Review of Fundamentals of Language, by Roman Jakobson \& Morris Halle. International Journal of American Linguistics 23, 234-42.

- (1957c). Syntactic Structures. The Hague: Mouton.

. (1959). Review of Verbal Behavior, by B.F. Skinner. Language 35, 26-58.

. (1964a). Current Issues in Linguistic Theory. The Hague: Mouton.

. (1964b). The Logical Basis of Linguistic Theory. In Proceedings of the Ninth International Congress of Linguists, Cambridge, Mass., August 27-31, 1962, ed. Horace G. Lunt, 914-78. The Hague: Mouton.

- (1967). Some General Properties of Phonological Rules. Language 43, 102-28.

. (1969). Linguistics and Politics. New Left Review 57, 21-34.

. (1975). The Logical Structure of Linguistic Theory. New York: Plenum. Reprint, Chicago: University of Chicago Press, 1985.

- (1976). Problems and Mysteries in the Study of Human Language. In Language in Focus: Foundations, Methods and Systems: Essays in Memory of Yehoshua Bar-Hillel (1915-1975), ed. Asa Kasher, 281-357. (Boston Studies in the Philosophy of Science 43.) Dordrecht: Reidel. Repr. in Reflections on Language. New York: Pantheon, 1976, 135-228, in turn repr. in On Language, New York: New Free Press, 1998.

. (1989). A Generalization of X-bar Theory. In Studia linguistica et orientalia memoriae Haim Blanc dedicata, ed. Paul Wexler, Alexander Borg, and Sasson Somekh 86-93. Wiesbaden: Harrassowitz.

Chomsky, Noam, \& Morris Halle. (1968). The Sound Pattern of English. New York: Harper \& Row. Chomsky, William. (1952). David Kimhi’s Hebrew Grammar (Mikhlol) Systematically Presented and Critically Annotated. Philadelphia: Bloch. Reprint Jacksonville, Fla.: Bloch, n.d.

Daniels, Peter T. (in preparation). Review of Linguistics and the Formal Sciences: The Origins of Generative Grammar, by Marcus Tomalin. LINGUIST List.

Encrevé, Pierre. (1997). Lancien et le nouveau: Quelques remarques sur la phonologie et son histoire. Langages 125: 100-123.

_ (2000). The Old and the New: Some Remarks on Phonology and Its History. Folia Linguistica 34: 56-84.

Goldsmith, John. (2008). Generative Phonology in the Late 1940s. Phonology 25, 37-59.

Goodman, Nelson. (1943). On the Simplicity of Ideas. Journal of Symbolic Logic 8, 107-21. . (1951). The Structure of Appearance. Cambridge: Harvard University Press.

Goodman, Nelson, \& W.V. Quine. (1947). Steps toward a Constructive Nominalism. Journal of Symbolic Logic 12, 105-22.

Gordon, Cyrus H. (1986). The Pennsylvania Tradition of Semitics. Atlanta: Scholars Press.

Gutman, Daniel. (1970). The Morphophonemics of Biblical Hebrew (and a brief comparison with Israeli Hebrew). Ph.D. Dissertation, University of Texas.

Harris, Zellig S. (1936). A Grammar of the Phoenician Language. (American Oriental Series 8.) New Haven: American Oriental Society.

- (1939). Development of the Canaanite Dialects: An Investigation in Linguistic History. (American Oriental Series 16.) New Haven: American Oriental Society.

- (1940). Review of Foundations of Language, by L.H. Gray. Language 16, 216-30.

. (1941). The Linguistic Structure of Hebrew. Journal of the American Oriental Society 61, 143-69. 
. (1942a). Morpheme Alternants in Linguistic Analysis. Language 18, 169-80.

. (1942b). The Phonemes of Moroccan Arabic. Journal of the American Oriental Society

62, 309-18.

. (1944). Simultaneous Components in Phonology. Language 20, 181-205.

. (1948). Componential Analysis of a Hebrew Paradigm. Language 24, 87-91.

. (1951). Methods in Structural Linguistics. Chicago: University of Chicago Press.

. (1970). Papers in Structural and Transformational Linguistics. Dordrecht: Reidel.

Jakobson, Roman. (1948). Russian Conjugation. Word 4, 155-67.

Joos, Martin (ed.). (1957). Readings in Linguistics [I]. Reprint, Chicago: University of Chicago

Press, 1966.

- (1964). A Chapter of Semology in the English Verb. In 15th Georgetown University Round

Table, ed. C.I. Stuart, 59-72. Washington, D.C.: Georgetown University Press.

Kautzsch, E. (1910). Gesenius' Hebrew Grammar. Trans. A.E. Cowley. Oxford: Clarendon.

Kilbury, James. (1976). The Development of Morphophonemic Theory. Amsterdam: John

Benjamins.

Kiparsky, Paul. (1994). Pāṇinian Linguistics. In Encyclopedia of Language and Linguistics, ed.

R. Asher \& J.M.Y. Simpson, 6: 2918-23. Oxford: Pergamon.

Koerner, E.F. Konrad. (1995). Chomsky's Readings of the Cours de linguistique générale. In Professing Lingustic Historiography, 96-114. Amsterdam/Philadelphia: John Benjamins.

- (2001). On 'Influence' in Linguistic Historiography: Morphophonemics in American Structuralism. Logos and Language 2 no. 2, 1-20.

- (2002). On the Origins of Morphophonemics in American Linguistics. In Toward a History of American Linguistics, 210-52. London: Routledsge.

- (2003). Remarks on the Origins of Morphophonemics in American Structural Linguistics. Language \& Communication 23, 1-43.

- (2004a). On 'Influence' in Linguistic Historiography: Morphophonemics in American

Structuralism. In Essays in the History of Linguistics, 65-100. Amsterdam/Philadelphia: John Benjamins.

_ (2004b). Zellig Sabbetai Harris: A Complete Bibliography of His Writings, 1932-2002. In Essays in the History of Linguistics, 239-57. Amsterdam/Philadelphia: John Benjamins.

Koerner, E.F. Konrad, \& Matsuji Tajima. (1986). Noam Chomsky: A Personal Bibliography 1951-1986. Amsterdam/Philadelphia: John Benjamins.

Levi, Judith N. (1972). Middle Weak Verbs in Modern Hebrew: Two Morphophonemic Analyses. M.A. thesis, University of Chicago.

Lunt, Horace G. (ed.) (1964). Proceedings of the Ninth International Congress of Linguists, Cambridge, Mass., August 27-31, 1962. (Janua Linguarum Series Maior 12.) The Hague: Mouton.

Malone, Joseph L. (1993). Tiberian Hebrew Phonology. Winona Lake, Ind.: Eisenbrauns.

Mithun, Marianne. (1996). The Description of the Native Languages of North America: Boas and After. In Handbook of North American Indians, vol 17: Languages, ed. Ives Goddard, 43-63. Washington, D.C.: Smithsonian Institution.

Moses, Rae Arlene. (2008). Subterranean Linguistics, an Undergraduate Linguistics Curriculum, and the Evolution of a Department. Paper presented at the annual meeting of the North American Association for the History of the Language Sciences, Chicago.

Murray, Stephen O. (1994). Theory Groups and the Study of Language in North America: A Social History. Amsterdam/Philadelphia: John Benjamins. 
Nevin, Bruce. (1992). Zellig S. Harris: An Appreciation. California Linguistic Notes 23/2 (SpringSummer): 60-64.

Nöldeke, Theodor. (1890). Delectus veterum carminum arabicorum. (Porta Linguarum Orientalium 13.) Berlin: Reuther.

Semaan, K.I. (1968). Linguistics in the Middle Ages: Phonetic Studies in Early Islam. Leiden: Brill.

Swadesh, Morris, \& Charles F. Voegelin. (1939). A Problem in Phonological Alternation. Language 15, 1-10.

Thatcher, G.W. (1942). Arabic Grammar of the Written Language, 4th ed. Edited by R. [scil.A.] S. Tritton. London: Lund, Humphries.

Tomalin, Marcus. (2006). Linguistics and the Formal Sciences: The Origins of Generative Grammar. (Cambridge Studies in Linguistics 110.) Cambridge: Cambridge University Press.

Watt, W.C. (1995). Zellig Sabbatai Harris 1909-1992: A Biographical Memoir (National Academy of Sciences Biographical Memoirs 87.) Washington, D.C.: National Academies Press.

Wells, Rulon S. (1947). Immediate Constituents. Language 23, 81-117.

. (1949). Automatic Alternation. Language 25, 99-116. 


\title{
Grammar and language in Syntactic Structures Transformational progress and structuralist 'reflux'
}

\author{
Pierre Swiggers \\ (University of Leuven [K.U.L.])
}

\begin{abstract}
In his review of Chomsky's Syntactic Structures (1957), R.B. Lees praised the work as a pioneering effort in constructing a truly scientific theory of language. Very soon, Chomsky's 1957 book was regarded as inaugurating the 'generative revolution' in linguistics. The present study focuses on the use made by Chomsky, in his 1957 book, of key concepts such as 'structure,' 'level', 'grammar' and 'language', while relating his argumentation to theory formation in linguistics in the 1950s. It is shown that, from the point of view of theory construction, Syntactic Structures has an ambivalent status: the work goes beyond distributionalism in showing the acceptability of level mixing, and in extending syntactic analysis to the relationships between utterances, but at the time of addressing the issue as to what it is to 'understand' a sentence, the work relapses into American structuralist orthodoxy. Also, in Syntactic Structures, Chomsky reverts to the Bloomfieldian skeptical attitude concerning the use of meaning in linguistic description, and no reference is to be found here to the speaker's 'competence'. As a result, the book appears to be rooted in the structuralist tradition, reflecting the structuralist concern with rigorous methodology; its distinctive quality was to deal with linguistic methodology as constituting the core of a general theory of grammar.
\end{abstract}

"Whether the change that actually took place - the advent of and eager reception of the approach called transformation theory - should be described as internal or external, as a revision and rehabilitation of Descriptive Linguistics, or as a displacement of it, is no simple one, for which reason I save it for another day"

(Wells 1963: 48).

\section{o. Introduction}

In 1957 Noam Chomsky's (b. 1928) Syntactic Structures came out. In his lengthy review of the book, which appeared in the same year, Robert Lees (1922-1996) praised the work as 
...one of the first serious attempts on the part of a linguist to construct within the tradition of scientific theory-construction a comprehensive theory of language which may be understood in the same sense that a chemical, biological theory is ordinarily understood by experts in those fields. (Lees 1957: 377) ${ }^{1}$.

Within the historiographical literature, the rise of transformational grammar has been described and appreciated in divergent ways, ${ }^{2}$ partly in line with divergent predispositions of the respective historiographers, and partly in accordance with the specific focus - on sociological aspects, on rhetorical strategies, ${ }^{3}$ on methodological principles, or on general theoretical statements ${ }^{4}$ — of these studies.

The aim of this paper is not to make judgments on the historiographical treatment of the early phase of transformational grammar, ${ }^{5}$ nor to evaluate the claims made, at one time or another, regarding the (possible) superiority of the transformational model with respect to other models. The scope of the present contribution, offered as a homage to Konrad Koerner, is much more limited and modest: I am mainly interested in a number of key concepts as these appear, in a more or less explicit formulation, in Chomsky's 1957 book. ${ }^{6}$ This examination will involve an analysis of (only part of)

1. Lees (1957: 377-8) adds: 'It is not a mere reorganization of the data into a new kind of library catalog, nor another speculative philosophy about the nature of Man and Language, but rather a rigorous explication of our intuitions about our language in terms of an overt axiom system, the theorems derivable from it, explicit results which may be compared with new data and other intuitions, all based plainly on an overt theory of the internal structure of languages; and it may well provide an opportunity for the application of explicit measures of simplicity to decide preference of one form over another form of grammar.'

2. See, e.g., Hymes/Fought (1975), Maher (1980), Newmeyer (1980, second ed. 1986), Murray (1984, Chapter 9), Koerner (1989), Harris (1993), Matthews (1993).

3. See Harris (1989).

4. Chomsky's theoretical work has attracted the attention of philosophers; for selections of essays, see, e.g., Harman (ed. 1974) and Kasher (ed. 1991).

5. See esp. Murray (1981 [and cf. Historiographia Linguistica 9.185-7 (1982)]), Newmeyer (1986), and the retrospective assessment in Koerner (1989).

6. Two major works by Chomsky which precede his Syntactic Structures will not be dealt with here: (1) his Ph.D. dissertation (Chomsky 1955a), which I have not been able to see in its original form (the text was incorporated, in a revised form, into Chomsky 1975); (2) the typescript The Logical Structure of Linguistic Theory (Chomsky 1955b), of which a book version was prepared by Chomsky in the 1970s (published as Chomsky 1975). [On the revisions of the 1975 published version, see Boal (1984), a manuscript which I have not seen, but which is referred to by Koerner 1989 and Harris 1993.] - For fuller bibliographical details on Chomsky's writings, see Koerner/Tajima (1986). 
Chomsky's argumentation, and will relate it to theory-formation and work in linguistics in the 1950s.

\section{1. 'Structure': A significant singular?}

Chomsky's Syntactic Structures deals with the description of structure at the level of syntax. Throughout the book, Chomsky favors the singular form structure, as can be gathered from the following selection of passages:

This study deals with syntactic structure both in the broad sense (as opposed to semantics) and the narrow sense (as opposed to phonemics and morphology).

(Chomsky 1957: 5);

The ultimate outcome of these investigations should be a theory of linguistic structure in which the descriptive devices utilized in particular grammars are presented and studied abstractly, with no specific reference to particular languages. (Chomsky 1957: 11);

I think that we are forced to conclude that grammar is autonomous and independent of meaning, and that probabilistic models give no particular insight into some of the basic problems of syntactic structure. (Chomsky 1957: 17);

This is the basic requirement that any conception of linguistic structure (i.e., any model for the form of grammars) must meet. (Chomsky 1957: 68).

Two points deserve our attention at this stage: (1) on the one hand, Chomsky does not comment on a possible distinction between structure and structures; $;$ (2) on the other hand, he does not offer, at least not straightforwardly, a definition of 'structure'. Both points are related, in my view: (i) Chomsky's interest is in formulating the descriptive devices for presenting a grammar - or, crucially, the descriptive devices by which extant/possible grammars can be comparatively evaluated - : such an aim is central to a theory of linguistic structure, with 'structure' as a global cover-term (for both 'structuring' and 'structuration'); (ii) in his 1957 book Chomsky explores the possibility of construing a formalized theory for the structural description of natural languages; as a consequence the emphasis is not on the notion of 'structure' itself (which hence can be left undefined), but on the construction of a formal representation for sentences.

The issue of the singular structure vs. the plural structures is not, in my view, a futile question. First, there is the fact that the singular structure occurs in labelling terms such as phrase structure or transformational structure, where the term stands for

7. To account for the title Syntactic Structures in terms of the co-presence of phrase structure and transformational structure would be missing the important fact that these are segments of the grammar as a whole. 
'structural model' (or 'model structure'). Second, the use of the singular structure is completely in line with the methodologically grounded use of the term by Zellig Harris (1909-1992) in expressions such as 'distributional structure' or 'linguistic structure' (see, e.g., Harris 1954, 1957). ${ }^{8}$ Thirdly, and perhaps most importantly, the use of the term structure as referring to a model (and theory) of description raises the fundamental problem of the correspondence between the structure set up by the linguist and the structure used by the speaker. In Syntactic Structures Chomsky does not speak about interiorized knowledge of linguistic structure, but he establishes a link between the grammar and the speaker's behavior. After having rejected the conception of grammar as (the description of) the structure of the corpus of utterances handled by the linguist, he defines grammar as a non-finite projective description: 'Any grammar of a language will project the finite and somewhat accidental corpus of observed utterances to a set (presumably infinite) of grammatical utterances' (Chomsky 1957: 15), and he adds:

In this respect, a grammar mirrors the behavior of the speaker who, on the basis of a finite and accidental experience with language, can produce or understand an indefinite number of new sentences. Indeed, any explication of the notion "grammatical in L" (i.e., any characterization of "grammatical in L" in terms of "observed utterance of L") can be thought of as offering an explanation for this fundamental aspect of linguistic behavior. (Chomsky 1957: 15).

Such a statement can be or should be read as rejecting the distinction drawn between an 'instrumentalist' and a 'realist' (or: 'subjective' vs. 'objective') conception of linguistic structure; the formal description of grammar is said to determine structure in such a way that it corresponds to the use the speaker makes of the structure. Whereas in Syntactic Structures Chomsky is quite allusive on this matter, in a 1977 interview he recalled the crucial issue at stake then:

In American linguistics - in fact, also in European structuralism of the thirties, forties, and early fifties - there was very intensive work, as you know, in developing procedures that in principle, one hoped could be applied in a mechanical way to a corpus of data so as to produce, finally, a grammar of that corpus. Well, a crucial question arises at that point; it's essentially the question of realism, you might say. That is the question, What is the nature of these procedures? Are they simply a device for bringing organization to chaos? And, is it the case that one set of

8. It should be noted that in his 1954 paper Harris proposed a working definition of 'structure': 'For the purposes of the present discussion, the term structure will be used in the following non-rigorous sense: A set of phonemes or a set of data is structured in respect to some feature, to the extent that we can form in terms of that feature some organized system of statements which describes the members of the set and their interrelations (at least up to some limit of complexity). In this sense, language can be structured in respect to various independent features' (Harris 1954: 146). 
procedures is as good as any other set? Or, is there a kind of truth claim involved in those procedures? Well, if there is a truth claim, then that means that the system that arises by applying the procedures is claimed to be represented in the mind in some fashion. That is, one claims, at least, that the procedures correspond in some fashion to what the child is doing when he acquires language, and that the result of applying the procedures corresponds in some fashion to the mental representation of the language in his brain. And in fact that conclusion had been drawn. For example, it had been drawn by Charles Hockett in a very perceptive, brief paper that appeared in the late 1940s, where he took a very strong realist position and said, in effect, that the grammar that the linguist constructs is a representation of synaptic connections in the brain and that the procedures of analysis correspond to what the child is doing when he works with the data and develops that grammar. (Saporta/Chomsky 1978: 303-4).

It may be worthwhile to dig further into this. Hockett's short paper, published in 1948, was in fact a squib that followed hot on the tracks of a review published by Preston (1948). Taking issue with the mentalist assumptions of the author (viz. C. de Goeje) whose book he was reviewing, Preston had affirmed that 'Structure is a series of statements. The structure of a given language or language corpus does not exist until it is stated' (Preston 1948: 131). Hockett's reaction was not meant to question the nature of linguistic description, but to show the pitfalls of assuming a gap between some 'objective' structure of the linguistic facts and the (subjective) structure the linguist constructs out of these. In his reaction Charles F. Hockett (1916-2000) noted two important points: (i) the fact that the linguist's description is never fully reducible to the materials of his corpus; (ii) the fact that the difference between the linguist's analysis and the speaker's behavior (Hockett refers to the child or language learner) is one of (degree of) explicitness, not of nature.

The analysis of the linguistic scientist is to be of such a nature that the linguist can account also for utterances which are not in his corpus at a given time. That is, as a result of his examination he must be able to predict what other utterances the speakers of the language might produce, and, ideally, the circumstances under which those other utterances might be produced. [...] The essential difference between the process in the child and the procedure of the linguist is this: the linguist has to make his analysis overtly, in communicable form, in the shape of a set of statements which can be understood by any properly trained person, who in turn can predict utterances not yet observed with the same degree of accuracy as can the original analyst. The child's 'analysis' consists, on the other hand, of a mass of varying synaptic potentials in his central nervous system. The child in times comes to behave the language; the linguist must come to state it. (Hockett 1948: 270-1).

Although Chomsky in his Syntactic Structures eludes issues concerning the 'nature' of linguistic structure, and discards the Markov-type view of the speaker as a machine for producing, in different stages, sentences of a language, it is clear that at the time 
he conceived of linguistic theory as a description of the speaker's linguistic intuitions. This can be gathered from both Lees's review of Syntactic Structures, ${ }^{9}$ and from Chomsky's statements at the 1958 Third Texas Conference on Problems of Linguistic Analysis in English. ${ }^{10}$

\section{2. 'Levels'}

At one point, though, in Syntactic Structures, Chomsky does use the plural structures. The passage in which the plural form occurs is about the tripartite arrangement of grammars, as combining a phrase structure, a transformational structure, and a set of morphophonemic rules (which serve to convert the string of words yielded by transformations into a string of phonemes). ${ }^{11}$ Chomsky then points out that, whereas

9. 'The term 'intuition' may also be used in a different sense in connection with linguistic theories. The empirical data which a linguistic theory must explain consists not only of noises which talking people produce, but also of various kinds of judgments they can make and feelings they may have about linguistic data. For example, a speaker knows which sounds or words rhyme, and he can say when a sentence is grammatically permitted or excluded, whether or not he has ever before heard the particular rhyme or sentence in question. These judgments are sometimes referred to as linguistic intuitions. They are part of the linguistic data to be accounted for' (Lees 1957: 376) [with correction of Lees's spelling 'rime' to 'rhyme'].

10. See the summarizing account in Matthews (1993: 201): 'Toward the end, Chomsky says that he dislike[s] reliance on intuition as much as anyone, but if we are in such a bad state that it is only intuition that we are using, then', he feels, 'we should admit it. We must, however, 'try to refine it by testing. If we can then 'get to a point where we have refined our basis by theoretical investigations and operational tests', he will be 'very happy to stop saying that we start with the intuition of the native speaker' (Hill, ed. 1962[1958]: 177f.). An example of such refinement would perhaps be the procedures which are envisaged a little later to 'elicit differential responses' bearing on grammaticalness (181). But for the moment reliance on the speakers' intuitions cannot be avoided. 'Intuition', Chomsky said, 'is just what I think I am describing.' The empirical data that I want to explain', he goes on, 'are the native speaker's intuitions' (158). If that is not accepted as 'the purpose of linguistic study', he is 'lost' (168). These remarks are almost all from interchanges with Hill, who drew him out repeatedly on this point. In another passage, Hill remarks that 'if I took some of your statements literally, I would say that you are not studying language at all, but some form of psychology, the intuitions of native speakers.' That', Chomsky replied, 'is studying language' (167)' (Matthews summarizes here Chomsky 1962 [conference paper of 1958] and portions of the relevant discussions at the 1958 Texas Conference).

11. I will not enter into a discussion of the adequacy of ordering the set of morphophonemic rules after the transformational structure; as well known, some transformations should be directly linked with morphophonemic shapes (e.g., introduction of question particles in the interrogative transformation; a different type of stems used in passive transformations, etc.). 
phrase structure cannot be broken down into sublevels (at the level of phrase structure there is no ordering into a higher and a lower level), on the transformational level a distinction has to be made between kernel sentences and derivations:

On the transformational level, an utterance is represented even more abstractly in terms of a sequence of transformations by which it is derived, ultimately from kernel sentences (more correctly, from the strings which underlie ${ }^{12}$ kernel sentences). There is a very natural general definition of "linguistic level" that includes all of these cases, and as we shall see later, there is good reason to consider each of these structures to be a linguistic level. (Chomsky 1957: 47; italics mine).

Since 'structure' is equated here with 'level', it might have been more accurate to speak of 'representations'. As a matter of fact, we are dealing here with the actualized representations, obtained through the application of descriptive devices. In his 1957 book, Chomsky defines a 'linguistic level' as a set of descriptive devices, or as a method of representing utterances (Chomsky 1957: 109). The notion of 'linguistic level' was a central one within Bloomfieldian linguistics, as it was coupled with the applicational scope of techniques such as segmentation, contrasting, substitution, etc. As a general rule, Bloomfieldians stuck to the principle that distinct levels should not be mixed: the reason for this was the assumption that a grammar was the realization of a (linear) discovery procedure, yielding definitive solutions at every distinct level, with the higher levels being seen as built up of the lower level forms. ${ }^{13}$ However, as shown by a number of linguists working in the structuralist tradition, ${ }^{14}$ phonemic analysis is at times crucially dependent on morphological information. In order to avoid the danger of circularity, it is important to co-define pairs of phoneme sets and morpheme sets, and a procedure of adjustment. Interdependence of levels, though, still remained a matter

12. The first edition of Syntactic Structures has the erroneous spelling underly here; in later printings the error is corrected.

13. For a clear statement on the 'ascending' order of levels (following directly after a passage rejecting the use of 'meaning'), see Trager/Smith (1951: 81): 'The procedure followed in this Outline has endeavored to use the meaning of recurring partials only as a short cut to the establishing of contrasting structural features, $[\ldots]$ and to go forward on the assumption that microlinguistic analysis can and must deal with statements about the distributions of the elements rigidly observed on ascending levels of complexity of organization. The realization of the extreme importance of levels in the observation and classification of events in the whole field of human behavior has been and will doubtless continue to be one of the most important criteria for scientific work in the social sciences. [...] It is probably true that in linguistics, because of the extremely formal and handleable nature of the data, the greatest progress in organization on the proper levels has been made?.

14. Especially with respect to the 'feedback'-relation between phonemic and morphemic analysis, see Harris (1951), Hockett $(1947,1955)$, and Pike $(1947,1952)$. 
of ad hoc intervention. Chomsky's strategy in Syntactic Structures consists in making interdependence of levels part of the formal system of grammar (now including also syntax), governed by the principle of simplicity: 'simplicity is a systematic measure; the only ultimate criterion in evaluation is the simplicity of the whole system' (Chomsky 1957: 55-6). The issue then is no longer one of discovering the 'correct' phonemic or morphemic output, but that of developing an evaluation measure for strings representing linguistic structure. Interdependence of levels therefore is no longer an objectionable step in establishing structure, but becomes an expedient quality of the metalinguistic ${ }^{15}$ aims of a linguistic theory.

Given such a theory, we can attempt to construct grammars for actual languages, and we can determine whether or not the simplest grammars that we can find (i.e., the grammars that the general theory compels us to choose) meet the external conditions of adequacy. We shall continue to revise our notions of simplicity and our characterization of the form of grammars until the grammars selected by the theory do meet the external conditions. Notice that this theory may not tell us, in any practical way, how to actually go about constructing the grammar of a given language from a corpus. But it must tell us how to evaluate such a grammar: it must then enable us to choose between two proposed grammars. (Chomsky 1957: 54).

\section{3. 'Grammar' and 'language'}

What then is a grammar for Chomsky in Syntactic Structures? The general answer to this question is that grammar is a formal description. More specifically, a grammar of a language is a generating device, or a set of devices. The notion of 'generate' in Syntactic Structures has a definite extensionalist ring: the grammar of language L generates the grammatical sequences in $\mathrm{L}$, separated from the ungrammatical sequences. And a language is defined, by stipulation, as a set of sentences: 'From now on I will consider a language to be a set (finite or infinite) of sentences, each finite in length and constructed out of a finite set of elements' (Chomsky 1957: 13). This definition is stipulative in three respects: (i) a language is reduced to a set of strings (viz. sentences); (ii) the component members are assigned a finite length; (iii) these finite length members are made up of elements from a finite set.

15. Or, more precisely, of the 'metametalinguistic' aims, since, as Chomsky rightly points out (1957: 54 fn. 3), linguistic theory is formulated in a 'metametalanguage' to any language for which a grammar is constructed. 
Stipulative definitions share with postulates the characteristic of containing the T-theoretical required conditions. The disadvantage they generally have is that they are (very) restrictive. In the present case, it is interesting to briefly confront the above definition of 'language' with definitions found in major textbooks of linguistics that appeared before Syntactic Structures; ${ }^{16}$ in the textbooks, reference is made to (a) the symbolic nature of language; (b) the social dimension of language; (c) the conventional character of linguistic forms.

The general advantage of a stipulative definition is that it is highly controllable (also for the reader). The definition of 'language' in Syntactic Structures, apart from being controllable, has the advantage of being 'open': it allows one to subsume under the concept of 'language' every set of sentences that can be formulated in terms of a construction relation holding between elements and strings, and - with respect to the set of sentences constituting the language in question - it imposes only a very general, internal condition, viz. of grammaticalness. There is, in addition, an important operational aspect involved: the definition of language in these terms entails its being defined by its 'alphabet' (the set of constitutive symbols) and by the constructed (grammatical) sentences. This constitutes the basis for evaluating the adequacy of descriptive grammar formats. Chomsky first examines the adequacy of two (types of) models: ${ }^{17}$ the finite state Markov process model (based on a communication theory model) ${ }^{18}$ and the phrase structure grammar model (which applies the analysis into immediate constituents). The finite state model falls short (a) of accounting for all the grammatical English sentences, and (b) of generating only sentences, to the exclusion of nonsentences. The empirical proof of this inadequacy is given by the fact that a finite state grammar cannot define the extension, scope and insertion of recursive devices; the basic reason for its failure lies in the nature of human languages, which are 'non-finite state. The second type, phrase structure grammar, is superior to it in that it can account for complex strings such as

i. $\quad a b, a a b b, a a a b b b$ ( $n$ occurrences of $a$ followed by $n$ occurrences of $b$ )

ii. $a a, b b, a b b a, b a a b$ (any string of symbols followed by its mirror image).

16. See, e.g., Sapir (1921: 8): 'Language is a purely human and non-instinctive method of communicating ideas, emotions and desires by means of voluntarily produced symbols'; Bloch/Trager (1942: 5): 'A language is a system of arbitrary vocal symbols by means of which a social group co-operates'. Compare Hall (1964: 158): 'Language is an institution whereby humans communicate and interact with each other by means of habitually used vocal-auditory arbitrary symbols'.

17. See also Chomsky (1956).

18. More specifically the model put forward by Shannon/Weaver (1949: 15-17). 
Chomsky (1957: 35-43) then shows the phrase structure to be inadequate in order to deal with three types of processes:

1. formation of sentences by conjunction (in fact: conjunction with partial blending): e.g., the scene of the movie was in Chicago + the scene of the play was in Chicago $\rightarrow$ the scene of the movie and the play was in Chicago, ${ }^{19}$

2. the appearance of discontinuous elements with auxiliary verbs (e.g., have -V (past participle); to be -V(ing);

3. the active-passive relation.

While it can be argued that a phrase structure grammar extended with a structural description of the internal build-up of syntagms and with a device for handling nonlinear constituency, can be made to cope with the processes listed in (1) and (2), the active-passive relation cannot be dealt with in a pure phrase structure grammar, since it exceeds the limits of a specifically attested phrasal string ( = token string) or its typerepresentation. In order to be able to deal with the active-passive relation, the phrase structure model should be supplemented with (a) a categorical description of predicates, and (b) a rather complex 'rephrasing component', accounting for linearization and for morphosyntactic adjustments in the 'target string. Chomsky, however, does not go into an examination of how a phrase structure model could possibly be extended and enriched; ${ }^{20}$ he considers that attempts to remedy its deficiencies will 'lead to the development of ad hoc and fruitless elaborations' (Chomsky 1957: $41 \mathrm{fn} .6$ ), and asserts that an adequate account of linguistic structure cannot do without a transformational component, i.e., a component that contains rules operating on a given string with a given constituency and converting this into a new string with a new constituent structure. ${ }^{21}$ At least three formative types of strings can be distinguished:

19. Chomsky does not enter into a discussion of what he considers to be a 'constituent' in these sentences ('of the movie' and 'of the play' are said to be 'actually constituents' of these sentences), nor does he consider problematic cases (the conjunction/blending process does not give the same result in the case of: the father of the bride was from Chicago + the father of the groom was from Chicago).

20. For the issue of discontinuities in a phrase structure model, see Chomsky (1953); on its handling in morphological description, see Harris (1945).

21. As noted by Harris (1962: 19), transformational analysis is, in comparison with immediate constituent analysis and string analysis, the 'most refined'; but Harris observes that the three are 'relevant, for language has the properties of all three'. Contrary to Chomsky, Harris offers a more oecumenical view of extant syntactic models: 'For each of these types of analysis can describe all the sentences of a language (though at very different cost in complexity of the description). This is so because the complex detail of each language and, not to put too fine a point on it, the irregularities and the not-fully-carried-out analogies, force each type of analysis to provide in its statements for cases of special subsets of word-categories or structures; 
a. the strings underlying kernel sentences; these strings are terminal strings of a phrase structure grammar;

b. the kernel sentences, obtained by applying obligatory transformations to the strings in (a)

c. the optionally transformed sentences, obtained by applying optional transformations on (a)-type or (b)-type strings.

From this it follows that there is an evaluation measure ${ }^{22}$ for grammars of natural languages: as the latter are non-finite state and since they display relationships between sentences that can be captured under the term 'transformation', a model incorporating the level of transformational structure will provide a simpler ${ }^{23}$ account. Simplicity, as seen above, is not a matter of concision or elegance: it is a matter of (higher) systematicity, ${ }^{24}$ across (classes of) descriptive statements. ${ }^{25}$

\section{Grammar and meaning: The structuralist 'reflux'}

Chomsky's Syntactic Structures combines the legacy of constituent analysis ${ }^{26}$ and of Item-and-Arrangement modelling, ${ }^{27}$ with ideas stemming from attempts at

and statements of this form can be used to describe any special cases that diverge from the main rules and elements, or even any entirely different classes of sentences. The difference is rather in how the three analyses interrelate the sentences and sentence-segments of the language: For each characterization of a sentence relates that sentence to its decomposition products and also to other sentences having a similar decomposition' (Harris 1962: 18-19).

22. This is the weakest requirement that can be placed on the relationship between a theory of linguistic structure and a grammar/set of grammars. Chomsky is aware of the fact that the majority of the extant linguistic models try to define a stronger type of (deciding) relationship between theory and descriptive outcome. In subsequent work Chomsky (see, e.g., 1964, 1965) was to introduce a theory of adequacy criteria for judging grammars.

23. At one point, 'simple' is equated with 'natural' (Chomsky 1957: 68); this seems to me slightly inaccurate, since the simplicity condition is not one of naturalness, but one of (theoryinternal) systematicity.

24. Recall that it is within the overall view of the systematicity of the grammar form that Chomsky finds a straightforward justification for mixing levels: if interdependence of levels leads to simpler statements in the form of the grammar, and when the interdependence is consistently handled in the grammar, this will be to the benefit of the description of linguistic structure.

25. I.e., statements applying to kernel sentences and to non-kernel sentences.

26. As expounded in Wells (1947), to whom Chomsky $(1957: 28,52)$ refers; the classic textbook exposition is that in Gleason (1955, Chapter 10).

27. The concept of 'Item-and-Arrangement' is accurately defined in Hockett (1954). 
axiomatizing $\operatorname{syntax}^{28}$ and from discussions of general methodology. The book went beyond distributionalism in showing the acceptability of level mixing, and in extending syntactic analysis to the relationships between utterances; it also pointed out the weaknesses of constituent analysis in its treatment of subconstituency relations. But at the moment of addressing the moot question of what it is to 'understand' a sentence, the work shows a curious relapse into an orthodox brand of American structuralism. The central question raised in Chapter 9 'Syntax and Semantics' is 'How are the syntactic devices available in a given language put to work in the actual use of this language?' (Chomsky 1957: 93). The question is not answered in a theoretical way; Chomsky seems to assume that it was (sufficiently) answered by offering a fragment of a transformational grammar of English in a preceding chapter (Chapter 7: 'Some Transformations in English'), to judge from the following passage:

The grammar of a given language must show how these abstract structures are actually realized in the case of the language in question, while linguistic theory must seek to clarify these foundations for grammar and the methods for evaluating and choosing between proposed grammars. [...] The requirement that this theory shall be a completely formal discipline is perfectly compatible with the desire to formulate it in such a way as to have suggestive and significant interconnections with a parallel semantic theory. What we have pointed out in $\$ 8$ is that this formal study of the structure of language as an instrument may be expected to provide insight into the actual use of language, i.e., into the process of understanding sentences. (Chomsky 1957: 102-3).

Understanding sentences involves the understanding of their representation at each level; and while Chomsky admits that at least components of sentences have meaning - he remains unclear as to how to describe the (possible) meaning of a 'transformation' - , one would have expected a statement on the representation of semantic contents. But at this point, Chomsky reverts to the skeptical position held by Leonard Bloomfield (1887-1949): ${ }^{29}$

28. Here one should mention Harwood's (1955) attempt to axiomatize a fragment of Immediate Constituent analysis.

29. As a direct consequence of his neo-positivist view of science (cf. Hiż/Swiggers 1990), Bloomfield was skeptical concerning the possibility of using, from an operational point of view, meaning in linguistic description; the two basic reasons for his skeptical attitude were: (a) on the one hand, the fact that the meaning (of the vast majority) of linguistic forms is not fully describable (or statable); (b) on the other hand, the fact that the meaning of a linguistic form is not identically distributed over the totality of the speakers of a language L. In Chapter 9 of his Language, Bloomfield makes explicit how far, and for what purpose, meaning can be incorporated in a theory of language; his skeptical attitude is concisely expressed in the following 
I am not acquainted with any detailed attempt to develop the theory of grammatical structure in partially semantic terms or any specific and rigorous proposal for the use of semantic information in constructing or evaluating grammars. It is undeniable that "intuition about linguistic form" is very useful to the investigator of linguistic form (i.e., grammar). It is also quite clear that the major goal of grammatical theory is to replace this obscure reliance on intuition by some rigorous and objective approach. There is, however, little evidence that "intuition about meaning" is at all useful in the actual investigation of linguistic form. I believe that the inadequacy of suggestions about the use of meaning in grammatical analysis fails to be apparent only because of their vagueness and because of an unfortunate tendency to confuse "intuition about linguistic form" with “intuition about meaning”. (Chomsky 1957: 93-4).

Chomsky then adduces arguments in order to support his defeatist attitude, but the problem ${ }^{30}$ with his arguments is that he (a) either combats semantically based statements that have no direct consequence for syntactic analysis (e.g., the idea that

passage (from another chapter in Language): 'Actually, however, our knowledge of the world in which we live is so imperfect that we can rarely make accurate statements about the meaning of a speech-form. The situations (A) which lead to an utterance (B), and the hearer's responses (C), include many things that have not been mastered by science. Even if we knew much more than we do about the external world, we should still have to reckon with the predispositions of the speaker and the hearer. [...] It is true that we are concerned not so much with each individual as with the whole community. We do not inquire into the minute nervous processes of a person who utters, say, the word apple, but content ourselves rather with determining that, by and large, for all the members of the community, the word apple means a certain kind of fruit. However, as soon as we try to deal accurately with this matter, we find that the agreement of the community is far from perfect, and that every person uses speech-forms in a unique way' (Bloomfield 1933: 74-5). - For a study of the attitude taken towards meaning in Bloomfieldian linguistics, see Koerner (1970).

30. I refrain from a detailed discussion of Chomsky's arguments, which would lead us too far. I will limit myself to a brief comment concerning Chomsky's attack on the assertion [117(i) in Chomsky (1957: 94)] that 'two utterances are phonemically distinct if and only if they differ in meaning.' Chomsky's criticism has a number of defects: (i) it misses the point that the assertion is intended to be operational in the direction form to meaning, not in the opposite way (hence, synonyms cannot be used as a counterexample to the assertion; incidentally, in taking 'bachelor' and 'unmarried man' as synonyms, Chomsky neglects their distributional non-equivalence: bachelor's degree; * unmarried man's degree); (ii) it passes over the system-internal validity of a phonemic description (cf. Chomsky's remarks accompanying some of his counterexamples: 'may coexist even within one style of speech', 'in many dialects'); (iii) homonymous forms ('homonymity') do not invalidate 'difference in meaning' as a criterion for phonemic distinctness: on the one hand, phonemic non-distinctness does not imply morphemic/morphosemantic identity, and, on the other hand, it should be remembered that 
grammatical sentences are those that have semantic significance, or the assertion that morphemes are the smallest elements that have meaning), or (b) takes issue over the use of meaning criteria, but without considering the correspondences that indeed hold between the forms to which the criterion is applied. This is the case, e.g., of his criticism of the assertion that between an active and its corresponding passive sentence there holds a relation of synonymy. ${ }^{31}$ Chomsky observes that

we can describe circumstances in which a 'quantificational' sentence such as "everyone in the room knows at least two languages" may be true, while the corresponding passive "at least two languages are known by everyone in the room" is false, under the normal interpretation of these sentences - e.g., if one person in the room knows only French and German, and another only Spanish and Italian. This indicates that not even the weakest semantic relation (factual equivalence) holds in general between active and passive. (Chomsky 1957: 100-101).

But his counterexample needs some qualification ('under the normal interpretation') and only shows that in some cases the active sentence and its straightforward passive transform (may) differ in truth value; however, from this counterexample one cannot conclude that (a) there is not 'even the weakest semantic relation' 32 involved here, nor (b) that there is no semantic relation holding in general between active and passive.

Curiously, Chomsky then relativizes his downgrading of the appeal to semantics, ${ }^{33}$ but subsequently resumes an 'operational' stand, stressing that at the present stage, semantic clues are too vague, and therefore of little or no use in stating the formal linguistic structure. The study of (significant ?) 'correspondences' between formal and semantic 'features' (Chomsky 1957: 102) ${ }^{34}$ is put into perspective for a 'general theory

'differing in meaning' was used as a (first) criterial test with simple morphemes, given that larger contexts serve to distinguish relations such as polysemy and homonymy.

31. In Syntactic Structures Chomsky uses the term synonymity (and also the term homonymity).

32. 'Factual equivalence' is not, in my view, the weakest semantic relation.

33. 'These counterexamples should not, however, blind us to the fact that there are striking correspondences between the structures and elements that are discovered in formal, grammatical analysis and specific semantic functions' (Chomsky 1957: 101).

34. Chomsky uses the term 'features', but it remains unclear how, in his view, such features are arrived at. At the end of Chapter 9 of Syntactic Structures, Chomsky refers to 'presumed' features of meaning, and suggests a distribution-based study of (significant) differences between forms: 'In general, when we distribute a sequence of morphemes in a sequence of blanks we limit the choice of elements that can be placed in the unfilled positions to form a grammatical sentence. Whatever differences there are among morphemes with respect to this property are apparently better explained in terms of such grammatical notions as productivity, freedom of combination, and size of substitution class than in terms of any presumed feature of meaning' 
of language that will include a theory of linguistic form and a theory of the use of language as subparts' (Chomsky 1957: 102).

\section{Epilogue: A new 'flux'}

Chomsky's Syntactic Structures was a work rooted in the American structuralist tradition (cf. Hymes/Fought 1975: 1044-53, 1067-76, 1080-7); it was inspired by the structuralist concern with rigorous methodology, by the emphasis laid on the formalization of descriptive representations, and by the distrust of 'intuition'; the methodological problems tackled by Chomsky were those addressed already by linguists such as Harris, Hockett, and Pike, and even the concept 'transformation' had its origin in their writings. Chomsky departed from his structuralist predecessors in paying little attention to the problem of linguistic levels and of the descriptive techniques (and notations) associated with distinct levels. As a matter of fact, Syntactic Structures with its focus on a single level of description within distributionalist taxonomy propounded interdependence of levels as an overall evaluation measure. In Chomsky's view linguistic levels are a derivative notion with respect to structural descriptions; he also made it clear that field techniques for data collection and data analysis should be sharply distinguished from constraints and principles to be observed in grammar construction. This view - made explicit by Chomsky in the early 1960s, and vehemently criticized by structural linguists advocating a rigid distinction between the phonemic, morphophonemic and morphemic levels - is closely tied up with Chomsky's strategy in carrying the methodological discussion to another stage: from the outset, he presents his book as a contribution to a (formalized) general theory. The general theory is one about the formal definition of grammar, i.e., about the specification of the form of grammar. For Chomsky, the aim of linguistic theory is to establish a formal concept of grammar as a device that enumerates the sentences of a language in such a way that for each sentence of the language one can associate with it its (correct) structural description (cf. Chomsky 1962).The discussion thus became a 'foundational' one, concerning the form of grammar and concerning the comparative evaluation of grammatical formats. But then again, the structuralist 'reflux' is undeniable: the properly linguistic argumentation in Syntactic Structures is based on distributional grounds and on statable, i.e., formalizable relationships. And, as noted above, semantics is eschewed. Also, no reference can be found to the speaker's 'competence' or 'interiorized knowledge', the key notion in what Chomsky later called the 'cognitive revolution' brought

(Chomsky 1957: 105). Explanation of formal distribution is presented here as a substitute for 'talk about meaning. 
about by generative grammar. ${ }^{35}$ But at the time Syntactic Structures rolled off the press, Chomsky was already moving ahead.

Let us take a look at a passage in Lees's review:

Perhaps the most baffling and certainly in the long run by far the most interesting implications of Chomsky's theories will be found in their cohesions with the field of human psychology. Being totally incompetent in this area, I shall allude to only one possible consideration, but one which I find extremely intriguing. If this theory of grammar which we have been discussing can be validated without fundamental changes, then the mechanism which we must attribute to human beings to account for their speech behavior has all the characteristics of a sophisticated scientific theory. We cannot look into a human speaker's head to see just what kind of device he uses there with which to generate the sentences of his language, and so, in the manner of any physical scientist confronted with observations on the world, we can only construct a model which has all the desired properties, that is, which also generates those sentences in the same way as the human speaker. If the model has been rendered maximally general, it should predict correctly the human speaker's future linguistic behavior. We may then attribute the structure of this model to the device in the human

35. See Chomsky (1992: 9-11): 'The rise of generative grammar in the 1950s, a major factor in the cognitive revolution, also resurrected traditional ideas. The Cartesians, in particular, had applied their ideas on the nature of the mind to the study of language, which was commonly viewed as a kind of "mirror of mind", reflecting the essential properties of mind. [...] The cognitive revolution of the 1950s, then, should be understood, I believe, as having recovered independently the insights of earlier years, abandoning the barren dogmas that had impeded understanding of these questions for a very long period; and then applying these classical ideas, now reconstructed in a new framework, in new ways, and developing them along lines that would not have been possible in an earlier period, thanks to new understanding in the sciences, technology and mathematics that had developed during this century. From the point of view adopted in this so-called "cognitive revolution", the central problems of the study of language are essentially the following four:

The first question, a preliminary to any further inquiry, is this: What is the system of knowledge incorporated in the mind/brain of a person who speaks and understands a particular language? [...] A theory concerned with this topic for a particular language is called "a grammar of that language", or in technical terms, "a generative grammar of the language" [...]

How is this knowledge of language used in thought or expression of thought, in understanding, in organizing behavior, or in such special uses of language as communication, and so on? [...] Assuming some kind of answer to the first and central problem of characterizing the knowledge attained, we can turn to a third problem: to find the physical mechanisms that exhibit the properties that we discover in the abstract investigation of language and its use, that is, the physical mechanisms of the brain that are involved in the representation of knowledge, and the physical mechanisms of the different systems of the brain that access and process this knowledge. [...]

The fourth problem is to explain how the knowledge of language and ability to use it are acquired'. 
head, and say that we understand human speech behavior better than before. (Lees 1957: 406).

And so it happened ... In the first issue of volume 35 of Language, a year and a half after the publication of Lees's review, Chomsky published his review of Skinner's Verbal Behavior, ${ }^{36}$ in which he assumes a very different tone ${ }^{37}$ from the one he had used in his Syntactic Structures. The review introduced the notion of 'innate grammatical schematism', and speaks of the 'remarkable ability' to understand new sentences, to note certain ambiguities, to distinguish sentences from non-sentences, and of the grammar that each individual has 'somehow and in some form internalized' (Chomsky 1959: 56). We touch here upon new perspectives - integrating linguistics, psychology, and epistemology —, upon new issues for wide-ranging controversies - with behaviorists and empiricists upon new intellectual challenges: in short, a new phase in the search for a theory of linguistic structure. ${ }^{38}$ But that part of its history has to be saved for another day.

\section{References}

Bloch, Bernard \& George L. Trager. 1942. Outline of linguistic analysis. Baltimore, Md.: Linguistic Society of America at the Waverly Press.

Boal, Iain A. 1984. Chomsky and the State of Linguistics. Unpublished typescript.

Chomsky, Noam. 1953. "Systems of Syntactic Analysis". Journal of Symbolic Logic 18. 242-256. Chomsky, Noam. 1955a. Transformational Analysis. Ph.D. dissertation, University of Pennsylvania. Chomsky, Noam. 1955b. “The Logical Structure of Linguistic Theory”. Ms., dated June 1955. Available from Columbia University Psychology Library.

Chomsky, Noam. 1956. "Three Models for the Description of Language ". IRE (Institute of Radio Engineers) Transactions on Information Theory 2. 113-124.

36. For a study of this review (and of later reactions to it), see Swiggers (1995).

37. See, e.g., the following passage: 'Careful study of this book (and of the research on which it draws) [...] indicates, furthermore, that the insights that have been achieved in the laboratories of the reinforcement theorist, though quite genuine, can be applied to complex human behavior only in the most gross and superficial way, and that speculative attempts to discuss linguistic behavior in these terms alone omit from consideration factors of fundamental importance that are, no doubt, amenable to scientific study, although their specific character cannot at present be precisely formulated. Since Skinner's work is the most extensive attempt to accommodate human behavior involving higher mental faculties within a strict behaviorist schema of the type that has attracted many linguists and philosophers, as well as psychologists, a detailed documentation is of independent interest. The magnitude of the failure of this attempt to account for verbal behavior serves as a kind of measure of the importance of the factors omitted from consideration, and an indication of how little is really known about this remarkably complex phenomenon' (Chomsky 1959: 28).

38. Cf. the passage quoted in note 35. See also Kasher (ed. 1991) and Matthews (1990). 
Chomsky, Noam. 1957. Syntactic structures. The Hague: Mouton.

Chomsky, Noam. 1959. "Review of Verbal Behavior, by B.F. Skinner". Language 35: 1. 26-59.

Chomsky, Noam. 1962. "Transformational Approach to Syntax". Third Texas Conference on

Problems of Linguistic Analysis in English, ed. by A.A. Hill, 124-185. Austin, Texas: The University of Texas.

Chomsky, Noam. 1964. Current issues in linguistic theory. The Hague: Mouton.

Chomsky, Noam. 1965. Aspects of the theory of syntax. Cambridge: M.I.T. Press.

Chomsky, Noam. 1975. The logical structure of linguistic theory. New York: Plenum Press.

Chomsky, Noam. 1992. "On the Nature, Use and Acquisition of Language". Thirty Years of Linguistic Evolution, ed. by M. Pütz, 3-29. Amsterdam/Philadelphia: John Benjamins.

Fodor, Jerry A. \& Jerrold J. Katz, eds. 1964. The structure of language; readings in the philosophy of language. Englewood Cliffs, N.J.: Prentice-Hall.

Gleason, Henry A. 1955. An introduction to descriptive linguistics. New York: Holt.

Hall, Robert A. 1964. Introductory linguistics. Philadelphia: Chilton Books.

Harman, Gilbert, ed. 1974. On Noam Chomsky : critical essays. Garden City, N.Y.: Anchor Press.

Harris, Randy Allen. 1989. "Argumentation in Syntactic Structures". Rhetoric Society Quarterly 19. 103-124.

Harris, Randy Allen. 1993. The linguistics wars. New York: Oxford University Press.

Harris, Zellig S. 1945. “Discontinuous Morphemes”. Language 21: 3. 121-127.

Harris, Zellig S. 1951. Methods in structural linguistics. Chicago: The Univ. of Chicago Press. (Repr. as "Phoenix Books" P 52 with the title Structural Linguistics, 1960; 7th impression, 1966; 1984.) [Preface signed "Philadelphia, January 1947"].

Harris, Zellig S. 1954. "Distributional Structure”. Word 10: 2. 146-162.

Harris, Zellig S. 1957. "Co-Occurrence and Transformation in Linguistic Structure”. Language 33: 3. 283-340.

Harris, Zellig S. 1962. String analysis of sentence structure (= Papers on Formal Linguistics, 1). The Hague: Mouton.

Harris, Zellig S. 1981. Papers on syntax. Dordrecht: Reidel.

Harwood, F.W. 1955. "Axiomatic Syntax: The Construction and Evaluation of a Syntactic Calculus". Language 31: 3. 409-413.

Hill, A.A., ed. 1962. Third Texas Conference on Problems of Linguistic Analysis in English, May 9-12, 1958. Austin: University of Texas.

Hiż, Henry \& Pierre Swiggers. 1990. “Bloomfield, the Logical Positivist”. Semiotica 79. 257-270. Hockett, Charles F. 1947. "Problems of Morphemic Analysis". Language 23: 4. 321-343.

Hockett, Charles F. 1948. “A Note on 'Structure””. IJAL 14. 269-271.

Hockett, Charles F. 1954. “Two Models of Grammatical Description”. Word 10. 210-234.

Hockett, Charles Francis. 1955. A manual of phonology. Baltimore: Waverly Press.

Hymes, Dell H. \& John G. Fought. 1975. American structuralism. The Hague: Mouton.

Kasher, Asa, ed. 1991. The Chomskyan turn. Cambridge, Mass.: Basil Blackwell.

Koerner, E.F.K. 1970. "Bloomfieldian Linguistics and the Problem of 'Meaning': A chapter in the history of the theory and study of language". Jahrbuch für Amerikastudien 15. 165-183.

Koerner, E.F.K. 1989. “The Chomskyan 'revolution' and its historiography. Observations of a bystander". Practicing linguistic historiography : selected essays, ed. by E.F.K. Koerner, 101-146. Amsterdam/Philadelphia: John Benjamins.

Koerner, E.F.K., Matsuji Tajima \& Carlos Peregrín Otero. 1986. Noam Chomsky : a personal bibliography, 1951-1986. Amsterdam/Philadelphia: John Benjamins.

Lees, Robert B. 1957. “Review: Syntactic Structures by Noam Chomsky”. Language 33. 375-408. 
Maher, J. Peter. 1980. “The Transformational-Generative Paradigm: A Silver Anniversary Polemic”. Forum Linguisticum 5: 1. 1-35.

Matthews, P.H. 1990. “Language as a Mental Faculty: Chomsky's Progress”. Encyclopaedia of Language, ed. by N.E. Collinge, 112-138. London: Croom Helm.

Matthews, P.H. 1993. Grammatical theory: from Bloomfield to Chomsky. Cambridge: Cambridge University Press.

Murray, Stephen O. 1981. "Review of Newmeyer, 1980: Linguistic Theory in America". Historiographia Linguistica 8. 107-112.

Murray, Stephen O. 1984. Group formation in social science. Edmonton: Linguistic Research Institute.

Newmeyer, Frederick J. 1980. Linguistics in America: The first quarter-century of transformationalgenerative grammar. New York: Academic Press.

Newmeyer, Frederick J. 1986. "Has There Been a 'Chomskyan Revolution' in Linguistics?” Language 62: 1. 1-18.

Pike, Kenneth L. 1947. “Grammatical Prerequisites to Phonemic Analysis”. Word 3. 155-172.

Pike, Kenneth L. 1952. "More on Grammatical Prerequisites”. Word 8. 106-121.

Preston, William D. 1948. "Review of C.H. de Goeje, Études linguistiques caribes II”. IJAL 14. 131-134.

Sapir, Edward. 1921. Language, an introduction to the study of speech. New York: Harcourt Brace \& company.

Saporta, Sol \& Noam Chomsky. 1978. "An Interview with Noam Chomsky”. Linguistic Analysis 4. 301-319.

Shannon, C.E. \& Warren Weaver. 1949. The Mathematical Theory of Communication. Urbana: University of Illinois Press.

Swiggers, P. 1995. "How Chomsky Skinned Quine: Or, What 'Verbal Behavior' Can Do". Language Sciences 17: 1. 1-18.

Trager, George L. \& Henry Lee Smith. 1951. An outline of English structure. Norman, Okla.: Battenburg Press.

Wells, Rulon S. 1947. “Immediate Constituents”. Language 23: 2. 81-117.

Wells, Rulon S. 1963. "Some Neglected Opportunities in Descriptive Linguistics”. Anthropological Linguistics 5: 1. 38-49. 

PART II

The cognitive revolution 



\title{
Chomsky's other Revolution
}

\author{
R. Allen Harris \\ Department of English, University of Waterloo
}

Noam Chomsky is closely associated with the eponymous Chomskyan Revolution, a dramatic shift of allegiances, interests, and methodologies in linguistics over the decade or so following his 1957 Syntactic Structures. But these events did not occur in isolation. The developments in linguistics, and Chomsky's currents of influence more generally, were shaped by movements in other fields, chiefly mathematics, philosophy, and psychology; in turn, Chomsky's picture of linguistics, and his associated arguments, shaped developments in those fields as they participated in another revolution, an umbrella revolution, the Cognitive Revolution.

The Cognitive Revolution, also dating to the 1950s but still today, grew largely out of artificial intelligence and psychology, dilating to include disciplines such as philosophy, anthropology, the neurosciences, literary criticism, and even several distinctly non-Chomskyan frameworks within linguistics. All histories of this revolution name Chomsky prominently among the founding figures, on the basis of the shared features between his approach to linguistics and the model of mind that anchored the revolution, and on the basis of his systematic dismissal of the psychological framework that cognitive revolutionaries forcefully rejected, behaviorism. This chapter charts the interpenetration of Chomskyan linguistics, Cognitive Psychology, and Artificial Intelligence, as the Cognitive Revolution took form. It pays particular attention to Chomsky's collaborations with George Miller, another universally identified founding figure of the Cognitive Revolution, whose work profoundly and directly shaped Cognitive Psycholinguistics; and to the consonance Chomsky's model had with the algorithmic, information-processing, computational picture of mental life that was among the first principles of the Cognitive Revolution.

\section{Chomsky's other revolution}

The rise of 'cognitive science' as an umbrella category covering much work in linguistics as well as in psychology, philosophy, computer science and artificial intelligence, has taken place for the most part under a Chomskyan mantle. 
There was an upheaval of decisive proportions in linguistics in the late nineteen-fifties whose consequences are still widely in evidence, an upheaval propelled in very large measure by the claims, instruments, and arguments of Noam Chomsky (b. 1928). The upheaval is controversial. In particular, the term revolution was contested from the outset, and it remains at the centre of debates over the outcome of that shift (see, for instance, Searle 2002; Bromberger \& Searle 2002; Chomsky \& Searle 2002). This situation on its own is probably enough to invalidate Kuhn's (1962) model for that shift, in which a revolution, after a period of contention, settles into paradigmatic normal science. Indeed, Percival (1976) pointed out that paradigm did not apply to Chomsky's program in the mid seventies, since that program was not "a conceptual framework shared by all the members of the profession" (289), an observation that is even more apposite to the field of linguistics fifty years after the upheaval; thirty after Percival's observation.

But there is another Kuhnian train of events in which Chomsky played a legendary role, one for which the word revolutionary is widely used, with little or no controversy: the rise of cognitive science. Richardson (1998) describes this train as "the spectacular developments in psychology, linguistics, philosophy of mind, and neuroscience ... [which] form the central story of Anglo-American intellectual life from the 1950s to the present" (1998: 39). Virtually all historians of the cognitive revolution, amateur and professional, foreground Chomsky. Cognitive Scientist Paul Thagard (2005), for instance, reels off the familiar role call thusly:

There is no canonical list of the "founders" of cognitive science, but such a list could not omit the following figures who were active in the mid-1950s eruption of ideas that provided the intellectual origins of the field: Noam Chomsky, George Miller, Marvin Minsky, Allen Newell, and Herbert Simon. (2005: 320).

And Margaret Boden's (2006) massive, two-volume study, Mind as Machine: A History of Cognitive Science, features Chomsky very prominently. "The cognitive revolution," she says, "starts with psychology" (282) - in particular, with "the psychological work inspired by Noam Chomsky" (283). In fleshing that claim out, her section, "Pointers to the Promised Land," unfolds a chronicle entitled "Chomsky Comes on the Scene" (296-298).

"More than any other figure," David Golumbia argues, "Noam Chomsky defined the intellectual climate in the English-speaking world in the second half of the twentieth century. ... [N]ot only did Chomsky redefine the entire academic discipline of linguistics, but his work has been something close to definitive in psychology, philosophy, cognitive science, and even computer science." (Golumbia 2009: 31). More than any other figure, arguably, is hyperbolic, though Golumbia's case is very persuasive. But the general scope and the multidisciplinary range Golumbia gives to Chomsky's influence is not. 
While Chomsky's influence has not been uniform, stable, or cumulative in any of the fields Golumbia itemizes, and while it has seen a notable decline in recent decades, it has unquestionably been massive with respect to their collective transformation of the intellectual landscape over the second half of the twentieth century. In this essay, I examine the intersection of Chomsky's activities with the development of two of these fields: the shift towards cognitivism in psychology; and the growth of artificial intelligence, the cognitive wing of computer science,. I am interested, specifically, in how a research program founded on two books with negligible overt attention to mental activity or knowledge representation - The Logical Structure of Linguistic Theory and Syntactic Structures - backstopped the cognitive revolution.

\section{Cognitive psychology}

[B]y the end of the 1950's the distant mutterings of a scientific revolution were in the air, impelled by Chomsky's generative and transformational grammar.

Psychology and language have long commingled, but their relationship had gone largely underground in the first half of the twentieth century. This relationship resurfaced at a workshop of psychologists and linguists at Cornell University in 1951, which led to the formation of an interdisciplinary Committee on Linguistics and Psychology the following year, a Summer Institute seminar a year later, and a nine-author monograph the year after that, Psycholinguistics: A Survey of Theory and Research Problems (Carroll et al. 1954). ${ }^{1}$ This new hybrid subdiscipline, psycholinguistics, was emerging just as Chomsky was going through graduate school.

One of the psychologists on the 1952 Committee was George A. [Armitage] Miller (b. 1920), soon to become Chomsky's strongest advocate in psychology, and the

1. See Weiss (1925) for a very brief and very behaviorist account of the intersection of psychology and linguistics at the quarter century. Roger Brown (1970: vii) gives the 1951 Cornell workshop as the official birth site of psycholinguistics. The word itself, psycholinguistic, dates to considerably earlier — A.F. Chamberlain used it in 1894 (Chamberlain 1894: 454) — though it does not seem to have had much currency, and certainly no disciplinarity, until the mid 1950s. Carroll et al. (1954) is almost universally cited not by its authors, as I have cited it here, but by its editors, Charles Osgood and Thomas Sebeok. No doubt their editorial work was heroic, given the number and variety of the monograph's authors, and the remarkably brief completion time, but such a citation misrepresents both the structure of the book, which, until I actually consulted it, I long believed to be an edited collection, and the remarkable cohesiveness of the principals in this story. 
most important force in psycholinguistics as it mutated rapidly in cognitive directions over the latter part of the 1950s, into the 1960s. His talk on Chomsky, transformational grammar, and psychology "became famous on the university lecture circuit" (Crowther-Heyck 1999: 53). Miller is especially interesting, too, as a representative case study in the swift disciplinary shift of the umbrella field - from psychology as "the science of behavior," in the conventional definition with which he opens his 1951 textbook, Language and Communication (Miller 1951: 1), to psychology as "the science of mental life," in the more controversial terms he used for the subtitle of his 1962 textbook, Psychology (Miller \& Buckhout 1962b).

When he met Chomsky, Miller was an established psychologist, actively forging links between linguistics and psychology by way of information theory, cybernetics, and symbolic logic. A survey article he wrote in 1954, for instance, introducing work in "Communication" relevant to psychology, included Jakobson, Fant, and Halle's Preliminaries to Speech Analysis (Jakobson, Fant, \& Halle 1952) and Zellig Harris's Methods in Structural Linguistics (Harris 1951[1947]), alongside work by Claude Shannon (Shannon 1951), Rudolph Carnap and Yehoshua Bar-Hillel (Carnap \& Bar-Hillel 1952), and Benoit Mandelbrot (Mandelbrot 1953). He could not, in short, have been better prepared for the work of Chomsky, whom he met in September of the year he published that survey. In Bernard J. Baars's phrasing, Chomsky sounds like an ingénue at a Hollywood soda counter: "George A. Miller discovered Chomsky, and became his advocate among psychologists" (1986: 193). The meeting occurred at a symposium on information theory in Cambridge. Chomsky was at Harvard, a Junior Fellow in the Society of Fellows; Miller was at M.I.T., in its Research Laboratory of Electronics (RLE). Within two years, they had switched institutions - Chomsky now in the RLE, working on Victor Yngve's machine translation project, Miller in the psychology department at Harvard, where he would soon found the Center for Cognitive Studies with Jerome Seymour Bruner (b. 1915) - but they remained in close contact.

The 1954 information-theory symposium was hosted by the RLE, and another followed in 1956, at which they both gave major papers. Miller's paper was a version of his classic $7 \pm 2$, magical-number paper (Miller 1956), Chomsky's, his hugely influential “Three Models for the Description of Language" (Chomsky 1956b). The symposium was wide-ranging - information theory was growing faddishly in the mid-fifties and many disciplines were represented - but the dominant theme was a view of the brain as an information processor, with a strong subtheme that a certain information-processing machine, the computer, could converge with the brain in important and revealing ways.

The symposium was a confluence of transformational generative grammar, information-processing psychology, and artificial intelligence, the gathering of ideas that are widely understood to have ignited the cognitive revolution. Miller dates the "moment of conception" for cognitive science to the second day of the symposium when it became clear that a concept of mind was necessary for solving the important 
problems of psychology, and that the tools for solving those problems were meshing before his eyes. "I went away from the Symposium with a strong conviction," Miller later remembered,

...more intuitive than rational, that human experimental psychology, theoretical linguistics, and computer simulation of cognitive processes were all pieces of a larger whole, and that the future would see progressive elaboration and coordination of their shared concerns. (Miller 1979: 9)

Miller and Chomsky collaborated extensively over the next several years. They spent the summer of 1957 together at Stanford, both families living together in a fraternity house. On paper, Chomsky was Miller's teaching assistant for a seminar on mathematical psychology, but it was Chomsky's work they taught. "We worked together that summer and tried to teach Chomsky's semantics and Chomskyan syntax to students, who were all professors themselves," Miller later recalled. "That was an interesting summer” (Hébert 2006). They were soon publishing together (Chomsky \& Miller 1958; Chomsky \& Miller 1963; Chomsky \& Miller 1957; Miller \& Chomsky 1963). More significantly, Miller developed an empirical research program based on the Syntactic Structures grammar which is widely regarded as having triggered the explosion of cognitivist psycholinguistic research and the accompanying disciplinary growth. Miller was a maturing giant in psychology — "if there were a retrospective Nobel Prize in Psychology for the mid-1950s," Bruner has written, "George Miller would win it hands down ... on the basis of [his $7 \pm 2$ paper alone] (though he had lots of other arrows in his quivers)" (Bruner 1983: 97) - and his endorsement of Chomsky's linguistics was effectively a Cognitive Seal of Approval.

These developments were multiplex, for Miller and for cognitivists generally, but, in line with Kuhn's observations, they reflect two central motives: the drive away from a science of behavior and the drive toward a science of mental life. Chomsky was deeply implicated in both. The repulsion from behaviorism that characterized the early growth of cognitive science is summed up almost entirely in Chomsky's lionized review of B.F. Skinner's Verbal Behavior (Chomsky 1959; Skinner 1957). The propulsion toward mental representations and processes was powerfully aided by Chomsky's linguistic arguments, chiefly represented by the book that came out the same year as Skinner's, Syntactic Structures (Chomsky 1957).

\section{Out with the science of behavior}

The contemporary linguistic assault on associationist learning theory began with Noam Chomsky's gloves-off critical review of Skinner's Verbal Behavior. 
Chomsky's legendary assault on B.F. [Bhurrus Frederic] Skinner (1904 - 1990) circulated for some time before it was published in 1959 as the featured piece in the premier linguistics journal, Language. It is a long, meticulous, devastating review, meant less to evaluate a particular book than to eradicate the line of thought it represented. Perhaps because Chomsky was largely unknown in psychology at the time, Skinner thought that Miller had masterminded it (Crowther-Heyck 1999: 53, 63n109), but it is vintage Chomsky, with the characteristic ad hominem disdain that attends most of his polemics. Miller had certainly seen it before publication, as had many scholars in the emerging cognitivist circle centered in Cambridge, and he was highly receptive. Miller had little trouble shedding the behaviorism he initially identified with. Looking back now, he sees his early behaviorist moves as a type of fakery:

In 1951, I apparently still hoped to gain scientific respectability by swearing allegiance to behaviorism. Five years later, inspired by such colleagues as Noam Chomsky and Jerry Bruner, I had stopped pretending to be a behaviorist. (Miller 2003: 141)

Miller, it is clear, was never a pure behaviorist, but it is doubtful if anyone was a pure behaviorist in the 1950s. Mid-century psychologists, despite largely sharing one ideological banner, evinced that ideology in a variety of forms(see Kantor 1971; Staddon 1993, and Zuriff 1985 for various taxonomies). Most psychologists methodologically allied to operant conditioning were self-consciously neobehaviorist by that point, attempting to assimilate developments in other fields and other areas of psychology with the Watson-Skinner tradition of learning theory. Miller regarded his 1951 textbook, Language and Communication as "behavioristic" at the time, for instance (Miller 1951: 73), but once Verbal Behavior came out, and he saw what a truly behaviorist account of language and communication would look like, he came to regard it retrospectively as "eclectic, not behavioristic" (Miller 2003: 141). His work in the late forties and early fifties was characterized by a restless search for more revealing methods to investigate psychology generally and psychology of language specifically, and his book shows the results of that search.

Most of the emerging cognitivists were equally suspicious of behaviorist theories of human learning, regarding them as antithetical to the information-processing view of the brain. George Mandler (b. 1924), a Harvard psychologist at the time, remembers Cambridge as a "nest of antibehaviorist developments" in the early fifties (Mandler 2002: 343). He thinks it was "likely that Chomsky's review of Skinner's Verbal Behavior put him [that is, Skinner] beyond the pale of the burgeoning cognitive community" (Mandler 2002: 341), but for this community Skinner was very close to the pale already. His work with rats and pigeons did not, to anyone's satisfaction in that group, extend itself well to specifically human abilities, abilities without even the sliver of a presence in pigeons and rats - such as, quintessentially, language. Chomsky's review 
was playing to the gallery. "I thought it was damning," Miller has said of the review; adding, however, "I made [Chomsky] take out some of the worst slurs before it was published." (Hébert 2006). Even with the toning down Miller accomplished, the veil over Chomsky's insults was diaphanously thin indeed: superficial alone is used four times, pointless five, empty six, vague seven; we also get confused, absurd, futile, grossly in error; a theory that "operates at a level so gross and crude that no answers are suggested to the most elementary questions" (Chomsky 1959: 54).

Its fame is well earned. The review is not just ruthlessly acerbic. It is ruthlessly efficient (Hébert 2006), exposing how "the insights that have been achieved in the laboratories of the reinforcement theorist, though quite genuine, can be applied to complex human behavior only in the most gross and superficial way" (Chomsky 1959: 28). But it is a mistake to regard this review as meeting, by any clear standards of argument, the mandate it is almost universally held to have satisfied by most cognitivists (and which Chomsky later encouraged - Chomsky 1967: 146): the intellectual obliteration of behaviorism. ${ }^{2}$ It is unquestionably and convincingly hard on core aspects of Skinner's program. But Skinner was not representative. He was a "respected but atypical behaviorist" (Baars 1986: 142), one for whom, while he did not explicitly endorse the label himself until later (Skinner 1974: 16ff), the phrase Radical Behaviorist was tailor-made. In particular, Skinner's claims about the extrapolation of experimentally manipulated animal behavior to the understanding of human capacities were not widely endorsed by other psychologists. ${ }^{3}$ Further, "Skinner is much more tentative and cognizant of the incompleteness of his ideas in [Verbal Behavior] than one would surmise from Chomsky's review" (Agassi 1997: 147n4). Still, the gallery, as galleries will, egged on by the scornful tone, read the review not as a careful dismantling of one theorist's research program, but as the public execution and ignominious burial of an entire psychological tradition, with salt sown over the grave. And the gallery grew.

2. See MacCorquodale (1969) for a late but very thorough answer to Chomsky's review, Andresen (1991) for an overview of the reception and an outline of the intellectual response to Chomsky's review, and Virués-Ortega (2006) for another overview, with observations from Chomsky. Skinner himself seems never to have commented on the review in print.

3. In fact, this is more than apparent in Chomsky's review, which notes on the first page that "Skinner's confidence in recent achievements in the study of animal behavior and their applicability to complex human behavior does not appear to be widely shared. In many recent publications of confirmed behaviorists there is a prevailing note of skepticism with regard to the scope of these achievements," and documents this skepticism well (Chomsky 1959: 26n1). One might also note the pair of mainstream psychology reviews, predating Chomsky's, that were markedly critical of Verbal Behavior (Morris 1958; Osgood 1958), or Tikhomirov's review in Word (Tikhomirov 1959). 
Chomsky's review also highlighted, as the strongest counter-evidence to Skinner's animal-extrapolation program, the

...fact that all normal children acquire essentially comparable grammars of great complexity with remarkable rapidity[,] suggest[ing] that human beings are somehow specially designed to do this, with data-handling or 'hypothesisformulating' ability of unknown character and complexity. (Chomsky 1959: 58)

And, while he was clear that "[a]t the moment, the question [about the ultimate character of this ability] cannot be seriously posed" (1959: 59), he offered the hope that "the study of linguistic structure may ultimately lead to some significant insights into this matter" (Chomsky 1959: 58-59).

\section{In with the science of mental life}

[T] he behaviorist theory was fundamentally dead, and ... the problem was [now] to reconstruct a kind of mentalism that would work, at least in some areas of psychology and presumably in linguistics, since that seemed to be where the action was.

— Jerry Fodor (in Baars 1986: 356)

The game plan for a study of linguistic structure which would prototype the science of mental life was laid out in Syntactic Structures, and in the massive Logical Structure of Linguistic Theory, a purple-ink hectographed version of which was in circulation among the vanguard. ${ }^{4}$ The importance of Logical Structure to the growth and impact of Chomskyan research in its first decade would be difficult to over-estimate. As dense as the book is, as restricted as its availability was, and as partially read as it was, even by those few who had access to copies, the very existence of the manuscript stood as guarantor to any gaps of coverage or generality of explication that might be perceived in Syntactic Structures. ${ }^{5}$ Its sheer mass, level of detail, style of exposition, even

4. There is no definitive count, so far as I know, of the number of copies in circulation; the usual quantity cited is "a couple of dozen" (Sheehy 2004: 67); the first-run of a hectograph could produce between 20 and 80 copies. Hectography was a laborious and messy process, mostly used (from the late nineteenth to the the mid twentieth century) for school bulletins, church newsletters and the like. It must have been a monumental chore to run off copies of a 919 page document. For a description of hectography, see Hanley, easily retrievable via Google Books (http://books.google.ca/books).

5. Chomsky regularly cited Logical Structure in this regard, particularly in his overviews of transformational generative grammar. Syntactic Structures has a dozen citations alone. 
its relative impenetrability for most linguists, assured the community that Transformational Generative Grammar was a complete and resilient theoretical edifice. The highly influential review of Syntactic Structures by Robert Lees (1922-1996), for instance, is (much like Chomsky's review of Skinner, in reverse) not about the book under review so much as it is about the emerging paradigm it represents, and for which Logical Structure stands bond:

The reviewer was privileged to read a first version of the larger work - The logical structure of linguistic theory, pp. $752+$ li (Cambridge, Mass., 1956) - and now finds it difficult to refrain from referring to topics and results which appear there but not in the book under review. This discussion may therefore serve in part as a preview of the author's detailed statement of his theory of language. (Lees 1957a: 375n1)

Prominent in Lees' review was the assurance that "in the long run by far the most interesting implications of Chomsky's theories will be found in their cohesions with the field of human psychology" (Lees 1957a: 406), and within the decade Chomsky was defining linguistics as a "branch of cognitive psychology" (Chomsky 2006[1968]: 1).

There are, however, no mentions of cognition, psychology, or mental life anywhere in Syntactic Structures; ditto with Logical Structure. That is not to say these themes weren't in Chomsky's mind at the time - who can say? - only that the cohesions with psychology that Lees advertises, and that came to be one of the most powerful selling points of transformational grammar, are more a product of creative hermeneutics than of careful composition. In fact, there is only one word with a prominent psychological lineage that has any substantial presence in both books, and that word is behavior. But it was clearly behavior with a twist.

Behavior in Chomsky's early work had two distinct senses, neither of which linked to its familiar operational meaning in the psychology of the time. In one sense, usually hitched to linguistic, it meant the way people understood their language - for instance, the awareness that actives and passives are related structures or recognizing that "Colorless green ideas sleep furiously" is 'grammatical,' while "Furiously sleep ideas green colorless" is not. For instance, in Logical Structure, Chomsky argues that "a systematic approach which defines grammatical sentences in terms of the rules ... would represent a fundamental contribution to our understanding of linguistic behavior" (Chomsky 1956a: IV-121). That is, rules help explain how speakers understand syntactic relatedness and grammaticality. Or, in Syntactic Structures, he says that "certain linguistic behavior that seems unmotivated and inexplicable in terms of phrase structure appears simple and systematic when we adopt the transformational point of view" (Chomsky 1957: 75). This use of behavior is effectively indistinguishable from knowledge, and represents the highest cognitive quotient in his work of the period. He frequently connects it with the only mentalist term that permeates Syntactic Structures and Logical Structure: intuition - as in, most clearly, when he says that if one could 
build a rule set that "corresponds to the 'intuitive sense of grammaticalness' of the native speaker," one would "have succeeded in giving a rational account of this behavior, i.e., a theory of the speaker's linguistic intuition." Building a grammar, in short, is modeling what speakers know about their language. "This," he adds, "is the goal of linguistic theory." (Chomsky 1956a: I-40).

The other sense of behavior is quite different, however. It does not reference speaker knowledge. It directly references the properties of abstract linguistic elements. Thus, when he says " $[w]$ e shall see that their behavior is very regular and simply describable," he is talking about auxiliary verbs. (Chomsky 1957: 38). When he says "we can investigate the place of its major constituent break by considering its behavior under certain transformations," he is talking about the verb-preposition construction (as in "thought of" or "laughed at;" Chomsky 1956a: IX-702). It is this second usage, and, in general, Chomsky's relentless talk of grammars and words and rules in dynamic, process-oriented, even anthropomorphic terms that triggered the bulk of psycholinguistic research in the late-fifties turn toward "mental life."

This mental-operation usage of behavior, very possibly entangled with the cognitive usage, led to an understanding of transformational grammar's links to psychology which (1) eventually led to a break between them, but, in the short term, (2) led to a surge of cognitivist psycholinguistic research. Crucially, under this construal, transformations were seen to correspond with mental events in a quite direct way. John Bissell Carroll (1916-2003), surveying the recent psycholinguistic surge in 1964, reported that "[t]housands of contributions to linguistics and the psychology of language" were published in the first few years of the 1960s, and attributed "this intense activity" to "working out, testing, elaborating, and refining the theories and new ideas of the previous decade" (Carroll 1964: 119). While that decade included the work he had helped initiate with the Committee on Linguistics and Psychology and its associated monograph (Carroll et al. 1954), work involving communication theory and the testing of Whorfian notions, it was clear that the bit was firmly in the transformationalist's mouth. After a very brief overview, Carroll begins explicating "Chomsky's (1957) sketch of a new linguistic theory" (Carroll 1964: 119). Summing up the work of the leading figure - in both that surge and in its transformational character - George Miller, Carroll found support for the conclusion

...that the 'transformations' underlying variations in linguistic structure correspond to 'mental operations' that have to be carried out in a certain order and in a definite amount of time in order to achieve certain results (Carroll 1964: 122).

This conclusion was precisely what Miller was arguing that the research showed, and what Chomsky appeared to be arguing as well with his dynamic metaphors of grammar. The earliest attempt to investigate the psychological reality of transformations began with what was later dubbed the 'correspondence hypothesis', a conjecture that the more transformations differentiated two sentences, the longer it would take for people to relate them (see Miller \& Buckhout 1962b: 757ff; Miller \& McKean 1964: 298f, 
reporting on work with Dan Slobin). In another overview of psycholinguistics the same year as Carroll's, A. Richard Diebold was even more effusive about the positive results pouring in. "It is especially exciting," he crowed, "that the work of Miller and others is beginning to offer corroboratory support for the 'psychological reality' of many of the abstract characterizations of the user's linguistic competence which are contained in a formalized generative grammar" (A. Richard Diebold 1964: 227). The transformational research in psycholinguistics snowballed into the 1970s. Samuel Fillenbaum's 1971 survey in the Annual Review of Psychology runs to over fifty pages, for instance, with constant mentions of Chomsky, transformations, competence, performance, deep structure, surface structure and other contributions from his expanding and shifting lexicon, and the title of one textbook in the early 70s made Chomsky's work definitional of the subfield: Psycholinguistics: Chomsky and Psychology (Greene 1972).

\section{Artificial Intelligence}

I must admit to taking a copy of Noam Chomsky's Syntactic Structures along with me on my honeymoon in 1961.

- Don Knuth (2003)

The second day of the 1956 Information Theory Colloquium made such an epochshifting impression on Miller because of two papers in particular (and perhaps also, though he doesn't mention it, because he gave a variant of his own groundbreaking $7 \pm 2$ paper that day). One, of course, was Chomsky's "Three Models." The other was by Allen Newell (1927 - 1992) and Herbert A. [Alexander] Simon (1916 - 2001). The abstract for their revolutionary paper, "The Logic Theory Machine - A Complex Information Processing System," reads, in part:

In this paper we describe a complex information processing system ... capable of discovering proofs for theorems in symbolic logic. This system, in contrast to the systematic algorithms that are ordinarily employed in computation, relies heavily on heuristic methods similar to those that have been observed in human problem solving activity. The specification is written in a formal language, of the nature of a pseudocode, that is suitable for coding for digital computers. (Newell \& Simon 1956: 61)

Newell and Simon were talking about abilities characteristic of intelligence, and they were talking about them as emanating from a machine. They were soon putting it this way:

There are now in the world machines that can think, that can learn and that can create. Moreover, their ability to do these things is going to increase rapidly until - in a visible future - the range of problems they can handle will be coextensive with the range to which the human mind has been applied. (Simon \& Newell 1958: 8) 
Newell and Simon had made their way to Cambridge that fall from the Dartmouth Summer Research Conference on Artificial Intelligence. The term conference is somewhat misleading. The event was a one-month, small-group, think-tank - including John McCarthy (b. 1927), Marvin Minsky (b. 1927), Nathaniel Rochester (1919 - 2001), and Claude Shannon (1916 - 2001) - at which the field of artificial intelligence was born (the phrasing having been coined in the 1955 proposal for that conference, by McCarthy, Minsky, Rochester, and Shannon). Bringing the product of that research into contact with psychology and linguistics at the symposium was a major impetus to the cognitive revolution.

Whatever Chomsky thought at the time of Newell and Simon's attempt to model human reasoning by mechanical means (later, he expressed only contempt - e.g., (Chomsky 2006[1968]: 85), Newell and Simon were clearly impressed with Chomsky's formal arguments about language, seeing them as closely aligned with their own research. Simon, for instance, characterizes the two papers, and the research programs they represent, as sharing a deep intellectual bond:

Historically the modern theory of transformational linguistics and the information-processing theory of cognition were born in the same matrix - the matrix of ideas produced by the development of the modern digital computer, and in the realization that, though the computer was embodied in hardware, its soul was a program. One of the initial professional papers on transformational linguistics and one of the initial professional papers on information-processing psychology were presented, the one after the other, at a meeting at M.I.T., in September 1956 [citing them]. Thus the two bodies of theory have had cordial relations from an early date, and quite rightly, for they rest conceptually on the same view of the human mind. (Simon 1996[1969]: 75) ${ }^{6}$

Chomsky's relation to artificial intelligence is somewhat cloudier than that with psychology. To begin with, there was a tradition of intermittent contact between linguists and psychologists, which had started to increase markedly just before Chomsky came on the scene. No such tradition existed in the beginnings of artificial intelligence - the Dartmouth gathering was dominated by mathematicians and engineers ${ }^{7}-$ until the Cambridge Information Theory Colloquium. But it is easy

6. Newell and Simon (Newell and Simon 1972: 4) date the cognitive revolution not quite to the symposium, as Miller does, but to the same year, because 1956 saw the publication of these two papers, along with Miller's $7 \pm 2$ results, and Bruner, Goodnow, and Austin's Study of Thinking (Bruner, Goodnow, and Austin 1986[1956]).

7. Simon was an economist, Newell a mathematician who wrote his doctorate under Simon; McCarthy, Minsky and Shannon were all mathematicians, Shannon having a degree in electrical 
to see why Chomsky's paper made such an impression on the AI community. There was an extremely important point of contact. All of the AI pioneers were versed in the narrow artificial languages of symbolic logic and computer programming; and Chomsky was well versed in logic and mathematics. That is, the AI folk were used to thinking in the language of mathematics; Chomsky in the mathematics of language. As Miller recalls, "Other linguists had said language has all the formal precisions of mathematics, but Chomsky was the first linguist to make good on the claim. I think that was what excited all of us" (1979: 8). ${ }^{8}$ If any contemporary work in linguistics promised to expand the range of computers until it became coextensive with range of the human mind - making language tractable to practical, applied, programming tasks - it was Chomsky's mathematically amenable models. The first area in which this range looked to be expanding was machine translation.

\section{Machine Translation}

Another important gap that also has significant practical implications lies in the area of simulation of natural language processes. Here, interest in language translation and in the improvement of computer programming languages has already led to exciting progress - as illustrated, for example, by the work of Chomsky and Yngve.

- Herbert A. Simon (1961: 117)

Chomsky's relation with machine translation is complicated and uncertain. Two things, however, are clear. First, Chomsky now disavows any interest in, involvement with, or sympathy for, the enterprise of computer translation. Officially, his first academic post was as a researcher on Victor Yngve's Machine Translation project, in the

engineering as well; Rochester was an electrical engineer. Rounding out the group were Oliver Selfridge (1926 - 2008) and Trenchard More, mathematicians, Arthur Samuel (1901 - 1990), an electrical engineer, and Ray Solomonoff (b. 1926), a physicist best known for his work in mathematics.

8. Miller was a psychologist by training (with lower degrees in English and Speech), but he studied mathematics at the Princeton Institute for Advanced Study in 1950, had a strong interest in computation, and had ties to members of the AI community. For instance, he obtained the funding for Minsky and Dean Edmond project to build an array of 'artificial neurons' (vacuum tubes), in an early connectionist experiment, which learned a path through a maze (Cordeschi 2007: 279n4). 
RLE, at M.I.T., but he reports taking the job under protest and then not contributing to the project at all:

While he was being interviewed by laboratory director Jerome Wiesner for the position, Chomsky stated that the project had "no intellectual interest and was also pointless' ... He actually 'never touched the translation project' (Barsky 1997: 86)

Second, however, he was perceived overwhelmingly by the AI community to be a Machine Translation researcher, which, in that predominantly applied-computing milieu, added considerable attraction to his work, and that view of Chomsky's early career remains common in AI circles. Coulter, for instance, says that "Chomsky was originally preoccupied by the technical problems posed by the project of achieving high-quality machine translation between natural languages" (Coulter 2003: 439-440). And the importance of Machine Translation research, which begat computational linguistics, for the development of Artificial Intelligence in the United States is difficult to overestimate. Winfred Lehmann went so far as to say that " $t]$ hrough work towards MT, scores of students with positions throughout the country have been trained at the Linguistics Research Center alone. The field of Artificial Intelligence would probably not have developed without such support." (Lehmann 1980: 188). ${ }^{9}$

Chomsky's role in the RLE project is difficult to reconstruct, but he does not seem to have been very active in any obvious, hands-on way. He regularly produced versions of his work for the RLE Quarterly Report in the mid-fifties, and wrote at least one analysis explicitly for the Machine Translation project, with Fred Lukoff (Chomsky \& Lukoff 1955; see Lees 1957b: 6n2), and did some minor chores, such as translating an abstract from Hebrew to English for Machine Translation, an M.I.T. newsletter (Bar-Hillel 1956). But the archives of Machine Translation include no mention of direct activity. The closest they come is a brief remark by Yngve that reads like a justification of Chomsky's presence in the lab. Commenting on the failure to obtain "an adequate description" of German for the recognition routines they are developing, he says that "perhaps linguists have not known how to make such a grammar, or how to tell a good grammar from a bad one," and adds that "[i]t is these problems that have been occupying N. Chomsky. He has been working on a theory of grammar that gives many new and powerful insights into the structure of language" (1956: 45). This is cheek-by-jowl with notes on Applegate, Lees, and Matthews directly building such a description of German. On the other hand, those same archives brim with references to Chomsky's

9. George Miller has a presence in this work as well (see Miller \& Beebe 1956, which mentions, without citation, Chomsky on grammaticality). The same issue of Mechanical Translation that includes Miller and Beebe (1956) has a very early (pre-publication?), brief, favorable notice of Syntactic Structures, focusing on the Chomsky Hierarchy argument for transformations (Ulvestad 1956). 
models and citations of his work. It would be easy to get the impression from reading Machine Translation in the late fifties and early sixties that the RLE project was essentially Chomsky's augmented no doubt by the knowledge that many of its personnel (Lees, Morris Halle, G.H. Matthews) were strongly allied to his approach. The AI community certainly regarded the primary force of Chomsky's contribution to be in the area of Machine Translation, as witnessed by Simon's session-opening address at the 1961 IRE session on Modeling Human Mental Processes (Simon 1961: 117). ${ }^{10}$ Yehoshua BarHillel, Chomsky's close friend and the first leader of the RLE Machine Translation project, argued strongly for a transformational approach to translation and computational linguistics (Bar-Hillel 1966: 4-7). In a survey of "Syntactic Analysis of English by Computer" for the 1963 Joint AFIPS Computer Conference, ${ }^{11}$ Daniel Bobrow includes more mentions of Chomsky than all other linguists combined, including people like Harris and Yngve, who were heavily and directly involved in computational projects (Bobrow 1963).

In the linguistics community, also, the impression was fostered that Chomsky's research implicated computers and electronic translation work. In part, there was the lineage. Zellig Sabbatai Harris (1909-1992) was not only his thesis and dissertation supervisor, he was also the intellectual source of transformational grammar. He was additionally well-known for his interest in computers; his approach to transformations encompassed practical problems of interest to the AI community, including information retrieval (Harris 1952), as well as machine translation (Harris 1954); and he was explicit about the computational amenability of transformational grammar. "[S]ince transformational methods are entirely formal," he wrote, "the obtaining of the normal form can be done mechanically. In fact, it can be done in principle by a computer, and in principle for all sentences of the language" (Harris 1964: 421).

Lees' promotional review of Syntactic Structures, too, highlights "the field of machine translation" as an area "in which Chomsky's conception of grammar may prove to be of the utmost importance" (Lees 1957b: 406). Lees was speaking from experience. He used Chomsky's arguments and instruments regularly, as did all of

10. The session, incidentally, included a dialogue project involving Carol Chomsky. Tracing her computational work in the period would make for a fascinating project. She had a position on the Machine Translation project earlier than Noam, from 1951 to 1953, under Yehoshua Bar-Hillel, followed by a position on Harris's Transformations and Discourse Analysis Project (TDAP) at the University of Pennsylvania, 1955 to 1959, after which she moved back to M.I.T., working in the Lincoln Laboratory, 1959 to 1962 (Hutchins 2000: 78). Aravind K. Joshi and Phil Hopely report that the project outlined in the 1961 Mental Processes session, a question-and-answer application about baseball (Bert F. Green et al. 1961), developed out of program that Carol Chomsky took with her when she moved from the TDAP back to M.I.T. (Joshi \& Hopely 1996: 294).

11. That is, the American Federation of Information Processing Societies, which combined both the Institute of Electrical and Electronic Engineers Computer Society and the Association for Computing Machinery. 
the RLE Machine Translation group, in the research that came out of that project (see Lees 1957b; Yngve 1957; Yngve 1960). Again, however, the perception of Chomsky's sponsorship relied more on hermeneutics than on argumentation when it comes to Chomsky's work itself. Certainly there is no overt concern with translation issues in Syntactic Structures, nor in Logical Structure, and no such concern manifests in his subsequent work.

\section{A device of some sort}

Syntactic investigation of a given language has as its goal the construction of a grammar that can be viewed as a device of some sort for producing the sentences of the language under analysis.

— Noam Chomsky (1957: 11)

"[A] grammar," Lees said, explicating the Syntactic Structures model (Lees 1957a: 384), "may be described as though it were a kind of machine," and while telephone switchboards had been used extensively in information theory analogies, and all sorts of other devices were theoretically possible, it was clear to everyone what sort of machine a Chomskyan grammar resembled, almost to the point of identity. And, just in case it wasn't clear, Lees went on. "[T]he derivations" of such a grammar, under the right conditions, he added, "may be mechanized inside an actual physical machine, such as an electronic computer" (Lees 1957a: 385). Lees was here continuing Chomsky's policy of fostering a strong sense of affinity between his formal approach and the computational approach to language.

Chomsky was, in the early years, thoroughly enmeshed in the computational community. He attended and gave talks at information theory conferences, which were heavily populated by computer science people. He attended and gave talks at more specifically computational venues, such as, with Miller, a Symposium on Pattern Recognition (Chomsky \& Miller 1957), an International Symposium on Automata Theory (see Koerner \& Tajima 1986: 20), and a summer school in programming at the University of Michigan in 1958, where he gave a lecture entitled "Linguistics, Logic, Psychology, and Computers." He published in the journals that were defining computer science, such as Information and Control, the Journal of Symbolic Logic, and IRE Transactions. He placed chapters in books like Computer Programming and Formal Systems (Chomsky \& Schutzenberger 1963) and Computer Programming and Artificial Intelligence: An Intensive Course for Practicing Scientists and Engineers (see Chomsky 1958). He published on topics, like push-down storage, which were of interest almost exclusively to computer scientists (Chomsky 1962).

What he said in many of these publications had a pessimistic cast about the immediate prospects of computationally implementing a natural-language grammar. 
His most widely cited and influential finding - announced in "Three Models," the paper that helped launch the cognitive revolution, and repeated in Syntactic Structures - was in fact a negative 'proof' about the descriptive incapacity of finite state grammars (Markov processes) to handle the full richness of natural languages. Prior to "Three Models," developing out of work by Claude Shannon (1948) and endorsed by Charles Hockett (1955), there was a vigorous research program attempting to analyze natural languages (for applications such as Machine Translation) in terms of finite state grammars. And, much as Chomsky's assault on Skinner helped to clear the decks for psychologists' embrace of generative grammar and its associated hypotheses, his systematic discounting of finite state grammars helped clear the deck for computer scientists' embrace of transformational grammar. Those arguments also substantially reduced, by association, the cachet of information theory. To replace those research programs, Chomsky offered a new picture of language, and a new methodology to research it:

[W] e picture a language as having a small, possibly finite kernel of basic sentences with phrase structure in the sense of $\$ 3$, along with a set of transformations which can be applied to kernel sentences or to earlier transforms to produce new and more complicated sentences from elementary components. We have seen certain indications that this approach may enable us to reduce the immense complexity of actual language to manageable proportions and; in addition, that it may provide considerable insight into the actual use and understanding of language. (Chomsky 1956b: 124)

"Certain indications" is not, on the face of it, incendiary talk, but there is a noteworthy similarity here between Chomsky's phrasing and Watson and Crick's phrasing, in their revolutionary DNA paper. "It has not escaped our notice," they remark, "that the specific pairing we have postulated [i.e., the double helix structure of DNA] immediately suggests a possible copying mechanism for the genetic material" (1953: 737). Chomsky does not reach quite the level of smug faux-humility that Watson and Crick achieve in this most famous of litotes in the history of science. ${ }^{12}$ His paper is nowhere near as earth shattering as theirs, his understatement not so elaborate. But his tone,

12. Compare Watson, on the initial idea:

My pulse began to race. If this was D.N.A., I should create a bombshell by announcing its discovery. The existence of two intertwined chains with identical base sequences could not be a chance matter. Instead it would strongly suggest that one chain in each molecule had at some earlier stage served as the template for the synthesis of the other chain. (Watson 1968: 118).

And here is Crick: "The structure of D.N.A. ... immediately gave the game away, suggesting only too vividly how nucleic acid could be replicated exactly. (Crick 1988: 60). 
like theirs, is of conspicuously muted triumph: the "certain indications" are for reducing "immense complexity" into "manageable proportions;" thereby yielding "considerable insight" into a notoriously difficult problem, "the actual use and understanding of language."

It is not understatement, however, that made this paper famous in artificial intelligence. It is the establishment of the "Chomsky Hierarchy," and its implications for computational modeling of language. Chomsky argues that finite state grammars are not sufficient to bring immense complexity into manageable proportions. Nor are phrase structure grammars. One must go up the hierarchy of descriptive power yet further, to transformational grammars. And it is only on that level of the hierarchy, the transformational level, where one might be able to gain considerable insight into the use and understanding of language. Ostensibly here, in the "Three Models" paper, Chomsky is talking about the activity of a linguist, studying the cognitive resources of speakers and hearers. But in this context - read at the Information Theory symposium, published in the transactions of the Institute of Radio Engineers - the management and use and understanding of language have, in a phrase used in other contexts by Chomsky, a "systematic ambiguity." They can certainly apply to the linguist and to cognitive resources. But there are two more construals as well, both of which were mutually reinforcing in the developing cognitive science community. Actual use, in particular, very naturally suggests verbal behavior; that is, dynamic performance. And actual ... understanding equally suggests cognitive processing. More crucially, in the context of computer science and the nascent artificial intelligence movement, manageable proportions meant (or at least evoked) computationally tractable proportions, while use and understanding implied computational use and computational understanding.

Chomsky's discussion of systematic ambiguity in Aspects presents the term, and the concept, grammar, in two distinct but parallel frames, referring, "first, to the native speaker's internally represented 'theory of language,' and, second, to the linguist's account of this" (Chomsky 1965: 25). But there is a third way that grammar could be, and rampantly was, taken by the cognitive community - as a program implemented on a computer to generate, understand, translate, and otherwise deploy natural languages. This usage falls directly into line with grammar as "a kind of machine" in Lees' terms, and as "a device," in Chomsky's regular phrasing (e.g., Chomsky 1956a: X-728; 1956b: 114; 1957: 11). The Machine Translation people - including, notably, those working with Chomsky in the RLE - certainly used grammar with a systematic human/computer variation (e.g., Yngve, 1957; Yngve, 1960). And the more general AI community embraced that usage. Indeed, the Chomsky Hierarchy was widely perceived in AI to concern the sorts of programs that might be written to simulate human performance, so that both "Three Models" and Syntactic Structures were widely read in the AI community as outlining the conditions computational grammars would have to 
meet in order to approach human facility. This ambiguity was compounded further by the general vocabulary of process and performance in Chomsky's arguments.

Systematic ambiguity, in fact, is one of the rhetorical ways in which multidisciplinary research develops. Leah Ceccarelli, in particular, has carefully documented the way key phrases can be taken differently by different disciplinary, or subdisciplinary, groups, leading to an umbrella unity that covers divergent research paths (Ceccarelli 2001). Cognitive science is clearly such an umbrella, and the strains of research in psychology and artificial intelligence, while strongly overlapping, had somewhat different construals of Chomsky's instruments and arguments (see Boden 2006: 297, on this). Moreover, those construals departed markedly from Chomsky's intentions for linguistics, at least if we judge retrospectively, knowing the way his theories developed and the claims he later made.

But the single most representative term of the theory was so inherently dynamic that ambiguity must have seemed impossible. Transformation means alteration of state, change of form, movement between conditions, and so on, in every discipline that employs it (chemistry, biology, geology...). And Harris had self-consciously borrowed it from mathematics (Harris 1964: 419), where it codes an operation - a mental operation, when performed by a mathematician, a mechanical operation when performed by a computer. Further, it is (1) exactly the sort of operation that was expanding to machines in the 1950s, and (2) exactly the sort of operation that sponsored the concomitant expansion of the word intelligence toward machinery. Moreover, it was Chomsky's innovation to conceive the behavior of transformations in linguistics derivationally (Harris 1952: 6), so that they operated, one after the other in a sequence, very closely parallel to routines in lines of code; in fact, Harris saw this use of transformations, "in the theory of Noam Chomsky and in the applications by his students ... as instructions in the course of generating sentences" (Harris 1965: 370). The appeal for artificial intelligence researchers is not hard to fathom.

Don Knuth, the venerable, uniquely sobriquetted, Professor Emeritus of The Art of Computer Programming at Stanford, captures the eureka-spirit that Chomsky's work triggered for many computer scientists in this period, hinging on the conflation of mechanical and mental grammatical instantiation:

I found the mathematical approach to grammar immediately appealing - so much so, in fact, that I must admit to taking a copy of Noam Chomsky's Syntactic Structures along with me on my honeymoon in 1961. During odd moments, while crossing the Atlantic in an ocean liner and while camping in Europe, I read that book rather thoroughly and tried to answer some basic theoretical questions. Here was a marvelous thing: a mathematical theory of language in which I could use a computer programmer's intuition! The mathematical, linguistic, and algorithmic parts of my life had previously been totally separate. (Knuth 2003: iii) 


\section{The mental as mechanical}

New metaphors were coming into being in those mid-1950s and one of the most compelling was that of computing.

— Jerome S. Bruner (1983: 274)

Nowhere did the computational modeling of mind and the mental model of computation come together more completely than in George Miller, Eugene Galanter, and Karl Pribram's book, Plans and the Structure of Behavior - it fully epitomizes the themes and trends of the first wave of the cognitive revolution - and nowhere, outside of linguistics, is the influence of Chomsky more pervasive, Chomsky perceived as the architect of a plan-based, information-processing cognitive psychology. This extrapolated Chomsky of Plans is not the one we can see from the vantage of his later career, nor from his later pronouncements about both psychology and artificial intelligence, but there is certainly precedent for it his work at the time. "The built-in structure of an information-processing (hypothesis-forming) system," he said, counterposing his theory of mind to Skinner's, "must ... enable it to arrive at the grammar of a language from the available data in the available time" (Chomsky 1959: 58), in phrasing that could have come directly from Newell and Simon's work on the Logic Theory Machine, or on their later General Problem Solver.

Newell and Simon, whose paper shared the stage with Chomsky's and with Miller's at the 1956 Cambridge colloquium, are the other presiding spirits of Plans and the Structure of Behavior, rounding out the computational cognitivism of the book. "The notion of a Plan that guides behavior," Miller, Galanter, and Pribram note at the outset, is "quite similar to the notion of a program that guides an electronic computer" (Miller, Galanter, \& Pribram 1960:2), and they directly invoke the artificial-intelligence research coming out of Simon and Newell's lab at the RAND corporation. ${ }^{13}$ Language, however, is the quintessential behavioral structure in the book (Miller, Galanter, \& Pribram, 1960: $14 \mathrm{n} 8$ ), not logic, nor general problem solving. Indeed, language is inextricably bound to human planning in all its aspects:

In man we have a unique capacity for creating and manipulating symbols, and when that versatility is used to assign names to TOTE [Test-Operate-Test-Exit] units, it becomes possible for him to use language in order to rearrange the symbols and to form new Plans. We have every reason to believe that man's verbal abilities are very intimately related to his planning abilities. (Miller, Galanter, \& Pribram 1960: 38)

13. For Research ANd Development, begun by the US Air Force in 1946 with Douglas Aircraft, and becoming a separate non-profit company in 1948. 
The specific chapter on language, devoted entirely to explicating and endorsing the Syntactic Structures model, is called "Plans for Speaking." It fully conceptualizes Chomsky's grammar in the dynamic, mechanical frame that was so appealing to psychologists and AI scientists of the period, a grammar directly involved in the production and comprehension of speech. Here are Miller, Galanter, and Pribram, for instance, on issues of ambiguity (the resolution of which was an important selling point for transformational grammar):

The person must be aware of the underlying structure of the sentence in order to understand it or to know how to apply various transformations to it. "They are cooking apples" has one structure if it means "My friends are cooking apples," but a different structure if it means "Those apples are good only for cooking, not for eating." If the person has in mind the structure : (They) [(are cooking) (apples)], then he can apply a passive transformation to it and so obtain "Apples are being cooked by them." But if the person has in mind the structure (They) [(are) (cooking apples)], then the passive transformation is not relevant. If the complete hierarchy, and not just the terminal string of words organized by the hierarchy, were not represented cognitively, we would not know which transformations could be applied to it, and we would not be able to recognize the intrinsic ambiguity of the utterance. (Miller, Galanter, \& Pribram 1960: 153)

The chapter is a set piece, and the authors bring it round to something of a crescendo, which holds the preceding account of transformational grammar as an exemplum for understanding and replicating cognition as a whole. "[I]f the speculations of the present authors are correct," they say, "nearly all of man's behavior is similarly organized. We might speak metaphorically of a general grammar of behavior, meaning that the grammar of a language was only one example of a general pattern of control that could be exemplified in many other realms of behavior" (Miller, Galanter, \& Pribram 1960: 155).

This view of Chomsky as a computational cognitivist, and transformational grammar as the computational-cognitivist vanguard of the revolutionary movement in psychology and computer science, centred on the brain as an information process device, foundered within a decade, and does not fit the picture Chomsky, and his promotional historians, paint of his early scholarship. But the image was very representative of the period, dissipating only through the sixties and into the early seventies. Miller was a close friend, collaborator, and enthusiastic supporter, who had not only shared the podium and the pen with him, but shared a house with him. Moreover, Chomsky had read the manuscript in advance, commenting on it (Miller, Galanter, \& Pribram 1960: viii), and it is difficult to believe that he opposed Plans with any vehemence, if at all. He and Miller continued to collaborate, prominently including two articles in The Handbook of Mathematical Psychology (Chomsky \& Miller, 1963; Miller \& Chomsky, 1963), alongside a chapter by Newell and Simon (Newell \& Simon, 1963), in a book co-edited by one of Miller's coauthors on Plans and the Structure of Behavior (Luce, Bush, \& Galanter 1963). 


\section{Conclusion}

Machine translation is a very low level engineering project, and artificial intelligence is largely fraud, dismissed by most serious scientists and lacking any results, as its leading exponents concede, after 45 years of endless hype.

-Noam Chomsky (quoted in Barsky, 1998)

The shift of attention, resources, and style in linguistics which Chomsky effected fits the bill for a Kuhnian scientific revolution except for the part where a new stable paradigm replaces the old, but that may have more to do with the sort of enterprise linguistics is (part natural science, part social science, part humanities) than with the motives, the mechanisms, or the scope of the shift. The same resemblances and differences from Kuhn's template also attend the broader intellectual shift Chomsky is associated with (though it takes the label with far less controversy): the Cognitive Revolution. The differences, in this case, too, are probably because of the domain, but here the scale is altogether distinct from linguistics. Cognitivism is a very broad series of developments, touching in some way all of the fields in which humans study humans. That scope alone makes it closer kin to modernism or romanticism than to molecular biology or quantum physics. And Chomsky, as we have seen, is a major figure in the early years of its revolution, embraced at the time, and cited relentlessly in subsequent histories.

Cognitive science has disciplinary status, with degrees and specific faculty, at a goodly number of institutions, but its essence is multi- and inter-disciplinary. Even its specific disciplinary status, at those institutions where it has such, is mostly in associated with, or has hived off of, departments like psychology, computer science, or philosophy, and often it has a high proportion of adjunct professors and cross-appointments. Paul Thagard puts it this way, "[c] ognitive science is the interdisciplinary study of mind, embracing psychology, artificial intelligence, philosophy, neuroscience, linguistics, and anthropology" (Thagard 2005: 317). There are major stories implicating aspects of cognition to be told about Chomsky's engagement with philosophy and neuroscience, lesser ones about anthropology, and others in literary studies, composition, communication studies, and evolutionary psychology - to say nothing of political science, media studies, and rhetoric, in his sideline career as public intellectual. His influence, as Golumbia reminds us, is enormous. But all of these other stories follow the first cognitive wave by a decade, or several, and gained their impetus from that surge.

The cognitive revolution, following Miller, got its first powerful multidisciplinary surge with the confluence of neo-behaviorist psychology, generative linguistics, and artificial intelligence, at the 1956 Cambridge Colloquium. Chomsky's revolutionary role was key. But his subsequent role in psychology and artificial intelligence, and in linguistics, has not remained central. Chomsky himself is quite sanguine about the relation of his 
work to cognitive science. Noting the decline of his influence in his home discipline, he has said that "if the kind of linguistics I am interested in survives in the United States, it may very likely be in [the network of connections loosely around the cognitive sciences], rather than in linguistics departments" (Chomsky 2004: 36). The indications that he is right, however, are not compelling. A brief look at psycholinguistics is instructive.

After early success, the correspondence hypothesis - that there is a direct, information-processing impact of transformations in speech production and comprehension - failed to pan out. Even before any of the research was published, Chomsky was denouncing the correspondence hypothesis as an "utterly mistaken view" (Chomsky 1961: 14), but he had a suggestion. In a highly influential paper with Miller, Chomsky endorsed a somewhat more subtle route, which still had inherently dynamic characteristics, for investigating " $t \mathrm{t}]$ he psychological plausibility of a transformational model of the language user" (Miller \& Chomsky 1963: 481). Among other things, that paper introduced the competence/performance distinction, disengaging transformational grammars from any direct claims about language use, and it distended the correspondence hypothesis into a suggestion that "performance on tasks requiring an appreciation of the structure of transformed sentences is some function of the nature, number and complexity of the grammatical transformations involved" (Miller \& Chomsky 1963: 481). "Some function of ..." was generally taken to mean something like "corresponds in an indirect and possibly measurable way to." This suggestion — dubbed the Derivational Theory of Complexity - fueled the continued expansion of psycholinguistic research, under the near total hegemony of transformational grammar, into the early 1970s. But it foundered too (Watt 1970), and psycholinguistics separated almost completely from the Chomskyan approach. Chomsky's reaction? Repudiation. "He’s since disavowed this whole thing," Miller has lamented, "but at the time he thought it was an interesting thing to do. Later he said, 'Nobody would do anything that stupid!'” (Baars 1986: 208). "By the middle $1970 \mathrm{~s} . .$. psycholinguistics largely severed its ties with linguistics and became absorbed into mainstream cognitive psychology" (Tanenhaus 1988: 11)

Relations aren't much better with the artificial intelligence community. Chomsky's disdain for many, if not all, computational approaches to cognition has alienated such prominent figures as Roger Schank and Marvin Minsky. Schank says, simply, "Noam Chomsky represents everything that's bad about academics" (Brockman 1996: 174), and Chomsky's differences with Minsky are what apparently prevented M.I.T., despite housing two such giants, from assuming a major institutional role in cognitive science under the Sloan Foundation ("II]t was all too apparent as Barbara Partee has put it, that M.I.T. was not the home for interdisciplinary cooperation that the Sloan Foundation was looking for" (Partee 2005).

The trajectory of Chomsky's influence on the cognitive sciences, in fact, is perhaps best described as attenuating oscillation: sometimes up, sometimes down, but overall steadily declining from the peak reached in the 1970s. His Syntactic Structures 
sketched an approach that was immensely attractive for an algorithmic, informationprocessing model of mind. His review of B.F. Skinner's Verbal Behavior dismantled the psychological framework that cognitive revolutionaries overthrew. His collaboration with George Miller, and good relations with figures like Newell and Simon, spread his fame far and wide, for defining linguistics, hitherto a field chiefly with a cultural and anthropological cast, as "a branch of cognitive psychology." But his work has receded in cognitive science to little more than historical interest. Even in linguistics, the approaches most in consonance with the methods and claims of cognitive science define themselves in opposition to the Chomskyan frameworks.

\section{References}

Agassi, Joseph. 1997. "The Novelty of Chomsky's Theories". The future of the cognitive revolution, ed. by David Martel Johnson \& Christina E. Erneling. New York: Oxford University Press.

Andresen, Julie T. 1990. "Skinner and Chomsky Thirty Years Later or: The return of the repressed". The Behavior Analyst 14. 49-60.

Baars, Bernard J. 1986. The cognitive revolution in psychology. New York: Guilford Press.

Bar-Hillel, Yehoshua. 1956. "Can Translation be Mechanized? [Abstract]". Mechanical Translation 3. 67.

Bar-Hillel, Yehoshua \& Aldo Ghizzetti. 1966. "Four Lectures on Algebraic Linguistics and Machine Translation". Automatic Translation of Languages: Papers Presented at NATO Summer School Held in Venice, July 1962, 1-26. Oxford: Pergamon.

Barsky, Robert F. 1997. Noam Chomsky : a life of dissent. Toronto: ECW Press.

Bobrow, Daniel G. 1963. "Syntactic analysis of English by computer: a survey". The Fall Joint AFIPS Computer Conference. Las Vegas: Association for Computing Machinery.

Boden, Margaret A. 2006. Mind as machine : a history of cognitive science. Oxford; New York: Clarendon Press; Oxford University Press.

Brockman, John. 1996. The third culture : beyond the scientific revolution. London: Simon \& Schuster.

Bromberger, Sylvain \& John R. Searle. 2002. "Chomsky's Revolution". The New York Review of Books 49. 60-61.

Brown, Roger. 1970. Psycholinguistics. New York: Free Press.

Bruner, Jerome S. 1983. In search of mind : essays in autobiography. New York: Harper \& Row.

Bruner, Jerome S. 2004. "A Short History of Psychological Theories of Learning". Daedalus 133. $13-20$.

Bruner, Jerome S., Jacqueline J. Goodnow \& George A. Austin. 1986[1956]. A study of thinking. Edison, NJ: Transaction.

Carnap, Rudolf \& Y. Bar-Hillel. 1952. "An Outline of a Theory of Semantic Information". Technical Report, Research Laboratory of Electronics. Cambridge, Mass: Massachusetts Institute of Technology.

Carroll, John B. 1964. "Linguistics and the Psychology of Language". Review of Educational Research 34. 119-126. 
Carroll, John B., Susan M. Ervin, Joseph H. Greenberg, James J. Jenkins, Floyd G. Lounsbury, Leonard D. Newmark, Sol Saporta, Donald E. Walker \& Kellogg Wilson. 1954. Psycholinguistics: A Survey of Theory and Research Problems. Baltimore: Waverly Press.

Ceccarelli, Leah. 2001. Shaping science with rhetoric : the cases of Dobzhansky, Schrödinger, and Wilson. Chicago: University of Chicago Press.

Chamberlain, Alexander F. 1894. "Anthropological Psychology: Linguistics (and Related Subjects)". American Journal of Psychology 6. 453-456.

Chomsky, Noam. 1956a. Logical Structure of Linguistic Theory [Indicated to be a revision of Chomsky 1955a preserved on microfilm at the M.I.T. Humanities Library. PDF available for download at http://alpha-leonis.lids.mit.edu/chomsky/. Revised again \& published as Chomsky 1975.].

Chomsky, Noam. 1956b. “Three Models for the Description of Language ". IRE(Institute of Radio Engineers) Transactions on Information Theory 2. 113-124.

Chomsky, Noam. 1957. Syntactic structures. The Hague: Mouton.

Chomsky, Noam. 1958. "Linguistics, Logic, Psychology, and Computers". Computer programming and artificial intelligence : an intensive course for practicing scientists and engineers; lectures given at the University of Michigan, ed. by John W. Carr. Ann Arbor, Mich.: Univ. of Michigan College of Engineering.

Chomsky, Noam. 1959. "Review of Verbal Behaviour, by B.F. Skinner”. Language 35: 1. 26-59.

Chomsky, Noam. 1961. "On the notion of 'rule of grammar". Structure of language and its mathematical aspects: Proceedings of the twelfth Symposium in Applied Mathematics, held in New York City, April 14-15, 1960, ed. by Roman Jakobson. Providence, R.I.: American Mathematical Society.

Chomsky, Noam. 1962. “Context-Free Grammars and Pushdown Storage”. M.I.T. RLE Quarterly Progress Report 65. 187-194.

Chomsky, Noam. 1965. Aspects of the theory of syntax. Cambridge: M.I.T. Press.

Chomsky, Noam. 2004. The Generative Enterprise Revisited: Discussions with Riny Huybregts, Henk van Riemsdijk, Naoki Fukui, \& Mihoko Zushi. Berlin, New York: Mouton de Gruyter.

Chomsky, Noam. 2006. Language and mind. Cambridge; New York: Cambridge University Press.

Chomsky, Noam \& Fred Lukoff. 1955. "Construction of the German Verb Phrase". Mechanical Translation Group Memorandum. Cambridge, Mass.: M.I.T. Research Laboratory of Electronics.

Chomsky, Noam \& George A. Miller. 1957. “Pattern Conception”. Proceedings of the University of Michigan Symposium on Pattern Recognition. University of Michigan.

Chomsky, Noam \& George A. Miller. 1958. "Finite state languages". Information and Control 1: 2. 91-112.

Chomsky, Noam \& George A. Miller. 1963. "Introduction to the Formal Analysis of Natural Languages". Handbook of mathematical psychology, ed. by R. Duncan Luce, Robert R. Bush \& Eugene Galanter. New York: Wiley.

Chomsky, Noam \& Marcel-Paul Schützenberger. 1963. "The algebraic theory of context-free languages”. Computer Programming and Formal Systems, ed. by P. Braffort \& David Hirschberg, 118-161. Amsterdam: North Holland.

Chomsky, Noam \& John R. Searle. 2002. “Chomsky's Revolution: An Exchange”. The New York Review of Books 49. 64-65.

Cordeschi, Roberto. 2007. “AI TURNS FIFTY: REVISITING ITS ORIGINS”. Applied Artificial Intelligence 21: 4-5. 259-279. 
Coulter, Jeff. 2003. "Projection Errors and Cognitive Models". Journal of the Learning Sciences 12: 3. 437-443.

Crick, Francis. 1988. What mad pursuit : a personal view of scientific discovery. London: Weidenfeld \& Nicolson.

Crowther-Heyck, Hunter. 1999. "George A. Miller, Language, and the Computer Metaphor of Mind”. History of Psychology 2. 37-64.

Diebold, A. Richard, Jr. 1964. "Review of Psycholinguistics: A Book of Readings, by Sol Saporta”. Language 40. 197-260.

Golumbia, David. 2009. The Cultural Logic of Computation. Cambridge: Harvard University Press.

Green, Bert F., Jr., Alice K. Wolf, Carol Chomsky \& Kenneth Laughery. 1961. "Baseball: an automatic question-answerer". The Western Joint IRE-AIEE-ACM Computer Conference. Los Angeles, California: Association for Computing Machinery.

Greene, Judith. 1972. Psycholinguistics: Chomsky and Psychology. Harmondsworth: Penguin.

Hanley, Edmund C. 1939. “Double-surfaced Hectograph”. Popular Science 135: 5. 193.

Harris, Zellig S. 1964. "Transformations in Linguistic Structure". Proceedings of the American Philosophical Society Held at Philadelphia for Promoting Useful Knowledge 108. 418-422.

Harris, Zellig S. 1965. “Transformational Theory”. Language: Journal of the Linguistic Society of America 41: 3. 363-401.

Harris, Zellig S. 1951. Methods in structural linguistics. Chicago: The Univ. of Chicago Press.

Harris, Zellig S. 1952. "Discourse Analysis". Language: Journal of the Linguistic Society of America 28: 1. 1-30.

Harris, Zellig S. 1954. “Transfer Grammar”. International Journal of American Linguistics 20. 259-270.

Hébert, Richard. 2006. “The Miller's Tale: A Genealogy of the Father of the Cognitive Revolution”. Observer 19:June.

Hockett, Charles Francis. 1955. A manual of phonology. Baltimore: Waverly Press.

Hutchins, W. John. 2000. Early years in machine translation : memoirs and biographies of pioneers. Amsterdam/Philadelphia: John Benjamins.

Jakobson, Roman, G.G.M. Fant \& Morris Halle. 1952. "Preliminaries to Speech Analysis". Technical Report of the Acoustics Laboratory. Cambridge, Mass: Massachusetts Institute of Technology.

Joseph, John Earl. 2002. From Whitney to Chomsky : essays in the history of American linguistics. Amsterdam/Philadelphia, PA: John Benjamins.

Joshi, Aravind K. \& Phil Hopely. 1996. “A Parser from Antiquity”. Natural Language Engineering 2. 291-294.

Kantor, J.R. 1971. "Behaviorism in the history of psychology". The aim and progress of psychology and other sciences; a selection of papers, ed. by J.R. Kantor. Chicago: Principia Press.

Knuth, Donald Ervin. 2003. Selected papers on computer languages. Stanford, Calif.: CSLI Publications Center for the Study of Language and Information.

Koerner, E.F.K., Matsuji Tajima \& Carlos Peregrín Otero. 1986. Noam Chomsky : a personal bibliography, 1951-1986. Amsterdam/Philadelphia: John Benjamins.

Kuhn, Thomas S. 1962. The structure of scientific revolutions. Chicago: University of Chicago Press.

Lees, Robert B. 1957. “Review: Syntactic Structures by Noam Chomsky”. Language 33. 375-408.

Lees, Robert B. 1957. “Structural Grammars”. Mechanical Translation 4: 1\&2. 5-10.

Lehmann, Winfred P. 1980. "Linguistics at Wisconsin (1937-41) and at Texas (1949- ): A Retrospective View". First person singular. Papers from the Conference on an Oral Archive for the 
History of American Linguistics : (Charlotte, NC, 9 - 10 March 1979), ed. by Boyd H. Davis, XIII, 239 S. Amsterdam: John Benjamins.

Luce, R. Duncan, Robert R. Bush \& Eugene Galanter. 1963. Handbook of mathematical psychology. New York: Wiley.

MacCorquodale, K. 1969. "B.F. Skinner's "Verbal Behavior": A retrospective appreciation”. Journal of the Experimental Analysis of Behavior 12. 831-841.

Mandelbrot, Benoit. 1953. Contribution à la théorie mathématique des communications. Paris: Inst. de statistique de l'université de Paris.

Mandler, George. 2002. "Origins of the cognitive (r)evolution" [Fall 2002]. Journal of the History of the Behavioral Sciences 38: 4. 339-353.

Miller, George A. 1951. Language and communication. New York: McGraw-Hill.

Miller, George A. 1954. "Communication”. Annual Review of Psychology 5. 401-420.

Miller, George A. 1956. "Human Memory and the Storage of Information". Institute of Radio Engineers [now, Institute of Electrical and Electronics Engineers] Transactions on Information Theory 2. 129-137.

Miller, George A. 1979. "A very personal history”. Occasional Paper. Cambridge, Mass: M.I.T. Center for Cognitive Science.

Miller, George A. 2003. “The cognitive revolution: a historical perspective”. Trends in Cognitive Sciences 7: 3. 141.

Miller, George A. \& J.G. Beebe. 1956. "Some Psychological Methods for Evaluating the Quality of Translations". Machine Translation 3. 73-80.

Miller, George A. \& Robert Buckhout. 1962. Psychology: the Science of Mental Life. New York: Harper \& Row.

Miller, George A. \& Noam Chomsky. 1963. "Finitary models of language users”. Handbook of mathematical psychology, ed. by R. Duncan Luce, Robert R. Bush \& Eugene Galanter. New York: Wiley.

Miller, George A., Eugene Galanter \& Karl H. Pribram. 1960. Plans and the structure of behavior. New York: Holt.

Miller, George A. \& Kathryn Ojemann McKean. 1964. "A chronometric study of some relations between sentences". The Quarterly Journal of Experimental Psychology 16. 297-308.

Morris, C. 1958. "A review of B.F. Skinner, Verbal Behavior". Contemporary Psychology 3. 212-214.

Newell, Allen \& Herbert A. Simon. 1956. “The Logic Theory Machine-A Complex Information Processing System”. Institute of Radio Engineers [now, Institute of Electrical and Electronics Engineers] Transactions on Information Theory 2. 61-79.

Newell, Allen \& Herbert A. Simon. 1963. "Computers in psychology”. Handbook of mathematical psychology, ed. by R. Duncan Luce, Robert R. Bush \& Eugene Galanter. New York: Wiley.

Newell, Allen \& Herbert A. Simon. 1972. Human problem solving. Englewood Cliffs, N.J.: PrenticeHall.

Osgood, Charles E. 1958. "A Question of Sufficiency: A Review of B.F. Skinner, Verbal Behavior”. Contemporary Psychology 3. 209-212.

Osgood, Charles E. 1975. "A Dinosaur Caper: Psycholinguistics Past, Present, and Future". Developmental Psycholinguistics and Communication Disorders 263. 16-26.

Partee, Barbara H. 2005. Reflections of a formal semanticist as of Feb 2005. Amherst: University of Massachusetts.

Percival, W. Keith. 1976. “The Applicability of Kuhn's Paradigms to the History of Linguistics”. Language 52: 2. 285-294. 
Richardson, Alan. 1998. "Brains, Minds, and Texts: A Review of Mark Turner's The Literary Mind”. Review 20. 39-48.

Searle, John R. 2002. "End of the Revolution”. New York Review of Books 49: 3. 33-36.

Shannon, C.E. 1948. "A Mathematical Theory of Communication". Bell System Technical Journal 27. 379-423, 623-656.

Sheehy, Noel. 2004. Fifty key thinkers in psychology. London; New York: Routledge.

Simon, Herbert A. 1961. "Modeling human mental processes". The Western Joint IRE-AIEE-ACM

Computer Conference. Los Angeles, California: Association for Computing Machinery.

Simon, Herbert A. 1996 [1969]. The sciences of the artificial. Cambridge, Mass.: M.I.T. Press.

Simon, Herbert A. \& Allen Newell. 1958. "Heuristic Problem Solving: The Next Advance in Operations Research". Operations Research 6. 1-10.

Skinner, B.F. 1957. Verbal behavior. New York: Appleton-Century-Crofts.

Skinner, B.F. 1974. About behaviorism. New York: Knopf \& Random House.

Staddon, J.E.R. 1993. Behaviorism : mind, mechanism and society. London: Duckworth.

Tanenhaus, M.K. 1988. "Psycholinguistics: An Overview". Linguistics : the Cambridge survey, ed.

by Frederick J. Newmeyer. Cambridge: Cambridge University Press.

Thagard, Paul. 2005. "Being Interdisciplinary: Trading Zones in Cognitive Science”. Interdisci-

plinary collaboration : an emerging cognitive science, ed. by Sharon J. Derry, Morton Ann

Gernsbacher \& Christian D. Schunn. Mahwah, N.J.: Lawrence Erlbaum.

Tikhomirov, O.K. 1959. "Review of Verbal Behavior". Word 15. 362-367.

Ulvestad, B. 1956. "Noam Chomsky- Syntactic Structures”. Machine Translation 3. 89.

Virués-Ortega, J. 2006. “The case against B.F. Skinner 45 years later: An encounter with N. Chomsky". The Behavior Analyst 29. 243-251.

Watson, James D. 1968. The double helix: a personal account of the discovery of the structure of DNA. London: Weidenfeld \& Nicolson.

Watson, James D. \& Francis Crick. 1953. "Molecular structure of nucleic acids: a structure for deoxyribose nucleic acid". Nature 171. 737-738.

Watt, W.C. 1970. "On two hypotheses concerning psycholinguistics". Cognition and the development of language, ed. by John R. Hayes, Roger Brown \& Carnegie-Mellon University. New York: Wiley.

Weiss, Albert P. 1925. "Linguistics and Psychology". Language 1. 52-57.

Yngve, V.H. 1956. "Mechanical Translation Research at M.I.T." Mechanical Translation 3. $44-45$.

Yngve, V.H. 1957. “A Framework for Syntactic Translation”. Machine Translation 4. 59-65.

Yngve, V.H. 1960. "A Model and an Hypothesis for Language Structure”. Proceedings of the American Philosophical Society.

Zuriff, G.E. 1985. Behaviorism : a conceptual reconstruction. New York: Columbia University Press. 


\title{
Chomsky between revolutions ${ }^{\star}$
}

\author{
Malcolm D. Hyman \\ Max Planck Institute for the History of Science, Berlin
}

The revolutionary nature of Chomskyan linguistics must be considered within the framework of another 'revolution', in psychology, from behaviorism to cognitivism. George Miller dates this paradigm shift to a conference held at M.I.T. in 1956, in which Chomsky participated. This change of focus is, in turn, related to the development of the digital computer and the promise of understanding and modeling thought using the techniques of computer science. Chomsky evolves from behaviorism to mentalism between Syntactic Structures (1957) and Aspects of the Theory of Syntax (1965). This led psycholinguists to consider the relationship between deep structure and surface structure in processing. However the results were not very promising, and Chomsky himself seemed to abandon psychological reality as a relevant consideration in linguistic analysis. His focus on intuition favored rationalism over empiricism, and innate structures over acquired behavior. This biological turn - the search for the language 'organ', the 'language acquisition device', etc. - became the new foundation for a science of linguistics. This, however, leads to problems with evolutionary biology, and Chomsky's appeal to biology has explained little and created serious conundrums. The biological approach is linked to the claims of the 'poverty of the stimulus', i.e. the claim that children learn the structures of language with remarkably little input, and therefore must have innate structures that explain this human capability. This has been attacked from two fronts: first, suggestions that the stimulus is not as poor as claimed, and second, hypotheses that language learning does not require a richly structured and highly restricted learning mechanism. These approaches divorce cognitivism from Chomskyan linguistics, and pursue instead such language acquisition theories as statistical language learning, latent semantic analysis, and agent-based modeling. Chomsky's resolute antiempiricism ends up isolating his linguistic theory from the forefront of current trends in biology and psychology.

*This paper is respectfully dedicated to Konrad Koerner, in appreciation of the rigor, high professional standards, and untiring labor he has consistently brought to the field of linguistic historiography. 


\section{o. Introduction}

There has been much argument about whether a "Chomskyan revolution" in linguistics took place; and among those who believe it did, about exactly when, and in what it consisted. This is not my present topic. ${ }^{1}$ For the moment, I shall simply echo Agassi (1997) in concluding that there are "reasons for doubting that Chomsky's theory is either entirely new or entirely correct." In this paper I wish to consider another revolution in which Chomsky is often implicated: the "cognitive revolution" of the 1950s and 1960s. ${ }^{2}$ This revolution, just as the linguistic one, has been hotly contested. ${ }^{3}$ I follow Greenwood $(1999,1)$ in concurring with Galison, who rejects as explanatorily useful "'all-inclusive" breaks" in the history of science, which entail "incommensurable [...] paradigms that pass each other like ships in the night" (Galison 1997, 13). Instead of concentrating on rupture épistémologique (so Bachelard), I prefer to write of a "cognitive turn" - or, for reasons that will become clear, "cognitive turns" within psychology during this period. ${ }^{5}$

\section{The "cognitive revolution"}

According to the conventional story, behaviorism - which rejected explanations in terms of "mental" or "cognitive" states in favor of those directly linking an overt "stimulus" and "response" - dominated American theoretical psychology from John B. Watson's "behaviorist manifesto" of 1913 until the eclipse of behaviorist ideas in the 1950s. ${ }^{6}$

1. But I refer the reader to the critical review of Koerner (1983) and to Newmeyer's (1986) response to Koerner and his other critics. Note that in his dialogue with Rieber, Chomsky repeatedly insists that he in no way views his work as revolutionary (Chomsky 1983, 60).

2. Probably the best known account - readable, although not always reliable — is Gardner (1985).

3. Valuable literature includes Greenwood (1999), Reed (1997), Shanker (1997), and Leahey (1992).

4. For theoretical discussions concerning the applicability of the Kuhnian concepts of "revolution" and "paradigm" to linguistics, see: Percival (1976), Murray (1980), Koerner (2006, 2809-2810); in psychology, Weimer and Palermo (1973), Leahey (1992), Mandler (2007, 165). I believe that the concept of "incommensurability" in the history of science must be dealt with in another fashion; for some programmatic remarks in this regard, see Hyman (2007).

5. Compare the phrase "linguistic turn," which originated with Gustav Bergmann (1953).

6. See e.g. Leahey $(1992,313)$ : "Belief in a cognitive revolution is an entrenched part of modern psychology's form of life." Yet the considerable variety of research published in American 
In that decade a new "cognitive psychology" arose, and an interdisciplinary venture that came later to be called "cognitive science" had its "unofficial launching" (Gardner $1985,7)$. George Miller, a major participant in these changes, dates (in an admittedly personal and anecdotal account) the "cognitive revolution" to September 11, 1956, "the second day of a symposium organized by the 'Special Interest Group in Information Theory' at the Massachusetts Institute of Technology" (Miller 2003, 142), at which, inter alios, Allen Newell and Herbert Simon spoke on a "logic machine," and Noam Chomsky presented transformational generative grammar. Seminal contributions to this "revolution" from its early days include Bruner, Goodnow, and Austin (1956) on cognitive strategies; ${ }^{7}$ Miller (1956) on the limitations memory imposes upon human information processing; Chomsky (1957) on natural-language syntax; Newell, Shaw, and Simon (1958) on problem solving; ${ }^{8}$ Brown (1958) on the relation between language and thought; and Miller, Galanter, and Pribram (1960) on plans.

What unites the apparently diverse projects comprising the "cognitive revolution" is not immediately obvious. Leahey sees cognitivism as "a new form of behavioralism [sic; to be distinguished from classical "behaviorism"] based on a new technology, the computer" (1992, 316). Greenwood (1999) identifies a decisive shift from the "intervening variables" (e.g. "pure stimulus act") posited by the more liberal varieties of behaviorism (such as Hull's) to the developed "hypothetical constructs" (such as "short-term memory") posited by the cognitivists. ${ }^{9}$ Shanker sees not one revolution, but two: a genuine cognitive revolution that found its inspiration in the ideas of the Würzburg school, Gestalt psychology, Piaget, and Vygotsky; and an artificial intelligence revolution that, despite its embrace of such new concepts as automata and recursive-function theory, remained basically behavioristic and mechanistic $(1997,45)$.

Much, though not all, of the work heralded as "cognitive" is connected in some way to the digital computer — ranging from work that relies directly on computer modeling; to work employing formalisms and concepts drawn from areas of theoretical "computer

journals during this period that did not follow behaviorist lines undermines the account of a behaviorist "hegemony" (Greenwood 1999, 18). Nor did behaviorism really constitute a unified paradigm: there were vast differences between Watson and Hull, or Skinner and Tolman!

7. Greenwood $(1999,18)$ observes that theories such as those of Newell, Shaw, and Simon (1958) developed largely independently of Bruner, Goodnow, and Austin (1956).

8. These authors acknowledge their indebtedness to the Denkpsychologie of Otto Selz and his student Adriaan de Groot (Shanker 1997, 52 n. 1; Greenwood 1999, 17; Mandler 2007, 111-114).

9. Cf. Chomsky $(1957,49)$ : "Any scientific theory is based on a finite number of observations and it seeks to relate the observed phenomena and to predict new phenomena by constructing general laws in terms of hypothetical constructs such as (in physics, for example) 'mass' and 'electron' [emphasis mine]." 
science," such as automata theory; to work that relies on an "information processing" paradigm, which describes the encoding, rule-based processing, and storage of information mentally. ${ }^{10}$ Sometimes the digital computer has been taken as the central metaphor of cognitive psychology (e.g. Gigerenzer \& Sturm 2007). But we must bear in mind that the computer was not just a tool ready to be taken over by psychologists; much of the pioneering work that led to advances in computer science was carried out by theorists (such as Alan Turing, John von Neumann, and Norbert Wiener) that were themselves interested in understanding and modeling the mechanisms of thought.

Perhaps the best candidate for characterizing the early cognitivist endeavors in contrast with earlier American work in the behaviorist and associationist traditions is a heightened "[c] onsideration of structure" (Mandler 2007, 174). A crucial cognitive structure picked up by cognitivists from earlier traditions is the schema. ${ }^{11}$ One antecedent is the British psychologist Sir Frederic Charles Bartlett, who took the term from the British neurologist Henry Head (1920) and employed it for the unconscious mental structures he posited in his theory of memory (Bartlett 1932). Another is Jean Piaget, who used the term in a variety of applications: for sensorimotor schemata (such as the infant's "schème de succion"; Piaget 1936; Maury 1997, 68-77), conceptual schemata, and operative schemata (Mandler 1983, 102-103). ${ }^{12}$ Karl Lashley had also used the term, in such expressions as "schemata of action" $(1951,122)$. In cognitive psychology, "A schema is considered to be a cognitive structure (i.e. an organized body of knowledge) that controls various kinds of perceiving, thinking, or acting" (Mandler 1983, 100). In the words of Kintsch $(1998,412)$, "A knowledge system [...] must include schema-like structures with default-slots and procedural knowledge that links cognition and action [...]." Following Bartlett, schemata have played an especially important role in the theory of memory. ${ }^{13}$ Structures akin to the schema have also been proposed: these include most notably scripts (Schank \& Abelson 1977) and frames (Barsalou 1992). The key point here is that the schema is a complex structure, capable of recursively embedding other schemata, and therefore fundamentally different from the S-R and associative chains posited by earlier theories.

But where does Chomsky stand in the cognitivist tradition? Greenwood $(1999,18)$ argues that "Computational theories of information processing [such as that of Newell,

10. Yet "information" as a term is rarely defined; many authors "confess that they have no account of what 'information' is" (Reed 1997, 266). For a perspicuous study of the uses and abuses of the term "information" in the modern world see Nunberg (1996).

11. See Neisser (1976, 286-292), Shanker (1997, 50-52), Mandler (2007, 172, 241).

12. Piaget's discussions of schemata are both quite complex and confusing, and the term changes significance considerably in the course of development of his ceuvre.

13. For a review, see Alba and Hasher (1983). 
Shaw, and Simon (1958)] [...] seem to have developed largely independently of the work of Noam Chomsky (1957) and George Miller (1962) on psycholinguistics, which did so much to legitimize the 'rule-following' explanatory paradigm for the explanation of linguistic processing and other symbolic processes that came to be exploited by computational theories of cognition." Gardner $(1985,216)$ admits that "While his approach arose from many of the same roots as artificial intelligence, several of Chomsky's main ideas are not readily implemented in computational formats. For example, there is no guarantee in principle that one can parse sentences using transformational grammatical approaches." If "Syntactic Structures was the snowball which began the avalanche of the modern 'cognitive revolution," as Lightfoot $(2002, \mathrm{v})$ has it, then we must be all the more amazed that there is so little psychological language or psychological subject matter therein.

\section{From "structures" to "aspects"}

In 1957 Chomsky published Syntactic Structures [henceforth SS], which he drafted in 1956 on the basis of lecture notes for a course at M.I.T.; the book is essentially an outline of Chomsky's manuscript The Logical Structure of Linguistic Theory [henceforth LSLT] (Chomsky 1955-1956), which he began in 1953 - augmented with some material from Chomsky (1956) (Murray 1980, 77, 86 n. 22). In SS Chomsky rejects two grammatical models: one based on finite state Markov processes (cf. Chomsky 1956, 114-116), and the other on phrase structure grammar (formally defined in Chomsky 1956, 117). He then elaborates a third model that combines a phrase structure component - immediate constituent analysis along the lines of e.g. Wells (1947) formalized via Post production (or "tag") systems (Post 1943) ${ }^{14}$ - combined with a transformational component, inspired by the work of Chomsky's teacher, Zellig Harris (1952; 1954; 1957). SS also contains a well-known methodological excursus, in which discovery procedures, decision procedures, and evaluation procedures for grammars are contrasted (Chomsky 1957, 49-60).

SS is largely concerned with formal and methodological aspects of linguistic theory. Chomsky's interest in mathematical considerations is well in evidence into the early 1960s. Publications on formal language theory after SS include Chomsky (1958), Chomsky and Miller (1958), Chomsky (1959b; 1959c; 1962; 1963), Chomsky and Schützenberger (1963). At the time that Chomsky was working on formal language theory and applications to natural languages, researchers in the emerging field of computer science were applying similar approaches to the analysis of artificial

14. See Greibach 1981a. 
programming languages. Notably, Backus (1960) and Naur et al. (1960) defined a metasyntax for specifying the syntax of programming languages (originally ALGOL) that became known as Backus-Naur Form (BNF). Ginsburg and Rice (1962) demonstrated that ALGOL was equivalent to a context-free (or Type 2, in the typology of Chomsky 1959b) language; thus BNF could express the grammar of all context-free languages and was equivalent to one form of Chomsky's phrase structure rules. The polymath (and ardent anti-neo-Darwinist) Marcel-Paul Schützenberger, who started working on contextfree languages in the late 1950s (Lallement \& Perrin 1997), ${ }^{15}$ discovered algebraic formulations for these languages (Schützenberger 1961). A subsequent jointly-authored paper (Chomsky \& Schützenberger 1963) contains an important theorem named for the authors. Kuroda (1964) succeeded in showing that each of the languages in the typology of Chomsky 1959b (now known as the "Chomsky hierarchy") corresponds to a specific kind of automaton. Chomsky's papers of this period, as well as work inspired by him, form a core part of the theory of automata and languages in computer science as described in such authoritative surveys as Hopcroft, Motwani, and Ullman (2006). ${ }^{16}$

Although Chomsky in these years was evidently very concerned with mathematics, neither SS nor LSLT show evidence of the psychological and biological concerns that would occupy him later. In both works, Chomsky's position is largely compatible with behaviorist orthodoxy. Thus he objects "that the theory of meaning fails to meet certain minimum requirements of objectivity and operational verifiability" (Chomsky 1955-1956, 2). He suggests that mentalism can be ruled out "for what were essentially Bloomfield's reasons, i.e. its obscurity and general uselessness in linguistic theory" (op. cit., 20) and asserts that the "introduction of dispositions (or mentalistic terms) is either irrelevant, or trivializes the theory" (op. cit., 21). He repeatedly expresses admiration for "such operational devices as the pair test" (op. cit., 34).

Chomsky $(1957,13)$ equates grammaticalness with acceptability to a native speaker and assumes that such a speaker's intuitions about sentences can constitute the basis for a scientific theory of language. Nevertheless, he adds, "We can take certain steps towards providing a behavioral criterion for grammaticalness [...]," although he does not specify what these might be. Chomsky here seems somewhat uneasy at not being able to provide an objective, overt behavior as a basis for the theory. LSLT is more detailed, but seems to show a greater ambivalence about the relation between intuitive judgments and behavior. Chomsky writes that "we will regard a linguistic theory as successful if it manages to explicate and give formal justification and

15. We may observe that Schützenberger is already cited by Chomsky and Miller (1958).

16. Greibach $1981 \mathrm{~b}$ offers a detailed survey of formal language theory from 1936 through 1964, with a limited discussion of developments through the late 1970s. 
support for our strong intuitions about linguistic form for many languages ${ }^{17}$ within the framework of an integrated, systematic, and internally motivated theory [emphasis mine]" (1955-1956, 55). He then adds, "But 'intuition,' of course, is an extremely weak support. The program of linguistic research would be a much clearer one if we could show experimentally that these intuitions have distinct behavioral correlates [emphasis mine]" (ibid.). Yet he cautions, "But we must be careful not to exaggerate the extent to which a behavioral reinterpretation of intuition about form will actually clarify the situation" (ibid.). Finally, "It appears then that in a certain sense the ultimate criterion remains the speaker's intuition about linguistic form [...], since only this can tell us which behavioral tests are to the point" (op. cit., 58). Moreover, we cannot take the procedure of relying on speakers' intuitive judgments as beyond the neo-Bloomfieldian pale. Chomsky dutifully observes, "Hockett has pointed out [note omitted] that the sequences generated by the grammar as grammatical sentences must be acceptable, in some sense, to the native speaker [...]" (op. cit., 55). In SS Chomsky refers to this criterion as the "external conditions of adequacy [emphasis original]" (1957, 49).

Chomsky does not dwell much on the speaker whose acceptability judgments provide the ultimate data for his theory. He does mention that the speaker "on the basis of a finite and accidental experience with language, can produce or understand an indefinite number of new sentences" (1957, 15; cf. op. cit., 75). There is here, of course, the germ of an idea that we will find fully grown in Chomsky's later writings. Elsewhere Chomsky observes that if natural language could be captured by a finite state grammar, we could "view the speaker as being essentially a machine of the type considered [i.e. a finite state automaton]" (op. cit., 20). In one passage only does Chomsky consider learnability: "Similarly, he [i.e. the speaker of English] will be able to recall [the grammatical but nonsensical sentence] (1) much more easily than [the ungrammatical string] (2), to learn it much more quickly, etc." (op. cit., 16). Note that measurement of the speed of recall and of learning are common behaviorist techniques. ${ }^{18}$

Thus in 1957 Chomsky seems a behaviorist, rather than a mentalist. A grammar is a scientific theory, rather than something instantiated in the mind of a speaker. Instead of Universal Grammar (UG), we have only "Language" with a capital "L" $(1957,14)$, together with some scattered remarks in $L S L T .{ }^{19}$ The "poverty of the

17. These words have been inserted by hand in the typescript.

18. Indeed, the term "learning" itself was laden with behaviorist overtones; $c$. Mandler (2007, 242-243). For the record, this sentence falsifies Lightfoot's (2002, x) claim that in 1957 "matters of learnability had not yet been raised explicitly" by Chomsky.

19. E.g. "If we had such grammars for every language, we could attempt to abstract from them, and to construct a general theory of the elements of which languages are composed" (Chomsky 1955-1956, 7). 
stimulus" argument has not been made, although it is hinted at in the allusion to the speaker's "finite and accidental experience with language." Chomsky appears to be thinking much more along mathematical than psychological lines, and the only hint of an interest in the biology of language is given by the appearance of the name "Eric Lenneberg" (cf. Lenneberg 1967) in the acknowledgements of the preface $(1957,6){ }^{20}$ But things are about to change.

Chomsky's review of Skinner (1957) is conventionally taken as marking the final defeat of behaviorist orthodoxy and seems to some the pièce de résistance of his career. ${ }^{21}$ The review seems to show Chomsky's ideas in transition. On the one hand, the term "mentalistic" in his text connotes (perhaps only for rhetorical effect? but there is no evidence that it is so) a lack of proper scientific rigor. Witness: "the talk of 'stimulus control' simply disguises a complete retreat to mentalistic psychology" (Chomsky 1959a, 32); "this terminological revision adds no objectivity to the familiar 'mentalistic' mode of description" (op. cit., 36). On the other hand, the modish term "information processing" is now in evidence; Chomsky refers to "the ways in which [the organism] processes input information [emphasis mine]" (op. cit., 27); "process information" occurs (in quotation marks) on p. 43; and the works of Bruner, Goodnow, and Austin (1956) and Newell, Shaw, and Simon (1958) are cited approvingly (Chomsky 1959a, 57 n. 48). Chomsky also describes as "an extremely interesting and insightful paper" Lashley's contribution to the 1948 Hixon symposium (Lashley 1951). This paper (a cognitive turn in its own right), which discusses subtle phenomena of morphosyntax in the general context of temporally- and spatially-sequenced behavior, is often considered to be quite ahead of its time, and it only began to attract significant attention in the 1960 s. $^{22}$

Most importantly, however, in his review of Skinner, Chomsky brings nativism into the scenario of child language acquisition:

20. Unpublished work by Lenneberg (= Lenneberg 1960) is twice cited in Chomsky (1959a). Lenneberg (1967) contains an extensive appendix "The formal nature of language" (pp. 397-442) written by Chomsky.

21. Still, in its aftermath, as Greenwood $(1999,2)$ reminds us, "behaviorists continued to maintain their in-house journals, their own APA division, and a sizable professional membership." It is also worth pointing out that some scholars, including ones whom no one would accuse of sympathy for Skinner's agenda, have expressed quite ambivalent reactions to the review: see e.g. Baker and Mos (1983, 403-404), Lieberman (1991, 138-140), Agassi (1997, 143).

22. For further discussion, see Mandler (2007, 190-194); also Gardner (1985, 192-193), Weimer and Palermo $(1973,232)$. N.B. also the reference to Lashley's paper at Chomsky $(1983,42)$. 
It is often argued that experience, rather than innate capacity to handle information in certain specific ways, must be the factor of overwhelming dominance in determining the specific character of language acquisition, since a child speaks the language of the group in which he lives. But this is a superficial argument. As long as we are speculating, we may consider the possibility that the brain has evolved to the point where, given an input of observed Chinese sentences, it produces (by an 'induction' of apparently fantastic complexity and suddenness) the 'rules' of Chinese grammar, and given an input of observed English sentences, it produces (by, perhaps, exactly the same process of induction) the rules of English grammar [...]. (Chomsky 1959a, 44)

In this striking passage, Chomsky implies (but merely implies, of course!) that some innate characteristic of the organism is a factor of greater importance than mere linguistic data in the course of acquiring language. ${ }^{23}$ The passage just quoted shortly follows one in which Chomsky observes that the gaping response behaviors of a nestling thrush "are genetically determined and mature without learning" (op. cit., 43). We should not fail to notice that he will come later to characterize the human language faculty in precisely the same way. ${ }^{24}$ The final section of the review, to which greater attention has often been paid, does little more than recapitulate the points Chomsky has already suggested above: (1) all "normal" children in some sense acquire the grammar belonging to the language of the community in which they live; (2) such grammars constitute exceedingly complex generative devices; (3) they are acquired with astounding rapidity; and (4) no mechanism is known that can account for these facts (op. cit., 57-58).

Chomsky's second monograph, Aspects of the Theory of Syntax (1965) evidences more changes still. First, we find at the outset a bevy of Enlightenment thinkers to whom obeisance is paid - César Chesneau, sieur Du Marsais; Denis Diderot; Friedrich Wilhelm Christian Karl Ferdinand Freiherr von Humboldt.... Such luminaries had been first trotted out by Chomsky for the European audience at the Nineteenth International Congress of Linguistics (1962) in Cambridge, Massachusetts (Koerner 1983, 156). From

23. The inverted commas around "induction" are perhaps noteworthy, since Chomsky will later argue the child exhibits grammatical regularities that could not possibly be induced from the limited data to which (s)he is exposed.

24. Agassi $(1997,145)$ suggests that Chomsky's nativism is inspired by the the theory of innate releasing mechanisms (such as imprinting) demonstrated by Heinroth and Lorenz. Such mechanisms are present at birth and need only slight experience to become functional. Just how much Chomsky owes to Lorenz is open to doubt, but the juxtaposition I have cited is hardly accidental. Note that Chomsky uses "released" in the technical sense of the biological theory on p. 43; see also the discussion of imprinting on p. 41. 
now on, we find them regularly appearing in Chomsky's writings, with Descartes taking center stage when Chomsky "came out of the closet" as a Cartesian in Chomsky (1966) (Hintikka 1999, 133). Second, Chomsky is now willing to say that "linguistic theory is mentalistic, since it is concerned with discovering a mental reality underlying actual behavior" (Chomsky 1965, 4). ${ }^{25}$ Third, "Universal Grammar" (albeit dressed in lower-case letters) has appeared: "The grammar of a particular language, then, is to be supplemented by a universal grammar [...]" (op. cit., 6). Fourth, generative grammar has become a theory of the linguistic competence of "an ideal speaker-listener, in a completely homogeneous speech-community, who knows its language perfectly"; ${ }^{26}$ errors of performance are abstracted away (op. cit., 1965, 3). Fifth, grammar is no longer a scientific theory (as in SS), nor something that (with due hedging) "[the child] [...] has in some sense constructed [...] for himself" (Chomsky 1959, 57); rather, "every speaker of a language has mastered and internalized a generative grammar that expresses his knowledge of his language" (Chomsky 1965, 8). In sum: Chomsky's thinking has in a decade evolved remarkably.

\section{Chomsky among the cognitivists}

George Miller (1962) was among the first to present the new Chomskyan picture of linguistics to the psychological community, in a presidential address delivered to the Eastern Psychological Association in Atlantic City, New Jersey. In addition to explaining some basic concepts of linguistics and recalling some (by then classic) experiments from the 1950s, Miller presented the results of experiments on arbitrary centerembedding, as well as error rate and time performance analysis results for tasks involving sentences with transformations of various types (including kernel sentences, with no transformations). Research such as Mehler (1963) continued the analysis of the effects of number and type of transformations on recall. While a number of early studies suggested a correlation between the typology of sentences implied by generative transformational grammar, Miller and McKean (1964) seemed to offer stronger evidence for the psychological reality of particular transformations themselves. The construct

25. In a long note, however, Chomsky insists that embracing the label of mentalism does not commit the linguist to Bloomfield's (false) mentalism vs. mechanism dichotomy (Chomsky 1965, 193-194 n. 1)

26. The necessity for imagining an ideal speech community of this sort will later be removed by Chomsky’s focus on "I-Language” (e.g. Chomsky 1997). 
validity of this experiment was subsequently questioned, and its results became suspect (Fodor, Bever, \& Garrett, 1974, 231-234). ${ }^{27}$

One of the most important discussions of Chomsky's theories and their psychological applications is found in the influential text of Neisser (1967, 242-276). Neisser generally approves of the work of Miller (1962), Mehler (1963), Savin and Perchonock (1965), etc. A revealing feature of Neisser's account, however, is his discussion of antecedents for Chomsky's work; he draws frequent parallels between the work of Chomsky and that of the Gestalt psychologists (who are sometimes supposed to be an important influence on the early cognitivists). Thus: ambiguous sentences play an important role for Chomsky, just as ambiguous figures played for the Gestalt school $(1967,245)$; Chomsky and the Gestalt psychologists had common enemies in the behaviorists and associationists (op. cit., 246); the Gestalt psychologists, like Chomsky, were nativists, "believing that the perceptual processes were largely determined by necessary and innate principles rather than by learning" (ibid.); the idea that linguistic surface structures can be understood in terms of deep structures has an analog in the concept of "ideal figures" in Gestalt psychology (op. cit., 269).

With the publication of Chomsky (1965) aspects of the new "Standard Theory" were incorporated into experimental designs. Thus instead of investigating the relation between kernel sentences and sentences to which various transformations had applied, psycholinguists turned to the investigation of the interrelation of surface structure and deep structure in processing. Mehler and Carey (1967), for instance, sought to demonstrate that in processing sentences subjects had access to both surface and deep structure. In Russia, A.R. Luria noted Chomsky's contributions (in particular the differentiation between surface and deep structure in syntax) appreciatively and expressed optimism concerning the potential that generative transformational grammar offered to the psychological study of the production and understanding of language (Luria 1979, 156-161).

Much early psycholinguistic research along generativist lines focused on attempting to find a correlation between the complexity of a sentence (as somehow experimentally measured) and the derivational history of the sentence (as posited by the grammatical theory). The hypothesis that the complexity of a sentence was correlated with the number of rules employed in its derivation came to be known as the Derivational Theory of Complexity (DTC). Experimental evidence against DTC accumulated in the latter part of the 1960s (Fodor, Bever, \& Garrett 1974, 319-328). With evidence mounting against DTC, it seemed that phenomena other than grammatical derivation were needed to explain sentence perception.

27. Cf. the remarks on the reinterpretation of the results of these early experiments in Akhutina $(2002,44)$. 
By the mid-1970s, debates about syntactic theory had become extremely heated. ${ }^{28}$ Psychologists, who could scarcely afford to keep abreast of the latest theoretical quarrels, started to become disenchanted of generative grammar. ${ }^{29}$ Bever in 1975 described the situation poignantly:

It is no revelation to an audience of linguists that the field is in great disarray at the moment. There are as many revisions of transformational grammar as there are self-proclaimed theorists. Some researchers even question whether the domain of grammar is itself a discrete part of language structure. Arguments and theories slip past each other because of the lack of shared conceptual assumptions about what a grammar is for: we are paralyzed by the frenzied virtuosity of our scholastic momentum, which generates a counter-argument for every technical proposal. (Bever 1975, 63-64)

It may also have been somewhat disheartening for experimental psychologists to consider that Chomsky was not much interested in their confirming (or disconfirming) evidence. $\mathrm{He}$ insists that "linguistic evidence" is sufficient confirmation for a linguistic theory, without the need for corroborating "psychological evidence" (i.e. experimental evidence) (Chomsky 1983). Thus, Chomsky laments, "A demonstration of psychological reality requires evidence about reaction time or something of that sort" (1983, 46); "even the weakest evidence concerning reaction time, etc., is held to bear on 'psychological reality" (ibid.). ${ }^{30}$ Chomsky and Lasnik $(1993,509)$ have now denied that parsing must be an easy or rapid process, ${ }^{31}$ and even a staunch generativist such as Newmeyer concedes, "I do not know of any psycholinguists who would agree with Chomsky \& Lasnik on this point" (Newmeyer 1998, 312).

Gardner $(1985,214)$ has observed that "the majority of workers [ $\left.\mathrm{sic}^{32}\right]$ in psychology have remained skeptical about the overall relevance of his theory for their pursuits." Yet, Gardner insists, "[t]here is one area of psychology where Chomsky's ideas and example have had enormous influence: the psychology of language, or psycholinguistics" (ibid.).

28. See e.g. Huck and Goldsmith (1995).

29. Thus Baker and Mos $(1983,405)$ : "The loss of unanimity within linguistics appears, currently, to be causing psychologists to step back from contact with linguists since, obviously, they are not prepared to resolve the problem."

30. Occasionally Chomsky has noted psycholinguistic findings with approval, e.g.: "In fact, grammatical transformations characteristically reduce the amount of grammatical structure in phrase-markers in a well-defined way, and it may be that one consequence of this is to facilitate the problem of speech perception by a short-term memory of a rather limited sort" (Chomsky 1967, 435).

31. The claim is repeated by Chomsky $(1997,121)$.

32. Shades of Nietzsche's philosophical laborers? 
A survey of contemporary research does not bear this claim out; or at least, we must admit that this "enormous influence" has waned. Such a major work as Levelt (1989) contains only a single reference to Chomsky. And a recent important contribution to developmental psycholinguistics, despite a chapter of nearly 100 pages on morphology and syntax, contains a mere two references to Chomsky's work (and both critical!), specifically to Chomsky and Halle (1968) on generative phonology (Jaeger 2005). This (negative) evidence suggests the marginality, to say the least, of Chomsky to the contemporary enterprise of psycholinguistics.

Chomsky's writings are well known and often read. His ideas about language are common knowledge. Why then the failure of psychologists to engage with him? Chomsky considers such cognitive capacities as social cognition, music appreciation, number sense, language, spatial cognition, and face recognition as essentially distinct in structure and independent of one another $(1983,33)$. He says, "I'd like to think of the system of cognitive structures as in effect a system of 'mental organs,' each of which is quite specific, highly articulated, developing in a particular manner that is intrinsically determined - if the biologists are right, genetically coded - with, of course, complex interactions that are also very largely predetermined" (op. cit., 35). Such a Balkanized view of cognition does not, of course, make a general psychology possible. But Chomsky is not interested in a general psychology; he is interested in "a reasonable version of a 'faculty psychology" (op. cit., 36). Is it not fair to conclude that if this is a program for a revolution, it is a program for a medieval revolution?

Bloomfield, while adopting a nominally behaviorist position (this was a change of heart; he had once been committed to mentalism), essentially divorced linguistics from psychology (Bloomfield 1933; cf. Huck \& Goldsmith 1995, 23-24). Chomsky in effect continued Bloomfield's program of anti-psychologism by other means (Baker \& Mos 1983). (And this claim perhaps lends an additional dimension to Koerner's (1983, 161) insistence on the essential continuity between Chomsky's program and that of the neo-Bloomfieldians.) Some of the most important psychologists of the twentiethcentury believed that the study of general cognition and language could not be divorced - Wundt, Piaget, Bühler, Vygotsky. And their practice reflected their belief. Bühler is particularly exemplary, as he both influenced, and was influenced by, the Prague Circle linguists: he is acknowledged in both Trubetzkoy (1939) and Jakobson (1941); and, alongside his not inconsiderable achievements in general and developmental psychology, he made a significant contribution to the development of phonological theory (Bühler 1931). ${ }^{33}$

33. Already in Die Krise der Psychologie (1927) Bühler drew attention to the importance for psychology of phonology and the abstraction it presupposes. On Bühler's ideas concerning phonology, see Innis $(1982,11-18)$. 
It is now high time to reconsider the so-called "cognitive revolution." Certainly alliances formed between individuals such as Chomsky and Miller. Yet psychologists by and large abandoned behaviorism for their own reasons and adopted new methods and perspectives in accord with their own interests. Some came later to recant "cognitivism" - not to rejoin the behaviorist faithful - but to chart new courses. ${ }^{34}$ There was no single cognitive revolution, but rather a number of cognitive turns. Or to put it differently: not a revolution so much as a series of student uprisings. To believe that Chomsky (1959) quashed behaviorism is to believe myth and not history. One author has remarked, "It is striking that even close followers of Chomsky did not see the destructive genie they were bringing into their field under the rubric of 'psychological explanation'" (Reed 1997, 263). Thus, in the same author's analysis, Miller, Galanter, and Pribram (1960), who styled themselves "subjective behaviorists," replaced a behaviorist program concerned only with behavioral inputs and outputs with a "cognitive" program concerned only with behavioral inputs and outputs "as constrained by specific rules" (Reed 1997, 264).

\section{Introspection and intuition}

In the psychology laboratory of Wilhelm Wundt, experimental subjects were trained to attend to their inner awareness of sensory stimuli; the chronoscope was then used as an instrument to measure the time the subjects took to come to this state of awareness. With introspection (Selbstbeobachtung) as a shared method, a debate arose between Wundt's student Edward Bradford Titchener and the psychologists of the Würzburg school. The Würzburg school claimed the discovery of "imageless thought" - that is, thought unaccompanied by conscious representations (Mayer \& Orth 1901). In their experimental protocols the Würzburgers noticed "a residue, an indefinable and unanalyzable something" (Evans 1975, 341) that they called Bewusstseinlagen (Mayer \& Orth 1901, 6), or "dispositions of consciousness." These Bewusstseinlagen, a kind of imageless thought, seemed to be borderline phenomena, somewhere between consciousness and the unconscious. From this beginning the Würzburg school developed the concept of Aufgaben 'tasks' - determining tendencies inaccessible to consciousness

34. As various papers in Johnson and Erneling (1997) show. With the passing of years authors have distanced themselves from their once revolutionary work. Consider, for instance, that Bruner $(1997,286)$ accepts this evaluation of his own early work: "concept attainment studies have steadily retreated from formalistic conclusions since the Bruner-Goodnow-Austin book (1956) of 40 years ago."

35. I borrow this translation from Mandler $(2007,78)$. 
(Mandler 2007, 93-97). Meanwhile, Titchener opposed any idea of "imageless thought"; he was a "sensationalist," meaning that he believed thought must always be accompanied by sensation. On Titchener's view, "the only scientific means of understanding mental structure was through introspection, practised under the most rigorous experimental conditions" (Kroker 2003, 83), and the Würzburg psychologists had simply been too lax in their methods of introspection. For Titchener, the report of introspection must be a report of a conscious experience, and no concept of the unconscious could have a proper place in a genuinely introspectionist psychology.

With the rise of behaviorism in America, psychologists came to reject introspection as a legitimate method of experimental inquiry. At the same time, the behaviorists had no interest in the unconscious phenomena the Würzburg school had discovered, since they avoided recourse to mentalistic explanation in general. Although the cognitive psychology that grew up in the 1950s and 1960s had little interest in introspection either, the unconscious processes that had been posited by the Würzburgers were "rediscovered" at this time. ${ }^{36}$ Chomsky accepts introspection in a limited form but insists that "[a]ny interesting generative grammar will be dealing, for the most part, with mental processes that are far beyond the level of actual or even potential consciousness" (Chomsky 1965, 8). ${ }^{37}$ Yet, as we have seen, Chomsky embraces speakers' intuitions as the primary data of a linguistic theory, despite his caveat that a speaker's "statements about his intuitive knowledge of the language are [not] necessarily accurate" (ibid.). It will be useful to refer to Chomsky's position as "intuitionism." I shall show in what follows that Chomsky came to intuitionism with a certain ambivalence, and that his intuitionism had far-reaching consequences both within and beyond linguistic theory.

The first statements in LSLT concerning intuition are quite negative: "Thus if one of the basic undefined terms of linguistic theory is 'intuition', and if we define phonemes in this theory as elements which our intuition perceives in a language, then the notion of phoneme is as clear and precise as is 'intuition'" (Chomsky 1955-1956, 21). In short, the linguist "should try to avoid such notions as 'intuition" (op. cit., 22). These statements are quite remarkable given the appeals to intuition that I have quoted earlier. In the absence of a reliable technique for constructing a phonemic system, Chomsky later argues, we have only our intuition that e.g. /p/ and /b/are distinct in English; but

36. On this "rediscovery of the unconscious" see Mandler (2007, 226-231); and on later rediscoveries Kihlstrom, Barnhardt, and Tataryn and (1992). At least one direct link is that mentioned in note 9 above (Selz had studied with the Würzburg psychologists).

37. Chomsky insists that linguistics is sterile if it does not accept "introspective judgments of the informant (often, the linguist himself)" (1965, $194 \mathrm{n}$. 1). But it seems that this introspection is limited to mental contents and does not extend to mental processes. For a relevant point concerning introspection, see Neisser $(1967,249)$. 
"[f]ortunately, in the case of phonemic distinctness the pair test enables us to avoid this reliance on intuition" (op. cit., 36). Three pages later Chomsky comes to the question of how we can determine that Colorless green ideas sleep furiously is a grammatical sentence, whereas Furiously sleep ideas green colorless is an ungrammatical string. "The only thing we can say directly is that the speaker has an 'intuitive' sense of grammaticalness" (op. cit., 39). Chomsky admits that there is a problem here, but he sees a way out:

Suppose that we can (i) construct an abstract ${ }^{38}$ linguistic theory in which grammaticalness is defined, (ii) apply this linguistic theory in a rigorous way to a finite sample of linguistic behavior thus generating a set of 'grammatical' sentences, [note omitted] and (iii) demonstrate that the set of grammatical sentences thus generated, in the case of language after language, corresponds to the 'intuitive sense of grammaticalness' of the native speaker. In this case, we will have succeeded in giving a rational and general ${ }^{39}$ account of this behavior, i.e. a theory of the speaker's linguistic intuition. This is the goal of linguistic theory. (Chomsky 1955-1956, 39-40)

Chomsky admits intuitions concerning linguistic form, while denying intuitions concerning linguistic significance. Before a linguistic theory is constructed, the linguist must rely on speakers' intuitions; whereas "[a]fter a linguistic theory has been constructed, the subject matter of linguistic description is determined by the theory itself. The success of the theory is determined in part by its efficacy in reconstructing intuition [emphasis mine]" (op. cit., 40).

The argument here is subtle. But Chomsky is motivated by a serious problem. On his view, analysis of a corpus of utterances is inadequate for theory building, because the corpus constitutes a finite sample of linguistic behavior. ${ }^{40}$ In principle an arbitrary number of grammars might be constructed that would generate only those sentences in the corpus. But any of these grammars might be vitiated by adding an additional sentence to the corpus. A corpus is finite, whereas a speaker's linguistic capability includes the ability to produce, understand, and render grammaticality judgments on infinitely many sentences. As Chomsky has repeatedly stated over the years, the most basic fact about a language is that it involves a discrete infinity (Chomsky 1967, 434; Chomsky 1983, 38; Chomsky 2000, 19). A grammar is a model not of a finite portion of a speaker's behavior, but of a speaker's infinite language capacity. And so a linguistic theory cannot rely on behavioral observations, which are always finite. Like it or not, the linguist must deal with the speaker's intuitions.

38. Inserted by hand in the typescript.

39. Inserted by hand in the typescript.

40. There is the further problem that the corpus may (and, if sufficiently large, will almost certainly) contain performance errors. 
If a linguistic theory generates predictions that contradict a native speaker's intuitions, then, Chomsky argues, something must be wrong with the theory. This statement is not limited to intuitions concerning grammaticality. If a linguistic theory asserted that John finished eating contained only a single word or identified -er in mother, father, brother, sister as a morpheme, that theory would be equally wrong (Chomsky 1955-1956, 55). ${ }^{41}$ The linguist may rely on operational tests, but only insofar as they correspond to a native speaker's intuitions; "we must be careful not to exaggerate the extent to which a behavioral reinterpretation of intuition about form will actually clarify the situation" (op. cit., 56).

We have not yet considered the case in which a speaker does not have a clear intuition concerning the grammaticality of a particular string. Yet this is by no means an uncommon case, as the number of sentences with a prefixed question mark in publications on syntax demonstrates. Chomsky deals with this question at the beginning of SS. There his position is that the external conditions of adequacy for a grammar dictate that it (1) generate all the strings that a speaker intuitively judges as definite sentences and (2) does not generate any string that a speaker intuitively judges as a definite non-sentence. "In many intermediate cases," Chomsky writes, "we shall be prepared to let the grammar itself decide, when the grammar is set up in the simplest way so that it includes the clear sentences and excludes the clear non-sentences" (Chomsky 1957, 14).

The consequences of Chomsky's intuitionism within linguistics involved a movement away from empirically grounded methods. Linguists were free to hand-pick their examples, and virtually no work in syntactic theory attempted to discover whether a survey of more linguistic data might falsify the theory. ${ }^{42}$ Although León (2005) is undoubtedly correct in arguing that corpus linguists are engaging in myth-making when they claim that Chomsky prevented corpus-based research for twenty or thirty

41. But here we run into serious difficulties. Chinese speakers consider sentences as sequences of $z i^{4}()$, monosyllabic morphemes (which correspond to characters in the writing system) (Read et al. 1986). Here $z i^{4}$ 字 constitutes what Chao $(1968,136)$ calls the "sociological word." But this unit is not at all coincident with the $c i^{2}$ (詞), the linguistic terminus technicus for 'word'. Moreover Chinese speakers who have not learned alphabetic writing are unable to segment utterances into individual speech sounds (phonemes), although they have no difficulty segmenting utterances into syllables (Read et al. 1986). (This result holds true for most illiterate speakers or speakers literate only in a non-alphabetic writing system.) It seems obvious to say that speakers unacquainted with the concept morpheme will be unable successfully to segment utterances into morphemes, even though such speakers are surely in the majority. It does not help to say that we must first acquaint the speakers with the relevant linguistic concepts, since we will then have taught them the (operationalized) concepts of a particular linguistic theory, which is what we were trying to establish in the first place.

42. See Pullum and Scholz (2002) for the empirical falsification of a selection of concrete linguistic claims from the generativist literature. 
years, it is difficult not to believe that corpus linguistics ${ }^{43}$ and other empiricist endeavors within linguistics suffered a loss of prestige during the years in which generative grammar held its ascendancy. ${ }^{44}$ In these years, publications in linguistics proudly proclaimed their rationalist or even metaphysical orientation, as indicated by such titles as "The metaphysics of coarticulation" (Hammarberg 1976). Of course Chomsky never had the power to suppress all linguists who held competing views. Nevertheless, one sees, for a not inconsiderable time, the triumph of Chomsky's rationalism over empiricist linguistics.

Hintikka (1999) argues that many philosophers (he emphasizes Saul Kripke in particular) embraced Chomsky's intuitionism. For Hintikka, Chomsky, as a Cartesian (and hence committed to some version of innatism), is at least consistent in invoking intuitionism - as is any philosopher committed to "Platonic anamnesis, Aristotelian forms, Cartesian innate ideas, or Kantian transcendental deductions" (Hintikka 1999, 131). But few contemporary philosophers are committed to any of these; their reliance on intuition, Hintikka asserts $(1999,127)$, comes from their "attempt to get on the bandwagon of transformational grammar."

\section{The appeal to biology}

In 2000 Chomsky wrote: 'The 'biolinguistic' approach is at the core of the modern study of language, at least as I understand it. The program was formulated with relative clarity about forty years ago" (Chomsky 2000, 24). Chomsky does not specify which or whose formulations he is thinking of, but I presume that he includes his own work. Forty years before Chomsky's article, Eric Lenneberg had published an important paper "Language, evolution, and purposive behavior," which reflected in part ideas that had emerged from his discussions with Chomsky and Miller (Lenneberg 1960). The paper was reprinted in the influential anthology of Katz and Fodor (1964) and is cited by Chomsky (1965). The phrase "about forty years ago" also can be construed

43. Fillmore's $(1991,35)$ caricature of the armchair linguist from the perspective of the corpus linguist is too amusing not to quote here: "Armchair linguistics does not have a good name in some linguistics circles. A caricature of the armchair linguist is something like this. He sits in a deep soft comfortable armchair, with his eyes closed and his hands clasped behind his head. Once in a while, he opens his eyes, sits up abruptly shouting, "Wow, what a neat fact!", grabs his pencil, and writes something down. Then he paces around for a few hours in the excitement of having come still closer to knowing what language is really like. (There isn't anybody exactly like this, but there are some approximations.)"

44. The rise of corpus linguistics in the 1990s had much to do with the availability of cheap computer processing time and computer storage. 
to include Chomsky's own early publications. Although biological language has not always been noticed by readers of Chomsky's early writings, it is not hard to find. Consider the following examples:

- "One would naturally expect that prediction of the behavior of a complex organism (or machine) would require, in addition to information about external stimulation, knowledge of the internal structure of the organism, the ways in which it processes input information and organizes its own behavior. These characteristics of the organism are in general a complicated product of inborn structure, the genetically determined course of maturation, and past experience." (Chomsky 1959a, 27)

- $\quad$ "Some recent studies have stressed the necessity for carefully analyzing the strategies available to the organism, regarded as a complex 'information-processing system' [...]. These may be largely innate, or developed by early learning processes about which very little is yet known." (Chomsky 1959a, 57 n. 48)

- "The problem of mapping the intrinsic cognitive capacities of an organism and identifying the systems of belief and the organization of behavior that it can readily attain should be central to experimental psychology. However, the field has not developed in this way." (Chomsky 1965, 56-57)

- "One would guess, rather, that it is the mentalistic studies that will ultimately be of greatest value for the investigation of neurophysiological mechanisms, since they alone are concerned with determining abstractly the properties that such mechanisms must exhibit and the functions they must perform." (Chomsky 1965, 193 n. 1)

The discussion of the organism in terms of innate and genetically determined factors suggests that Chomsky was likely interested in, and attracted by, the rapidly developing field of molecular genetics. After the two papers of Watson and Crick elucidating the double helix structure of DNA (1953a) and presenting its genetic implications (1953b), molecular biology began a period of rapid growth. By 1960 molecular genetics was a highly visible research area (Rheinberger, forthcoming). At the same time exciting developments were occurring in brain science. Hubel and Wiesel (1959) identified receptors in the primary visual cortex of the cat and noted that certain receptors were specific to motion in a particular direction. Subsequent work by Hubel and Wiesel turned up even more specific types of receptors. These results promised exciting new possibilities for understanding brain processes, although they were quite controversial at the time and were received with some skepticism (Coren 2003, 98). Rapid progress in both molecular genetics and the understanding of brain function may have suggested to Chomsky that biology was nearing the point where it could aid in the explanation of mental functions and relate these to the genetic constitution of the organism. I suggest that at this time Chomsky decided biology could offer what psychology could 
not, and he chose a "biolinguistic" approach. Having committed himself to the biological enterprise, Chomsky could appease critics who found his mentalism and intuitionism incompatible with a genuinely scientific approach to language.

Chomsky's biolinguistic approach led him to the conception of "mental organs," including a "language organ":

So, using the term "organ" in a slightly extended sense to include something like, say, the circulatory system - not the usual sense - we might regard the body as a system of physical organs, each with its specific properties and peculiarities and with a mode of interaction, all genetically determined in basic outline, but modified in various ways in the course of growth. Now, I think that there is every reason to suppose that the same kind of "modular" approach is appropriate for the study of the mind - which I understand to be the study at an appropriate level of abstraction of properties of the brain - and in particular for the general system of cognitive structures, which does not exhaust the mind, but is the part we're talking about. That is to say, I'd like to think of the system of cognitive structures as in effect a system of "mental organs," each of which is quite specific, highly articulated, developing in a particular manner that is intrinsically determined - if the biologists are right, genetically coded - with, of course, complex interactions that are also very largely predetermined. (Chomsky 1983, 35)

In Chomsky's view language is a neural representation of linguistic rules (Chomsky 1983, 38). An I-language is a state of a person's brain (Chomsky \& Lasnik 1993, 508; Chomsky 1997, 119). Each person possesses a "language organ," whose "initial state is an expression of the genes, comparable to the initial state of the human visual system, and appears to be a common human possession to close approximation" (Chomsky $2000,19)$. The initial state $\left(S_{0}\right)$ of the language organ is a language acquisition device (LAD). "The existence of such a LAD is sometimes regarded as controversial, but it is no more so than the (equivalent) assumption that there is a dedicated language module that accounts for the linguistic development of an infant as distinct from that of her pet kitten (or chimpanzee, or whatever), given essentially the same experience" (ibid.).

It is quite noteworthy that Chomsky apparently regards the existence of a dedicated language module as uncontroversial. This assumption follows quite naturally from his idea that mind can be conceived as a set of distinct modules, which may equally be regarded as "organs." A similar view is most famously articulated by Fodor (1983). Chomsky endorses a view of mental modularity that differs from Fodor's, which he characterizes as input/output systems; by contrast, Chomsky conceives of modules as cognitive systems that "enter into perception and action" (Chomsky 2000, 20). A further variety of modularity, termed "representational modularity," has been proposed by Jackendoff, who posits "integrative modules, which are responsible for integrating particular levels of representation, and interface modules, which are responsible for communication among representations" (Jackendoff 2000, 3). 
Jackendoff's account is intended to address concerns that if information is completely encapsulated within independent modules, no integration is possible (and thus it is difficult to understand how action, conscious awareness, etc. would ever be possible) (Jackendoff 2000, 19). Although Jackendoff's account is in certain ways compatible with the cognitive architectures proposed by psycholinguists such as Levelt (1989), Jackendoff seems quite at a loss when he has to develop the neurophysiological implications of his version of modularity:

My inclination is to think that all the levels of representation - the integrative processors - are innate, and that some of the interface processors are innate but others are not. [...] At this point I don't fully understand the logical and neurological issues involved in making a claim that an interface module is learnable, so I will have to leave it at that. (Jackendoff 2000, 22)

The idea of language as a "mental organ" has been explored at some length by Anderson and Lightfoot (2000). ${ }^{45}$ The essence of this view is that:

Children acquire a productive system, a grammar, in accordance with the requirements of the genotype. If asked to say quite generally what is now known about the linguistic genotype, we would say that it yields finite grammars, because they are represented in the finite space of the brain, but that they range over an infinity of possible sentences. Finite grammars consist of a set of operations allowing for infinite variation in the expressions that are generated. The genotype is plastic, consistent with speaking Japanese or Quechua. It is modular and uniquely computational. (Anderson \& Lightfoot 2000, 703)

On Lightfoot's view the (generative/Chomskyan) linguist is really a kind of biologist: "Linguists seek to describe the mental systems that Japanese or Cornish people have, their language 'organs.' [...] Linguists also specify the genetic information, common to the species, which permits the growth of mature language organs in Cornish, Japanese, Dutch, Kinande and Navaho children" (Lightfoot 2002, v).

The modularity of Chomsky and those who follow in his footsteps has met with frequent derision. "Modular theories owe much to phrenology," Philip Lieberman $(1991,13)$ writes, scathingly. Similarly:

This essentially phrenological concept of psychological explanation is with us still, promoted by unabashed cognitivists (e.g. Fodor, 1983). For example, at present many researchers seem very excited about using modern imaging technology to 'locate' the neural substrate of thought, emotion, or whatever. The only sense in which such 'discoveries' are explanatory is in that they reveal a correlation

45. See also the more expansive and popular treatment: Anderson and Lightfoot (2002). 
between one kind of explicit behavior (whatever the patient thinks he or she is doing) and observable neural activity (Reed 1997, 272 n. 1).

Although organs such as the "language organ" are purportedly functional rather than physical organs (here the term "organ" has been pushed well beyond its accepted use in biology), proponents are eager to find physical correlates for behavioral phenomena. Thus Anderson and Lightfoot $(2000,704)$ write, “These modules may or may not be separately represented in neural tissue. For example, Grodzinsky [2000] recently argued that movement relations - and not other aspects of syntactic form - are computed by specific tissue within the classical Broca's area. The claim of modularity does not in any sense rest on such physical separation, however."

Thus claims of modularity are frequently translated into claims of brain localization. These claims can be traced back to Paul Broca's identification in 1861 of the posterior third of the inferior frontal gyrus ("Broca's area") with the control of speech. But claims of localization are quite problematic. "Indeed, the more we know about the brain the more we find that strict localization of language functions is not the case" (Tomasello 1995, 143). Virtually every student will have encountered in a textbook the claim that damage to Wernicke's area causes a type of aphasia known as fluent aphasia or Wernicke's aphasia. But in the late 1970s two physiologists found themselves having to ask "Wernicke's region - where is it?" (Bogen \& Bogen, 1976). These two authors note the vast disparity in the ways in which different authors depict Wernicke's area and lament, with respect to a particular simplification, "There are a lot of molecular biologists and quantum physicists and mathematicians who are educated, sophisticated people, and who are now taking an interest in language; if you teach them this simpleminded version, how will they feel several years from now when they realize they have been talked down to?" (Bogen \& Bogen 1976, 841-842). A paper from early in this century decomposes Wernicke's area into separate subsystems, implicated in functions ranging from sound perception, speech perception, speech production, verbal recall, mimicry, and the memorization of novel words (Wise et al. 2001). Functionally, things are not much clearer. As Tomasello notes, even Pinker has to admit: "But to be honest, no one knows what either Broca's area or Wernicke's area is for" (Pinker 1994, 311 qtd. by Tomasello 1995, 143).

The concept of a "language module" responsible for Universal Grammar (UG) has been widely criticized as biologically implausible. ${ }^{46}$ UG contains a set of fixed principles and some parameters that may be set upon exposure to linguistic data. In Chomsky's terms, every human at birth has the same $\mathrm{S}_{0}$ of the language organ. From $\mathrm{S}_{0}$ the development of the language organ is constrained by its own principles and by the

46. There is the further problem here of what is ascribed to UG. What does UG contain? Tomasello (2004) surveys quite a few proposals and finds no agreement whatsoever. 
linguistic data to which it is exposed. Chomsky provocatively asserts, "A rational Martian scientist, studying humans as we do other organisms, would conclude that there is really only one human language, with some marginal differences [...]" (Chomsky 1997, 121-122). But, as Lieberman points out, Chomsky's hypothesis completely ignores a key fact of evolutionary biology: genetic variation. The genes that determine some aspect of the structure of a mammal exhibit about 10\% variation (Lieberman 1991, 131). As Lieberman concludes, "A biologically plausible Universal Grammar cannot have rules and parameters that are so tightly interlocked that the absence of any single bit of putative innate knowledge makes it impossible for the child to acquire a particular language" (1991, 132). (Or, we might say, if this hypothesis were correct, we would expect not infrequently to see otherwise normal children who were completely incapable of learning a language.)

In fact, Chomsky has asserted that UG is "counterfunctional." ${ }^{37}$ For Chomsky, I-language is so autonomous that he imagines, "Some other organism might, in principle, have the same I-language as Peter, but embedded in a performance system that uses it for locomotion" (Chomsky 1997, 120). A reluctant critic writes, "One might think that Chomsky, as the leading exponent of the idea that we are endowed with an innate 'language organ', would be at the forefront of the attempt to provide a reasonable account of its evolution in the species" (Newmeyer 1998, 305). But Chomsky feels no need to explain UG in terms of natural selection. Indeed, UG might simply be an emergent phenomenon of our large brains, or of some unknown attributes of neurons, or something else of this kind. Yet then we run into even greater problems. "[Chomsky] wants language, at one and the same time, to be an epiphenomenon and an 'organ', the latter by definition a product of a dedicated genetic blueprint. But it cannot be an 'organ', even in a metaphorical sense, if it is simply a consequence of a big brain" (Newmeyer 1998, 316).

Although Chomsky's arguments have generally found an unfriendly audience among evolutionary biologists, at least one biologist is (up to a point) sympathetic. Stephen Jay Gould $(1993,321)$ writes, "I can't prove that language was not the selected basis of increasing brain size, but the universals of language are so different from anything else in nature, and so quirky in their structure, that origin as a side consequence of the brain's enhanced capacity, rather than as simple advance in continuity from ancestral grunts and gestures seems indicated."

Chomsky's appeal to biology has explained little and created serious conundrums. Thus, "While Chomsky and many other linguists posit an organ responsible for language competence, neuropsychologists are studying how this organ materializes in the cortex. The locus of the language organ, however, remains elusive. Even though it is relatively easy to delineate a network of neural areas actively involved when adults use

47. But cf. e.g. Chomsky $(1967,435)$ for some ways in which UG might be adaptive. 
language, it is still not known whether developing infants utilize similar structures when they use or acquire language" (Mehler, Christophe, \& Ramus 2000, 68).

It is reasonable in conclusion to say that Chomsky's appeal to biology has raised more questions than it has answered. Chomsky's views concerning the nature of language, however, are not his only contribution. He has worked to create an elegant and economical way of describing linguistic phenomena. Newmeyer concludes, "I hope to have demonstrated successfully that [Chomsky's] published remarks on language evolution can and should be evaluated independently of his theory of language per se" (Newmeyer 1998, 318). Chomsky's formalisms - from SS, to the Standard Theory, to $\mathrm{GB}$, principles and parameters, and the minimalist program - have grown in elegance; and analyses within these frameworks are capable of shedding real light on linguistic data. Yet Chomsky's appeal to biology has resulted in little more than confusion.

\section{Fate of "the poverty of the stimulus"}

The "poverty of the stimulus," an expression introduced by Chomsky (1980), occurs in much subsequent work in linguistics. The history of the concept is traced by Thomas (2002) (but see the criticisms of Scholz \& Pullum (2002)). The term is used in diverse ways, as suggested by Pullum and Scholz's $(2002,11)$ remark, "Such is the prestige of Chomsky's pronouncements that this scare-quoted but undefined phrase was quickly picked up and repeated by others." I shall take the "poverty of the stimulus" (POS) to refer to the proposition that the linguistic data to which a child is exposed is in itself insufficient for the child to acquire the grammar of the language (or in Chomsky's terms, to acquire the I-language). Pullum and Scholz survey a range of arguments that have been advanced for POS and determine that they are all inadequate. Since POS is a key argument advanced for linguistic nativism (see e.g. Anderson \& Lightfoot 2000, 710-711) - and sometimes the only argument advanced! - it is crucial for the nativists' claims. Sampson (2002) adds empirical data in support of the arguments of Pullum and Scholz (2002) and in general inveighs against linguistic nativism. Scholz and Pullum (2002) respond to their critics, and suggest that the term "poverty of the stimulus" is little more than a shibboleth: "'Poverty of the stimulus' does indeed have a sociological function: it is used by authors to identify themselves as being generative linguists who endorse some nativist line on acquisition" (Scholz \& Pullum 2002, 194).

In this final section of the paper, I will not discuss particular arguments for or against POS. These may be found in the literature I have surveyed above. I see POS as a continuation of arguments that appear already in nuce in LSLT. Chomsky has, from the beginning, been concerned with the question: given the (apparently) impoverished linguistic data to which a child is exposed, how does the child rapidly and with (seemingly) little effort develop a rich and complex internal grammar? It is of 
course controversial that the data are so impoverished. This is denied, for instance, by Sampson (2002). And authors such as Lieberman see no reason that general learning mechanisms cannot account for language acquisition: "we probably learn many, if not all, of the automatized motor control patterns and rules of syntax by means of general cognitive mechanisms" (Lieberman 1991, 142). I shall not here take a position on whether the stimulus is in fact impoverished. What I wish to do, instead, is to consider the implications of POS. How, from the limited data to which a child is exposed might a complex grammar be acquired? Chomsky finds it necessary to postulate a language faculty with an $\mathrm{S}_{0}$ that "consists of a rich system of principles, with some parameters of variation. The fixed principles are highly restrictive" (Chomsky 1997, 121). But recent research in a variety of areas from developmental psycholinguists to computational modeling is yielding evidence suggesting that language learning might not require a richly structured and highly restricted learning mechanism. Humans may indeed have brain mechanisms specialized for language (cf. Lieberman 1991, 109), but these may be considerably less rich and restricted than Chomsky supposes. The principle of parsimony dictates that we consider the simplest means by which a human might arrive at a full-fledged grammar. In pointing to some recent lines of research, I aim to show that Chomsky - and many other generative linguists - are increasingly divorced from contemporary developments in the "cognitive sciences."

I shall briefly survey three areas of research, highlighting the potentials they offer in explaining language acquisition. These are: statistical language learning, latent semantic analysis, and agent-based modeling. I emphasize that none of these approaches has yet succeeded in providing a complete and convincing account of how humans learn languages. They have not even come close. We cannot expect that this goal will be reached quickly or easily. Nevertheless, these approaches demonstrate that complex linguistic knowledge can be acquired without positing a highly-structured and highly-constrained autonomous language faculty of the Chomskyan sort. In conclusion, I shall mention one novel and surprising development that stems from the POS argument.

\subsection{Statistical language learning}

Recently distributional and statistical approaches, which had largely fallen out of favor with the collapse of neo-Bloomfieldian linguistics, have made a comeback in developmental psycholinguistics. Studies have demonstrated that infants possess a greater capacity for learning than was previously supposed and therefore suggest that innate capacities need not play so great a role. Saffran, Aslin, and Newport (1996) have shown that eight-month-old infants can use transitional probabilities to segment fluent speech into words. Mintz, Newport, and Bever (2002) have demonstrated that distributional information is sufficient for classifying many lexical items as nouns or verbs. These results do not imply that distributional information alone is sufficient for 
grammatical category formation, nor do they imply that the child is a tabula rasa; in fact, it is necessary to presuppose certain "computational biases." Nevertheless, they prove that distributional information is a much richer predictor of grammatical category than was traditionally assumed. Newport and Aslan (2004) have established that statistical learning is not limited to computations over adjacent items. Further, since there is a correlation between particular computational biases and language structures, the work "suggests that natural language structures may be formed, at least in part, by the constraints and selectivities of what human learners find easy to acquire" (Newport \& Aslan 2004, 159). The work of Thompson and Newport (2007) has extended the statistical learning approach to the acquisition of phrase structure, showing that transition probabilities between words can be used to determine phrase boundaries. These studies provide strong support for the hypothesis that statistical and distributional information plays an important role in language acquisition, and that a limited set of statistical "computations" is capable of accounting for the acquisition of linguistic structure in multiple domains.

\subsection{Latent semantic analysis}

An average American child in late elementary school acquires 10-15 new words each day. ${ }^{48}$ This same child reads about 50 paragraphs of text each day. Studies of vocabulary learning show that when a child is exposed to 50 paragraphs of age-appropriate text, the child should acquire no more than 2.5 words (Landauer \& Dumais 1997, 221-223). How to account for this discrepancy? This phenomenon of "excess learning" might prima facie indicate an impoverished stimulus. But in fact latent semantic analysis (LSA), a technique that computes a semantic space from word contiguity data, models human vocabulary acquisition in an impressive number of respects (Landauer 2007). LSA involves the computation of a vector space model from a large sample of language, followed by a dimensionality reduction via singular value decomposition (Jackson 2003, 189-196). This dimensionality reduction allows semantic similarity between lexical items to be induced reliably through inductive learning (Landauer \& Dumais $1997,213)$. LSA accurately simulates human behavior in a variety of linguistic tasks; for example, it mimics human judgments of the similarity of word meanings (Landauer 2007 , 5). Although LSA is far from a complete theory of human language use - it in no way models language production, it is insensitive to syntax, and it lacks any propositional component -, it demonstrates that the acquisition of semantic relations from exposure to a finite amount of linguistic data can be accomplished through simple means, with

48. We can assume that virtually all these words will come from reading, because the active spoken vocabulary accounts for only a small percentage of recognition vocabulary. No more than 100 words a year are learned by direct instruction (Landauer \& Dumais 1997, 222). 
no need for positing an innate mechanism incorporating arbitrary constraints. Current research is extending the model to incorporate syntactic aspects, such as word order (Dennis 2007).

\subsection{Agent-based modeling}

Research with artificial agents (both robotic and simulated) has shown that interaction between uncoordinated agents equipped with mechanisms for perception and action whose behavior is minimally constrained can lead to regularities similar to those observed in human language (Steels 1998, 385). These regularities emerge through selforganization and selective pressures. This type of modeling demonstrates mechanisms by which language might be acquired without positing specialized innate capabilities. Experiments have simulated the formation of a shared lexicon by agents engaged in adaptive games (Steels 1998, 391-393); the emergence of shared phonemic inventories comparable to those of human languages, together with strong combinitoriality and phonotactics (Oudeyer 2006); and the emergence of morphosyntactic regularities in shared languages (Batali 1998). This work suggests that "grammatical regularities manifest in human language could emerge as a result of non-genetic cultural processes among a population of animals with the cognitive capacities required for communication, but who do not initially share a co-ordinated communication system" (Batali 1998 , 406). Instead of supposing that human brains adapted to language in the course of evolution, it may be the case that "the process itself by which languages are formed develops and selects just those which can be learnt. It is languages which adapt to a generic brain, and not the contrary" (Oudeyer 2006, 62).

The three research areas surveyed demonstrate that there is an abundance of strong, empirically grounded research in the cognitive sciences that points not just beyond POS arguments, but beyond the grounds that led Chomsky and his followers to these arguments in the first place. Meanwhile, though, Chomsky's nativism has unexpectedly spread to new domains. Mikhail (2007) describes a research program entitled "universal moral grammar" (UMG) that is explicitly intended to parallel Chomsky's program in linguistics. ${ }^{49}$ Thus UMG takes over the competence/performance dichotomy, the distinction between descriptive and explanatory adequacy, Chomskyan modularity, and an "argument from the poverty of the moral stimulus." This argument holds that examples of moral behavior are inadequate to acquire UMG, which is a "system [that] enables individuals to determine the deontic status of an infinite variety of acts and omissions" (Mikhail 2007, 144). It is hard to see UMG as anything other than natural law - dressed up in last season's fashions.

49. In fact, Mikhail thanks Chomsky for "helpful feedback" $(2007,151)$. 


\section{Conclusion}

There were many cognitive turns in the latter part of the twentieth century, and history will no doubt judge many of them false ones. Chomsky's position is enigmatic. He is at once at the center - inspiring George Miller, making seminal contributions to the nascent discipline of theoretical computer science, and creating vocabulary that is used today by many linguists who reject most of his foundational positions. Yet he is also at the periphery, at odds with such heroes of his contemporary revolutionaries as Piaget and Vygotsky, moving ever further from the modern psycholinguistics that he had once inspired, devising computational theories that resist computational implementation, and in the end holding firm to his Wundertheorie account ${ }^{50}$ of human language. In some sense, we may view Chomsky's alignment with biology as prescient, given the increasing importance of neurolinguistics today. But Chomsky's cavalier disregard for key principles of mainstream evolutionary theory, together with his resolute antiempiricism create a chasm between Chomsky's work and contemporary research in biology that simply cannot be bridged. Likewise, his anti-empiricism separates him from contemporary psychology, which is a maturing empirical discipline. Chomsky's ideas have certainly been influential - but more often than not as foils for those of others.

\section{References}

Agassi, Joseph. 1997. “The Novelty of Chomsky's Theories”. The future of the cognitive revolution, ed. by David Martel Johnson \& Christina E. Erneling, 136-148. New York: Oxford University Press.

Akhutina, T.V. 2002. Neirolingvisticheskii analiz dinamicheskoi afazii, 2d ed. Moscow: Terebinf. Alba, Joseph W. \& Lynn Hasher. 1983. "Is memory schematic?" Psychological Bulletin 93: 2. 203-231.

Anderson, Stephen R. \& David Lightfoot. 2000. “The human language faculty as an organ”. Annual Review of Physiology 62. 697-722.

Anderson, Stephen R. \& David Lightfoot. 2002. The language organ : linguistics as cognitive physiology. Cambridge ; New York: Cambridge University Press.

Backus, John W. 1960. "The syntax and semantics of the proposed international algebraic language of the Zurich ACM-GAMM conference”. Proceedings of the International Conference on Information Processing, Paris 15-20 June 1959, 125-132. Paris: UNESCO.

Baker, William J. \& Leendert P. Mos. 1983. "Mentalism and language in (and out of) psychology". Journal of Psycholinguistic Research 12: 4. 397-406.

Barsalou, Lawrence W. 1992. "Frames, concepts, and conceptual fields". Frames, fields, and contrasts : new essays in semantic and lexical organization, ed. by Adrienne Lehrer \& Eva Feder Kittay, 21-74. Hillsdale, N.J.: L. Erlbaum Associates.

Bartlett, Frederic C. 1932. Remembering; a study in experimental and social psychology. New York; Cambridge, Eng.: Macmillan Co.; University Press.

50. Cf. Mandler 2007, 213. 
Batali, John. 1998. "Computational simulations of the emergence of grammar". Approaches to the evolution of language : social and cognitive bases, ed. by James R. Hurford, Michael StuddertKennedy \& Chris Knight, 405-426. Cambridge, UK ; New York: Cambridge University Press. Bergmann, Gustav. 1953. "Logical positivism, language, and the reconstruction of metaphysics". Rivista Critica di Storia della Filosofia 8. 453-481.

Bever, Thomas G. 1975. "Psychologically real grammar emerges because of its role in language acquisition”. Georgetown University Round Table on Languages and Linguistics, 1975: Developmental psycholinguistics : theory and applications, ed. by Daniel P. Dato, 63-75. Washington: Georgetown University Press.

Bloomfield, Leonard. 1933. Language. New York: H. Holt \& Company.

Bogen, J.E., G.M. Bogen, Stevan R. Harnad, Horst D. Steklis, June Lancaster \& Robin Fox. 1976. "Wernicke's Region - Where Is It?" Origins and Evolution of Language and Speech, 834-843. New York: New York Acad. of Sciences.

Brown, Roger. 1958. Words and things. Glencoe, Ill.: The Free Press.

Bruner, Jerome S. 1997. "Will cognitive revolutions ever stop? " The future of the cognitive revolution, ed. by David Martel Johnson \& Christina E. Erneling, 279-292. New York: Oxford University Press.

Bruner, Jerome S., Jacqueline J. Goodnow \& George A. Austin. 1986[1956]. A study of thinking. Edison, NJ: Transaction.

Bühler, Karl Ludwig. 1931. "Phonetik und Phonologie". Travaux du Cercle linguistique de Prague 4. 22-53.

Chao, Yuen Ren. 1968. A grammar of spoken Chinese. Berkeley: University of California Press.

Chomsky, Noam. 1955-1956. “The Logical Structure of Linguistic Theory”. Unpublished Ms.

Digitized copy of microfilm provided by Harvard College Library.

Chomsky, Noam. 1956. "Three Models for the Description of Language “. IRE(Institute of Radio Engineers) Transactions on Information Theory 2. 113-124.

Chomsky, Noam. 1957. Syntactic structures. The Hague: Mouton.

Chomsky, Noam. 1958. "Some properties of phrase structure grammars". Quarterly Progress Report of the M.I.T. Research Laboratory of Electronics 49. 108-111.

Chomsky, Noam. 1959a. "Review of Verbal Behaviour, by B.F. Skinner”. Language 35: 1. 26-59.

Chomsky, Noam. 1959b. "On certain formal properties of grammars". Information and Control 2: 2. 137-167.

Chomsky, Noam. 1959c. "A note on phrase-structure grammars". Information and Control 2: 4. 393-395.

Chomsky, Noam. 1962. "Context-Free Grammars and Pushdown Storage”. M.I.T. RLE Quarterly Progress Report 65. 187-194.

Chomsky, Noam. 1963. "Formal properties of grammars". Handbook of mathematical psychology, ed. by R. Duncan Luce, Robert R. Bush \& Eugene Galanter, Vol 2: 323-418. New York: Wiley.

Chomsky, Noam. 1965. Aspects of the theory of syntax. Cambridge: M.I.T. Press.

Chomsky, Noam. 1966. Cartesian linguistics: a chapter in the history of rationalist thought. New York: Harper \& Row.

Chomsky, Noam. 1967. “The formal nature of language”. Biological foundations of language, ed. by Eric H. Lenneberg, 397-442. New York: Wiley.

Chomsky, Noam. 1980. Rules and representations. New York: Columbia University Press.

Chomsky, Noam. 1983. "Dialogue I. Noam Chomsky's views on the psychology of language and thought". Dialogues on the psychology of language and thought: conversations with Noam Chomsky, Charles Osgood, Jean Piaget, Ulric Neisser, and Marcel Kinsbourne, ed. by Robert W. Rieber, Noam Chomsky \& Gilbert Voyat. New York: Plenum Press. 
Chomsky, Noam. 1997. "Language from an internalist perspective". The future of the cognitive revolution, ed. by David Martel Johnson \& Christina E. Erneling, 118-135. New York: Oxford University Press.

Chomsky, Noam. 2000. "Linguistics and brain science". Image, language, brain: papers from the First Mind Articulation Project Symposium, ed. by Alec Marantz, Y. Miyashita \& Wayne A. O’Neil, 13-28. Cambridge, Mass.: M.I.T. Press.

Chomsky, Noam \& Morris Halle. 1968. The sound pattern of English. New York: Harper \& Row. Chomsky, Noam \& Howard Lasnik. 1993. “The theory of principles and parameters”. Syntax: Ein internationales Handbuch zeitgenössischer Forschung/An International Handbook of Contemporary Research, ed. by Joachim Jacobs, Arnim von Stechow, Wolfgang Sternefeld \& Theo Vennemann, 1: 506-569. Berlin: Walter de Gruyter.

Chomsky, Noam \& George A. Miller. 1958. "Finite state languages”. Information and Control 1: $2.91-112$.

Chomsky, Noam \& Marcel-Part Schützenberger. 1963. "The Algebraic Theory of Context-Free Languages”. Computer Programming and Formal Systems: Studies in Logic, ed. by P. Braffort \& D. Hirshberg, 118-161. Amsterdam: North-Holland.

Coren, Stanley. 2003. "Sensation and perception”. Handbook of Psychology, Volume 1: History of Psychology, ed. by Donald K. Freedheim, 85-108. Hoboken, N.J.: Wiley.

Dennis, Simon. 2007. "Introducing Word Order within the LSA Framework". Handbook of latent semantic analysis, ed. by Thomas K. Landauer, 449-479. Mahwah, N.J.: Lawrence Erlbaum Associates.

Evans, Rand B. 1975. “The origins of Titchener's doctrine of meaning”. Journal of the History of the Behavioral Sciences 11: 4. 334-341.

Fillmore, Charles J. 1991. “"Corpus linguistics” or "computer-aided armchair linguistics"'. Directions in Corpus Linguistics: Proceedings of Nobel Symposium 82, Stockholm, 4-8 August 1991, ed. by Jan Svartvik, 35-60. Berlin: Walter de Gruyter.

Fodor, Jerry A., Thomas G. Bever \& Merrill F. Garrett. 1974. The psychology of language: an introduction to psycholinguistics and generative grammar. New York: McGraw-Hill.

Fodor, Jerry A. 1983. The modularity of mind : an essay on faculty psychology. Cambridge, Mass.: M.I.T. Press.

Galison, Peter Louis. 1997. Image and logic : a material culture of microphysics. Chicago: Univ. of Chicago Press.

Gardner, Howard. 1985. The mind's new science : a history of the cognitive revolution. New York: Basic Books.

Gigerenzer, Gerd \& Thomas Sturm. 2007. "Tools = theories = data? On some circular dynamics in cognitive science". Psychology's territories : historical and contemporary perspectives from different disciplines, ed. by Mitchell G. Ash \& Thomas Sturm, 305-342. Mahwah, N.J.: Lawrence Erlbaum Associates.

Ginsburg, Seymour \& H. Gordon Rice. 1962. "Two families of languages related to ALGOL". Journal of the Association for Computing Machinery 9: 3. 350-371.

Gould, Stephen Jay. 1993. Eight little piggies : reflections in natural history. New York: Norton.

Greenwood, John D. 1999. "Understanding the "cognitive revolution" in psychology". Journal of the History of the Behavioral Sciences 35: 1. 1-22.

Greibach, Sheila A. 1981a. "Comments on the roots of theorems and languages both easy and hard”. ACM SIGACT News 13: 1. 26-29.

Greibach, Sheila A. 1981b. "Formal languages: origins and directions". Annals of the History of Computing 3: 1. 14-41. 
Grodzinsky, Yosef. 2000. “The neurology of syntax: Language use without Broca’s area”. Behavioral \& Brain Sciences 23: 1. 1.

Hammarberg, Robert. 1976. “The Metaphysics of Coarticulation”. Journal of Phonetics 4. 353-363.

Harris, Zellig S. 1952. "Discourse Analysis”. Language 28: 1. 1-30.

Harris, Zellig S. 1954. “Transfer Grammar”. International Journal of American Linguistics 20. 259-270.

Harris, Zellig S. 1957. "Co-Occurrence and Transformation in Linguistic Structure”. Language 33: 3. 283-340.

Head, Henry, Gordon Holmes, George Riddoch, W.H.R. Rivers, James Sherren \& Theodore Thompson. 1920. Studies in neurology, in conjunction with W.H.R. Rivers [and others]. London: H. Frowde.

Hintikka, Jaakko. 1999. “The Emperor's New Intuitions”. Journal of Philosophy 96: 3. 127-147.

Hopcroft, John E., Rajeev Motwani \& Jeffrey D. Ullman. 2007. Introduction to automata theory, languages, and computation. Boston: Pearson/Addison Wesley.

Hubel, David H. \& Torsten N. Wiesel. 1959. "Receptive fields of single neurons in the cat's striate cortex". Journal of Phsyiology 148: 3. 574-591.

Huck, Geoffrey J. \& John A. Goldsmith. 1995. Ideology and linguistic theory : Noam Chomsky and the deep structure debates. London; New York: Routledge.

Hyman, Malcolm D. 2007. "Semantic networks: a tool for investigating conceptual change and knowledge transfer in the history of science". Übersetzung und Transformation, ed. by Hartmut Böhme, Christof Rapp \& Wolfgang Rösler, 355-367. Berlin: Walter de Gruyter.

Innis, Robert E. \& Karl Bühler. 1982. Karl Bühler, semiotic foundations of language theory. New York: Plenum Press.

Jackendoff, Ray. 2000. "Fodorian modularity and representational modularity". Language and the brain : representation and processing, ed. by Yosef Grodzinsky, Lewis P. Shapiro \& David Swinney, 3-30. San Diego: Academic Press.

Jackson, J. Edward. 2003. A user's guide to principal components. Hoboken, N.J.: WileyInterscience.

Jakobson, Roman. 1941. Kindersprache, Aphasie und allgemeine Lautgesetze. Uppsala: Almquist \& Wiksell.

Jaeger, Jeri J. 2005. Kid's slips : what young children's slips of the tongue reveal about language development. Mahwah, NJ: Lawrence Erlbaum.

Johnson, David Martel \& Christina E. Erneling. 1997. The future of the cognitive revolution. New York: Oxford University Press.

Katz, Jerrold J. \& Jerry A. Fodor. 1964. The Structure of Language: Readings in the Philosophy of Language. Englewood Cliffs, NJ: Prentice-Hall.

Kihlstrom, John F., Terrence M. Barnhardt \& Douglas J. Tataryn. 1992. “The psychological unconscious: found, lost, and regained". American Psychologist 47: 6. 788-791.

Kintsch, Walter. 1998. “The Representation of Knowledge in Minds and Machines”. International Journal of Psychology 33: 6. 411-420.

Koerner, E.F.K. 1983. “The Chomskyan 'Revolution' and Its Historiography: A Few Critical Remarks”. Language \& Communication 3: 2. 147-169.

Koerner, E.F.K. 2006. "The development of linguistic historiography - history, methodology, and present state". History of the Language Sciences/Geschichte der Sprachwissenschaften/Histoire des sciences $d u$ langage, ed. by Sylvain Auroux, E.F.K. Koerner, Hans- J. Niederehe \& C.H.M. Versteegh, 2802-2820. Berlin and New York: Walter de Gruyter. 
Kroker, Kenton. 2003. “The progress of introspection in America, 1896-1938”. Studies in History \& Philosophy of Biological \& Biomedical Sciences 34: 1. 77.

Kuroda, S.-Y. 1964. "Classes of languages and linear-bounded automata". Information and Control 7: 2. 207-223.

Lallement, Gerard \& Dominique Perrin. 1997. “Obituary: Marcel-Paul Schützenberger (1920-1996)”. Semigroup Forum 55: 2. 135-151.

Landauer, Thomas K. 2007. "LSA as a theory of meaning". Handbook of latent semantic analysis, ed. by Thomas K. Landauer, Danielle S. McNamara, Simon Dennis \& Walter Kintsch, 3-34. Mahwah, N.J.: Lawrence Erlbaum Associates.

Landauer, Thomas K. \& Susan T. Dumais. 1997. "A Solution to Plato's Problem: The Latent Semantic Analysis Theory of Acquisition, Induction, and Representation of Knowledge". Psychological Review 104: 2. 211-240.

Lashley, Karl S. 1951. "The Problem of Serial Order in Behavior”. Cerebral mechanisms in behavior: the Hixon Symposium, ed. by Lloyd Alexander Jeffress, 112-136. New York: Wiley.

Leahey, T.H. 1992. "The mythical revolutions of American psychology". American Psychologist 47: 2.308 .

Lenneberg, Eric H. 1960. "Language, evolution, and purposive behavior”. Culture in History: Essays in Honor of Paul Radin, ed. by Stanley Diamond, 869-893. New York: Columbia University.

Lenneberg, Eric H. 1967. Biological foundations of language. New York: Wiley.

Léon, Jacqueline. 2005. "Claimed and Unclaimed Sources of Corpus Linguistics". The Henry Sweet Society Bulletin 44. 34-48.

Levelt, W.J.M. 1989. Speaking : from intention to articulation. Cambridge, Mass.: M.I.T. Press.

Lieberman, Philip. 1991. Uniquely human : the evolution of speech, thought, and selfless behavior. Cambridge, Mass.: Harvard University Press.

Lightfoot, David. 2002. "Introduction”. Syntactic structures, ed. by Noam Chomsky. Berlin; New York: Mouton de Gruyter.

Luria, A.R. 1979. Jazyk i soznanie. Moscow: Izdatel'stvo MGU.

Mandler, Jean M. 1983. "Structural invariants in development". Piaget and the Foundations of Knowledge, ed. by Lynn S. Liben, 97-124. Hillsdale, N.J.: Lawrence Erlbaum.

Mandler, George. 2007. A history of modern experimental psychology: from James and Wundt to cognitive science. Cambridge, Mass.: M.I.T. Press.

Maury, Liliane. 1997. Piaget et l'enfant. Paris: Presses Universitaires de France.

Mayer, August \& Johannes Orth. 1901. "Zur qualitativen Untersuchung der Association". Zeitschrift für Psychologie und Physiologie der Sinnesorgane 26. 1-13.

Mehler, Jacques. 1963. "Some effects of grammatical transformations on the recall of English sentences". Journal of Verbal Learning and Verbal Behavior 2: 4. 346-351.

Mehler, Jacques \& Peter Carey. 1967. "Role of surface and base structure in the perception of sentences". Journal of Verbal Learning and Verbal Behavior 6: 3. 335-338.

Mehler, Jacques, Anne Cristophe \& Franck Ramus. 2000. "How infants acquire language: some preliminary observations". Image, language, brain : papers from the First Mind Articulation Project Symposium, ed. by Alec Marantz, Y. Miyashita \& Wayne A. O’Neil, 51-75. Cambridge, Mass.: M.I.T. Press.

Mikhail, John. 2007. "Universal moral grammar: theory, evidence and the future". Trends in Cognitive Sciences 11: 4. 143-152.

Miller, George A. 1956. "Human Memory and the Storage of Information". Institute of Radio Engineers [now, Institute of Electrical and Electronics Engineers] Transactions on Information Theory 2. 129-137. 
Miller, George A. 1962. "Some psychological studies of grammar”. American Psychologist 17: 11. $748-762$.

Miller, George A. 2003. “The cognitive revolution: a historical perspective”. Trends in Cognitive Sciences 7: 3. 141.

Miller, George A., Eugene Galanter \& Karl H. Pribram. 1960. Plans and the structure of behavior. New York: Holt.

Miller, George A. \& Kathryn Ojemann McKean. 1964. "A chronometric study of some relations between sentences”. The Quarterly Journal of Experimental Psychology 16. 297-308.

Mintz, Toben H., Elissa L. Newport \& Thomas G. Bever. 2002. “The distributional structure of grammatical categories in speech to young children”. Cognitive Science 26: 4. 393.

Murray, Stephen O. 1980. "Gatekeepers and the "Chomskian revolution"'. Journal of the History of the Behavioral Sciences 16: 1.73-88.

Naur, Peter, John W. Backus, Friedrich L. Bauer, Julien Green, Charles Katz, John McCarthy, Adam J. Perlis, Heinz Rutishauser, Klaus Samelson, Bernard Vauquois, Joseph Henry Wegstein, Adriaan van Wijngaarden \& Michael Woodger. 1960. "Report on the algorithmic language ALGOL 60". Communications of the Association for Computing Machinery 3: 5. 299-314.

Neisser, Ulric. 1967. Cognitive psychology. New York: Appleton-Century-Crofts.

Newell, Allen, J. C. Shaw \& Herbert A. Simon. 1958. "Elements of a theory of human problem solving”. Psychological Review 65: 3. 151-166.

Newmeyer, Frederick J. 1986. "Has There Been a 'Chomskyan Revolution' in Linguistics?” Language: Journal of the Linguistic Society of America 62: 1. 1-18.

Newmeyer, Frederick J. 1998. “On the supposed 'counterfunctionality' of Universal Grammar: some evolutionary implications". Approaches to the evolution of language : social and cognitive bases, ed. by James R. Hurford, Michael Studdert-Kennedy \& Chris Knight, 305-319. Cambridge, UK ; New York: Cambridge University Press.

Newport, Elissa L. \& Richard N. Aslin. 2004. "Learning at a distance I. Statistical learning of non-adjacent dependencies". Cognitive Psychology 48: 2. 127.

Nunberg, Geoffrey. 1996. "Farewell to the information age". The Future of the Book, ed. by Geoffrey Nunberg, 103-138. Berkeley: University of California Press.

Oudeyer, Pierre-Yves. 2006. Self-organization in the evolution of speech. Oxford ; New York: Oxford University Press.

Percival, W. Keith. 1976. “The Applicability of Kuhn's Paradigms to the History of Linguistics”. Language 52: 2. 285-294.

Piaget, Jean. 1936. La naissance de l'intelligence chez l'enfant. Neuchatel, Paris: Delachaux \& Niestlé.

Pinker, Steven. 1994. The language instinct. New York: W. Morrow and Co.

Post, Emil L. 1943. "Formal Reductions of the General Combinatorial Decision Problem". American Journal of Mathematics 65: 2. 197-215.

Pullum, Geoffrey K. \& Barbara Scholz. 2002. "Empirical assessment of stimulus poverty arguments". Linguistic Review 19. 9-50.

Read, Charles, Yun-fei Zhang, Hong-yin Nie \& Bao-qing Ding. 1986. “The Ability to Manipulate Speech Sounds Depends on Knowing Alphabetic Writing”. Cognition: International Journal of Cognitive Science 24: 1-2. 31-44.

Reed, Edward. 1997. "The cognitive revolution from an ecological point of view". The future of the cognitive revolution, ed. by David Martel Johnson \& Christina E. Erneling, 261-273. New York: Oxford University Press.

Rheinberger, Hans-Jörg. Forthcoming. "Internationalism in the history of molecular biology: global and local patterns". The Globalization of Knowledge and Its Consequences, ed. by Jürgen Renn. 
Saffran, Jenny R. \& Richard N. Aslin. 1996. "Statistical learning by 8-month-old infants". Science 274(5294). 1926-1928.

Sampson, Geoffrey. 2002. "Exploring the richness of the stimulus". Linguistic Review 19: 1/2. 73.

Savin, Harris B. \& Ellen Perchonock. 1965. "Grammatical structure and the immediate recall of English sentences". Journal of Verbal Learning and Verbal Behavior 4: 5. 348-353.

Schank, Roger C. \& Robert P. Abelson. 1977. Scripts, plans, goals, and understanding : an inquiry into human knowledge structures. Hillsdale, N.J.; New York: L. Erlbaum Associates.

Scholz, Barbara C. \& Geoffrey K. Pullum. 2002. "Searching for arguments to support linguistic nativism”. Linguistic Review 19: 1/2. 185.

Schützenberger, Marcel-Paul. 1961. “Some remarks on Chomsky context-free languages”. Quarterly Progress Report of the M.I.T. Research Laboratory of Electronics 68. 155-170.

Shanker, Stuart. 1997. "Reassessing the cognitive revolution". The future of the cognitive revolution, ed. by David Martel Johnson \& Christina E. Erneling, 45-54. New York: Oxford University Press.

Skinner, B.F. 1957. Verbal Behavior. New York: Appleton-Century-Crofts.

Steels, Luc. 1998. "Synthesizing the origins of language and meaning using coevolution, selforganization and level formation". Approaches to the evolution of language : social and cognitive bases, ed. by James R. Hurford, Michael Studdert-Kennedy \& Chris Knight, 384-404. Cambridge, UK ; New York: Cambridge University Press.

Thomas, Margaret. 2002. "Development of the concept of "the poverty of the stimulus."“. The Linguistic Review 19. 51-71.

Thompson, S.P. \& E.L. Newport. 2007. "Statistical learning of syntax: The role of transitional probability". Language Learning and Development 3. 1-42.

Tomasello, Michael. 1995. "Language is Not an Instinct. Review of The Language Instinct". Cognitive Development 10. 131-156.

Tomasello, Michael. 2004. "What Kind of Evidence Could Refute the UG Hypothesis? Commentary on Wunderlich". Studies in Language: International Journal Sponsored by the Foundation 'Foundations of Language' 28: 3. 642-645.

Trubetzkoy, Nikolaj Sergeevi. 1939. “Grundzüge der Phonologie”. Travaux du Cercle Linguistique de Prague 7.

Watson, James D. \& Francis Crick. 1953a. "Molecular structure of nucleic acids: a structure for deoxyribose nucleic acid”. Nature 171. 737-738.

Watson, James D. \& Francis Crick. 1953b. "Genetical implications of the structure of deoxyribonucleic acid”. Nature 171: 4361. 964-967.

Watson, John B. 1913. "Psychology as the behaviorist views it". Psychological Review 20: 2. 158-177.

Weimer, Walter B. \& David S. Palermo. 1973. "Paradigms and normal science in psychology". Science Studies 3: 3. 211-244.

Wells, Rulon S. 1947. "Immediate Constituents". Language: Journal of the Linguistic Society of America 23: 2. 81-117.

Wise, Richard J.S., Sophie K. Scott, S. Catrin Blank, Cath J. Mummery, Kevin Murphy \& Elizabeth A. Warburton. 2001. “Separate neural subsystems within 'Wernicke’s area”. Brain 124. 1. 
PART III

\section{Evolutions}





\title{
What do we talk about, when we talk about 'universal grammar', and how have we talked about it?
}

\author{
Margaret Thomas \\ Boston College
}

\begin{abstract}
This article sketches the history of 'universal grammar' as a term and as a concept, attending in particular to the range of expressions that have been used to label what human languages have in common. I focus on three contexts: medieval speculative grammar, which developed a concept of universal grammar without using that name; seventeenth- and eighteenth-century Europe, the acknowledged heyday of western "craving for universals" (Robins 1990: 16), when terms and concepts for universal grammar proliferated; and Chomskyan generative grammar, which has adapted and reinvented universal grammar as a theoretical trademark. Chomsky asserts the continuity of seventeenth-century and generative universal grammar, while differentiating his use of the term from earlier usage and from contemporary Greenbergian terminology. I examine Chomsky's shifting assignment of the expression 'universal grammar' to different lexical subclasses (modified count noun; mass noun; proper noun), as a tool for understanding the recent development of this notion in western language science.
\end{abstract}

\section{Introduction}

"Theories of universal grammar in the late 20th century" is the title of an essay Bernard Comrie contributed to volume 2 of History of the Language Sciences, co-edited by E.F.K. Koerner. Comrie's essay begins with the claim that "The late 20th century is unusual in having two at times radically different approaches to the investigation of language universals" (2001: 1461). Those two approaches are that of Chomskyan generative grammar, and Greenbergian language typology.

Comrie's statement is arresting, on at least two counts: first, because it implies that in the usual case only a single such approach prevails; and second, because the ease with which Comrie moves from the term 'universal grammar' (now principally associated with Chomsky) in his title to the term 'language universals' (associated with Greenberg) in his opening sentence curiously undermines his assertion of their radical differences. It seems to me, rather, that there have existed for a long time a complex and 
heterogeneous family of concepts with overlapping boundaries to which one could apply the cover term 'universal grammar' - concepts variously subsumed under that exact name, or varieties of it, or labeled otherwise but treated as if they pointed out (something like) the same referent. Even within Chomsky's own use of the expression 'universal grammar' over the past 50 years, both evolution and discontinuity are apparent. Moreover, diverse scholars' invocations of universal grammar (under that label, or others) have served diverse roles in language science.

My purpose in this essay is to explore what it is that we have talked about, when we have talked about universal grammar, and what words we have used to do the talking. While in no way presuming the vast erudition that informs the work of E.F.K. Koerner, I take inspiration from one trend in his writings, namely, his essays probing the history of key expressions in the language sciences, such as 'synchronic' (Koerner 1989), 'metalanguage' (Koerner 1995), and "language as a système où tout se tient" (Koerner 1999). Through these and other studies, Koerner has modeled how inquiry into the specific terms scholars have used in discussion of language can open understanding into the history of linguistics.

\section{Origin of 'universal grammar' in western language science}

We will start with modern linguistics' use of the term 'universal grammar', go quickly backward to locate a starting point, then work our way up to the present. Over the past 50 years, universal grammar has been a cornerstone of Chomskyan generative linguistics. Some scholars, like Wasow (2001: 299), introduce that expression as if Chomsky had invented it. But Chomsky himself has always been at pains to indicate otherwise. The manner in which he typically links modern 'universal grammar' to earlier usage of the term is telling. (1) and (2) reproduce representative passages.

1.... [A] general theory of linguistic structure that aims to discover the framework of principles and elements common to attainable human languages [... ] is now often called 'universal grammar' (UG), adapting a traditional term to a new context of inquiry. (Chomsky 1986: 3)

2. Adapting traditional terms to a special usage, we call the theory of the state attained [in first language acquisition] its grammar, and the theory of the initial state Universal Grammar (UG). (Chomsky 1995b: 14)

Deferring the matter of the intriguing heterogeneity of Chomsky's definitions of 'universal grammar' (to which we return to below), a motif in (1) and (2) is the assertion that generative grammar has adapted the term to a new context. If by 'adapting' Chomsky means that his usage preserves the essential sense of the expression while accommodating it to present-day language science, then he seems to endorse the continuity through time of a core meaning of the term. Chomsky's (1966) controversial account of the 
history of linguistics linked modern universal grammar to late seventeenth- and early eighteenth-century general grammar. Others have identified earlier versions of universal grammar, whether or not they accept Chomsky's assertion of continuity with generative grammar. Padley (1976: 157) located what he calls "the first self-consciously universal grammars" in the early 1600s, in works that explicitly use that term. Still others - among them Kelly (1971), Bursill-Hall (1976), Fredborg (1980), and Robins (1988) — go back to the thirteenth-century speculative grammarians for the first articulations of something like universal grammar, before the term itself came into circulation. I will accept medieval language science as the starting point, and move forward from there.

It is worth mentioning in this context the famous assertion of Roger Bacon (c. 1214-1292/94) from his 1270 Greek Grammar, that "the substance of grammar (grammatica) is one and the same in all languages, even if there are accidental variations" (ed. Nolan \& Hirsch 1902: 27; trans. Kelly 1969: 354). Many of the profuse modern citations of Bacon's remark treat it as signaling continuity of inquiry into universal grammar from the thirteenth century forward (Thomas 2002). But as Hovdhaugen (1990) has pointed out, when Bacon's statement is read in its original context, what it actually asserts is the universality of techniques for linguistic analysis; that is, Bacon probably meant something like "[ $t]$ he science of describing and analysing language" is the same for all languages (Hovdhaugen 1990: 127). Therefore, Bacon's claim is not the most appropriate launching-point for a history of universal grammar.

\section{The concept of universal grammar in the thirteenth century}

Setting aside Roger Bacon, there is nonetheless work from his time that is relevant to our topic. One such text is a commentary on Priscianus Maior written around 1250 and ascribed to Robert Kilwardby (1215-1279), although Pinborg (1975), Lewry (1975), and Covington (1984: 134) dispute that attribution. The author of the commentary likens grammatica to the study of geometry, in the sense that just as geometry abstracts away from the properties of individual lines and figures to study shape itself, grammatica abstracts away from the properties of individual languages like Latin or Greek (Thurot 1868: 127; Fredborg et al. 1975). This provocative simile conceives of grammar in a manner designed to meet Aristotle's definition of a science: science investigates the properties of a genus, generalizing across exemplars of the genus; therefore grammatica is a science insofar as its object is not the features of (say) Latin, but rather the features that make a language, a language.

In this sense, the commentary attributed to Kilwardby seems to prepare the way for the late thirteenth-century flourishing of speculative grammar (Bursill-Hall 1971; Covington 1984). Speculative grammarians actually paid little attention to languages other than Latin. Their work, however, contributed to what later came to be called 
'universal grammar', in that it re-oriented grammatica toward the study of the general properties of language. What is also of interest here is that although thirteenth-century grammarians adopted the expression 'grammatica speculativa' for their distinctive approach to language study, and although they freely coined many new terms for their conceptual innovations, they apparently did not create a label for their implicit notion of universal grammar. Rather, they re-defined - perhaps, in Chomsky's terms, adapted to a new context - the familiar term 'grammatica'. What 'grammatica' had meant before the late thirteenth century was a framework and categories for analysis of Latin, or else it was an alternate name for the Latin language itself. Among speculative grammarians, 'grammatica' came to refer to the properties of human language at large. Those properties included the grammatical superstructure that had been developed by Greco-Roman language scholars - now attributable to all languages — including eight parts of speech and four levels of increasing organizational complexity (littera 'elements [including both letters and individual sounds], sillaba 'syllables', dictio 'words', oratio 'sentences'). Speculative grammarians also developed an elaborate metalinguistic vocabulary for discussing relationships between semantic units and syntactic forms. They treated those relationships as universal on the grounds that they were based on parallels between thought and language.

\section{Terms and concepts for universal grammar in the seventeenth and eighteenth centuries}

The speculative grammarians' specific style of inquiry into grammatica as they defined it was abandoned by the following generation of grammarians and the topic fell out of fashion. The chief complaint was that speculative grammar had developed excessive technical apparatus that provided little new insight. Moreover, critics argued against the isomorphism of thought and language, striking at the heart of the claim that grammatica was necessarily universal. But after a period when the notion lay fallow, interest in universal grammar re-emerged in the 1600s, now explicitly associated with that label (among others). Three characteristics of seventeenth- and eighteenthcentury universal grammar stand out. First, grammarians identified an opposition between universal grammar - under various names - and the features that distinguish languages from each other, often called 'particular grammar'. Pariente (1992: 623) wrote that during the French Enlightenment, grammarians' "inaugural gesture ... [was to] cut themselves off from particular grammars." A second characteristic is related: language science in this interval prioritized universal grammar over particular grammars. That prioritization was signaled in diverse ways, such as through the convention of first exposing foreign language learners to universal grammar, then subsequently to a particular grammar of the target language. Particular grammars continued to be produced and were valued for their utility in language pedagogy. 
But in Pariente's terms, universal grammar cut itself off from particular grammar, not vice versa.

A third characteristic is that seventeenth- and eighteenth-century terms and definitions of universal grammar varied, such that individual scholars employed expressions like 'universal,' 'general', and 'rational grammar', in heterogeneous ways. Some grammarians distinguished among them; others in the same period apparently treated them as equivalent; still others defined them on idiosyncratic grounds, or employed other expressions (Donzé 1967: 174-5). This complicates study of how concepts were developed and terms defined.

These general characteristics of universal grammar in the 1600s are apparent in the writings of German grammarians Wolfgang Ratke (1571-1635) and his sometimescollaborator Christoph Helwig (1581-1617) (see Padley 1985: 244-248; Juntune 1985). Ratke and Helwig both argued that foreign-language learning is best undertaken from a position of knowledge of the properties of language at large. Ratke (1619) assumed that learning necessarily proceeds from the general to the particular. Helwig's 1619 Libri Didactici comprises first a universal grammar, followed by fairly conventional learners' grammars of Latin, Greek, Hebrew, and Chaldean. Helwig's and Ratke's texts show that from quite early in the seventeenth century, some grammarians presupposed the existence of a universal grammar distinct from the grammars of individual languages, and moreover accepted that language learning should be grounded in the common features of all languages.

Other grammarians held similar assumptions, although often under different terms. In England, Francis Bacon (1561-1626) divided grammar into "two sorts": 'Philosophical' and 'Literary' (1623/1905: 523). In Auroux's (1983: 5) definition, 'philosophical' as well as 'rational' grammars indicate "a linguistic theory providing an explanation of how reason functions in a given language." These terms not only admit the existence of properties common across all languages, but assert that they exist because they are produced by human reason. Later, John Wilkins (1614-1672) used the expression 'Natural Grammar' (1668: 297), a label that brings along its own burden of connotations but shares with 'rational' and 'philosophical' the depiction of universal grammar as shaped by forces outside of human agency.

A variety of expressions for 'particular grammar' also sprang up. Bacon contrasted 'Philosophical Grammar' not only to 'Literary', but also to 'Simple' (1623/1905: 524) grammar. In 1638, Tommaso Campanella (1568-1639) distinguished 'philosophical' from what he called 'civil grammar', the former based on human reason and the latter defined by "the authority of the best authors" (Padley 1976: 161-2). John Wilkins asserted that "Natural Grammar (which may likewise be stiled Philosophical, Rational and Universal)" contrasts with 'Instituted Grammar', which "doth deliver the rules which are proper and peculiar to any one Language in Particular" (1668: 297). Thus on one hand, we have varied depictions of universal grammar as 'rational', 'philosophical', and 'natural'. On the other hand, the expressions 'particular,' 'special', 'literary', 
'simple', 'civil', and 'instituted' emerged to label locally or culturally specified features of grammar.

The member of this family of terms most identified with the seventeenth century is, however, 'general grammar. The German scholar Johann Heinrich Alsted (1588-1638) pioneered the term 'general grammar' in his 1630 encyclopedia, defining it as "the pattern of every particular grammar whatsoever", including "features common to all languages" (1630: 265, 278; cited in Salmon 1988: 68-69). Auroux suggested that some scholars distinguished 'universal grammar', defined as "the exhaustive description of the elements of all known languages", from 'general grammar', which referred to abstractions that generalized over the features of all languages (1983: 4). Some, but not all, grammarians distinguished 'general grammar' from 'rational grammar', on the grounds that while general grammar called attention to the shared properties of languages, rational grammar focused on the source of those properties. It is significant that Claude Lancelot (c. 1616-1695) and Antoine Arnauld (1612-1694) named their famous 1660 Port Royal Grammaire générale et raisonnée both a 'general' and a 'rational' grammar, as if to acknowledge, but then bridge, a gap between the two expressions. Certain eighteenth-century French grammarians followed suit, separating but linking together general and rational grammar in works like Nicholas Beauzée’s (1717-1789) Grammaire générale, ou exposition raisonnée des éléments nécessaires du langage (1767/1974).

Joly (1972: 16), however, has pointed out that English grammarians of the same period avoided the term 'general grammar' so as to distance themselves from French Cartesianism, even if the two groups' overall projects seem congruent (Auroux 1983: 4). Alongside Bacon's 'Philosophical Grammar' and Wilkins' 'Natural Grammar', James Harris favored 'Universal Grammar' (sometimes 'Grammar Universal') over the expression 'general grammar. For Harris, universal grammar was "that Grammar, which without regarding the several idioms of particular Languages, only respects those Principles, that are essential to them all" (1751:221; emphasis in the original). But regardless of their differences in point of view or focus of attention, English grammars shared with French grammaire générale a distinction between universal and particular grammars, and a prioritization of universal over particular grammar. In this sense all these terms are members of the same conceptual family.

What happened next was that the glamour of universal grammar again receded. Cohen $(1977$ : 62-73; 81-85) has narrated the story of how commitment to philosophical and universal grammar eroded in England after 1730, as recorded in school textbooks. As a first step, grammarians abandoned the presentation of universal grammar separately from, and prior to, particular grammars. Instead, texts began to introduce and define philosophical-grammatical terms alongside the details of specific languages rather than treating universal grammar as prerequisite knowledge. Then writers started to demote remarks about universal grammar into footnotes at the bottoms of 
pages. As the eighteenth century advanced, such footnotes became less elaborate and printed in incrementally smaller type. Eventually, remarks about universal grammar were reduced to incidental comments or references to other texts. With that, universal grammar literally dropped off the pages of pedagogical texts in England.

Universal grammar did not, however, disappear without a trace. Jumping ahead to 1860, a passage from Heymann Steinthal (1823-1899) makes an intriguing contribution to the history of universal grammar, even as it denies its existence. Steinthal wrote that "A universal grammar is no more conceivable than a universal form of political Constitution or of religion, or than a universal plant or animal form" (1860: 104-105; trans. Jespersen 1924: 48). Steinthal's declaration that it is impossible, or even absurd, to imagine universal grammar deserves close attention. The passage communicates Steinthal's rejection of seventeenth- and eighteenth-century craving for universals, probably in part motivated by a drive to declare his independence of his intellectual father-figure, Wilhelm von Humboldt (1767-1836), for whom universals had retained a certain allure (Sweet 1980: 503). Steinthal's comparison of universal grammar to the novel concepts of 'universal plant or animal form' is provocative. In debunking the plausibility of universal grammar in these terms, Steinthal took it for granted that readers would recognize a universal plant or animal form as patently impossible. Of course, there is no independent form that constitutes the essence of plant-ness or of animal-ness. But a universal plant or animal form does exist in the sense of sets of formal characteristics common to all plants or to all animals; if there were no such sets of characteristics, it is unclear how we would be able to use the terms 'plant' or 'animal.' This also is true for the terms 'political constitution' and 'religion,' the other two legs of Steinthal's comparison. Therefore, what Steinthal denies must be a form- or substance-oriented notion of universal grammar. It seems significant that in this passage he represented the key term as a singular count noun with the indefinite article, ' $[e]$ ine allgemeine Grammatik' - 'a universal grammar'. That usage was not unique to Steinthal, although the tradition in his day was to refer to 'universal grammar' as an abstract mass noun (except in contexts where the reference was to physical materials created to teach universal grammar). It is as if Steinthal needed first to make universal grammar particular and concrete so as to reject it, a move that leaves the door open for conceptualization of universal grammar on some other basis.

We will return below to another example of how the expression 'a universal grammar' has been used differently from 'universal grammar'.

\section{Universal grammar in the twentieth century}

Moving into the twentieth century, Ferguson (1978: 9) credited Aginsky and Aginsky (1948) with introducing the expression 'language universals', writing from within the 
milieu of European-oriented linguistics transplanted to New York City during World War II. The terms 'universals of language' and 'universals in language' appear in free variation alongside the slightly different term 'language universals' in the work of Joseph H. Greenberg (1915-2001), who credited expatriate linguists Roman Jakobson (1896-1982) and André Martinet (1908-1999) as having influenced his early graduate studies at Columbia University (Greenberg 1986: 152-155).

Much has already been written about the bifurcation of twentieth century interest in universal grammar into Greenbergian versus Chomskyan strands, and about each group's perception of what it does and doesn't share with the other (e.g. Abraham 1989; Newmeyer 1995). Regarding these issues from the point of view of the words used to talk about universal grammar, Greenbergian employment of 'language' rather than Chomskyan 'grammar' is obviously salient. Nor does it appear accidental that Greenberg labels his central object of study with a plural count noun, 'universals', a term that admits the notion of a collection of linguistic features or claims even as it asserts their unity, in contrast with the synthetic, centripetal, term 'universal grammar'.

Moreover, it is significant that Greenberg moves flexibly between the more explicit post-modified expression 'universals of language' and the pre-modified collocation 'language universals'. By supporting both expressions in a context where 'universals' remains as the lexical head of the phrase, the Greenbergian tradition cultivates a fine terminological distinction. The narrow-scope technical term 'universals of language' names Greenberg's central object of typological interest, while the less explicit, more referentially diffuse term 'language universals' serves as a cover term for both Greenbergian and Chomskyan approaches without adopting the nomenclature of generative grammar. By this light, it is not accidental that Greenberg's milestone publications $(1963,1978)$ present his work as focusing on 'universals of language', while his essay arguing for the complementary nature of typological and generative linguistics (1991) capitalizes on the expression 'language universals'.

Turning finally to the language used in generative literature to discuss universal grammar, the term emerges in three guises in Chomsky's writings, each with its own complexities. It appeared first with the indefinite article - 'a universal grammar' - in Chomsky's depictions of what he identifies as 'Cartesian linguistics'. Thus in an offhand remark in The Logical Structure of Linguistic Theory, completed in the mid 1950s, Chomsky refers to (unspecified) 'earlier attempts to develop a universal grammar' (1956/1975a:108). Nine years later, he wrote that eighteenth-century grammarians aimed to supplement 'the grammar of a particular language' with 'a universal grammar' (1965: 6). Into the 1970s, Chomsky continued to refer to 'a universal grammar', and sometimes 'a rational' or 'a philosophical grammar' (1972: 14-15), in discussion of seventeenth- and eighteenth-century language science. As Chomsky incorporated the term more and more deeply into his own theory-building - in his words, as he adapted it to the 
new context of inquiry - the indefinite article disappeared. (3) and (4) are typical of Chomsky's usage from the mid to late 1970s into the late 1980s.

3. Let us define 'universal grammar' (UG) as the system of principles, conditions, and rules ... of all human languages not merely by accident but by necessity (Chomsky 1975b: 29)

4. We may think of universal grammar as a system of principles which characterizes the class of possible grammars by specifying how particular grammars are organized (what are the components and their relations), how the different rules of these components are constructed, how they interact, and so on (Chomsky 1977: 180)

In these 1970s definitions of 'universal grammar' as a "system of principles, conditions, and rules" constraining human language, Chomsky treats the term as a mass noun. This contrasts with the historical concept, to which he refers to as ' $a$ universal grammar.' The difference is a small. But if as a thought experiment one were to invert the assignment of lexical forms to contexts, it becomes apparent that this small difference carries meaning. (For example, note how it would go against the grain if Chomsky were to write that the Port-Royal grammarians 'elaborated on seventeenth-century universal grammar,' while calling his own work 'the development of a universal grammar'). The mass-noun form of the term that Chomsky seems to reserve for discussion of modern generative grammar presupposes the existence and stability of universal grammar, whereas the indefinite article plus count noun version registers the referent of universal grammar into the discourse as if de novo. So within the tableau Chomsky sets for his readers, it makes sense to use ' $a$ universal grammar' in historical references, and 'universal grammar' with respect to Chomsky's own work. Moreover, for Chomsky to shift between the two provides an inconspicuous way for him to index their differences while asserting their relatedness.

Generative linguistics at large seems to have followed Chomsky's lead in talking about universal grammar in these two subtly different ways, although the vast majority of that talk is about contemporary universal grammar, rather than universal grammar in the thirteenth or seventeenth centuries. But starting in the late 1980s into the early 1990s, universal grammar in a third guise emerged in generative literature, namely in the re-creation of the term as a proper noun, signaled by the use of upper case initial ' $U$ ' and 'G'. Compare (1) from 1986 to (2) from 1995; and compare (3) and (4) from the 1970s to (5) and (6) from 1995 and 2000.

5. In this conception, Universal Grammar (UG) is a system of subtheories, each with certain parameters of variation (Chomsky 1995a: 2)

6. The theory of the initial state [of the child language learner] is sometimes called "Universal Grammar" (UG), adapting a traditional notion to a somewhat different context (Chomsky 2000: 81) 
To be sure, seventeenth-century grammarians also varied in their practice of using upper versus lower case, but they did so in a context where standards of typography were just emerging. Writing in the late twentieth century, adoption of capital-U-Universal capital-G-Grammar seems more self-conscious and more likely to be intended as a communicative gesture. Once 'Universal Grammar' was introduced as a proper noun through Chomsky's writings, it quickly became an industry standard, as if the community of generativists instantly recognized its utility and appropriateness. I surveyed not only Chomsky's writings, but also about 25 books on generative grammar by other writers - textbooks, monographs, summaries or digests of particular subfields within generative linguistics - and discovered a sharp change around 1986 to 1988. Before that point, lower-case 'universal grammar' is consistently indexed in the backs of books under the letter ' $G$ ' as in 'grammar, universal' and only occasionally under ' $U$ ' for 'universal grammar.' But from the late 1980s, universal grammar is no longer listed in the indices as 'grammar, universal,' but rather exclusively as the proper noun 'Universal Grammar'. With this change, generativism seems to stake out a copyright on the term, implicitly claiming the freedom to define the referent of proper-noun 'Universal Grammar' free of the impediments of convention. I suspect that the switch to upper case 'Universal Grammar' correlates with increasing layers of abstractness in Chomsky's definitions of universal grammar, from the 1970 s "system of principles" referenced in (3) and (4) to the present-day "system of subtheories" cited in (5), or "theory of the initial state" of the child language learner cited in (2) and (6).

As a final observation about the terms for talking about universal grammar, the ubiquitous alphabetic acronym 'UG' deserves notice. This abbreviation seems inevitable once proper-noun 'Universal Grammar' was established, and in fact, most texts only initiate the concept as capital-U-Universal capital-G-Grammar before abandoning that expression for the irresistible convenience and clubbiness of ' $U G$ '. As a further step in the speciation of Chomskyan universal grammar, the abbreviation 'UG' seems to take on an independent life. For example, in Gene Searchinger's very successful 1995 videotape The Human Language Series, Part 2, the expression 'universal grammar' is first heard in an interview with University of Pennsylvania psycholinguist Lila Gleitman, then repeated a few minutes later in a clip featuring syntactician Howard Lasnik, now of the University of Maryland. Both speakers exclusively employ the full expression 'universal grammar', not 'UG'. However, following each speaker's use of the term 'universal grammar', the videographer cuts to a black screen, across which large, white, capital letter ' $U$ ' and capital letter ' $G$ ' move from left to right. Thus the viewer is tutored in this expression, with its importance highlighted by presenting it in the absence of any other visual or auditory stimulus, despite the fact that the tape contains no subsequent use of the abbreviation ' $\mathrm{UG}$ ', and therefore there is no communicative necessity for listeners to be introduced to it. 


\section{Conclusion}

Shay (1981: 93) adverted to a remark by the twelfth-century philosopher John of Salisbury, who wrote that already by his day "more time has been taken up discussing universals than was required by the Caesars for conquering the world". The term 'universal grammar' was not yet in circulation in the twelfth century, but grammarians conceived of the theoretical importance of defining the shared properties of human languages. In this way the history of universal grammar began before it was named. In the 1600s and 1700 s, European language scholars not only profusely named and re-named various conceptualizations of universal grammar, but also separated study of universal grammar from study of particular grammars. By doing so, they defined the differences between the two, and confronted questions about their relationships to each other. Modern Greenbergian typological research and Chomsky's generative grammar differentially carry forward these preoccupations. In Chomsky's favored description, he has "adapt[ed] a traditional term to a new context", by attributing new meanings to 'universal grammar', and by seeking out new ways of modifying the term to meet the exigencies of the roles assigned to it in generative theory. Thus in the study of language, discussion of universals has persisted up to the present in a Babel of terms and concepts.

\section{References}

Abraham, Werner. 1989. "Language Universals: The Chomskyan Approach vs. Greenberg's Typological Approach”. Belgian Journal of Linguistics 4. 9-25.

Aginsky, Burt W. \& Ethel G. Aginsky. 1948. “The Importance of Language Universals”. Word 4. $168-172$.

Auroux, Sylvain. 1983. "General Grammar and Universal Grammar in Enlightenment France" [Spring]. General Linguistics 23: 1. 1-18.

Bacon, Francis. 1905. De dignitate et augmentis scientiarum, Books II-IX London: George Routledge and Sons.

Bacon, Roger, 1902. The Greek grammar of Roger Bacon and a fragment of his Hebrew grammar ed. by Edmond Nolan \& S.A. Hirsch. Cambridge: University Press.

Beauzée, Nicholas. 1974. Grammaire générale, ou exposition raisonée des éléments nécessaires du langage: Vols. 1 \& 2. Stuttgart-Bad Cannstatt: Friedrich Frommann.

Bursill-Hall, Geoffrey L. 1971. Speculative grammars of the Middle Ages : the doctrine of partes orationis of the Modistae. The Hague: Mouton.

Bursill-Hall, Geoffrey L. 1976. "Some Notes on the Grammatical Theory of Boethius of Dacia”. History of linguistic thought and contemporary linguistics, ed. by Herman Parret, 164-188. Berlins Walter de Gruyter.

Campanella, Tommaso. 1638. Philosophiae rationalis partes quinque: Pars prima: Grammatica. Paris. Chomsky, Noam. 1965. Aspects of the theory of syntax. Cambridge, Mass.: M.I.T. Press.

Chomsky, Noam. 1966. Cartesian linguistics: a chapter in the history of rationalist thought. New York: Harper \& Row.

Chomsky, Noam. 1972. Language and mind. New York: Harcourt Brace Jovanovich. 
Chomsky, Noam. 1975a. The logical structure of linguistic theory. New York: Plenum Press. Chomsky, Noam. 1975b. Reflections on language. New York: Pantheon Books.

Chomsky, Noam. 1977. Language and responsibility. New York: Pantheon Books.

Chomsky, Noam. 1986. Knowledge of language : its nature, origin, and use. New York: Praeger.

Chomsky, Noam. 1995a. Barriers. Cambridge, Mass.: M.I.T. Press.

Chomsky, Noam. 1995b. The Minimalist Program. Cambridge, Mass.: M.I.T. Press.

Chomsky, Noam. 2000. New horizons in the study of language and mind. Cambridge; New York: Cambridge University Press.

Cohen, Murray. 1977. Sensible words : linguistic practice in England, 1640-1785. Baltimore: Johns Hopkins University Press.

Comrie, Bernard. 2001. “Theories of Universal Grammar in the Late 20th Century”. History of the language sciences: Vol. 2, ed. by Sylvain Auroux, E.F.K. Koerner, Hans-Joseph Niederehe \& Kees Versteegh, 1461-1467. Berlin; New York: Walter de Gruyter.

Covington, Michael A. 1982. Syntactic theory in the High Middle Ages. Modistic models of sentence structure. Ph.D. Thesis, Yale University.

Donzé, Roland. 1967. La grammaire général et raisonnée de Port Royal. Berne: Éditions A. Francke.

Ferguson, Charles A. 1978. "Historical Background of Universals Research”. Universals of human language, ed. by Joseph H. Greenberg, 7-31. Stanford: Stanford University Press.

Fredborg, Karin Margareta, Lauge Nielsen Green-Pedersen \& Jan Pinborg. 1975. The Commentary on "Priscianus Maior" ascribed to Robert Kilwardby. Copenhague: Université de Copenhague.

Fredborg, Karin Margareta, Konrad Koerner, Hans- J. Niederehe \& R.H. Robins. 1980. "Universal Grammar According to Some 12th-Century Grammarians". Studies in Medieval linguistic thought: Dedicated to Geoffrey L. Bursill-Hall on the occasion of his sixtieth birthday on 15 May 1980, 69-84. Amsterdam: John Benjamins.

Greenberg, Joseph H., ed. 1963. Universals of language. Cambridge, Mass.: M.I.T. Press.

Greenberg, Joseph H., ed. 1978. Universals of human language. Stanford: Stanford University Press. Greenberg, Joseph H. 1986. "On Being a Linguistic Anthropologist”. First Person Singular II: Autobiographies by North American scholars in the language sciences, ed. by E.F.K. Koerner, 141-166. Amsterdam/Philadelphia: John Benjamins.

Greenberg, Joseph H. 1991. "Two Approaches to Language Universals”. New vistas in grammar, invariance and variation, ed. by Linda R. Waugh \& Stephen Rudy. Amsterdam/Philadelphia: John Benjamins.

Harris, James. 1751. Hermes; or, A philosophical enquiry concerning language and universal grammar. London: H. Woodfall for J. Nourse \& P. Vaillant.

Helwig, Christoph. 1619. Libri Didactici, Grammaticae Universalis, Latinae, Graecae, Hebraicae, Chaldaicae. Geissen: Chemlin.

Hovdhaugen, Even. 1990. "Una et Eadem: Some Observations on Roger Bacon's Greek Grammar”. De ortu grammaticae: Studies in Medieval grammar and linguistic theory in memory of Jan Pinborg, ed. by Geoffrey L. Bursill-Hall \& Jan Pinborg. Amsterdam: John Benjamins.

Jespersen, Otto. 1924. The philosophy of grammar. London: George Allen \& Unwin.

Joly, André. 1972. "Introduction". James Harris: Hermès ou recherches philosophiques sur la grammaire universelle. Traduction et remarques par François Thurot (1796) ed. by André Joly, 1-144. Geneva: Droz.

Juntune, Sarah. 1985. "Christoph Helwig's Allgemeine sprachkunst: One of the First Universal Grammars". Rekonstruktion und Interpretation: Problemgeschichtliche Studien zur Sprachtheorie von Ockham bis Humboldt ed. by Klaus D. Dutz \& Ludger Kaczmarek, 91-123. Tübingen: Gunter Narr. 
Kelly, Louis Gerard. 1969. 25 centuries of language teaching. Rowley, Mass.: Newbury House.

Kelly, L.G. 1971. "De modis generandi: Points of Contact Between Noam Chomsky and Thomas of Erfurt”. Folia Linguistica: Acta Societatis Linguisticae Europaeae 5. 225-252.

Koerner, E.F.K. 1989. "Sur l'origine du concept et du term de 'synchronique' en linguistique". Practicing linguistic historiography : selected essays, ed. by E.F.K. Koerner, 257-266. Amsterdam/ Philadelphia: John Benjamins.

Koerner, E.F.K. 1995. “'Metalanguage’ in Linguistic Historiography”. Professing linguistic historiography, ed. by E.F.K. Koerner. Amsterdam/Philadelphia: John Benjamins.

Koerner, E.F.K. 1999. "The Authors of the Idea of Language as a 'système où tout se tient'” Linguistic historiography: Projects \& prospects, ed. by E.F.K. Koerner. Amsterdam/Philadelphia: John Benjamins.

Lancelot, Claude \& Antoine Arnauld. 1966 [1660]. Grammaire générale et raisonnée, ou La grammaire de Port-Royal. Stuttgart-Bad Cannstatt: Frommann.

Lewry, Osmund, O.P. 1975. “The Problem of Authorship”. The Commentary on Priscianus maior Ascribed to Robert Kilwardby, ed. by Karin Margareta Fredborg, Lauge Nielsen Green-Pedersen, Lauge Nielsen \& Jan Pinborg. Copenhagen: Cahiers de l'Institute du Moyen-Age Grec et Latin.

Newmeyer, Frederick J. 1995. "Linguistic Diversity and Universal Grammar: 40 Years of Dynamic Tension within Universal Grammar". History of linguistics 1993: Papers from the Sixth International Conference on the History of the Language Sciences (ICHoLS VI), Washington, D. C., 9-14 August 1993, ed. by Kurt R. Jankowsky. Amsterdam/Philadelphia: John Benjamins.

Nolan, Edmond \& S.A. Hirsch. 1902. The Greek grammar of Roger Bacon and a fragment of his Hebrew grammar: Cambridge: Cambridge University Press.

Padley, G.A. 1976. Grammatical theory in Western Europe 1500-1700: The Latin tradition. Cambridge: Cambridge University Press.

Padley, G.A. 1985. Grammatical Theory in Western Europe 1500-1700: Trends in vernacular grammar I. Cambridge: Cambridge University Press.

Pariente, Jean-Claude. 1992. "La position de la grammaire rationelle”. Philosophy of language: An international handbook of contemporary research: Vol. I, ed. by Marcelo Dascal, Dietfried Gerhardus, Kuno Lorenz \& Georg Meggle, 620-637. Berlin: Walter de Gruyter.

Pinborg, Jan. 1975. "Introduction to the Text". The commentary on Priscianus maior ascribed to Robert Kilwardby, ed. by Karin Margareta Fredborg, Lauge Nielsen Green-Pedersen, Lauge Nielsen \& Jan Pinborg. Copenhagen: Cahiers de l'Institute du Moyen-Age Grec et Latin.

Ratke, Wolfgang. 1619. Grammatica universalis pro didactica Ratichii / Allgemeine Sprachlehr nach der Lehrart Ratichii. Köthen.

Robins, R.H. 1990. "Constraints and Intentions in the Organization of the History of Linguistics". Understanding the historiography of linguistics: Problems and projects: Symposium at Essen, 23-25 November 1989, ed. by Werner Hullen, 11-19. Munster: Nodus Publikationen.

Salmon, Vivian. 1988. "Pre-Cartesian Linguistics". The study of language in 17th-century England (2nd ed.), ed. by Vivien Salmon, 63-85. Amsterdam/Philadelphia: John Benjamins.

Searchinger, Gene (producer, writer, director). 1995. The Human Language Series: Part 2. Acquiring the Human Language [Videotape]. New York: Ways of Knowing.

Shay, James. 1981. "The Past is Prologue: Two Intellectual Ancestors of Medieval Grammar". Texas Linguistic Forum 17. 89-101.

Steinthal, Heymann. 1860. Charakteristik der hauptsächlichsten Typen des Sprachbaues. Berlin: Ferd. Dümmler's Verlagsbuchhandlung.

Sweet, Paul R. 1980. Wilhelm von Humboldt: A biography: Vol. 2. Columbus, Ohio Ohio State University. 
Thomas, Margaret. 2002. "Roger Bacon and Martin Joos: Generative Linguistics' Reading of the Past”. Historiographia Linguistica 29: 3. 339-378.

Thurot, Charles. 1868. Notices et extraits de divers manuscrits latins pour servir à l'histoire des doctrines grammaticales au moyen âge. Paris: Imprimerie Impériale.

Wasow, Thomas. 2001. "Generative Grammar". The handbook of linguistics, ed. by Mark Aronoff \& Janie Rees-Miller, 295-318. Malden, Mass.: Blackwell.

Wilkins, John. 1668. Essay Towards a Real Character and a Philosophical Language. London: Gellibrand. [Available electronically from Early English Books Online]. 


\title{
Migrating propositions and the evolution of Generative Grammar
}

\author{
Marcus Tomalin
}

This chapter considers the way in which linguistic theories develop (or 'evolve'). Taking the 'Research Program' model of scientific theory development as a starting point, the discussion focuses on the intricate relationship between Generative Grammar and Relational Grammar during the period 1965-1988. In particular, the emergence of both the Unaccusative Hypothesis and the Universal Alignment Hypothesis in the Relational Grammar framework is discussed at length, and the subsequent incorporation of both these hypotheses into mainstream Generative Grammar during the early 1980s is closely scrutinised. This case study raises difficult questions about the circumstances in which particular linguistic propositions are able to migrate between distinct Research Programs. Explorations such as this inevitably rely greatly on the careful analysis of specific historical examples of theory construction. Consequently, this chapter argues that historiographical investigations must necessarily form an essential part of any general and theoretical assessments of the mechanisms of linguistic theory development.

\section{Traditions, programs, and theories}

This chapter examines the complex relationship between Generative Grammar (GG) and Relational Grammar (RG) during the period 1965-1988, a topic that has been strangely neglected in the historiographical literature. While texts such as Newmeyer (1986), Harris (1993), and Huck \& Goldsmith (1995) have examined the relationship between GG and Generative Semantics in some detail, RG has received less sustained attention. ${ }^{1}$ Conveniently, though, Huck and Goldsmith's discussion in particular provides a useful starting point for this chapter since it draws heavily upon specific theoretical models of scientific theory development. Crucially, they classify GG as a distinct Research Program (RP) which comprises a body of falsifiable propositions'

1. Other important accounts of the history of GG include Matthews (1993), Graffi (2001), and Tomalin (2006). 
and which has a 'sociological dimension' (Huck \& Goldsmith 1995: 5-6). Specifically, they distinguish between three different kinds of propositions:

- core propositions: researchers adopt a consistent methodological policy of not allowing these hypotheses to be damaged by disconfirmation; the core is protected, unchangeable.

- auxiliary propositions : researchers are willing to revise or replace these propositions.

- orientational propositions: these determine the ultimate goals of the research program; like core propositions they are 'irrefutable in practice', but the difference is that they express desiderata.

In this framework, the core of the RP is defended and remains largely unchanged, and scientific progress occurs if changes to the set of auxiliary propositions leads to the discovery of previously unexpected facts without inducing a significant loss of empirical content. ${ }^{2}$

Over the years, a wide range of models for scientific theory development have been proposed, from the positivistic analyses of Pierre Duhem (1861-1916), Karl Popper (1902-1994), and Carl Gustav Hempel (1905-1997), to the more flexible approaches of Imre Lakatos (1922-1974), Paul Feyerabend (1924-1994), Stephen Toulmin (b.1922), and Larry Laudan (b.1941), to more recent analyses that have been influenced by research into computational models, non-classical logic, and model-theoretical semantics. ${ }^{3}$ These approaches will not be compared and contrasted in this chapter, and the basic analytical framework adopted in the following discussion is essentially that outlined by Theo Kuipers in his 'Laws, Theories, and Research Programs' (2007). ${ }^{4}$ One pleasing feature of this framework is that it synthesises ideas derived from the work of Thomas Kuhn (1922-1996), Lakatos, Laudan, Henk Zandvoort (b.1951), Ilkka Niiniluoto (b.1946) and others. Essentially, Kuipers identifies four distinct kinds of RPs - descriptive, explanatory, design, and explicative - and it is the second type that will concern us primarily. Explanatory RPs 'are directed at the explanation and further prediction of the observable individual and general facts in a certain domain of phenomena' (Kuipers 2007: 59). They can be associated with specific Research Traditions

2. These propositions are given in Huck \& Goldsmith 1995: 6. Huck and Goldsmith's approach draws heavily upon the work of Imre Lakatos.

3. Some of the key texts include Duhem (1954), Popper (1959), Hempel (1965), Lakatos (1970), Toulmin (1972), Feyerabend (1975), and Laudan (1977). For a pertinent example of more recent research that draws upon techniques developed in the context of modern logic and Artificial Intelligence, see Aliseda (1997) and (2006). The model-theoretic view of scientific theories is discussed in Suppes (1969), Suppe (1989), and Chakravartty (2001).

4. I will not discuss in detail important topics such as the 'internal' and 'external' phases of RP development, the epistemological stratification of an RP, and so on. For more information about such things, see Kuipers 2007: 1-95. 
(RTs). Therefore Kuipers proposes the hierarchical model in Figure 1 which provides an ontological stratification for a generic RT.

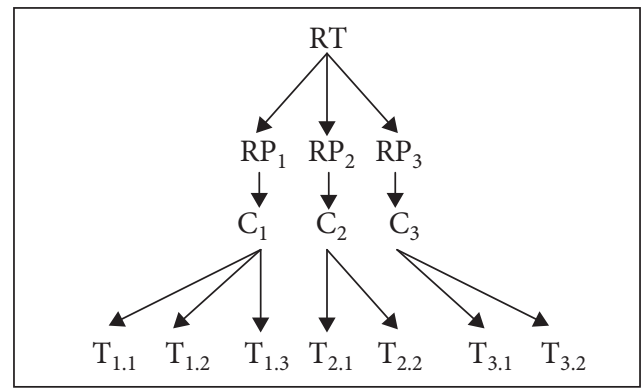

Figure 1. Hierarchical Model of an RT

$\mathrm{RT}$ is here associated with three constituent RPs which are in turn each associated with a respective core theory (e.g., $\mathrm{C}_{1}, \mathrm{C}_{2}, \mathrm{C}_{3}$ ) and a respective set of specific theories (e.g., $\mathrm{T}_{1.1}, \mathrm{~T}_{1.2}, \mathrm{~T}_{1.3}$ ), the members of which all share the same core. Adopting this model, Generative Linguistics (GL) (including generative syntax, generative phonology and other sub-domains) can be identified as a distinct RT, and GG - that is, GL research that is concerned primarily with syntax — can be viewed as an RP which has a core and an associated set of theories. This seems reasonable since the phrase 'generative grammar' is standardly used to refer to different theories of generative syntax that have been proposed during the period 1950s-present, and, given this, it would be misleading to classify GG as being simply a 'theory'. Indeed, Kuipers explicitly identifies 'transformational generative grammar' as providing a representative example of an explanatory RP (Kuipers 2007: 60). ${ }^{5}$

These analytical categories will enable the development of GG to be examined in some detail in the following sections, and the emphasis will be descriptive rather than prescriptive throughout. In other words, no attempt will be made to legislate about the way in which linguistic theories ought to evolve. In particular, the emergence of both the Unaccusative Hypothesis and the Universal Alignment Hypothesis within RG will be assessed, and the subsequent incorporation of both these hypotheses into mainstream GG during the early 1980s will be scrutinised. Curiously, although the general patterns of these interactions are quite well-known, they have never been examined in any great detail; yet a careful discussion of these complex topics sheds light both on these particular associations and (more importantly) upon the broader topic of linguistic theory development in general.

5. It would be possible, of course, to view GL as forming part of a larger research endeavour that was explicitly associated with Structuralism. However, a broader analysis of this kind will not be attempted in this chapter. 


\section{Aspects of the base}

In Aspects of the Theory of Syntax (1965), Chomsky outlined the version of GG that became known as the Extended Standard Theory. In this approach, the syntactic component generates two structural levels, Deep Structure and Surface Structure; the structures associated with the former are interpreted by the semantic component, while the structures associated with the latter are interpreted by the phonological component. The rules in the base generate Deep Structures, and transformations act upon Deep Structures to create Surface Structures. ${ }^{6}$ As Aspects progresses, Chomsky subclassifies rule types into lexical formatives, subcategorisation, and selectional rules, but despite these sorts of twists and turns, the central idea is always that the base constitutes a set of ordered rewriting rules that is located in the syntactic component, and that the Deep Structures it generates are interpreted by the semantic component. An example of the kind of tree-based representation advocated in Aspects is given in Figure 2. In this framework, traditional grammatical roles such as 'subject' and 'direct object' are represented primarily in configurational terms. For example, if the 'subject-of' relation holds between the NP of a sentence which takes the form NP-Aux-VP and the whole sentence, then 'sincerity' is the subject of the sentence in Figure 2 because it occupies this position in the tree. Similarly, if 'direct_ object-of' is a relation that holds between the NP of a VP which takes the form V-NP, then 'the boy' in Figure 2 is the direct object (Chomsky 1965: 68-69). Crucially, grammatical relations are defined in terms of linear order and phrase structure configurations.

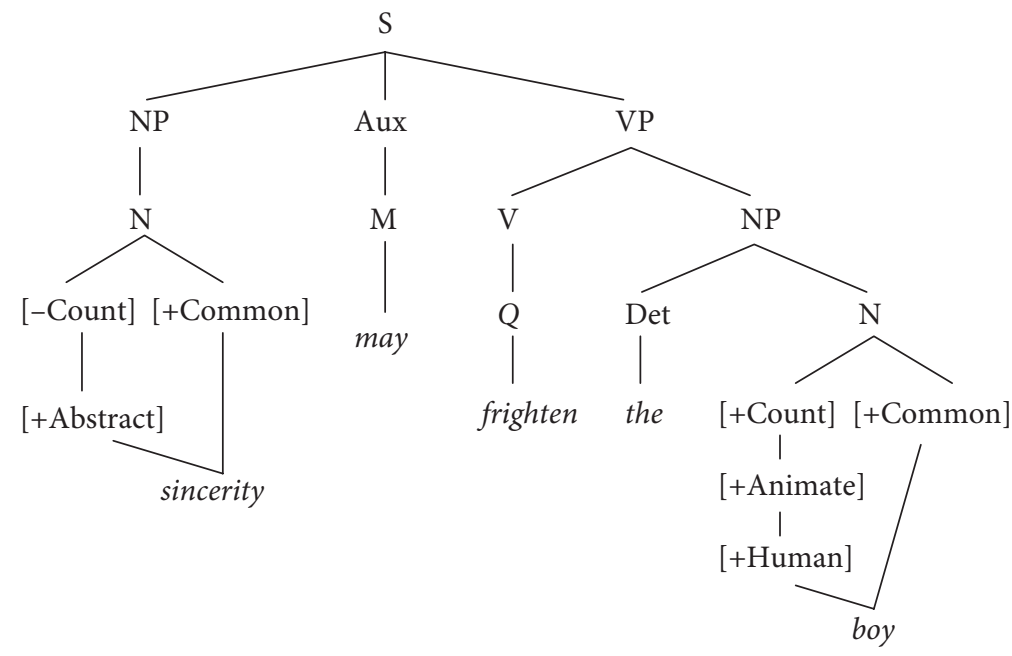

Figure 2. Tree Diagram for 'Sincerity may frighten the boy'

6. For more information concerning the role of the base in early GG, see Chomsky (1955), Chomsky (1957), and Tomalin 2006: 163-167. 
This much is uncontroversial, but how should Aspects-style Extended Standard Theory be analysed given the skeletal RT framework in Figure 1? This task is complicated by the fact that (like other such texts) Aspects offers a gradual development of certain ideas - some propositions are rejected, new ones are added, and others are revised as the argument unfolds - and this process is not merely one of simple accumulation. Despite its mathematical tendencies, Aspects does not present (and, to its credit, never claims to present) a comprehensive, strictly axiomatic-deductive syntactic theory. Rather it is a building-site, an incomplete work-in-progress that is full of hesitations, tentative assumptions, and extensive alterations. The opening sentence captures this perfectly: ' $[\mathrm{t}] \mathrm{his}$ study will touch on a variety of subjects in syntactic theory and English syntax, a few in some detail, several quite superficially, and none exhaustively' (Chomsky 1965: 3). Since (as noted earlier) RTs are defined in part by the theories with which they are associated, these vagaries at the level of theory exposition are unavoidable.

Despite these non-trivial problems, though, Huck and Goldsmith boldly attempted to summarise the key elements of Extended Standard Theory, focusing on core and orientational propositions. However, the ontological stratification they offer can be stated in greater detail. Assuming that GL (as outlined in Chomsky (1955)) had arguably become an incipient RT by 1965 , then it can be associated with a number of inter-related RPs which focused on different linguistic levels (e.g., syntax, phonology, semantics, and so on). Aspects (which concentrates primarily on syntax) provides a revised sketch of the GG program while expounding a particular cluster of theories. Conveniently, Chomsky states explicitly that the GG program is 'explanatory' rather than merely 'descriptive' (Chomsky 1965: 34), and he provides an itemised list of the core assumptions which form the basis of any generative syntactic theory. Such a theory should provide (Chomsky 1965: 31):

i an enumeration of the class $s_{1}, s_{2}, \ldots$ of possible sentences

ii an enumeration of the class $S D_{1}, S D_{2}, \ldots$ of possible structural descriptions

iii an enumeration of the class $G_{1}, G_{2}, \ldots$ of possible generative grammars

iv specification of a function $f$ such that $S D_{f(i, j)}$ is the structural description assigned to sentence $s_{\mathrm{i}}$ by grammar $G_{j}$, for arbitrary $i, j$

$\mathrm{v}$ specification of a function $m$ such that $m(i)$ is an integer associated with the grammar $G_{i}$ as it value

Any syntactic theories developed within the Extended Standard Theory RP must conform to these constraints. They are criteria for adequacy; therefore they form the core of the program, and they are common to all theories that are clustered with that particular RP. In addition, there are other orientational and methodological assumptions which also form part of the core. These mainly provide guidance as to the manner in which syntactic research should be undertaken, and they include such things as the 
distinction between competence and performance, and the reliance on native speaker intuition to determine grammaticality.

While the core of an RP generally changes infrequently, the theory-specific auxiliary propositions are much more malleable. Indeed, Chomsky himself repeatedly modifies these as Aspects progresses. For example, he initially presents morphemes as being indivisible lexical items before subsequently arguing that they should be viewed as collections of sublexical features. Similarly, he suggests that the lexicon should be separate from the rewriting rules and that these rules should constitute a concatenation-system rather than a set-system. ${ }^{7}$ In all of these cases, there are many other options that could have been adopted instead, but doing so would not have a profound impact on the RP core.

\section{The creation of Relational Grammar}

Aspects outlined a particular RP, and RG undoubtedly had its conceptual roots in the disputes that occurred when certain linguists began to probe Extended Standard Theory with sustained intensity. ${ }^{8}$ These disputes led to the creation of Generative Semantics, and they eventually prompted Paul Postal (b.1936) and David Perlmutter (b.1938) to develop RG in the early 1970s. Although the complex relationships between GG, Generative Semantics, and RG have never been assessed in appropriate detail, some of the more obvious interconnections have been acknowledged. For instance, Randy Harris refers to the 'partial competition, partial alliance' (Harris 1993: 220) that initially existed between Generative Semantics and RG, and he observes that RG 'headed off in an early dogleg from generative semantics' (Harris 1993: 250). However, although RG is often viewed as providing an alternative to GG, it certainly originated as part of the GG program. This is most apparent in texts such as 'The Relational Succession Law' which Perlmutter and Postal drafted in 1972. This paper explores cyclic 'ascension' rules (e.g., it-replacement, pronoun-replacement, subject-raising), and the main contention is that the effect of certain transformations is determined by grammatical relations. Perlmutter himself has stated explicitly that this paper 'antedates the development of RG' (Perlmutter 1983: x), yet he confirms that, with its focus upon crosslinguistic regularities not captured by the GG framework, it was 'one of the motivations for a relationally based theory of clause structure' (Perlmutter 1983: x). Consequently, papers such as this provide alternative theories within the GG framework. A rough attempt to capture this state of affairs is given in Figure 3:

7. These topics are addressed in Chomsky 1965: 68-69, 75-84, 86, 124 respectively.

8. An engaging eye-witness account of some of these development can be found in Lakoff (1989), while Harris (1993) offers an approachable discussion of the whole GG vs. Generative Semantics conflict. 


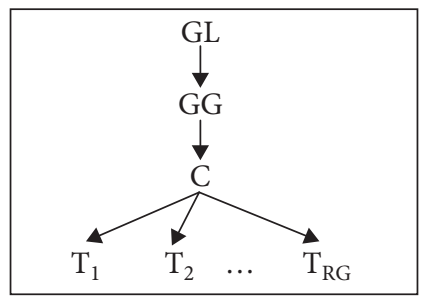

Figure 3. RG within the GG Framework (c.1970-1974)

Here the early RG work is viewed as outlining a cluster of theories which forms an independent branch of the GG program. These alternative theories (e.g., $\mathrm{T}_{\mathrm{RG}}$ ) share the GG core, but, at this stage of development, they are not associated with an alternative RP. However, as RG developed, some of the core GG assumptions were rejected, and as a result of this intricate process, the theoretical studies which provided the foundation for the later RG research of the mid to late 1970s began to elaborate a new RP. ${ }^{9}$ Writing in the early 1980s, Perlmutter recalled that ' $[\mathrm{t}$ ] he emergence of relation grammar (RG) in the 1970s was a direct challenge to some of the most basic assumptions of syntactic theory' (Perlmutter 1983: ix). This can be seen clearly in its treatment of grammatical relations. In mature RG, these undefined, irreducible primitives (e.g., 1 = Subject, 2 = Direct Object, and 3 = Indirect Object) are not defined in configurational terms. Instead, graph-theoretical structures, called relational networks, were introduced. The network for the sentence 'Louise reviewed that book' is given in Figure $4 .{ }^{10}$

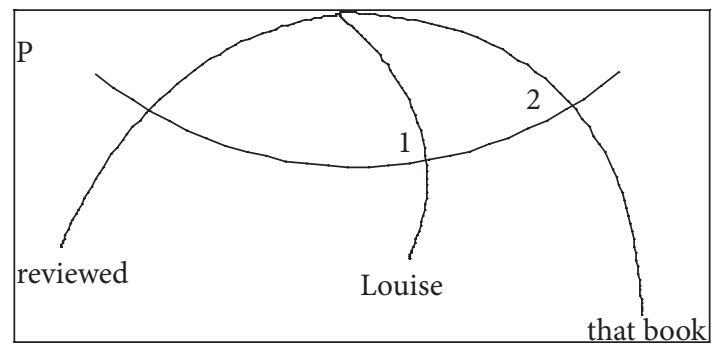

Figure 4. Relational Network for an Active Structure

9. Johnson and Postal indentified two main 'stages' in the development of RG - Stage 1 (1972-1975) and Stage 2 (1975-1980) — and they dated the origins of Arc Pair Grammar to 1977 (Johnson \& Postal 1980). In their analysis, Stage 1 involved several attempts to modify the basic GG framework, and it was not until Stage 2 that a clear separation from GG became necessary. A general overview of the RG approach to syntax can be found in Blake (1990).

10. These examples are taken (with minor modifications) from Perlmutter \& Postal 1978: 16ff. 
Here ' $\mathrm{P}$ ' identifies the predicate, while 1 and 2 indicate Subject, and Direct Object respectively. There is no attempt to analyse either the tense of the verb or the internal structure of the NP 'that book'; the central focus is primarily upon the grammatical relations. Importantly, the relational networks abstract away from linear order: if the order of the elements P, 1, and 2 in Figure 4 were permuted (e.g., 2, P, 1), the grammatical relations would remain the same.

The RG analysis of the passive form of 'Louise reviewed that book' is given in Figure 5. This network has two strata: the first is identical to that in Figure 4; the second indicates that two alterations have occurred. Specifically, the NP associated with the 2-relation (i.e., 'that book') in the first stratum is associated with the 1-relation in the second stratum, while the NP associated with the 1-relation initially, is associated with the 2-relation in the second stratum. The notation 2 indicates that the subject NP has become a 'chômeur' (which means 'unemployed' in French): the subject of the active sentence (i.e., Louise) now occupies a peripheral, optional position in the passive sentence, and therefore (using the RG-terminology) it has been put 'en chômage'. As these examples indicate, the RG approach to grammatical relations was consciously chosen as an alternative to the standard tree-based GG framework, and Perlmutter and Postal were particularly disturbed by the fact that Extended Standard Theory did not enable a universal analysis of passivization to be constructed. They noted that in GG the passive transformation invariably postposed preverbal NPs and preposed postverbal NPs, and argued (robustly) that a 'universal' analysis of passivization was impossible in such a framework (Perlmutter \& Postal 1983[1978]: 9).

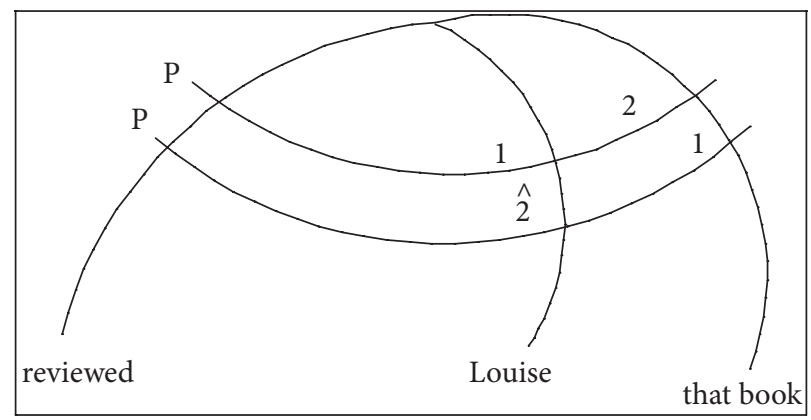

Figure 5. Relational Network for a Passive Structure

As this fleeting summary shows, although RG initially emerged within the GG program, it eventually came to provide a markedly different analysis of syntactic phenomena. Therefore, if GG and RG had become distinct entities by the mid 1970s, what sort of entity was RG? Did it outline a new and distinct RT, or did it simply determine a separate RP within the GL tradition? Over the years, varying degrees of separation have been suggested. For example, Perlmutter and Postal's writings are littered with comments such as 'it is necessary to abandon the structuralist-transformational 
approach' (Perlmutter 1983: ix), which suggests a complete separation. However, they also repeatedly acknowledge 'the influence of the transformational framework out of which RG developed' (Perlmutter 1983: xiv), and this suggests that some connections were retained, allowing for the possibility that RG defined a distinct RP within the GL tradition. More recently, though, Giorgio Graffi has argued that 'RG goals were radically different $[\ldots]$ from those of the 'standard' theory and of the Chomskian program as a whole' (Graffi 2001: 412), while in texts such as Susumu Kuno and Ken'ichi Takami's Functional Constraints in Grammar (2004), RG and GG are explicitly treated as entirely separate 'frameworks' (Kuno \& Takami 2004: 18). Comments such as these imply that (by the late 1970s) mature RG had effectively removed itself from the GL tradition, and initiated an alternative stance. However, if RG is to be viewed as defining a distinct RT, then it should be possible to identify distinctive orientational and core propositions which provide guidance for the research undertaken within that framework. Helpfully, Perlmutter identifies two 'basic claims' which distinguished RG from GG (Perlmutter 1983: ix-x):

1.1 The grammatical relations needed for individual grammars and for crosslinguistic generalizations cannot be defined in terms of other notions, but must be taken as primitive notions of syntactic theory.

1.2. It is necessary to posit distinct syntactic (i.e., nonsemantic, nonthematic) levels.

There is no doubt that these ideas were characteristic of the RG approach and that virtually all research conducted with that basic framework adopted these propositions. But how should these 'claims' be classified? Crucially, are they core or auxiliary propositions? To start with proposition 1.1, given the list of core assumptions that was presented in Aspects, the requirement for structural descriptions to be enumerated does not make strong claims about whether grammatical relations should be primitive or not. Indeed, as the 1970s progressed, the notion of $\theta$-roles became increasingly prominent in GG and analyses based on linear order and constituent structure were reconsidered. Clearly, this development suggests that the GG program was sufficiently flexible to accommodate changes of this kind. Proposition 1.2 is more problematical. The GG program explicitly identified Deep Structure and Surface Structure as distinct syntactic levels. Therefore any theory which rejected the centrality of these arguably modified the GG core and, as such, removed itself from the GG program. ${ }^{11}$ Consequently, since RG analyses permitted multiple strata, it is reasonable to claim that (at

11. It should be noted that, during the late 1960 s and 1970 s various GG formalisms regularly adopted levels other than Deep Structure and Surface Structure. For instance, some transformational rules were associated with the syntax, others with the lexicon. Also, some movement operations could apply at the level of Logical Form. However, in all these variations, Deep Structure and Surface Structure were usually recognised as being crucial levels. 
some point in the mid 1970s) RG separated itself from the GG program and initiated a new RP. Nonetheless, it is not immediately apparent whether RG ever entirely freed itself from the GL tradition. In Figure 6, the dotted arrows indicate uncertain associations and the brackets indicate entities of doubtful ontological status.

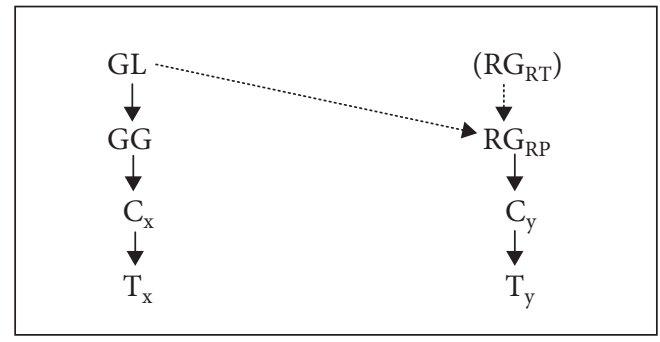

Figure 6. $\mathrm{RG}$ as an Independent RP

Larry Laudan (in particular) has argued convincingly that, in order to survive, theories need to be associated with specific RPs, and there seems to be little doubt that RG did indeed determine a new RP. ${ }^{12}$ However, whether it managed to establish its own $\mathrm{RT}$ is less clear (hence the notation ' $\left(\mathrm{RG}_{\mathrm{RT}}\right)$ ' in Figure 6). Did a new RP (or RT) emerge in the mid 1970s when relational networks were introduced, or did the program/tradition not acquire a clear identity until the emergence of Arc Pair Grammar towards the end of the decade? Even in the latter case, the connections with GG are conspicuous. For instance, Arc Pair Grammar can be viewed as a model-theoretic approach to syntax since (like RG) it contains rules which define well-formedness criteria for syntactic objects. Consequently, it explicitly rejects GG's fundamental generative-enumerative assumptions. ${ }^{13}$ However, rules of this kind were initially discussed at length in Perlmutter's 1968 GG-based $\mathrm{Ph} . \mathrm{D}$. thesis where they were introduced as 'filters' on SSs, so it would be misleading to

12. Laudan discusses the way in which theories can pass from one research tradition to another in Laudan (1977), Chapter 3 (especially p.94).

13. Concerning RG rules which specify well-formedness criteria, Perlmutter \& Postal 1983[1974] contains the following passage as part of a discussion of the Passive rule: ' $[\mathrm{t}] \mathrm{he}$ underlying idea is that the rules of grammar are of two types, those which positively sanction the presence of arcs in RNs [Relational Networks] [...] and those which negatively sanction the occurrence of arcs $[\ldots]$ The definition of well-formedness is then, very roughly, that an arbitrary RN is well-formed with respects to G [a grammar] if every arc in it is positively sanctioned by any rule in G' (Perlmutter \& Postal 1983[1974]: 18). Since it adopts this kind of approach more extensively, Arc Pair Grammar can be viewed as an early attempt to outline a form of Model-Theoretic Syntax. Approachable overviews to this broad topic can be found in Pullum \& Scholtz (2001) and Pullum (2007). 
claim that this marked a complete break with GG. Rather, a formal procedure that had a less privileged status in GG was accorded a more fundamental role in Arc Pair Grammar (and in RG). In many respects, then, RG selected, re-emphasised, and refocused particular ideas that had been presented less clearly within the GG program. Nonetheless, a persistent problem is that there are no watertight criteria for identifying an RT-RP pairing, and most models of scientific theory development generally assume that these associations are one-to-many mappings (as in Figure 1). However, this reveals a weakness in the rather simplistic set-theoretical representations that are often used to represent the ontological stratification of RTs, RPs, and theories. Actual historical examples, such as the emergence of RG, demonstrate that it is quite possible for a given RP to be indeterminately associated with more than one RT (at least for a short period of time), and that it can exist in the twilight zone between several RTs. In order to capture this in a strictly set-theoretical analytical framework, mathematical objects such as non-classical sets (e.g., fuzzy sets) may be required in order to achieve greater representational accuracy.

Setting these thorny issues to one side for the time being, there is no doubt that two prominent hypotheses which were associated with RG proved to be remarkably influential. The consistent focus on primitive grammatical relations enabled Perlmutter and Postal (and others) to offer provocative reassessments of traditional notions such as transitive and intransitive verbs. In fact, RG predicts the existence of four kinds of 'structure':

i. A structure contains both a 1-arc and a 2-arc

ii. A structure contains a 1-arc and no 2-arc

iii. A structure contains a 2 -arc and no 1-arc

iv. A structure contains neither a 1-arc nor a 2-arc

Intriguingly, structures of type (iii) had not been recognised as a distinct class. Adopting terminology that had been suggested by Geoffrey Pullum, Perlmutter and Postal proposed that an initial stratum in a relational network that is subjective and intransitive should be classified as 'unergative', while a stratum that is objective and intransitive should be classified as 'unaccusative'. Accordingly, the Unaccusative Hypothesis was proposed:

The Unaccusative Hypothesis:

The initial stratum of some basic clauses is unaccusative

Although unaccusatives had usually been lumped together with subjective intransitives, Perlmutter and Postal showed that sentences 'Martians dream' and 'Martians exist' can be associated with very different underlying structures, despite their superficial similarity. During the late 1970s Perlmutter (in particular) presented these provocative ideas at a 
number of conferences, and, as a result, the RG formulation of the Unaccusative Hypothesis gradually began to enter the consciousness of the wider linguistics community. Crucially, the Unaccusative Hypothesis has strong connections with similar ideas that had been proposed in earlier GG (and especially Generative Semantics) literature. For instance, in his 1962 thesis, Postal had commented that there were 'strong formal reasons' for analysing certain intransitive subjects as being derived from Deep Structure objects (Postal 1979[1962]: 25), and later GG syntacticians such as Charles Fillmore (b.1929) and Joseph Emonds (b.1940) adopted similar analyses with varying degrees of explicitness. Once again, then, the threads that connect GG and RG are apparent. ${ }^{14}$

Whatever the exact details of its origin, the Unaccusative Hypothesis emphasises the extent to which syntactic considerations depend upon 'semantic roles' (Perlmutter \& Postal 1984[1978]: 97). In order partly to clarify this dependency, Perlmutter and Postal introduced the Universal Alignment Hypothesis (Perlmutter \& Postal 1984 [1978]: 97):

\section{The Universal Alignment Hypothesis:}

There exist principles of universal grammar which predict the initial relation borne by each nominal in a given clause from the meaning of the clause.

The basic insight is that semantic considerations (i.e., the 'meaning of the clause') determine the nature of the initial grammatical relations that are present in a given clause, and Perlmutter and Postal emphasised that, if the Universal Alignment Hypothesis holds, then 'the assignment of initially intransitive clauses to the unergative or unaccusative type is completely determined by universal principles' (Perlmutter \& Postal 1984[1978]: 97). Yet again, this claim has its roots in research that appeared as part of the GL tradition, specifically in the Generative Semantics program. For example, the Universal Base Hypothesis proposes that (at a particular level of representation) the linguistic structures in all the world's languages are produced by the same generative base, and, from the mid 1960s onwards, this idea had been explored extensively in the GG/ Generative Semantics framework by such people as George Lakoff (b.1941), Emmon Bach (b.1929), James McCawley (1938-1999) and John Robert (Haj) Ross (b.1938). For instance, in his 1970 paper 'On Declarative Sentences', Ross stated the Universal Base Hypothesis as follows: '[ $t$ ]he deep structures of all languages are identical, up to the ordering of constituents immediately dominated by the same node' (Ross 1970[1968]: 260). When the various formulations of the Universal Base Hypothesis and the Universal Alignment Hypothesis are juxtaposed, it becomes clear that the latter provides yet

14. Perlmutter traced the origins of the idea back as far as a review that Edward Sapir had written in 1917 (Perlmutter 1978: 186n). For an entertaining attempt to track the development of the idea through the decades, see Pullum 1991: 147-158. 
another example of an idea that had surfaced within the GG program but which was effectively reformulated and re-expressed more explicitly in the RG program. ${ }^{15}$

\section{Reformulating Relational Grammar}

Initial research in the RG framework was presented in unpublished manuscripts and at conferences long before it appeared in print. Therefore the Unaccusative Hypothesis and the Universal Alignment Hypothesis became known to the wider linguistics community (gradually) during the period 1974-1977, and certain GG syntacticians were quick to recognise the importance of these hypotheses. Some people responded by attempting to re-express certain RG insights in terms of the GG program, and texts such as Andrew Radford's Italian Syntax: Transformational and Relational Grammar (1977) and Alec Marantz's Chomsky-supervised doctoral thesis, On the Nature of Grammatical Relations (1981), were largely inspired by RG. Other researchers followed this basic pattern, and, crucially, Luigi Burzio (b.1943) re-expressed the Unaccusative Hypothesis in terms of the P\&P framework in a series of publications in the early 1980s which culminated in his 1986 monograph Italian Syntax (a modified version of his 1981 M.I.T. thesis). In this influential work, Burzio considered sentence pairs such as 'Giovanni arriva' and 'Giovanni telefona' and he claimed that

The material [...] will provide several arguments, some directly related to Perlmutter's observation, for the idea that the superficial subject of verbs like arrivare [...] is the D-structure direct object: an idea which corresponds to the "Unaccusative Hypothesis" of Perlmutter (1978), and other related works in Relational Grammar. (Burzio 1986: 20-21)

Rather than using relational networks and other RG-specific paraphernalia, Burzio specified three verb classes - (i) transitive verbs (e.g., 'Giovanni esamina il caso'), (ii) intransitive verbs (e.g., 'Giovanni telefona'), and (iii) unaccusative verbs (e.g., 'Giovanni arriva') - and suggested that class (iii) was distinguished from class (ii) by the fact that, at the Deep Structure level, the Surface Structure subject initially occupies the direct object position before later moving to the subject position (as a result of Move $a$ ): ${ }^{16}$

[e] arriva Giovanni $\rightarrow$ Giovanni $_{i}$ arriva $_{i}$

15. The specific works alluded to here are Lakoff (1965), Bach (1968), McCawley (1976[1967]), and Ross (1970). The basic insight of the Universal Base Hypothesis was influentially reformulated by Richard Kayne (1994).

16. In fact, Burzio strangely (and unhelpfully) changed Perlmutter's terminology, using the term 'ergative' rather than the term 'unaccusative' (Burzio 1986, 27-31). I have used 'unaccusative' in the main text in a slightly anachronistic way simply in order to avoid confusion. 
In structures such as this, the NP is assigned a theme/patient role in the V-comp position, and this is required by the verb 'arriva'. However, the Extended Projection Principle (EPP) forces the noun to move to the subject position. Crucially, the pretransformation position is not ungrammatical, but it does have a different discourse interpretation. Despite many critical differences in specific technical detail, the fundamental Unaccusative Hypothesis insight remains the same. During the 1980s, unaccusative verbs were widely adopted in the mainstream GG literature, and the RG origins of this category were sometimes grudgingly acknowledged. ${ }^{17}$ As early as 1981, for example, Chomsky noted that Burzio's analysis of unaccusatives was 'based in part on ideas of David Perlmutter' (Chomsky 1981: 282.n35). So, the Unaccusative Hypothesis migrated from RG to GG during the period 1978-1986, but this was not a unique displacement. Several other RG hypotheses were adopted/adapted by GG researchers, and the Universal Alignment Hypothesis experienced a similar fate.

In his 1988 monograph Incorporation (a revised version of his Chomsky-supervised 1985 doctoral thesis), Mark Baker (b.1959) explored (amongst other things) alternative methods by which referential expressions are encoded in grammatical functions, and he analysed some of the ways in which complex predicates are built up out of elementary units. This prompted him to reconsider the semantic relationships specified by $\theta$-roles in P\&P; he introduced 'a guiding principle of grammar which characterizes the level of D-Structure' (Baker 1988: 46), and he called this principle The Uniformity of Theta Assignment Hypothesis:

The Uniformity of Theta Assignment Hypothesis:

Identical thematic relationships between items are represented by identical structural relationships between those items at the level of D-Structure.

Despite lingering vagaries concerning $\theta$-roles (Baker 1988: 47), the Uniformity of Theta Assignment Hypothesis ensured that semantic roles were assigned in a uniform manner at the level of Deep Structure. Although Baker does not emphasise the conceptual lineage of the Uniformity of Theta Assignment Hypothesis explicitly in the main body of his text, he does refer to its origins in a later footnote: '[ $t$ ]here is also an important conceptual similarity between the Uniformity of Theta Assignment Hypothesis and the "Universal Initial Assignment Hypothesis" of Relational Grammar [...] A similar idea motivated much of the work in generative semantics' (Baker 1988: 449.n6). This comment creates a number of uncertainties. For instance, what exactly is/was the 'Universal Initial Assignment Hypothesis'? While it is possible that this is simply a bizarrely bungled attempt to write 'Universal Alignment Hypothesis', this explanation would be more convincing if Alec Marantz had not also referred to a 'Universal Initial

17. For more information see Levin \& Rappaport (1995). 
Assignment Hypothesis' in his 1984 monograph (Marantz 1984: 339). Since Marantz's monograph is a revised version of his 1981 doctoral thesis, it is possible that he had access to earlier pre-publication drafts of Perlmutter's and Postal's RG articles which used this name instead. Unfortunately, none of the participants in these exchanges can now recall the details of these naming conventions. ${ }^{18}$ Despite these opacities, the Uniformity of Theta Assignment Hypothesis was enthusiastically adopted by the GG community, and it continues to retain a prominent (if disputed) place in the Minimalist Program (MP). ${ }^{19}$ Chomsky publicly endorsed it in 1988, commenting that while earlier versions of the hypothesis (in Generative Semantics and RG) had 'proved unfeasible, in fact, more or less vacuous,' Baker's reworking of the same basic idea was 'meaningful, in fact extremely strong' (Chomsky 1988: 66). Therefore, after almost twenty years, an hypothesis which had emerged as part of Generative Semantics and which had been refashioned in RG, was eventually (re)reformulated in the context of GG.

\section{The mechanics of proposition migration}

In order to model these developments using the theoretical framework adopted in this chapter, it is necessary to clarify the status of the Unaccusative Hypothesis and the Universal Alignment Hypothesis in RG. They are both self-professed 'hypotheses' (i.e., a particular kind of proposition), but where are they located in the ontological stratification outlined in Figure 1? Do they form part of the RG program core or are they optional auxiliary propositions which were initially associated only with a specific theories? To consider the Unaccusative Hypothesis first, this hypothesis was first discussed at length in Perlmutter's 1978 paper 'Impersonal Passives and the Unaccusative Hypothesis', and since RG research had been progressing for several years by this point,

18. For some reason, these sorts of errors and confusions are frequent in texts discussing the relationship between RG and GG; even in supposedly expository and clarificatory historical studies. For instance, when discussing Baker's 1988 reformulation of the Universal Alignment Hypothesis, Randy Harris refers to Baker's hypothesis as the 'Universal Theta Assignment Hypothesis' (Harris 1993: 254), where 'Universal' should in fact be 'Uniformity of'. Other popular expansions (which have been picked here virtually at random) include such things as 'Uniform Theta-Role Assignment Hypothesis' (Vivian James Cook \& Mark Newson 2007: 122), 'Uniform Thematic Alignment Hypothesis' (Patrick Farrell 2005: 214), and 'Uniform ThetaAssignment Hypothesis' (Andrew Radford 1997: 274). Given the inherent complexity of these topics even when the relevant terminology is used consistently, these creative reformulations are rather less than helpful.

19. For one fairly recent discussion of the Uniformity of Theta Assignment Hypothesis in an expository text that outlines the framework of the MP, see Adger 2003: 138-141. 
the Unaccusative Hypothesis seems to have been an auxiliary proposition (at least initially): it was not at first an essential component of the RG program, though arguably it became so eventually. As for the Universal Alignment Hypothesis, it cannot really be viewed as being a core proposition either, since its validity was debated explicitly in the RG literature. Most famously, Carol Rosen concluded that it was 'untenable' (Rosen 1984[1981]: 61). Seemingly, then, the Universal Alignment Hypothesis was an auxiliary proposition that could be optionally accepted or rejected by RG researchers.

Given this, since the Unaccusative Hypothesis and the Universal Alignment Hypothesis were both reformulated in the P\&P framework during the 1980s, they provide revealing examples of auxiliary proposition migration. Simply, this occurs when an auxiliary proposition (e.g., an hypothesis) associated with a given RP is adopted and re-expressed by another RP. Obviously, this process can involve either RPs within the same RT (intra-RT migrations) or else RPs associated with different RTs (inter-RT migrations). Such migrations are of considerable interest since they appear to be central to certain theory development strategies, but, despite this, they have received surprisingly little attention so far. For instance, Laudan explicitly recognises that an entire theory can break away from one RT and associate itself with another, commenting that ' $\mathrm{t}$ ] his process of theory separation is a fascinating one and deserves to be studied in some detail' (Laudan 1977: 94). However, in his 1977 monograph and in subsequent work he never focuses on this phenomenon in any great detail, and he certainly does not explore the way in which subcomponents of a given theory (e.g., specific propositions) are sometimes borrowed by an RP belonging to a separate RT.

A simple schematic representation of the kind of inter-RT auxiliary proposition migration that is exemplified in the Unaccusative Hypothesis and Universal Alignment Hypothesis case-studies is given in Figure 7. Here, hypothesis $\mathrm{P}_{\mathrm{p}}$ (which is one of the propositions associated with the $\mathrm{m}^{\text {th }}$ theory of the $\mathrm{i}^{\text {th }} \mathrm{RP}$ associated with $\mathrm{RT}_{1}$ ) migrates to the $\mathrm{n}^{\text {th }}$ theory of the $\mathrm{j}^{\text {th }} \mathrm{RP}$ associated with $\mathrm{RT}_{2}$. This alters the set of propositions associated with theory $\mathrm{T}_{2 . \mathrm{j} . \mathrm{n}}$, and therefore that theory develops as a result of this modification. If other theories associated with $\mathrm{RP}_{2 . \mathrm{j}}$ come to adopt the same proposition, then, in time, it may become part of $\mathrm{C}_{2 . j}$ - that is, a part of the propositional core of $\mathrm{RP}_{2 . j}$. Figure 7 captures (albeit crudely) the main characteristics of this specific theory development strategy. However, an abstract, skeletal account such as this necessarily leaves many issues unaddressed. For instance, as mentioned earlier, the Unaccusative Hypothesis and Universal Alignment Hypothesis examples both involve auxiliary propositions. This raises the question as to whether it is possible for propositions in the core to migrate between RTs or RPs. Also, the Unaccusative Hypothesis and the Universal Alignment Hypothesis can both be stated in conveniently general terms without the need for highly specific program-internal structures, processes, and categories. Consequently, they can be reformulated fairly easily in different theoretical frameworks. By contrast, it would be much more 
difficult to migrate a proposition which depended upon core assumptions that were central to a particular RP.
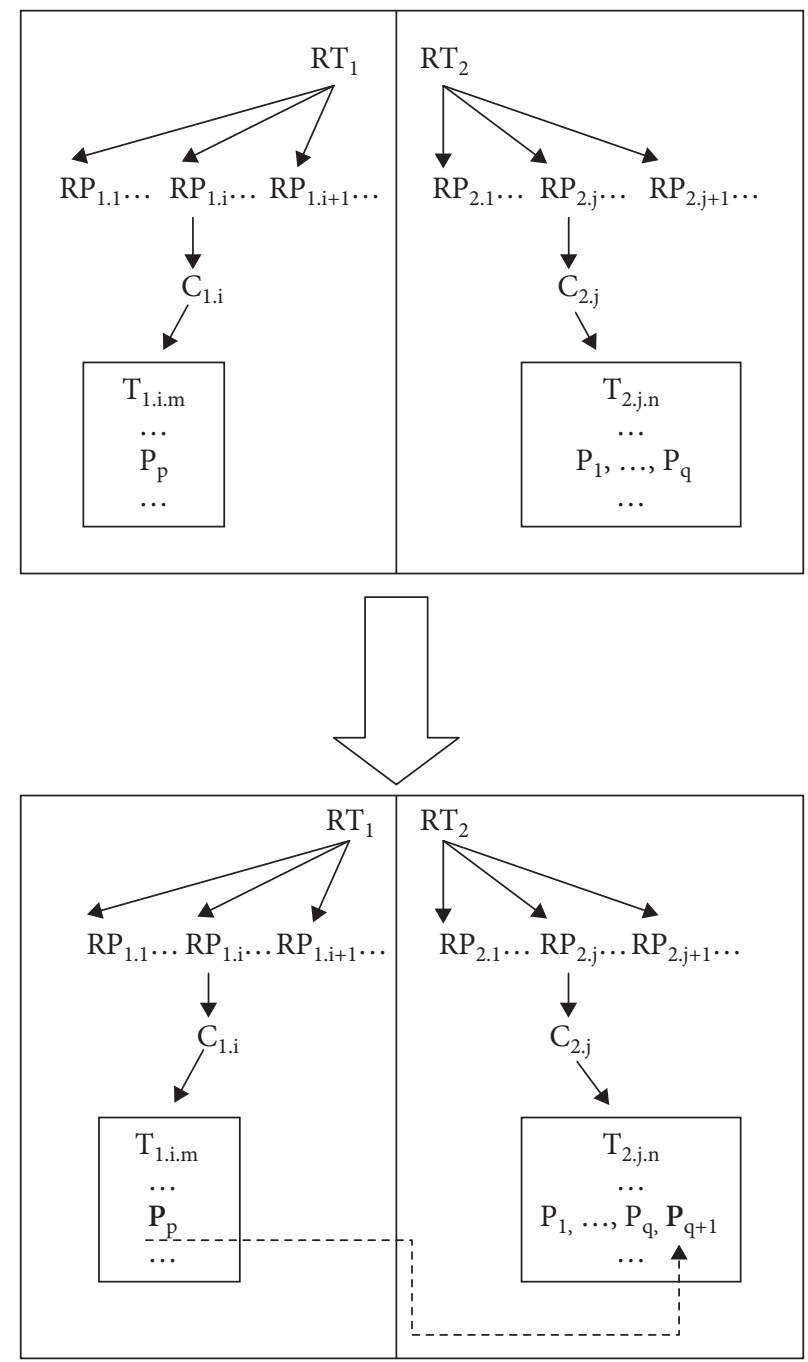

Figure 7. Inter-RT Proposition Migration

Another complexity concerns successive migrations. The two examples discussed in this chapter demonstrate that a particular proposition can migrate repeatedly, moving from $\mathrm{RP}_{1}$ to $\mathrm{RP}_{2}$ to $\mathrm{RP}_{3}$ and so on, thus forming a migration chain. More specifically, the Unaccusative Hypothesis and the Universal Alignment Hypothesis both provide instances of circular successive migration: the Unaccusative Hypothesis, for example, 
originated in the GG program (admittedly in an inchoate form); it then migrated to RG where it was reformulated; it then migrated from RG back into a later version of GG, where it was again reformulated. As a result of this odyssey, the hypothesis ended up back in the RP in which it originally developed, but with renewed prominence and in a modified form as a result of its journey through RG. And the same is true of the Universal Alignment Hypothesis. Circular migration patterns such as these have never been studied in the context of scientific theory development, yet they appear to be an essential aspect of certain kinds of RP evolution. If this is so, then it is reasonable to ask why it should occur, and again RG perhaps provides a few insights. For instance, it is certainly the case that during the 1970s, RG provided a framework that simplified the analytical task that GG had pursued ever since the mid 1950s. Specifically the relational networks proposed in the 1970s did not provide a detailed analysis of such things as internal-NP structure, although such detail was not beyond the scope of the RG framework. The guiding idea was to focus the analysis upon grammatical relations in order to account for phenomena such as passives, dative movement, relativization, topicalization, and so on. Consequently, RG intentionally concentrated on a more restricted range of linguistic structures, and this enabled it to elaborate and refine generalisations that had lurked within GG without ever rising to prominence. These generalisations highlighted structures and patterns that had not been revealed so clearly previously, and therefore they acquired influential status, as a result of which they were borrowed and re-expressed by certain GG researchers.

\section{Conclusion}

As this chapter has shown, the intricate relationship between GG and RG during the period 1965-1988 provides an illuminating case-study of the way in which linguistic theories and RPs evolve. When analysed using the conventional framework sketched in Figure 1, the emergence of RG as an independent RP can be scrutinised in some detail. However, the sheer complexity of the connections that relate GG and RG, during the years 1972 to 1975 in particular, suggest that overly simplistic analytical models of scientific theory development can be unhelpfully misleading. For instance, as noted earlier, since it is clear that (in practice) RPs can be associated with more than one RT, even if only for a short stage in their development, then this should be reflected explicitly in the modelling of such phenomena. As a result, the conventional one-to-many mappings from RTs to RPs, and from RPs to theories, do not adequately capture the complex patterns that one observes in the available data. In addition, although some philosophers of science, such as Laudan, have commented on the way in which theories can disassociate themselves from one RP and associate themselves with another, far less attention has been paid to the way in which propositions from 
one theory sometimes migrate to theories associated with different RPs. There is no doubt, though, that the GG program evolved in the 1980s partly as a result of certain propositions from RG being reformulated in the GG framework, and these examples of proposition migration merit close attention. In the case of the Unaccusative Hypothesis and the Universal Alignment Hypothesis, these were auxiliary hypotheses which had originated (in an imprecise way) within GG, but which had subsequently taken on greater importance and precision as part of RG, and which were eventually re-expressed (by Burzio and Baker respectively) in the P\&P framework. Little is known for certain about the particular conditions which prompt these sorts of cyclic proposition migrations, and it is currently not at all clear whether they occur in some kinds of scientific enquiry more frequently than in others. In the context of the physical sciences, texts such as Donovan et al (1988) have attempted to provide detailed historiographical analyses of specific instances of scientific theory development in order to compare and contrast a range of different methodological perspectives. So far, few such studies have been published which focus primarily on the evolution of linguistic theories, yet clearly discussions of this kind could helpful elucidate many issues which currently remain opaque.

As the above comments demonstrate, in order to understand and how and why linguistic theories evolve, it is essential to delve deeply and carefully into the history of linguistics. Attentive historiographical explorations are of especial importance when the broad topic of linguistic theory development is addressed, partly because it is still sometimes assumed that since linguistics is a 'science' (whatever that means exactly), then it must necessarily behave precisely like every other scientific discipline. This rather naïve stance presupposes that all sciences operate in exactly the same way - an assumption that has been largely rejected by those who disavow the existence of a single scientific method. Indeed, proponents of methodological pluralism maintain that a wide range of different scientific methods is deployed by a wide range of different sciences, and, accepting this, it is of considerable interest to determine whether there is anything distinctive about the particular methodologies and developmental strategies used by researchers working in different sub-branches of linguistics. ${ }^{20}$ To this end, preliminary descriptive studies such as the one sketched in the present chapter provide a way of identifying and classifying distinctive approaches that have been adopted at key moments in the history of linguistics.

20. For brief discussions of several different views concerning linguistics' status as a science, see Koster 2005: 350-358 and Tomalin 2006: 198-200. During the past fifteen years or so there have been several explorations of the diversity of scientific enquiry of which Galison \& Stump (1996) has been one of the most influential. For a recent discussion of methodological pluralism, see Sankey (2008; esp. Chapter 6). 


\section{References}

Adger, David. 2003. Core syntax : a minimalist approach. Oxford ; New York: Oxford University Press.

Aliseda, Atocha. 1997. Seeking explanations : abduction in logic, philosophy of science and artificial intelligence.

Aliseda, Atocha. 2006. Abductive reasoning: logical investigations into discovery and explanation. Dordrecht, The Netherlands: Springer.

Bach, Emmon. 1968. "Nouns and Noun Phrases". Universals in linguistic theory, ed. by Emmon Bach \& Robert T. Harms, 90-122. New York: Holt, Rinehart \& Winston.

Baker, Mark C. 1988. Incorporation : a theory of grammatical function changing. Chicago: University of Chicago Press.

Blake, Barry J. 1990. Relational grammar. London ; New York: Routledge.

Burzio, Luigi. 1986. Italian syntax : a government-binding approach. Dordrecht ; Boston: D. Reidel Pub. Co.; Kluwer Academic Publishers.

Chakravartty, Anjan. 2001. "The Semantic or Model-Theoretic View of Theories and Scientific Realism”. Synthese 127: 3. 325-245.

Chomsky, Noam. 1955. “The Logical Structure of Linguistic Theory”. Ms., date June 1955. Available from Columbia University Psychology Library.

Chomsky, Noam. 1957. Syntactic structures. The Hague: Mouton.

Chomsky, Noam. 1965. Aspects of the theory of syntax. Cambridge: M.I.T. Press.

Chomsky, Noam. 1981. Lectures on Government and Binding: The Pisa Lectures. Holland: Foris Publications.

Chomsky, Noam. 1988. Generative Grammar: its basis, development, and prospects. Kyoto: Kyoto University of Foreign Studies.

Cook, V.J. \& Mark Newson. 2007. Chomsky's universal grammar : an introduction. Malden, MA ; Oxford: Blackwell.

Donovan, Arthur L., Larry Laudan \& Rachel Laudan. 1988. Scrutinizing science : empirical studies of scientific change. Dordrecht ; Boston: Kluwer Academic Publishers.

Duhem, Pierre Maurice Marie. 1954. The aim and structure of physical theory. Princeton: Princeton University Press.

Farrell, Patrick. 2005. Grammatical relations. Oxford ; New York: Oxford University Press.

Feyerabend, Paul. 1975. Against method: outline of an anarchistic theory of knowledge. London: NLB; Humanities Press.

Galison, Peter \& David J. Stump. 1996. The Disunity of science : boundaries, contexts, and power. Stanford, Calif.: Stanford University Press.

Graffi, Giorgio. 2001. 200 years of syntax : a critical survey. Philadelphia: John Benjamins.

Harris, Randy Allen. 1993. The linguistics wars. New York: Oxford University Press.

Huck, Geoffrey J. \& John A. Goldsmith. 1995. Ideology and linguistic theory : Noam Chomsky and the deep structure debates. London; New York: Routledge.

Hempel, Carl G. 1965. Aspects of scientific explanation, and other essays in the philosophy of science. New York: Free Press.

Johnson, David E. \& Paul Martin Postal. 1980. Arc pair grammar. Princeton, N.J.: Princeton University Press.

Kayne, Richard S. 1994. The antisymmetry of syntax. Cambridge, Mass.: M.I.T. Press.

Koster, Jan. 2005. "Is Linguistics a Natural Science?” Organizing grammar : studies in honor of Henk van Riemsdijk, ed. by Henk C. van Riemsdijk \& Hans Broekhuis, 350-358. Berlin ; New York: Mouton de Gruyter. 
Kuipers, Theo A.F. 2007. General philosophy of science : focal issues. Amsterdam/London: Elsevier/North Holland.

Kuno, Susumu \& Ken'ichi Takami. 2004. Functional constraints in grammar: on the unergativeunaccusative distinction. Amsterdam: John Benjamins.

Lakatos, Imre. 1970. "Falsification and the Methodology of Scientific Research Programmes". Criticism and the growth of knowledge, ed. by Imre Lakatos and Alan Musgrave. Cambridge: Cambridge University Press.

Lakoff, George. 1965. On the nature of syntactic irregularity. Cambridge, Mass.: Harvard University Press.

Lakoff, Robin. 1989. “The Way We Were: Or, The Real Actual Truth about Generative Semantics: A Memoir”. Journal of Pragmatics: An Interdisciplinary Monthly of Language Studies 13: 6. 939-988.

Laudan, Larry. 1977. Progress and its problems : toward a theory of scientific growth. Berkeley: University of California Press.

Levin, Beth \& Malka Rappaport Hovav. 1995. Unaccusativity : at the syntax-lexical semantics interface. Cambridge, Mass.: M.I.T. Press.

McCawley, James D. 1976 [1967]. "Concerning the Base Component of a Transformational Grammar". Grammar and meaning : papers on syntactic and semantic topics, ed. by James D. McCawley, 35-58. New York: Academic Press.

Marantz, Alec. 1981. On the nature of grammatical relations. Ph.D. Thesis, M.I.T.

Marantz, Alec. 1984. On the nature of grammatical relations. Cambridge, Mass.: M.I.T. Press.

Matthews, P.H. 1993. Grammatical theory: from Bloomfield to Chomsky. Cambridge: Cambridge University Press.

Newmeyer, Frederick J. 1986. “Has There Been a ‘Chomskyan Revolution' in Linguistics?” Language 62: 1. 1-18.

Perlmutter, David M. 1968. Deep and surface structure constraints in syntax, Ph.D. Thesis, M.I.T.

Perlmutter, David M. 1978. "Impersonal Passives and the Unaccusative Hypothesis". Proc. of the Fourth Annual Meeting of the Berkeley Linguistics Society, 157-189. Berkeley, California.

Perlmutter, David M. 1983. Studies in relational grammar 1. Chicago: Univ. of Chicago Press.

Perlmutter, David M. \& Paul Postal. 1983 [1972] “The Relational Succession Law”. Studies in relational grammar 1, ed. by David M. Perlmutter, 32-52. Chicago: Univ. of Chicago Press.

Perlmutter, David M. \& Paul M. Postal. 1983[1978]. “Towards a Universal Characterisation of Passivization”. Studies in relational grammar 1, ed. by David M. Perlmutter, 3-29. Chicago: Univ. of Chicago Press.

Popper, Karl R. 1959. The logic of scientific discovery. New York: Basic Books.

Postal, Paul. 1979[1962]. Some Syntactic Rules in Mohawk. New York: Garland Publishing.

Pullum, Geoffrey K. 1991. The great Eskimo vocabulary hoax, and other irreverent essays on the study of language. Chicago: University of Chicago Press.

Pullum, Geoffrey K. 2007. “The Evolution of Model-Theoretic Frameworks in Linguistics”. Proceedings of the Model-Theoretic Syntax at 10 workshop at ESSLLI 2007, 1-10. Trinity College Dublin.

Pullum, Geoffrey K. \& Barbara Scholz. 2001. "On the Distinction between Model-theoretic and Generative-enumerative Syntactic Frameworks". Paper presented at the 4th conference on Logical Aspects of Computational Linguistics, Le Croisic, France.

Radford, Andrew. 1977. Italian syntax : transformational and relational grammar. Cambridge ; New York: Cambridge University Press. 
Radford, Andrew. 1997. Syntax : a minimalist introduction. Cambridge England ; New York, NY: Cambridge University Press.

Rosen, Carol G. 1984 [1981]. “The Interface between Semantic Roles and Initial Grammatical Relations". Studies in relational grammar. 2, ed. by David M. Perlmutter \& Carol G. Rosen, 38-77. Chicago ; London: University of Chicago Press.

Ross, John R. 1970[1968]. “On Declarative Sentences'”. Readings in English transformational grammar, ed. by Roderick A. Jacobs \& Peter S. Rosenbaum, 222-272. Waltham, Mass.: Ginn.

Sankey, Howard. 2008. Scientific realism and the rationality of science. Aldershot, England ; Burlington, VT: Ashgate.

Suppe, Frederick. 1989. The semantic conception of theories and scientific realism. Chicago: University of Illinois Press.

Suppes, Patrick. 1969 [1960]. "A Comparison of the Meaning and Uses of Models in Mathematics and the Empirical Sciences". Studies in the methodology and foundations of science. Selected papers from 1951 to 1969, ed. by Patrick Suppes, 10-23. Dordrecht: Reidel.

Tomalin, Marcus. 2006. Linguistics and the formal sciences: the origins of generative grammar. Cambridge ; New York: Cambridge University Press.

Toulmin, Stephen Edelston. 1972. Human understanding. Vol.1. Oxford: Clarendon Press. 


\title{
Universalism and human difference in Chomskyan linguistics
}

\section{The first 'superhominid' and the language faculty}

\author{
Christopher Hutton \\ The University of Hong Kong
}

Chomskyan linguistics is defined by its commitment to universalism and to belief in the existence of a shared species-wide language faculty grounded in human biology. The claim is that all human beings are linguistically one, and that human unity is the product of biological endowment. This paper argues that there is a profound contradiction at the heart of this project, which can be seen in the tension between universalism and rationalism on the one hand, and Romantic notions of mother tongue, native speaker, and intuitions about biological structure, on the other. There is one feature in common, however, between the universalistic framework and the Romantic-intuitive one. Neither is easily reconcilable with mainstream evolutionary theory. Conventional evolutionary theory is based on natural selection acting on intra-species variation, but Chomskyan linguistics seeks to avoid at all costs a characterization of humankind that includes any significant differences in biological inheritance or variation. In order to defend this core postulate of identity Chomsky is willing to present as reductionalist a view of the subject matter of linguistics as is necessary. Having linked language to biology, Chomsky must bracket out all forms of variation from his model in order to sustain this vision of human equality. But this idealization is only required because of the biolinguistic framework itself, and the insistence that there is a deterministic relationship between human biology and language. Ultimately the theory is driven by an ideological or political ideal of absolute human equality, a concept completely alien to the biological sciences. By linking human linguistic endowment to biology, Chomskyan linguistics is in danger of lending support to an idea quite antithetical to its universalism, namely that human beings and human societies are shaped by profound differences in their biolinguistic heritage.

\section{Introduction}

Chomskyan linguistics is defined by a fundamental commitment to universalism and to the existence of a shared species-wide language faculty grounded in human biology. 
This biological endowment, the language faculty, is the defining feature of a common humanity, and is presumed to be in essence invariant. The initial state of the language faculty is 'uniform for the species'; it is a 'special characteristic of humans, with properties that appear to be unusual in the natural world' (Chomsky 1995: 14; Lieberman 2006: 5). The universalism that this implies is not restricted to contemporary humanity. It radically separates human beings not only from all other animals, but also from humankind's hominid ancestors. There is now, and only ever has been, one language faculty. For Smith (1999: 1), this implies the further claim that 'there is really only one human language' and that 'the immense complexity of the innumerable languages we hear around us must be variations on a single theme. The language faculty is an 'organ' of the human body, which 'grows' rather than is learned in the traditional sense.

Any theory based on a search for an underlying identity inevitably creates classes of phenomena which defy, or appear to defy, reduction to the underlying unity. In defending this core universalist thesis, Chomskyan linguistics must maintain and justify the boundary between system and environmental 'noise', the core and the periphery, sameness and difference. One such problematic class of phenomena is the variation acknowledged to exist in the rule systems of the world's languages. With respect to this form of variation, Chomsky argues that the language faculty and Universal Grammar (UG) can permit only a highly constrained set of variant realizations of the same set of underlying principles, giving rise to the restricted class of the grammars of individual languages (Chomsky 2007). A further class of phenomena has been categorized as belonging to 'performance' as opposed to 'competence' (Chomsky 1965: 3-4), or more generally as 'external language' or 'E-language' as against abstract and internal language universals or 'I-language'. The latter is defined as (Chomsky 2007: 14):

a state of the computational system of the mind/brain that generates structured expressions, each of which can be taken to be a set of instructions for the interface systems within which the faculty of language is embedded.

E-language is understood to lie outside the purview of the theory and to resist systematic study. In the context of Chomskyan discussions of evolutionary biology, the terms FLB (the faculty of language 'in the broad sense') and FLN (the faculty 'in the narrow sense') have also been employed (Hauser, Chomsky \& Fitch 2002; Bever \& Montalbetti 2002).

The claim of Chomskyan linguistics to be an empirical science has been formulated as follows (Smith 1999: 11):

Like physics, but unlike logic or literary criticism, linguistics is an empirical science. That is, on a Chomskyan interpretation, which takes the speaker's mentally represented grammar to be the correct focus for investigation, it makes sense to claim that one analysis is right and another wrong. Every time a linguist describes a sentence or postulates a principle, he or she is making innumerable empirically testable predictions. [...] By contrast, a literary critic who claims that 
'a song is a form of linguistic disobedience,' or a logician who says that 'nothing is both an $\mathrm{X}$ and a non-X' are not formulating hypotheses to be checked out and tested by their colleagues. The observations may be useful, insightful, even inspired, but they are not empirical.

The question naturally arises as to which methodology should be brought to bear on this boundary between core and periphery, and by which criteria particular phenomena are apprehended and classified. Within Chomskyan linguistics, the primary data available for analysis has been provided by 'native speaker' intuitions. This allows the linguist to work with authentic sentences and test generalizations which can then be fed into the theoretical discussions of the model as a whole. The aim is to characterize the nature and boundaries of Universal Grammar, and to do this it must be shown that UG can account for any 'naturally occurring' feature of any human language. Chomskyan linguistics seeks to study language ('I-language') as a natural object, analogous to the human heart or human vision, and this suggests an orientation towards natural science. But access to the basic data required to understand the properties of that organ is mediated through the culturally and historically quite 'local' notion of native speaker.

The concept of native speaker is rooted in a tradition of thought apparently quite antithetical to Chomskyan linguistics, namely the language and identity politics of European Romanticism and identity theory. To be a native speaker within that tradition is to have been shaped in a profound sense by the modes of thought, associations and emotional bonds of a particular linguistic-cultural complex. These structures of thought and habits of mind are pre-rational, in that their basic nature is formed in the intimacy of the domestic sphere in the earliest years of childhood. The child is not taught what to feel or how to speak, but absorbs a set of emotional associations, responses and associations which lay down the basic framework long before the child enters formal schooling and the domain of writing, and becomes aware of explicit notions of linguistic correctness. This view of language is integral to the Romantic notion of 'mother-tongue' (Grimm 1851; Hutton 1999; Davies 2003).

Yet there is no empirical, socio-culturally neutral way to demonstrate that a particular individual is a native speaker with intuitions of relevance to a particular set of sentences (Harris 1981: 76). The identification of a native speaker, and more importantly, the assumption of a relationship between a speaker and a particular sample sentence, invokes a set of socio-culturally-defined relationships and categories. Put another way, the knowledge of the native speaker stands in a very uncertain relation to the competence of what in Chomskyan theory the 'ideal speaker-listener' or the 'idealized native speaker' (Chomsky 1965: 3-4, 24). These are precisely the kinds of issues that Chomsky sees as a distraction from the core aims of the theory. Chomsky recognizes that, trivially, everyone is a native speaker of the steady state which they have reached in acquiring language (Paikeday 1985: 75). Yet for Chomskyan theory, the Romanticintuitive response to the language data remains necessary, since there must be a way of 
producing and authenticating 'data' and the native speaker's judgments must in theory be as far as possible uncontaminated by the explicit, normative meta-linguistics of the formal culture to which the native speaker belongs. In practice, the linguist often doubles as the native speaker, or the issue of the provenance of the data is simply ignored. 'Natural language', in addition to its biological associations, thus takes on an additional set of meanings associated within Romantic conceptions of the natural, including the spontaneous, the untutored, and the intuitive. A telephone directory, a brand name, a Dada poem, Finnegans Wake, a road-sign, a menu, the speech of a beginning second language learner, do not have native speakers in this sense. Further, the use of intuition in the classification of natural phenomena belongs to a tradition of scientific thinking associated with figures such as Johann Wolfgang von Goethe (1749-1832), and Goethe's anti-Darwinian successors within modern biological thinking (Seamon \& Zajonc 1998).

On the surface, at least, there is a profound contradiction between Chomsky's linguistic universalism and rationalism and the grounding of the theory in the Romantic ideal of the intuitive relationship to mother tongue. The first suggests that all human beings are linguistically one and that human unity is provided by virtue of biological endowment. The second regards human identity as shaped by social and cultural environment of early childhood, and as formed at the profoundest level by the conceptual world of the native language. There is one feature in common, however, between these two frameworks. Neither sits comfortably with mainstream evolutionary theory, as it has been elaborated since the work of Charles Darwin (1809-1882). The idea of the absolute panchronic invariance of the language faculty across the species is difficult to absorb within the basic assumptions of evolutionary theory, since evolution is regarded as causing change by acting on variation. Chomsky occupies an exceptionalist and highly unorthodox position in relation to the general framework of evolutionary theory, even granted the complex contemporary debate about the place of natural selection and variation within evolutionary theory (Lieberman 1989: 223). On the other side of the intellectual divide, the heirs of the Romantic movement have been the strongest opponents of evolutionary theory. Darwin's theory is seen as crudely materialistic, and as positing a universe without ultimate meaning or teleology. While this is not the rhetorical substance of Chomsky's objections to evolutionary theory, Chomsky does appeal to Goethe's notion of Urform ('original form, i.e. the 'primordial plant') as 'a kind of generative principle that determines the class of physically possible organisms', drawing a parallel with Humboldt's notion of 'linguistic form' (Chomsky 2002: 66).

\section{The object of study}

Linguistics has been divided internally over whether its primary terminological and metaphorical commitment should be to the natural sciences or to the disciplines of 
culture and society, or simultaneously to both. It has consistently invented and reinvented its object of study as ontologically sui generis, as a 'third thing' (tertium quid) between nature and culture. This has involved a state of continual alienation from the methodologies of both the sciences and the humanities, masked in part by the circulation and exchange of a wide range of terms and metaphors. In the nineteenth century, the use of organic or naturalistic metaphors, referred to by Alter (1999: 7) as 'conceptual transfers', masked what in retrospect can be seen as an increasingly profound disengagement from mainstream natural science, but this did not lead to an integration with the social sciences and humanities.

The ambiguities inherent in the exceptionalism of linguistics can be traced in relation to the rise of uniformitarianism in natural science, that is, the idea that the same processes or causes of change operate universally in the object under study (see Christy 1983). Uniformitarianism reached its purest expression in the theory of natural selection, but had been elaborated in various disciplines, notably geology in the writings of James Hutton (1726-1797) and Sir Charles Lyell (1797-1875). It was contrasted with an often Biblically-inspired 'catastrophism', but in various forms the debate between gradualism and catastrophism continues to this day. If uniformitarianism were to be applicable within linguistics, then this would suggest that the individual human will, and human culture, played little or no role in language change. If language were subject to the same laws regardless of culture, geography or history, then it could be studied within the framework of the natural sciences. If by contrast language were a creature of the human will operating within the matrix of time, context and culture, then there could be no general propositions that science could prove about it. Thus Jacob Grimm (1785-1863), in his essay on the origin of language, was moved to stress that language was not subject to 'rigid and eternal natural law', with its universal concepts such as 'light' and 'gravity', and that it partakes of human freedom (Grimm 1851: 51): 'Nicht starr und ewig wirkendem naturgesetz, wie des lichts und der schwere, anheim gefallen waren die sprachen, sondern menschlicher freiheit in die warme hand gegeben' ('Languages are not subject to rigid and eternal natural law as are light and gravity. They were proffered unto the warm hand of human freedom'). But this position ultimately condemned the study of language to marginality when set against the rising power of modern science.

The challenge for linguistics became that of clarifying the scientific status of its organicist terminology. Grimm's essay is full of organic metaphors consistent with his Romantic heritage, and 'references to botany, comparative anatomy, physiology, and natural sciences' were common among Grimm's contemporaries (Koerner 1989: 357). But were these merely botanical metaphors, or was there a sustainable claim to be made for the study of human language to be classified under the natural sciences, following the same methods and with the same epistemological status? In the history of this question, the case of August Schleicher (1821-1868) is clearly fundamental, given his famous assertion that languages are 'natural organisms' (Naturorganismen) which escape control of the human will (Schleicher 1873: 6-7). However this should not be 
read as implying that all aspects of languages fall under the natural sciences (see Schleicher 1865; Koerner 1989: 210-232). The study of language responded to these challenges by embracing uniformitarianism, for example in the programmatic statements of the Neogrammarians (see Koerner 1989: 79-100), but the status of its biological metaphors was left unclear. Biological processes operated on and within the speakers of languages, but to what kinds of forces were their languages subject?

To put the matter at its simplest, a plant could be examined through a microscope, but a language was only available as a stable object of the gaze through the medium of writing, or later was to be graspable and reproducible through sound recording and the instruments of acoustic phonetics. While the genealogical tree was a powerful and resonant image of linguistic evolution, the overt mechanisms of linguistic transmission were entirely social. At the same time, there seemed to many to exist an unbridgeable gulf between human language and the rest of the animal kingdom, and this was taken as a strike against Darwin's theories: 'I must call it inconceivable that any known animal could ever develop language' (Müller [1873] 1996: 182). Arguably the nineteenth century encounter was inconclusive, with the study of language torn between assimilation to the natural sciences, and methodological and disciplinary autonomy.

In the Cours de Linguistique Générale (Saussure 1922), the organicism of linguistics was buttressed by an explicit methodological defence of the need for idealization. The synchronic system was viewed as an organic whole, an organism (Koerner 1989: 275), a mutually-defining structure that was neither directly steered by considerations of evolutionary competition nor by the human will. The phenomenon of human language could not be studied as a totality, but the underlying systems of each langue could be represented within a single, universal framework, a 'general linguistics'. There was no way to apply biological understandings of variation and adaptation to Saussure's model; nor was there a teleological direction to language change which might be dictated by culture, human intervention, or agency. When viewed from the point of view of culture, language was a complex organism that escaped the operation of the human will. When viewed from the point of view of biology, the system of langue was a socio-cultural, not biological, organism, identified and apprehended only through a conscious act of idealization and systemization. Linguistics was able to meet the demands of uniformitarianism, but only through idealizing out the dimension of time from its core construct, langue.

\section{Evolutionary theory}

Evolutionary theory is grounded in variation or difference. Without variation, there can be no evolution: 'Competition + variation + replication = natural selection + evolution' (Sterelny 2007: 18). If the language faculty or 'language organ' is invariant across the species, then there are two possible scenarios. Either this cross-species identity evolved 
out of intra-species variation (so that invariance was the outcome of evolutionary processes acting on variation), or it sprang fully-formed into being in a 'catastrophic' leap. The first view is that of Steven Pinker, i.e. that the modern singular invariant unity of human language is derived from conventional, gradualist evolutionary processes (Pinker \& Bloom 1990). The second 'saltational' (i.e. the anti-gradualist or 'leap') view is that of Chomsky. Attempts to defend Chomsky's paradigm within an evolutionary framework have been argued in terms of an organ evolving for one reason, but then in a 'catastrophic leap', beginning to function as a language organ (Bickerton 1990; Pinker 1992: 378). For Hauser, Chomsky and Fitch (2002) the faculty of language 'in the broad sense' (FLB) includes a sensory-motor system, a conceptual-intention system, as well as computational mechanism for recursion. In the narrow sense, it consists only of recursion, and 'currently appears to lack any analog in animal communication' (Hauser, Chomsky \& Fitch 2002: 1571). This faculty is held to be relatively recent in human evolutionary history, and rather than emerging as an adaptive product of natural selection, aspects of FLN are hypothesized to be 'spandrels, by-products of preexisting constraints rather than end products of a history of natural selection' (Hauser, Chomsky \& Fitch 2002: 1574). In particular, it is denied that FLN evolved 'from direct shaping by natural selection targeted at communication' (Hauser, Chomsky \& Fitch 2002: 1574).

A spandrel is a design feature which arises as a side-effect of adaptation, rather than through natural selection, and then acquires what is termed 'exaptive value, where a feature which has evolved under one set of conditions finds a use or function in another, quite independent of its evolutionary history (see Gould \& Lewontin 1979; Gould 2002). Simply put, the language faculty evolved for one reason (not communication), perhaps as a contingent by-product of adaptation, but then relatively suddenly took on a new specific and fundamental role. It did not arise out of a highly protracted gradual process of evolution. This puts Chomsky firmly in the anti-gradualist or 'catastrophist' camp, seemingly aligned with the evolutionary biologist Stephen Jay Gould (1941-2002). Gould offered a view of evolution as much more conservative than classic gradualist theory would suggest, characterized by 'punctuated equilibrium', and driven by catastrophic events as much as by gradual, adaptive selection. Gould's main intellectual opponents have been Richard Dawkins and Daniel Dennett (Sterelny 2007), the latter also, not surprisingly, a strong critic of Chomsky (Dennett 1995).

More recently, Chomsky has aligned himself with evolutionary developmental biology or 'Evo Devo'. For example so-called 'Hox genes' (genes that regulate fundamental aspects of morphological development) can be shown to exist in virtually every species of animal, but their function varies dramatically depending on the action of 'genetic switches' (Carroll 2005). The emphasis within Evo Devo on modularity, and the finding that the diverse range of morphological phenomena is not necessary reflected in terms of diversity at the gene level, have obvious appeal for Chomsky, given his understanding of linguistics (Chomsky 2007: 18). Chomsky also sees new trends in 
contemporary evolutionary theory as undermining the idea that proponents of 'ahistorical biological explanation' occupy an extreme position (Chomsky 2007: 12).

In Chomsky's account, the transition from an initial state (no language organ) to a final state (fully modern language organ) is viewed as instantaneous, as 'the result of some genetic event that rewired the brain, allowing for the origin of modern language with the rich syntax that provides a multitude of modes of expression of thought' (Chomsky 2005: 3). What is the nature of this 'rewiring' or 'Great Leap Forward' (Chomsky 2005: 12)?

An elementary fact about the language faculty is that it is a system of discrete infinity. Any such system is based on a primitive operation that takes $n$ objects already constructed, and constructs from them a new object: in the simplest case, the set of these $n$ objects. Call that operation Merge. Either Merge or some equivalent is a minimal requirement. With Merge available, we instantly have an unbounded system of hierarchically structured expressions. The simplest account of the 'Great Leap Forward' in the evolution of humans would be that the brain was rewired, perhaps by some slight mutation, to provide the operation Merge, at once laying a core part of the basis for what is found at that dramatic 'moment' of human evolution, at least in principle; to connect the dots is no trivial problem.

Chomsky considers then rejects the idea of a two-stage development (Chomsky 2005: 12):

There are speculations about the evolution of language that postulate a far more complex process: first some mutation that permits two-unit expressions (yielding selectional advantage in overcoming memory restrictions on lexical explosion), then mutations permitting larger expressions, and finally the Great Leap that yields Merge. Perhaps the earlier steps really took place, but a more parsimonious speculation is that they did not, and that the Great Leap was effectively instantaneous, in a single individual, who was instantly endowed with intellectual capacities far superior to those of others, transmitted to offspring and coming to predominate, perhaps linked as a secondary process to the SM system for externalization and interaction, including communication as a special case.

That individual must have been in that time and place a kind of superhominid, who then was able to dominate in evolutionary terms, produce more offspring than competitors, and ultimately populate the entire planet. Accepting this as historically plausible involves the proposition that, at historical moment $\mathrm{T}$, there was an individual A (the clinguistic Adam') who by virtue of genetic endowment is superior to all others. This superiority was based on the biology of the language faculty. This implies that one human being can be biologically superior to another by virtue of linguistic-genetic endowment.

Chomsky's desire to avoid even a two-stage gradualism leads him to affirm that it is possible for human beings to have radically, i.e. qualitatively, different abilities based on their genetic endowment, and for this to be produced by an apparently causeless, or random, mutation. Given this scenario, it is hard to see why there should not be an unbounded number of subsequent moments like $\mathrm{T}\left(\mathrm{T}_{1}-\mathrm{T}_{\mathrm{n}}\right)$, and many individuals 
like Adam $\left(A_{1}-A_{n}\right)$. If this form of mutation happened once, then similar or even quite distinct mutations could have arisen many times. The argument against this is that the modern language organ is in fact identical across the species. But this requires accepting the characterization of language, linguistics and the language faculty put forward by Chomsky himself, within the closed circle of definitions through which it operates.

Extrapolating from Chomsky's position, the inference must be that A, living at time T, was the first 'superhominid', that is, the first modern human being. A's parents and all other hominids living at that time were on the other side of the species divide. An evolutionary leap was made through one mutation from non-human or pre-human to human, which 'rewired' the brain to produce a qualitatively different and cognitively more sophisticated being. Since pre-humans and humans could interbreed, the mutation spread, and all the off-spring of the original superhominid ultimately became superhominids, or modern humans. If possession of the language faculty is the defining quality of the human species, then the claim is that modern humans emerged with a single, instantaneous 'catastrophic' mutation. Not only that, but - for Chomsky this is the simplest explanation available which is consistent with the state of knowledge in evolutionary biology. Chomsky's discussion finishes with a characteristic piece of rhetoric (2005: 12):

At best a reasonable guess, as are all speculations about such matters, but about the simplest one imaginable, and not inconsistent with anything known or plausibly surmised. In fact, it is hard to see what account of human evolution would not assume at least this much, in one or another form.

Put another way, in order to preserve the outlines of Chomsky's linguistic theory, the biological history of humanity must include a 'Great Leap Forward' of the kind he outlines. Indeed this must be the central and defining moment in the history of humankind.

\section{Instant linguistics}

The evolutionary leap from no-language to language is paralleled in Chomsky's account of the language learning abilities of the child (Chomsky 2005: 12):

Similar questions arise about growth of language in the individual. It is commonly assumed that there is a two-word stage, a three-word stage, and so on, with an ultimate Great Leap Forward to unbounded generation. That is observed in performance, but it is also observed that at the early stage the child understands much more complex expressions, and that random modification of longer ones even such simple changes as placement of function words in a manner inconsistent with UG or the adult language - leads to confusion and misinterpretation. It could be that unbounded Merge, and whatever else is involved in UG, is present at once, but only manifested in limited ways for extraneous reasons (memory and attention limitations and the like $[\ldots])$. 
In other words, there is an instantaneous developmental leap in the child's biological development, which is masked from clear view by aspects of performance. From the diversity of experience, children 'arrive at comparable grammars, indeed almost identical ones' (Chomsky 1977: 98). One formulation can be found in Hauser, Chomsky and Fitch (2002: 1577):

A child is exposed to only a small proportion of the possible sentences in its language, thus limiting its database for constructing a more general version of that language in its own mind/brain.

However it is unclear to which developmental process the acquisition of language is being compared: vision, walking, sexual maturation? It is asserted that children 'receive little or no explicit instruction' (Salkie 1990: 23), and language learning is described in terms of its effortlessness, instantaneous, or remarkable rapid accomplishment. In what sense do the thousands of hours spent by children immersed in, and interacting with, the linguistic world around them, amount to an effortless or near-instantaneous accomplishment? Pinker claims that children are 'not corrected for speaking ungrammatically' (Pinker 1996: 1). But how do we know when a child is being corrected for speaking 'ungrammatically' or when some other moral, cultural or linguistic principle is at stake? Again, the answer lies solely within the definitional circle of Chomskyan theory itself.

Within the Chomskyan paradigm, a familiar motif is that language is not learned, it grows, in a way which is intended to be more than a metaphorical parallel with other organs such as the heart or lungs (Smith 1999: 23):

Chomsky has strikingly suggested that, just as the heart and the rest of the circulatory system are organs with their own structure and functions, language is a kind of 'mental organ' interacting with other mental organs. Like the circulatory system, language is common to the species; like the circulatory system, it develops largely under genetic control, rather than being the fruit of learning or manipulation; like the circulatory system it is subject to impairment or failure independently of other organs.

The developmental process involved has even been compared to the growth of hair (Lightfoot 2005: 58).

The sui generis nature of this construct of the language faculty makes it difficult to give an empirical basis to the claim about language acquisition. One cannot compare something which the theory itself has set up to be incomparable. This is to leave aside the documentation by Tomasello (2003) of the intensive imitation involved in child language learning. The underlying issue with acquisition can also be put in terms of how unity arises out of diversity, that is, the question of how the experiential diversity of the child nonetheless leads to underlying unity of the final state. For Chomsky, that the child achieves the final state so rapidly and unerringly is proof of the underdetermination of language by experience, and of the implausibility of empirical models of 
language learning given the 'poverty of stimulus' (Chomsky 2007: 18). Even the severest of the Darwinist critics of Chomsky, Daniel Dennett, accepts that a small number of 'developmental triggers' set in motion the processes of language-acquisition, and 'a few environmental conditions subsequently do some minor pruning or shaping, into which ever mother tongue the child encounters'. The child can discern in the environmental noise enough to set the system to accord with the particular variant or 'mother tongue' (Dennett 1995: 388).

There are further parallels to set alongside that between the superhominid and the child. The first is that between the child and the linguist: 'language acquisition is rather like theory construction' (Chomsky 2009: 20). The second is between the 'leap' of the first superhominid and the Chomskyan 'revolution' itself, with Chomsky's own Great Leap Forward at its centre. Linguistics in its pre-Chomskyan state was a paradigm that understood language in taxonomic terms or as a 'finite state grammar' (Hauser, Chomsky \& Fitch 2002: 1577). The implication was that this model was suitable only for describing the primitive language of animals, pre-human hominids, and the child in the brief developmental period before its grammar reaches the completed final state. The Chomskyan 'leap' was to a system of linguistics that could explain and reflect the qualities of human language, in particular its formal properties. As with the first superhominid, the Chomskyan mutation did not have an identifiable pre-history, and involved the original application of the properties of formal systems which had been elaborated outside linguistics as a discipline. Chomskyan linguistics understood itself as a revolutionary break with the past, and this self-understanding has been on the whole been successfully communicated to the wider academic world. Against this rhetoric of revolution, we can set Koerner's 'gradualist' deconstruction of Chomsky's own historical narrative (Koerner 1989: 101-146), as well as Tomasello's painstaking empirical documentation of the gradual acquisition of language and the central role played by repetition therein (Tomasello 2003).

\section{Linguistics and systems theory}

One paradigm within which the Chomskyan construct can be usefully discussed is modern systems theory, including the foundational semiotic theories of C.S. Peirce (1839-1914) and the ecological semiotics of Jakob Johann von Uexküll (1864-1944). Systems theory, associated in particular with Karl Ludwig von Bertalanffy (1901-1972), covers a wide range of approaches, with a complex relationship to evolutionary theory as well as to the social and political sciences. The notion of autopoiesis, for example, a term derived from evolutionary biology, is used to refer to systems that reproduce themselves autonomously: 'law produces by itself all the distinctions and concepts which it uses [...] the unity of law is nothing but the fact of this self-production, this 
"autopoiesis" (Luhmann 2004: 70). Within this conception of systems theory, the autonomy of biological and social systems means that there is no systematic or causal link between system-internal processes and the external environment. While the external environment is necessary for the system, since it provokes and stimulates it, there is no systematic or causal relationship. From the point of view of the system, the environment is unstructured and disordered 'noise.' The system only communicates with itself through its autopoieitic codes. In social science, systems theory is associated with a rejection of the relevance of subjectivity, intention and human agency in steering and changing the direction of system. A striking example of this is the vision of a systems linguistics laid out in Saussure's Cours (1922). The nature of langue is such that it cannot be steered by the conscious intervention of its speakers; it is a social and psychological fact, but of an abstract kind emerging into view through the adoption of a particular point of view by the linguist. The system changes under the stimulation of individual acts of speaking, but there is no systematic or predictable causal link between the system of langue and its unstructured and multifarious environment. Under stimulation from parole, the system of langue restructures itself through autopoeisis. The system is made up of interdefining elements and self-referential quality contrasts with the lack of any principled relationship to the external world. In Chomsky's case, the disorder, which he characterizes, citing William James' (1842-1910), as 'blooming, buzzing confusion’ (Chomsky 2007: 17), triggers particular parameters in the system, but does not, and cannot, impact on the core nature of the system itself.

Chomskyan theory, even within the broad range of system theoretical approaches, stands out in the extremity of the divorce between system and 'noise' or 'chaotic environment' (Lightfoot 2005: 48). In contrast to Luhmann's systems model of law, time plays no role in Chomskyan linguistics. The system is in its essence invariant, and, once the Great Leap Forward has been accomplished by genetic mutation (itself non-causally linked to any particular external or internal event), and spread by the evolutionary success of its bearers, the system itself never fundamentally changes.

\section{Conclusion}

One line of argument has been that there is a set of practices that we call science and that Chomskyan linguistics falls short of this in one or other respects, in particular because it appears to reject the neo-Darwinian synthesis. While it might be possible to make such an argument, that is not what is being proposed here. What is striking, however, is that Chomskyan linguistics seeks an affiliation with the biological sciences, at the same time as it proposes the most fundamental revision in evolutionary thinking since Darwin. The basic assertions about the language faculty have remained constant 
through the shifts in the nature of the formal model, the formal complexities of which have masked a radically reductive biolinguistic framework. As the biolinguistic frame has become more explicit, the inner logic of the theory and its core idealization of the language faculty has increasingly brought into focus Chomsky's radical exceptionalism with regard to evolutionary biology. Yet there has been no sophisticated and genuinely cross-disciplinary discussion of the role of idealization within linguistics in relation to scientific methodology. An education in linguistics, if it merely takes the form of induction into one of the contemporary schools of formal linguistics, is highly impoverished intellectually. To present the human language faculty as a radically autonomous, timeless and perfectly self-referential entity requires a great deal more theoretical justification than assertions about the centrality of idealization to science.

Chomsky identifies the language faculty as the essence of what it is to be human. He seeks to avoid at all costs a characterization of humankind that includes any significant differences in biological inheritance or variation. In order to defend this core idealization Chomsky is willing to present as reductionalist a view of the subject matter of linguistics as is necessary. The authenticity of the native speaker in Romantic terms is required to create data for the operation of the theory, in that only a 'naturally occurring' native speaker can authenticate 'naturally occurring' data. The concept of native speaker remains however an awkward and indigestible 'trace' of the world of E-language in the architecture of the theory, symptomatic of the problematic uses of the ideas of the 'natural' within the modern study of language.

Chomskyan theory offers a rationalist, universalist account of human nature. Ultimately, the central idealizations of the theory serve a political-ideological purpose rather than any recognizable scientific goal. Having linked language to biology, Chomsky must bracket out all forms of variation from his model in order to sustain this vision of human equality. But this idealization is only required because of the biolinguistic framework itself, and the insistence that there is a deterministic relationship between human biology and language. The underlying presumptions of the model could be used to explain or justify human inequality by pointing to the competitive evolutionary advantage of exaptive changes in the human language faculty. This is not to imply that Chomsky believes that human beings vary biologically as individual and groups in respect of their language faculty. But for someone who has linked empiricist ideas of human plasticity to 'manipulation and domination and control' (Chomsky 1988: 244; McGilvray 1999: 16-17), this is a remarkable blind-spot. Ideas of human genetic fixity (rather than plasticity) have been similarly open to abuse, with individuals and groups deemed incorrigible on the basic of their inherited biological nature (Hutton 2005). Like Oedipus at the crossroads before Thebes, Chomskyan linguistics has by its own internal logic threatened to stumble onto the very conclusion it seeks at all costs to avoid, namely that human beings and human societies are shaped by profound differences in their biolinguistic heritage. 


\section{References}

Alter, Stephen G. 1999. Darwinism and the linguistic image : language, race, and natural theology in the nineteenth century. Baltimore: Johns Hopkins University Press.

Bever, Thomas \& Mario Montalbetti. 2002. “Noam's Ark”. Science 298. 1565-1566.

Bickerton, Derek. 1990. Language \& species. Chicago: University of Chicago Press.

Carroll, Sean B. 2005. Endless forms most beautiful: the new science of evo devo and the making of the animal kingdom. New York: Norton.

Chomsky, Noam. 1965. Aspects of the theory of syntax. Cambridge: M.I.T. Press.

Chomsky, Noam. 1977. Language and responsibility. New York: Pantheon Books.

Chomsky, Noam. 1988. Language and politics. Montréal ; New York: Black Rose Books.

Chomsky, Noam. 1995. The Minimalist Program. Cambridge, Mass.: M.I.T. Press.

Chomsky, Noam. 2002 [1966]. Cartesian Linguistics: A Chapter in the History of Rationalist Thought. 2nd ed. Christchurch, New Zealand: Cybereditions.

Chomsky, Noam. 2005. “Three Factors in Language Design” [Winter]. Linguistic Inquiry 36: 1. 1-22.

Chomsky, Noam. 2007. "Of Minds and Language”. Biolinguistics 1. 9-27.

Chomsky, Noam. 2009. "Opening Remarks". Of minds and language : a dialogue with Noam Chomsky in the Basque country, ed. by Massimo Piattelli-Palmarini, Pello Salaburu Etxeberria \& Juan Uriagereka. Oxford ; New York: Oxford University Press.

Christy, Craig. 1983. Uniformitarianism in Linguistics. Amsterdam: John Benjamin.

Dennett, Daniel Clement. 1995. Darwin's dangerous idea : evolution and the meanings of life. New York: Simon \& Schuster.

Davies, Alan. 2003. The native speaker : myth and reality. Clevedon; Buffalo: Multilingual Matters.

Gould, Stephen Jay \& Richard C. Lewontin. 1979. “The Spandrels of San Marco and the Panglossian Paradigm: A Critique of the Adaptationist Programme”. Proceedings of the Royal Society of London B. 581-598.

Gould, Stephen Jay. 2002. The structure of evolutionary theory. Cambridge, Mass.: Belknap Press of Harvard University Press.

Grimm, Jacob. 1851. Über den Ursprung der Sprache. Berlin: K. Akademie der Wissenschaften. Harris, Roy. 1981. The language myth. New York: St. Martin's Press.

Hauser, M.D., Noam Chomsky \& W.T. Fitch. 2002. “The Faculty of Language: What Is It, Who Has It, and How Did It Evolve? "Science 298. 1569-1579.

Hutton, Christopher. 1999. Linguistics and the Third Reich: mother-tongue fascism, race, and the science of language. London; New York: Routledge.

Hutton, Christopher. 2005. Race and the Third Reich : linguistics, racial anthropology and genetics in the dialectic of Volk. Cambridge: Polity.

Koerner, E.F.K. 1989. Practicing linguistic historiography : selected essays. Amsterdam/Philadelphia: John Benjamins.

Lieberman, Philip. 1989. "Some Biological Constraints on Universal Grammar and Learnability”. The Teachability of Language, ed. by Mabel Rice \& Richard L. Schiefelbusch, 199-225. Baltimore: P.H. Brookes.

Lieberman, Philip. 2006. Toward an evolutionary biology of language. Cambridge, Mass.: Belknap Press of Harvard University Press.

Lightfoot, David. 2005. "Plato's Problem, UG, and the Language Organ". The Cambridge Companion to Chomsky, ed. by James A. McGilvray, 42-59. Cambridge, UK ; New York: Cambridge University Press. 
Luhmann, Niklas, Klaus A. Ziegert \& Fatima Kastner. 2004. Law as a social system. Oxford ; New York: Oxford University Press.

McGilvray, James A. 1999. Chomsky: language, mind, and politics. Cambridge, UK; Malden, Mass.: Polity Press.

Müller, Friedrich Max. 1996[1873]. “Lectures on Mr Darwin's Philosophy of Language”. The Origin of Language, ed. by Roy Harris, 147-233. Bristol: Thoemmes Press.

Paikeday, Thomas M. \& Noam Chomsky. 1985. The native speaker is dead! : an informal discussion of a linguistic myth with Noam Chomsky and other linguists, philosophers, psychologists, and lexicographers. Toronto; New York: Paikeday Pub.

Pinker, Steven. 1992. "Review of Derek Bickerton, Language and Species, Chicago, 1990”. Language 68. 375-382.

Pinker, Steven. 1996. Learnability and cognition : the acquisition of argument structure. Cambridge, Mass.: M.I.T. Press.

Pinker, Steven \& Paul Bloom. 1990. Natural language and natural selection. Cambridge, Mass.: Massachusetts Institute of Technology Center for Cognitive Science.

Salkie, Raphael. 1990. The Chomsky update : linguistics and politics. London ; Boston: Unwin Hyman.

Saussure, Ferdinand de. 1922. Cours de linguistique générale. Paris: Payot.

Schleicher, August. 1865. Über die bedeutung der sprache für die naturgeschichte des menschen. Weimar: H. Böhlau.

Schleicher, August. 1873. Die Darwinsche theorie und die sprachwissenschaft. Offenes sendschreiben an herrn Ernst Häckel. Weimar: Böhlau.

Seamon, David \& Arthur Zajonc. 1998. Goethe's way of science : a phenomenology of nature. Albany, NY: State University of New York Press.

Smith, Neil. 1999. Noam Chomsky: Ideas and Ideals. New York: Cambridge University Press.

Sterelny, Kim. 2007. Dawkins vs. Gould : survival of the fittest. Thriplow; Lanham, Md.: Icon \& National Book Network.

Tomasello, Michael. 2003. Constructing a language : a usage-based theory of language acquisition. Cambridge, Mass.: Harvard Univ. Press. 



\title{
The evolution of meaning and grammar
}

\section{Chomskyan theory and the evidence from grammaticalization*}

\author{
T. Craig Christy \\ University of North Alabama
}

Central to Chomskyan language theory, often seen as a Kuhnian revolution, is the claim that universal grammar (UG) is innate and that it comprises the principles and parameters which constitute and constrain possible human language grammars. In this model, grammar is essentially a programmed fait accompli, and the causes of language change are sought principally in the reanalyses resulting from the language acquisition process.

An alternate approach, grammaticalization, would appear to be potentially at odds with this view, depending on the degree of specificity assigned to UG. In studies of grammaticalization, distinct, restricted, and therefore virtually predictable pathways of change (as opposed to random parameter settings) and evolving (as opposed to innate) grammatical categories have been identified as the linguistic/pragmatic outcomes of children's and adult speakers' use of language. In the generative perspective, language change is seen as resulting directly from the acquisition process, rather than from language usage. Evidence from grammaticalization studies makes it clear that understanding the nature of language development and change requires that actual usage, performance, be taken into account - not just competence. In assessing whether these approaches can be brought into alignment, a variety of issues are examined: unidirectionality in grammaticalization, the linguistic views of Antoine Meillet and Michel Bréal, the poverty of the stimulus argument and UG, grammaticalization and uniformitarianism, the central role of pragmatics and discourse analysis, the relationship between UG and grammatical categories, evidence from pidgin and creole studies as a challenge to the bioprogram hypothesis, acquisition of ASL as evidence of UG being innate abstract patterning, the loss of expressivity as a factor in grammaticalization, and the emergence of apparently new linguistic categories and their relation to cognition.

\footnotetext{
*This research was supported by the University of North Alabama, and by Friends of the Department of Foreign Languages.
} 


\section{Introduction}

Central to Chomskyan language theory, which some have accorded the status of a Kuhnian revolution, ${ }^{1}$ is the claim that all languages share a common underlying universal grammar, that this universal grammar is innate, and that it is comprised of a set of principles (fundamental configuring forces) and parameters (selection options for the resulting configurational transformations) which constitute and constrain possible human language grammars. In this model, grammar is essentially - and, in all events, ultimately - a programmed fait accompli, and the causes of language change are sought principally in the reanalyses characteristically carried out and observed in the course of language acquisition. Based on unique inferences about the systemic patterning informing input from adult speech, the grammar each child constructs is necessarily different from that actually underlying this input, and is, consequently, capable of generating output that would not emerge from the adult grammar.

An alternate approach, grammaticalization, so christened by Antoine Meillet $(1866-1936)^{2}$ in 1912, and the focus of intense research over the past two decades, would appear to be potentially at odds with this view (depending on the degree of specificity assigned to UG) for the simple reason that, in studies of grammaticalization, distinct pathways of change and evolving (as opposed to innate) grammatical categories have been identified as the linguistic/pragmatic outcomes of speakers' use of (as opposed to children's acquisition of) the language. Thus, on the one hand, grammaticalization studies, which have multiplied exponentially since the 1980s to become a major current in linguistic research, have yielded firm evidence of the evolution of grammatical distinctions; of grammar. In Chomskyan theory, on the other hand, universal grammar, being innate, is by definition fixed, not evolving. Whether these two approaches are seen as incompatible hinges largely on the scope assigned to 'universal grammar', on the one hand, and to 'grammar' as used to designate the systematic regularities and structures of languages, on the other. And while Chomsky's formalist approach recognizes autonomous phonological, morphosyntactic and semantic components, and privileges 'competence', the functional, usage-based orientation of grammaticalization research underscores the blurring of categorical boundaries involved in language changes, and accords priority to 'performance.' Despite these differences, which have been hotly debated in the literature, a rapprochement of these two approaches is by no means beyond reach, a position for which Newmeyer (1998), for example, has advocated: “...crucially," he says, "there is nothing that we find in grammaticalization that is incompatible

1. See, e.g., Searle 1972, Murray 1980, and Newmeyer 1980.

2. For a brief overview of Meillet's linguistic work see Christy 2005. 
with any well established principle of generative grammar" (292). ${ }^{3}$ In a similar vein, Bisang (2001) advocates for "...the serious and open-minded cooperation of different linguistic schools" if we are to achieve a better understanding of both universal grammar and the evolution of linguistic structures (218).

Does the evolutionary nature of grammaticalization challenge the revolutionary status of Chomskyan theory? The fundamental categorical nature of some grammaticalization outcomes suggests that these may not be simply selection options within universal grammar. Meillet, for instance, maintained that “...the 〈〈grammaticalization〉〉 of certain words creates new forms, introduces categories which had no linguistic expression, [and] transforms the system as a whole" (1921 [1912]: 133). ${ }^{4}$ On the other hand, the fact that the universe of paths of grammaticalization appears to be relatively restricted could be seen as suggesting that grammaticalization operates exclusively within the 'principles and parameters' of universal grammar. In exploring these questions I will also consider the complications associated with strictly segregating diachronic from synchronic data, as well as the lexical-to-functional semantic trajectory associated with grammaticalization, which can also be seen as a development from a more iconic or motivated to a more arbitrary or unmotivated state. In this regard it will also be useful to consider whether the transparency-to-opaqueness cline associated with etymological development is of a kind with the overall process of grammaticalization (often called 'semantic bleaching'); that is, with the evolution from lexeme to grammatical marker.

\subsection{Universal grammar}

Recognized as the chief exponent of linguistic nativism/rationalism in modern linguistics, Noam Chomsky (1928-) is well known for his view that all languages share a common structural basis - common foundational rules that define the organizational pathways available to languages. These common rules constitute a master template, a

3. See particularly Chapter 5, "Deconstructing Grammaticalization", in which he acknowledges contributions from both approaches while discounting claims that grammaticalization challenges generative grammar. Everett (1996) declares: "Setting aside rather wild claims from both sides ... it doesn't seem to me that there is any incompatibility at all between grammaticalization and Chomskyan theory". Von Fintel (1995: 176, note 1)considers “... whether the very phenomenon of grammaticalization presents a threat to the legitimacy of generative grammar" and concludes "It seems to me that it doesn't even though some authors do see the apparently gradual and squishy nature of grammaticalization as an embarrassment for the clear-cut lexical/functional dichotomy built into generative grammar".

4. “...la 〈〈grammaticalisation〉〉 de certain mots crée des formes neuves, introduit des catégories qui n'avaient pas d'expression linguistique, transforme l'ensemble du système" (1921: 133; translations mine:CC). 
universal grammar that channels and limits linguistic structure. The absence of specific kinds of expressions in child language acquisition - despite the fact that children have no evidence that these expressions are grammatically illicit - is often cited as corroborating the existence of an underlying, universal set of constraints. Thus the kinds of errors children do make, as they acquire language, appear to be underwritten by the rules of grammar as manifested in one or another language, though not in their own. Expressions that would never occur in any language, at least not in any known or studied language, are simply not observed. A parallel might be drawn here with phonetics: certain sounds - for example whistles, or labiodentals produced by bringing the lower front teeth into contact with the upper lip - simply do not figure in the inventory of known language sounds, though both are readily produced. Coupled with the poverty of the stimulus argument - that is, the claim that children acquire language from a comparatively impoverished inventory of examples - the fact that children's overall language performance falls consistently within the limitations of rules known to inform the structures of all languages provides strong evidence of universal grammar, of the language faculty being in some sense hard-wired in the brain. ${ }^{5}$ Chomsky's focus, in short, is not so much on the observable data of language as on the implications the data portend for an understanding of the basic functioning of the mind. Chomsky challenged prevailing linguistic theory with questions it was at pains to answer: How do children acquire language in such a remarkably brief period of time? Why do all languages, despite surface variations, show an underlying uniformity of structure and organization? How does child language acquisition relate to language change? In doing so he expanded the purview of linguistics beyond what he saw as essentially a focus on the classification and analysis of surface phenomena, and in effect set in motion in linguistic science what Thomas Kuhn (1922-1996), in his well-known Structure of Scientific Revolutions (1962), defines as a revolution. However, Chomsky himself would sooner see his contribution as being, instead, pre-Galilean; as at best laying the groundwork for a more comprehensive future theory of language that would perhaps incorporate advances from biology, cognitive science and other areas. Chomsky's approach set in motion a 'paradigm shift' in which the study of language facts and language behavior ceased to be an end in itself, and became, instead, the means for inferring the otherwise not directly observable workings of the mind. In aspiring, for example, to elucidate the deep-rooted differences at large in sentences which, on the surface, seemed syntactically identical, or whose ambiguity suggested multiple resolutions of what appeared to be a

5. As Chomsky asserts, "Knowledge of the properties of empty categories is part of the framework that the human mind brings to the problem of language acquisition. The elements of this framework are not learned and could not be learned by the child in the time available and on the evidence available..." (1988: 91). 
single simple structure, Chomsky brought a formalist and mentalist perspective to what had been a predominantly objectivist method of analysis.

\subsection{Causes of language change}

The special importance of language acquisition in Chomskyan theory extends beyond the evidence it appears to offer of a universal, biologically determined language faculty. Central to the theory is the claim that language change is primarily to be accounted for as the result of language learners' reanalyses, that it is rooted in inter-generational differences. In acquiring language, each child in effect, albeit unconsciously, constructs a grammar that can generate the observed forms, but which is in fact different from the grammar behind the parents' speech. Overtly, the speech of parents and children appears uniform, though this apparent uniform output is in fact something of a mirage, to the extent that it is actually the product of different underlying grammars. Over time, these underlying differences in the child's grammar will give rise to linguistic forms that would never have been generated by the parent's grammar. In this way language, both gradually and imperceptibly, undergoes changes, and these changes are regular because they are the output either of rules, or of rule reorderings. The grammar of adults, by contrast, is seen as essentially fixed, invariant in any significant way. That is, the overall architecture of linguistic structures, fixed during the acquisition process, remains essentially intact, impacted only by superficial changes. Once the language acquisition process has run its course, the resulting rule architecture is for all practical purposes permanent, immutable, and subject only to rule additions, which, as regards their impact on the grammar, are merely supplementary rather than transformative in nature.

\subsection{Grammaticalization and language change}

This rather rigid, and limiting, account of language change runs counter to the findings of current research in grammaticalization. Although in some ways a moving target, with linguists differing at times markedly in their understanding of its reach, fundamentally grammaticalization is the process whereby lexical terms, through frequent recurrence in specific contextual frames, and under the influence of discoursepragmatic cues, take on routinized, grammatical meanings. This process is continuous, with grammaticalized forms themselves in time becoming potential candidates for further grammaticalization. It is also generally agreed that this process is unidirectional in that it almost always shows a movement from a less grammatical to a more grammatical state. ${ }^{6}$ The definition of grammaticalization as "....an evolution whereby

6. The claim for unidirectionality in grammaticalization has been the topic of heated debate. For an overview and indication of potential counterexamples see Traugott 2001. 
linguistic units lose in semantic complexity, pragmatic significance, syntactic freedom, and phonetic substance, respectively" (Heine \& Reh 1984: 15) underscores the manifold nature of this process which, in effect, steers and suffuses language development on all levels of analysis. The net impact of grammaticalization, a movement from a more motivated to a less motivated state, from more independent to less independent, ${ }^{7}$ from more concrete to more relational meaning, is an increase in form at the expense of content, an evolution that can be seen as a shift from a state of greater iconicity or relative transparency to a state of increased arbitrariness and etymological opacity. The following examples illustrate the grammaticalization process: ${ }^{8}$

(1) The French pas, as in Il ne va (pas) [He doesn't go (a step)] started as a way of reinforcing negated motion verbs, but was then extended to non motion verbs and understood as part and parcel of negation: Il ne sait pas [He doesn't know].

(2) The motion verb going to in I am going [in order] to see the castle becomes a marker of futurity, and is then extended to such sentences as I am going to like Bill.

In both cases reanalysis, analogy and reinterpretation propel the development of grammatical meaning out of lexical meaning. The fact that grammar appears to be in a constant state of emerging, ${ }^{9}$ guided by conversational implicatures and associated inferences, presents a challenge to the Chomskyan position which considers grammatical - more specifically syntactic- categories innate, with grammar being effectively shielded from language usage. Grammaticalization theory seeks the locus of change, and thereby the genesis of grammar, in the usage of all speakers, and does not disproportionately value those changes that are generated by speakers whose overall grammatical structure has not yet been finalized. The issue of whether or when the grammatical blueprint of a language is fixed or 'finalized' is itself in fact crucial.

It is a commonplace of linguistics since at least the nineteenth century that there is no essential difference separating the processes of language origin and development from those of change. This is the uniformitarian axiom. ${ }^{10}$ If we take grammaticalization

7. Hopper \& Traugott 1993: 62.

8. These examples are excerpted from Hopper \& Traugott 1993: 58-61.

9. On emergence cf. Hopper in his article "Emergent Grammar": "The notion of emergence is a pregnant one. It is not intended to be a standard sense of origins or genealogy, not a historical question of 'how' the grammar came to be the way it 'is', but instead it takes the adjective emergent seriously as a continual movement towards structure, a postponement or 'deferral' of structure, a view of structure as always provisional, always negotiable, and in fact as epiphenomenal, that is, at least as much an effect as a cause" (1987: 142).

10. See Christy 1983. Cf. Bréal's statement in his 1883 essay “The Intellectual Laws of Language: a Sketch in Semantics": “...the same laws whose operation we can observe in accessible periods operated also in the most distant past” (Wolf 1991: 137), and,in his 1887 review of 
to be the quintessential process for linguistic development and change throughout the history of language, this could be seen as ultimately and paradoxically implying a nonuniformitarian "...stage of language in which there were only lexical items", a conclusion which Traugott (2001), for example, opposes:

...claiming that grammatical items originate in lexical ones does NOT entail hypothesizing a language state in which everything is lexical. This would be true only on a creationist view of language development, the Chomskyan position that the language capacity emerged suddenly, full-fledged. I submit that the creationist view is in error, not unidirectionality (5-6).

The innovations emerging from the grammar underlying the usage of language learners as well as those emerging from the grammar underlying the usage of adult speakers have, in consonance with this axiom, at all times and in all languages contributed to the emergence and restructurings of grammar. Thus to localize language change exclusively in the language acquisition process is a distortion. Moreover, just as the generativists emphasize that divergent grammars underlie the speech of adults and children, we can also say that no two individuals of any age share an identical grammar. Given this built-in potential for variation, innovations should be just as likely to emerge in adult speech as in children's speech. In this sense it is absurd to speak of 'finalized' grammatical structure constraining the innovation potential of adult speakers. To insist on this is the equivalent of imposing on adult language functioning the equivalent of a critical period hypothesis. The evidence of grammaticalization suggests, instead, that language acquisition, in the broadest sense, is an ongoing, openended process in which the ratios of thought and linguistic structure are in fact ever in flux. The elements of language, precisely because they function in combinations, not in isolation, are constantly subject to reinterpretation and redeployment to signal new gradations of meaning and aspectual nuance.

The French linguist Michel Bréal (1832-1915) speaks in this regard of words 'contaminating' each other (Wolf 1991: 137), of yielding their autonomy to expedite the expression of thought, observing that "...meaning subordinates the matter of language to itself"; "...the operation of thought...separates itself from the form to which it is linked...[and] works to change that form... Mens agitat molem [Mind moves matter]"

Arsène Darmesteter's La vie des mots, where he observed that "Whoever takes note of how meanings change will find himself in the process of discovering how they developed in the first place" (Wolf 1991: 174). Equally explicit is this statement in his 1866 "On the Form and Function of Words": "It is therefore not just at the origin of races that the creation of languages is to be placed: we create them at every moment; for every change which affects them is of our own doing. ...even the most insignificant of grammatical changes find their principal cause in human thought" (Wolf 1991: 61). 
(Wolf 1991: 171, note 30;173). Once a lexical item is perceived in such a fashion that its original content no longer enters consciousness, it is, as it were, free to become the vessel of a re-imagined relational matrix. "11 "It is the mind," Bréal says, "which animates the verb by endowing it with transitive force, links and subordinates prepositions, and strips words of their proper meaning in order to redeploy them as the limbs and joints of speech" (Wolf 1991: 91) [italics added].

This statement of grammaticalization, avant la lettre, would today be expressed as lexemes losing their autonomous status to become grammatical markers. Importantly, Bréal realizes that grammatical categories are neither immutable nor innate, but rather the current exponents of a process which is ongoing and which benefits from losing track of its origins:

The parts of speech given in grammars - nouns, verbs, pronouns, adverbs, prepositions, conjunctions - have not always existed. They are the result of long evolution, whose most recent consequences are still coming to light (Wolf 1991: 170).

In Bréal's view, sound change, by efficiently effacing word origins, is actually a boon to language evolution: it "free[s] words from the shackles of tradition..." (Wolf 1991: 168), thus rendering them sign vehicles much more able to accommodate abstract thought: "Overawareness of etymology is often harmful to the expression of thought, for it may disturb that thought with all kinds of false reflexions" (Wolf 1991: 168). ${ }^{12}$

The fact that what are acknowledged as grammatical categories evolve over time - and in different ways and to varying degrees across languages - makes it clear that the elements of universal grammar, the operations of the human faculty of reason, ${ }^{13}$ must be principles of intellection of a far more fundamental nature than those represented by traditional grammatical categories suggest. While this may seem at first a trivial observation, it calls due attention to the very real issue of delimitation involved in comparing and contrasting whether and to what extent Chomsky's approach to language is at variance with the claims and findings of grammaticalization. One is

11. Bréal uses the term specialization, along with contamination to refer to the product and process involved in the evolution of grammatical relations (See Wolf 1991: 143). In current usage, grammaticalization refers to both the process and its outcome.

12. See Christy 2000 for further discussion of the importance, to linguistic devleopment, of the etymon lapsing from awareness.

13. In his scathing critique of Chomsky, "The History of Linguistics and Professor Chomsky" (1970: reprinted in Aarsleff 1982), Aarsleff underscores the need to understand universal grammar as a concept implicit in empiricist (Locke, Condillac)as well as in rationalist (Descartes, Port-Royal grammaire générale)conceptualizations of language: "Both modes in the study of language made the same basic assumptions regarding reason and the uniformity of human nature, and both were directed toward the same subject matter and aim; only their methods of approach were different" (1982: 111). 
reminded of the nature-nurture debates that once dominated, and detained, debates in the biological and social sciences. Whether these two approaches are adjudged antithetical and incompatible hinges entirely on the degree of specificity assigned to the innate versus the experiential component. The importance of evidence from grammaticalization research to generative grammar might in fact be usefully likened to the proclaimed 'paradigm shift' in biology, where the tree-of-life conceptualization of life, premised exclusively on vertical inheritance from progenitors, has had to make room for the evidence of horizontal gene transfer. ${ }^{14}$ Crucial in both cases is the sustained interaction of synchronic with diachronic elements.

On the one hand we could maintain that there is no ultimate incompatibility between the Chomskyan and grammaticalization positions, since the necessarily highly abstract nature of universal grammar would not exclude subsequent grammatical developments. On the other hand, just because new grammaticalizations emerge from the common universal grammatical core does not require that they are already present in this core. Then again, it is by no means certain that we can declare a category absent just because it has no formal expression. Bréal was explicit on this point, particularly in his 1868 essay "The Latent Concepts of Language" in which, as if in anticipated commentary on the relative reach of explanations rooted in universal grammar versus grammaticalization, he declares that we must not

...deny a priori to other races the existence of any notion not formally marked in their language. The mind penetrates the matter of language and fills in its cracks and crevices. By refusing to acknowledge in a people any concepts except those which are formally represented, we lay ourselves open to the possibility of neglecting what is most lively and original in their thought. Since languages do not all express the same things, it is also possible for them to differ in what they leave unexpressed. It is not enough, in order to grasp the structure of a language, to analyze its grammar and to reduce its words to their etymological meanings. We must enter into a people's way of thinking and feeling. It is solely on this condition that comparative philology can fulfill its ultimate goal, which is to help us to discover the workings of human reason, and to reveal the historical laws of its development. (Wolf 1991: 92) ${ }^{15}$

We might say that language merely suggests, while the mind interprets. The circumstances of usage, today the subject matter of pragmatics and discourse analysis, animate the manifest message, imbuing it with the emotional and intellectual content to which the elements of language can only point. Accordingly, all manner of contextual

14. Cf. Gogarten 2000: "Once thought to be a static, unchanging record of the history of life, the genome is actually plastic and ever evolving."

15. On Bréal's latent concepts see Christy 2003. On the role of absence and unexpressed elements in language see Christy 2007. 
content, including what is not expressed linguistically, must be factored in if we are to have a chance at "enter[ing] into a people's way of thinking and feeling". This same point is made again in Bréal's 1887 review of Arsène Darmesteter's (1846-1888) La vie des mots (1887):

A language derives its character as much from what it leaves understood as it does from what it makes explicit. A good balance here makes a good language, just as the balance of solid and void makes good architecture (Wolf 1991: 172).

Bréal's claim that "We must enter into a people's way of thinking and feeling" calls to mind his discussion of Wilhelm von Humboldt's (1767-1835) concept of the 'inner form' of language, ${ }^{16}$ which Bréal understands to refer to that component, unique to each and every language, which is non-innate, subject to change over time, and which is and functions as the "memory of the maternal language [which] ...imposes itself on the parts of the language which have remained free-floating, and guides them into preestablished frameworks" (Wolf 1991: 170-171). We might take this somewhat obscure interpretation of Humboldt's obscure concept as meaning that the transformations any given language undergoes betoken cumulative pressures and constraints associated with the history of that language. In this view, change in language reflects first and foremost the influence of internal forces specific to a given language, and only indirectly, if at all, universal grammar. It is easy to see how the question of the compatibility, or incompatibility, of universal grammar and grammaticalization might ultimately devolve into an academic quibble, predicated on definitions and issues of specificity. ${ }^{17}$ Thus Meillet's claim that grammaticalization “... creates new forms [and] introduces categories which had no linguistic expression [and] transforms the system as a whole (1921 [1912]: 133) could be understood to mean that new linguistic categories evolve for the very first time in language, or that they evolve for the first time in a given language. Moreover, these categories, even though hitherto unexpressed in language, may have always already been latent components of a universal innate intellectual endowment, 'categories in waiting', as it were, or may be entirely novel outcomes of complex linguistic and pragmatic forces interacting to package and deliver meaning. The net impact of Meillet's observation, and of grammaticalization, is a recalibration of the system of language, a shift towards greater efficiency ${ }^{18}$ in the delivery of meaning, more

16. On Humboldt's concept of inner language form see Christy 1985.

17. See 1.4 below regarding attempts to square non-random pathways of grammaticalization with requirements of principles and parameters theory.

18. Van Gelderen (2004) sees grammars that are more grammaticalized as being simultaneously more economical. 
specifically a shift in the ratio of meaning delivered grammatically versus meaning delivered lexically, a ratio that might conceivably be used as a criterion in language typology. ${ }^{19}$

After discussing grammaticalization in relation to the principles and parameters approach of universal grammar, Hopper and Traugott, in their pioneering work Grammaticalization (1993), advocate a compromise position in which universals are themselves understood as more abstract potentialities subject to modification:

An alternative approach, more akin to the objectives of researchers in grammaticalization, is to regard the universal component as one which does not 'completely determine the nature of linguistic structure', but rather as one which characterizes broader properties of the human constitution and can be modified by outside stimuli (Jackendoff 1983) and by the functional purposes to which language is put (Givón 1989). We will adopt this more flexible view of universals. (35)

Bréal's persuasive pronouncements on the unexpressed in language certainly leave room for this latter interpretation, which is otherwise seemingly buttressed by the fact that grammaticalization is somewhat predictable precisely because it appears to draw on a limited inventory of cognitive pathways. A few examples will help drive this point home.

\subsection{Universal grammar and pathways of grammaticalization}

One of the more profound findings of grammaticalization research has been that, cross-linguistically, the same pairings of lexical items with grammatical forms recur

19. Cf. Hopper and Traugott's formulation: "It is often difficult to establish firm boundaries between the categories represented on clines [of grammaticalization], and indeed the study of grammaticalization has emerged in part out of a recognition of the general fluidity of socalled categories" (1993: 7). In his 1869 review of Bréal's “Les Idées Latentes du Langage” " "The Latent Ideas of Language"] of 1868, Steinthal pondered whether a typology of languages might be established based on what languages leave unexpressed, but acknowledged the challenges that constructing such a typology would entail: "Wie sollen wir die Denkoperationen des Polynesiers erforschen, wenn sie von den unsrigen abweichen und doch nicht ausgedrückt sind?" ["How are we to investigate the thought processes of the Polynesian if they diverge from our own yet are not expressed?”](284; cf. Christy 2002: 4). Since the products of grammaticalization are still expressed forms, albeit with a higher degree of understood content, they might sooner provide a basis for establishing a linguistic typology which would track the ratio of meaning delivered grammatically versus meaning delivered lexically. 
over and again. For example, be going to figures frequently in future constructions (English We're going to eat; French Nous allons manger), as do want/desire (English I will go; Chinese Wo yao qu [yao = want $]$ ). The fact that fulfilling a purpose is, by default, activity in the future gives rise to the inference that $g o$ is a signal of future time, as does the movement from place to place implicit in the meaning of $g o .^{20}$ Likewise with want/desire (Old English willan), where the inference of futurity arises from the fact that what is desired is clearly absent in the present. In their World Lexicon of Grammaticalization (2002), a superb resource for grammaticalization research, Heine and Kuteva synthesize an enormous amount of data from a wide variety of languages, the net impact of which is to document the astonishing uniformity of grammaticalization pathways. This element of uniformity, of virtual predictability of pathways of change runs counter to the generativist assumption that parameter setting is entirely random. ${ }^{21}$ As Roberts and Roussou (2003) point out,

The claim that grammaticalization follows a pathway of language change, that is, expresses a tendency, poses a challenge to the standard Principles and Parameters approach to syntactic change...the principle theoretical question that arises is whether language change is a deterministic process...whether we can identify clear pathways of change that make languages converge onto certain parametric settings (3).

To reconcile the undeniable evidence of non-random pathways of grammaticalization with the theoretical requirement that parameter setting be a random process, that no pathways or 'drift' be identifiable in diachronic change, they observe that by far the majority of parametric changes, but not all, exhibit a reduction in markedness, though this analysis seems more an attempt to defend principles and parameters at all costs than an acceptance of compelling evidence from grammaticalization studies

20. While Heine and Kuteva (2002: 160-164) differentiate among allative go to,expressing motion toward a place,future go to, and purpose go to, all three appear to apply in a sentence such as We're going to eat. The future sense of the going to/gonna construction is also referred to as the planned or intentional future (Cf. Andersen 2001: 34).

21. As Roberts and Roussou put it, "In the context of the theory of principles and parameters (whether in its minimalist formulation or otherwise), we can view parameters as creating a space of possible variation within which grammatical systems are distributed. The natural view of synchronic variation among grammatical systems is to think of them as randomly scattered in this space; and the natural view of diachronic change is to see it as a natural 'walk' around this space. The prediction is then that there are no pathways or 'drift' in diachronic change ..." (2003: 3-4). 
(2003: 4; Klausenburger 2008: 175-176). ${ }^{22}$ The following examples from the World Lexicon convey a sense of the uniform cognitive pathways under discussion: ${ }^{23}$

FRONT > BEFORE: Chinese qian 'front' > qian san nian 'the last three years' INSTRUMENT > MANNER: German mit 'with' as in mit dem Schirm 'with the umbrella' > mit as in mit Absicht 'with purpose = on purpose. Cf. Sie schlug ihn mit dem Schirm 'She hit him with her umbrella'/Sie schlug ihn mit Absicht 'She hit him on purpose'.

GIVE > DATIVE: Chinese gei 'give' > gei ta 'to him/her'

KEEP > CONTINUOUS/DURATIVE MARKER: English keep > keep signaling

COME TO > CHANGE OF STATE: English come > come true, come undone

Abstracting common cognitive denominators from a mass of widely divergent languages whose grammatical categories, at least from the perspective of formal analysis, intersect and overlap in irregular ways, is no easy task: indeed, the ultimate nature of the underlying conceptual processes is frequently less than clear. Accordingly, we find, throughout the Lexicon, improvisational statements of the following sort, which serve simultaneously to illustrate just what is understood by 'pathways of grammaticalization': ${ }^{24}$

'This appears to be (an instance of) a (more general) process whereby/according to which'

- “...verbs are grammaticalized to auxiliaries denoting tense or aspect functions" 311)

- “...lower numerals are pressed into service to function as number markers, typically on nouns" (303)

22. Using “...a theory of markedness which has the effect of creating 'basins of attraction'(in the sense of complexity theory)within the parameter space ....we retain the explanatory force of the notion of parametric change, but make it compatible with the evidence that changes tend naturally to go in certain directions but not others - grammaticalization being a prime example. More generally, we see this as a way of reconciling the tension between descriptive and explanatory adequacy in diachronic syntax..." (Roberts and Roussou 2003: 4). As Klausenburger concludes, "Ockhamite reasoning selects the invisible hand approach over the markedness account, as this extra layer leads to a less parsimonious solution in Roberts and Roussou 2003” (2008:182).

23. These examples, with selected evidence from more widespread languages, are excerpted from Heine \& Kuteva 2002.

24. The importance of the 'pathways' concept to research in grammaticalization is underscored by its prominence in the literature. Cf., e.g., Fischer et al. 2000, Brinton 2009, Hopper and Traugott 1993: 30, Bybee et al. 1994: 253 ff., Givón 2000: 209 ff., Heine and Kuteva 2007: 53 ff., Lehmann 1985, Diessel 1999: 115-155, Bisang 1998: 19, Yap and Matthews 2008: 309 ff., Givón 2009: 97-120, Croft 2000: 156-165, and Heine, Claudi, and Hünnemeyer 1991: 171 ff. 
- “...certain body parts, on account of their relative location, are used as structural templates to express deictic location" (214)

- “...generic nouns like 'person' and 'thing', either on their own or as part of some noun phrase, are grammaticalized to pronouns” (209)

- "...grammatical markers having a spatial base serve as conceptual templates for comparative markers" (201)

- “...locative markers are grammaticalized to markers of cause" (200)

- “...process verbs are grammaticalized to auxiliaries denoting tense or aspect functions" (185)

- “...spatial concepts, including motion in space, are used as structural templates to express temporal concepts" (183)

- "...grammatical aspect functions are conceptualized and expressed in terms of locative concepts" (179)

- “...spatial concepts are used to also express causal relations" (172)

- "...process verbs, on account of some salient semantic property, give rise to grammatical markers expressing case relations" (165)

- “...verbs denoting location or motion serve as structural templates to express relational adpositional or subordinating concepts” (79)

At a minimum this uniformity makes explicit that grammars are constructed in ways that reveal the workings of fundamental common cognitive strategies, but whether we are dealing here with reflections of the delimiting principles and parameters underlying universal grammar, or simply with artifacts of a combinatorial regime which generates a finite number of possible sequencing configurations, remains beyond demonstration. On the other hand the ultimate status of cognitive and structural uniformity is, at least as regards differences between the perspectives of universal grammar and grammaticalization, perhaps less important than determining whether language change is to be traced predominantly to the language acquisition process.

\subsection{Evidence from Pidgins, Creoles, and ASL}

Pidgin and creole languages have often been viewed as optimal crucibles for gleaning a glimpse into the evolution of language. As macaronic amalgams bereft of grammar, pidgins, so the argument goes, should, in the process of being acquired by children and morphing into creoles, reveal exclusively the unfolding of the unadulterated innate language program. While the concept is not without appeal, it is nevertheless fraught with complications. A possible test of the hypothesis - one thinks, for instance, of Bickerton and Givón's once proposed desert-island experiment (Banks 2008) — entails complications ranging from 'forbidden-experiment' ethical concerns to the dangers of underestimating elusive grammatical undercurrents that might in fact be bubbling up from one or more of the languages here in contact. In the final analysis, what appears clear is that, along with young children, older children and adults also contribute to the 
innovations which spawn grammaticalizations. As Hopper \& Traugott point out, “... the study of creoles confirms the conclusion that children and adults do not contribute to change in fundamentally different ways" (1993: 209), ${ }^{25}$ though Slobin (1994: 129$130),{ }^{26}$ looking at language acquisition in general, sees the contributions of adults and children as resulting from different processes:

I propose ...that children come to discover pragmatic extensions of grammatical forms, but they do not innovate them; rather, these extensions are innovated diachronically by older speakers, and children acquire them through a prolonged developmental process of conversational inference (Slobin, 1994: 129-130).

Thus it is a gross oversimplification to speak of grammarless pidgins of adults and grammaticalized creoles of their children. At the most, we are dealing with a difference not of kind, but of degree.

This conclusion crucially challenges the nativist position that the grammar of creoles, which seemingly emerges ex nihilo (with pidgins seen as lacking a formal grammatical system), is in fact a reflection of the innate language program, and therefore a certain confirmation of Chomskyan theory, a view reflected in Bickerton's (1988) bioprogram hypothesis. Creole grammar, like the output of grammaticalization as documented cross-linguistically, no doubt does reflect certain innate cognitive limitations and dispositions, but these are not limited to the language acquisition process. From the perspective of grammaticalization, the evidence from pidgins and creoles thus appears to provide a corrective to the Chomskyan position on language change and universal grammar, as well as a unique window on the grammaticalization process as it operates on the input from a variety of languages in contact. Newmeyer (1998), however, does not see this evidence as undermining the generativist position, but instead as supporting the claim for universal grammar: “...while adults," he says, "may modify pidgins into something more creole-like, it is only children who literally have the ability to create creoles, that is to create a new grammatical system" (73). Once again, if viewed in a relative, rather than absolute, perspective, the issue of whether common pathways of grammaticalization betoken constraining parameters of universal grammar, or rather simply common cognitive strategies that emerge as consequences of certain semantic nuclei co-occurring in certain combinations, is much less important than the reality that these common pathways do in fact exist. The fact that they have been detected in both the homogenous context of development in a given language as well as in the heterogeneous context of languages in contact does strongly suggest the influence of common cognitive constraints, whether or not these are seen as innate imprints.

25. In this regard Hopper \& Traugott also refer to Bybee \& Slobin 1982.

26. Cited in Comajoan and Saldanya (2005: 45). 
The operation of common cognitive as well as neurologically based constraints is furthermore indicated by evidence from child acquisition of American Sign Language (ASL), in which yet a third input stream is in play, namely 'language on the hand'. In her article "How the Brain Begets Language", Petitto (2005) finds that “... innate abstract patterning in the mind emerges, whether through speech or signing..., in the form of similar syllabic structures (92), and that sensitivity to patterning, "...in particular, the rhythmic patterns that bind syllables ...into babbles, and then into words and sentences" (93), is localized in Wernicke's area of the brain, the implication being that this brain tissue is specialized not just for the processing of speaking and hearing, but, more abstractly, for "....aspects of the patterning of natural language" (96). In other words, for "...both language on the hands and language on the tongue ... there exists tissue in the human brain dedicated to a function of human language structure independent of speech or sound" (97). Petitto's finding that language appears to be "...written into neural tissue" (101), which she sees as corroborating the universal principles proposed by Chomsky, meshes equally well with the idea of fundamental cognitive constraints on language evolution, which leaves aside the polarized issue of which speakers initiate language change and when. While fundamental, universal cognitive principles figure in both universal grammar and grammaticalization, there remain differences in regard to the degree of specificity of these principles and their domain of operation. As grammaticalization research has documented, common grammaticalization pathways are always subject to erupting, in the speech of speakers of all ages, given the appropriate discourse-pragmatic contextualization. As Hopper and Traugott claim:

The perspective of grammaticalization challenges virtually all of these claims [of changes being the result of new parameter settings]. Fundamentally, the approach from grammaticalization argues that the grammaticalization of lexical items or constructions is enabled by pragmatic factors; indeed, much of grammaticalization in its early stages is the conventionalizing in certain local contexts of conversational inferences as morphosyntactic reanalysis occurs. (1993: 207)

Thus, contrary to the Chomskyan perspective, which privileges child language acquisition as being the sole source of rule reordering, simplification or loss, while acknowledging only the possibility of rule addition in post-acquisition speech, it is clear that, under conducive contextual conditions, grammaticalization can and does emerge, with no associated restrictions as to speaker age. For that matter, since no two speakers of any language have an identical understanding of that language, it follows that all communication is ultimately inference based. And since inferencing is always in play, the potential for grammaticalization to take place is always present. 
Meillet suggested that the ground for grammaticalization was particularly fertile in cases where words and phrases were operating under diminished expressivity owing to their frequent occurrence in fixed contexts. ${ }^{27}$ In this sense, the net impact of grammaticalization can be seen as a mechanism which cyclically replaces one marker of a specific category with another, as illustrated by, for instance, the replacement of inflected with periphrastic future forms in the development from Latin to French, with these periphrastic future forms themselves subsequently transitioning back into inflected forms: Latin amabo > amare habeo > French aimerai (Hopper \& Traugott 1993: 22). This is not to suggest that speakers were in any way aware of diminished expressivity, but rather that, once spawned in the interplay of context and inference, equivalent new, and therefore more expressive, forms would come to be favored. Grammaticalization thus makes available alternate means of signaling specific semantic content, means which, since novel, are also more expressive, and therefore come to be used more often, become routinized, lose expressivity, and thus themselves become potential input for subsequent grammaticalizations.

However, while grammaticalization is an open-ended process in which grammaticalized forms themselves are subject to further grammaticalization, it is not limited to revitalizing existent categories. To repeat Meillet's prolific insight, grammaticalization "... creates new forms [and] introduces categories which had no linguistic expression” (1921 [1912]: 133). Of course absence of linguistic expression does not necessarily equate with an absence in thought, as Bréal's position on latent ideas makes clear. Thus it could be debated whether evolution in grammar reflects evolution in thought, or rather merely the unfolding of cognitive constraints and potentialities.

\subsection{Grammaticalization in diachronic and synchronic perspective}

One thing that grammaticalization studies make abundantly clear is that it is counterproductive to segregate synchronic from diachronic analysis. The interpenetration of the two perspectives is indispensable to charting the pathways along which change takes place, and revitalized, or even novel, grammatical categories evolve. The key word here is perspective: whether the diachronic or synchronic perspective is adopted, the fact remains that the subject of analysis is a single ongoing process of reanalysis and reinterpretation in which the substance of language takes a back seat to the substance of thought. Hopper and Traugott's assessment underscores the interplay of

27. "If then a grouping of words becomes frequent, if it is often repeated, it ceases to be expressive and is more and more reproduced automatically by speakers" (1921 [1912]:135-136). 
these two perspectives (note in particular such qualifying terms as "more synchronic" and "primarily"):

From this [diachronic] perspective, grammaticalization is usually thought of as that subset of linguistic changes through which a lexical item in certain uses becomes a grammatical item, or through which a grammatical item becomes more grammatical. The other perspective is more synchronic, seeing grammaticalization as primarily a syntactic, discourse pragmatic phenomenon, to be studied from the point of view of fluid patterns of language use. (1993: 2)

Seen broadly as a source of ongoing reanalyses and recalibrations of the material of language, grammaticalization is so fundamental, so pervasive, that it is often difficult to decide just what can and cannot be ascribed to it. Consistent with his view of grammaticalization as being related to a loss of expressivity in language, Meillet, for instance, also associated this process with word order phenomena. In Latin, he observed, word order could be used expressively to emphasize specific sentence elements since explicit grammatical endings conveyed syntactic relations. This contrasts sharply with, say, modern English or French, where syntactic relations are conveyed by word order itself. Grammatical word order is thus yet another manifestation of the grammaticalization process, of the creation of grammatical tools:

The phenomenon is of the same order as the 'grammaticalization' of this or that word; in place of having a word, used in a group of others and taking on the character of a 'morpheme' through routinization, we have here a manner of grouping words. And here we truly have an instance of the creation of new grammatical tools, not just transformation (1921[1912]: 148). ${ }^{28}$

It could even be maintained that this particular type of grammaticalization, where position alone now conveys the meaning previously attached to linguistic substance (word endings), in fact represents the extreme case of this process in which content is ever yielding to form. In this case the 'cline of grammaticality' laid out by Hopper and Traugott as "content item > grammatical word > clitic > inflectional affix" (1993: 7) might be revised to 'content item $>$ grammatical word $>$ clitic $>$ inflectional affix $>\emptyset$ '.

\subsection{Conclusions}

Though he does not use the term grammaticalization per se, the description of the language 'machine' Langacker gives in his 1977 article "Syntactic Reanalysis" aligns closely with the central features of the grammaticalization process, and is particularly apt as a characterization of the overarching nature and impact of this process:

28. Expressive inversions in languages with grammatical word order are essentially reserved for stilted or theatrical registers: for example, To the market we shall go. 
It would not be entirely inappropriate to regard [each] language...in [its] diachronic aspect as [a] gigantic expression-compacting machine ... requir[ing]... as input a continuous flow of creatively produced expressions formed by lexical innovation,... lexically and grammatically regular periphrasis, and...the figurative use of lexical or periphrastic locutions. The machine does whatever it can to wear down the expressions fed into it. It fades metaphors by standardizing them and using them over and over again...[,] attacks expressions of all kinds by phonetic erosion...[,] bleaches lexical items of most of their semantic content...[,] and forces them into service as grammatical markers. It chips away at the boundaries between elements and crushes them together into smaller units. The machine has a voracious appetite. (106-107; cited by Campbell \& Janda 2000: 3 ; italics mine)

Morphosyntactic change, idiomatization, cliticization, lexicalization, even etymology writ large can in effect all be subsumed under grammaticalization: "It is a macro-level phenomenon which cannot be reduced to the properties of the corresponding microlevel phenomena" (Haspelmath 2004: 26; cited in Brinton \& Traugott 2005: 22).

Tracing, diachronically, the etymology of a word, noting gradual shifts in its meaning over time is, in essence, analogous to tracing, synchronically, pathways of grammaticalization that are dependent likewise on gradations of meaning, in this case multiple meanings associated with context-driven ambiguity. In the case of going to cited above, for example, the two interpretations - motion towards or future action are co-present and the "bridging context" (Brinton \& Traugott 2005: 26) powering the grammaticalization is evident. ${ }^{29}$ As Brinton \& Traugott emphasize, "An ambiguous bridging context, in which both the old and the new meaning can occur, is a prerequisite for grammaticalization" (2005: 109). ${ }^{30}$ With gonna (< going to), in addition to the associated sound change and boundary loss, the resulting new sense of 'planned future' - as opposed to 'future tense' - once again underscores the ability of grammaticalization to not only revitalize existing categories, but to create new ones. ${ }^{31}$

Where does this leave us in assessing whether the categories and meanings spawned in the grammaticalization process support or undermine Chomskyan linguistic theory, which privileges both universal grammar and the language acquisition process? Meillet's early claim that grammaticalization “...creates new forms, [and]

29. “'Gradualness' is thus a primarily diachronic term characterizing changes from one state to another over time. It should be contrasted with 'gradience,'which is a synchronic term characterizing the continuum between one linguistic category and another" (Brinton \& Traugott 2005: 27).

30. Consider He is going to work (ambiguous) vs. He is going there to work (unambiguous). Similarly, while He must be here could signal either obligation or surmisal, He must be here by eight is unambiguous.

31. That be going to takes on the meaning of "...planned future....is not surprising considering its origins in a purposive construction” (Brinton \& Traugott 2005: 30). 
introduces categories which had no linguistic expression..." (1921 [1912]: 133) has been robustly substantiated by decades of research. But do these categories, more often fluid than fixed, in any way map onto cognitive categories? Are the remarkably uniform pathways of grammaticalization a reflection of underlying principles of universal grammar? Are linguistic categories then epiphenomenal, or are they, instead, emergent? Clearly there are certain biologically rooted constraints on neural activity and operations, but just how specific are these constraints and how strictly do they shape and delimit linguistic processes? Does the complex, non-linear nature of language evolution not tip the scales in favor of emergent features, of new cognitive categories? All these are questions which defy certain or easy answers. That being said, and leaving aside hairsplitting over theoretical and ideological tenets and terminology, the Chomskyan and grammaticalization perspectives, as regards the extent to which principles of universal grammar and pathways of grammaticalization are potentially in alignment, are far from being diametrically opposed. Nevertheless, actual language usage, critical to grammaticalization - to the evolution of grammar - remains peripheral in Chomskyan theory, which privileges innate grammar.

On the issue of language change, therefore, there is significant divergence. There is no doubt that language usage is grossly undervalued in Chomskyan theory. Furthermore, grammaticalization research has made it absolutely clear that speakers of all ages are involved in the negotiation of meaning and the resultant evolution of linguistic forms. Language change cannot, therefore, be accounted for exclusively as an artifact of the language acquisition process, a conclusion further buttressed by research of pidgin and creole languages. Current and future research into the evolution of grammar will no doubt contribute to the forging of a middle ground between these two positions. As we await that day, and monitor the mechanics of the 'expression-compacting machine', of grammaticalization, we can ponder, with Bréal, Vergil's sage dictum: Mens agitat molem.

\section{References}

Aarsleff, Hans. 1970. “The History of Linguistics and Professor Chomsky”. Language: Journal of the Linguistic Society of America 46: 3. 570-585.

Aarsleff, Hans. 1982. From Locke to Saussure : essays on the study of language and intellectual history. Minneapolis: University of Minnesota Press.

Andersen, Gisle. 2001. Pragmatic Markers and Sociolinguistic Variation. Amsterdam/Philadelphia: John Benjamins.

Banks, Eric. 2008. "Return to Fantasy Island: An Embattled Scholar Still Champions His Dream Experiment in Language Formation”. The Chronicle Review 54: 37 (May 23, 2008). 7-10.

Bickerton, Derek. 1988. "Creole Languages and the Bioprogram". Linguistics: The Cambridge Survey, ed. by Frederick J. Newmeyer, 268-284. Cambridge: Cambridge University Press. 
Bisang, Walter. 1998. "Grammaticalization and Language Contact”. The Limits of Grammaticalization, ed. by Anna Ciacalone Ramat \& Paul J. Hopper, 13-58. Amsterdam/Philadelphia: John Benjamins.

Bisang, Walter. 2001. Aspects of Typology and Universals. Berlin: Akademie Verlag.

Bréal, Michel. 1868. The Latent Concepts of Language (Les idées latentes du langage). Paris: Hachette.

Bréal, Michel. 1883. "The Intellectual Laws of Language: A Sketch in Semantics (Les Lois Intellectuels du Langage: Fragment de Sémantique)". Annuaire de l'Association pour l'Encouragement des Études Grecques 17. 132-142.

Bréal, Michel. 1887. “The History of Words (L'Histoire des Mots)”. Revue des Deux Mondes 4. 187-212.

Brinton, Laurel J. \& Elizabeth Closs Traugott. 2005. Lexicalization and language change. Cambridge, UK ; New York: Cambridge University Press.

Brinton, Laurel J. 2009. "Pathways in the Development of Pragmatic Markers in English". The Handbook of the History of English, ed. by Ans van Kemenade \& Bettelou Los. Oxford: Blackwell.

Bybee, Joan L., Revere D. Perkins \& William Pagliuca. 1994. The Evolution of Grammar: Tense, Aspect, and Modality in the Languages of the World. Chicago: University of Chicago Press.

Bybee, Joan L. \& Dan I. Slobin. 1982. "Why Small Children Cannot Change Language on Their Own". Papers from the 5th International Conference on Historical Linguistics = Referate von der Fünften Internationalen Konferenz für Historischen [sic] Sprachwissenschaft, ed. by Anders Ahlqvist, 29-38. Amsterdam: John Benjamins.

Campbell, Lyle \& Richard Janda. 2001. "Introduction: Conceptions of Grammaticalization and Their Problems". Language Sciences 23: 2-3. 93-112.

Chomsky, Noam. 1988. Language and problems of knowledge: The Managua Lectures. Cambridge, Mass.: M.I.T. Press.

Christy, Craig. 1983. Uniformitarianism in Linguistics. Amsterdam: John Benjamins.

Christy, Craig. 1985. "Humboldt's 'Inner Language Form' and Steinthal's Theory of Signification". Semiotics 1984, ed. by John N. Deely and Semiotic Society of America. Lanham, MD: University Press of America.

Christy, Craig. 2000. "Bréal and the Semantics of Etymological Development: On the Need to Forget in Order to Re-member". The history of linguistic and grammatical praxis : (Leuven, 2nd - 4th July, 1998), ed. by Piet Desmet. Leuven: Peeters.

Christy, Craig. 2002. "From Articulation to Comprehension: Steinthal and the Dynamics of Linguistic Intangibles". Chajim H. Steinthal: Linguist and Philosopher in the 19th Century, ed. by Hartwig Wiedebach \& Annette Winkelmann, 3-16. Leiden: Brill.

Christy, Craig. 2003. “Tooke’s 'Abbreviation' and Bréal's 'Latent Ideas': A New Perspective on Grammaticalization”. History of Linguistics 1999 (Studies in the History of the Language Sciences Vol. 99), ed. by Sylvain Auroux. Amsterdam: John Benjamins.

Christy, Craig. 2005. "Antoine Meillet". The encyclopedia of language and linguistics, ed. by E.K. Brown, R.E. Asher \& J.M.Y. Simpson, 761-762. Amsterdam/Oxford: Elsevier.

Christy, Craig. 2007. “The Presence of Absence in Saussure's Linguistic Theory”. History of linguistics 2002 : selected papers from the Ninth International Conference on the History of the Language Sciences, 27-30 August 2002, São Paulo-Campinas, ed. by Eduardo Guimarães and Diana Luz Pessoa de Barros. Amsterdam/Philadelphia: John Benjamins Pub. Co.

Comajoan, Llorenç \& Manuel Pérez Saldanya. 2005. "Grammaticalization and Language Acquisition: Interaction of Lexical Aspect and Discourse". Selected Proceedings of the 6th Conference 
on the Acquisition of Spanish and Portuguese as First and Second Languages, ed. by David Eddington, 44-55. Somerville, MA: Cascadilla Proceedings Project.

Croft, William. 2000. Explaining Language Change: An Evolutionary Approach. Harlow, UK: Longman/Pearson.

Diessel, Holger. 1999. Demonstratives: Form, Function, and Grammaticalization. Amsterdam/ Philadelphia: John Benjamins.

Everett, Dan. 1996. "Grammaticalization” [September 3]. Linguist List 7: 1227.

Fischer, Olga, Anette Rosenbach \& Dieter Stein. 2000. Pathways of Change: Grammaticalization in English. Amsterdam/Philadelphia: John Benjamins.

Givón, Talmy. 1989. Mind, code, and context : essays in pragmatics. Hillsdale, N.J.: L. Erlbaum Associates.

Givón, Talmy. 2000. "Internal Reconstruction: As Method, As Theory". Reconstructing Grammar: Comparative Linguistics and Grammaticalization, ed. by Spike Gildea, 107-159. Amsterdam/Philadelphia: John Benjamins.

Givón, Talmy. 2009. The Genesis of Syntactic Complexity: Diachrony, Ontogeny, Neuro-Cognition, Evolution. Amsterdam/Philadelphia: John Benjamins.

Gogarten, Peter. 2000. “Horizontal Gene Transfer - A New Paradigm for Biology”. Paper presented at the Esalen Center for Theory and Research Conference on Evolutionary Theory, Downloaded 9/7/2009 from http://www.esalenctr.org/display/confpage.cfm?confid = 10\&pageid = 105\&pgtype $=1$.

Haspelmath, Martin. 2004. "On Directionality in Language Change with Particular Reference to Grammaticalization". Up and down the cline - the nature of grammaticalization, ed. by Olga Fischer, Muriel Norde \& Harry Perridon, 17-44. Amsterdam/Philadelphia: John Benjamins.

Heine, Bernd, Ulrike Claudi \& Friederike Hünnemeyer. 1991. "From Cognition to Grammar — Evidence from African Languages". Approaches to Grammaticalization: Volume I, Focus on Theoretical and Methodological Issues, ed. by Elizabeth Closs Traugott \& Bernd Heine, 149-187. Amsterdam/Philadelphia: John Benjamins.

Heine, Bernd \& Tania Kuteva. 2002. World Lexicon of grammaticalization. New York: Cambridge University Press.

Heine, Bernd \& Tania Kuteva. 2007. The Genesis of Grammar: A Reconstruction. Oxford: Oxford University Press.

Heine, Bernd \& Mechthild Reh. 1984. Grammaticalization and Reanalysis in African Languages. Hamburg: Helmut Buske.

Hopper, Paul J. \& Elizabeth Closs Traugott. 1987. "Emergent Grammar”. Proceedings of the annual meeting of the Berkeley Linguistics Society, 13: General session and parasession on grammar and cognition, ed. by Jon Aske, VII, 472 p. Berkeley, Calif.: Berkeley Linguistics Society.

Hopper, Paul J. \& Elizabeth Closs Traugott. 1993. Grammaticalization. Cambridge ; New York, NY: Cambridge University Press.

Jackendoff, Ray. 1983. Semantics and cognition. Cambridge, Mass.: M.I.T. Press.

Klausenburger, Jurgen. 2008. "Can Grammaticalization be Parameterized?” Theoretical and Empirical Issues in Grammaticalization, ed. by Elena Seoane and María José López-Couso. Amsterdam/Philadelphia: John Benjamins.

Kuhn, Thomas S. 1962. The structure of scientific revolutions. Chicago: University of Chicago Press.

Langacker, R.W. 1977. "Syntactic Reanalysis". Mechanisms of syntactic change, ed. by Charles N. Li. Austin: University of Texas. 
Lehmann, Christian. 1985. "Grammaticalization: Synchronic Variation and Diachronic Change". Lingua e Stile 20. 303-318.

McGilvray, James A. ed. 2005. The Cambridge companion to Chomsky. Cambridge, UK ; New York: Cambridge University Press.

Meillet, Antoine. 1912. "Lévolution des Formes Grammaticales". Scientia (Rivista di Scienza) XII: 26. 6.

Meillet, Antoine. 1921. Linguistique Historique et Linguistique Générale. Paris: Champion.

Murray, Stephen O. 1980. "Gatekeepers and the 'Chomskian revolution"'. Journal of the History of the Behavioral Sciences 16: 1.73-88.

Newmeyer, Frederick J. 1980. Linguistic theory in America: The First Quarter Century of Transformational Generative Grammar. New York: Academic Press.

Newmeyer, Frederick J. 1998. Language Form and Language Function. Cambridge, MA: M.I.T. Press.

Pagliuca, William. ed. 1994. Perspectives on Grammaticalization. Amsterdam/Philadelphia: John Benjamins.

Petitto, Laura-Ann. 2005. "How the Brain Begets Language". The Cambridge companion to Chomsky, ed. by James A. McGilvray, 84-101. Cambridge, UK ; New York: Cambridge University Press.

Roberts, Ian \& Anna Roussou. 2003. Syntactic change: A Minimalist Approach to Grammaticalisation. Cambridge: Cambridge University Press.

Searle, John R. 1972. "Chomsky's revolution in linguistics" [June 29, 1972]. The New York Review of Books.

Slobin, Dan I. 1994. “Talking perfectly: Discourse origins of the present perfect”. Perspectives on Grammaticalization, ed. by William Pagliuca, 119-133. Amsterdam/Philadelphia: John Benjamins.

Steinthal, Heymann. 1869. "Review of Bréal, “The Latent Concepts of Language" ("Les idées latentes du langage”)". Zeitschrift für Völkerpsychologie und Sprachwissenschaft 6. 281-284.

Traugott, Elizabeth Closs. 2001. Legitimate Counterexamples to Unidirectionality. Downloaded 8/23/2009 from http://www.stanford.edu/ traugott/papers/Freiburg.Unidirect.pdf.

Van Gelderen, Elly. 2004. Grammaticalization as Economy. Amsterdam/Philadelphia: John Benjamins.

von Fintel, Kai. 1995. "The formal semantics of grammaticalization”. Proceedings of the North East Linguistic Society (Papers from the Workshop on Language Acquisition and Language Change), 25.2, 175-189.

Wolf, George. 1991. Michel Bréal: The Beginnings of Semantics. Stanford: Stanford University Press.

Yap, Foong Ha \& Stephen Matthews. 2008. “The Development of Nominalizers in East Asian and Tibeto-Burman Languages". Rethinking Grammaticalization: New Perspectives, ed. by María José López-Couso and Elena Seoane, 309-341. Amsterdam/Philadelphia: John Benjamins. 



\title{
Chomsky in search of a pedigree
}

\author{
Camiel Hamans ${ }^{1}$ \& Pieter A.M. Seuren ${ }^{2}$ \\ ${ }^{1}$ Dutch Delegation PES-group, European Parliament, Belgium/France/ \\ ${ }^{2}$ Max Planck Institute for Psycholinguistics, The Netherlands
}

\begin{abstract}
This paper follows the changing fortunes of Chomsky's search for a pedigree in the history of Western thought during the late 1960s. Having achieved a unique position of supremacy in the theory of syntax and having exploited that position far beyond the narrow circles of professional syntacticians, he felt the need to shore up his theory with the authority of history. It is shown that this attempt, resulting mainly in his Cartesian Linguistics of 1966, was widely, and rightly, judged to be a radical failure, even though it led to a sudden revival of interest in the history of linguistics. Ironically, the very upswing in historical studies caused by Cartesian Linguistics ended up showing that the real pedigree belongs to
\end{abstract} Generative Semantics, developed by the same 'angry young men' Chomsky was so bent on destroying.

\section{1. "Bitter"}

Before we engage in a discussion of Chomsky's (b. 1928) historical vagaries, a few words must be said about the other great dispute Chomsky was involved in during the late 1960s and early 1970s: the vexed question of 'lexicalism' versus 'transformationalism', intricately mixed up with the debate between interpretive and generative semanticists.

In his 1976 book on word formation, Mark Aronoff, who was perhaps the first but in any case the most important linguist to restore to morphology its rightful place in generative linguistics, makes a central reference to Chomsky's 'Remarks on Nominalization' of 1967 (published in Chomsky 1972a). This study, he says, heralded the rebirth of morphology in the new paradigm. Yet not everybody was equally enthusiastic (Harris 1993: 139). Aronoff writes (1976: 6): “'Remarks on Nominalization’ was long and bitterly opposed, mainly, I believe, on esthetic grounds." And a few lines further down he speaks again of the "critics of the new esthetic."

Aronoff was not the only one who spoke of bitter strife. The same word "bitter" is used by Huck \& Goldsmith (1995: viii-ix):

Among these [academic arguments], Chomsky's dispute with the Generative Semanticists in the late 1960s particularly stands out. The dispute was notable not simply because it became so bitter, but also because it involved a goodly 
proportion of the theoretical linguistics community of the time and represented what has clearly been the most serious organized challenge to Chomsky's vies to date.

The qualification "bitter" is also found in Seuren (1998: 520): "What followed was a bitter and personal conflict between the so-called 'lexicalists', who sided with Chomsky, and the generative semanticists' school of 'transformationalists.' In this connection, it is hardly surprising that Randy Harris (1993) qualifies this episode as a "linguistics war."

As it was, the opposition between the lexicalists and the transformationalists was just one aspect of the wider, and even more bitter, conflict between the advocates of Autonomous Syntax, commanded by Chomsky, and those of what came to be called Generative Semantics, mainly George Lakoff (b. 1941), James D. McCawley (1938-1999), Paul M. Postal (b. 1936) and John R. (Haj) Ross (b. 1938). For the Chomskyans, syntax was "autonomous and independent of meaning" (Chomsky 1957: 17). Any semantics for natural language had to be grafted upon already given syntactic structures, be they surface structures or deep structures or both. Autonomous syntax was thus closely associated with what became known as interpretive semantics. By contrast, the generative semanticists gave primacy to meaning and regarded language as an intermediary device to convert semantic representations into surface structures according to well-defined grammatical processes. In Koerner \& Asher (1995), an encyclopedic survey of the history of linguistics, ample attention is paid to the 'war' between Autonomous Syntax and Generative Semantics, as can be seen from the fact that two sizeable articles are devoted to this issue (Harlow 1995; McCawley 1995).

In this context, it is at least remarkable that so little is said about this issue in Barsky (1997), which is partly based on extensive correspondence between that author and Chomsky. Two pages, from page 149 to page 151, is all Barsky spends on the question, while ten pages are devoted to this subject in Chomsky \& Ronat (1979). What is most striking is that Chomsky minimizes his own role in this respect and dismisses the whole issue as a quarrel between two groups of his students or followers. In a letter to Barsky of April 3rd 1995, Chomsky writes:

The 'discussion' between, say, Jackendoff and others (many of them not any student: Lakoff, Postal, etc.) was from about 1966 or so. I was never really part of it. [...] My own participation in the debate was in 1969, at a conference in Texas, where I flew in and flew out immediately at the impassioned request of a former student there, Stanley Peters, who wanted me to make some public response to the by then rather hysterical tone of the generative semanticists, all pretty childish in my opinion, and in $1969 \mathrm{I}$ had quite different things on my mind.

These "quite different things" were, of course, his anti-war activity with regard to the Vietnam War, which was raging at the time. "Therefore," Chomsky wrote on August 14th 1995 (Barsky 1997: 151) "I hardly would have had time for 'power struggles', even if I had been interested." Yet Huck \& Goldsmith (1995) quote extensively from the 
private correspondence conducted during the period concerned between Chomsky on the one hand and McCawley and Ross on the other. Some of these letters, which deal explicitly with the different views of the authors concerned, have the length of a publishable paper. Moreover, the last two papers, of a total of three, in Chomsky (1972) specifically aim to destroy Generative Semantics - despite the Vietnam War. All this lends little credibility to what Chomsky wrote about the matter to Barsky.

\section{2. "Remarks on Nominalization"}

Of course, everyone is entitled to their own memories and everyone will no doubt be inclined to bend their own history in their own favor. Yet one may say with equal validity that others are entitled to a correction of such subjective memories, especially when the record is there. And the record says that Chomsky's 1967 M.I.T. lectures, prepared during his sabbatical leave at Berkeley in 1966-1967 and issuing in his paper 'Remarks on Nominalization', were widely perceived as a counterattack by Chomsky against the burgeoning Generative Semantics ideas that were being developed (Harris 1993: 139):

There was no puzzlement about where these lectures - the 'Remarks' lectures, named after the famous paper that came out of them [...] - were aimed. Everyone immediately perceived them as an attack on generative semantics, a reactionary attempt to cut the abstract legs out from underneath the upstart model. The best term for the lectures is Newmeyer's. He calls them a "counteroffensive" (1980: 114; 1986: 107), which captures the air of reaction, assault, and upping-the-ante in which they were received. Chomsky, though - here the story gets particularly bizarre says he wasn't much interested in generative semantics or in abstract syntax at the time, that he knew "virtually nothing about" either, that he barely noticed the work that Postal, Lakoff, Ross, and McCawley were up to. His 1967 lectures, he says, were just a delayed reaction to Lees' Grammar of English Nominalizations (written in the very late fifties with considerable input from Chomsky).

That Chomsky's 1967 'Remarks' lectures should merely be a "delayed reaction" to Lees' 1960 book is highly implausible. In the feverish climate of M.I.T. linguistics of the day, reactions were never delayed. And Chomsky had already reacted to Lees' views on nominalization in Aspects (1965: 184-192). Moreover, the 'Remarks' paper was published in Chomsky (1972), a collection of three papers, two of which were explicitly directed at Generative Semantics. It would hardly make sense to include the 'Remarks' paper if it were not meant to serve the same purpose.

There can be little doubt that those who saw these lectures as an "attack on generative semantics" did so because Chomsky's lexicalism would reduce the 'depth' and the abstractness of grammars compared with those envisaged by the 'transformationalists', who were at the same time generative semanticists. 
Curiously, however, this 'attack' missed the central issue, as the question of lexicalism versus transformationalism is, in fact, independent of whether one prefers Autonomous Syntax or Generative Semantics. Even though 'transformationalism' implied greater abstractness, one could, at the time, perfectly well be a generative semanticist and accept Chomsky's lexicalism, or be an autonomous syntactician and accept the transformationalism of Ross, Lakoff, McCawley and Postal.

What Chomsky implicitly attacked, in his 'Remarks' paper, was the general movement in the direction of what was perceived at the time as greater 'abstractness, but was, in fact, the still mysterious, closed gate of semantics - a movement that had already become apparent in Bach \& Harms (1968), a collection of four papers from a symposium held at the University of Texas in April 1967 on 'Universals in Linguistic Theory?

Meanwhile, Chomsky's following had dwindled, as most of his followers had moved over to Generative Semantics. In 1972, the Berkeley philosopher Searle wrote (Searle 1972):

It is one of the ironies of the Chomsky revolution that the author of the revolution now occupies a minority position in the movement he created. Most of the active people in generative grammar regard Chomsky's position as having been rendered obsolete by the various arguments concerning the interaction between syntax and semantics.

This movement away from Chomsky and towards Generative Semantics had started some four or five years earlier. In 1968, Lakoff, McCawley and Ross gave very successful courses during the Linguistic Institute summer course at Illinois, organized by the prestigious Linguistic Society of America, which provided Generative Semantics with wide publicity throughout the world of linguistics. This was followed, in 1969, by a meeting of the Chicago Linguistics Society dominated by the ideas developed in the now publicly recognized Generative Semantics movement. Seuren concludes (1998: 503): "By 1969 virtually the whole world of theoretical linguistics was agreed that Generative Semantics was the word." At that moment the ominous second Texas Conference took place, where Chomsky clashed publicly and with great bitterness with the generative semanticists, whose "by then rather hysterical tone" he found "pretty childish."

Huck \& Goldsmith (1995: 115, 125, 134, 162) quote Lakoff, Ross and Postal in regard to an incident that happened during this meeting. After Chomsky had presented his paper, Ross stepped forward during question time presenting counterexamples (no doubt in the brilliant and playful fashion that those who know Ross are well-acquainted with). Chomsky, however, cut him short saying that "no individual linguistic examples could possibly be counterexamples to his proposals" (Huck \& Goldsmith 1995: 115), upon which Ross turned round and walked away. "We saw this treatment of Ross as scandalous and aggressive behavior" (ibid.). Postal concluded (Huck \& Goldsmith 
1995: 162) that "disagreeing with Chomsky, even then the most renowned and influential person in the field, would have a high price."

\section{Appointments}

In the same letter to Barsky as has been quoted from above (Barsky 149-151), Chomsky depicts himself as an impartial figure standing above the warring factions. This, Chomsky says, appears from the fact that not one of his own associates was appointed at the M.I.T. linguistics department, while all departmental vacancies were systematically filled with generative semanticists. Again, this is more than a little disingenuous. Jim McCawley accepted an appointment at the University of Chicago as early as 1964. Paul Postal left for New York in 1965 - that is, before Chomsky's sabbatical year at Berkeley. George Lakoff was never formally associated with M.I.T. in any way whatsoever. After he obtained his Ph.D. at Indiana in 1967, he had a brief spell at Harvard, exchanged for an appointment at the University of Michigan in Ann Arbor, after which he moved to Berkeley. The only one among the generative semanticists to have full-time employment at the M.I.T. linguistics department was Haj Ross. Ross was appointed in 1966, while he was still working under Chomsky, who supervised his brilliant 1967 dissertation Constraints on Variables in Syntax. He was dismissed from M.I.T. in 1985 on charges of corruption of minors, because he had allegedly brought some wine or pot to a student party.

\section{4. “Gutter"}

The debate between transformationalists and lexicalists, or between generative and interpretive semanticists, was not the only one that Chomsky was involved in at the time. In 1966 he published Cartesian Linguistics, his view of the history of linguistics and of his intellectual predecessors, followed by a few pages in Language and Mind (Chomsky 1968: 5-20) on the same subject. In 1962, at the International Congress of Linguists held at Harvard, Chomsky had given one of five plenary lectures (Koerner 1989: 116-117). Here, he professed, for the first time, his intellectual debt to De Saussure, Humboldt and Port-Royal, in particular the Grammaire générale et raisonnée (1660), written by Arnault and Lancelot (see Seuren 1998: 47-48). Cartesian Linguistics elaborates on that first plenary lecture. It was written for a lecture course at Princeton, preceded by a sabbatical period. Barsky (1997: 104) writes that the lectures were well received. Yet this cannot be said of the reception of Cartesian Linguistics in the world at large.

Apart from the over-enthusiastic Kampf (1967), written by one of those who had attended the lectures and published in a Princeton in-house publication, and from 
"the nearly hysterical reception that has greeted Cartesian Linguistics" among nonspecialists (Aarsleff 1970: 583), its reception among those who were better informed was highly critical (cp. Miel 1969; Salmon 1969; Aarsleff 1970, 1971). Chomsky never replied in public to his critics. According to a letter he wrote to Barsky on March 31st, 1995 (Barsky 1997: 105):

I've never bothered to respond, because [...] my contempt for the intellectual world reaches such heights that I have no interest in pursuing them into their gutter, unless there are serious human interests involved.

Yet in the same letter he does present a response, of sorts (Barsky, ibid.). Referring to Aarsleff (constantly mis-spelt "Aarslef" by both Chomsky and Barsky), and acknowledging that Aarsleff's critique had by then been widely accepted, Chomsky writes (Barsky, ibid.):

Aarslef[f] wrote savage denunciations of Cartesian Linguistics (in Language, and elsewhere), claiming that I had made this idiotic error, which he did make a year after Cartesian Linguistics, and which is explicitly and unambiguously rejected in Cartesian Linguistics.

This "idiotic error" would have been that, in his monumental work The Study of Language in England, 1780-1860 of 1967, Aarsleff "described traditional universal grammar as solely 'Cartesian' in origin, completely ignoring the quite obvious Renaissance and earlier origins that are emphasized in Cartesian Linguistics" (Barsky, ibid.).

Chomsky was not the only one to react negatively with regard to Aarsleff's critique of Cartesian Linguistics (further discussed below). Harry Bracken (1984: xi) describes Aarsleff in terms that one would use for a charlatan: "The kind of scholarship manifested by Aarsleff differs in quantity but not in quality from that recently displayed by Trevor-Roper in identifying the Hitler 'diaries'" (which as one remembers, turned out to be a forgery). Bracken's book contains two essays "dealing with propaganda directed against Chomsky" (Bracken 1984: x). In the book, he argues that the opposition to Chomsky, especially that coming from Aarsleff, is politically motivated, as Chomsky's stance, both academically and politically, is a menace for the powers that be. We read (Bracken 1984: 123):

Aarsleff is not really engaged in a dispute over scholarship. He correctly sees that Chomsky's efforts threaten liberalism itself. He correctly sees that Chomsky is seeking to 'corrupt the youth. [...] [H]e is responding as a guardian of one of our ideological heroes. To that end he has produced two papers calculated to intimidate those who challenge the accepted version of our intellectual history.

It will be obvious to any impartial beholder that this kind of 'exegesis' has nothing whatsoever to do with academic argument and is more akin to what Chomsky (2002b: 18) describes as "manufacture of consent," something the established order is said to be guilty of. Yet Chomsky does not dissociate himself from Bracken, as he should have 
done if he really preferred not to "pursue [the intellectual world] into [its] gutter" (Chomsky 1998: 92-93):

There has been some interesting work in the past few years, for example, on the philosophical origins of racism, particularly by Harry Bracken, which suggests a much more complex history. [...] I think it is not an exaggeration to see in Cartesian doctrine a conceptual barrier - a modest one, as Bracken carefully explains - against racism.

\section{5. "Professor"}

Let us now have a closer look at Aarsleff's influential critiques (1970, 1971). First, however, it must be mentioned that there is an, again bitter, emotional side to the story: Chomsky was extremely angry at Aarsleff's critiques. This is perhaps understandable, in that Aarsleff's style of writing shows his irritation at Chomsky's cheek in writing with apparent authority on matters Aarsleff felt he didn't know the first thing about. The title alone of his 1970 article in Language shows his temper: 'The history of linguistics and Professor Chomsky' (italics added).

Aarsleff formulates two requirements for adequate historiography (Aarsleff 1970: 571): "adequate scholarship; and the over-all coherence of the entire history that is presented, without omission or neglect of material that is relevant, either by the writer's own standards or by those of the figures he deals with and cites." In the eyes of Aarsleff, Chomsky failed dismally on both counts. Chomsky's references and quotes are highly selective. Thus, in his discussion of the encyclopédiste Du Marsais (1676-1756) - an essential figure in Chomsky's story - Chomsky cites a memorial article by D'Alembert. Yet, in doing so, he (no doubt on purpose, in Aarsleff's view) omits the passage immediately preceding his quote, in which Du Marsais is described as an anti-mentalist and an opponent of Cartesian ideas. According to Aarsleff, Chomsky used antiquated and thus inferior secondary sources, and had not read the essential primary texts. The lineage Chomsky sees in the history of universal grammar from Descartes, via the British Platonists, Leibniz, Kant, the Von Schlegel brothers, to Humboldt is, therefore, basically flawed.

As regards the history preceding the great works of Port-Royal and their alleged indebtedness to Descartes, Aarsleff merely summarizes (1970: 572-573) the critiques by Karl Zimmer (1968), Robin Lakoff (1969), Vivian Salmon (1969) and Jan Miel (1969), all of whom point out that the idea of a universal theory of language and of universal grammar does not go back to Descartes or to the Port-Royal educationalists but to a much older tradition that was still very much alive in the seventeenth century.

Moreover, Aarsleff points out that there is a clear historical line from Port-Royal to Locke, so debunked by Chomsky as a die-hard adherent of empiricism - a label 
Chomsky apparently confuses with 'positivism', the much later philosophy according to which all reality is matter and all knowledge is based on observables. In fact, however, Locke was much more of a rationalist than nineteenth-century scholarship had him be. Chomsky should have seen this in the literature cited by him (Aarsleff 1970: 572-573):

Locke was very sympathetic to the Jansenists of Port-Royal; he owned their works and read them. His political philosophy would seem to have received significant impulses from Pierre Nicole, who with Arnauld was responsible for the PortRoyal logic, which is so closely related to the Grammar that it must be called its twin. Apart from the last point about Locke, this could all quite easily have been learned from the relevant secondary sources, most of it in fact from Sainte-Beuve's Port-Royal, now one hundred and ten years old, to which Chomsky makes some convenient references (e.g. 1966: 75, 104, 105). It would also seem potentially dangerous to ignore the fact that the Port-Royalists had significant disagreements with Descartes - Arnauld, for instance, over innateness.

The opposition between rationalism and empiricism, during the eighteenth and nineteenth centuries, was not nearly as deep and fundamental as claimed by Chomsky in Cartesian Linguistics. In fact, as Aarsleff tries to make clear, Locke felt that he was building on and elaborating Descartes' work.

Aarsleff clearly shows that Du Marsais, far from being the staunch supporter of Descartes that Chomsky describes him as, differed considerably with Descartes on the issue of innate ideas and was more in agreement with a Lockean version of rationalism, also expressing his indebtedness to Sanctius (see Seuren 1998: 67-69). Needless to say, Aarsleff is keen to point out that Chomsky would have found all that in the sources cited by him, had he been more diligent in reading them.

By far the most important figure, however, in the tradition of universal grammar was Condillac, whose Essai sur lorigine des connoissances of 1746 appeared ten years later in an English translation with the subtitle "A Supplement to Mr. Locke's 'Essay on the Human Understanding"'. Aarsleff (1974) describes in detail the enormous influence of this work on several generations of philosophers not only in France, in particular the 'Idéologues', but also in Germany. It cannot be denied, therefore, that Locke had a considerable influence on eighteenth-century linguistic theory. One can thus only conclude that Chomsky badly underestimated the place and role of Locke in the debates on universal grammar that took place in the seventeenth and eighteenth centuries.

The next milestone in Chomsky's pilgrimage, Johann Gottfried Herder, was no more an heir to Descartes than Du Marsais or Condillac were. In fact, Herder leans heavily on Condillac in his famous and prize-winning treatise Abhandlung über den Ursprung der Sprache of 1772. It is fair to say that, through Condillac, who, though rather misrepresented by Herder, still influences him throughout, Herder lands in the non-Cartesian camp rather than anywhere else. Or, as Aarsleff puts it (1970: 579), his work is "simply a reflection of Locke's rationalism through Condillac." 
Not even the last of Chomsky's chosen forbears, Wilhelm von Humboldt, was a Cartesian. The traditional view (Salus 1976: 96) has it that Humboldt was strongly influenced by Herder. Aarsleff (1982: 335-353) disagrees. According to him, the traditional view goes back to two nineteenth-century biographies by Rudolf Haym, one about Humboldt and one about Herder. Aarsleff places von Humboldt in the tradition of Condillac and the Idéologues, whom he met and frequented personally in the Parisian salons towards the close of the eighteenth century, as he conducted his studies. Seuren (1998: 108-120) devotes an extensive section to von Humboldt, in which he stresses his lack of theoretical consistency. In any case, no matter how or to what extent Herder, Condillac, the Idéologues or Madame de Staël and her guests may have influenced him, von Humboldt's lineage must be traced back to Locke, not to Descartes.

\section{6. "Cartesian"?}

Other commentators on Cartesian Linguistics were equally critical. In his (1972) article, Keith Percival takes a dim view of Chomsky's interpretation of what Descartes said about language. Then, in Percival (1976), he concludes, having compared the method applied by Vaugelas (1647) with that employed in the Grammaire Générale et Raisonnée (1660) (Percival 1976: 381-382):

[T]he Grammaire Générale was not a reaction against a previously held linguistic theory. Arnauld and Lancelot did not repudiate Vaugelas - they transcended him completely and in the process incorporated many of his ideas. The term 'pure descriptivism' does not seem particularly apt as a characterization of Vaugelas' attitude to usage, and if Vaugelas is to be described as a pure descriptive, then so must the authors of the Grammaire Générale, for they too accepted the classical view of the role of usage in grammatical description.

This makes one wonder if the Grammaire Générale itself does indeed have to be reckoned to be part of the tradition of universal grammar. Seuren (1998: 47) brands the Grammaire Générale, apart from a few passages that are reminiscent of Sanctius, the great Spanish innovator of linguistic theory discussed further below, as a more or less conventional work, written along the lines of current grammar books of the period.

Another critic was Peter Salus in his (1976) survey of theories of universal grammar between the years 1000 and 1850. Salus shows that universalist theories of grammar do not originate with Descartes and Port Royal, and perhaps a few early isolated Medieval or Renaissance harbingers, as is suggested in Chomsky $(1966,1968)$, but can boast an age-old tradition that can be traced back to the Athenian Academy as it developed after Plato. From there, it found its way to the Alexandrian grammarians (in particular the world's first syntactician Apollonius Dyscolus, who lived and worked in Alexandria during the second century CE), to the Neo-Platonists Philo ( $\pm 25 \mathrm{BCE}- \pm$ 
50CE) and Plotinus (205-270) with his school, till it found its final formulation in Antiquity in Priscian's Institutiones Grammaticae (early sixth century). Similar views are found in the writings of leading Medieval authors and Church Fathers, such as Anselm of Canterbury (1033-1109), Abelard (1079-1142), Bonaventure (1217-1274), Thomas Aquinas (1225-1294) or Roger Bacon ( \pm 1214- \pm 1293$)$.

The highly influential school of the Modists ( $\pm 1250- \pm 1320)$ likewise held a universalist theory of grammar. Salus writes (1976: 86-87):

The Modistae, who follow close on the heels of Kilwardby and Bacon, attempt to derive their grammatical formulations from formal logic and from metaphysics. Unfortunately, the Modistae used Latin as their metalanguage - in fact, they seem to have seen Latin as the ideal underlying the other (European) languages or at least as the most perfect shadow of the ideal (underlying) form. "Latin became for them the specification of the general grammar, the word-classes and syntax of the perfect language" (Bursill-Hall 1972: 19). [...] [W]e can consider the Modistae, with their many treatises and conflicting views, as the 'second wave' of speculative grammarians and view Bacon, Kilwardby, et al. as the 'première vague. [...] The Modistae framed their theory within the system of Donatus and Priscian, but they restated the definitions of the word-classes and their accidents in semantic terms, deriving their terminology from the logical theories of the two Englishmen mentioned so often (Bacon and Kilwardby), Petrus Hispanus (1205-1377), and St. Anselm. [...] Modistic grammatical theory depended upon a relationship of the closest type between the operation of the mind and the structure of reality and the central concerns of the Modistae were those of universals, adequacy, deep structure, and the incorporation of meaning into general grammatical statements.

By about the middle of the fourteenth century the Modistae had lost out to the nominalists. Yet, as observed by Covington (1982: 40-41), the nominalists had no grammatical theory to replace Modistic doctrine, as a result of which "Modistic grammar kept being taught in the schools, in less philosophical and more practical versions, as late as the 16th century" (Seuren 1998: 31-32).

\section{7. "Misleading survey"}

Later commentators tend to reject the historical claims made by Chomsky in Cartesian Linguistics. In a study on the Dutch grammarian Vossius, Rademaker writes (1992: 121-122):

In his preface to the Nouvelle Méthode, Lancelot declared explicitly his indebtedness to Sanctius and his imitators Scioppius (1576-1649) and Vossius. [...] Very important is the treatment of ellipsis in the Nouvelle Méthode, and it is clear that Lancelot owed much to the treatment of ellipsis in Sanctius and Vossius.

In the Grammaire Générale of 1660 we do not find explicit reference to the work of Vossius, but here, too, we can find traces of his influence. The authors of this 
famous book made the claim to write a general or universal grammar enunciating principles applicable to all languages, but they used as their sources the studies on the Latin language of precursors such as Scaliger, Sanctius, Scioppius and Vossius. In fact, the Grammaire Générale is following an impressive amount of Humanist and 17 th-century practice.

A further comment that is typical of the way Cartesian Linguistics has been received is Subbiondo (1995: 176):

The critics of Chomsky's Cartesian Linguistics attacked the interpretation of the history of seventeenth-century linguistics for giving too much credit to Descartes for advancing rational grammar in the seventeenth century. For example, Vivian Salmon (1969: 178) convincingly argued "The essential features of the theory, however, were derived from a logical and grammatical tradition which had been developing, without any real interruption, since the early Middle Ages." Salmon's review, as well as that of [Robin] Lakoff (1969), sketched a rich and diverse panorama of grammarians who had connected theories of language with those of mind long before Descartes and who influenced seventeenth-century linguistics.

Sharbani Banerji, who is generally appreciative of Cartesian Linguistics, frankly admits its weak points. In particular, he is of the opinion that the book does not deserve the qualification "survey", even though Chomsky (2002a: 104) calls it that, though Chomsky admits that this "survey is very fragmentary and therefore in some ways a misleading one." One of the reasons why Cartesian Linguistics cannot be called a "survey" is, according to Banerji (2003), that:

[...] many of the thinkers, scholars, philosophers, etc., whom Chomsky quotes profusely in this book, were not at all engaged in linguistic or grammatical studies. For example, Descartes hardly paid any attention to language. [...] Several of them were even antagonistic to the 'Cartesian Doctrine' that Chomsky draws out from their works. For example, Vaugelas, de la Mettrie, J.G. Herder etc., were more of empiricists.

James McGilvray, who wrote the well-nigh jubilant Introduction to the second edition of Cartesian Linguistics, goes even further, commenting (2002a: 15-16): "Descartes did little more than put a label on the problem."1

1. During 1973 there was an, again extremely bitter, exchange between George Lakoff and Chomsky in The New York Review of Books (George Lakoff 1973; Chomsky 1973), brought on by a letter that George Lakoff wrote in response to John Searle's lengthy article in the same New York Review of Books (Searle 1972). The main bone of contention was Chomsky's search for a pedigree in Cartesian philosophy. Although this exchange attracted a great deal of public attention at the time, both authors are guilty of such notional, terminological, textual, and historical confusions, both being driven by a personal animosity of such proportions, that a detailed analysis would reveal more about their personalities than about the issues at hand. 


\section{Minerva}

At the University of Salamanca, the Spaniard Franciscus Sanctius or Sánchez de las Brozas (1523-1600), already referred to earlier, went his own universalist way. Sanctius was a converted Christian, of Jewish or Muslim extraction, which made him politically suspect and an obvious prey for the savage officers of the Holy Inquisition who badly harassed him for extended periods. His principal work Minerva, seu de causis linguae Latinae (Lyon 1562; Salamanca 1587) leaves no doubt that for Sanctius all languages are essentially 'logical' in their universal underlying structure but not, or much less, in their manifold external manifestations. This makes it necessary to postulate rule systems to fill the gap between, on the one hand, the underlying universal 'logical language' and, on the other, the less 'logical' vernaculars found in the world at large. Sanctius is particularly impressed by the fact that the underlying 'logical language' must be taken to contain elements that do not appear in actual spoken languages and must thus have been lost on the way from the depths of thoughts to the surface sounds of the words spoken. This led him to posit an essentially transformational theory of grammar, in which ellipsis plays a central role, along with other transformational processes (see Seuren 1998: 41-46).

Around the year 1650, Sanctius was discovered and then carefully studied by the Frenchman Lancelot, who was so impressed with Sanctius that he radically rewrote, and quadrupled the size of, his textbook Nouvelle Méthode pour facilement et en peu de temps comprendre la language latine for its third edition of 1653 (see Robin Lakoff 1969). Lancelot subsequently tried to incorporate Sanctius' ideas into the Grammaire générale et raisonnée of 1660, only to find that this would have provoked the displeasure of king Louis XIV, who, in his policy of imposing strict Roman-Catholic orthodoxy, was set to eradicate Jansenism and Port Royal with it, and who would have looked on any 'promotion' of Sanctius' ideas with considerable suspicion, given that Sanctius had been targeted by the Inquisition (see Seuren 1998: 46-48). As a result, whatever of Sanctius' radically universalist concept of grammar found its way into the Grammaire générale et raisonnée turned out, in the end, to be precious little.

Before Robin Lakoff published, in 1969, her masterful review of Brekle's edition of the Grammaire générale et raisonnée, she had had occasion to discuss its contents with Chomsky and others, which explains how and why Chomsky reacts to her views in Chomsky (1968), before the review had appeared. There we read (Chomsky 1968: 15-16):

It seems, however, that the concept of ellipsis is intended by Sanctius merely as a device for the interpretation of texts. Thus, to determine the true meaning of an actual literary passage, one must very often, according to Sanctius, regard it as an elliptical variant of a more elaborate paraphrase. But the Port-Royal theory and its later development, particularly at the hands of the encyclopedist Du Marsais, gave a rather different interpretation to ellipsis. The clear intent of 
philosophical grammar was to develop a psychological theory, not a technique of textual interpretation.

Robin Lakoff's reply to this sad misconception was as simple as it was lethal (Robin Lakoff 1969: 367-368):

Sanctius, Chomsky would say, was an applied linguist, not a theorist. But since the Minerva is inaccessible to anyone who does not read Latin, Chomsky has been forced to rely on the judgments of writers like Sahlin (1928), some of whose comments on S[anctius] demonstrate an amazing lack of perception, much like her lack of perception that Chomsky derides with reference to the G[rammaire] G[énérale] R[aisonnée]. But no one who takes the trouble to read S[anctius] carefully could think of him as primarily a textual critic. The first passage Sahlin cites [...] should be sufficient evidence that he is not.

In addition to rubbing in that Chomsky lacks the scholarly preparation necessary for independent historical work, Lakoff then stresses, correctly, that Sanctius, and, accordingly, the third edition of Lancelot's Nouvelle Méthode, cannot be regarded as precursors of the ideas Chomsky held around 1969 but are a clear prelude to the school of Generative Semantics that Chomsky had just begun to attack so savagely.

In this connection, it must be mentioned that the debate between Chomsky with his autonomous syntax theory on the one hand and the angry young generative semanticists on the other had focused on the question of whether or not one should assume the reality of an underlying purely syntactic deep structure. The generative semanticists maintained that whatever 'deep structure' is reasonably assumed should count as both an underlying syntactic and an underlying semantic structure. In their view, 'deep structure' is both syntactically and semantically relevant and explanatory. Chomskyan 'autonomous syntax', by contrast, maintained that the notion of 'deep structure' made sense only in the context of syntax, whereas any semantic interpretation should be considered a totally independent matter (one that did not really interest him).

Despite the numerous notional and terminological equivocations in the debates that went on during that period, it was clear that this was the real issue (see Seuren 1972). It is the question of whether language as a whole and grammar in particular should be considered 'mediational' (Seuren 2004) between thought and sound, which is the traditional view implicitly held by all philosophers of language during the ages, or should be taken to constitute a separate, essentially syntactic, system that happens to be used for the expression of meanings but could conceivably equally well be used for quite different purposes, the view held by Chomsky and his followers but by no-one else in the history of mankind. What Robin Lakoff showed in her 1969 review was (a) that Descartes has little to do with the whole issue but that Sanctius is the relevant historical source to go to, and (b) that Chomskyan autonomous syntax has no roots at all in history, while Generative Semantics does, being of a piece with the whole of 
tradition and with Sanctius' theory of language in particular, that being the first more or less explicit account of the traditional view.

Peter Salus was another early critic drawing attention to the pivotal role played by Sanctius in shaping the notion of 'deep structure' (Salus 1969, 1971). In his much longer article in Parret (1976), he concludes (Salus 1976: 89):

That this, plus the Cartesian notions of innateness, gave rise to the universalist, rationalist notions of language of Du Marsais and many others from the late seventeenth century on is beyond question.

In dealing with Leibniz and Locke, Salus follows Aarsleff. According to Salus (1976: 91):

[Locke] is not the hard-nosed empiricist he is frequently set up to be. Further, Locke seems to see ideas as mediated to the mind through language. [...] Descartes, Locke, and Leibniz [are] closer than one would think them to be from a reading of nineteenth- and twentieth-century scholarship. [...] Schools and opinions are not as easily separated as people would like them to be.

The same point can be made regarding James Harris (1709-1780), whom Chomsky describes as a fervent anti-Cartesian although Harris, in his Hermes of 1751, never mentions the names of Descartes, Arnauld, Lancelot or Port Royal, while often respectfully referring to Sanctius. Salus comments (1976: 93) that this shows "how deep the roots of English philosophical grammar lie."

\section{Conclusion}

In general, one cannot but come to the conclusion that history lends no support to Chomsky's claim that the ideas he put forward in his 'Remarks on Nominalization' of 1967 are to be traced back in any sense whatsoever to Descartes. On the contrary, there is overwhelming evidence that the entire tradition of philosophical grammar led up to the ideas propagated by his enemies, the generative semanticists. American structuralism and early, strictly syntactically oriented, generative grammar were no more than temporary deviations in the history of linguistic ideas.

By 1965, Chomsky could rightly have the feeling that he had won over those parts of the world of linguistics that mattered. After the explosive publication of Syntactic Structures (1957), which was, however, very limited in scope, and after the ensuing crusade carried out with all means at his disposal (see Koerner 1989), the publication of Aspects in 1965 appeared to have settled the issue, at least as far as the theory of syntax was concerned. This is how John Joseph describes the situation of that moment (Joseph 2002: 62-63):

Chomsky attracted talented disciples from various fields and was enormously successful in getting both publicity and government funding. Despite the begrudging stance of many senior structuralists against its leading ideas, 
transformational-generative grammar became mainstream linguistics in America around the mid-1960s and was on its way to having this status world-wide, the first unified paradigm since the Neogrammarians to do so.

The time had now come for further expansion. The first priority was phonology, which could do with a generative shot. This materialized in the long delayed publication of The Sound Pattern of English in 1968, written with the help of his associate Morris Halle. Excursions into philosophy became more and more frequent, though the philosophers proved less obliging than the phonologist Morris Halle in shoring up his, on the whole insubstantial or at any rate unoriginal philosophical ideas.

Semantics was obviously another urgent priority, but here he only found enemies. The Californian logician Richard Montague, in particular, was extremely hostile to Chomsky's approach, which he considered basically misguided. He begins his 'English as a formal language' of 1966 as follows (Thomason 1974: 188):

I reject the contention that an important theoretical difference exists between formal and natural languages. On the other hand, I do not regard as successful the formal treatments of natural language attempted by certain contemporary linguists. Like Donald Davidson, I regard the construction of a theory of truth or rather, of the more general notion of truth under an arbitrary interpretation as the basic goal of serious syntax and semantics; and the developments emanating from the Massachusetts Institute of Technology offer little promise towards that end.

Not being at all a 'semantic animal' himself, Chomsky understandably refrained from further attempts at developing a semantics for his grammar, preferring, in the end, to stick to what he had learned from logicians in his earlier years, that formally defined languages should be 'interpreted upon' a model. And he left it at that, contenting himself with the half-baked notions of his 'interpretive semantics'.

To make things worse, some of his own students and colleagues went their own way in broaching semantic themes - a development that Chomsky saw as little less than treason, especially because he was rapidly losing his formerly numerous audience to Ross (McCawley and Postal had already left M.I.T. and Lakoff never was there). Joseph comments (Joseph 2002: 63):

Within a short time, however, dissent erupted within the generative ranks, led by some of Chomsky's most talented followers. The central issue was Chomsky's insistence upon the radical autonomy of syntax. [...] This radical version of the structuralist priority of form over meaning conflicted with the common intuition that meaning perhaps need not, but can, determine syntax to a degree sufficient to render the 'autonomy' of syntax virtually non-existent.

In his interview with John Goldsmith, Jackendoff says (Huck \& Goldsmith 1995: 100): "What was significant about that time was it was the first time that generative grammarians 
had broken rank. [...] That period was the first time that there was disagreement." It all looked very much like revolt in an army that is about to win the battle, and it put an end to any hopes Chomsky may have had of launching a semantics campaign.

What remained was the consolidation of what he desired to see as his supremacy by means of a historical pedigree. Hence his Cartesian Linguistics (1966), and to some extent also his Language and Mind (1968). But here, too, he was thwarted by an overwhelming majority of critics, all showing, politely or harshly, his lack of expertise and his partisan quasi-scholarship. Yet, owing to the position Chomsky had meanwhile managed to acquire in the media, the publication of Cartesian Linguistics did lead to a general upswing in studies on the history of linguistics and related subjects. Ironically, however, this upswing in historical studies ended up showing that the real pedigree belongs to the school of Generative Semantics, formed by the very same bunch of 'angry young men' he was so bent on destroying.

\section{References}

Aarsleff, Hans. 1967. The study of language in England, 1780-1860. Princeton, N.J.: Princeton University Press.

Aarsleff, Hans. 1970. “The History of Linguistics and Professor Chomsky”. Language: Journal of the Linguistic Society of America 46: 3. 570-585.

Aarsleff, Hans. 1971. “'Cartesian Linguistics': History or Fantasy?” Language Sciences 17. 1-12. Aarsleff, Hans. 1974. "The tradition of Condillac. The problem of the origin of language in the eighteenth century and the debate in the Berlin Academy before Herder". Studies in the history of linguistics : traditions and paradigms, ed. by Dell H. Hymes, 93-156. Bloomington/ London: Indiana University Press.

Aarsleff, Hans. 1982. From Locke to Saussure : essays on the study of language and intellectual history. Minneapolis: University of Minnesota Press.

Aronoff, Mark. 1976. Word formation in generative grammar. Cambridge, Mass.: M.I.T. Press.

Bach, Emmon \& Robert T. Harms. 1968. Universals in linguistic theory. S.l.: Harcourt Inc College. Banerji, Sharbani 2003. "Review of Noam Chomsky, Cartesian Linguistics. A Chapter in the History of Rationalist Thought. Second edition, edited, with an Introduction by James McGilvray" [July 3rd 2003]. Linguist List 14: 2061.

Barsky, Robert F. 1997. Noam Chomsky : a life of dissent. Toronto: ECW Press.

Bracken, Harry M. 1984. Mind and language : essays on Descartes and Chomsky. Dordrecht; Cinnaminson, N.J.: Foris Publications.

Bursill-Hall, Geoffrey L. 1971. Speculative grammars of the Middle Ages : the doctrine of partes orationis of the Modistae. The Hague: Mouton.

Chomsky, Noam. 1957. Syntactic structures. The Hague: Mouton.

Chomsky, Noam. 1965. Aspects of the theory of syntax. Cambridge: M.I.T. Press.

Chomsky, Noam. 1966. Cartesian linguistics: a chapter in the history of rationalist thought. New York: Harper \& Row.

Chomsky, Noam. 1967. "Remarks on nominalization". Studies on semantics in generative grammar, ed. by Noam Chomsky, 11-61. The Hague: Mouton. 
Chomsky, Noam. 1968. Language and mind. New York: Harcourt Brace \& World.

Chomsky, Noam. 1972. Studies on semantics in generative grammar. The Hague: Mouton.

Chomsky, Noam. 1973. "In response to "Deep language"”' [July 19, 1973]. The New York Review of Books.

Chomsky, Noam. 1998. On language : Chomsky's classic works 'Language and responsibility' and 'reflections on language' in one volume. New York: The New Press.

Chomsky, Noam. 2002a. Cartesian Linguistics: A Chapter in the History of Rationalist Thought. 2nd ed. Christchurch, New Zealand: Cybereditions.

Chomsky, Noam. 2002b. Media control : the spectacular achievements of propaganda. New York: Seven Stories Press.

Chomsky, Noam \& Morris Halle. 1968. The sound pattern of English. New York: Harper \& Row.

Chomsky, Noam \& Mitsou Ronat. 1979. Language and responsibility : based on conversations with Mitsou Ronat. New York: Pantheon Books.

Covington, Michael A. 1982. Syntactic Theory in the High Middle Ages. Modistic Models of Sentence Structure. Ph.D. Thesis, Yale University.

Harlow, Stephen J. 1995. “Evolution of Transformational Grammar”. Concise history of the language sciences : from the Sumerians to the cognitivists, ed. by E.F.K. Koerner \& R.E. Asher. New York: Pergamon.

Harris, Randy Allen. 1993. The linguistics wars. New York: Oxford University Press.

Huck, Geoffrey J. \& John A. Goldsmith. 1995. Ideology and linguistic theory: Noam Chomsky and the deep structure debates. London; New York: Routledge.

Joseph, John Earl. 2002. From Whitney to Chomsky: essays in the history of American linguistics. Amsterdam/Philadelphia: John Benjamins.

Kampf, Louis 1967. "Review of Cartesian Linguistics, by N. Chomsky". College English 28. 403-408.

Koerner, E.F.K. 1989. “The Chomskyan 'revolution' and its historiography. Observations of a bystander”. Practicing linguistic historiography : selected essays, ed. by E.F.K. Koerner, 101-146. Amsterdam/Philadelphia: John Benjamins.

Koerner, E.F.K. \& R.E. Asher. 1995. Concise history of the language sciences : from the Sumerians to the cognitivists. New York: Pergamon.

Lakoff, George. 1973. "Deep language" [February 8, 1973]. The New York Review of Books.

Lakoff, Robin. 1969. "Review of Grammaire generale et raisonnee, ou La grammaire du Port Royal. (By C. Lancelot \& A. Arnauld.) Ed. Herbert H. Brekle. 2 vols. Stuttgart-Bad Cannstatt, Friedrick Fromann Verlag. 1966". Language 45. 343-364.

McCawley, James D. 1995. "Generative Semantics". Concise history of the language sciences : from the Sumerians to the cognitivists, ed. by E.F.K. Koerner and R.E. Asher. New York: Pergamon.

Miel, Jan 1969. "Pascal, Port-Royal, \& Cartesian linguistics". Journal of the History of Ideas 30. 261-271.

Newmeyer, Frederick J. 1986[1980]. Linguistics in America: The first quarter-century of transformational-generative grammar. New York: Academic Press.

Parret, Herman. 1976. History of linguistic thought and contemporary linguistics. Berlin ; New York: Mouton de Gruyter.

Percival, W. Keith 1972. "History of Linguistic Thought and Contemporary Linguistics". Cartesian studies, ed. by R.J. Butler. Oxford: B. Blackwell.

Percival, W. Keith 1976. "On the non-existence of Cartesian linguistics". History of linguistic thought and contemporary linguistics, ed. by Herman Parret. Berlin ; New York: de Gruyter. 
Rademaker, Cornelis S.M. . 1992. "Gerardus Joannes Vossius (1577-1649) and the study of Latin grammar". The History of linguistics in the Low Countries, ed. by J. Noordegraaf, C.H.M. Versteegh \& E.F.K. Koerner. Amsterdam/Philadelphia: John Benjamins.

Sahlin, Gunvor. 1928. César Chesneau du Marsais et son rôle dans lévolution de la grammaire générale. Paris: Presses Universitaires.

Salmon, Vivian 1969. "Review of Cartesian Linguistics (Chomsky 1966)". Journal of Linguistics 5. 165-187.

Salus, Peter H., Robert I. Binnick, Alice Davison, Georgia M. Green \& Jerry L. Morgan. 1969. “PREPre-Cartesian Linguistics". Papers from the Fifth Regional Meeting of the Chicago Linguistic Society, April 18-19, 1969, 429-434. Chicago: U. of Chicago, Dept. of Ling.

Salus, Peter H. 1971. “The Modistae as Proto-Generativists”. Papers from the Seventh Regional Meeting, Chicago Linguistic Society. April 16-18, 1971, 530-534. Chicago: Chicago Ling. Soc.

Salus, Peter H. 1976. "Universal grammar 1000-1850". History of linguistic thought and contemporary linguistics, ed. by Herman Parret, 85-101. Berlin ; New York: de Gruyter.

Searle, John R. 1972. "Chomsky's revolution in linguistics" [June 29, 1972]. The New York Review of Books.

Seuren, Pieter A.M. 1972. "Autonomous Versus Semantic Syntax". Foundations of Language 8. 237-265.

Seuren, Pieter A.M. 1998. Western linguistics. An historical introduction. Oxford ; Malden, Mass.: Blackwell.

Seuren, Pieter A.M. 2004. Chomsky's minimalism. New York: Oxford University Press.

Subbiondo, Joseph L. 1995. "Universal language schemes and seventeenth-century Britain". Concise history of the language sciences : from the Sumerians to the cognitivists, ed. by E.F.K. Koerner \& R.E. Asher. New York: Pergamon.

Thomason, Richard H. (ed.). 1974. Selected Papers of Richard Montague. Newhaven-London: Yale University Press.

Zimmer, Karl E. 1968. "Review of Cartesian Linguistics, by N. Chomsky”. International Journal of American Linguistics 34. 290-303. 


\title{
The "linguistic wars"
}

\section{A tentative assessment by an outsider witness}

\author{
Giorgio Graffi \\ University of Verona
}

In the last two decades a debate developed about the historiography of the so-called "linguistic wars" of the late 1960s and the early 1970s, the fight between "generative semantics" (GS) and "extended standard theory" (EST). This historiographical debate looks as rough as the original "wars" themselves: according to Newmeyer $(1986 ; 1996)$, the collapse of generative semantics was mainly due to its intrinsic weaknesses, while several other scholars (e.g., Huck \& Goldsmith 1995; R.T. Lakoff 1989; Murray 1994) stress sociological reasons for the victory of EST, notably the rhetorical ability and the academic strength of Chomsky and his staunch followers. The aim of this article is to offer an external assessment of the "linguistic wars" based on the evidence provided by an outside observatory: the community of Italian linguists during the 1970s. The article first reviews the recent debate about the "linguistic wars". Then the Italian reception of both GS and EST is sketched: it is shown that GS was initially preferred, but later abandoned. Since every kind of generative linguistics had very little space in Italian universities at that time (Italian academic linguistics was almost exclusively historically-oriented), sociological factors cannot be assumed to have played any role in this abandonment. Therefore, a not merely sociological explanation for the "victory" of EST over GS has to be found.

\section{The linguistic historiography concerning the generative semantics vs. interpretive semantics debate}

In the last two decades or so a debate has developed about the so-called "linguistic wars" of the late 1960s and the early 1970s, namely those between "generative semantics" (henceforth GS) and "interpretive semantics" (IS), also called "extended standard theory" (EST). This debate sometimes looked as rough as "linguistic wars" themselves (see, e.g., Newmeyer 1986; 1996; R.T. Lakoff 1989; Harris 1993; Huck \& Goldsmith 1995). It is clear that these "wars" ended with the "victory" of EST over GS. Less clear are the factors of the demise of GS. The basic historiographical problem in need of solution is therefore the following one: was the fall of GS mainly due to its lack of consistency and to its empirical falsification (as suggested by Newmeyer 1986 and 1996) 
or to sociological reasons (as the other historiographers maintain)? Let's begin by reviewing the different positions of those who have tried to characterize the "linguistic wars".

The initial impetus for the debate was provided by Newmeyer's overview of generative grammar (Newmeyer 1986), the first edition of which dates back to 1980. Frederick J. Newmeyer (b. 1944), a former adherent of GS, devoted a chapter (Chapter Four) to "the rise of Generative Semantics", and the subsequent one to "the linguistic wars", which deals, among other things, with "the collapse of Generative Semantics" (see Newmeyer 1986: 132-8). According to Newmeyer (id.: 133), "the fact was that generative semantics destroyed itself". Summarizing Newmeyer's discussion, it can be said that the causes of this 'self-destruction' were: (1) the failed attempt by GS to represent every aspect of linguistic behavior (including typically pragmatic facts) by means of structural representations (in general, tree diagrams); (2) its "whimsical style of presentation", which caused many people to feel that such a theory lacked scientific seriousness; (3) the lack of a firm institutional organization: even though at a given time (approximately, between the late 1960s and the early 1970s) generative semanticists were the majority among generative linguists, they were never able to create a research center comparable to the M.I.T. linguistics department, where in this same period EST was being worked out by Chomsky and his students. The end result of all such factors was the abandonment of GS by its leaders (the most outstanding of whom were George Lakoff [b. 1941], James D. McCawley [1938-1999], Paul M. Postal [b. 1936] and John Robert Ross [b. 1938]) and the consequent "victory" of EST. In the final section of the chapter, Newmeyer speaks of "the legacy of Generative Semantics", namely its insights that were later taken over by EST and its descendants: among them, "the idea of lexical decomposition" as well as "the nonexistence of extrinsic rule ordering, post-cyclic lexical insertion, and treating anaphoric pronouns as bound variables" (Newmeyer 1986: 138).

One of the first reactions to Newmeyer's reconstruction came from Robin Tolmach Lakoff (b. 1942). In her view, Newmeyer "is to be admired for working through a formidable amount of complex, contradictory, and often ill-expressed prose in an attempt to make sense of fifteen years of theoretical developments in linguistics" (R.T. Lakoff 1989: 939). Nevertheless, "Newmeyer misleads the reader and distorts the facts", since "[n]o one who lived through the period as a participant in the "linguistics wars' can claim the status of disinterested observer" (id.: 940). Since Newmeyer was a participant in such "wars", his reconstruction of them is unavoidably biased. Actually, the space devoted by R.T. Lakoff to the discussion of Newmeyer's book is rather limited: little more than a couple of footnotes (p. 956 and 976) and some scattered references.

R.T. Lakoff's paper is, however, important, since it explicitly makes an attempt at reconstructing both the basic theoretical tenets of GS and the overall climate in which the "linguistic war" between GS and EST (or IS) developed. According to her 
reconstruction, the seed of the bitter fight between generative semanticists on the one hand and Chomsky with his staunch followers on the other lies in a deeply different conception of what language is and what the goals of linguistics are. The first group (GS) would have been constituted by "humanists [...] For them, the promise was made in Chomsky's statement that language was a window to the mind, a way to enter that black box, to see how people actually worked" (R.T. Lakoff 1989: 945). The other group (EST), mainly formed by "mathematicians and logicians, by temperament if not by trade $[\ldots]$ were concerned with predictable regularities, patterns that recurred, and the formalisms necessary to capture those generalizations" (id.: 944). In Lakoff's view, the first approach to language and linguistics (namely, the "humanistic" one) is by far the more adequate, or, at the very least, the "formalistic" approach is in itself insufficient: "only part of our work can be concerned with recurring regularities for which formal rules can be written - the rest is more like exegeses of Hamlet" (id.: 985). Given this essential difference between the basic views of the two groups, and given the fact that the "humanists" were attracted by Chomskian linguistics as offering "a window to the mind", it was somewhat obvious that the generative semanticists first found their inspiration more in Chomsky's non-technical works, such as Cartesian Linguistics or Language and Mind, than in his "paradigm-making" Aspects of the Theory of Syntax. In fact, they were especially fascinated by the idea of "linguistic universals", and such universals were basically conceived as being of a semantic nature: "deep structure" as exemplified in Aspects, which contained categories such as articles or modals, and was presented in a SVO order, could clearly not claim to be universal (cf. R.T. Lakoff 1989: 941). Of course, "Chomsky in Aspects spoke of universals of form and substance, clearly indicating that the former were the more interesting" (id.: 980). Generative semanticists, on the other hand, were interested in substantive universals. According to R.T. Lakoff (id.: 962), "[t]he operative assumptions defining generative semantics were these: universality, natural logic, abstractness, continuousness". As she notes (p. 961), the last mentioned assumption, namely that there are no definite boundaries between linguistic categories, nor between the notions of "grammatical" and "ungrammatical", "was perhaps the only one (maybe because it came late) not to be vigorously resisted by CTG ('Classical Transformational Grammar')/EST". This remark is more significant than it would appear to be at first sight: the assumption that linguistic categories are "continuous" marks, in a sense, the "beginning of the end" for GS, as will be seen in Section 3., below. This is probably the reason why this assumption was not "vigorously resisted" by GS opponents, namely EST linguists.

R.T. Lakoff's article also contains much material of an anecdotal character which deals with the atmosphere of the struggle between GS and EST in the years between late 1960s and early 1970s. She describes this struggle as a more or less direct offshoot of the attitude held by generative grammarians against the so-called "Bad Guys" (i.e., the post-Bloomfieldian linguists) and, in general, against any people not inclined to 
accept Chomsky's approach to language. This deeply polemical attitude subsequently developed within the generative school itself. "Much of the fun was in the fighting, and without fun, there was no GS" (R.T. Lakoff 1989: 970). One interesting, as well as puzzling, feature of Lakoff's reconstruction is her assessment of the positions of GS on the one hand and of EST on the other in terms of gender differences: EST showed a prevailing interest for what is formal and structural, whereas GS was more concerned with the complexity of linguistic data. These different attitudes may be traced back to the different ways in which males or females relate themselves to the world:

We can see formalism as maximally non-interactive; and autonomous language theories as treating language as an external, impersonal object. On the other hand, a theory that is concerned with language as an interactive strategy, linking people with one another more or less successfully, is closer to the way women tend to approach the world. (id.: 974)

I leave readers to form their own assessment of this line of argument.

The final part of the article is devoted to the cause of the decline of GS. According to R.T. Lakoff (1989: 981), this lay mainly in the admission that the complexity of language could not be constrained in the format of a grammar: "we began to move away from the idea that social and psychological context could be represented as the basis of syntax in a syntax-central grammar such as GS was". Generative semanticists therefore turned their attention to the pragmatic and social aspects of language, and did away with a formal approach to linguistic facts. They adopted a "functional" approach to language: "the forms language takes are determined in large measure by the functions to which it is put [...] Any theory of language must begin with these functions, and see linguistic form as an artifact thereof" (id.: 984). According to Lakoff " $[t]$ he fissures separating early T(ransformational) G(rammar), classical TG, EST, and G(overnment) $\mathrm{B}$ (inding) are at least as deep as those dividing GS and what its developers are doing today" (id.: 983).

In short, it can be said that R.T. Lakoff sees the "linguistic war" as due to an irreconcilable difference between the views of language held by generative semanticists on the one hand and EST-representatives on the other. She names the abandonment of a formal approach to language as the reason for the decline of GS. According to her, the development of both theories contains some unbridgeable "gaps" between their different chronological phases.

The first book-length treatment of the debate between GS and IS/EST is 1993 book by Randy A. Harris (b. 1956), which gives a detailed and colorful picture of the "linguistics wars" (the shift from adjective to substantive is Harris' work, I think). Harris' attitude is certainly well-balanced: he is neither an enemy of GS nor of EST. His review of the theses and of the arguments of both sides is a correct and very detailed one; his portrayal of the main figures involved in the "wars" (Chomsky, G. Lakoff, 
McCawley, Postal, and Ross, above all) is never unfair (with the exception of his qualification of Dougherty, too hastily dismissed as a "mere polemicist": Harris seems to ignore Dougherty's important contribution to the interpretive theory of pronouns; see Dougherty 1969; also Koerner 2002: 113, which qualifies Harris' assessment of Dougherty as "uncharitable").

In Harris' reconstruction, the decline of GS was mainly due to the lack of a unitary research program: Postal turned from GS to Relational Grammar; G. Lakoff adopted various kinds of "cognitive grammar" in successive years; Ross stressed the continuous ("squishy", in his own terms) nature of linguistic phenomena, but he never worked out an organic model to describe them (Lakoff himself attempted a similar enterprise, developing what he called a "fuzzy grammar", but, as has just been said, he successively developed his research in other directions); and McCawley continued developing a kind of "abstract syntax" which was reminiscent of the 1960s and therefore was "out of step with the times" (Harris 1993: 224). On the other side of the battlefield, Chomsky worked out a research program, firstly dubbed R(evised)EST, then G(overnment) B(inding)-theory, headed by himself and by himself alone, and "anyone in his [Chomsky's] immediate framework who begins working on a strand that is uncongenial to him, or even just uninteresting, rapidly becomes, by definition, out of the program" (id.: 234). Furthermore, one typical feature of GS was that of stimulating interest in a whole series of problems, without offering a clear solution to any of them.

Generative semantics [...] failed for the reason most research programs fail. You can't keep scientists' attention for too long without giving them something to do. They need handles. They need results. The motive forces that gave rise to generative semantics never went away, but Montague grammar, and relational grammar, and nongenerative approaches now looked much more promising. Too, Chomsky engineered another motivation for linguists, restricting the grammar, and provided them with a new set of tools. (id.: 242)

Harris (1993: 248ss.) states that GS left two kinds of legacy: on the one hand, it gave impulse to many models which became alternatives to the Chomskian one, such as pragmatics-oriented linguistics, relational grammar, and, to a certain extent, even sociolinguistics or functionalism; however, the most direct descendant of GS is surely Cognitive Grammar. On the other hand, many GS insights were later adopted by the Chomskian approach: for example, lexical decomposition, or May's $(1977 ; 1985)$ treatment of quantifiers. This, however, had already been noted by Newmeyer (1986: 138), as Harris (1993: 254) explicitly recognizes.

The "linguistic wars" are also the topic of Chapter 15 ("Permanent Chomskian Civil War in Linguistics") of Murray (1994), which is a "social history" (as its subtitle expressly says) of North American linguistics during the 20th century. The basic tenet underlying Murray's book is "[t]hat 'good ideas' are not sufficient to account 
for the history of science" (p. 22); such a tenet, Murray continues, "is the raison dêtre for the sociology of science" (ibid.). Decidedly, Murray does not consider Chomskian linguistics as a 'good idea': in general, Murray (possibly because he is a sociologist) fully disagrees with approaches to languages and linguistics such as the Chomskian one, given its programmatic discarding of any social or communicative consideration. Murray (1994; see especially ch. 9) also rejects Chomsky's reconstruction of the beginnings of generative grammar: in Murray's view, this linguistic theory was not so hindered by post-Bloomfieldians as Chomsky likes to stress. Rather, it was Chomsky's and other generative grammarians' attitude towards post-Bloomfieldians that was highly aggressive.

The most central of them [the post-Bloomfieldians, G.G.] actively fostered Chomsky's and Lees's careers. In terms of aggression, the Chomskians struck first. Their revolutionary rhetoric was not a reaction to the incomprehension of the 'establishment', nor a defense against neophobia or persecution by angry elders (Murray 1994: 244).

According to Murray (p. 434), Chomsky's subsequent attitude towards generative semanticists was not so different from that which Chomsky held towards linguists of the past generation, and the latter attitude can even be considered as a direct offshoot of the former. This thesis has already been advanced by Harris (1993), as Murray stresses, and also by R.T. Lakoff, as has been seen above. According to Murray (1994: 436), the decline of GS was essentially due to the lack of "intellectual leadership". By contrast, Chomsky was a real "intellectual dictator":

Constant purges, persistent rhetoric about a sacred 'revolution' accompanied by persistent misgovernment as judged by any external standards recall Stalin [...]. The 'Cultural Revolution' of Mao Zedong (another Stalinist) is an even better political analog for the Chomskian regime: the aging dictator questions the zeal and loyalty of his former followers, and encourages the ferocity of the young, who gladly challenge 'traditions' of all ages. (Murray 1994: 445).

Let's now turn to the assessment of "linguistic wars" by Geoffrey J. Huck (b. 1944) and John A. Goldsmith (b. 1951). Their central point is the rejection of the thesis that GS was abandoned because it was falsified. According to their view, "if the theory of Generative Semantics had been falsified, why are its central claims by and large still accepted?" (Huck \& Goldsmith 1995: 92). Among such "central claims", Huck and Goldsmith list those already stressed by Harris, such as lexical decomposition and the analysis of quantifiers, to which they add the attempt to constrain the power of grammars:

The idea that there are target structures that the derivational constraints applying to semantic representations conspire to make surface structures conform to in fact offered a Generative Semantics equivalent of Emonds's theory of structure preservation. (id.: $50-1$ ). 
In Huck and Goldsmith's view, both Generative Semantics and Interpretive Semantics had similar aims and both made important contributions to the development of theoretical syntax, but all too often they were unable to understand each other. This appears clearly from the debate over certain empirical issues. Huck and Goldsmith quote three of them as typical: the respectively transformation (McCawley 1968 vs. Chomsky 1971); the "Adverb Preposing" rule (G. Lakoff 1972 vs. Chomsky 1975a); and the analysis of remind as a "surface verb", namely as a case of a lexical insertion following transformational rules (Postal 1970 vs. Chomsky 1972). "Real issues were in fact raised in these exchanges, but were obscured as each side proved unwilling to engage with the other on exactly the other's terms" (Huck \& Goldsmith 1995:77). The reasons for this "lack of communication" between the two sides lay, according to Huck and Goldsmith, in the different view of linguistics held by GS on the one hand and by IS/EST on the other: the former mainly held a "mediational orientation", that is it attempted to give an explanation of the sound/meaning relation; the latter held a "distributional orientation", since it aimed at describing and explaining the rules governing the occurrence of the linguistic elements (see Huck \& Goldsmith 1995: 7-21). In the year following the publication of Aspects, Chomsky shifted from such a distributional orientation to a "psychological orientation" (cf. id.: 24-27): but GS did not accept this shift, since it was itself nearer to the more formal approach of LSLT (Chomsky 1975c[1955-56]; cf. Huck \& Goldsmith 1995: 25). Generative semanticists "were in general committed to discovering structural solutions to semantic problems" (id.: 26) and "the psychological and distributional orientations of the Aspects program were linked in a way that was simply not possible in the Generative Semantics program" (id.: 27). Huck \& Goldsmith therefore conclude that one cannot speak of any "winner" or "loser" of the "linguistic wars". The decline of Generative Semantics was mainly due to external and organizational reasons: while Interpretive Semantics could rely on a

1. McCawley's "respectively transformation" and Lakoff's analysis of some cases of "Adverb Preposing" aimed at demonstrating that the same rules would account both for syntactic and semantic phenomena, and therefore there would be no more need for two kinds of rules (i.e., syntactic and semantic) and for a level of deep structure distinct from semantic interpretation, contrary to what was assumed by Chomsky (1965). Postal's analysis of remind as a "surface verb" derived the sentence John reminds me of a gorilla from an underlying structure more or less as I perceive John similar to a gorilla: the verb remind would then be inserted after the application of some transformations, and this would falsify another assumption of Chomsky (1965), i.e., that all lexical insertions apply before the application of any transformation. Chomsky essentially replied that all such analyses were based on several equivocations. In his view, McCawley treated two different phenomena, one syntactic and the other semantic, as a unitary one; Lakoff maintained that the "standard" approach would have to resort to two different rules of Adverb Preposing, while it actually needed just one; and Postal's analysis of remind, besides postulating some transformations which are not fully motivated, missed some important regularities which can be stated only at the deep structure level. 
definite and strong academic location (the Linguistics Department of M.I.T.), no similar opportunity was offered to Generative Semantics. The Linguistics Department of the University of Chicago, which could have been the center of a Generative Semantics school, thanks to the presence in its staff of people like James D. McCawley, N. Akatsuka McCawley, and Jerrold Sadock, was generally an eclectic department where a lot of different research trends were cultivated. The other main generative semanticists besides J. McCawley (namely, G. Lakoff, Postal and Ross) were scattered throughout the USA (Lakoff at Berkeley, Postal at the IBM research center, and Ross at M.I.T., where he was obviously isolated). Hence, the organizational structure of GS was much less than that of IS: and this explains why, whereas IS (EST) subsequently developed into GB theory etc., GS as such disappeared.

The second part of Huck \& Goldsmith's book consists of four interviews with as many protagonists of the "linguistic wars": Ray S. Jackendoff (b. 1945), George Lakoff, John Robert Ross, and Paul Postal, whose opinions about the story only partly confirm, in my view, the authors' reconstruction of events. In particular, Lakoff's listing of the commitments of the four leaders of GS movement (beside himself, McCawley, Ross and Postal) shows an attitude toward the "psychological orientation" which is more problematic than it appears from Huck \& Goldsmith's discussion. According to Lakoff (see Huck \& Goldsmith 1995: 109 ff.), the four linguists shared the same commitments during the years when they worked within a common framework, but they "gave them different priorities" (id.: 109). Such commitments, in Lakoff's words, were: the Cognitive Commitment ("to take seriously empirical results about the nature of mind and to make the theory of language fit with those results"); the Generalization/Full Range Commitment ("to seek maximal generalizations over the full range of linguistic data, both within and across all domains of language"); the Fregean Commitment ("to characterize semantics using the tools of formal logic"); and the Formal Symbol System Commitment ("the commitment to the central Chomskyan metaphor, namely, that a language is a formal symbol system"). Lakoff, in his own words, had his "priorities in the order given" and, at the time of the interview (1992), he declared to "still hold the Cognitive and Generalization/Full Range Commitment", while he had been "forced by empirical data to abandon both the Fregean and Chomskyan commitments" (id.: 109-110).

Ross had the Generalization/Full Range Commitment first, the Chomskyan Commitment second, the Cognitive Commitment third and the Fregean Commitment, if at all, at a distant last. [...] Postal also placed the Generalization/ Full Range Commitment first and the Chomskyan Commitment second, with the Fregean Commitment a distant third (if at all), and no Cognitive Commitment at all. [...] McCawley's story is much more complicated. McCawley had an additional commitment that was (and still is) primary - what we will call the Solid Ground Commitment. McCawley wants to do theoretical linguistics at all times using ideas and representational techniques that he feels are well understood, like formal logic and classical transformational grammar. [...] He would split the Fregean 
commitment into two parts: (Frege-1) a commitment to empirically established ideas in logic. (Frege-2) a commitment to the formal mechanisms of existing logic. He ranks (1) above (2). [...] Jim [McCawley] also has a subtler version of the Chomskyan Commitment, which again is split into two parts: (Chomsky-1) a commitment to make use of the symbolic representations that have come out of generative grammar to the extent that they are useful for characterizing syntactic phenomena. [...] (Chomsky-2) a commitment to the detailed entailments of the mathematics of the theory of formal grammars [...] Thus, Jim seems to have the following rankings:

1. Solid Ground

2. Generalization

3. Frege-1 (apparently a consequence of (2))

4. Chomsky-1 (apparently a consequence of (1))

5. Frege-2 (apparently a consequence of (1))

6. Cognitive

(id.: 110-1).

According to Lakoff, the commitments of generative semanticists and those of Chomsky "were incommensurable and no amount of evidence or argument would have mattered" (id.: 112). As far as the decline of GS is concerned, Lakoff seems to adhere both to an external and an internal explanation. The external reason was that the generative semanticists were too weak with respect to Chomsky:

In 1967, when Chomsky started attacking us, I was 26, Haj [i.e., Ross] and Jim [i.e., Mc Cawley] were 29, and Paul [i.e., Postal] was 30. We were kids, with no position at all, and we got sucked into a fight with the most powerful linguist in history — a fight on his terms. (id.: 116).

The internal reason was that both Generative and Interpretive Semantics failed from an empirical point of view:

If the Interpretivists had given up and declared Generative Semantics to have "won," I would still have given up on formal logic and transformational derivations and moved on to work on Cognitive Linguistics, and so would be at odds with both Generative Semanticists and Intepretive Semanticists. (id.: 117)

Huck \& Goldsmith (1995) was directly answered by Newmeyer (1996: ch. 10). Newmeyer maintains a position which was more alluded to than explicitly stated in his 1986 book: GS was abandoned because it was falsified. This happened because

...its core principles were refuted. Phenomenon after phenomenon in the 1970 s was uncovered that pointed to nonsemantically based principles applying at the level of deep or surface structure. Linguists abandoned generative semantics to develop models of grammar which gave prominence to those levels. (Newmeyer 1996: 137) 
In particular, two core principles of GS were falsified: the non-existence of a level of deep structure, that is of "a level segregating the lexical and nonlexical rules" (p. 135) and the idea that "all profound syntactic generalizations are semantically based" (ibid.). About the alleged shared positions of both GS and IS (the analysis of quantifiers, lexical decomposition, constraints on grammatical rules), Newmeyer maintains that such similarities are only apparent, to a large extent, and the interpretive approach showed itself to be superior. Newmeyer (ibid.) is also skeptical about "external" explanations of the fall of GS, such as those proposed in Huck \& Goldsmith (1995: ch. 4), which attempt to motivate the decline of GS on the basis of its overly weak roots in the US academic system. If the eclecticism of the Linguistics Department of the University of Chicago was actually an obstacle to the development of GS, the same theoretical framework was predominant in other departments (Newmeyer quotes Berkeley, Illinois, Michigan, Ohio State and Texas). Newmeyer's conclusion is therefore that "people ceased to do generative semantics because they ceased to believe it" (Newmeyer 1996: 137). That conclusion is based on a precise position about what can effect changes in scientific paradigms: "I believe that, in general, scientists can be counted on to make their theoretical choices on rational grounds" (ibid.).

The "linguistic wars" are dealt with in the final pages (493-527) of Seuren's (1998) very original contribution to the history of linguistics, and especially of semantics. Pieter A.M. Seuren (b. 1934), who has been one of the European linguists who adhered to the GS movement, to which he made some important contributions (see e.g., Seuren $1969 ; 1974$ ), is clearly sympathetic with it and bitterly opposed to the EST linguists and to Chomsky in particular. He first states that "[g]enerative semantics was less a theory of meaning than a contribution to the theory of syntax" (Seuren 1998: 474-5). Concerning the impact of generative semantics, Seuren (p. 475) writes that "by 1970 generative semantics was the dominant trend in theoretical linguistics." In his view, the GS movement "is comparable in important respects to that of the Neogrammarians in 19th century Germany, except that its history has been a great deal less fortunate." (p. 502)

What, then, were the causes of the decline of a movement that, at a certain date, appeared to be the "winning" one on the world linguistic scene? According to Seuren, they were mainly sociological reasons, connected with Chomsky's rhetorical skill: " $[t]$ he onslaught on generative semantics was based entirely on claims to prestige and on other sociological factors, leading to wholesale rejection and even utter derision" (p. 475). Chomsky and his followers were so clever as to attack generative semantics "where it was most vulnerable" (ibid.). For their part, the defenders of GS "were unable to separate essential from peripheral issues" (p. 510). In fact, the debate centered around seven topics: (a) Ross' analysis of auxiliaries as main verbs; (b) the status of nominalizations as transformations or lexical entries; (c) the question of lexical 
insertion and the status of 'deep structure'; (d) the analysis of lexical predicates ('prelexical syntax'); (e) the derivational constraints; (f) Postal's analysis of remind; and (g) the status of thematic roles or functions (cf. p. 518). In actual fact, Seuren maintains, the choice in favor of GS or EST was not determined by the solution of any of these topics; and the debate brought about no decisive proofs (or disproofs) for any of the competing theories. "The real issue was, and is, whether the transformational rules should take semantic representations as input. It is a question of the overall superiority of one theory over another" (p. 521).

It would seem, in hindsight, that the sudden collapse of generative semantics [...] was due $[\ldots]$ mostly to the generative semanticists' inability to find an answer to the obfuscations, equivocations, false rhetoric and other unprofessional forms of sophistry employed by Chomsky in his war against them. (ibid.)

The sociological factors that led to the decline of generative semanticists was the atmosphere of freedom and anarchy which prevailed among them, contrasted with what happened in "the circles around Chomsky, where strict discipline and obedience ('loyalty') is exacted” (p. 513). "This idealistic attitude inspired many but it had disastrous organizational consequences for the movement, which lacked the machinery required for a systematic spreading of the word" (ibid.). Seuren's conclusion about Chomsky's attitude is very critical: "Largely as a result of Chomsky's actions, linguistics is now sociologically in a very unhealthy state" (p. 526).

Koerner (2002: ch. 6) makes an attempt both at providing a new assessment of the "linguistic wars" and at "assessing the assessment", namely at providing a critical evaluation of such works as Newmeyer 1986, R.T. Lakoff 1989, Harris 1993, Huck \& Goldsmith 1995 and Seuren 1998. He first observes that the debate in the historiography of linguistics about such a rather limited episode has been surprisingly large; and the episode itself, consisting of "theoretical disagreements and counter-proposals, which ought to have been quite normal within any given framework", looks, "at least in hindsight, to have been blown out of all proportion" (Koerner 2002: 108). He also states that

This episode saw some rather bitter exchanges between Chomsky and several of his students on the place of semantics in syntax, all of which appear to have ended with Chomsky's position holding ground, though perhaps not because he necessarily had all the best arguments on his side. (p. 106)

As far as Koerner's "assessment of the assessment" is concerned, it should be noted that he shares R.T. Lakoff's judgment that Newmeyer's account is essentially biased. Koerner (2002: 111) also remarks that "Lakoff's exposé is biased, too, but it has the advantage that the reader is aware of this right from the start." About Harris (1993), Koerner (id.: 112) says that it could be ranked "higher [...] in scholarly terms than Newmeyer's Linguistics in America". Koerner, however, is also not completely satisfied 
with Harris' book: he remarks that it is exaggerated, exactly as Newmeyer's is, the latter by its restraining linguistic theory in America to generative linguistics, the former "since in order to have 'war' one must also have, for of all intents and purposes, troops and not a mere handful of soldiers, most of whom want to be captains" (ibid.). Furthermore, Koerner does not share Harris' final assessment of the GS/IS debate, namely that GS "helped ensure a healthier and more diverse field" (Harris 1993: 432). On the other hand, Koerner certainly does not share Seuren's catastrophic conclusion quoted above. Indeed, Koerner is critical of the generative framework as a whole. In his view, "where the treatment of meaning is concerned, GS provided many more promissory notes than actual solutions" (Koerner 2002: 126). To support this conclusion, Koerner quotes an important witness in Chafe (2002: 251), where the following statement can be read: "the generative semanticists conceived of semantics as structured in a form still dictated by generative syntax". GS, therefore, was still aiming at giving a formal explanation of meaning: but, Koerner (2002: 127) remarks, “'the study of meaning' [...] may elude a formal treatment by linguists". This is the reason, Koerner implicitly suggests, why GS eventually failed. In recent years, however, "the field of linguistics generally was well on the road to recovery from the Chomskian hegemony, even in North America" (ibid.).

One can therefore conclude that according to Koerner GS failed on account of its internal weakness, which was not, however, restricted to GS alone, but belonged to the generative paradigm as a whole. Furthermore, another important remark by Koerner about GS is the following one: "even on the metalevel of their argumentation, one cannot find many common denominators among the leaders of the GS school" (Koerner 2002: 120). In other words, GS lacked a unitary 'research program'. Koerner also lists other facts that could have been responsible for the collapse of GS, namely the 'external', sociological factors already stressed by Huck \& Goldsmith, to which he adds this further one: "the late 1960s and 1970s witnessed the creation of many linguistics programs and departments [...], and more often than not the jobs were filled by M.I.T. graduates" (Koerner 2002: 125-6). This fact had as its consequence that Chomskian "orthodoxy" became increasingly widespread, while the followers of other trends, such as the former GS, had to take refuge in other departments or to develop other new frameworks, such as "Relational Grammar [...], Generalized (or Head-Driven Phrase Structure Grammar) [...], Cognitive Grammar [...], or, more recently, Optimality Theory” (p. 126).

Let's now attempt to summarize the discussion so far. First of all, it is self-evident that Newmeyer is more or less isolated, in his "anti GS" and "pro IS" position, with respect of the other scholars we have quoted. On the other hand, some assessments are apparently shared by all. One such assessment is, so to speak, tacitly assumed: no scholar taking part in the debate (including Newmeyer) restates Chomsky's characteristic slogan in the epoch of the "linguistic wars", namely that the larger part of GS proposals were no more than "notational variants" of EST proposals (see, e.g., Lakoff 1971a: 265-7; Chomsky 1972: 74-5). Furthermore, there is a general 
agreement on the outcome of the "war": GS "lost" and EST "won". It must also be added that several scholars converge on other points: for example, the lack of an academically institutionalized basis is considered one of the causes of GS's defeat both by Newmeyer and by his opponents; and the fact that the GS leaders lacked a unitary research program is also stressed by Koerner. Furthermore, Koerner (diverging on this topic from G. Lakoff) also espouses the view that GS tried to constrain every aspect of meaning into a formal framework, not dissimilar from that of "classical" generative grammar; and this, although in different terms and, obviously, with a different aim, has also been maintained by Newmeyer.

Hence, we are now faced with the basic historiographical problem raised at the beginning of the present paper, namely which the main reasons were for the fall of GS: its empirical falsification or sociological factors? To solve this problem, some preliminary remarks have to be made. First of all, it should be noted that the debate on the "linguistic wars", being mainly of US origin, tends to be consistently biased by personal views. For example, a large part of the observations by the scholars we have just reviewed deal with Chomsky's personal attitude and behavior, and/or with the problems of US academy (see especially R.T. Lakoff and Murray; the other critics of Newmeyer's approach are also full of anecdotes about Chomsky's unfairness). Such facts are undoubtedly important (although I will not even attempt to discuss them here): but it might be asked whether anything more substantial, or at any rate anything new, could possibly be gained by adopting a more "distant" point of view. As Koerner (2002[1983]: 154) reminds us, "[i]deally, the historian should be at a certain distance from his subject, in the sense that he should have no personal stake in the outcome of his research but be guided by a desire to set the record straight". This ideal is very difficult to attain if the matters the historian tries to assess are more or less contemporary to him: this is the case with the "linguistic wars", and therefore no one who witnessed them (including the author of the present essay) can pretend to be totally unbiased. Nevertheless, the point of view of scholars geographically distant from the topics dealt with can at least soften such a bias. I will therefore aim to contribute to the assessment of the GS/EST debate by showing how it was perceived and what its outcome was from a "peripheral" country, in this case Italy. In so doing, it should be possible to "put on hold" the more specifically US aspects of the debate and to give a more neutral answer to our "basic historiographical question".

\section{Generative grammar in Italy between the late 1960 s and the early 1970 s}

When the "linguistic wars" broke out, generative grammar had just arrived in Italy and it had hardly penetrated any academic institution. Indeed, the Italian academic 
establishment (with very few exceptions) was hostile to any kind of theoretical linguistics, generative or of any other type. Until the 1960s, (almost) the only kind of linguistic research done was in the field of historical linguistics, in the Indo-European and in the Romance or (more seldom) Germanic domain, which was taught under the specifically Italian label of glottologia (i.e., "science of language"): the first chairs of General Linguistics (linguistica generale) were created only in 1967 and were assigned to scholars who were not generative linguists. At the end of the 1960s, the only real group of generative linguists was to be found at the Institute of Psychology of the Italian Research Council (Consiglio Nazionale delle Ricerche, "CNR") in Rome; this group was made up of some young researchers led by Domenico Parisi (b. 1934). An "external" member of the group was Annarita Puglielli (b. 1941), who graduated in Rome with a thesis in English language and literature and subsequently obtained a Ph.D. at Cornell University, under the guidance of F. Agard, with a dissertation entitled The Predicate Phrase in Italian. This group was, however, strongly active, and in 1969 it organized a conference explicitly devoted to "Italian transformational grammar". Since the early 1970s, some other small groups of young scholars interested in generative grammar began to gather in other places as well: one of them was the University of Padua, mainly due to the initiative of Lorenzo Renzi (b. 1939), at that time an associate professor of Romance Philology. Another group was forming at the Scuola Normale Superiore of Pisa, around Alfredo Stussi (b. 1939), a professor of History of the Italian Language. To these small groups some other more or less isolated scholars could be added (for more information about the beginnings of generative grammar in Italy, see Graffi 1990). At any rate, all these more or less scattered linguists had one feature in common: very few of them held any permanent academic job, and those of them who did, like Renzi or Stussi, were not professors of linguistics, but of other disciplines. It must be added that, despite their interest in generative grammar, most of their research did not deal with theoretical linguistics, but with other topics, namely those they were professors of.

It should be plain that, in such a situation, the preference for one or another contestant of the "linguistic wars" could hardly have any impact on the academic career of any of these linguists: the majority of the Italian linguistic establishment of the time distrusted theoretical linguistics in general, and generative grammar in particular. To present oneself as a "Generative semanticist" or as a "Interpretive semanticist" would have made no difference at all. Nevertheless, the splitting of the generative school had its effects in Italy too: in general, the Rome CNR group opted for Generative Semantics, and this choice was maintained until about the mid 1970s by most scholars interested in generative grammar. Later, as we shall see, other linguists preferred to follow the EST path, among them even some who had initially chosen GS. In general, the debate between the two diverging approaches was followed quite attentively by the small Italian generative community. Since one cannot believe that Italian generative linguists would have opted for one or another "party" out of academic interests, 
this is the reason why Italian interventions in the matter could represent a more balanced witness of the "linguistic wars". I also believe that several of these interventions, although they date back almost forty years, are still more useful than some more recent treatments when it comes to understanding the issues which really brought about the "wars". Let's therefore examine some of these interventions.

\section{3. "Chomsky's two souls": the assessment of the GS vs. EST debate by some Italian linguists during the 1970s}

The CNR-group headed by Parisi (see above) adopted the Generative Semantics framework since at least the late 1960s. Within this framework, it developed many original views, the best presentation of which was a volume written by Parisi and his collaborator Francesco Antinucci (Parisi \& Antinucci 1973). In the same year, Parisi and another member of the CNR-group, Cristiano Castelfranchi (b. 1944), gave a talk at the 7th Congress of the Italian Linguistic Society significantly entitled "I limiti di Chomsky" ("Chomsky's limitations"; Parisi \& Castelfranchi 1975). Before presenting such limitations, the authors also listed major Chomsky's attainments: the working out of the concept of 'linguistic competence'; the choice of the sentence as the basic grammatical unit; the recognition of a 'deep' and a 'surface' level in the organization of language and the necessity of connecting both levels; the choice of the speaker's judgments as the basic empirical data; and the view of linguistics as part of a more general science of mind (cf. Parisi \& Castelfranchi 1975: 339-40). On the other hand, Chomsky's major limitations are the following ones, according to Parisi and Castelfranchi: (1) the insight that linguistics is a part of psychology is not actually implemented (id.: 340-1). (2) Chomsky's nativism (namely, his assumption that language is to some degree inborn) is little more than an assertion of principle. In particular, it does not even attempt to refer to biology or to ethology: where this last point is concerned, it especially suffers from the self-imposed limitation of not comparing human with animal communication systems (id.: 341-2). (3) Chomsky's rediscovery of traditional 'rationalistic' grammar is only partial and superficial. Chomsky and his strict followers did not actually revive the way of thinking of people like the Port-Royal scholars and others following this same tradition, namely a trend where grammar, logic, rhetoric and philosophy join together (id.: 342 ). (4) Chomsky overstates linguistic uniformity, while he understates the phenomena of linguistic diversity (id.: 342-3). (5) Meaning receives only a marginal role in Chomsky's system of grammar and syntax is autonomous from semantics. This point, the authors maintain, is strictly connected to the preceding ones: the purely programmatic character of Chomsky's nativism and of his statements that linguistics is part of psychology are due to the fact that his linguistic universals are purely formal, wholly disconnected from universals of cognition. Furthermore, the assumption of the autonomy of syntax and the 
correlative neglect of semantics, pragmatics and communicative intentions cannot help but produce a break with the study of animal communication. Traditional rationalistic grammar, by contrast, attempted at strictly connecting grammar and logic, namely syntax and semantics (id.: 343-4). Besides these limitations concerning Chomsky's general theoretical framework, Parisi \& Castelfranchi listed five further ones more strictly connected with Chomsky's system of grammar, namely: (6) discourse units larger than sentences are not taken into account; and (7) grammatical categories and functions are defined in a formalistic way, given the lack of attention to semantics. This too "surfaceoriented" approach has other consequences: (8) transformational rules are wholly arbitrary; (9) the so-called 'deep' structure is very similar to surface structure; and (10) the linguistic universals proposed by Chomsky at most describe a regularity, without explaining it (id.: 344). According to Parisi \& Castelfranchi (p. 345), all these limitations have a single source: "the never superseded belief, typical of structuralism and which still conditions the development of linguistic studies, that linguistics is a thing in itself". Their conclusion, therefore, is that "we have to cut the last ties which continue to hold Chomsky in the tradition of structuralism and to be more Chomskian than Chomsky himself” (p. 346).

As the attentive reader has surely realized for himself, the bulk of Parisi \& Castelfranchi's arguments about Chomsky's "limitations" are very close to criticisms of Chomsky made by several generative semanticists we have presented in Section 1, and especially to those of R.T. Lakoff. The major difference is perhaps that Parisi \& Castelfranchi's criticism is essentially of a scientific nature, with very little or no personal attack. Actually, they also raise a criticism to Chomsky expressly qualified as a "more ad personam" one, namely "the fact that he [Chomsky] has never accepted a real confrontation with the criticisms raised against him" (Parisi \& Castelfranchi 1975: 345). There is not in their paper, however, any hint to the "warlike" attitude which would seem to have characterized generative grammar since its beginnings in R.T. Lakoff's reconstruction (see above). Moreover, while R.T. Lakoff seems to disagree with the violent critical attitude of Chomsky and his first followers towards structuralism, Parisi \& Castelfranchi's explicit goal, as has just been seen, is to "outdefeat" structuralism, so to speak, and to fully implement what they consider to be Chomsky's more fruitful ideas. At any rate, their paper presented the common core of Chomsky and the followers of GS as well as the disagreements between them in a startlingly clear way that has no match in any contemporary intervention from the other shore of the Atlantic (to my knowledge, at least).

Another member of the CNR-group, Francesco Antinucci (b. 1947), investigated the causes of the "linguistic wars" in a paper which appeared shortly after that of Parisi \& Castelfranchi (Antinucci 1976). Once again, these causes are not traced back to academic and/or personal factors, but to (often hidden) conceptual disagreements. The title of the article alludes to "Chomsky's two souls" ("le due anime"): the author's 
goal, in his own words, "is to show that two deeply different views of language and of the tasks of linguistic theory coexist within T[ransformational] G[rammar]" and that "both such views originate and coexist since the beginnings of TG in the work of Chomsky himself" (Antinucci 1976: 168). Antinucci does not give any specific label for these different views: however, one could dub the first view a "formalistic" and the second a "cognitive" one. To illustrate them, Antinucci starts from Chomsky's first published book, Syntactic Structures (Chomsky 1957). Antinucci (1976: 169) maintains that the formalistic view is expressed by a quotation such as the following one, which can be found in the initial pages of Chomsky (1957):

From now on I will consider a language to be a set (finite or infinite) of sentences, each finite in length and constructed out of a finite set of elements. All natural languages in their spoken or written forms are languages in this sense, since natural language has a finite number of phonemes (or letters in its alphabet) and each sentence is representable as a finite sequence of these phonemes (or letters), though there are infinitely many sentences. Similarly, the set of 'sentences' of some formalized system of mathematics can be considered a language. The fundamental aim in the linguistic analysis of a language $\mathrm{L}$ is to separate the grammatical sequences which are the sentences of $\mathrm{L}$ from the ungrammatical sequences which are not sentences of $\mathrm{L}$ and to study the structure of the grammatical sequences (Chomsky 1957: 13).

According to Antinucci (1976: 174), the psychological-cognitive view appears much later in Chomsky's book, specifically in Chapter 8, where Chomsky announces that "[w]e shall now proceed to formulate the linguist's goals in quite different and independent terms, which, however, lead to very similar notions of linguistic structure" (Chomsky 1957: 85). Chomsky (id.: 87) also states:

What we are suggesting is that the notion of "understanding a sentence" be explained in part in terms of the notion of "linguistic level". To understand a sentence, then, it is first necessary to reconstruct its analysis on each linguistic level; and we can test the adequacy of a given set of abstract linguistic levels by asking whether or not grammars formulated in terms of these levels enable us to provide a satisfactory analysis of the notion of "understanding."

Commenting on both views, Antinucci (1976: 176) remarks that we have to deal "with two very different ways of characterizing language and the tasks of linguistic theory". The essential task of the former one is to develop "the most general and simple system to reach the goal of enumerating the possible combinations" (p. 172). The second one, which Antinucci (p. 176) qualifies as "more traditional", aims at "building a theory which accounts for what Chomsky calls 'understanding a sentence.' But to do this "means to study that capacity which allows one to pass from the phonetic form of a sentence to its meaning" (ibid.). It must also be remarked that 
...the theoretical machinery developed to solve the first task also works with the second one. It is however fundamental to realize the casual character of this coincidence, if one aims at a correct understanding of what subsequently happened during the development of Transformational Grammar. (ibid.; original emphasis)

The chance character of this coincidence, Antinucci goes on, began to be neglected in Chomsky's subsequent works, especially in Aspects of the Theory of Syntax (Chomsky 1965), where such a coincidence "is no longer casual, but definitive and no longer called into question" (Antinucci 1976: 177). "In a nutshell, it can be said that Chomsky (1965) represents a much more precise and detailed formulation of the point of view presented in Chapter 8 of Chomsky (1957), without however rejecting (pay close attention to this fact!) the point of view presented in Chapter 2-6" (id.: 178). In Antinucci's reconstruction, the splitting of the generative school into GS on the one hand and EST on the other has its origin in this ambiguity of Chomsky's view of language. The cognitive view of linguistics was pursued by GS to its extreme consequences: GS identified deep structures with semantic representations, complicated the transformational machinery in order to account for the relation between semantic representations and surface structures and, to attain this goal, also had to enrich this machinery with a new and more powerful device, the so-called "global derivational constraints" (id.: 179-80). Chomsky, instead of accepting this development of his cognitive view of language, reacted against GS by recovering the formalistic point of view, not explicitly but de facto. Together with Jackendoff, he worked out a new theory (EST) where deep structure is no longer the only input to semantic interpretation and the task of transformations is not that of directly relating sound-meaning pairs. The motivations for taking this step, Antinucci maintains (p. 181), can only be of a syntactic-distributional nature; that is, they come from the formalistic view of linguistic theory, the first one adopted by Chomsky (1957), "where such devices were indeed motivated wholly independently of the problem of accounting for the notion 'understanding a sentence' (p. 183). GS and EST therefore represent the respective developments of "Chomsky's two souls." Hence the arguments by means of which each school attempts to show its superiority over the other "can hardly achieve their goal, since they presuppose agreement on how to approach language and therefore on the fundamental tasks of linguistic theory" (p. 186). This is Antinucci's conclusion.

In a paper more or less contemporary with Antinucci's (Graffi 1975), ${ }^{2}$ the author of the present paper (b. 1949) came to a very similar assessment of the GS

2. The title of the paper means "Equivalent or incompatible?" Although it appeared in the proceedings of the 7th Congress of Italian Linguistic Society, actually it was not presented on that occasion (June 1973), but rather was written and completed some months later (Spring 1974) 
vs. EST debate: far from being mere "notational variants" of each other (cf. above: p. 15). GS and EST actually showed a very different conception of language and linguistics. Comparing the respective treatment of four different phenomena by GS and EST (quantifiers, negation, pronominalization, and those related to focus, topic and presupposition), I noticed that the GS analyses were led by the aim to make logic, linguistics and psychology coalesce; whereas EST analyses (especially, Jackendoff's) kept these three disciplines clearly distinct from one another (cf. Graffi 1975: 329). Of course, Chomsky had explicitly defined linguistics as "a branch of psychology", but I remarked from the start (p. 288) that Chomsky's actual work was conducted in an "almost exclusively formalistic perspective". Just like Antinucci, I therefore found the real point of opposition between GS and EST in their respective views of linguistics: "cognitive" vs. "formalistic". At the end of the essay, I addressed the topic of the distinction between competence and performance, which the latest GS papers (e.g., G. Lakoff 1971b; McCawley 1972) tended in fact to obliterate. I depicted this last step taken by generative semanticists as a real turnabout within contemporary linguistics:

...what was the greatest pride of structuralism, the proposal of an idealizing, abstract, description of linguistic facts (a proposal certainly received by Chomsky) is being labeled as an unpardonable error (Graffi 1975: 335)

It now seems to me that, by making such remarks, I was pointing to what was then becoming the most typical feature of GS in its "last" period, namely around the mid 1970s: the desire to jettison abstraction and to investigate linguistic phenomena even in their most minute details.

In 1979, an anthology appeared in Italian containing translations of some essays by generative semanticists (G. Lakoff, R.T. Lakoff, McCawley, Postal, Ross), edited by Guglielmo Cinque (Cinque 1979). The editor (b. 1948), after graduating at the University of Padua with a dissertation in the History of the Italian language, spent a considerable time in Berkeley, where, among other things, he took part in a research project on semantics and pragmatics jointly headed by C. Fillmore, G. Lakoff and R.T. Lakoff. In the opening lines of his introduction, Cinque (1979: 11) states that Generative Semantics “[...] can by now be considered as definitively ended". Hence, Cinque attempted to describe "the essential reasons which led to its abandonment" (ibid.). In a nutshell, Cinque sees these "essential reasons" as lying in the contrast between the aims

and was published in July 1975. At the time of its composition, I was a graduate student at the "Scuola Normale Superiore" of Pisa; since I graduated in Philosophy, I was interested in linguistics especially as a source of epistemological and methodological problems. Antinucci's paper appeared in June 1976 and it was completed, I suppose, several months before (at that time, the journal "Lingua e Stile" had a long waiting list). These are the reasons why the two papers, while sharing several similar conclusions, do not refer to each other. 
of GS on the one hand and its explanatory power on the other. Cinque sees the aim of GS as its attempt to account for any linguistic phenomenon, be it syntactic, semantic, pragmatic, social or whatsoever, by means of the same theoretical machinery (essentially, "abstract structures" and transformations governed by "global derivational constraints"). According to Cinque (1979: 32),

a logical flaw underlies this assumption. To keep fields separate which show properties and principles that are very different from each other does not mean we deny the obvious relationships existing between such fields. It simply means that we tackle what naturally comes together while dealing separately with phenomena which appear to be essentially unhomogeneous from each other.

Another typical assumption of late GS was that of the "squishy" nature of linguistic categories: there would be no definite boundaries between, e.g., nouns and verbs, rather all parts of speech would lie on a "continuum" (see, e.g., G. Lakoff 1973; Ross 1972). "It is difficult to imagine an end point more distant than this one from any degree of explanatory adequacy that is found in any of today's most advanced sciences" (Cinque 1979: 33). The essential flaw of GS, in Cinque's view, lies exactly in this lack of restrictiveness:

Successive theories within the evolution of the GS research program have characteristically been theories each with less empirical content than the preceding one: both because of their increasingly diminished restrictiveness in specifying the notion of possible grammar and because of the continuous increase in the kinds of phenomena which were considered to fall under their domain; moreover this occurred without any corresponding increase in the explanatory depth of the theory (Cinque 1979: 36).

This situation, according to Cinque, was the reason why, around 1974-75, GS was abandoned, at least as a unitary research program. Cinque closes his essay by listing some important "historical merits" of GS, such as the following ones: the stress on the necessity of distinguishing between the syntactical form of sentences and their logical form, as well as some empirical observations and generalizations which EST capitalized on (e.g., the "island phenomena" of Ross 1967; the "surface structure constraints" of Perlmutter 1970; G. Lakoff’s 1968 and McCawley’s 1971 remarks about pronominalization phenomena; Postal's 1971 treatment of the so-called "cross-over phenomena").

\section{Conclusion: What lesson can be drawn from the Italian reception of the "linguistic wars?}

Let's try to summarize how the "linguistic wars" were perceived by the Italian generative linguists during the 1970s. As has been seen, the adoption of GS tenets was 
fairly widespread: moreover, this confirms Seuren's statement (see above: 12) that by 1970 GS was the dominant linguistic trend. In fact, people like Castelfranchi, Parisi or Antinucci explicitly worked within a GS framework. Cinque, as has been said, had been a collaborator of G. Lakoff and other generative semanticists. As for myself, I was looking at the debate from an outsider's position (that of a young philosopher interested in methodological questions) and I was therefore "neutral" between the two opposing parties. As has been said in Section 2, at that time generative linguistics of any tendency was very weak, in Italy, from the academic point of view: hence the option for either of the two conflicting schools, GS or EST, could hardly have any consequence for anyone's academic career. Hence, it does not come as a surprise that the assessment of the debate by all the linguists we have quoted looks essentially fair and unbiased, also with some deep insights into its conceptual roots. Such roots were seen by all interveners as lying in "Chomsky's two souls", the formalistic and the cognitive ones. From this starting point, the commonly shared conclusion was not that GS and EST were merely "notational variants" of each other, but that they represented, on the contrary, two quite different ways of conceiving linguistics. This was essentially the conclusion drawn by Antinucci and myself. Parisi \& Castelfranchi, on the other hand, explicitly opted for the "cognitive soul" and therefore considered Chomsky's work as a fundamental step in the development of linguistics which had, however, to be surpassed. Nevertheless, GS eventually declined in Italy more or less as in the USA: Parisi and the CNR group developed a kind of cognitive linguistics along their own paths, which shared very few similarities with the original GS, although it was certainly inspired by it (more or less as happened with G. Lakoff). Antinucci first dealt with questions of linguistic typology, producing a very original book on the subject (Antinucci 1977); later, he devoted himself, more than to linguistics, to general questions of cognition, also studying the primates from this point of view. In 1979, as has already been seen above, a former generative semanticist such as Cinque explicitly maintained that the research program of GS had already come to its conclusion. In subsequent years, Cinque adopted the research program which was the most direct offshoot of EST, Chomsky's "Government-Binding Theory," and made many important contributions to it (see, e.g., Cinque 1995). ${ }^{3}$

What lesson can we draw from all these facts concerning the issue we are presently dealing with, namely the assessment of the "linguistic wars"? In a nutshell, that the collapse of GS was not essentially due to external, academic or sociological reasons, but mainly to the impossibility for it to reach the goals it had set itself. Such

3. I also adhered to the Government-Binding paradigm, and published some papers and textbooks within this framework, before devoting myself almost entirely to the history of linguistics. 
goals were, as has been seen, the construction of a system of cognitive linguistics able to account for every aspect of meaning, including the pragmatic and social ones: but these were impossible to reach with a system like that which characterized GS, namely the machinery of tree diagrams and transformational rules essentially inherited from Chomsky's early work. Actually, a similar conclusion has already been drawn by G. Lakoff, in his interview with Huck and Goldsmith (see above: 401). As will be remembered (see ibid.), Lakoff rejected the criticism of having attempted to reduce every linguistic fact to syntax, but the point seems to me rather marginal: what really matters is Lakoff's recognition that, whatever the outcome of the "linguistic wars" may have been, he would have abandoned formal logic and transformational derivations for cognitive linguistics. Therefore, GS's fall was due mainly to "internal" reasons, in the USA as in Italy, and, no doubt, all over the world. However great Chomsky's academic power, his rhetorical ability, and M.I.T.s organizational strength may have been, these cannot have been the real reasons for the decline of the generative paradigm dominant at the beginning of the 1970s.

At this point, one could reasonably raise an objection: Lakoff is right, neither GS nor EST could "win", since both were basically wrong; nevertheless, the former disappeared as such, while the latter consistently developed, first becoming GovernmentBinding Theory and eventually the Minimalist Program, without any significant break between such different phases and under Chomsky's constant leadership. Is this not a sign of Chomsky's rhetorical ability and M.I.T.'s organizational capacity?

I would like to give to this objection a historiographical answer, not a theoretical one. In other words, I will not discuss the merits, or the flaws, of Chomsky's research programs since the 1970s, which probably would involve an overall assessment of his work. I will therefore take an "agnostic" position: whether Chomsky's theory is the most insightful view of language of any time, or whether it is the dirtiest trick in the history of linguistic studies, one has to explain why it recovered, after a period of crisis, during which GS was dominant. Besides, I do not mean that generative grammar, in any of its variants, has ever been the universally accepted form of linguistics: many trends developed and are still developing independently from it, some with a critical attitude towards it (think, e.g., of sociolinguistics, or of the several kinds of functionalism, etc.). The historiographical problem we are investigating is restricted to generative linguistics: namely, why did EST eventually survive and develop while GS disappeared?

The answer I am going to propose is the following one: Chomsky recovered from the crisis he undoubtedly suffered between the end of the 1960s and the early 1970s by asserting an explicit reconciliation of his "two souls", namely the formalistic soul and the cognitive one. This recovery began with a very technical essay, written in 1971 and published as Chomsky (1973), and found its first systematic presentation, technical as well as popularizing, in Chomsky (1975b). In these essays, Chomsky's most challenging 
idea was to substantiate his former claims that linguistics is part of psychology (Chomsky 1965), which until then had seemed merely programmatic, by asserting that some apparently purely linguistic theoretical constructs are really psychological hypotheses. Actually, this step had already been taken in the preceding years: but it was difficult to convince anyone that phrase structure or transformational rules have real psychological content. The so-called "Derivational Theory of Complexity" worked out by some psycholinguists in the late 1960s, initially seemed promising in this sense: sentences derived by means of more transformations apparently took longer to process than other ones derived by means of less transformations. But shortly after its formulation, such a theory faced several conclusive counterexamples. Chomsky never disavowed his former views, and always maintained that the problem of "psychological reality" is a pseudo-problem: to say that a theory is psychologically real, in his view, means no more than to say that it is true (cf. e.g., Chomsky 1980: 107). Nevertheless, this position sounded unconvincing to most linguists: as has been seen in the preceding section, both scholars inspired by GS (like Parisi, Castelfranchi and Antinucci) as well as those who were essentially "neutral" (like myself) felt unsatisfied with Chomsky's statements about the psychological character of his linguistic rules.

Chomsky's strategy changed with his 1973 article. Instead of presenting a whole system of phrase structure and transformational rules, as he had done in works such as Chomsky (1957) or Chomsky (1965), he focused his attention on the conditions on rules. In so doing, he developed some ideas that he had presented in some of his earlier papers, like Chomsky (1964), but he especially capitalized on Ross's (1967) detailed work on "syntactic islands". As is well known, Ross had shown that the application of transformational rules, like those which form wh-questions or relative clauses, does not always generate grammatical sentences, being blocked in some given contexts (the "islands"). Chomsky (1973) started a research program attempting to explain Ross's "island conditions" by deriving them from some very abstract principles (the labels and nature of which we can pass over here). Such principles, together with another feature of transformational rules, namely their "context-dependency", were assumed by Chomsky to form part of what he called "Universal Grammar" (UG), which is to say, in his own words:

the system of principles, conditions and rules that are elements or properties of all human languages not merely by accident but by necessity - of course, I mean biological, not logical, necessity. Thus UG can be taken as expressing "the essence of human language". UG will be invariant among humans. UG will specify what language learning must achieve, if it takes place successfully (Chomsky 1975b: 29).

This "psycho-biological" interpretation of linguistic theory was therefore arrived at starting from the investigation of the formal tools of transformational grammar: the empirically observed result that transformational rules are subject to given constraints 
was used to draw the conclusion that such constraints are of a biological nature. The formalistic and the cognitive "souls" of Chomsky no longer coincided by mere chance, as happened in Chomsky (1957) and as was noted by Antinucci (1976), but the first one had become the key to discovering the other. Of course, this passage was considered by many critics as unjustified, and many scholars still today reproach Chomsky's linguistics for only alleging its "psychological reality." On the other hand, several linguists found the possibility that transformational generative grammar, which until then had been felt to be of a purely abstract, formal nature, could have a cognitive impact, very attractive. Furthermore, this linking of the formal approach with the cognitive one had been reached in the opposite way of that of GS: while GS attempted to give a whole picture of the mind-language relationship by continuously enlarging its empirical domain and providing its technical machinery with new devices (see Cinque's remarks presented in the preceding section), EST's trademark was the reduction of the generative power of transformations. Of course, it can be debated whether this step taken by Chomsky was a real scientific discovery or simply a new rhetorical move devoid of significance: but at any rate it made EST appear to be a research program deserving to be further developed and deepened, which was not the case with GS, as G. Lakoff himself bore witness. This can explain, in my view, why GS was later felt as the "loser" and EST (and its descendants) the "winner" of the "linguistic wars".

\section{References}

Antinucci, Francesco. 1976. "Le due anime di Noam Chomsky". Lingua e Stile 11. 167-187.

Antinucci, Francesco. 1977. Fondamenti di una teoria tipologica del linguaggio. Bologna: Il Mulino.

Chafe, Wallace L. 2002. "Searching for Meaning in Language: A Memoir". Historiographia Linguistica 29. 245-261.

Chomsky, Noam. 1957. Syntactic structures. The Hague: Mouton.

Chomsky, Noam. 1964. Current issues in linguistic theory. The Hague: Mouton.

Chomsky, Noam. 1965. Aspects of the theory of syntax. Cambridge: M.I.T. Press.

Chomsky, Noam. 1971. "Deep Structure, Surface Structure, and Semantic Interpretation".

Semantics. An Interdisciplinary Reader in Philosophy, Linguistics and Psychology, ed. by

Danny D. Steinberg \& Leon A. Jakobovits, 183-216. Cambridge: C.U.P.

Chomsky, Noam. 1972. "Some Empirical Issues in the Theory of Transformational Grammar".

Goals of Linguistic Theory, ed. by Stanley Peters, 63-130. Englewood Cliffs, N.J.: Prentice-Hall.

Chomsky, Noam. 1973. "Conditions on Transformations". A Festschrift for Morris Halle ed. by

Stephen R. Anderson \& Paul Kiparsky, 232-286. New York: Holt, Rinehart \& Winston.

Chomsky, Noam. 1975a. "Questions of form and interpretation”. Linguistic Analysis 1. 75-109.

Chomsky, Noam. 1975b. Reflections on language. New York: Pantheon Books.

Chomsky, Noam. 1975c. The logical structure of linguistic theory. New York: Plenum Press.

Chomsky, Noam. 1980. Rules and representations. New York: Columbia University Press.

Cinque, Guglielmo, ed. 1979. La semantica generativa. Torino: Boringhieri. 
Cinque, Guglielmo. 1995. Italian syntax and universal grammar. Cambridge ; New York: Cambridge University Press.

Dougherty, Ray C. 1969. “An Interpretive Theory of Pronominal Reference”. Foundations of Language 8. 488-519.

Graff, Giorgio. 1975. "Equivalenti o inconciliabili? Su alcuni sviluppi recenti della linguistica trasformazionale". Teoria e storia degli studi linguistici (Atti del VII Convegno internazionale di studi della Società di Linguistica Italiana), ed. by Ugo Vignuzzi, Giulianella Ruggiero \& Raffaele Simone, 281-338. Roma: Bulzoni.

Graffi, Giorgio. 1990. "Generative Grammar in Italy”. Grammar in Progress. GLOW Essays for Henk van Riemsdijk ed. by Joan Mascaró \& Marina Nespor, 147-152. Dordrecht: Foris.

Harris, Randy Allen. 1993. The linguistics wars. New York: Oxford University Press.

Huck, Geoffrey J. \& John A. Goldsmith. 1995. Ideology and linguistic theory : Noam Chomsky and the deep structure debates. London; New York: Routledge.

Koerner, E.F.K. 2002. Toward a history of American linguistics. London ; New York: Routledge.

Lakoff, George. 1968. Pronouns and reference (parts I and II). Bloomington, Ind.: Indiana University Linguistics Club.

Lakoff, George. 1971a. "On Generative Semantics". Semantics. An Interdisciplinary Reader in Philosophy, Linguistics and Psychology, ed. by Danny D. Steinberg \& Leon A. Jakobovits, 232-296. Cambridge: C.U.P.

Lakoff, George. 1971b. "Presupposition and Relative Well-formedness". Semantics. An Interdisciplinary Reader in Philosophy, Linguistics and Psychology, ed. by Danny D. Steinberg \& Leon A. Jakobovits, 329-340. Cambridge: C.U.P.

Lakoff, George. 1972. "Linguistics and Natural Logic". Semantics of natural language, ed. by Donald Davidson \& Gilbert Harman, 545-665. Dordrecht: Reidel.

Lakoff, George. 1973. "Fuzzy Grammar and the Performance/Competence Terminology Game”. Papers from the Ninth Regional Meeting, Chicago Linguistic Society, ed. by Claudia Corum, T. Cedric Smith-Stark \& Ann Weiser. 271-291. Chicago: Chicago Ling. Soc.

Lakoff, Robin T. 1989. “The Way We Were: Or, The Real Actual Truth about Generative Semantics: A Memoir”. Journal of Pragmatics: An Interdisciplinary Monthly of Language Studies 13: 6. 939-988.

May, Robert. 1977. The Grammar of Quantification, Ph.D. Dissertation, M.I.T..

May, Robert. 1985. Logical form : its structure and derivation. Cambridge, Mass.: M.I.T. Press.

McCawley, James D. 1968. "The Role of Semantics in a Grammar”. Universals in Linguistic Theory, ed. by Emmon Bach \& Robert T. Harms, 125-169. New York: Holt, Rinehard.

McCawley, James D. 1971. "Where do NPs Come from?” Semantics. An Interdisciplinary Reader in Philosophy, Linguistics and Psychology, ed. by Danny D. Steinberg \& Leon A. Jakobovits, 217-231. Cambridge: C.U.P.

McCawley, James D. 1972. “A Program for Logic”. Semantics of natural language, ed. by Donald Davidson \& Gilbert Harman, 488-544. Dordrecht: Reidel.

Murray, Stephen O. 1994. Theory groups and the study of language in North America : a social history. Amsterdam/Philadelphia: John Benjamins.

Newmeyer, Frederick J. 1986. Linguistic theory in America. Orlando: Academic Press.

Newmeyer, Frederick J. 1996. Generative linguistics : a historical perspective. London: Routledge.

Parisi, Domenico \& Francesco Antinucci. 1973. Elementi di grammatica. Torino: Boringhieri.

Parisi, Domenico \& Cristiano Castelfranchi. 1975. "I limiti di Chomsky". Teoria e storia degli studi linguistici (Atti del VII Convegno internazionale di studi della Società di Linguistica Italiana), ed. by Ugo Vignuzzi, Giulianella Ruggiero and Raffaele Simone, 339-346. Roma: Bulzoni. 
Perlmutter, David M. 1970. "Surface Structure Constraints in Syntax". Linguistic Inquiry 1. 187-256.

Postal, Paul M. 1970. “On the Surface Verb 'Remind””. Linguistic Inquiry 1. 37-120.

Postal, Paul Martin. 1971. Cross-over phenomena. New York: Holt Rinehart \& Winston.

Ross, John R. 1967. Constraints on Variables in Syntax, Ph.D. Dissertation, M.I.T.

Ross, John R. 1972. “The Category Squish: Endstation Hauptwort”. Papers from the Eighth Regional Meeting, Chicago Linguistic Society, ed. by Paul M. Peranteau, Judith N. Levi \& Gloria C. Phares. 316-328. Chicago: Chicago Ling. Soc.

Seuren, Pieter A.M. 1969. Operators and nucleus: a contribution to the theory of grammar. London: Cambridge University Press.

Seuren, Pieter A.M. 1974. Semantic syntax. London: Oxford University Press.

Seuren, Pieter A.M. 1998. Western linguistics. An historical introduction. Oxford ; Malden, Mass.: Blackwell.

Steinberg, Danny D. \& Leon A. Jakobovits. 1971. Semantics; an interdisciplinary reader in philosophy, linguistics and psychology. Cambridge: Cambridge University Press. 
PART IV

The past and future directions 



\title{
British empiricism and Transformational Grammar
}

\author{
A current debate
}

\author{
Jacqueline Léon
}

Université Paris-Diderot, Histoire des Théories linguistiques

Our aim in this paper is to show, that, although Chomsky's interest in empiricist British linguistics was always very limited, and the controversy of Transformational Grammar against British empiricism was led more by NeoFirthians against Chomsky than by Chomskyans against Firth and his followers, the debate has gone through different phases since the 1950s, and is not yet over. It was very vivid in the 1960s, when British empiricist linguists, such as Randolph Quirk and M.A.K. Halliday, discussed mostly grammaticalness and competence versus performance acceptability and gradience. Contrary to what happened with the Neo-Bloomfieldians, the debate did not touch on the validity of corpora. After a decline of several decades, the discussion was revived in the 1980s-90s with the rise of large computerized corpora. At this point the debate concerned mostly new topics still pertaining to TG, such as corpora, statistics, and creativity. It was carried out within the area of computational linguistics and is still currently vivid. The issue is to investigate whether this debate with TG is still relevant, in particular for corpus linguistics, or whether these arguments are past their time and are revived only for strategic reasons, in pretending to justify the emergence of a new linguistics.

\section{o. Introduction}

One of the first Ph.D.s supervised by Chomsky bore on Firthian linguistics. However, Chomsky's interest in empiricist British linguistics was always very limited, if not totally absent, and the controversy was led more by Neo-Firthians against Chomsky than by Chomskyans against Firth and his followers. Yet, it should be said that this mostly unilateral debate is worth investigating. It has gone through different phases since the 1950s, and is not yet over. This debate concerns mainly the views of the 'first' Chomsky before 1965, that is, Transformational Grammar (TG).

Our aim in this paper is to show, that as early as the 1960s, there was a debate among British empiricist linguists about TG assumptions which referred mostly to 
grammaticalness and competence versus performance acceptability and gradience. Contrary to what happened with the Neo-Bloomfieldians, it did not touch on the validity of corpora. The strength of the arguments raised in the 1960s diminished in the following decades while the Neo-Firthians' works evolved into the creation of corpora and grammars. There was a revival of interest in the 1980-90s with the appearance of large computerized corpora. At this point the debate concerned mostly new topics still pertaining to TG, such as corpora, statistics, and creativity, and is still currently vivid. We will discuss whether this debate with TG is still relevant, in particular for corpus linguistics, or whether these arguments are past their time and are revived only for strategic reasons.

\section{Chomskyans and British empirical linguistics}

\subsection{Chomsky's answers to Halliday's remarks at the 9th International Congress of Linguists in 1962}

It seems that the 9th International Congress of Linguists was the only encounter between Neo-Firthians and Chomsky (Chomsky 1964a). In his reaction to Chomsky's presentation, Halliday (b. 1925) first praised TG, saying, "The view of language as 'rulegoverned creativity' is especially to be welcomed" (Chomsky 1964a: 987). He then criticized Chomsky's hegemonic stance rejecting all other models, and challenged TG on fourteen points which can be summed up as the interdependence between systems (negation and aspect for instance), the role of intonation in grammar, the levels above sentences, particularly texts, the theoretical status of intuition, lexicalness and grammaticalness, texts as situational context, and variety of language according to use. In other words, he addressed the issue of how a theory of contextual meaning can be adapted to the transformational model.

These points were ignored by Chomsky, who asserted that the only model to be considered as an alternative to TG was the structural distributionalist model. Actually, in 1962, the Neo-Bloomfieldians were the only opponents worthy of being fought and defeated, and the Neo-Firthians were regarded as absolutely inoffensive.

\subsection{Postal against Halliday}

Neo-Firthians seemed to become more dangerous in 1966 when Halliday published his paper 'General Linguistics and its application to language teaching' (McIntosh \& Halliday 1966). This paper, which reprised some views of Halliday's paper "Categories of the theory of grammar" previously published in 1961 in Word, was strongly criticized by Paul Postal (b. 1936) in his 1969 review in Language. In his review, Postal attempted to assimilate Halliday's approach to that of the Neo-Bloomfieldians, fighting both 
movements as a single enemy. ${ }^{1}$ Halliday was viewed as a behaviourist and a physicalist "noise is said to be the substance of language" (Postal 1994[1969] : 150) - advocating a positivist and antimentalist philosophy of science. The Firthian assumption that texts, written or spoken, was the basic linguistic material for the observation and study of language, was interpreted by Postal as

Halliday's failure to make an explicit distinction between language and speech, i.e. between the system of internalized linguistic knowledge, which is the language, and the actual use of this to produce linguistic performances. (Postal 1994[1969] : 149).

\subsection{Langendoen, Firth and Robins}

According to the lists of Chomsky's Ph.D. students (Koerner et al. 1986; Otero 1994), Terence Langendoen (b. 1939) was the first who obtained his Ph.D. supervised by Chomsky (1964b). With respect to Chomsky's indifference to British empirical linguistics, it may seem strange that his first Ph.D. student focused on Firth and Neo-Firthians.

Actually, Robert Lees (1922-1996) was Chomsky's first Ph.D. student. ${ }^{2}$ As he finished before the Department of Linguistics was created at M.I.T., his degree was in Electrical Engineering. On the other hand, Langendoen was the first to complete a degree in linguistics. Here are the circumstances explaining how he came to work on Firthian linguistics. In January 1964, Chomsky had been asked by Bernard Bloch (1907-1965), then chief editor of Language, to review Studies in Linguistic Analysis edited by Firth (1890-1960) in 1957. He "could not make sense" of the book and apparently felt relieved when Langendoen proposed that he would write the review (Langendoen 1964a).

It was not surprising that Langendoen was involved with this book mainly dealing with prosody and Indian languages, as he had done fieldwork in India studying the phonology of Mundari, a language of Bihar. For personal reasons, Langendoen had to obtain his Ph.D. very rapidly. He had access to the British linguistic literature at the Kennedy School of Mission where he worked as a visiting lecturer, and Chomsky accepted the supervision of his dissertation on Modern British Linguistics which was

1. In order to to launch an attack on the current enemy of the mid-1970s, i.e. generative semantics, Katz and Bever (1994[1976]) used the same device consisting in assimilating the new approach to Neo-Bloomfieldian empiricism in order to disqualify generative semantics and position TG as a revolution marking the defeat of empiricism.

2. I am grateful to Terry Langendoen for giving me the precious pieces of information appearing in this paragraph. Responsibility for the use and interpretation of them in this paper is of course mine. 
completed the same year (Langendoen 1964b). The other committee members were Peter H. Matthews (b. 1934), and Morris Halle (b. 1923) who said he was quite interested in Firth's analysis of prosody, but particularly liked the chapter on Malinowski (1884-1942).

Therefore, although the fact that Langendoen worked on Firthian Linguistics had little to do with Chomsky's current interests or strategies, his dissertation, published in 1968, probably constitutes one of the most fruitful discussions by Chomskyans on British empirical linguistics of that period. Besides, it led into an interesting exchange with the Neo-Firthian Robert Robins (1921-2000).

Langendoen read Firth with the new Chomskyan glasses of rationalism and innate structures. He considered Firth to be a behavioristic distributionalist making "catalogs of 'observables' neatly arranged in tables" (Langendoen 1964a: 308), who only differed from Bloomfield (1887-1949) in that he asserted that the study of meaning was central to linguistics. Langendoen (1968) pursued his criticism of Firth's ideas on meaning based on the notion of context of situation, which ran counter to Chomskyan creativity: "his view is based on the opinion that language is not 'creative' and that a person is totally constrained essentially to say what he does by the given social situation" (Langendoen 1968: 3). ${ }^{3}$ In his review, Robins (1969) reproached Langendoen for having left aside Firth's works on the history of linguistics as well as many Neo-Firthian works on collocations, context of situation and prosody. Taking up the long controversy, dating back to antiquity, of whether word meaning or sentence meaning should have priority, Robins pointed out that Firth and Malinowski were on the side of the priority of sentence meaning, from which word meanings were derived by abstraction. On the contrary, Langendoen, following semantic options favoured by TG linguists, chose to start with word meanings.

Robins questioned Langendoen's interpretation of Firth, asserting that Firth did not deny creativity in language. On the contrary, according to Firth, creativity is performed within the essential diversity of socially and contextually determined language in use. More specifically, Robins related infinite creativity to the Firthian notion of 'renewal of connection,' which, he said, Langendoen seemed to have misunderstood. The notion of 'renewal of connection' appeared in Firth's work in 1952 as a strong empiricist point, urging the constant reapplication of the linguist's abstractions to the flux of experience :

The linguist must be clearly aware of the levels at which he is making his abstractions and statements and must finally prove his theory by renewal of connection with

3. Conversely, Langendoen praised the dissertation of John Lyons (b. 1932) on semantics, completed under the direction of W.S. Allen (b. 1918) and R.H. Robins in 1961, which made use both of Firthian semantics and Chomskyan theory (Lyons.1963). 
the processes and patterns of life. Without this constant reapplication to the flux of experience, abstract linguistics has no justification (Firth, 1968[1952]: 19).

The direct controversy between British empiricists and Chomskyans stopped there. Facing the growing success of TG, the Neo-Firthians tried to take up the challenges it presented in order to assess their own assumptions.

\section{Challenging TG in the 1960s: Quirk and Halliday}

In the 1960s, British linguists shared common views inherited from the British tradition such as interlocked levels of lexis and grammar, the importance of text and context, the crucial role of use, and the centrality of applied and descriptive linguistics. Some of them were more particularly Firth's views: meaning by collocation and restricted languages. The two main figures who challenged Chomsky's TG were Randolph Quirk (b. 1920) and MAK Halliday.

\subsection{Quirk: Eliciting linguistic performance as the source of evidence for theories of language}

By his training and his attention to syntax, Quirk's career is rather singular. He claimed a multifaceted affiliation, combining British empiricism and American structuralism. After a degree in Old English, he chose to complete his Ph.D. in syntax, and spent a post-doc year (1951-52) in the United States where he met Bernard Bloch at Yale, Freeman Twaddell (1906-1982) at Brown, Roman Jakobson (1896-1982) at Harvard, and Kenneth Pike (1912-2000) and Charles Fries (1887-1967) at Ann Arbor. Obviously, he did not belong to Chomsky's earlier followers. ${ }^{4}$

Though his interest in grammar moved him away from the Firthian concern with meaning and lexis, Quirk remained linked to the British empirical tradition with the importance he gave to Henry Sweet's inheritance of "lexicographical syntax," use, and search for grammatical patterns. One of his main mentors was Fries, to whom he owed the idea of working on recorded conversations, which was coherent with the British phonetic tradition.

His diverse sources partly explain why his notion of use changed over the years, particularly when he faced TG approach. When he started the Survey of English Usage

4. In his autobiography, he tells how he was dismayed by the 'fascistic' intolerance of the Young Turks who, in 1962 at the International Congress in Cambridge, deserted American structuralism to become fanatical about TG, after having used structuralism against their senior teachers (Brown \& Law 2002). 
(SEU) in 1960, his aim was to describe English syntax from the study of use. His aim was to provide "descriptive analysis - systematic and as complete as possible - of English grammatical usage, so that a body of data can be available for a new and objectively based prescriptivism." (Quirk 1968[1960]: 49). As the SEU subtitle indicates, he attempted to describe the "full range of co-existing varieties and strata of educated English, spoken as well as written at the present time."

In his early work in the early 1960s, use is defined as ordinary language. Language, he said, "is rooted in the ordinary events of every day and in ordinary men's usage" so that linguists "need to pay special attention to language in its most ordinary, everyday manifestations" (Quirk 1962: 66). Very early, however, he envisaged elicited data in addition to attested corpus data for his investigation of use. In particular, he aimed at accounting for the discrepancy between what one will accept as a hearer and what one will produce as a speaker. In his early study on restrictive relatives, Quirk observed that educated English speakers used who much more frequently than that when the antecedent was human, while they did not make any distinction between who and that in an acceptance test (Quirk 1968[1958]).

Attempting to develop tests accounting for these phenomena, he criticized distributionalist methods, most notably Harris's substitution techniques and acceptance tests, which, he said, "investigate what is barely possible rather what than is actual and normal in linguistic behaviour" (Quirk 1968[1960]: 81).

On the other hand, considering Chomsky's nonsensical sentences in Syntactic Structures, he claimed that it is only with corpora of natural usage that collocations can be distinguished, enabling us to deny the linking of colourless and green, or green and ideas, despite the fact that such linking is permitted at the level of basic syntactical structure. At this stage, he remained an empiricist and advocated inductive methods. Rules can be formulated from the patterns emerging from a corpus of natural usage (that is, numerous, attested recorded or transcribed data), while paying attention to variation.

After the publication of Aspects, Quirk and Svartvik (1966) expressed great interest in the double dichotomy of competence/performance and grammaticality/acceptability. Although they did not deny the idea of competence, they aimed at investigating it experimentally by testing performance. They opted for the study of acceptability and performance.

While there can be little doubt that there is something called 'competence' which underlies but has by no means a necessary one-for-one correspondence with 'performance', there must remain a very great deal of doubt as to whether it is accessible to experimental investigation. We would hope, however, that light can be thrown on this deeper faculty by the study of performance ... and at any rate it is with performance, via acceptability, that we shall be concerned in the present study." (Quirk \& Svartvik 1966: 11) 
They adopted a psycholinguistic approach, challenging Chomsky's wariness concerning performance, which could be only defined negatively as "whatever the grammar does not account for" (Abney 1996: 5).

It should be noted that Quirk and Svartvik's approach was more cognitivist than behaviouristic and they compared their inquiry with GA Miller's perceptual one. For Quirk, acceptability is a multifaceted phenomenon which cannot be reduced to a strict judgment of yes or no. This view rests on his distrust of intuition; that is, introspection into one's own usage. Quirk assumed that, very often, there was no relationship between the speakers' beliefs about their own usage and their actual use (as observed in a corpus for example). Therefore he distinguished between performance tests eliciting a subject's use and judgment tests eliciting his attitude. Thus, testing acceptability, Quirk \& Svartvik (1966) and Greenbaum \& Quirk (1970) came to the conclusion that gradience can be shown at this level. ${ }^{5}$

The application of judgment tests showed that very few sentences are considered by the speakers to be either wholly acceptable or wholly unacceptable. Performance and judgment are in a deliberate reciprocal relation, so there is a deliberate reciprocal relation between corpus and elicitation. Therefore, one cannot rely upon corpus alone or upon introspection alone. Both need to be supplemented by experimental evidence.

Quirk also discussed Lees' views on adjective structures, and did not hesitate to challenge 'generalized grammatical transformation, considering that gradience and Halliday's delicacy are more easily applicable to certain type of phenomena. Like Halliday, he questioned the need to regard such divergent theories as mutually exclusive.

Chapter 12 of the second edition of The Use of English, published in 1968[1962], may be considered as the most Chomskyan part of Quirk's work. He addressed the Chomskyan issue of creativity, acknowledging the extreme complexity of its mechanism: "we have decoding devices in our linguistic faculty that enable us to understand 'new' sentences and new interrelations of sentences and their parts" (Quirk 1968 [1962]: 208). He also proposed the investigation of selection rules controlling the formation of acceptable linguistic sentences, accepting the even if rules should be recursive, linguists are nevertheless far from agreement on the types of rules they should be.

5. The idea that acceptability can be gradient is compatible with Chomsky's views. Concerning grammaticality, the issue is more questionable. According to Katz \& Bever (1976), Chomskyan grammaticality cannot lead to gradients. They argue that, even if Chomsky proposed a theory of degrees of grammaticality (Chomsky 1964b), this does not imply gradience. Actually, as each ungrammatical string is assigned to some category representing the nature of its departure from grammaticality, such a theory involves absolute categories, not a gradient. 
As seen in this section, Quirk did not reject Chomsky's TG but attempted to challenge it in the area of performance, conceived of as use. Contrary to Katz and Bever (1994[1976]) who denied any empirical character to linguistics (Sampson 2001), Quirk attempted to combine a cognitive approach with inductive corpus-based methods. Recognizing creativity and some TG properties of rules such as recursivity, he did not work outside the Chomskyan paradigm. On the contrary, he tried to widen it by investigating performance on cognitive bases.

From the diversity of his data (artificial data produced in an experimental situation, and written and spoken data attested in a corpus of usage), the first corpus of usage systematically built by a linguist was developed. In fact, the SEU was the first sampled and representative corpus of variation in English.

\subsection{Halliday : Lexicality vs. grammaticality}

Halliday's profile, marked by World War II, is more common for British linguists of his generation. Mobilized in the army during their studies, these linguists had to contribute to the war effort with their knowledge of several non-European languages. Halliday had learnt Chinese at the SOAS, was mobilized in the Intelligence service, and eventually prepared his Ph.D. on Chinese, supervised by Firth, Wang-Li and Robins (Brown \& Law 2002).

In the 1960s, Halliday's work, clearly claiming his Firthian affiliation, focused on collocation meaning (Firth 1951), collocation investigation from corpus data, and the continuum between lexis and grammar (lexicogrammar). Contrary to Quirk's concern with corpora of ordinary usage, Halliday's corpus is a corpus of texts, and his conception of language is language in activity; that is, as a social object. He developed Firth's pioneering sociolinguistic notion of "speech community" into the notion of "register" in the 1960s, and into sociosemiotics through collaboration with the sociolinguist Basil Bernstein.

Additionally, he claimed that linguistics belongs to natural, empirical sciences, just like physics. Linguistics, he says, is a mixture of natural sciences, logic and mathematics, and social behavioral sciences: "Language ... can be thought of as ...organized noise used in social situations or in other words 'contextualized systematic sounds'” (McIntosh \& Halliday 1966: 3).

Unlike some of Quirk's views which could be regarded as compatible with Chomsky, Halliday's empiricist approach was totally inconsistent with Chomsky's cognitive views. Instead of investigating "ragbag" performance, he challenged the competence notion of grammaticality. ${ }^{6}$

6. "Competence (in its original sense) refers to the natural language in its idealized form; performance refers to everything else - it is a ragbag including physiological side-effects, 
After asserting in his paper of 1961 that "colourless green ideas sleep furiously" is "unlexical," Halliday proposed the supplementation of grammaticality with the notion of lexicality which can be conceived in terms of degrees (see his remarks at the 9th Congress of Linguists in 1962, $\$ 1$ above). As a nondiscrete notion, lexicality can be interpreted probabilistically. Linguists have to deal with language events and to describe languages as predictions according to oppositions such as possible/ impossible for grammar, but as likely/unlikely for lexis.

Many points here are incompatible with Chomsky's theory: regarding language events and lexis as linguistic objects, taking into account context of situation, probabilities as a property of lexicogrammar, and finally, the fact that the limit between 'very unlikely' and 'impossible' is often difficult to determine. Continuum as a key notion in Halliday's approach is completely irreconcilable with Chomsky's view. See the following excerpt:

The patterns can be thought of as predictions about language events, predictions which first distinguish between what is possible and what is impossible, and then within what is possible, show what is more likely and what is less likely; but the line between impossible and very unlikely is often difficult to draw... in English, for example 'easiest' is more likely that 'most easy' although both are possible. (Halliday et al. 1964: 137-138)

See, by contrast, Chomsky's views on the inconsistency of an approximate conception of grammaticalness:

Evidently, one's ability to produce and recognize grammatical utterances is not based on notions of statistical approximation and the like. The custom of calling grammatical sentences those that "can occur, " or those that are "possible", has been responsible for some confusion here. It is natural to understand "possible" as meaning "highly probable" and to assume that the linguist's sharp distinction between grammatical and ungrammatical is motivated by a feeling that since the 'reality' of language is too complex to be described completely, he must content himself with a schematized version replacing "zero probability, and all extremely low probabilities, by impossible, and all higher probabilities by possible." (Hockett, A Manual of Phonology, 1955: 10). We see, however, that this idea is quite incorrect, and that a structural analysis cannot be understood as a schematic summary developed by sharpening the blurred edges in the full statistical picture. If we rank the sequences of a given length in order of statistical approximation to English, we will find both grammatical and ungrammatical sequences scattered throughout the list ; there appears to be no particular relation between order of approximation and grammaticalness. (Chomsky 1957: 16-17).

mental blocks, statistical properties of the system, subtle nuances of meaning and various other things all totally unrelated to each other. (Halliday 1978: 37). 


\section{Transformational Grammar and corpora: A current issue?}

\subsection{Transition phase: $1970-80$ s}

In the 1970-80s, the British linguists carried out corpus-based grammars and collocation searches without any new challenges to TG. Quirk's psycholinguistic experiments and performance testing gave way to the constitution of corpora on variations of English, following the pattern of the SEU and its immediate descendent, The Brown Corpus. These corpora no longer questioned competence and performance directly. Instead, they addressed the issues of corpus representativeness and of genres as variation factors, evolving into the making of grammars based on actual usage (Quirk et al. 1972).

Following Halliday, Sinclair undertook corpus-based studies on collocations. While Halliday's line was more lexicogrammar-oriented, Sinclair was more interested in lexis itself. His conception of corpora was quite different from the views of Quirk and his followers about representative corpora based on samples and genres. For Sinclair, corpora should be made of authentic and integral texts that can be expanded indefinitely. Every text is the sample of a whole language. However, his theoretical and methodological options encountered technical limits as they required huge amounts of data which largely exceeded computer capacities in the 1960s. So he was forced to stop collocation studies and devote himself to Discourse Analysis until large computerized corpora became available in the late 1980s.

As for Halliday, he developed his systemic functional grammar and social semiotics in connection with the ethnography of communication (Dell Hymes) and sociolinguistics (Basil Bernstein), which were on the rise in the USA. Meanwhile, he went on with his critiques of Chomsky's TG. While acknowledging that Chomsky was the first to show that natural language could be dealt with as a formal system (1978), he pointed out the cost of its very high degree of idealization, which led Chomskyan linguistics to a certain kind of reductionism: "If you are interested in linguistic interaction, you don't want the high level of idealization that is involved in the notion of competence; you can't use it, because most of the distinctions that are important to you are idealized out of the picture" (Halliday 1978: 37).

It should be said that Halliday's and British linguists' work contributed to the general functionalist trend of the period. They attempted to show that grammar cannot be studied in an isolated way, pointing to the necessity of describing language in context. In particular, variation in actual usage (as attested in corpora) may be determined by grammatical, lexicogrammatical and discursive features. It can be said that their works constituted some of the attempts at the recontextualization of grammar, which TG endeavoured to decontextualize (Geeraerts 2003). 


\subsection{Chomsky's arguments on corpora revisited in the 1990s}

With the rise of large computerized corpora appearing in the 1990s, TG issues were newly challenged by corpus linguists, in order to legitimate their claim of making Corpus Linguistics an autonomous and unified linguistic field (See Léon 2005, 2008). Two types of questions were discussed: the relevance of corpora, and language creativity, which originated from the two trends generally acknowledged among British corpus studies: corpus-based and corpus-driven trends. Corpus-based linguists, Quirk's followers, hold the view that corpora are example sets devised to test existing theoretical assumptions. They tried to revive Chomsky's arguments against corpora and statistics dating back to the 1950-1960s in order to contradict them and legitimate corpusbased research as a new linguistics. They claimed a theoretical program, systematically opposed to the Chomskyan model : performance against competence, linguistic description against universals, use of quantitative methods in addition to qualitative methods, empiricist approach against rationalist approach.

Conversely, the corpus-driven approach, held by Sinclair's followers, does not involve any a priori theoretical view as it assumes that theory is induced from the corpus: "large quantities of 'raw' text are processed directly in order to present the researcher with objective evidence" (Sinclair, 1991: 1). ${ }^{7}$

\subsection{Chomsky's arguments against corpora}

As seen before, arguments against corpora, Markov chains and statistics did not belong to the British empirical debate in the 1960s. It was a controversy between Chomsky and the Neo-Bloomfieldians. However, according to Quirk's followers of the 1990s, Chomsky had crushed the first generation of corpus linguistics. His criticisms against corpora, statistics, and the Markov model of the 1950-60s are put forward to account for the decline of corpus studies: "the impact of Chomskyan linguistics was to place the methods associated with Computer Corpus Linguistics in a backwater, where they were neglected for a quarter of a century" (Leech 1992: 110).

This statement involves two assumptions which would turn out wrong. First, the early computerized corpora should be regarded as the revival or the continuation of the American Structuralists' conception of corpora. As we saw, this is contradictory with the proper British tradition of corpora which flourished in the 1960-70s. Second,

7. It should be said that Halliday did not share this rather positivistic view. For him grammar does not emerge from corpora: "the corpus does not write the grammar for us. Descriptive categories do not emerge out of the data. Description is a theoretical activity" (Halliday, 2002: 406). 
Chomsky's criticisms were actually equally concerned with every statistical model, but were virulent enough to stop any corpus researchers. We will examine this point, limiting ourselves to reporting Chomsky's arguments against the use of corpora and statistics.

Chomsky's conception of corpora, developed in 1956-59, involved several points: language is infinite, unlike the Neo-Bloomfieldian conception of language as a finite set of utterances; any corpus should be projected by the grammar; grammaticality is not a probabilistic notion; and lastly, language is innovative according the principle of linguistic creativity. See the following excerpts:

On what basis do we actually go about separating grammatical sequences from ungrammatical sequences ?... First, it is obvious that the set of grammatical sentences cannot be identified with any particular corpus of utterances obtained by the linguist in his field work. Any grammar of a language will project the finite and somewhat accidental corpus of observed utterances to a set (presumably infinite) of grammatical utterances. In this respect, a grammar mirrors the behavior of the speaker who, on the basis of a finite and accidental experience with language, can produce or understand an indefinite number of new sentences. (Chomsky 1957: 15).

The notion "grammatical in English " cannot be identified in any way with the notion "high order of statistical approximation" to English. (Chomsky 1957: 16)

If we rank the sequences of a given length in order of statistical approximation to English, we will find both grammatical and ungrammatical sequences scattered throughout the list. (Chomsky 1957: 17)

We constantly read and hear new sequences of words, recognize them as sentences, and understand them. It is easy to show that the new events that we accept and understand as sentences are not related to those with which we are familiar by any simple notion of formal (or semantic or statistical) similarity or identity of grammatical frame. Talk of generalization in this case is entirely pointless and empty. It appears that we recognize a new item as a sentence not because it is generated by the grammar that each individual has somehow and in some form internalized. And we understand a new sentence, in part, because we are somehow capable of determining the process by which this sentence is derived in this grammar. (Chomsky 1959: 56).

The debate between Chomsky and the Neo-Bloomfieldians, which took place in 1958 when he was invited by Archibald Hill (1902-1992) to the University of Arizona, is very enlightening. Corpora appear twice in Chomsky's hypothetico-deductive machinery: first as the input which should be analyzed by the theory, and second as the output generated by the grammar. Only the first corpus is 'natural. To study a language which he does not know, the linguist should start from a natural corpus of sentences provided by an informant. The second corpus, containing ill-formed as well as wellformed sentences, should be tested by the informant in order to validate the grammar, 
and therefore the linguistic theory. Chomsky disagreed with the Neo-Bloomfieldians on the adequacy of generating natural corpora. Any natural corpus is skewed and cannot be generated, since it may produce non-sentences (ill-formed sentences) or be incomplete :

Hill: It seems to me that if I were working with transformations, I would first select a representative sample of English sentences for my corpus. I would then try to see if by selection of kernel sentences within the corpus I could then generate the whole of the corpus. This is all that I would do.

Chomsky: It is almost impossible to generate a corpus without going beyond it. Any natural corpus will be skewed. Some sentences won't occur because they are obvious, others because they are false, still others because they are impolite. The corpus, if natural, will be so wildly skewed that the description would be no more than a mere list.

Hatcher: ${ }^{8}$ I have a corpus of about one hundred and twenty-five thousand sentences, and I do not find that it is skewed.

Chomsky : But you do not have a machine which generates all of your sentences. I don't believe you could get a machine which would generate just these sentences. If you want to generate just the corpus and nothing beyond it, it would be a miracle if you could give any description shorter than the corpus itself. (Chomsky, 1962: 159f.).

Further arguments against this kind of procedure, and more generally against empiricist methods, were developed later in Aspects (1965), by the time Chomsky introduced the distinction between competence and performance. Corpora are useless to study competence. Neither observed data nor inductive procedures from observed data will provide reliable information on the linguistic intuition of the speaker.

Note that Quirk was the only British linguist to have taken into account this critique in the 1960s. Deciding that the Survey should include not only a corpus of natural usage but also elicited data, he said that Chomsky's "objections to corpus studies (for example, that they can provide rules only for the generation of an identical corpus) are unsoundly based." (Quirk 1968[1965]: 168)

Another aspect pointed out by Chomsky is that he doubted that some sentences, although simple, might be found in any natural corpus, so that probability and grammaticality should be distinguished:

Chomsky : ... I think 'John ate a sandwich' is a highly unusual sentence that I would be unlikely to say in a lifetime. Just as I would be unlikely to say 'grass is green' or 'birds fly'. These sentences have zero probability. Maybe in talking about probability of sentences you mean grammaticality.

8. Anna Granville Hatcher (1905-1978). 
Stockwell: 9 You might say 'John is eating a sandwich' but not 'John eats a sandwich'

Chomsky: Probability has to do with the number of times you find a given item. If we take a sentence like 'John ate a sandwich' I would bet that you would not find it in all the sentences recorded in the Library of Congress. (Chomsky 1962[1958]: 180) ${ }^{10}$

The idea of grammar as a set of rules generating a set of sentences was probably quite difficult to understand for the linguists of that time. In particular, it seems that the misunderstanding stemmed from the fact that Chomsky spoke of types - abstract entities, i.e. sentences as they are generated by the grammar - while empiricists dealt with tokens - attested occurrences which can be observed in natural corpora (see Bundy 1999 on this point).

The argument that well-formed and (above all) simple sentences may never occur in any natural corpus was taken up by Sinclair (1984) when he distinguished wellformedness from naturalness: "Well-formedness and naturalness are independent variables" (Sinclair, 1984: 95). In a way, his view could be seen as an attempt to restate and solve the opposition of type vs. token. A simple sentence, such as 'Prince Charles is now a husband' can be syntactically well-formed, and yet native speakers may still feel that it is unnatural. Sinclair suggests that naturalness will always be probabilistic and therefore distinct from well-formedness, which is absolute; the textual evidence for naturalness is probabilistic.

\subsection{Chomsky, statistics and probabilities}

As for statistical properties of language and the use of probabilities, significant variations can be observed in Chomsky's position. As early as 1956, he rejected any statistical definition of grammaticality in terms of Zipf's law: ${ }^{11}$

There is no significant correlation between order of approximation and grammaticalness. If we order the strings of a given length in terms of order of approximation to English, we shall find both grammatical and ungrammatical strings scattered throughout the list..." (Chomsky 1956: 116).

9. Robert Stockwell (b. 1925).

10. This argument has been completed by the contrast between grammatical sentences and meaningful sentences exemplified by the famous 'Colourless green ideas sleep furiously'. The significant point here is that Chomsky refers to very simple sentences.

11. According to Zipf's law, empirical data on word frequencies may by represented by a harmonic law: when the words of a text are ranked in order of decreasing frequency, the frequency of a word is inversely proportional to its rank. Benoît Mandelbrot (b. 1924) developed a statistical model which provided a theoretical explanation for Zipf's law. 
Actually, as far as they do not concern syntax, he did not deny the interest of statistical studies:

Given the grammar of a language, one can study the use of the language statistically in various ways; and the development of probabilistic models for the use of language (as distinct from the syntactic structure of language) can be quite rewarding. (Chomsky, 1957: 17, note 4)

His main opposition centered on finite-state grammars and Markov's model, which involve syntactic issues, ${ }^{12}$ as they regard the sentence as a left-to-right finite state Markov process or verbal chain in which the probability of a word's occurrence is determined by the occurrence of the words preceding it. Chomsky used several arguments against this model. First, unlike phrase grammar and transformational grammar, finite-state grammar is unable to deal with recursivity. Secondly, Chomsky rejected Markov's model because it is unable to generate the set of grammatical sentences and will generate non-sentences as well.

However, when discussing Markov's model more thoroughly in their paper, Chomsky and Miller (1963) agreed that, though it cannot be implemented for syntax to provide the set of grammatical sentences, it can be applied for lower-level production, such as phonemes, letters and syllables. They agreed that Zipf's law as well as Mandelbrot's work, dealing with probabilities and word length, have to be taken seriously, and their results discussed and verified.

In short, Chomsky did not deny statistical studies but excluded them from his realm of interest. Counter to what is argued by current corpus linguists, his critiques had no bearing on early corpus-based studies which were mainly dedicated to word frequency counts.

\subsection{Linguistic creativity, memory and innateness}

Linguistic creativity appeared in 1956 and was defined by Chomsky as the ability of a native speaker to produce or understand new sentences and to reject ungrammatical sentences. Furthermore, Chomsky claimed that frequency of use does not have any role in the recognition of grammatical sentences. In other words, linguistic creativity is independent of frequency. Later, in his review of B.F. Skinner's Verbal Behavior (1959), he specifies that the faculty of recognition of grammatical sentences is not formal,

12. This is also Abney's position: ' ... the inadequacy of Markov models is not that they are statistical, but that they are statistical versions of finite - state automata! Each of Chomsky's arguments turns on the fact that Markov models are finite - state, not on the fact that they are stochastic. None of his criticisms are applicable to stochastic models generally.' (Abney 1996: 20) 
nor semantic, nor statistical, but belongs to infinite linguistic creativity where remembrance is of no use. However, it was only in 1962 at the 9th International Congress of Linguists that his views on linguistic creativity became central to his linguistic theory. Some fundamental aspects of Chomsky's linguistic theory are linked to linguistic creativity, such as the infiniteness and the innateness of the faculty of language. Besides, Chomsky insists on the ability of hearers not only to identify deviant sentences and but to give them an interpretation. ${ }^{13}$ Later in the same text, he specified that creativity refers to 'rule-governed creativity' by means of an explicit generative grammar, and not 'rule-changing creativity' which is involved in the ordinary everyday use of language (Chomsky 1964a[1962]: 921). For Chomsky "the 'creative' aspect of language" was associated with "the system of generative rules that assign structural descriptions to arbitrary utterances and thus embody the speaker's competence in and knowledge of his language." (Chomsky 1964a[1962]: 922). This argument was repeated in Aspects where the role of remembrance is denied in the use of language.

Sinclair's idiom principle puts into question Chomsky's concept of creativity. Sinclair (1991: 109) speaks of two complementary 'principles', namely the 'open-choice principle' when speakers choose words in rule-governed sequences, compatible with Chomsky's views and generally adopted by linguists, and the 'idiom principle' when they choose semi-preconstructed sequences, such as idioms, phrasal verbs or collocations. As Kennedy (1998) points out, TG tends to downplay the use of ready-made sequences of words, although there is no reason why many sentences cannot be treated as partially lexicalized rather than purely syntactically generated. He gives the example of at the moment which can be treated as a prepositional phrase or as a lexicalized unit. Kennedy claims that the use of partially lexicalized elements does not restrict the innovative property of language. A similar argument has been put forward by historians of linguistics, such as Joseph (2003), to show that Chomsky's conception of infinite linguistic creativity obliges him to reject any 'collocational' model, while for Sinclair and his followers, collocations do not involve a lack of creativity.

For corpus linguists of the Sinclair tendency, the use of high frequencies of preconstructed segments, such as collocations, gives new relevance to memory in language learning and production. Collocations reintroduce probabilities as a property of language.

13. See Joseph (2003) for his analysis of the asymmetry of Chomsky's linguistic creativity focusing on the speaker's production rather than the hearer's understanding. Hearers can only register passively what speakers have created. Furthermore two mechanisms of interpretation are at work in the hearer's understanding: for well-formed sentences, the interpretation is generally automatic and straightforward. For ill-formed sentences, a mechanism of imposing interpretation is often at play. 


\subsection{Intuition, use and corpora}

As early as 1958, Stockwell (Chomsky 1962[1958]) pointed out the circularity and the confusion between speaker's intuition and grammaticality in Chomsky's Syntactic Structures. Remember that intuition played a double role in his hypothetico-deductive method : intuition is the object of study and, at the same time, it permits the discovery of new linguistic knowledge.

In the 1960s, Quirk attempted to address this difficulty by using experimental tests which could take into account the discrepancy between speakers' intuition and their production. Contrary to intuition and corpus data, observations obtained by experimentation are repeatable.

Chomsky (2004[1982]) envisaged the issue of use only to state that our current cognitive knowledge makes investigation on this topic quite impossible, such as was performance in the 1960s :

The use of language is a result of interactions of the language faculty with other cognitive systems that govern thinking, intention, articulation, sense and so on... given the current situation that so little is known about the other cognitive systems that interact with the language faculty, it is not entirely clear whether a scientific theory of language use will ever be possible. (Chomsky 2004 [1982]: 8-9)

Current corpus linguists, and more generally tenants of empiricism in linguistics, question the opposition systematically claimed between attested data from corpora, and intuition, on behalf of use. Sinclair (1991) criticized the sole recourse to intuition as unable to deal with language use. First, properties such as grammaticality do not exist for the lexis. Besides, in large texts, the meaning of the most frequent words is not the meaning given by intuition. Language use seems to delexicalize the most frequent words by reducing their distinctive contribution to meaning. Kennedy (1998) assumes a mixed position associating intuition and corpus work. He acknowledges that corpora are not able to account for some aspects of language, such as the distinction between possible and impossible. Unlike many corpus linguists, Kennedy does not seem to advocate the sole recourse to attested data, considering that an element not occurring in a corpus does not mean that this element does not exist. Conversely, the occurrence of an element in a corpus does not establish its grammaticality:

Whether utterances which involve phonetic or syntactic reductions such as where you going?, wannanother one?, or Good that you got here early have to be accounted for grammatically will probably depend in the final analysis on frequency of occurrence and intuitive judgments as to what is 'normal'. (Kennedy 1998: 271f.) 
According to Sampson, the issue of possible/impossible cannot rely on intuition alone because of the impossibility of observing 'negative evidence. ${ }^{14}$ Linguistics is an empirical science. In the 1950-60s it was considered progress to replace crude observational evidence with intuitive data. But nowadays, with the availability of large amounts of computerized data, "there is really no good reason why linguistic research should be pursued in a less empirical manner than any other science." (Sampson 2001: 139)

\subsection{Large amount of data : A scientific status for linguistics?}

The availability of large amount of data is a crucial issue. Until the 1990s, linguistics had hardly any data and "was about where physics had been at the end of the fifteenth century, before technology had evolved to enable physicists to observe and to conduct experiments." (Halliday 2002: 7).

Halliday was always eager to include linguistics among experimental sciences. For Halliday et al. (1964), linguistics did not become a laboratory subject till the 1950s, with the appearance of tape recorders and computers, catching up with phonetics, which became a laboratory subject in the 1920s.

In the introduction of the first volume of his Collected works, Halliday (2002) returns to this point, considering that the evolution of the computer and of record instrumentation in the 1990s has revolutionized linguistics, as it makes large amounts of data available. Computerized corpora allow linguists to undertake quantitative analyses on a statistically significant scale. Additionally, the computer enables us to study sound waves and to test descriptive generalizations so as "to crack the semiotic code":

From all this it should be possible in the next decade or two to crack the semiotic code, in the sense of coming fully to understand the relationship between observed instances of language behaviour and the underlying system of language. (Halliday 2002: 8)

\section{Conclusion}

With the increasing power of computers and the availability of huge amounts of data, unthinkable in the 1960s, the debate between British empiricists and Chomskyans has known a revival. However, a shift can be observed, and it can be said that most of the key issues separating TG and Neo-Firthian empiricist approaches has become encompassed

14. Milner (1989) adopts the very opposite view: language data may be possible materially, that is, attested, and impossible in grammar 〈〈le possible de langue et le possible matériel sont disjoints $\rangle$ (Milner 1989: 83). 
into the more general opposition between computational formal linguistics, and corpus empirical linguistics.

Some corpus linguists, belonging originally to the Quirk and Leech group, have used some of early Chomsky's arguments against corpora and statistics, as mere strategic device of legitimation a contrario, sometimes attempting to found a "new - computational corpus - linguistics" (see Léon 2007). Some linguists even advocate the emergence of probabilistic linguistics challenging formal linguistics (Bod et al. 2003).

Some old issues are still vivid such as the double dichotomy competence/performance and grammaticality/acceptability. Some are on the rise such as the issue of variation, already tackled by Quirk in the 1960s and which TG still cannot account for. On the other hand, some linguists advocate reconciliation between both approaches. Finally other issues have been renewed such as the status of data for languages sciences and of linguistics as an experimental science (See Cori \& David 2008 for a critical analysis of corpus linguists' arguments).

While some aspects of empiricist methodology, worked out in the 1960s, have been abandoned, such as Quirk's psycholinguistic tests on performance as supplementary data for the study of variation, other aspects of the British tradition are still flourishing.

When he questioned grammaticality with the idea of "lexicogrammaticality" in 1962 (see discussion published in Chomsky 1964a), Halliday raised the issue of continuum versus absolute values of yes or no. Continuum and gradation for grammaticality and acceptability, promoted by Quirk and Halliday, are still advocated by current corpus linguists against the Chomskyan view of strict binary judgment. Through oppositions between possible/impossible or likely/unlikely, the debate between probabilistic properties of language and discreteness of grammar is still alive.

Contrary to Chomsky's claims in Syntactic Structures, Bod et al. (2003) consider that speaker's judgments on well-formedness of sentences are well-predicted by probabilistic methods.

Moreover, continuum between lexis and grammar or any other categories can still have descriptive or explanatory power for certain languages, and surpasses the mere Firthian/TG opposition.

The old opposition between competence and performance still gives rise to diverse options, even though for some corpus linguists the dichotomy is not so clear. In major cases, the generalization of computational language processing had a shifting effect on the dichotomy, insofar as it permits to handle both competence and performance and to use either formal or statistical methods. Competence is computable since it can be dealt with using discrete rules, whereas performance is not computable and is better handled with probabilities and continua. In doing so, these corpus linguists try to reconcile both positions. In fact, while some of them claim a clear distinction, others argue in favor of the complementary of both approaches (Habert \& Zweigenbaum 2002; Pereira 2000). 
The availability of data is a further key issue in the opposition between Chomskyan and empiricist approaches. For some authors, such as Halliday, huge quantities of computerized data equipped linguistics with laboratory (or observatory) instruments, which bestow it with the status of a real experimental science. In the same line of thought, Abney (1996) and Manning (2003) argue in favor of large amounts of corpus data, considering that generativists work on a very narrow class of artificial data, only produced on the basis of intuition, so that explanatory hypotheses are disconnected from verifiable linguistic data.

From the opposite point of view, formal computational linguists discuss the validity of attested data. The fact that new instruments make attested data more available does not imply that they make it grammatically possible. Moreover, new attested data are not necessarily new linguistic facts. As to the status of linguistics as an experimental science, it can be considered that it is the properties of examples, which can be easily manipulated by linguists, that bestow the status of experimental sciences to linguistics, and not the availability of huge amounts of data.

In some way or other, this diversity of positions shows that the discussion on TG principles based on Neo-Firthian views, far from being outdated, is still vivid. It is worth mentioning that whereas the debate was one-sided in the 1960s, it is now more balanced between formalists inspired by Chomskyan TG and corpus linguists coming from British empiricism. Even though it has mainly shifted to the debate on the relevance of corpus-based methods between computational formal linguists and corpus empirical linguists, it still raises current issues for language sciences.

\section{References}

Abney, Steven. 1996. "Statistical Methods and Linguistics". The balancing act : combining symbolic and statistical approaches to language, ed. by Judith L. Klavans \& Philip Resnik. Cambridge, Mass.: M.I.T. Press.

Bod, Rens, Jennifer Hay \& Stefanie Jannedy. 2003. Probabilistic linguistics. Cambridge, Mass.: M.I.T. Press.

Brown, E.K. \& Vivien Law. 2002. Linguistics in Britain : personal histories. Oxford, UK ; Boston: Blackwell.

Bundy, David. 1999. "De la notion d'adéquation. Un regard sur l'histoire et les fondements de la grammaire générative à travers les premiers travaux de Noam Chomsky”. Paper presented at the DEA université Paris III.

Chomsky, Noam. 1956. “Three Models for the Description of Language”. IRE(Institute of Radio Engineers) Transactions on Information Theory 2. 113-124.

Chomsky, Noam. 1957. Syntactic structures. The Hague: Mouton.

Chomsky, Noam. 1959. "Review of Verbal Behaviour, by B.F. Skinner”. Language 35: 1. 26-59.

Chomsky, Noam. 1962. "Transformational Approach to Syntax". Third Texas Conference on Problems of Linguistic Analysis in English, ed. by A.A. Hill, 124-185. Austin, Texas: The University of Texas. 
Chomsky, Noam. 1964a. "The Logical Basis of Linguistic Theory”. Proceedings of the Ninth International Congress of Linguists, Cambridge, Mass., August 27-31, 1962, ed. by Horace Gray Lunt. The Hague: Mouton.

Chomsky, Noam. 1964b. "Degrees of Grammaticalness". The structure of language; readings in the philosophy of language, ed. by Jerry A. Fodor \& Jerrold J. Katz. Englewood Cliffs, N.J.: Prentice-Hall.

Chomsky, Noam. 1965. Aspects of the theory of syntax. Cambridge: M.I.T. Press.

Chomsky, Noam. 2004[1982]. The Generative Enterprise Revisited: Discussions with Riny Huybregts, Henk van Riemsdijk, Naoki Fukui, and Mihoko Zushi. Berlin, New York: Mouton de Gruyter.

Chomsky, Noam \& George A. Miller. 1963. "Introduction to the Formal Analysis of Natural Languages". Handbook of mathematical psychology, ed. by R. Duncan Luce, Robert R. Bush \& Eugene Galanter. New York: Wiley.

Cori, Marcel \& Sophie David. 2008. "Les corpus fondent-ils une nouvelle linguistique". Langages 171. 111-129.

Firth, J.R. 1957[1951]. "Modes of Meaning”. Papers in Linguistics, 1934-1951, ed. by J.R. Firth. New York, NY; London, England: Oxford University Press.

Firth, John Rupert. 1968[1952]. "Linguistic Analysis as a Study of Meaning”. Selected papers of J.R. Firth, 1952-59, ed. by J.R. Firth \& F.R. Palmer, 12-26. Bloomington,: Indiana University Press.

Firth, John Rupert. 1968[1955]. "Structural Linguistics”. Selected papers of J.R. Firth, 1952-59, ed. by J.R. Firth \& F.R. Palmer, 35-52. Bloomington: Indiana University Press.

Geeraerts, Dirk. 2003. "Decontextualising and Recontextualising Tendencies in 20th Century Linguistics and Literary Theory”. Anglistentag 2002 Bayreuth ed. by Ewald Mengel, Hans-Joerg Schmid \& Michael Steppat, 369-379. Trier: Wissenschaftlicher Verlag.

Greenbaum, Sidney \& Randolph Quirk. 1970. Elicitation experiments in English; linguistic studies in use and attitude. Coral Gables, Fla.: University of Miami Press.

Habert, B. \& P. Zweigenbaum. 2002. "Régler les règles". TAL : Problèmes épistémologiques 43: 3. 83-105.

Halliday, M.A.K. 1961. "Categories of the Theory of Grammar". Word 17. 241-292.

Halliday, M.A.K. 1966. “Lexis as a Linguistic Level”. In Memory of J.R. Firth, ed. by C.E. Bazell, J.C. Catford, M.A.K. Halliday \& R.H. Robins. London: Longman.

Halliday, M.A.K. 1978. Language as social semiotic : the social interpretation of language and meaning. Baltimore: University Park Press.

Halliday, M.A.K. 2002. Collected works of M.A.K. Halliday. London: Continuum.

Halliday, M.A.K., Peter Strevens \& Angus McIntosh. 1964. The linguistic sciences and language teaching. London: Longmans Green.

Hockett, Charles F. 1955. A Manual of Phonology. Baltimore: Waverly Press.

Joseph, John E. 2003. "Rethinking Linguistic Creativity”. Rethinking linguistics, ed. by Hayley G. Davis \& Talbot J. Taylor. London; New York: Routledge Curzon.

Katz, Jerrold J. \& Thomas G. Bever. 1994[1976]. “The Fall and Rise of Empiricism”. Noam Chomsky: critical assessments, ed. by Carlos Peregrín Otero, 286-307. London ; New York: Routledge.

Kennedy, Graeme D. 1998. An introduction to corpus linguistics. London; New York: Longman. Koerner, E.F.K., Matsuji Tajima \& Carlos Peregrín Otero. 1986. Noam Chomsky : a personal bibliography, 1951-1986. Amsterdam/Philadelphia: John Benjamins.

Langendoen, D. Terence. 1964a. "Review of Studies in Linguistic Analysis Special Volume of the Philological Society 1957 Oxford : Basil Blackwell”. Language 40: 2. 305-321. 
Langendoen, D. Terence. 1964b. Modern British Linguistics: A Study of its Theoretical and Substantive Contributions, Ph.D. Dissertation, Massachusetts Institute of Technology.

Langendoen, D. Terence. 1968. The London School of Linguistics: A Study of the Linguistic Theories of B. Malinowski and J.R. Firth. Cambridge: M.I.T. Press.

Leech, Geoffrey, Bengt Sigurd, Jan Svartvik \& Sture Allan. 1992. "Corpora and Theories of Linguistic Performance”. Directions in Corpus Linguistics, 106-125. Berlin: Mouton de Gruyter.

Léon, Jacqueline. 2005. "Claimed and Unclaimed Sources of Corpus Linguistics". The Henry Sweet Society Bulletin 44. 34-48.

Léon, Jacqueline. 2007. "Empiricism versus Rationalism revisited. Current Corpus Linguistics and Chomsky's Arguments against Corpus, Statistics and Probabilities in the 1950-1960s". Linguistische und epistemologische Konzepte - diachron, ed. by S. Matteos \& P. Schmitter, 157-176. Münster: Nodus Publikationen.

Léon, Jacqueline. 2008. "Aux sources de la "Corpus Linguistics": Firth et la London School". Langages 171. 12-33.

Lyons, John. 1963. Structural Semantics. An Analysis of Part of the Vocabulary of Plato. Oxford: Basil Blackwell.

Manning, Christopher. 2003. "Probabilistic Syntax". Probabilistic linguistics, ed. by Rens Bod, Jennifer Hay \& Stefanie Jannedy, 289-341. Cambridge, Mass.: M.I.T. Press.

McIntosh, Angus \& M.A.K. Halliday. 1966. Patterns of language. Bloomington: Indiana University Press.

Milner, Jean-Claude. 1989. Introduction à une science du langage. Paris: Le Seuil.

Otero, Carlos Peregrín. 1994. Noam Chomsky : critical assessments. London ; New York: Routledge.

Pereira, F. 2000. "Formal Grammar and Information Theory : Together again?" Philosophical Transactions : Mathematical, Physical and Engineering Sciences 358. 1239-1253.

Postal, Paul. 1994[1969]. "A Review of McIntosh and Halliday, 'Patterns of Language : Papers in General, Descriptive and Applied Linguistics'”. Noam Chomsky : critical assessments, ed. by Carlos Peregrín Otero. London; New York: Routledge.

Quirk, Randolph. 1958. "From Descriptive to Prescriptive : an Example". English Language Teaching 12. 109-113.

Quirk, Randolph. 1968[1962]. The use of English. London: Longmans.

Quirk, Randolph. 1968. Essays on the English language, medieval and modern. Bloomington: Indiana University Press.

Quirk, Randolph. 1968[1960]. “Towards a Description of English Usage”. Essays on the English language, medieval and modern, ed. by Randolph Quirk, 70-87. Bloomington: Indiana University Press.

Quirk, Randolph. 1968[1965]. “Descriptive Statement and Serial Relationship”. Essays on the English language, medieval and modern, ed. by Randolph Quirk, 167-183. Bloomington: Indiana University Press.

Quirk, Randolph \& Jan Svartvik. 1966. Investigating linguistic acceptability. The Hague: Mouton.

Robins, Robert H. 1969 “Review of Langendoen”. Language 45. 109-116.

Sampson, Geoffrey. 2001. Empirical linguistics. London ; New York: Continuum.

Sinclair, John. 1984. "Naturalness in Language". Corpus Linguistics: Recent Developments in the Use of Computer Corpora in English Language Research, ed. by Aarts Jan \& Meijs Willem, 203-210. Amsterdam: Rodopi.

Sinclair, John. 1991. Corpus, concordance, collocation. Oxford: Oxford University Press. 


\title{
Historiography's contribution to theoretical linguistics
}

\author{
Julie Tetel Andresen \\ Duke University
}

Given the rich, multidisciplinary developments that have influenced linguistic theory and practice over the past fifty years, we historiographers are uniquely positioned to provide some much needed theoretical integration for the discipline in these post-Chomskyan times. We do so when we shift from practicing historiography as a subdiscipline to deploying it as a method of theoretical intervention. The goal of this essay is to sketch the results of a historiographicallyinformed critique of introductory linguistics textbooks - all of whose formats extend back to Leonard Bloomfield's Language (1933) - and to offer the outline of a newer developmental linguistics which is: (a) reframed pragmatically by establishing from the beginning an embodied brain embedded in a context; and (b) organized not around the questions: What is language? or What do we know when we know a language? but rather around: How is it that hearing a sequence of sounds (or seeing a sequence of signs or reading a sequence of words) have the effects that they do? This conceptual shift entails addressing two new questions: How does a living being become a languaging living being? and How do we become the particular languaging living beings that we do? In order to answer these questions, both a phylogenetic script and an ontogenetic script need to be provided. Such an approach avoids the problem of the linguist who inherits a construct (e.g. Universal Grammar) and then must retrofit it to contemporary evolutionary and neurological research. It offers instead to our students - the future of the field - a theoretical account of our subject matter (language/ languaging) whose evolutionary and neurological plausibility have been factored in from the beginning.

Professor Konrad Koerner's contribution to linguistic historiography can hardly be overestimated. Given the quantity and quality of his scholarship, the range of subjects he has investigated, and his formidable editorial and organization skills, it is not too much to say that he has done more than anyone else to put linguistic historiography on the international intellectual map. On the occasion that we honor his extraordinary contribution to our scholarly field, it seems fitting to consider, in turn, the contribution that our scholarly field makes to the discipline that constitutes our subject matter. 
In these past thirty years and more, since the first ICHoLS meeting that Professor Koerner hosted in Ottawa in 1976, we historiographers have plunged into the historical record of the discipline with great energy. We have worked to recover forgotten origins, to explore unknown or undervalued schools of thought, and to make sometimes surprising connections between scholars and ideas past and present. This is the kind of research that gives any discipline richness and depth. During these same decades, various groups of linguists - e.g. child language researchers, discourse analysts, neurolinguists, psycholinguists, syntacticians - have turned some very broad and sometimes disparate corners. We historiographers are uniquely positioned to provide some much needed theoretical integration for the discipline in these post-Chomskyan times. This is where we leverage our understanding of the discipline's past in order to open a path to the discipline's future. This is where we shift from practicing historiography as a subdiscipline to deploying it as a method of theoretical intervention.

Reading into the history of the discipline is a way of understanding our subject matter by reviewing the variety of ways it has been approached and theorized over time. It is also a way of finding the places in the old bones of linguistic theory that might need adjustment today. With something of the flavor of the good news and the bad news all at once, I note that the study of our subject matter can be undertaken from many different perspectives: e.g. artificial intelligence, biology, cognitive science, cultural anthropology, evolutionary biology, neuroscience, philosophy, primatology, psychology, sociology. Given this, and in addition to all the recent within-discipline developments, linguistics is currently suffering from an embarrassment of riches. As a result, the twentieth-century theoretical skeleton inherited from Saussure and Chomsky is bearing a larger load than it was intended to handle, and it is now subject to the pressures and misalignments due to this excess weight. In short, it is out of whack. These days I see my job as a disciplinary chiropractor. In order to facilitate a future for the field in which the incorporation of the latest findings from the social and biological sciences will be a matter not of concern but of course, not all my adjustments can be gentle. The goal of this essay is to sketch the results of a historiographically-informed chiropractic: namely, the outline of what can be called a developmental linguistics.

\section{What changes now that linguists have (re)discovered context?}

Linguistic historiography is not akin to mining for gold, that is, its interest does not derive from the possibility that reading the historical record of linguistics will yield truths about our subject matter that have been forgotten. Nevertheless, there are nuggets of wisdom to be gleaned from the old texts, one such gem being Ferdinand de Saussure's remark in the Cours de linguistique générale that "it is often easier to discover a truth than to assign to it its proper place" (1959 [1915]: 68). That observation 
came to mind some years ago, upon encountering a good third of the way through such a standard introductory text as An Introduction to Language, the unremarkable yet startling statement: "Actually, every utterance is some kind of speech act" (Fromkin, Rodman, Hyams 2003: 215). The question immediately arose: What would a linguistics textbook look like if the central insight of J.L. Austin's How To Do Things With Words (1962) were found not on page 215 but rather on page one? And the reason to worry about intro texts is that they expose the very real difficulty that linguists have had in integrating an understanding of context in the theoretical arena since Noam Chomsky exiled the examination of the conditions that contribute to the production of any given utterance from so-called hard core linguistics research, beginning in 1959 with his review of B.F. Skinner's Verbal Behavior (1957).

John Searle has put the matter nicely. "Often," he writes, "we can find out more about what is going on in a culture by looking at undergraduate textbooks than by looking at the work of more prestigious thinkers. The textbooks are less clever at concealment" (1998: 20). Searle most likely means that these texts, in presenting material whose complexities must necessarily be sifted out for beginning students, more readily expose to experienced observers the bare bones of a discipline's theoretical problems. This is certainly the case in linguistics. Our introductory linguistics textbooks attempt to do too much by trying to survey the increasing number of legitimate topics, e.g. Language and Brain, Language and Evolution, Language and Society, while at the same time, they do too little in that they do not pause to reimagine the whole. Thus they expose the distortion of the discipline recognized already decades ago by William Labov who resisted the term sociolinguistics, "since it implies that there can be a successful linguistic theory or practice which is not social" (1972: xv). In fact, there is a successful linguistic theory and practice which is not social, and it is called philology. In any case, Labov's resistance does not seem to have had much effect on the way introductory textbooks present the discipline. So-called sociolinguistic phenomena continue to be discussed in a separate chapter or chapter section, just as are so-called pragmatic phenomena. And syntax traditionally gets its own chapter, one with a Chomskyan spin, never minding the fact that everything in that chapter clashes with what is presented in the pages devoted to socio-pragmatics.

Now, the format of all introductory textbooks on the market today can be seen to exist in a lineage that extends to Leonard Bloomfield's masterful Language (1933). And here is where historiographic perspective becomes useful. When we take the long view of the discipline, we can see that one of the many things Chomsky changed about American linguistics was the shift in research agenda from: How do we (linguists) describe our subject matter? to What is the best way for us (linguists) to theorize how speakers have language organized in their heads? The previous generation of linguists, the Bloomfieldians, were interested in describing the structure of particular languages, and their relationship to the speakers of those languages was one of precedence and 
of perspective: precedence in that a linguist could only observe, record and/or describe after the fact what a speaker produces; and perspective in that a linguist was not limited to observing, recording and/or describing the productions of any one speaker but could take a more global view. However, Bloomfield acknowledged that this supposedly global view itself would always be limited, since no one observer (or group of observers) could have access to all utterances that all speakers of a language have uttered. In the case of English, the classes of nominative expressions and finite verb expression are so large - in fact, Bloomfield says that "the possibilities of combination are practically infinite" - that he cannot say for sure whether, for example, the sentence "a red-headed plumber bought five oranges" has ever been uttered (1933: 275).

Chomsky altered the descriptive and methodological landscape by arguing that "the possibilities of sentential combinations," while indeed "practically infinite," are not, in fact, infinitely variable. They too exhibit patterns. However, these patterns are not to be read off surface structures, that is, they are not to be found directly in the surface strings of the practically infinite set of sentences themselves. Rather, they are more abstract in that they are results of the actions and the interactions of two types of sentence-patterning rules, namely the phrase structure rules and the transformational rules. The methodological change that accompanied this theoretical innovation was the move away from scouring stodgy old surface structure corpora and toward a reliance on the linguist's own native speaker intuitions to relate the deep structure of sentences to the surface structure. For many years a kind of glamour clung to the activity of linguists' indulging these intuitions. However, with fifty years' hindsight, we can see that the practice eliminated all the surrounding phenomena - i.e. context - that contribute to the instantiation of any single utterance, not to mention the fact that intuitions about correctness do not necessarily coincide with actual naturalistic data. The variationist linguists among us have shown that introspective judgments about language, especially syntax, are often highly unstable and at variance with attested behavior (Rickford et al. 1995: 127). The point to make here is that Chomsky's approach to syntax was easily incorporated into the Bloomfieldian textual template, requiring only an updated chapter on syntax to replace the one Bloomfield entitled "Sentence Types."

In stepping away from corpora and into abstraction, the Chomskyan methodology identified structures that could be viewed retrospectively and from the point of view of the linguist-speaker. Thus was formal syntax brought into existence, for only in retrospect and in isolation from all surrounding utterances could the structure of any particular utterance be seen to pre-exist its appearance in discourse. The Chomskyan construct competence - often defined as the mental system that underlies a person's ability to speak and understand a given language and often identified as the proper object of linguistics - served as the harbor for the sentence pattern templates as they awaited instantiation. In their pre-existence, then, the abstract rules were theorized to 
represent the speaker's ability to produce sentences. Just as the observer/linguist and the speaker had merged, so the linguistic description of so-called non-surface regularities, seen from the perspective of the linguist-observer now inside the speaker's head, doubled as the mental explanation of that behavior. The approach that posits a language faculty as an autonomous, genetically determined, brain/mind module reflects what can be called cognitive philologism.

This label is clearly not meant as a compliment. However, it is also not meant to disparage philology or philologists as traditionally understood. Nineteenth-century philologists, as we all know, were motivated to reconstruct protolanguages as a representation of what the original language must have been in order to have given rise to the daughter languages said to have derived from it. Written records of the daughter languages, when available, were valuable guides, and the older the record, the potentially more valuable. The exact contents did not matter to the philologists, however, since they were interested in the records only as monuments of the languages they were studying, and they could study them precisely as if those monuments had been created for that kind of study. These written records are extremely useful, and they perfectly well serve the purposes of scholars who have nothing to do with the languages they study except study them, e.g. philologists.

Although there are certainly differences between nineteenth-century historical and comparative philology and twentieth-century structural linguistics, the structural linguists transferred the nineteenth-century philological understanding of ancient languages to the twentieth-century study of living languages. No moment can be identified when this transfer occurred; it had already happened by the time introductory twentieth-century linguistics textbooks identified nineteenth-century philology as part of the history of what they were doing. No authors consciously made the transfer. In fact, linguists at the time were quite sure they were breaking from philological tradition. When, in the early decades of the twentieth-century the focus of linguistic activity shifted from historical to structural perspectives and the nineteenth-century philologists were retroactively dubbed linguists, the bond between them was secure, and the die was cast as to what would count as linguistic methodology and purpose. Structural linguists deciphered and analyzed living monuments produced by native speakers that were severed from contexts just as historical linguists before them deciphered and analyzed ancient written monuments whose contexts were long gone. For the goal of reconstructing a language family or writing a grammar, the philological method is entirely appropriate. However, for the goal of providing a theory of what goes on in people's heads with respect to linguistic processing and production, the method is inappropriate.

Generativists created databases from their native speaker intuitions composed solely of what V.N. Vološinov indicted already eighty years ago as the "isolated, finished monologic utterance." These were sentences floating in contextless space on the page, standing 
open not to any possible sort of active response but only to passive understanding on the part of an analyzer. This is philologism, the inadvertent forgetting of context. The insufficiencies of the methodology were compounded by the generativists' allergy to anything that hinted of behaviorism and thus they were left to pursue a research agenda that has come to be associated with Chomsky's phrase poverty of the stimulus. One implication of the phrase involves the idea that certain surface features underspecify the properties of the grammar which produces them, thus making it difficult for learners to learn those properties. An example of such a feature would be the notion of structure dependence.

Chomsky introduced the idea of structure dependence as a hypothetical language universal by asserting that children create only structure-dependent grammars although no feature of the input eliminates structure-independence. Chomsky argued that English-learning children do not form structure-independent questions such as ${ }^{*}$ Is the man who __ tall is in the room? in spite of the fact that they are not exposed to structure-dependent examples upon which they could model their own linguistic behavior. That is, there are supposedly some grammatical mistakes that children might logically make on the basis of so-called simple induction but do not (Chomsky 1988: 7-12). Such a structure-independent example of the non-occurring form ${ }^{\star} I s$ the man who __ tall is in the room? eventually became the "the 'parade case' in discussions of the poverty of the stimulus" (Thomas 2002: 56). These days, however, with large databases only a google away, the revival of the use of corpora both in formal theoretical linguistics and in language acquisition studies provide ample evidence that children are, indeed, exposed to examples of the kinds of complex grammatical structures that Chomsky said children never hear or virtually never hear, which required him to posit the existence of inborn knowledge of very abstract features of language (Tomasello 1995: 144; Tomasello 2003: 288; Pullum 1996; Pullum \& Scholz: 2002).

The forgetting of context in generative syntax has led: (i) to an elaborate feedforward machinery that has no room for feed-back, and this is only one of the reasons that it has produced mental models that have nothing to do with psychology, as psychologist Michael Tomasello (2001) has so cogently pointed out; and (ii) to various iterations of a theory of grammar that has now dead-ended in the Minimalist Program. When generative grammar began, pragmatics and discourse analysis hardly registered on the radar screen, but now we have a richly-elaborated, more psychologically and pragmatically-informed construction grammar that extends back to Ronald Langacker's Foundations of Cognitive Grammar (1987) and extends forward to Adele Goldberg's Constructions at Work. The Nature of Generalization in Language (2006). Goldberg places herself in a lineage that includes Lakoff(1987), as well as Kay and Fillmore (1999). Even well-known proponents of generative grammar such Steven Pinker and Ray Jackendoff have stepped away from the Minimalist Program and tentatively embraced (at least some aspects of) construction grammar (Goldberg \& Jackendoff 2004; Jackendoff \& Pinker 2005; Pinker \& Jackendoff 2005). 
In general, constructionists understand constructions to be form-meaning pairings, e.g. the ditransitive construction $\mathrm{SubjVObj}_{1} \mathrm{Obj}_{2}$, which has a counterpart expression employing 'to' or 'for'. The two possibilities are exemplified by: Mary sent John a book and Mary sent a book to John. For constructionists such as Goldberg, the interest in this pair of utterances does not lie in the fact that they are paraphrases. Rather it lies in the many, often subtle ways they differ from one another either semantically or pragmatically (or both). One such difference involves the pragmatic conditions that determine whether the recipient argument (here: John) and/or the theme argument (here: $a$ book) is likely to be pronominal or not. It is remarkable to discover that, in both corpus and experimental studies, the theme argument of the ditransitive strongly tends to be new information, that is, it is not already given in the discourse context, and this tendency stands in contrast to the recipient argument which is typically pronominal. In other words, "the recipient argument of the ditransitive construction rarely introduces a new argument into the discourse" (Goldberg 2006: 139). This observation accounts for why She gave him a book is fully acceptable and why She gave a man them sounds so odd. The alternative construction with to is not so constrained. She gave a book to him and She gave it to a man are equally good.

In addition, for constructionists, it is the construction itself that is the primitive unit of syntactic representation, not so-called rules, nor grammatical categories such as verb, noun, adjective, subject, object, etc. Now, aspirant language-users (i.e. young children acquiring English) tend to exhibit verb-centered conservatism, meaning that they will readily substitute new nouns into particular and preferred general purpose verbal frames. There is also evidence that adults retain much verb-specific knowledge. However, one of the many reasons to like construction grammar is that it can be shown that constructions are sometimes better predictors of overall meaning than verbs. Goldberg notes that "when get appears in the VOL [verb-object-location] pattern, it conveys caused motion, but when it appears in the VOO [verb-object-object] pattern, it conveys transfer:

(1) a. Pat got the ball over the fence. get + VOL pattern $\rightarrow$ 'caused motion'

b. Pat got Bob a cake. get + VOO pattern $\rightarrow$ 'transfer'” (Goldberg 2006: 106)

It is pertinent to note that the strings VOL, VOO, and Subj $\mathrm{V} \mathrm{Obj} \mathrm{Obj}^{2}$ exist for ease of notation only, as nothing more than a way to represent a semi-abstract cognitive schema. The point here is that our judgments about She gave a man them and how we interpret one kind of get-phrase as opposed to another do not come from consulting an internal grammar that operates on sentences out of context; rather we are responding to the match or mismatch of a construction in comparison to the large experience we have had of similar constructions heard in contexts that have built up semi-abstract schemata to which cling chunks of semantic and discursive triggers. 
The question can now be answered: What changes now that linguists have (re) discovered context? The answer is: Everything. A responsible introduction to the discipline of linguistics for the next generation of students requires not merely that the chapters on syntax and pragmatics be recast, but rather that the statement "Actually, every utterance is a speech act" be put on page one and the entire textbook be rewritten from there. ${ }^{1}$ This is because the rediscovery of context changes not only the way we approach syntax/pragmatics but also the way we study children and language beginning with Jerome Bruner, the first one to put "pragmatics in the middle of things" in Child's Talk (1983) - to neurolinguistics, psycholinguistics, the evolution of language, and all the rest. Most linguists have learned the lesson that no linguistic phenomenon can be fully understood apart from context; and this same lesson renders the long-conventional organization of introductory textbooks to be little more than a convenient pretense.

When the dynamic life of our subject matter in all its situatedness is restored in our theory of language, a new relationship of linguist to subject matter becomes possible and new descriptive terrains open up. Bloomfield, like any good scientist, desired completeness, but he recognized a dual limitation, that of descriptive and observational inadequacy: no linguist could hope to list all the items a grammar could contain "since the possibilities of combination are practically infinite," just as no linguist could hope to have access to all utterances whose characteristics should be accounted for in a grammar. Chomsky collapsed the observer into the speaker and solved the problem of limitation by putting the conditions for generating a complete grammar inside every human being, along with a complete knowledge of the (linguistic) environment that is "evoked," as Chomsky says, at the appropriate time. In the kind of linguistics advocated here, by way of contrast, the drive for completeness is transformed into a taste for thick descriptions of individual development and an attention to historical trajectories the phylogenetic and the cultural - in all their detail.

\section{From language to languaging}

The last fifty years of Chomsky-inspired theorizing has steered our thinking about our subject matter - language - toward a dress covering the body of the mind. In this

1. Needless to say, I have put my money where my mouth is and done just that; and having done so, I can say that I sympathize with those authors who have chosen the additive strategy: "Hey, let's just add a new chapter and call it 'Psychological and Pragmatic Approaches to Grammar." Even I did not want to write Linguistics Reimagined. What an awful lot of trouble! 
framework, all the dresses, i.e. languages, in the world may look different, but they are all understood to be cut from the same cloth, i.e. they are products of and covers for a universal mind and language is a system that is everywhere the same. More precisely, they are projections of the human mind which is, indeed, The Human Mind, common to all. One of the more recent pronouncements by Chomsky is the following:

Going back to language, what you have is a system that is, as far as we know, essentially uniform. Maybe there was some speciation at one point but only one species survived, namely us; there seems to be no variation in the species. True, we find Williams' syndrome and Specific Language Impairment. But that's not variation in the species in any meaningful sense: those are deviations from the fixed system that occur now and then, but the basic system seems to be uniform. (2002: 147)

Please note that for Chomsky Williams' syndrome and SLIs are not seen as possibilities in human variation generally speaking, but rather as not counting as variation "in any meaningful sense." He has long identified his intellectual pedigree as one belonging to Descartes (Chomsky 1966), and he has remained true to it.

Clearly, several things have to happen at this point. First, we need a twenty-firstcentury linguistics that is inspired not by Descartes but by Darwin, one that recognizes that all variation is meaningful, for selection does not operate on essences, only on variation. Secondly, we need to abandon the idea that linguistics needs an object of study. Recall that Saussure was prompted to propose langue as the object of study in order to give linguists a province of their own that would not seep into sister disciplines, such as psychology and sociology. Chomsky acknowledged the importance of Saussure's move but proposed Humboltian-inflected competence instead and reiterated the need for such an object "if [linguistics] is to be a serious discipline" (1965: 4). Whatever uses the constructs langue and competence may have had, they have outlived their usefulness. They were never intended to have anything to do with neurology or psychology, and so it is no wonder that linguists have inherited a theoretical framework that is psychologically and neurologically uninformed and, worse, implausible. Third, in order to help effect the transition from one theoretical framework to another we are going to need some new metalanguage. The term languaging can help effect the transition.

In the developmental linguistics described here the need for an object of study is replaced with a multi-layered description of the instantiation, development, and maintenance of the languaging network in the species and the individual. Now, although our languaging activities and abilities are not coextensive with the whole of human cognition, it is nevertheless becoming evident in recent neuro- and psycholinguistic literature that one cannot turn too many corners in the brain without running into a structure or procedure that does not affect and has not been affected by the (at the 
very least) several hundred thousand years of languaging in the species as well as by the languaging experienced throughout the lifetime of an individual. More precisely, languaging can be understood:

i. to scaffold the cognition of human beings and to be an activity through which certain cognitive and conceptual developments are induced. In other words, the term languaging suggests deep-down cognitive as well as pervasive cultural effects that the term language is not currently theorized to have. One of those deep-down cognitive effects of languaging pertains to the ways different frames of reference intrinsic, relative and absolute - organize the spatial domain and thus literally orient languagers to particular spatial relations on the horizontal axis. Psycholinguist Stephen Levinson's remarkable Space in Language and Cognition (2003) demonstrates how deeply different orienting frames of reference penetrate nonlinguistic cognition and affect significant aspects of cultural life;

ii. to span the troublesome distinction between the terms language and speech that some theorists maintain. This embrace of the language-speech continuum expands the brain part of the brain-culture orientation of point (i) and highlights the importance of the basic sensory, perceptual and motor abilities that support languaging activities but are not speech specific. Their functioning comes crucially into view when they malfunction. For instance, individuals who are impaired in identifying and producing rapidly successive stimuli - elements occurring within 10 s of milliseconds embedded in ongoing speech, which is a critical time frame in terms of phonetic contrasts - will have various components of their languaging behaviors disrupted; and these disruptions extend to all their languaging behaviors, including reading and writing (Tallal \& Benasich 2002). Similarly, people with developmental stuttering have problems with motor tasks other than speech (Packman et al. 2007). One upshot of this general point is that the term Specific Language Impairment is a misnomer, since the deficits of most SLI children are not specific to language. More recently, the term language learning impairment (LLI) has been gaining currency to reflect that more global visual, auditory and motor problems that can disrupt language learning (Tallal \& Benasich 2002);

iii. to allow, precisely, for multimodality. This means that, even in the processing of speech, languaging is not solely an auditory activity. Two classic studies bring attention to the importance of vision in the ordinary linguistic processing of speech. McGurk and MacDonald (1976) show the degree to which visual information can affect auditory perception, while the work of Tanenhaus et al. (1995) stresses the role of vision in the processing of syntax;

iv. to include, crucially, gesture as a dimension of its multimodality. The dramatic case of IW comes into play here. At age nineteen, IW lost all sense of touch and proprioception below the neck. That meant that he lost all motor control that depends 
on bodily feedback. He slowly relearned to walk and eat and do everything else, not by his lost proprioception and spatial position sense, but rather by using cognition and vision. Of interest is that his speech and gesture (in the service of languaging) were not lost, while instrumental gesture was. That is, he cannot pick up a brick if he cannot see his hands. However, he can and does gesture while speaking, even if he cannot see his hands (Goldin-Meadow 2003: 242; McNeill 2005: 234-245;

v. to ease open the flattened space of the view of language held by those who imagine it to be a mapping between meaning and sound or, in updated Chomskyan terminology, between the sensory-motor and conceptual-intentional systems. This point furthers (i) and (ii), above, and is made in order to give linguists and neurobiologists room to move around in. We need richer ways of understanding the relationships between (what the Chomskyans presume to be the pre-given) sensory-motor and (what the Chomskyans presume to be the pre-given) conceptual-intentional systems than in terms of (presumably straight, two-dimensional, static, one-to-one) lines. The investigation of the ways that these dynamic systems intersect, interact, and affect one another is a significant part of the project of a developmental linguistics. Tomasello recognized the insufficiencies of this flattened space when he requested, with some exasperation, "Could we please lose the mapping metaphor please?" (2001);

vi. to orient the linguist and language/ing theorist to the over-richness of contexts, as Austin has taught us, in which all languaging occurs as well as to the underspecification of utterances in the sense that they can never fully convey all that is meant. As for the underspecification of utterances is concerned, what is taken to be meant always exceeds what is said. This is sometimes called the principle of ineffability. As for the over-richness of contexts, this would mean at the most mundane level that, for any given speech event, while it might be true that the sun is shining, it is four o'clock, and three chairs are present, none of these (or any of the almost infinite other aspects of the context of a speech event) may rise into pertinence. Nevertheless, those contextual resources are present and available;

vii. to underscore the idea, given the over-richness of contexts and the underspecification of utterances, that languaging is an orienting behavior. This means that each languaging living being in any given languaging situation will respond differently and will thus be oriented differently in his or her cognitive domain. This is so despite the fact that languaging living beings with long histories of interactions often manage to coordinate their behaviors very well. This is also so despite the fact that certain languages may tend to reliably induce certain cognitive and conceptual developments rather than others. The point here is that the brain organization that is created by and supports languaging activities (as well as other higher cognitive functions) may vary widely across individuals and in "idiosyncratic patterns that are as unique as their finger prints" (Elman et al. 1996: 248). This is to note once again that all variation is meaningful, in the sense, of "counts"; 
viii. to foreground the intersubjective nature of the activity, such that languaging is not a personal possession; and

ix. to be extendable to the term languaging living being, which is meant to replace the misleading terms speaker and listener and to move us out of the code theoretic framework in which they operate - hereby invoking Roy Harris's critique of Saussure's (in)famous picture of the talking heads. The term languaging living being is maximally flexible in that it does not specify a particular role, disposition or activity of the languaging living being at any given time, e.g. if a languaging living being is eavesdropping, then it can be said that the languaging living being's living is intertwined with the activity of eavesdropping. That is to say that eavesdropping - deliberate or inadvertent - is often a part of many of our daily activities, whether we are standing in line at a bank, eating lunch, or strolling through a mall.

Introducing an orientation toward languaging uncouples the study of our subject matter from a focus on the speaker. When this occurs, previously overlooked phenomena can come into view. For instance, although it is widely believed that children cannot learn a language by merely overhearing it, newer studies suggest that adults who regularly heard their heritage language during childhood but spoke only the majority language were able to acquire a more native-like accent when they came to learn the language later in life than those adults who had no exposure to the target language as children (Au et al. 2002). Another study demonstrates how second-born children at age 21 months and 24 months have more advanced pronoun production than firstborn children at those ages, although their general language development is not different. The idea here is that "children may discover the relations between pronouns and speech roles more easily from overheard speech and be more likely to make correct generalizations about the meaning of pronouns" (Oshima-Takane et al. 1996: 623). These findings remind the linguist how pervasive languaging is in our lives, how much of our lives are lived in a linguistic bath, even when we are not involved in the active production of an utterance or even active participants in a speech event. Overhearing is as much a linguistic activity as any other, a very particular one whose characteristics and consequences have only begun to be explored.

An orientation toward languaging also helps us reinterpret not only the massive neuro- and psychological literature that now exists but also the equally large amount of research on children and language that has been produced. Instead of thinking of language in terms of taking information in from the outside world in, languaging opens up not only a developmental space within the individual but also an intersubjective one where vocal and non-vocal activity can be seen as continuous. A decade and a half ago, Pinker could confidently state that "grammar development does not depend on overt practice, because actually saying something aloud, as opposed to listening to 
what other people say, does not provide the child with information about the language he or she is trying to learn" (1994: 280). Now, however, there is plenty of research to suggest that practice is important; children can and do use their own productions as the basis for further development (Nelson 2007). Goldstein and West (1999) similarly challenge the traditional view of articulatory development as being a matter of an internal program of physiological and cognitive maturation and offer instead a model of vocal development that relies on both proprioceptive and social feedback. Going even further beyond the listen-to-learn model, Goldstein, King, and West (2003) show how babbling both regulates and is regulated by social interaction. They thereby expand on the traditional view that foregrounds imitative learning when they demonstrate the (perhaps surprisingly) robust influence of non-auditory social stimulation on infant babbling. These two studies underscore how a more complete understanding of vocal ontogeny becomes possible when the total social environment of the infant is taken into account. For too long, linguists have overlooked not only the effect of the total social environment on aspiring languagers but also aspiring languagers' influence on their environments, which, in turns, affects development.

A fuller understanding of the term languaging will now unfold within a discussion of the constructivist epistemological framework.

\section{On constructivism}

The term constructivism is seemingly everywhere these days. Constructivism has arisen, in part, as a response to what is often called the rationalist-realist (think: Descartes) account of cognition, truth, science, and the world, generally speaking. Theorists involved in articulating a constructivist account of things are cognitive scientists, epistemologists, neuroscientists, philosophers, psychologists, and historians of science, and they are interested, in particular, in understanding and describing the processes and dynamics of cognition. The key idea is that organisms' experiences of the world are not prior to and independent of their sensory, perceptual, motor, and manipulative activities, but rather emerge from or, as it is said, are "constructed by" those activities. When it comes to human perceptual, conceptual and behavioral experiences, the role of language is seen to be a crucial part of that which needs to be understood and described. ${ }^{2}$

2. The terms constructivist and constructivism used here are not to be conflated with the concerns of social constructionism, which is also known sometimes as social constructivism. As Barbara Herrnstein Smith has pointed out, social constructionism is a critical stance that has been taken by cultural anthropologists, feminists and gender theorists, among others, in order to challenge frameworks in which racial categories, gender biases or certain sexual behaviors are deemed to be biological, natural, or even scientifically proven. These cultural 
One way to understand the constructivist framework and languaging as an orienting behavior is in contrast to a different approach to our subject matter that can be called "language as solving the serial interface problem." In this approach, the design features of language reflect the purpose for which it was designed, namely "the transmission of propositional structures through a serial interface" (Pinker \& Bloom 1990: 707). This statement about the design and purpose of language coheres in a larger epistemological framework most often known as rationalist realism whose parts may be schematized thusly:

i. there is an independent observer set over and against the world;

ii. science is an uncovering of a truth already there;

iii. social conditioning is an obstacle to understanding truth;

iv. mind/thought and language are personal possessions;

v. language is generated by a set of a priori rules or operations; and

vi. the purpose of language is to provide an objective match between our statements, thoughts, beliefs, descriptions or models and a fixed reality.

Although it is not at first evident, it is nevertheless the case that this framework carries with it a particular perspective on our perceptual apparatuses, most particularly vision, so that another point may be added here, namely:

vii. the purpose of vision is to provide an accurate reconstruction in perception of the physical world.

This last point carries with it the idea that vision, as such, is an exemplar of nature (rather than, say, nurture), that is, it is a specific pre-wired, innate capacity. The fact that stereoscopic vision is not present at birth but develops gradually and is not always achieved is explained by another innate mechanism, an "installation sequence" that programs the wiring to occur after birth (Pinker 1997: 238). This framework is the most familiar to most people, and standard introductory linguistics textbooks tend to assume some or all of the above points.

By way of contrast, the Chilean epistemobiologists Humberto Maturana and Francisco Varela, who introduced the term, have said: "Languaging [an activity and not a thing] is an orienting behavior that orients the orientee within his/her cognitive domain and that arises, both in phylogeny and ontogeny, through recurrent interactions with conspecifics" (1972: 30). And Tomasello has said: "In the current theoretical perspective, learning to use linguistic symbols means learning to manipulate (influence, affect) the interest and attention of another intentional agent with whom one is interacting intersubjectively" (1999: 131). These statements about languaging as an orienting

theorists typically stress the social side of human activity, speak of certain practices as being socially constructed, and often acknowledge deliberate political engagement (2005: 4-5). 
behavior cohere in a larger epistemological framework most often identified as constructivism whose parts may be schematized thusly:

i. the observer is a part of that which s/he is observing;

ii. science provides an explanation of a phenomenon that is acceptable to a body of observers;

iii. social conditioning is a key to understanding truth;

iv. mind/thought and language are intersubjective;

v. the patterned regularities to be found in the activity of languaging are a result of the history of recurrent interactions among conspecifics through which these regularities are instantiated, developed, and maintained both in sociocultural history and individual ontogeny; and

vi. in our languaging togther we tend to produce an effective coordination among statements, beliefs, assumptions, observations, practices and projects, all of which are independently mutable but mutually responsive.

For the constructivist, the workings of our perceptual apparatuses are not about taking an outside world in. Rather, in the domain of vision:

vii. what we see is a probabilistic manifestation of the past rather than a logical analysis of the present.

Although the following seems at first counterintuitive, recent work in vision theory directs our understanding toward the idea that the percepts that are entertained accord with the accumulated experience of what the retinal stimulus in question has typically signified in the history of the species and the individual (Purves \& Lotto 2003). In this framework, the development of stereoscopic vision after birth is, precisely, a developmental result which is explained in terms of both genetic and epigenetic factors.

In A Mind So Rare, psychologist Merlin Donald has an interesting chapter titled "Condillac's Statue" in which he asserts that Etienne Bonnot de Condillac in his Treatise on the Sensations (1754) is the first Constructivist (with a capital C in Donald's version). The gist of Donald's overall argument is the following:

Condillac proposed a much stronger, Constructivist version of Empiricism, one that... asserts that the very structure of the mind is set up in experience and that many of its highest capacities are not innate, in the sense of being implanted at birth, but instead are generated by the appropriate sequencing of early experience. In this view, the developing mind emerges in adulthood with a specific structure, not necessarily because that structure was innate but because it flowed naturally and inevitably from particular sequences of experience (2001:215)

Indeed, constructivists emphasize the importance of development, and this stands in contrast to anti-developmental models of human cognition that assume everything to be innate and that growth is merely an unfolding of structures that are already within. 
It is also true, as Donald says, that a central idea of constructivism is that "action begets self-knowledge" just as Condillac's statue ${ }^{3}$ gained knowledge through active exploration (2001: 226).

Maturana and Varela put the matter of continuous interaction with the environment in terms of "an unbroken coincidence of our being, our doing, and our knowing" (1992: 24). Evolutionary biologist Richard Lewontin, for his part, similarly outlines a constructivist view of development when he states: (i) that environment and organism are causally linked; (ii) that organisms "not only determine what aspects of the outside world are relevant to them by peculiarities of their shape and metabolism but they actively construct, in the literal sense of the word, a world around themselves;" and (iii) that organisms are in a constant process of altering their environment (2000: 54-55). This is to say that constructivists are concerned with agency. We get a taste of this in construction grammar and discourse analysis as well, where situated individuals, in particular discursive situations, are engaged not only in constructing utterances but also in constructing interactions over time, meaning that they are responsive. The concern for agency can be seen to have arisen to fill in a gap perceived in alternative models which comes into clarity, if, for conceptual effect, we reduce Skinner to Mr. Rats and Chomsky to Mr. Wires. The agentive dimension of how individuals assert identity through their linguistic and cultural practices is also at issue in the work of many anthropologically-inclined linguists, e.g. in the sociophonetics investigated by Norma Mendoza-Denton (2007), to name but one.

The first section of this essay ended with the idea that, in a developmental linguistics, the drive for completeness present in Bloomfield and Chomsky is transformed into a taste for thick descriptions of individual development and an attention to historical trajectories in all their detail. I invoke it here in order to emphasize the idea that descriptions characteristic of constructivist accounts of phenomena are generally long and sometimes complicated. This is so for two reasons: (i) constructivist accounts are less consolidated in certain disciplines than other accounts, e.g. those of rationalist realism, because the latter has a longer history in scientific discourse and is more widely assumed; and (ii) constructivists refuse succinct accounts that rely on a dualist framework where nature and nurture are viewed as causal alternatives, for those accounts short-circuit the details of the developmental story that needs to be told.

3. In his famous thought experiment, Condillac imagined an originally inanimate and insentient human being (a "statue") and wondered what it could come to know were it to acquire each of the senses in isolation from the others, or each in combination with just one or two others. Condillac pondered, for instance, what such a being endowed with only a sense of smell would think upon acquiring the power of hearing. His goal was to play out a scenario where his statue was able to learn everything it needed through experience acquired through the various senses (smell, hearing, vision, touch, taste). 
There is certainly a bond between the constructivists and Condillac in this taste for thick description, for Condillac was never one to stint on description. However, it is difficult to tell whether Condillac would have subscribed to any of the points listed for constructivism above and that distinguish it from rationalist realism. Donald notes that Condillac did not, for instance, realize the obstacles his statue faced to achieve symbolic cognition, and he did not question "the myth of the isolated mind," thus leaving his statue disconnected from society (2001: 227). However, Donald's claim is only that Condillac foreshadowed constructivism in some important ways, and this is an assertion that might warm many a linguistic historiographer's heart. First, it may well be that we historiographers are in part responsible for making this preeminent grammairien philosophe known to a wider audience. Second, Donald's reading reminds us that our interest in old texts does not put us completely out of touch with the present.

For the record, many constructivists, whether they know it or not, owe an intellectual debt to developmental psychologist Susan Oyama, particularly to her groundbreaking The Ontogeny of Information (1985). She is the one who has most clearly pointed the way out of the nature-nurture dilemma conceived in terms of nature as push from the genes and nurture as pull from the environment. Her developmental systems theory reformulates an understanding of development that does not collapse back into the old opposition in which nature and nurture are seen as alternative sources of causal power. Instead, she understands such things as genes and cultural environments to be inherited, and such things as nervous systems and table manners to be constructed results of interactions in the various environments in which they develop.

\section{A developmental linguistics begins}

The pragmatic reframing of the discipline requires directing the introductory exposition away from a theorized object of linguistic inquiry and toward an emphasis on what languages $d o$. Thus, the organizing question will no longer be What is language? or What do we know when we know a language? but rather: How is it that hearing a sequence of sounds (or seeing a sequence of signs or reading a sequence of words) has the effects that they do? This conceptual shift entails answering two new questions, namely: How does a living being become a languaging living being? and How do we become the particular languaging living beings that we do? In order to answer those questions, both a phylogenetic script and an ontogenetic script need to be produced.

Because living beings belonging to the lineage homo sapiens sapiens are the most likely living beings to become languagers - acknowledging that there are human beings with severe abnormalities who do not and that there are enculturated apes who 
do, to some degree - the story of the emergence and development of languaging in the species needs to be addressed. Although the topic of language and evolution has generated so much attention that no one individual could possibly master all that has been written on it, it is still possible to define a field of possibilities. In short, explanations congenial to a Chomskyan model of language (Pinker \& Bloom 1990; Pinker 1994; Hauser, Chomsky, Fitch 2002) do not explain the appearance in the hominid lineage of the so-called faculty of language as emerging from non-linguistic abilities or behaviors. In fact, they do not see the faculty of language as any kind of behavior at all. By way of contrast, explanations congenial to languaging as an orienting behavior (Maturana \& Varela 1972; Maturana \& Varela 1987; Maturana \& Mpodozis 1992; Tomasello 1999) do explain the appearance in the hominid lineage of languaging behavior as emerging from non-linguistic abilities and behaviors, namely the ability of one conspecific to affect the attention and behavior of another.

It is characteristic of Chomsky-inspired explanations - and unsurprisingly so, given its Cartesian cast - that the function of language is the transfer of information from one head to another, thus requiring that the story of the emergence of language be told in terms of some kind of prior cognitive development in the species. The story of that advance requires, in turn, some kind of cognitive leap, which used to be identified with the appearance of reason in the species. It is now identified with recursion - the center of the center of cognitive functioning that powers language - and how it might have become part of the human cognitive repertoire. To the extent that the faculty of language, theorized to be uniform in the species, is a modular faculty, it follows that particular languages do not affect individual human cognition any more than do particular clothing styles affect the body underneath.

It is characteristic of explanations in terms of languaging as an orienting behavior that no prior cognitive advance need be made in order for to humans to have entered the linguistic domain, which is understood as an expanded domain of behavioral coordination. In this framework, developments in human cognition have occurred as a result of developments in languaging abilities over the long haul and so much so such that the behavioral coordinations humans experience even before the moment of birth now have profound effects on their cognition as it develops over their lifetimes. And, of course, developments in human cognition have, in turn, an effect on the kinds of behavioral coordinations that can be made in languaging. This kind of explanatory framework has been called ecological (Hill 1974) in order to emphasize the idea that the languaging environment (my terminology, not Hill's) is the water in which humans swim. This kind of framework also favors the view that different languages can and do affect non-linguistic cognition differently, as Levinson's work on the varying spatial frames of reference in the world's languages strongly confirms.

Acknowledging linguistic relativity, however, is not to deny that human cognition has features that are shared by other, non-languaging primates. Take, for instance, the 
well-known semantic congruity effect. When asked to compare two large animals, such as a cow and an elephant, adult humans are much quicker to respond when the question is Which is larger? rather than Which is smaller? When asked to compare two small animals, such as an ant and a rat, they are much quicker to respond when the question is Which is smaller? rather than Which is larger? Recently it has been shown that there is a similar semantic congruity effect that appears when monkeys are asked to make numerical judgments. It thus seems to be that this effect is a consequence of the comparison process rather than stimulus encoding, that is, in the latter case whether or not the being in question possesses symbols to represent numbers precisely (Cantlon \& Brannon 2005; Cantlon \& Brannon 2006). In humans, the semantic congruity effect appears when we language but it is not caused by our languaging. One of the goals of a developmental linguistics is to sort out the nature of this hybrid human cognition.

The literature containing proposals for the originating scenario of the emergence of language in the species is too vast to review here. Those researchers who do not propose scenarios as such suggest instead associations or correlations between the development of certain behaviors in early humans and the emergence of language. This list of associations includes: the shift from arboreal to ground-dwelling life that required cooperation for defense, for the gathering of fruits and other vegetables and for hunting; the formation of coalitions or alliance for deceptive purposes; bipedalism in general; canine tooth reduction; tool use; and more accurate use of weapons (ability to aim). Bipedal locomotion, for instance, plays a critical and perhaps surprising role in vocal evolution, in that bipedalism frees the thorax of its support role during quadrupedal locomotion, and this freedom permits the uncoupling of breathing and striding necessary for the subsequent selection for vocal virtuosity and speech. It also plays a role in the expansion of the brain, for as humans lost body hair and moved to life in the savannahs of East Africa, they moved more in the hot sun and evolved more sweat glands. More sweat glands allowed the brain to cool and grow, with the result that humans are now the sweatiest of all mammals and have one of the largest brain-to-body ratios. In addition, the earliest fossil records of bipedalism in the hominid line are always accompanied by the reduction of the projecting canine teeth. In certain primates decreased tooth use is associated with increased stick use for finding food. That is to say that stick use for food foraging could double as a defensive weapon as well, one even more effective than canine teeth. So, it is possible, that the need for carrying such a dual-purpose tool may well have contributed to the development of habitual bipedalism. Lieberman associates syntactic abilities with our ability to put one foot in front of the next (2006).

A developmental linguistics understands the emergence of languaging in the species as an interlocked set of circumstances that involve the human body from the soles of the feet (bipedalism) to the top of the head (the prefrontal cortex) and many places in between (the larynx, the lungs, the sweat glands) and in continuous interactions with fellow humans: from the moment of birth in the way babies that are born (the 
birthcanal-babyhead ratio is far narrower in humans than any other primate's, thus suggesting that humans have required assisted births for several hundred thousand years), to the way babies are held and interacted with, to the way they are conceived (face-to-face sexuality, along with a shift in the female from estral cycles to nonseasonal sexuality). The particulars of the human way of living that have been conserved over many hundreds of thousands of years have necessarily produced and reflect human particulars in the cognitive domain, with the result that any human living being born and raised in the human world will be (more rather than less) ready to becoming a languaging living being. In addition to inheriting many primate-wide cognitive skills such as pattern recognition, categorization, and social relationships, they also come ready to be oriented. Tomasello $(1999,2003)$ has called this the capacity to understand conspecifics as intentional/mental agents like the self, and he argues that this biological adaptation is the only one necessary to account for all the species-unique aspects of human cognition.

Turning to the next question: How do we become the particular languaging living beings that we do? we will need an ontogenetic account of the individual's lifetime, which can easily begin at five months' gestation when hearing typically develops in the womb. Clearly this topic is as large and has an equally extensive literature as the topic of language and evolution. However, given the constraints of space, only one small aspect of it will be invoked here: namely, the between-group differences in humans regarding number, and it presents another dimension to the subject of numerical cognition, discussed above in terms of what humans and other primates share with respect to comparing large and small quantities. Numerical cognition is as good a topic as any other to suggest how a developmental linguistics theorizes the issue of linguistic relativism.

Although it is becoming rarer and rarer to find previously undiscovered languages, such languages sometimes have features that lie outside expectation and thus their discovery can affect the theoretical landscape. Two relatively recent reports on two relatively small groups in the Amazon, the Pirahã (c. 200 people) and the Mundurukú (c. 7000 people) are doing just that. The issue concerns the presence - or, more precisely, the absence - of a counting system and its effect on numerical cognition. These studies thus provide a new wedge into prying open the relationship between language and thought/cognition.

The Pirahã use a "one-two-many" system of counting which consists of the words hói ("one" or even "roughly one"), hoí ("two") and baagi or aibai ("many"). Hói can also mean "small" and can contrast with ogii ("big"). The researcher, Peter Gordon, had his participants perform tasks that involved nonverbal numerical reasoning and that required some combination of cognitive skills such as the need for memory, speed, and mental-spatial transformations. The opening task required that they match in one-toone correspondence a linear array of AA batteries with another set of AA batteries. The 
tasks then progressed to, e.g., matching nuts to the battery line and to matching a battery line that was unevenly spaced. In these experiments, "participants responded with relatively good accuracy with up to two or three items, but performance deteriorated considerably beyond that up to eight to ten items." Other tasks involved the researcher putting, say, up to eight nuts in a can and then withdrawing them one by one. The participants were asked, each time a nut was withdrawn, whether any nuts were left in the can. Again, performance accuracy fell off when numbers over three were involved. Gordon notes that the nonverbal numerical abilities of the Pirahã are greatly affected by their limited counting system and states that "the present study represents a rare and perhaps unique case for strong linguistic determinism" (2004: 498).

For the Mundurukú, the first task that Pierre Pica et al. asked of their participants was to state how many dots were present in displays of one to fifteen dots. In this way they were able to determine that the Mundurukú have set terms only for numbers one to five, that these expressions are long and that they often have as many syllables as the corresponding quantity. Predictably, Mundurukú do not perform well on tasks involving exact arithmetic with numbers larger than four or five. It seems that they do not use their numbers for counting sequences but rather for approximations. Thus, the word for five can be translated as "one hand" or a "handful" and was used to refer to six, seven, eight and even nine dots. Pica et al. then were interested to study whether the lack of a Mundurukú counting system above five affected their ability to apprehend large numbers. Here the answer seems to be No. That is, they succeeded in consistently identifying the more numerous set when asked to compare two sets of, say, twenty to eighty dots. Pica et al. conclude, further, that the Mundurukú can mentally represent numbers beyond their naming range and that they do not confuse number with other variables such as size and density. They are also able to add, subtract, and compare their approximate representations. Pica et al. state that "approximation is a basic competence, independent of language, and available even to preverbal infants and many animal species. We conclude that sophisticated numerical competence can be present in the absence of a well-developed lexicon of number words" (2004: 503). The idea is that their study provides a qualification to Gordon's, in that the lack of a number lexicon does not completely limit the ability to work with abstract number concepts.

Yet Gordon acknowledges the general consensus that there seem to be two kinds of numerical abilities: (i) an ability to enumerate accurately small quantities up to three (2004: 498) - in their fascinating book Where Mathematics Comes From. How the Embodied Mind Brings Mathematics Into Being, George Lakoff and Rafael Núñez state that this ability is called subitizing, from the Latin word for "sudden" (2000: 19), and they acknowledge that newborn babies along with a range of species from primates to pigeons are able to subitize, to estimate numbers, and to perform the simplest addition and subtraction; and (ii) an ability to estimate rather accurately large quantities without 
overt counting. Pica et al's point of contention with Gordon seems to be one of emphasis, of how strongly we wish to interpret the influence of language on cognition. ${ }^{4}$

The purpose here is not to deny the Pirahã and the Mundurukú the numerical abilities they have. Neither is it to collapse obvious differences into some instance of "the same" numerical abilities to be found in all languaging living beings in the world. Now, the potential for more elaborated forms of arithmetic and mathematics may be present in all humans. Indeed, it is reported that Pirahã children easily learn number words in Portuguese, but, as one might expect, Pirahã adults, who are farther along in their ontogenic drifts, are not similarly adept. It is reported that they lose interest in such number lessons.

However, this losing of interest is not only related to an individual's age, it also involves other aspects of the environment that either would or would not support an interest in number lessons, e.g. the existence of a counting routine or the custom of counting on fingers, which the Mundurukú do not have. As is evident from the case of the Pirahã and the Mundurukú, not all human groups have found it useful, desirable, or necessary to develop more elaborated forms of arithmetic and mathematics. Another way of saying this is that the more elaborated forms of arithmetic and mathematics that are commonplace in many parts of the world today have long cultural histories, the particular effects of which can be felt in the places where they have been important. The kind of mathematics that is used in today's computer technology, for instance, is not the invention of a single human but is rather the result of a complex tradition that has taken its course in a variety of social settings and as a result of many cultural contacts. It is a commonplace to note, for instance, that it took Western mathematicians many centuries to fully grasp the benefits of the Arabic numeral zero and that the zero radically transformed Western arithmetic.

In The Cultural Origins of Human Cognition, Tomasello engages, in several passages, with a range of historical and cultural in mathematical practices in an effort to show, precisely, how social those practices are, despite the fact that "nothing seems

4. Needless to say, the case of the Pirahã has caused quite a stir, and a back-and-forth debate on it occupied a good ninety pages in a recent issue of Language. One of the central points of contention concerned whether or not Pirahã exhibits recursion. What the debate seemed to boil down to was what definition of recursion one was going to use to determine the issue, either one from an earlier generative grammar understood as "the ability for one phrase to reoccur inside another phrase of the same type" or a more recent one understood as the "general ability to build phrases that contain phrases as subparts" (Nevens et al. 2009: 366-367, n. 11). Although Nevens et al. who are arguing against Pirahã exceptionality, take Pirahã researcher Daniel Everett to task for failing to distinguish between these two senses, it still should be pointed out that the terminological slippage is less Everett's problem and more symptomatic of a universalist approach trying to hold itself together in the face of counterevidence (see also Evans and Levinson, forthcoming). 
less social than mathematics" (1999: 185). Lakoff and Núñez, for their part, have a similarly multilayered view of mathematics as a "product of the neural capacities of our brains, the nature of our bodies, our evolution in our environment, and our long social and cultural history" (2000: 9). Their particular emphasis is on mathematics as a systematic extension of the mechanisms of everyday cognition, conceptualizations that involve, e.g. collections of objects in a bounded region of space (class), repeated actions (recursion), rotation (complex arithmetic), and motion and approaching boundaries (calculus) (2000: 28-29). As I stated earlier, the mechanisms of our everyday cognition have been significantly shaped by our languaging together, and it follows that thus so should our mathematics. It also follows that an individual's mathematical cognizing will be affected by the environment in which that individual's being, doing, and knowing is realized.

This brief sketch is intended to convey some of the richness and promise of the phylogenetic, ontogenetic, and cultural account of the multidimensional and multimodal phenomenon of languaging as it unfolds in a developmental linguistics framework.

\section{What to do next}

When I was a graduate student, I realized that what I wanted to do in life was to read the historical record of linguistics. ${ }^{5}$ I remember looking at the stacks of books on the shelf in the library, those thick German tomes proclaiming that linguistics began with Bopp and Grimm, and thinking, "Man, if I want to change how people think about the history of our discipline, it is going to take a lot of doing." It seemed quite a weighty undertaking back then. Now, all these years later, we historiographers - with Professor Koerner either leading the way or indicating important directions to take - have altered how our fellow linguists, historians of science, and researchers in various disciplines who have a stake in language theory think about the history of our discipline.

As I now make the chiropractic intervention in linguistic theory to allow room for the term languaging and the epistemological framework of constructivism, I cannot help but think, "Man, if I want to change how people think about our discipline, it is going to take a lot of doing." And that is not all. To change how most linguistic departments — or even any, besides my own! - present their introductory linguistic course will no doubt be a far more difficult undertaking than the labor of writing and rewriting Linguistics Reimagined over the last five or six years and probably even much more than the twenty years I spent inventing endless numbers of odd-ball linguistics courses so that I could get a new perspective on things and write the book in the first place. For

5. Well, it takes all kinds. 
some reason, however, this time around the prospect of effecting change does not feel so oppressive. Perhaps that is because I have already experienced "been there, done that" with respect to the discipline's history. Or perhaps this is because historiography is flourishing, and I know I do not have to do it all alone.

Historiographers subscribe to the idea that intellectual parentage is bestowed by the children. We, the current practitioners of a field, get to identify who our intellectual forbearers are; and we the historiographers get to write that history. Long ago, at the first ICHoLS in Ottawa, some of us proclaimed Condillac to be a significant part of the discipline. And so he is, now in more ways than one. As I look back over the last one hundred years and more of linguistic activity, I can see that reconstructing languages and writing grammars are fine things for linguists to do - even necessary things for them to do - but they are not the only things that someone who merits the name linguist or language theorist can or should do. There exists a long line of thinkers - philosophers, psychologists, semioticians - who have understood our subject matter it in all its situatedness: It includes, among others from the historical record, Pierre Bourdieu, Michel Foucault, William James, Humberto Maturana, B.F. Skinner, Francisco Varela, V.N. Vološinov, and Lev Vygotsky. As I and others write them into the historical record, the creaky old skeleton limbers up and the possibility of a renewed theoretical integration in twenty-first-century linguistics improves. In now moving toward an account of language/languaging that derives not from Descartes but from Darwin, we can pause to appreciate Chomsky for having brought questions about the biological nature of language to the fore and then turn the page.

\section{References}

Andresen, Julie T. (under consideration). Linguistics Reimagined.

Au, Terry Kit-fong, Leah M. Knightly, Sun-Ah Jun \& Janet S. Oh. 2002. "Overhearing a language during childhood". American Psychological Society 13:3. 238-243.

Austin, J.L. 1962. How to do things with words. Oxford: Clarendon Press.

Bloomfield, Leonard. 1933. Language. New York: H. Holt \& Company.

Bourdieu, Pierre \& John B. Thompson. 1991. Language and symbolic power. Cambridge: Polity. Bruner, Jerome S. 1983. In search of mind : essays in autobiography. New York: Harper \& Row. Cantlon, Jessica \& Elizabeth Brannon. 2005. "Semantic congruity affects numerical judgments similarly in monkeys and humans". PNAS 102: 45. 16507-16511.

Cantlon, Jessica. 2006. "Shared System for Ordering Small and Large Numbers in Monkeys and Humans". Psychological Science 17: 5. 402-407.

Chomsky, Noam. 1959. "Review of Verbal Behaviour, by B.F. Skinner". Language 35: 1. 26-59.

Chomsky, Noam. 1965. Aspects of the theory of syntax. Cambridge: M.I.T. Press.

Chomsky, Noam. 1966. Cartesian linguistics: a chapter in the history of rationalist thought. New York: Harper \& Row.

Chomsky, Noam. 1988. Language and problems of knowledge: The Managua Lectures. Cambridge, Mass.: M.I.T. Press. 
Chomsky, Noam. 2002. Nature and Language. Cambridge: Cambridge University Press.

Chomsky, Noam, M.D. Hauser \& W. Tecumseh Fitch. 2002. "Appendix. The Minimalist Program. A response to Pinker \& Jackendoff (2005)”. Retrieved online.

Donald, Merlin. 2001. A mind so rare : the evolution of human consciousness. New York: Norton.

Elman, Jeffrey, Elizabeth A. Bates, Mark H. Johnson, Annette Karmiloff-Smith, Domenico Parisi \& Kim Plunkett, eds. 1999. Rethinking Innateness. A connectionist perspective on development. Cambridge, Mass.: M.I.T. Press.

Evans, Nicholas \& Stephen C. Levinson. 2009. “The Myth of Language Universals: Language diversity and its importance for cognitive science”. Behavioral \& Brain Sciences 32(5). 408-428.

Fromkin, Victoria, Robert Rodman \& Nina M. Hyams. 2003. An introduction to language. Boston: Thomson/Heinle.

Foucault, Michel. 1971. "The Discourse on Language". Social Science Information 10.

Goldberg, Adele E. \& Ray Jackendoff. 2004. “The English Resultative as a Family of Constructions”. Language 80: 3. 532-568.

Goldberg, Adele E. 2006. Constructions at work : the nature of generalization in language. Oxford; Toronto: Oxford University Press.

Goldin-Meadow, Susan. 2003. Hearing Gesture. How Our Hands Help Us Think. Cambridge, MA: Harvard University Press.

Goldstein, Michael, Andrew King \& Meredith West. 2003. "Social interaction shapes babbling: Testing parallels between birdsong and speech". PNAS 100: 13. 8030-8035.

Goldstein, Michael \& Meredith West. 1999. "Consistent Responses of Human Mothers to Prelinguistic Infants: The Effect of Prelinguistic Repertoire Size”. Journal of Comparative Psychology 113: $1.52-58$.

Gordon, Peter. 2004. "Numerical Cognition without Words: Evidence from Amazonia”. Science 306. 496-499.

Harris, Roy. 1996. The language connection : philosophy and linguistics. Bristol: Thoemmes Press.

Hauser, M.D., Noam Chomsky \& W.T. Fitch. 2002. “The Faculty of Language: What Is It, Who Has It, and How Did It Evolve?” Science 298. 1569-1579.

Hill, Jane. 1974. "Possible Continuity Theories of Language”. Language 50: 1. 134-150.

Jackendoff, Ray \& Steven Pinker. 2005. "The nature of the language faculty and its implications for evolution of language (Reply to Fitch, Hauser, and Chomsky)". Cognition 97: 2005. 211-225. James, William. 1981 [1890]. The principles of psychology. Cambridge, Mass.: Harvard Univ. Press. James, William. 1981 [1907]. Pragmatism. Indianapolis: Hackett Pub. Co.

Karmiloff-Smith, Annette. 1998. "Development itself is the key to understanding developmental disorders". Trends in Cognitive Science 2: 10. 389-398.

Kay, Paul \& Charles Fillmore. 1999. "Grammatical constructions and Linguistic Generalizations: The What's X doing Y? Construction”. Language 75: 1. 1-33.

Labov, William. 1972. Sociolinguistic patterns. Philadelphia: University of Pennsylvania Press.

Lakoff, George. 1987. Women, fire, and dangerous things : what categories reveal about the mind. Chicago: University of Chicago Press.

Lakoff, George \& Rafael E. Núñez. 2000. Where mathematics comes from : how the embodied mind brings mathematics into being. New York, NY: Basic Books.

Levinson, Stephen C. 2003. Space in language and cognition: explorations in cognitive diversity. Cambridge ; New York: Cambridge University Press.

Lewontin, Richard C. 2000. The triple helix : gene, organism, and environment. Cambridge, Mass.: Harvard University Press. 
Lieberman, Philip. 2006. Toward an evolutionary biology of language. Cambridge, Mass.: Belknap Press of Harvard University Press.

Maturana, Humberto \& Jorge Mpodozis. 1992. Origen de las Espécies por medio de la Deriva natural o La diversificación de los linajes a través de la conservación y cambio de los fenotipos ontogénicos. Santiago, Chile: Museo Nacional de Historia Natural.

Maturana, Humberto \& Francisco Varela. 1972. Autopoiesis and Cognition. The Realization of the Living. Dordrecht: D. Reidel Publishing.

Maturana, Humberto R. \& Francisco Varela. 1987. The tree of knowledge : the biological roots of human understanding. Boston: New Science Library \& Random House.

McNeill, David. 2005. Gesture and Thought. Chicago: University of Chicago Press.

Mendoza-Denton, Norma. 2007. Homegirls : language and cultural practice among Latina youth gangs. Oxford: Blackwell.

Nelson, Katherine. 2007. Young minds in social worlds : experience, meaning, and memory. Cambridge, Mass.: Harvard University Press.

Nevens, Andrew, Pesetsky \& Cilene Rodrigues. 2009. "Piraha Exceptionality: A Reassessment". Language 85: 2. 355-404.

Oshima-Takane, Yuriko, Elizabeth Goodz \& Jeffrey L. Derevensky. 1996. "Birth Order Effects on Early Language Development: Do Secondborn Children Learn from Overheard Speech?” Child Development 67. 621-634.

Oyama, Susan. 1985. The ontogeny of information : developmental systems and evolution. Cambridge; New York: Cambridge University Press.

Oyama, Susan. 2000. Evolution's Eye. A Systems View of the Biology-Culture Divide. Durham, North Carolina: Duke University Press.

Packman, Ann, Chris Code \& Mark Onslow. 2007. "On the cause of stuttering: Integrating theory with brain and behavioral research". Journal of Neurolinguistics 20. 353-362.

Pica, Pierre, Cathy Lerner, Véronique Izard \& Stanislas Dehaene. 2004. "Exact and Approximate Arithmetic in an Amazonian Indigene Group". Science 306. 499-503.

Pinker, Steven. 1994. The language instinct. New York: W. Morrow and Co.

Pinker, Steven. 1997. How the mind works. New York: Norton.

Pinker, Steven \& Paul Bloom. 1990. Natural language and natural selection. Cambridge, Mass.: Massachusetts Institute of Technology Center for Cognitive Science.

Pinker, Steven \& Ray Jackendoff. 2005. “The faculty of language: what's special about it?” Cognition 95. 201-236.

Pullum, Geoffrey K. 1996. "Learnability, hyperlearning, and the poverty of the stimulus". Proceedings of the Berkeley Linguistics Society 498-513.

Pullum, Geoffrey K. \& Barbara Scholz. 2002. "Empirical assessment of stimulus poverty arguments”. Linguistic Review 19. 9-50.

Purves, Dale \& R. Beau Lotto. 2003. Why we see what we do : an empirical theory of vision. Sunderland, Mass.: Sinauer Associates.

Rickford, John R, Thomas Wasow, Norma Mendoza-Denton \& Juli Espinoza. 1995. “Syntactic Variation and Change in Progress: Loss of the Verbal Coda in Topic-Restricting As Far As Constructions". Language 71: 1. 102-131.

Saussure, Ferdinand de. 1959 [1916]. Course in general linguistics. New York: McGraw-Hill.

Searle, John R. 1998. Mind, language \& society : doing philosophy in the real world. New York: Basic Books.

Skinner, B.F. 1957. Verbal behavior. New York: Appleton-Century-Crofts.

Smith, Barbara Herrnstein. 2005. Scandalous knowledge : science, truth and the human. Edinburgh: Edinburgh University Press. 
Tallal, Paula \& April A. Benasich. 2002. “Developmental language learning impairments”. Development and Psychopathology 14. 559-579.

Tannenhaus, Michael, Michael J. Spivey-Knowlton, Kathleen Eberhard \& Julie Sedivy. 1995. "Integration of Visual and Linguistic Information in Spoken Language Comprehension". Science 268. 1632-1635.

Thomas, Margaret. 2002. "Development of the concept of "the poverty of the stimulus." The Linguistic Review 19. 51-71.

Tomasello, Michael. 1995. "Language is Not an Instinct. Review of The Language Instinct". Cognitive Development 10. 131-156.

Tomasello, Michael. 1999. The cultural origins of human cognition. Cambridge, Mass.: Harvard University Press.

Tomasello, Michael. 2001. "Could we please lose the mapping metaphor please?" Behavioral and Brain Sciences 24: 6. 1119-1120.

Tomasello, Michael. 2003. Constructing a language : a usage-based theory of language acquisition. Cambridge, Mass.: Harvard Univ. Press.

Voloshinov, V.N., Ladislav Matejka \& I.R. Titunik. 1973. Marxism and the philosophy of language. New York: Seminar Press.

Vygotsky, Lev Semenovich. 1962. Thought and language. Cambridge, Mass.: M.I.T. Press.

Vygotsky, Lev Semenovich. 1986. Thought and language. Cambridge, Mass.: M.I.T. Press. 



\section{Name index}

A

Aarsleff, Hans 12-13

Abelard, Pierre 386

Abelson, Robert P. 268

Abney, Steven 429, 437, 442

Abraham, Werner 25, 308

Adelung, Johann C. 7

Adger, David 329

Agard, Frederick B. 408

Agassi, Joseph 243, 266, 272-273

Aginsky, Burt W. 307

Aginsky, Ethel G. 307

Aikhenvald, Alexandra 47

Akhutina, T.V. 275

Alba, Joseph 268

Aliseda, Atocha 316

Allen, W.S. 426

Alsted, Johann Heinrich 306

Alter, Stephen G. 7, 341

Andersen, Gisle 364

Anderson, Stephen R. 285-286, 288

Andresen, Julie 243

Anipa, Kormi 39

Anselm of Canterbury 386

Antilla, Raimo 94

Antinucci, Francesco 409-413, $415,417-418$

Aquinas, Thomas 386

Arnauld, Antoine 10, 14, 306, $381,384-385,390$

Aronoff, Mark 377

Ascoli, Graziado 7

Aslin, Richard N. 157, 289

Attridge, Derek 53

$\mathrm{Au}$, Terry Kit-fong 456

Auroux, Sylvain 305-306

Austin, George A. 248

Austin, J.L. 447, 455

B

Baars, Bernard 240, 243

Badiou, Alain 45
Bach, Emmon 171, $326-327,380$

Backus, John W. 270

Bacon, Francis 305-306

Bacon, Roger 303, 386

Baker, William J. 272, 276-277

Baker, Mark 328-329, 333

Bally, Charles 88

Bandler, Richard 128

Banerji, Sharbani 387

Banks, Eric 366

Bar Adon, Aaron 171

Bar-Hillel, Yehoshua 77, 110, 188-189, 208-209, 240, 250-251

Barnhardt, Terrence M. 279

Barsalou, Lawrence 268

Barsky, Robert F. 13, 106-107, $117,154,250,258,378-379$, 381-382

Bartlett, Frederick C. 268

Basso, Keith 75

Batali, John 291

Baudouin de Courtenay, Jan 50-52, 120

Beach, Woodford 169

Beauzée, Nicholas 306

Beebe, J.G. 250

Beedham, Christopher 20, 24-28, 35, 38-39

Benasich, April A. 454

Benedict, Ruth 162

Berezin, Fedor 51-52

Bergmann, Gustav 266

Berkeley, George 116

Bever, Thomas 179, 275-276, $289,338,425,429-430$

Bisang, Walter 355, 365

Blake, Barry J. 321

Blake, Frank R. 84

Blanc, Haim 169, 172, 189

Bloch, Bernard 79, 89-93, 111, $117,124,126-127,174,188$, 209, 223, 425, 427
Bloom, Paul 343, 458, 462

Bloomfield, Leonard 2, 9-12,

$15,50,75-77,79,82-85$,

89, 91-94, 96, 111-114,

116, 120, 124, 126, 139, 151,

155, 160, 162, 172, 177-180,

209-210, 215, 221, 226-227,

270-271, 274-277, 289,

$397,400,423-426$,

$433-435,445,447-448$,

452,460

Boas, Franz 2, 76-80, 86, 114, 130, 175

Bobrow, Daniel 251

Bod, Rens 441

Boden, Margaret 238, 255

Bogen, J.E. 286

Bogen, G.M. 286

Bogorodickij, Vasilij 52

Bohas, Georges 187

Bolinger, Dwight 20, 23

Bonald, Louis Gabriel

Ambroise de 94

Bonaventure 386

Bopp, Franz 7-9, 467

Bourdieu, Pierre 468

Bracken, Harry 382

Brannon, Elizabeth 463

Bréal, Michel 358-363

Bresnan, Joan 20, 28, 30-31

Brinton, Laurel J. 371

Broca, Paul 286

Bromberger, Sylvain 238

Brown, A.F. 118

Brown, E.K. 427, 430

Brown, Roger 91, 93, 239, 267

Brugmann, Karl 52

Bruner, Jerome 157, 240-242, $248,256,267,272,278,452$

Buckhout, Robert 240, 246

Bühler, Karl L. 277

Bundy, David 436

Burnouf, Eugène 7

Bursill-Hall, Geoffrey 303, 386 
Burzio, Luigi 327, 328, 333

Bush, Robert R. 257

Bybee, Joan L. 365,367

C

Cairns, Vivika 39

Campanella, Tommaso 305

Campbell, George 7

Campbell, Lyle. 371

Carey, Peter 275

Cantlon, Jessica 463

Carnap, Rudolf 110, 112, 115-118, 122, 140, 152, 171, $175,181,240$

Carroll, John B. 85, 239, 246-247

Carroll, Sean B. 343

Carter, M.G. 187

Castelfranchi, Cristiano 409-410, 415, 417

Chafe, Wallace 406

Ceccarelli, Leah 255

Chakravartty, Anjan 316

Chamberlain, Alexander F. 239

Chao, Yuen Ren 281

Chayen, M. 170-171

Chesneau, César sieur

Du Marsais 273, 383-384, 388, 390

Chomsky, Carol 251

Chomsky, William 104, 172, 187,189

Christophe, Anne 288

Christy, T. Craig 341, 354, 358, 360-363

Church, Alonzo 112

Cinque, Guglielmo 413-415, 418

Claudi, Ulrike 365

Cobham, Catherine 39

Cohen, Murray 306

Colebrooke, Henry Thomas 7

Coleridge, Samuel T. 57

Comajoan, Lloren. 367

Comrie, Bernard 301

Condax, I.D. 132

Condillac, Étienne Bonnot de. $12,360,384-385$, 459-461, 468

Conrad, Rudi 22

Cook, Vivian James 329

Copernicus, Nicolas 3

Cordemoy, Gérauld de 10
Corder, S. Pit 6

Cordeschi, Roberto 249

Coren, Stanley 283

Cori, Marcel 441

Coulter, Jeff 250

Covington, Michael A. 303, 386

Cram, David 3

Crick, Francis 253, 283

Croft, William 365

Crowther-Heyck, Hunter 240, 242

Crystal, David 58

Culler, Jonathan 88

Curtius, Georg 8

Cziko, Gary 157

D

Daniels, Peter 89, 123, 211

Danks, Warwick 39

Darmesteter, Arsène 362

Darnell, Regna 75, 79

Darwin, Charles 3, 340, 342, 347-348, 453, 468

David, Sophie 441

Davidson, Donald 391

Davies, Alan 339

Dawkins, Richard 343

De Goeje, C. 219

De Groot, Adriaan 267

Dennett, Daniel 343, 347

Dennis, Simon 291

Descartes, René 10, 12-14, $62,274,360,383-385$, $387,389-390$, 453, 457

Diderot, Denis 273

Diebold, A. Richard 247

Diessel, Holger 365

Dingle, Herbert 36-37

Donald, Merlin 459

Donatus, Aelius 386

Donovan, Arthur 333

Donze, Roland 305

Dresher, B.E. 127

Duhem, Pierre 316

Dumais, Susan 290

Duncan, David 170

Dynes, Wayne R. 80

Dyscolus, Apollonius 385

E

Edmond, Dean 249
Einstein, Albert 3, 64, 75, 110, 154

Elman, Jeffrey 455

Emonds, Joseph 326, 400

Encrevé, Pierre 177

Erneling, Christina E. 278

Evan, William 154

Evans, Rand B. 278

Evans, Nicholas 466

Everett, Dan 355, 466

F

Falk, Julia S. 12, 86

Fant, Gunnar 240

Ferguson, Charles A. 307

Feyerabend, Paul 316

Fick, August 8

Fillenbaum, Samuel 247

Fillmore, Charles 22, 282, 326, 413, 450

Fine, Nathan 105

Firth, J.R. $85,423-427,430$, 440-442

Fischer, Olga 365

Fish, Stanley 53

Fitch, W. Tecumseh 149, 338, $343,346-347,462$

Fodor, Jerry 244, 275, 282, 284-285

Foucault, Michel 468

Fought, John 75, 85, 109, 111, $152,160,216,229$

Frachtenberg, Leo J. 79

Francis, W. Nelson 86

Fredborg, Karin M. 303

Freeman, Margaret 56

Frege, Gottlob 402-403

Fries, Charles 427

Fromkin, Victoria 45, 447

Fromm, Erich 111

Frost, Robert 54-55

G

Galanter, Eugene 256-257, 267,278

Galison, Peter L. 266, 333

Gandhi, Mahatma 45

Gardner, Howard 156, 159, 266-267, 269, 272, 276

Garrett, Merrill 275

Gass, Susan 5-6

Gazdar, Gerald E. 20, 38

Gebhart, A.L. 157 
Geeraerts, Dirk 432

Gesenius, Wilhelm 172

Gibson, James J. 127, 135

Gigerenzer, Gerd 268

Ginsburg, Seymour 270

Givon, Talmy 35, 363, 365-366

Gleason, Henry A., Jr. 11, 225

Gleitman, Lila 105, 157, 310

Goethe, Johan von 340

Goetze, Albert 107, 114, 121, 154

Gogarten, Peter 361

Goldberg, Adele 450-451

Goldin-Meadow, Susan 455

Goldsmith, John 106, 122, 169-170, 176, 180, 188, 276-277, 315-316, 319, 377-378, 380, 391, 395, 400-406, 416

Goldstein, Michael 457

Golumbia, David 238-239, 258

Goodman, Nelson 105, 117, 120, 158, 172, 174-175, 183

Goodnow, Jacqueline J. 248, 267, 272, 278

Gordon, Cyrus H. 173-174

Gordon, Peter 464-466

Gougenheim, Georges 85

Gould, Stephen Jay 287, 343

Graffi, Giorgio 315, 323, 408, 412-413

Gray, L.H. 174

Green, Bert F. 251

Greenbaum, Sidney 429

Greenberg, Joseph 301, 308,311

Greene, Judith 247

Greenwood, John D. 266-268, 272

Gregory, Amy 40

Greibach, Sheila A. $269-270$

Grimm, Jakob 7-8, 52, 339, 341, 467

Grodzinsky, Yosef 286

Gross, Maurice 20, 35, 122, 124

Guillaume, Jean-Patrick 187

Gumperz, John 75

Gutman, Daniel 171, 179, 211

$\mathrm{H}$

Habert, B. 441

Hall, Robert A. 20, 79, 223
Halle, Morris 89, 135, 159, 171, 178-179, 188-189, 240, 251, 277, 391, 426

Halliday, M.A.K. 24, 423-425, 427-433, 440-442

Hallward, Peter 45, 65

Hammarberg, Robert 282

Hammarström, Göran 20

Harlow, Stephen J. 378

Harman, Gilbert 20, 216

Harris, James 306, 390

Harris, Randy 93, 97, 106, $133,153,216,315,320$, $329,377-379,395$, 398-400, 405-406

Harris, Roy 339, 456

Harris, Zellig S. 75-77, 88, 90, 92, 94, 103-168, 173-179, $185,187-188,208,210,218$, 221, 224-225, 229, 240, 251, 255, 269, 428

Harwood, F.W. 226

Hasher, Lynn 268

Haspelmath, Martin 371

Hatcher, Anna Granville 435

Hauser, Marc D. 149, 155, 338, $343,346-347,462$

Hawking, Stephen W. 137

Head, Henry 268

Hébert, Richard 241, 243

Heine, Bernd 358, 364-365

Heinroth, Oskar 273

Heisenberg, Werner 63-64

Helbig, Gerhard 24

Helwig, Christoph 305

Hempel, Carl Gustav 316

Herder , Johann Gottfried $7-8,77,384-385,387$

Herman, Edward S. 95

Hill, Archibald A. 93, 159, 171, 211, 220, 434-435

Hill, Jane 462

Hintikka, Jaakko 274, 282

Hiraga, Masako 53-54, 56

Hirsch, S.A. 303

Hitler, Adolf 382

Hiz, Henry 104-105, 110, 126, $138,161,226$

Hjelmslev, Louis 131, 178

Hoberman, Robert D. 169

Hockett, Charles F. 11, 79, 109, 126, 131, 188, 219, 221, 225, 229, 253, 271, 431
Hoenigswald, Henry 187

Hoijer, Harry. 85, 175, 188

Honert, Daniel. 39

Honigman, John J. 162

Hopcroft, John E. 270

Hopely, Phil 251

Hopper, Paul 23, 358, 363, 365, 367-370

Hovdhaugen, Even 303

Hubel, David H. 283

Huck, Geoffrey J. 106, 276-277, 315-316, 319, 377-380, 391, 395, 400-406, 416

Huddleston, Rodney D. 24

Huehnergard, John 169

Hull, Clark L. 267

Humboldt, Wilhelm von 8-11, $13,15,47,273,307,340$, $362,381,383,385$

Hume, David 15

Hünnemeyer, Friederike 365

Hutton, Christopher 339, 349

Hutton, James 341

Hyams, Nina M. 447

Hyman, Malcolm 266

Hymes, Dell 77, 85, 92-93, $109,111,113,152,160,216$, 229, 432

I

Ingria, Robert 106

Innis, Robert E. 277

J

Jackendoff, Ray 149, 284-285, $363,378,391,402$, $412-413,450$

Jackson, J. Edward 290

Jaeger, Jeri J. 277

Jakobson, Roman 50, 52-56, 63-64, 77, 85, 92, 159, 177-179, 188, 240, 277, 308, 427

James, William 348, 468

Janda, Richard 371

Jespersen, Otto 11, $85-87,307$

Johnson, David E. 321

Johnson, David M. 278

Johnson, Stephen B. 123-124

Jolly, Julius 7

Joly, André 306 
Jones, William 7

Joos, Martin 46-47, 93, 113, $124,126,130-131,177$, 180,188

Joseph, John E. 1-2, 7, 9-10, $15,24-25,52,237$, 390-391, 438

Joshi, Aravind 123, 143-145, 155,251

Juntune, Sarah 305

K

Kac, Michael B. 144

Kampf, Louis 381

Kant, Immanuel 282, 383

Kantor, J.R. 242

Kasher, Asa 216, 231

Katz, Jerrold 282, 425, 429-430

Katz, Joshua T. 169

Kaufmann, Bruria 110, 154

Kautzsch, Emil 172, 209

Kay, Paul 85, 450

Kayne, Richard 327

Kelly, Louis G. 303

Kempton, Willett 85

Kennedy, Graeme 438-439

Kibbee, Douglas 75

Kihlstrom, John F. 279

Kilbury, James 171-172, 180

Kilwardby, Robert 303, 386

Kimhi, David 172, 187, 189

King, Andrew 457

Kintsch, Walter 268

Kiparsky, Paul 187

Kirchner, Robert 127

Klausenburger, Jurgen 365

Kleene, Stephen C. 112

Knuth, Donald 247, 255

Koerner, E.F. Konrad. 1-2, $10,12,16,20,24,50,63$, $75,79,87-88,92,120,122$, 169-170, 173-174, 176-179, $216,227,252,265-266,273$, 277, 301-302, 341-342, 347, $378,381,390,399,405-407$, $425,445-446,467$

Koster, Jan 333

Kouloughli, Djamel 187

Kripke, Saul 282

Kroeber, Alfred L. 85

Kroker, Kenton 279

Kruszewski, Mikolaj 50-54, 63-64
Kuhn, Thomas S. 3, 43, 75-76, 88-89, 94-95, 210, 238, 241, $258,266,316,353-354,356$

Kuipers, Theo $316-317$

Kuno, Susumu 323

Kuroda, S.-Y. 270

Kurylowicz, Jerzy 52, 60

Kuteva, Tania 364-365

\section{L}

\section{La Mettrie,} Julien Offray de 387

Labov, William 113, 447

Lakatos, Imre 316

Lakoff, George 14, 54, 89, 128, 326-327, 378-381, 387, 391, 396, 398-399, 401-403, 406-407, 413-416, 418, $450,465,467$

Lakoff, Robin 12, 14, 320, 383 , 387-389, 395-398, 400, 405, 407, 410, 413

Lallement, Gérard 270

Lamb, Sidney M. 20

Lancelot, Claude 10, 14, 306, $381,386,388-390$

Landauer, Thomas 290

Langacker, Ronald 370, 450

Langendoen, D. Terence 85, 425-427

Lashley, Karl 156, 268, 272

Lasnik, Howard 276, 284, 310

Laudan, Larry 316, 324, 330, 332

Laufer, Asher 132

Law, Vivien 430

Le Corbusier 2

Leahey, T.H. 266-267

Leech, Geoffrey N. 25, 433, 441

Lees, Robert 75, 89, 90, 93, 160, 215-216, 220, 230-231, $245,250-252,254,379$, 400, 425, 429

Lehmann, Christian 365

Lehmann, Winfred 250

Léon, Jacqueline 281, 433, 441

Lewontin, Richard C. 343,460

Leiber, Justin 75

Leibniz, Gottfried Wilhelm $7,383,390$

Lenneberg, Eric 272, 282

Lentin, Andr. 110

Levi, Judith N. 171, 194

Levi della Vida, Giorgio 173
Lévi-Strauss, Claude. 85

Levin, Beth 328

Levin, Samuel R. 86

Levine, Robert D. 97

Levinson, Stephen 454, 462, 466

Lewry, Osmund 303

Lieberman, Phillip 60, 272, $285,287,289,338$, 340, 463

Lightbown, Patsy 49

Lightfoot, David 269, 271, 285-286, 288, 346, 348

Lin Biao 96

Lin, Francis Y. 106, 157

Lisker, Leigh 110

Liszka, James Jacob 56

Liu Shaoqi 96

Locke, John 12-14, 360, 383-385, 390

Locke, William 90

Lorenz, Konrad 273

Lotto, R. Beau 459

Luce, R. Duncan 257

Luhmann, Niklas 348

Lukoff, Fred 118, 250

Luria, A.R. 275

Lyell, Charles 341

Lyons, John 20, 426

M

MacCorquodale, Kenneth 90, 243

MacDonald, John 454

MacFarquhar, Larissa 106

Machinist, Peter 169

Magill, Dennis 75

Maher, J. Peter 216

Maistre, Joseph de 94

Malinowski, Bronislaw 85, 426

Malone, Joseph L. 209

Malotki, Ekkehart 81

Manaster-Ramer, Alexis 144

Mandelbrot, Benoit 240, 436-437

Mandler, George 242, 266-268, 271-272, $278-279,292$

Mandler, Jean 268

Manning, Christopher 442

Marantz, Alec 327-329

Marken, Richard 157

Martin, Richard 105

Martin, Roger 20 
Martinet, André 77, 85, 92, 161, 308

Marx, Karl 93

Maslow, Abraham 162

Mathesius, Vilem 85

Matthews, G.H. 250-251

Matthews, P.H. 216, 220, 231, 426

Matthews, Stephen 365

Maturana, Humberto 458

Maury, Liliane 268

May, Robert 399

Mayer, August 278

McCarthy, John 248

McCawley, James D. 36, 106, $326-327,378-381,391,396$, 399, 401-402

McCawley, N. Akatsuka 402

McGilvray, James A. 349,387

McGurk, Harry 454

McIntosh, Angus 424, 430

McKean, Kathryn O. 246, 274

McNeill, David 455

Mehler, Jacques 274-275, 288

Meillet, Antoine 24, 353-355, $362,369-371$

Mendoza-Denton, Norma 460

Miel, Jan 382-383

Mikhail, John 291

Mill, John Stuart 50-51

Miller, George. 237-243, 246-250, 252, 256-260, 265, 267, 269-270, 274-275, 278, 282, 292, 429, 437

Milner, Jean-Claude 440

Minsky, Marvin 238, 248-249, 259

Mintz, Toben 289

Montague, Richard 391, 399

Montalbetti, Mario 338

Montgomery, Philip 188

More, Trenchard 249

Morris, Desmond 61

Mos, Leendert P. 272, 276-277

Moses, Rae Arlene 174

Motwani, Rajeev 270

Mpodozis, Jorge 462

Mufwene, Salikoko 43, 61-62, 66

Müller, Friedrich Max 342

Murray, Stephen O. 77, 80-81, 84-85, 89, 91, 93, 95-97, 113, 118, 122, 158-161, 174,
178, 189, 211, 216, 266, 269,

$354,395,399-400,407$

$\mathrm{N}$

Naur, Peter 270

Neisser, Ulric 268, 274-275, 279

Nelson, Katherine 457

Neumann, John von 268

Nevens, Andrew 466

Nevin, Bruce 124, 127, 132, 144, 146, 150, 174

Newell, Allan 238, 248, 256-257, 260, 267-268, 272

Newmeyer, Frederick J. 20, 159, 216, 266, 276, 287-288, 308, 315, 354, $367,379,395-396,399$, 403-407

Newport, Elissa. 157, 289-290

Newson, Mark 329

Newton, Isaac 3

Ngo, Thanh Nhan 129, 144

Nicole, Pierre 384

Nida, Eugene 114

Nietzsche, Friedrich 276

Niiniluoto, Ilkka 316

Nisbet, Robert A. 75, 94

Nolan, Edmond 303

Noldeke, Theodor 173

Nunez, Rafael 465, 467

\section{O}

Orth, Johannes 278

Osgood, Charles 239, 243

Oshima-Takane, Yuriko 456

Osthoff, Hermann 52

Otero, Carlos P. 425

Oudeyer, Pierre-Yves 291

Overbye, Dennis 108

Oyama, Susan 461

\section{$\mathbf{P}$}

Packman, Ann 454

Padley, G.A. 303, 305

Paikeday, Thomas M. 339

Palermo, David S. 266, 272

Palmer F.R. 26

Panini 79, 187

Paradowski, Michal 59

Pariente, Jean-Claude 304-305

Parisi, Domenico 408-410, 415,417
Partee, Barbara 259

Paul, Hermann 9, 11

Peirce, Charles S. 53, 55-56, 63-64, 347

Perchonock, Ellen 275

Percival, W. Keith 169, 172, $238,266,385$

Pereira, F. 441

Pergolesi, Giovanni Battista 5

Perlmutter, David 320-329, 414

Perrin, Dominique 270

Peters, Stanley 378

Petitto, Laura-Ann 368

Philo 385-386

Piaget, Jean 110, 267-268, 277, 292

Pica, Pierre 465-466

Pike, Kenneth L. 76-77, 114, 173, 221, 229, 427

Pinborg, Jan 303

Pinker, Steven 30, 45, 149, 286, $343,346,450,456,458,462$

Planck, Max 75

Plato 52, 55, 282, 385

Plotinus 386

Polomé, Edgar 171

Popper, Karl 316

Post, Emil 119, 145, 269

Postal, Paul 89, 97, 320-322, 324-326, 329, 378-381, 391, 396, 399, 401-403, 405, 413-414, 424-425

Poupynin, Youri 25

Powers, William T. 157

Preston, William D. 219

Pribram, Karl 256-257, 267,278

Priscian 386

Psimopoulos, M. 36-37

Puglielli, Annarita 408

Pullum, Geoffrey 281, 288, 324-326, 450

Purves, Dale 459

Putnam, Hilary 20

Q

Quine, W.V.O. 127, 175, 178

Quirk, Randolph 22-23, 413, 427-435, 439, 441

R

Rademaker, Cornelis 386-387 Radford, Andrew 20, 28-29, 327,329 
Radwanska-Williams, Joanna. $50-52,54,56,60,62-63$

Ramus, Franck 288

Rancière, Jacques 45

Rambow, Owen 145

Rapaport, David 110

Rask, Rasmus 7

Ratke, Wolfgang 305

Read, Charles 281

Reed, Edward. 266

Reeder, P.A. 157

Reh, Mechthild 358

Reid, Thomas 7

Rheinberger, Hans-Jörg 283

Renzi, Lorenzo 408

Rice, Gordon 270

Rickford, John R. 448

Rieber, Robert W. 266

Roberts, Ian 364-365

Robertson, Daniel 6, 9

Robins, Robert H. 301,

$$
\text { 425-427, } 430
$$

Robinson, Ian 20

Robinson, Jane 127

Rochester, Nathaniel 248-249

Rodman, Robert 45, 447

Ronat, Mitsou 155, 378

Rosen, Carol 330

Rosenbloom, Paul C. 119

Rosenthal, Franz 173

Ross, John R. 56, 143, 326-327, 378-381, 391, 396, 399, 402-404, 413-414, 417

Roussou, Anna 364-365

Runkel, Philip J. 157

Russell, Bertrand 112

Ryckman, Thomas A. 121-122, $128,141-142,146$

\section{$S$}

Sadock, Jerrold 402

Saffran, Jenny R. 289

Sag, Ivan A. 20

Sager, Naomi 123, 129, 144

Sahlin, Gunvor 389

Sainte-Beuve,

Charles Augustin 384

Saldanya, Manuel Pérez 367

Salkie, Raphael 346

Salmon, Vivian. 12, 306, $382-383,387$

Salus, Peter 385-386, 390

Samarin, William 75
Sampson, Geoffrey 288-289, 430, 440

Samuel, Arthur 249

Sanctius, Franciscus 12, 14, 384-390

Sanders, Carol 24

Sankey, Howard 333

Santiago, Alfredo Viola 84

Sapir, Edward 2, 8-9, 76-85, $88,110,113-114,121,124$, $140,162,188,223,326$

Sartre, Jean-Paul 45

Saussure, Ferdinand de 2, 7-11, 15, 19, 23-25, 37-39, $47-50,52-53,56,59,60$, 62, 64, 83, 87-88, 342, 348, $381,446,453,456$

Savin, Harris B. 275

Scaliger, Julius Caesar 387

Schank, Roger C. 259, 268

Schlegel, Friedrich 7, 383

Schleicher, August 8, 341-342

Schlieben-Lange, Brigitte 59

Scholz, Barbara C. 281, 288, 450

Schoorlemmer, Maaike 28, 35

Schützenberger, Marcel-Paul 110, 144, 252, 269-270

Scioppius, Caspar 386-387

Seamon, David 340

Searle, John 13-14, 238, 354, $380,387,447$

Sebeok, Thomas 239

Searchinger, Gene 310

Sechehaye, Albert 88

Segev, Thomas 161

Selfridge, Oliver 249

Selz, Otto 267, 279

Semaan, K.I. 173

Seuren, Pieter A.M. 57, 60, 63, 156, 378, 380-381, 384-386, 388, 390, 404-406, 415

Shanker, Stuart 266-268

Shannon, Claude 178, 223, 240, 248, 253

Shapiro, Michael 56

Shaw, George Bernard 43

Shaw, J.C. 267, 269, 272

Shay, James 311

Sibawayhi 173,187

Simon, Herbert 238, 247-249, 251, 256-257, 260, 267, 269,272
Sinclair, John 432-433, 436, 438-439

Skinner, B.F. 89-91, 156, 178, 231, 241-242, 244-245, 253, 256, 260, 267, 272, 437, $447,460,468$

Slobin, Dan 247, 367

Smith, Barbara Herrnstein 457

Smith, Henry Lee 188, 221

Smith, Neil 338, 346

Solomonoff, Ray 249

Sorace, Antonella 6, 9

Spada, Nina 49

Spencer-Brown, G. 126

Staël, Anne Louise Germaine de 385

Steels, Luc 291

Steinthal, Heymann 307,363

Sterelny, Kim 342-343

Stewart, Dugald 7

Stockwell, Robert 436, 439

Stravinsky, Igor 2, 5

Stump, David J. 333

Sturm, Thomas 268

Stussi, Alfredo 408

Subbiondo, Joseph 387

Suppe, Frederick 316

Suppes, Patrick 316

Svartvik, Jan 428-429

Swadesh, Morris 79, 180

Swanson, D.C. 174

Sweet, Henry 427

Sweet, Paul R. 307

Swiggers, Pierre 226, 231

$\mathrm{T}$

Tajima, Matsuji 10, 122, 170, $173,178-179,216,252$

Takami, Ken'ichi 323

Tallal, Paula 454

Tanenhaus, M.K. 259, 454

Tarski, Alfred 112

Tataryn, Douglas J. 279

Thagard, Paul 238, 258

Thatcher, G.W. 173

Theocharis, T. $36-37$

Thomas, Margaret 5-6, 46, $130,288,303,450$

Thomason, Richard H. 391

Thompson, Sandra 23

Thompson, Susan P. 290

Thompson, Theodore 295 
Thurot, Charles 303

Tikhomirov, O.K. 243

Titchener, Edward B. 278-279

Tobin, Y. 23

Tolman, Edward C. 267

Tomalin, Marcus 175, 211, $315,318,333$

Tomasello, Michael 286, $346-347,450,455,458$, 462, 464, 466

Toqueville, Alexis de 94

Toulmin, Stephen 316

Trager, George 79, 92-93, 188, 221, 223

Traugott, Elizabeth C. 357-359, $363,365,367-371$

Trevor-Roper, Hugh 382

Trubetzkoy, Nicolai 85,120 , 130-131, 157, 177, 277

Turing, Alan 125, 268

Twaddell, Freeman 427

\section{$\mathrm{U}$}

Uexkull, Karl Ludwig von 347

Ulaszyn, Henryk. 120

Ullman, Jeffrey D. 270

V

Vachek, Josef 85

Van Gelderen, Elly 362

van Voorst, Jan 179
Varela, Francisco 458, 460, 462, 468

Vater, Johann Severin 7

Vaugelas, Claude Favre de 385,387

Verkuyl, H.J. 27

Violi, Patrizia 56

Virués-Ortega, J. 243

Voegelin, Charles F. 92, 180, 188

Vološinov, V.N. 449, 468

von Fintel, Kai 355

Vossius, Gerhard 386

Vygotsky, Lev 267, 277, 292, 468

\section{W}

Wade, Terence 28

Wasow, Thomas 302

Watson, James D. 253, 283

Watson, John B. 242, 266-267

Watt, W.C. 174, 259

Waugh, Linda 54

Weaver, Warren 223

Weber, Jean Jacques 53

Weimer, Walter B. 266, 272

Weinreich, Uriel 92

Weiss, Albert P. 239

Wells, Rulon S. 104, 180, 215, 225, 269

Wernicke, Carl 286, 368

West, Meredith 457
Whitney, William Dwight 7-10

Whorf, Benjamin 76, 80-81, $85,115,140,246$

Wiener, Norbert 268

Wiesel, Torsten N. 283

Wiesner, Jerome 250

Wilkins, John 305-306

Wilkins, Wendy 32-35

Williams, Roger J. 108

Williams, J.C.P. 453

Wise, Richard 286

Wolf, George 358-362

Wolff, John U. 169

Wundt, Wilhelm 83,

$$
\text { 277-278 }
$$

Y

Yap, Foong Ha 365

Yates, Frances 141

Yngve, Victor $77,89,240$, 249-252, 254

Z

Zajonc, Arthur 340

Zandvoort, Henk 316

Zhedong, Mao. 96, 400

Zimmer, Karl 383

Zinman, M. Richard 94

Zipf, George K. 436

Zorn, Max 110

Zweigenbaum, P. 441 



\section{Subject index}

A

Abstraction in grammar 30 , $37,48,50,53,62,86-87$, $110,125,127,143,145,147$, 150-155, 160, 185, 188, 217, 221, 226, 230, 246-247, 271, 274, 277, 280, 293, 284, 303, 306, 310, 322, 330, $338,348,353,361,363,365$, $368,379-380,397,399,411$, 413-414, 417-418, 426-427, 436, 448, 450-451, 465

Acceptability 87, 140, 142, 215, 226, 270-271, 423-424, 428-429, 441, 451, 459

Acquisition 265, 272-273, 284, 288-291, 302, 346-347, 353-354, 356-359, 366-372, 450

Adequacy 82, 120, 156, 182-183, 220, 222-223, 225, 227, 271, 281, 291, 319, 365, 386, 411, $414,435,437,452$

Adjuncts 145-147

Adjunction 119, 123, $143-147,155$

Adverb preposing rule 401 Affix-hopping 208

Algebra 86, 110, 118, 150, 153,270

Algorithm 119, 122-123, 125, $128-129,135,152,156,237$, $247,255,260$

Allomorphs 125, 142, 148, 208-209

Ambiguity 22, 33, 140, 143, 254-255, 257, 356, 371, 412

American Sign Language 353, 366-368

Anarchism 111, 125, 405

Anthropology 47-48, 61, 63, $76-77,85,94,104,113$, $152,237,258,260,446$, 457,460
Aphasia 286

Arbitrary 12-13, 43, 48, 52-54, $56,115,120,132,145-146$, $223,274,280,291,355$, 358, 410

Arc Pair Grammar 321, 324-325

Artificial Intelligence 237, 239, 240, 247-249, 250, 252, 254-259

Autonomy of linguistics 45, $107,113,342,348,398$

Autonomy of the language faculty $289,347-348$, 349, 449

Autonomy of lexemes $359-360$ Autonomy of syntax 137, 217, $287,354,378,380,389$, 391, 409

Autopoiesis $347-348$

\section{B}

Behavior 127, 156, 218-219, 221, 230-231, 240-241, 243, 245-247, 256-257, 270-274, 278, 280-283, 286, 290-291, 356, 396, $434,448-450,454-455$, $457-459,462-463$

Behavioralism 267

Behaviorism 45, 53-54, 84, 89-96, 113, 155-157, 178, 209, 231, 237, 239-244, 258, 260, 265-272, 274, 277-279, 426, 437, 447, 450

Bias (scientific) 109, 116, 127,290

Biology 38, 45, 47, 49, 59-67, $112,135,142,149-150,155$, $157-158,216,255,265,270$, 272-273, 277, 282-288, 292, 337-349, 256-257, 361, 372, 409, 417-418, 446, $455,457,460,464,468$
Bioprogram Hypothesis 353,367

Biuniqueness 134

C

Change (language) 43, 48-53, 59-62, 66, 113, 118-119, 145, $341-342,353-372$

Classification $7-8,15,47$, $51,77,79-80,88,96,116$, 130, 139, 221, 289, 315, $317-318,323,325,333$, $339-340,356$

Cline $355,363,370$

Cognition 85, 96, 157, 245 , 248, 257-258, 259, 268, 269, 277, 353, 409, 415, 453-467

Cognitive Poetics $53-57$

Cognitive Science 45-49, 58, $62,64,76,83,93,119,133$, 155-159, 229-230, 237-260, 265-292, 345, 353, 356, 363, 365-372, 399, 402-403, 406, 411-413, 415-416, $418,429-430,439,446$, 449-451

Collocation 308, 426-427, 428, 430, 432,438

Commitments 402-403

Competence 11, 37, 47-48, 59, $62,155,156,215,229,247$, 259, 274, 287, 291, 320, 338-339, 353-354, 409, 413, 423-424, 428, 430, 432-433, 435, 438, 441, $448,453,465$

Components 57, 63, 119, 126, 134-136, 138, 151, 171, 176, 187, 192-193, 208, 222, 224, 226, 253, 269, 309, 318, 330, 354

Conditions of adequacy 222, 271,281 
Conditions on rules 134, 146, $148,153,172,180,207,225$, 309, 417

Constituent 34, 82-83, 86, 104, 109, 129, 143-144, 146-147, $151,182,223-226,269$, 323,326

Constraints 22-24, 46, 144-145, 152, 229, 278, 289-291, 309, 319, 323, 338, $343,354,356,359,367-369$, 372, 381, 400, 404-405, $407,412,414,417-418$

Constructivism 451, 457-461, 467

Context 95-96, 142-146, $185,228,278,309,357$, $361,368-369,371,417$, $424,426-427,430-432$, $446-452,455$

Contrast 28, 35, 87, 113, 115-116, 125-136, 138-139, 158, 221, 348, 454, 464

Co-reference 146, 148 Corpus Linguistics 21, 218-222, 280-282, 423-442

Creativity (linguistic) 11, 13, $63,80,88,371,423-424$, 426, 429-430, 433-434, $437-438$

Creoles 61, 353, 366-369, 372

Criteria 23, 96, 120, 122, 126, $129-133,137,142,156,180$, 183, 186, 204, 206, 222, 225, 227-228, 270-271, 319, $324-325,339,363$

Critical Period Hypothesis 49, 359

Cross-over phenomena 414

D

Deep Structure 14, 30, 82, 247, $265,275,318,323,326-328$, $378,386,389-390,397$, 401, 404-405, 410, 412, 448

Dependency 140-141, 144, 155, 326,450

Derivation 22, 33, 119-120, 181, 186, 189-190, 208-209, 221, 252, 255, 275, 400, 403, $405,412,414,416$
Derivational Theory of Complexity 259, 275, 417

Descriptive Linguistics 9, 19-28, 33-35, 37-38, 40, $46-48,60,77,83,86,112$, 114-117, 120-122, 124-125, 128-130, 132, 134, 137, 152, $174,177,180-183,187,215$, 229, 291, 316-317, 319, 365, $385,427,429,433,441$, 448,452

Developmental Linguistics 445-446, 453, $455,460-467$

Discourse Analysis 48, 65, $118,129,138-139,160$, $176,251,353,361,432$, 450,460

Discovery procedures 117 , 120-125, 182-183, 221, 269

Distribution 2, 86, 112, 115, $118,120,125-134,136-137$, 139-140, 149-150, 156, 183, $188,215,218,221,226-229$, 289-290, 401, 412, 424, 426, 428

Complementary

Distribution 127, 129, 133, 192

E

Economy 79, 120, 129, 179, 183, 288,362

Elegance 37, 120, 156, 175, $182-183,186-187,209$, 225,288

Elements 22, 24, 27, 39, 49, $51,54,56,58,60,77,81$, $83,87-88,110,115-117$, 120-121, 125-127, 129-130, 136-139, 141-142, 145, 148, $152,175,182-186,192,194$, 196-197, 221-225, 228, 246, 271, 279, 302, 304, 306, $322,328,348,356,359-361$, 370-371, 401, 411, 417, 438-439

Elicitation 429

Ellipsis 14, 55, 386, 388

Emergent Grammar 358

Empiricism 265, 292, 383-384, 423-442, 459
Endocentric constructions $143-147,151$

Etymology 53, 355, 358, $360-361,371$

Evolutionary biology 60, 62, $79,149,258,265,282$, 287-288, 291, 337-349, 445-446, 460-461, 464

Expansion 129, 144, 150-153, 159,255

Explanation 19-21, 35-36, 38, $51,58,61,84,109,111,122$, 130, 133, 155, 266, 269, 278-279, 283, 285, 291, $305,316-317,319,328$, $344-345,361,365,389$, 401, 403-404, 406, 414, 441-442, 449, 459, 462

Extended Standard Theory 32, $34,318-319,320,322,395$

Exocentric constructions 143,147

External (E-) Language 43, 57, $64,338,349$

F

Features 21, 51, 77, 79-80, 84, 115-116, 126-127, 129-133, $135-136,138,140,147,171$, 218, 221, 228, 237, 304-306, $308,320,343,372,432$, 450,458

Feedback 56-57, 156, 221, 455,457

Filter 324

Finite-State Grammar 437 Focus 83, 180, 413

Formalism 19-40, 76-77, 80-82, 84, 92-94, 104, $112,115,118-119,123,125$, $128,136,139,143-145$, 149-150, 156, 175-188, $211,217-218,221-222$, 226, 228-229, 247-249, 251-252, 267, 269-270, 272, 278, 288, 307, 323, 325-326, 347, 349, 354, $357,361,365,367,391$, 397-398, 401-403, 406-407, 409-413, 415-418, 432, 434, 437, $441-442,448,450$

Freierism 161-162 
Functionalism 28, 30, 53, 85, $323,354-355,363,398-399$, 416,432

Fuzzy 140, 325, 399

\section{G}

Gapping 142, 148

General Problem Solver 256

Generative Grammar 11-12, 19-40, 47, 58-59, 65, 95, 111, 118, 122, 152, 154, 156, 158-161, 169, 171, 187, 189, 210, 230, 239-240, $244-245,247,253,258$, $267,273-276,279,282$, 285, 288-289, 301-303, 308-311, 315-333, 340, 355, $361,377-392,395-418,438$, 450, 466

Generative Phonology 129, 152, 171, 180, 185, 209, 211, 277,317

Generative Semantics 14-15, 142, 315, 320, 326, 328-329, 377-381, 389-390, 392, 395-418, 425

Genetics 283

Government and Binding 147, 288, 402

Gradience 371, 423-424, 429

Gradualism 341, 344

Grammaticality 48, 92, 142-143, $210,245,250,280-281$, 320, 370, 428-431, 434-436, 439, 441

Grammaticalization $353-372$

\section{$\mathrm{H}$}

Head 143, 145, 151, 308, 406 Hierarchical Perceptual Control Theory 157

Hierarchy $127,132,144$, 150-151, 155, 157, 250, 254, 257, 270, 344

Historical Linguistics 7, 9, 46, $52,66,78,80,82,118,177$, 180, 189, 361, 408, 449

Hox genes 343

\section{I}

Iconicity $52-57,355,358$ Ideal speaker-listener 47, 234, 339
Idéologues 384-385

Idiom Principle 438

Imitation (in child language acquisition) 45, 346, 457

Immediate Constituents 104, 147, 151, 223-224, 226, 269

Innateness 12-13, 20, 30, $37-38,135,142,149,150$, 155, 157-158, 231, 273, 275, 282-283, 285, 287, 289, 291, 354, 358, 360-362, 366-368, 372, 384, 390, 426, 437-438, 458-459

Inner form 77-78, 362

Internal (I-) Language 46, $57-59,64,274,284$, 287-288, 338-339

Interpretive Semantics 378, 391, 395, 401, 403

Intuition (speaker's) 48, 59, $85,128,137,142-143$, 220, 227, 229, 245-246, 270-271, 278-282, 284, 320, 339-340, 391, 424, 429, 435, 439-440, 442, 448-449

Island phenomena 143-144, $147,155,414$

$\mathrm{J}$

Judgment (speaker's) 83, 116-117, 125-126, 134-136, 151, 154, 220, 270-271, 279-280, 290, 340, 409, $429,439,441,448,451$

\section{K}

Kernel sentences 120, 221, 225, $253,274-275,435$

L

Language Faculty 45-46, $57,63,65,273,289$, 337-349, 356-357, 439, 449

Language Function 149 Language Organ 149, 155, 284-287, 342-345

Languaging $452-468$

Langue 11, 37, 47-50, 54, 59, 62, $88,342,348,453$
Latent Semantic Analysis 289-291

Learning 5, 13, 157, 241-242, $271,273,275,283,287$, 289-290, 305, 345-347, $417,438,454,457-458$

Lexical decomposition 396 , 399-400, 404

Lexical insertion 57, 153, 396, 401

Lexicalism 377, 379-380

Lexicogrammar 430-432

Linguistic relativity $80,85,462$

Linguistic String Processor 144

Logic 34, 49-50, 57, 82-84, 93, 104-105, 109-112, 115, 126, 152, 174-175, 181, 188, 240, 244-247, 249, $256-267,285,316,323$, $338-339,384,386-388$, 391, 397, 402-403, 409-410, 413, 416

Logical form 57, 323, 414

London School 85

M

Mapping 30, 110, 115, 134, 153

Markedness 364-365

Markov process 178, 219, 223, 253, 269, 433, 437

Mathematics 30, 34-38, 49, 58, $76,109-112,115,118-119$, $126,145,150,152,154,157$, 174-176, 189, 230, 249, 255, 269-270, 272, 319, 325, 403, 411, 430, 465-467

Meaning 14, 23, 25, 39, 48-49, $51-53,55-57,65,85,92$, 125-127, 137-140, 142, 150, $152,156,217,221,225-229$, 278, 309, 326, 353-372, 378, 386, 391, 401, 404, 406-407, 409, 411-412, $416,424,426-427,430$, $439,451-452,456$

Medical Language Processor 144

Memory 47, 51, 53, 60, 267-268, 276, 344-345, 437-438, 464

Mentalism 91, 244, 270, 274, 277, 284 
Merge 60, 344-345

Metagrammar 121, 123, 142,155

Metalanguage 112, 129, 145-150, 158, 222, 302, 386,453

Metaphor 54, 112

Metatheory 62-67, 148-149, 152,155

Minimalism 34, 57-58, 147, $151,288,329,364$, 416,450

Modernism 1-2, 7, 15-16, 258

Modularity 57, 63, 153, 284-286, 291, 343, 462

Montague Grammar 391, 399

Morphology 26, 28, 34, 51-52, $76,79,82,87-88,115,117$, $171,174,176,180,184,187$, 193, 208, 217, 221, 224, 277, 343,377

Morphophonemics 54, 89, $125,127,136,144,152,155$, 171, 176-190, 193-195, 208, 220, 229

$\mathrm{N}$

Native speaker 47-48, 58-59, $62,115,117,126,134,136$, 151, 220, 246, 254, 270-271, 280-281, 320, 339-340, $349,436-437,448-449$

Nativism $272-273,275,288$, 291, 355, 367, 409

Natural Grammar 305-306

Naturalness 52, 225, 436

Negation 27, 81, 358, 413, 424

Neogrammarians 52, 342, 391, 404

Neuroscience 238, 258, 446, 457

Notation 19, 28, 33-38, 40, $114,118-119,121,125-126$, 146, 151, 153, 155, 171, 185, 208, 210, 229, 322, 324, $406,413,415,451$

Notational variants $35,114,119$, $151,406,413,415$

O

Objectivity 129, 137, 270, 272, 357

Ontology 59, 126-127, 317, 319, $324-325,329,341$
Open Choice Principle 438

Operator Grammar 140-141, 144-146, 148, 152-155

Optimality theory 118,406

\section{$\mathbf{P}$}

Pair Test 117, 126-127, 131, 270,280

Parole 37, 47-49, 59, 62, 88,348

Passive Voice 20-40, 192, 220, 224, 228, 245, 257, 322, 324, 329,332

Perception 126-127, 130-131, 156-157, 275-276, 284, 286, 291, 429, 454, 457-459

Performance $37,47-48,57$, 59, 142, 247, 254-255, 259, $274,280,287,291,320$, $338,345-346,354,356$, $413,424-425,427-430$, $432-433,435,439$, 441,465

Philology 7, 79, 82, 111, 361, 408, 447, 449-450

Philosophical Grammar 305-306, 308, 389-390

Philosophy 7, 12-13, 36, 58, $62,64,85,93,104-105$, $107,109,112,117,157$, 174-175, 181-183, 210, 216, 231, 237-238, 258, 282, 305-308, 384, 387-391, 409, 411, 415, 425, 446, 461

Phoneme 47-48, 83, 88-89, 93, 116-117, $119,126-127,129-136$, 139, 141, 148, 158, 181-185, 208, 217-218, 220-222, 227, 229, 279-281, 291, 411, 437

Phonetics 44, 49, 52, 54-55, $57,60,63-64,77,80,82$, $84,112,116,126-136,138$, $143,182,184,342,356,358$, 371, 411, 427, 439-440, 454,460

Phonology 28, 52, 54, 63-65, $76,78-79,82-83$, $87-88,94,126-135$,
138-139, 152-153, 171-172, 174, 176, 180, 184-185, 187-188, 208-209, 211, 277, 317-319, 354, 391, 425

Phrase-Structure

Grammar 110, 118, 143,147

Pidgins 366-369

Port Royal grammarians 10, 12, 14, 79, 85, 306, 309, $360,381,383-384,385$, $388,390,409$

Positivism 3, 226, 316, 384, 425,433

Poverty of Stimulus 45-46, 271-272, 288-289, 347, 356,450

Pragmatics 138, 361, 399, 410, 413, 447, 450, 452

Prague School 85, 87, 120, 124, 277

Presupposition 413

Principles and Parameters 46, $59,288,355,362-364,366$

Probability 217, 289-290, 431, 434-441, 459

Projection 151, 153, 155

Extended Projection Principle 328

Pronominalization $413-414$

Psychology 9, 30, 38, 48-49, 52-54, 84, 86, 90-91, 107, 112-113, 120, 151, 156-157, 159, 184-185, 220, 230-231, 237-260, 266, 268-270, 272, 274-288, 389, 401-402, 409, 411, 413, $417,446,450,453,456$, 459, 461

Cognitive psychology 156-157, 159, 239-241, 245, 256, 259-260, 267-268, 279

Gestalt psychology 85, 267, 275

Psychological reality 82, 246-247, 274, 276, $417-418$

Q

Quantifiers 399, 401, 404, 413 
R

Randomness 148, 152, 158

Realism 96, 157, 218-219, $457-458,460-461$

Recursiveness 65, 88, 111, $118-119,145,149,155,157$, $189,210-211,223,267-268$, $343,429-430,437,462$, 466-467

Reductions 124, 144-146, $148-151,153,155,158,290$

Register 141, 370, 430

Relational Grammar 315, 320-329, 399, 406

Repetition 54-55, 82, 117, 126, $134,138,148,377$

Requirements 112-113, 137, 140, $183,270,285$

Restatement 115, 117, 121, $123-125,175$

Rules 11, 30, 32, 34, 38-39, $88,110,114-120,129,135$, 143-148, 152, 155, 170, 172, 174, 177-180, 185, 188-189, 209-211, 220-221, 224-225, 245-246, 268-270, 273, 275, 278, 284, 287, 289, $309,318,320,323-324$, $338,355-357,368,388$, 396-397, 401, 404-405, 410, 416-417, 424, 428-430, 435-436, 438, $441,448,451,458$

Rewrite rules 143-144, 146, $155,185,210,318,320$

Rule-ordering 120, 147, 171-172, 174, 176-180, 186, 188-190, 204, 206-207, 209, 211, 220-221, 246, 318, $357,368,396$

\section{$S$}

Segmentation 15, 116, 126, 133-135, 221

Semantic Bleaching 355

Semantic Congruity Effect 463

Semantics 14-15, 23, 25-26, 28, $34-35,38,53,63-64,93$, $112,120,129,136-139,142$, $145,147,152-153,156,187$, 217, 226-229, 241, 289-291, $304,315-316,318-320,323$, $326,328-329,354-355$, $358,366-367,369,371$,
377-381, 386-392, 395-418, 425-426, 434, 438, 451, 463

Set Theory 110

SGML 138

Simplicity 118, 120, 132-133, $135-136,175,183,186,188$, $216,222,225$

Speech community $47,59-60$, $137,210,274,430$

Sociolinguistics 48, 65-66, $399,416,430,432,447$

Speculative Grammar 303-304, 386

Statistical learning theory 157 , 289-290

Statistics 128, 178, 424, 431, 433-438, 440-441

Strings 119, 123, 129, 141, 143-147, 151, 153, 155, 190, 208, 220-225, 257, 271, 280-281, 429, 436, 448, 451

Structuralism 22-25, 37-38, $46-52,59,63-65,76$, 87-88, 92-94, 218, 221, 225-229, 317, 322, 390-391, 410, 413, 427,433

Subjectivity 218-219, 278, 348

Sublanguage 112, 129, 139-142, $144,146-147,153$

Substitution test 126, 130-131, $133-136,221,428$

Surface Structure 34, 247, 275 , $318,323,327,378,400,403$, $410,412,414,448$

Syntax 9, 13-14, 22-23, 25-30, $33,35,38-39,51,56-57$, $63-66,75-77,79-80$, 82-83, 85-90, 93-94, 96-97, 115, 118-120, 134, 136-138, 143, 147, $152-153,155,169,172$, $178-179,180,182-184$, 187-188, 190, 192, 194-195, 208-211, 215-231, 241, $245,267,270,272$, 275-277, 281, 286, 289-291, 304, 317-319, $321-324,326-327,344$, $354,356,358,364-365,368$, $370-371,378-381,385-386$, 389-391, 398-399, 401, 403-406, 409-412, $414,416-417,427-428$,
436-439, 441, 447, 449, $451-452,454,463$

$\mathrm{T}$

Taxonomy 11, 38, 47, 114, $118,128,130-132$, 134-135, 158-160, 229, 242, 347

Teleology 340, 342

Terminal symbols 145, 153, 155

Theta Assignment Hypothesis $328-329$

Theta roles $28-29$

Topic 83, 85, 245, 332, 413

Trace Erasure Principle 155

Transformational derivation 403,416

Transformational grammar 11, 14, 88-89, 94-95, 118, 143-145, 152, 159, 215-231, 239-240, 244-246, 248, 251, 253-254, 257, 259, $267,269,274-276,282$, $317,322-323,327$, $378-381,388,391,397$, 402, 408, 412, 417-418, 423-442

Transformational rules 152, 323, 401, 405, 410, $416-417,448$

Transformational structure 217, 220, 225

Transformations 30, 34, 90, $110,115-119,128,142,144$, 147, 150-153, 185, 199, 208, 210, 220-221, 224-226, 229, 246-247, 250-251, 253-255, 257, 274-276, 318, 320, 322, 354, 362, 370, 401, 404, $412,414,417-418$, 429, 435

Tree-adjoining Grammar 123, 144-146, 155

Tree Structure 110, 142, 152 Typology 47, 80, 82, 86, 111, $114,187,270,274,301,308$, $311,363,415$

$\mathrm{U}$

Unaccusative Hypothesis 315, 317, 325-333

Unidirectionality 357,359 
Uniformitarianism 3, 43, 61, 341-342, 358-359

Universal Alignment Hypothesis 317, 326-333

Universal Base Hypothesis $326-327$

Universal Initial Assignment Hypothesis 328

Universal Grammar 29-30, 44-46, 58-59, 93, 123, 134, 142, 158, 271, 274, 286-287, 301-311, 326, 338, 354-357, $360-361,363-367,371-372$, $382-385,387,417,445$
Universalism 337-349, $385-386,388,390,466$

Universals of Grammar 79, $82-84,127,132-133$, 135-137, 145, 158, 287, 304, 307-308, 311, $338-339,363,380$, 386, 397, 409-410, 433,450

Usage 246, 354, 358-359, $361,372,385$, 428-435

Utterance 21, 78, 83-84, 115-116, 126-127, 134-136, 138, 143-144, 148, 151,
$156,187,210,218-219$, 221, 226-227, 280-281, 434, 439, 447-448, 452, $455-456,460$

W

Well-formedness 142, 324, 436, 441

X

X-bar 151

XML 138, 144

Z

Zeroing 148 


\section{Index of Noam Chomsky's cited works}

A

"After the Cataclysm:

Postwar Indochina and the Reconstruction of Imperial Ideology" (1979) 96

"The Algebraic Theory of Context-Free Languages" (1963) 252

Aspects of the Theory of Syntax (1965) 10, 47, 265, 273, 275, 279, 282, 308, 318-319, $379,401,412,416,435,453$

B

Barriers (1995) 309

C

Cartesian Linguistics

(1966) 10-15, 93, 230, 274, 282, 302-303, 306, 308, 377-392, 397, 462

"Chomsky's Revolution: An Exchange" (2002) 238

"Conditions on Transformations" (1973) 416

"Construction of the German Verb Phrase" (1955) 250

"Context-Free Grammars and Pushdown Storage" (1962) 252

Current Issues in Linguistic Theory (1964) 11, 88, 127-129, 131-135, 143, 159, $180,225,417$

D

"Deep Structure, Surface Structure and Semantic Interpretation" (1971) 401

"Degrees of Grammaticalness" (1964) 425, 429
Dialogues avec Mitsou Ronat (1977) 155

“Dialogue I. Noam Chomsky's Views on the Psychology of Language" (1983) 266, $272,276-277,280,284$

"Distortions at Fourth Hand" (1977) 96

\section{E}

"Explanatory Models in Linguistics" (1962) 37

F

"Finite State Languages" (1958) 241

"The Formal Nature of Language" (1967) 272

"Formal Properties of Grammars" (1963) 269

G

"A Generalization of X-Bar Theory" (1989) 169

The Generative Enterprise Revisited (2004) 259, 439

Generative Grammar: Its Basis, Development and Prospects (1988) 329

\section{I}

"In Response to 'Deep Language"' (1973) 14,387

"Introduction to the Formal Analysis of Natural Languages" (1963) 241, 257, 259, 437

K

"Knowledge of Language: its nature, origin, and use" (1986) 20
$\mathrm{L}$

Language and Politics (1988) 349

Language and Mind (1968/2006) 15, 46, $58,60,62-63,245$, 248, 308, 381, 385, 388, 392, 397

Language and Problems of Knowledge (1988) 356,450

Language and Responsibility (1977/1979/1998) 155, $309,346,378,383$

"Language from an Internalist Perspective" (1997) 274, 276, 284, 287, 289

Lectures on Government and Binding (1981) 328

"Linguistics and Brain Science" (2000) 280, 282,284

"Linguistics and Politics" (1969) 118, 189

"Linguistics, Logic, Psychology and Computers" (1958) 252

"The Logical Basis of Linguistic Theory" (1964) 10-11, 171, 178, 424-425, 438,441

Logical Structure of Linguistic Theory (1955/1956/1975) 38, $89,92,107,116$, 118-119, 122, 125, 127-128, 137-138, 141-142, 147, 154-155, 159, 170, 178-179, 216, 239, 244-246, 254, 269-271, 279-281, 308, 401 
M

The Minimalist Program

(1995) 20, 28, 302, 338

“The Minimalist Program.

A Response to Pinker \& Jackendoff" (2002)

453, 462

Morphophonemics of Modern

Hebrew (1951) 89,

117-123, 133, 155,

$169-211$

$\mathrm{N}$

Nature and Language

(2002) 453

New Horizons in the Study of Language and Mind (2000) 309

"A Note on Phrase-Structure Grammars" (1959) 269

\section{O}

"Of Minds and Language" (2007) 338, 343-344, 347-348

Of Minds and Language:

A Dialogue with Noam

Chomsky in the Basque Country (2009) 347

"On Certain Formal Properties of Grammars" (1963) 269-270

"On the Notion of 'Rule of Grammar"' (1961) 259
P

"Pattern Conception" (1957) 241, 252

"Problems and Mysteries in the Study of Human Language" (1976) 189

Q

"Questions of form and interpretation" (1975) 401

$\mathbf{R}$

Reflections on Language (1975) 15, 308, 416-417

"Remarks on Nominalization" (1967) $377,379-381,390$

"Review of A Manual of Phonology" (1957) 188

"Review of Fundamentals of Language" (1957) 188

"Review of Verbal Behavior" (1959) 37, $178,221,241-245,256$, $272-274,383,434$

Rules and Representations (1980) 288, 417

$S$

"Some Empirical Issues in the Theory of Transformational Grammar" (1972) 401, 406
"Some General Properties of Phonological Rules" (1967) 171, 209

"Some Properties of Phrase Structure Grammars" (1958) 269

Sound Pattern of English (1968) 89, 171, 209, 211, 277, 391

Syntactic Structures (1957) 20, $38,76,89,92,208,210$, 215-231, 241, 245-246, 252, 254-255, 257, 259, 267, 269-272, 281, 318, 378, 390, 411-412, 417-418, 431, 434, 437, 441

"Systems of Syntactic Analysis" (1953) 175, 211, 224

$\mathrm{T}$

"The Theory of Principles and Parameters" (1993) 276, 284

"Three Factors in Language Design" (2005) 28, 344-345

"Three Models for the Description of Language" (1956) 159, 223, 240, 252, 254, 269, 436

Transformational Analysis (1955) 118, 216

"Transformational Approach to Syntax" (1962) 435-436, 439 
It is not unusual for contemporary linguists to claim that "Modern Linguistics began in 1957" (with the publication of Noam Chomsky's Syntactic Structures). Some of the essays in Chomskyan (R)evolutions examine the sources, the nature and the extent of the theoretical changes Chomsky introduced in the 1950s. Other contributions explore the key concepts and disciplinary alliances have evolved considerably over the past sixty years, such as the meanings given "Universal Grammar", the relationship of Chomskyan linguistics to other disciplines (Cognitive Science, Psychology, Evolutionary Biology), and the interactions between mainstream Chomskyan linguistics and other linguistic theories active in the late 2oth century: Functionalism, Generative Semantics and Relational Grammar. The broad understanding of the recent history of linguistics points the way towards new directions and methods that linguistics can pursue in the future.

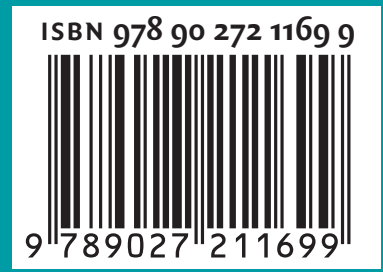

\section{John Benjamins Publishing Company}

